\title{
Review of the genus Chalcolepidius Eschscholtz, 1829 (Coleoptera, Elateridae, Agrypninae)
}

\author{
Sônia Aparecida Casari ${ }^{1}$
}

\begin{abstract}
Aвstract. The genus Chalcolepidius is revised. Type specimens of 65 nominal species, except C. costatus Pjatakowa, 1941, C. fleutiauxi Pjatakowa, 1941 and C. viriditarsus Schwarz, 1906, are examined. Eighty five species are studied, of which 34 are synonymyzed and 12 new species described; three species, C. alicii Pjatakowa, 1941, C. haroldi Candèze, 1878 and C. unicus Fleutiaux, 1910, formely included in this genus, are not congeneric and are removed; C. validus Candèze, 1857 is revalidated. The genus is now formed by 63 species. Redescriptions, illustrations and a key for the examined species, and a cladistic analysis for groups of species are also included. New synonyms established: C. apacheanus Casey, $1891=C$. simulans Casey, 1907 syn. nov. $=$ C. acuminatus Casey, 1907 syn. nov. $=$ C. nobilis Casey, 1907 syn. nov.; C. approximatus Erichson, $1841=$ C. aztecus Casey, 1907 syn. nov. = C. niger Pjatakowa, 1941 syn. nov.; C. attenuatus Erichson, $1841=$ C. cuneatus Champion, 1894 syn. nov. $=C$. tenuis Champion, 1894 syn. nov.; $C$. aurulentus Candèze, $1874=C$. candezei Dohrn, 1881 syn. nov. $=$ C. grossheimi Pjatakowa, 1941 syn. nov.; C. bomplandii Guérin, $1844=$ C. humboldti Candèze, 1881 syn. nov.; C. chalcantheus Candèze, $1857=$ C. violaceous Pjatakowa, 1941 syn. nov.; C. cyaneus Candèze, $1881=$ C. scitus Candèze, 1889 syn. nov. $=$ C. abbreviatovittatus Pjatakowa, 1941 syn. nov.; $C$. desmarestii Chevrolat, $1835=C$. brevicollis Casey, 1907 syn. nov.; C. gossipiatus Guérin, $1844=$ C. erichsonii Guérin-Méneville, 1844 syn. nov. $=C$. lemoinii Candèze, 1857 syn. nov.; C. inops Candèze, 1886 = C. murinus Champion, 1894 syn. nov.; C. jansoni Candèze, $1874=$ C. mucronatus Candèze, 1889 syn. nov.; C. lacordairii Candèze, $1857=$ C. exquisitus Candèze, 1886 syn. nov. $=$ C. monachus Candèze, 1893 syn. nov.; C. lenzi Candèze, $1886=$ C. behrensi Candèze, 1886 syn. nov.; C. oxydatus Candèze, $1857=$ C. jekeli Candèze, 1874 syn. nov.; C. porcatus (Linnaeus, 1767) $=$ C. peruanus Candèze, 1886 syn. nov. $=C$. flavostriatus Pjatakowa, 1941 syn. nov. $=$ C. herbstii multistriatus Golbach, 1977 syn. nov.; C. rugatus Candèze, 1857 $=C$. amictus Casey, 1907 syn. nov.; C. smaragdinus LeConte, $1854=$ C. ostentus Casey, 1907 syn. nov. $=$ C. rectus Casey, 1907 syn. nov.; C. sulcatus (Fabricius, 1777) $=$ C. herbstii Erichson, 1841 syn. nov; C. virens (Fabricius, 1787) $=$ C. perrisi Candèze, 1857 syn. nov.; C. virginalis Candèze, $1857=$ C. championi Casey, 1907 syn. nov.; C. viridipilis (Say, 1825) = C. debilis Casey, 1907 syn. nov.; C. webbi LeConte, $1854=$ C. sonoricus Casey, 1907 syn. nov.; C. zonatus Eschscholtz, $1829=$ C. longicollis Candèze, 1857 syn. nov. New species described: C. albisetosus sp. nov. (Ecuador), C. albiventris sp. nov. (Mexico: Veracruz), C. copulatuvittatus sp. nov. (Venezuela), C. extenuatuvittatus sp. nov. (Venezuela), C. fasciatus $\mathbf{s p .}$ nov. (Mexico: Durango), C. ferratuvittatus sp. nov. (Ecuador), C. proximus sp. nov. (Mexico: Sinaloa), C. serricornis sp. nov. (Mexico: Veracruz), C. spinipennis sp. nov. (Mexico: Veracruz), C. supremus sp. nov. (Venezuela), C. truncuvittatus sp. nov. (Mexico: Tamaulipas) and C. virgatipennis sp. nov. (Mexico: Durango). Redescribed species: C. angustatus Candèze, 1857, C. apacheanus Casey, 1891, C. approximatus Erichson, 1841, C. attenuatus Erichson, 1841, C. aurulentus Candèze, 1874, C. bomplandii Guérin-Méneville, 1844, C. boucardi Candèze, 1874, C. chalcantheus Candèze, 1857, C. corpulentus Candèze, 1874, C. cyaneus Candèze, 1881, C. desmarestii Chevrolat, 1835, C. dugesi Candèze, 1886, C. erythroloma Candèze, 1857, C. eschscholtzi Chevrolat, 1833, C. exulatus Candèze, 1874, C. fabricii Erichson, 1841, C. forreri Candèze, 1886, C. fryi Candèze, 1874, C. gossipiatus Guérin-Méneville, 1844, C. inops Candèze, 1886, C. jansoni Candèze, 1874, C. lacordairii Candèze, 1857, C. lafargi Chevrolat, 1835, C. lenzi Candèze, 1886, C. limbatus (Fabricius, 1777), C. mexicanus Castelnau, 1836, C. mniszechi Candèze, 1881, C. mocquerysii Candèze, 1857, C. morio Candèze, 1857, C. obscurus Castelnau, 1836, C. oxydatus Candèze, 1857, C. porcatus (Linnaeus, 1767), C. pruinosus Erichson, 1841, C. rodriguezi Candèze, 1886, C. rostainei Candèze, 1889, C. rubripennis LeConte, 1861, C. rugatus Candèze, 1857, C. silbermanni Chevrolat, 1835, C. smaragdinus LeConte, 1854, C. sulcatus (Fabricius, 1777), C. tartarus Fall, 1898, C. validus Candèze, 1857, reval., C. villei Candèze, 1878, C. virens (Fabricius, 1787), C. virginalis Candèze, 1857, C. viridipilis (Say, 1825), C. webbi LeConte, 1854, C. zonatus Eschscholtz, 1829.
\end{abstract}

KEYwords. Agrypninae; Chalcolepidius; Elateridae; Hemirhipini; revision.

1. Museu de Zoologia, Universidade de São Paulo. Av. Nazaré 481, 04263-000 São Paulo-SP, Brasil. E-mail: casari@usp.br. 


\section{INTRODUCTION}

The genus Chalcolepidius Eschscholtz, 1829 is recognized by the wide, arched, and almost parallel sided body, clothed with scale-like setae, usually metallic and very colorful, many times forming lateral bands on prothorax and elytra. The borders of mesosternal cavity are thick and horizontal basally, and the suture behind the mesosternal cavity is absent or obsolete. Previous workers have characterized the species especially by the pubescence coloration and the shapes of the scutellum and antennae. The majority of the species present scutellum folded (previously called triangular) and in several of them, a wide range of coloration variation is observed, showing a clear gradation when a large series is analyzed. This variation and the small number of specimens available to study, led the previous workers to describe specimens from different position of one range of coloration pubescence as different species.

The only revision of the genus was made a long ago in the nineteenth century, and the last identification key as well in 1886. Since that time, about forty species were described and, the lack of a recent taxonomic revision and an updated key, become the species identification a very hard task.

The goal of the present work is to revise the genus Chalcolepidius pointing out new morphological characters to recognize the species, to enumerate the intraspecific variations and present an identification key to species.

When this study was initiated, Chalcolepidius consisted of 88 species (about 160 nominal species), from which 105 nominal including 65 types, corresponding to 85 valid species were studied. Three valid species, C. costatus Pjatakowa, 1941, C. fleutiauxi Pjatakowa, 1941 and C. viriditarsus Schwarz, 1906, were not examined because the type material was not located and none specimen fitting in the original descrition was found.

Based on the morphology of these species, a new interpretation of the scutellum shape is presented. The coloration and some characters related to the male and female genitalia are also used to define the species.

In the present revision, the genus Chalcolepidius is constituted by 63 species. Three species, C. alicii Pjatakowa, 1941, C. haroldi Candèze, 1878 and C. unicus Fleutiaux, 1910, were removed from the genus and will be transferred to Alaus Eschscholtz, 1829. C. lafargi Chevrolat, 1835 and C. validus Candèze, 1857 are revalidated, 34 species are considered synonyms and twelve new species are described.

An identification key and redescriptions, illustrations and maps with the geographical distribution for all species studied are presented. In addition, a cladistic analysis for group of species is included.

\section{HISTORICAL REVIEW}

Eschscholtz (1829) erected Chalcolepidius shortly characterized by "scutellum obcordatum; metathorax carinatus", and included Elater porcatus Fabricius, E. striatus Fabricius, E. sulcatus Fabricius and E. virens Fabricius, and three new species, C. limbatus, C. smaragdulus and C. zonatus. He presented a diagnosis for each species, some of them later synonymized.

GeRMAR (1840) re-characterized Chalcolepidius and presented a key for 11 Elateridae genera. He was the first to draw attention on the absence of a distinct suture between the meso- and metasternum, behind the mesosternal cavity. Since this time, this character has been used as diagnostic feature of the genus.

ERICHSON (1841) treated of 18 Chalcolepidius species, and redefined C. porcatus (including Elater virens Fabricius and E. striatus Linnaeus as synonyms), C. limbatus (with Elater striatus Fabricius as synonym), $C$. zonatus Eschscholtz, $C$. lafargi Chevrolat, C. sulcatus (Fabricius), C. desmarestii Chevrolat, C. silbermanni Chevrolat, C. obscurus Castelnau, C. aequinoctialis Castenau and C. mexicanus Castelnau. He also described $C$. herbstii (including Elater sulcatus Herbst as synonym), C. approximatus, C. fabricii, C. sericeus, $C$. pruinosus, C. procerus, C. prasianus and C. attenuatus. Three species described by ERICHSON (l.c.) were considered as synonyms by CANDĖZE (1857): $C$. sericeus $=C$. silbermanni Chevrolat, 1835, C. procerus $=C$. dermarestii Chevrolat, 1835 and C. prasianus $=C$. viridipilis (Say, 1825).

LACORDAIRE (1857) redescribed the genus, enumerated the sexual differences and, by first time, observed the fringe of long cilia on tibiae of males. This character is not generic but it is present in a large group of species. He also divided the species into two groups based on antennal shape: flabellate in male and pectinate in female, with only one species of North America, C. viridipilis Say, or serrate in both sexes, including the remainder species. The last group, with serrate antennae, was subdivided according to the scutellum shape: horizontal on basal half and declivous or vertical on anterior half (including C. attenuatus Erichson and C. desmarestii Chevrolat from Mexico, and C. erichsonii Guérin-Méneville and C. gossipiatus Guérin-Méneville, from "Nouvelle Grenade") or scutellum horizontal, including species from hot areas of South America (C. herbstii Erichson, C. limbatus Eschscholtz, C. porcatus (Linnaeus) and C. zonatus Eschscholtz), Colombia ( $C$. bomplandii Guérin-Méneville and C. fabricii Erichson), Mexico, (C. approximatus Erichson, C. eschscholtzi Chevrolat, $C$. lafargi Chevrolat, C. pruinosus Erichson and C. silbermanni Chevrolat), United States (C. smaragdinus LeConte and $C$. webbi LeConte), and Antilles (C. obscurus Castelnau and $C$. sulcatus Fabricius). Besides the ERICHSON's (1841) synonyms, LACORDAIRE (l.c.) also considered as synonyms: C. limbatus Eschscholtz $(=C$. porcatus Olivier $=$ C. striatus Fabricius), $C$. silbermanni Chevrolat $(=C$. sericeus Erichson), and C. zonatus Eschscholtz (= var. smaragdulus $=$ C. costatus Dejean).

CANDĖZE (1857) redescribed the genus observing the arched body and "triangular scutellum" at the majority of species. He included a key for 31 species, separated in 4 sections based on, besides the scutellum and antennal shapes used by LACORDAIRE (l.c.), the length of $3^{\text {rd }}$ antennal segment. C. smaragdinus, which antennae were considered almost flabellate, and $C$. webbi were 
not included in the key nor in any section. Besides the synonyms presented by LACORDAIRE (l.c.), he also considered as synonyms: $C$. desmarestii Chevrolat $=C$. procerus Erichson, $C$. eschscholtzi Chevrolat $=C$. lafargei Chevrolat $=C$. mexicanus Dejean, $C$. gossipiatus Guérin-Meneville $=C$. erichsoni Guérin-Meneville, C. limbatus Eschscholtz $=C$. brullei Dejean $=C$. porcatus Dejean, $C$. obscurus Castelnau $=$ $C$. defloratus Dejean, C. porcatus (Linnaeus) $=C$. porcatus Fabricius $=C$. striatus Eschscholtz, $C$. sulcatus (Fabricius) $=$ C. sulcatus Eschscholtz, C. viridipilis (Say) $=C$. olivaceous Dejean $=C$. prasianus Erichson $=C$. viridipilis LeConte. CANDĖZE (1874) separated the 41 Chalcolepidius species, including 7 new species, into two sections. He put the species of the previous $2^{\text {nd }}$ and $3^{\text {rd }}$ sections in the same, considering that the length of $3^{\text {rd }}$ antennal segment did not justify the division. CANDĖze (1886), described seven new species and presented the geographical distribution and an identification key for 58 species, separated into three sections, according to the scutellar and antennal shapes. CANDĖzE (1890) described C. pistorius (Honduras), later synonymized under C. rugatus Candèze 1857 by CHAMPION (1894). CANDĖze (1891) catalogued 64 species separated into three sections, including new synonymizations: $C$. approximatus Erichson $=C$. longipennis Sturm, C. porcatus $($ Linnaeus $)=C$. guineensis $($ Linnaeus $)=C$. pulverulentus Herbst, and $C$. eschscholtzi Chevrolat was considered as a variation of $C$. lafargi Chevrolat. The Candèze's works represents the principal contribution to the knowledge of Chalcolepidius.

Gemminger \& Harold (1869) catalogued 32 species of Chalcolepidius and presented several variations, some of them in litt.

JANSON (1882) described Chalcolepidius buckley (Chuiguinda, Ecuador) and compared it with Chalcolepis luczoti Candèze, 1857. Later this species was synonymized under Chalcolepidius haroldi Candèze, 1878, that is herein excluded from the genus.

FleutiauX \& Sallé (1889) synonymized C. defloratus Dejean and C. Iherminieri Dupont under C. obscurus Castelnau. Fleutiaux (1911) treating of C. sulcatus Fabricius, C. obscurus Castelnau and $C$. porcatus Linnaeus, included $C$. validus Candèze as synonym of the first, and Elater guineensis Linnaeus, E. maximus Sulzer, E. pulverulentus Herbst and $E$. striatus Linnaeus as synonyms of $C$. porcatus.

Champion (1894) treating on 32 species (three new species) from Mexico and Central America, illustrated 27 of them with colored pictures. He also presented bibliographic catalogs, list of synonyms, discussion of diagnostic characters and geographical distribution for each species.

CASEy (1891) described C. apacheanus. CASEY (1907) studied the Chalcolepidius species with lateral margins of upper surface densely clothed with white or whitish setae, very numerous in Arizona and northern of Mexico. He presented an identification key, including 13 new species (C. abdominalis, C. acuminatus, C. amictus, C. arizonicus, C. aztecus, C. debilis, $C$. idoneus, $C$. nobilis, $C$. ostentus, $C$. rectus, $C$. simulans, $C$. sodalis, C. snowi) and new names for three of the CHAMPION's
(1894) illustrations: $C$. sonoricus for $C$. webbi (fig. 11.23), $C$. championi for $C$. virginalis variation (fig. 12.3) and $C$. brevicollis for $C$. desmaresti (fig.12.8). He considered $C$. substriatus Schwarz, 1906, as a variation of $C$. webbi LeConte, 1854, and C. parallelus Schwarz, 1906 a synonym of C. tartarus Fall, 1898. CASEY (1911) synonymized $C$. idoneus, $C$. abdominalis and $C$. arizonicus, described in 1907, under $C$. snowi Casey, 1907 and C. sodalis under C. aztecus Casey, 1907. The remainder species described by CASEY (1907) are herein synonymized.

SchWARZ (1906) redescribed the genus and presented a catalogue for 67 species divided into three groups, according to the scutellar and antennal shapes. He also presented colored illustrations for C. rubripennis and C. substriatus, the latter synonymized under $C$. webbi by Casey, 1907.

SCHENKLING (1925) and BlaCKWELDER (1944) catalogued respectively, 77 and 65 species to Chalcolepidius.

PJATAKOWA (1941) described eight species, but none type was located. It was possible to find specimens that fitted very well with the original descriptions of six of these species. $C$. alicii is herein removed from genus, and the following species are considered as synonyms: $C$. niger $=C$. approximatus Erichson, $C$. grossheimei $=C$. aurulentus Candèze, $C$. violaceous $=C$. chalcantheus Candèze, $C$. abbreviatovittatus $=C$. cyaneus Candèze, $C$. flavostriatus $=C$. porcatus. Any specimen corresponding to original description of C. costatus and C. fleutiauxi was studied.

GolBACH (1977), treating on the species from Central and South America of the third section of CANDÈzE (1857), studied 13 species, including an identification key, and described $C$. herbsti multistriatus, herein considered synonym of $C$. porcatus.

CASARI-CHEN $(1985,1994)$ presented a phylogenetic analysis for Hemirhipini genera and considered Lacais Fleutiaux, 1942 as sister-group of Chalcolepidius Eschscholtz, 1829.

\section{MATERIAL AND METHODS}

\section{Materials}

To the present work about 9,000 specimens were examined, belonging to the following institutions (curators parenthesized). The letters codes follow ARNETT et al. (1993) except for IAHC, ICNC, PCCV, SRGI. The codes DEIC, HMUG, HNHM and MCSN are used only in the type material informations and none specimen of these institutions were studied.

AMNH - American Museum of Natural History, New York, USA (L. Herman); BMHN - The Natural History Museum, London, United Kingdom (J.E. Beard, C.M. Hayek); CMNH Carnegie Museum of Natural History, Pittsburgh, Pennsylvania, USA (R.L. Davidson); DEIC - Institut fur Pflanzenschutzforschung, Eberswalde Finow, Gemany; DZUP - Departamento de Zoologia Universidade Federal do Paraná, Curitiba, Paraná, Brazil (G. Rosado Neto); EGRC - Edward G. Riley, Private Collection, Texas, USA; FSCA - Florida State Collection of Arthropods, Gainesville, Florida, USA (M.C. Thomas); HMUG 
- Glasgow University, Glasgow, United Kingdom; HNHM Hungarian Natural History Museum, Budapest, Hungary; IAHC - Instituto de Investigación de Recursos Biológicos Alexander von Humboldt, Vila de Leyva, Colombia (F. Fernández); IBSP Instituto Biológico, São Paulo, São Paulo, Brazil (S. Ide); ICNC - Instituto de Ciencias Naturales de la Universidad Nacional de Colombia, Santafé de Bogotá, Colombia (C. Martínez); IMLA Instituto Miguel Lillo, Tucuman, Argentina (A. L. Terán, R. Golbach); INPA - Instituto Nacional de Pesquisas da Amazônia, Manaus, Amazonas, Brazil (C. R. V. Fonseca); ISNB - Institut Royal des Sciences Naturelles de Belgique, Brussels, Belgium (J. Cools, P.Grootaert); IZAV - Instituto de Zoologia Agricola, Maracay, Aragua, Venezuela (L.J. Joly); JEWC - James E. Wappes Private Collection, Bulverde, Texas, USA; MCNZ Museu de Ciências Naturais, Porto Alegre, Rio Grande do Sul, Brazil (M.H.M. Galileo); MCSN - Museo Civico de Storia Naturale "Giacomo Doria", Genova, Italy; MCZC - Museum of Comparative Zoology, Cambridge, Massachusetts, USA (P.D.Perkins); MNHN - Museum National d'Histoire Naturelle, Paris, France (C. Girard); MNMS - Museo Nacional de Ciências Naturales, Madrid, Spain (C. Martín); MZSP - Museu de Zoologia da Universidade de São Paulo, São Paulo, Brazil; NHMW - Naturhistorisches Museum, Wien, Austria (P. Cate); OSUC - Ohio State University, Columbus, Ohio, USA (A.Sharkov); PCCV - Peter Cate Private Collection of Vienna, Vienna, Austria; SEMC - University of Kansas, Lawrence, Kansas, USA (R.Brooks); SRGI - Sergio Riese Private Collection, Genova, Italy; TAMU - Texas A\&M University, College Station, Texas, USA (E.G. Riley); UFPE - Universidade Federal de Pernambuco, Recife, Pernambuco, Brazil (R. C. Moura); UNAM - Universidad Nacional Autonoma, Mexico, Mexico (S. S. Fragoso); UFMT - Instituto de Biociências, Universidade Federal de Mato Grosso, Cuiabá, Mato Grosso, Brazil (R. D. Miyazaki); USNM - National Museum of Natural History, Smithsonian Institution, Washington, D.C., USA (D.G. Furth, Nathalia J. Vandenberg, G. House); ZMHB - Museum für Naturkunde der Humboldt Universitat, Berlin, Germany (M. Uhlig); ZMUC - Zoologisk Museum, Copenhagen University, Copenhagen, Denmark (O. Martin).

\section{Type Specimens}

During the preparation of this work, I have been in contact with Miss C. M. von Hayek (BMNH), who has studied the Chalcolepidius species about twenty years ago, and asked her for help, especially in regard to the type depositories. She kindly sent the drafts of her works that included important informations about several species of Chalcolepidius (including types depositories), and also some discussion on morphology and literature. Some of these precious informations are included herein as "Hayek, personal communication". The data of the not examined types were also taken from her drafts.

The type material of 65 species were examined, as follows (Institutions parenthesized): Chalcolepidius abdominalis Casey, 1907 (USNM), C. acuminatus Casey, 1907 (USNM), C. amictus Casey, 1907 (USNM), C. angustatus Candèze, 1857 (BMNH), C. apacheanus Casey, 1891 (USNM), C. approximatus Erichson, 1841 (ZMHB), C. arizonicus Casey, 1907 (USNM), C. attenuatus Erichson, 1841 (ZMHB), C. aurulentus Candèze, 1874 (BMNH), C. aztecus Casey, 1907 (USNM), C. behrensi Candèze, 1886 (ISNB), C. boucardi Candèze, 1874 (MNHN), C. brevicollis Casey, 1907(BMNH), C. chalcantheus Candèze, 1857 (BMNH), C. championi Casey, 1907 (BMNH), C. corpulentus Candèze, 1874 (BMNH), C. cuneatus Champion, 1894 (BMNH), C. cyaneus Candèze, 1881 (ISNB), C. debilis Casey, 1907 (USNM), C. desmarestii Chevrolat, 1835 (MNHN), C.dugesi Candèze, 1886 (ISNB), $C$. erichsonii Guérin, 1844 (MNHN), C. eschscholtzi Chevrolat, 1833 (MNHN), C. exulatus Candèze, 1874 (BMNH), C. fabricii Erichson, 1841 (ZMHB), C. forreri Candèze, 1886 (ISNB), $C$. fryi Candèze, 1874 (BMNH), C. gossipiatus Guérin, 1844 (MNHN), C. herbstii Erichson, 1841 (ZMHB), C. herbstii multistriatus Golbach, 1977, C. humboldti Candèze, 1881 (ISNB), C. idoneus Casey, 1907 (USNM), C. inops Candèze, 1886 (ISNB), C. jekeli Candèze, 1874 (MNHN), C. juani Candèze, 1889 (ISNB), C. lafargi Chevolat, 1835 (MNHN), C. lemoinii Candèze, 1857 (BMNH), C. lenzi Candèze, 1886 (ISNB), $C$. longicollis Candèze, 1857 (BMNH), C. mniszechi Candèze, 1881 (ISNB), C. monachus Candèze, 1893 (ISNB), C. morio Candèze, 1857 (BMNH), C. mucronatus Candèze, 1889 (ISNB), C. murinus Champion, 1894 (BMNH), C. nobilis Casey, 1907 (USNM), C. ostentus Casey, 1907 (USNM), C. oxydatus Candèze, 1857 (BMNH), C. perrisii Candèze, 1857 (MNHN), C. peruanus Candèze, 1886 (ISNB), C. pistorius Candèze, 1890 (ISNB), $C$. porcatus var. dimidiatus Candèze, 1874 (MNHN), C. prasianus Erichson, 1841 (ZMHB), C. procerus Erichson, 1841 (ZMHB), C. pruinosus Erichson, 1841 (ZMHB), C. rectus Casey, 1907 (USNM), C. rodriguezi Candèze, 1886 (ISNB), C. sericeus Erichson,1841 (ZMHB), C. scitus Candèze, 1889 (ISNB), C. silbermanni Chevrolat, 1835 (MNHN), C. simulans Casey, 1907 (USNM), C. snowi Casey, 1907 (USNM), C. sodalis Casey, 1907 (USNM), C. tartarus Fall, 1898 (MCNZ), C. tenuis Champion, 1894 (BMNH), C. virginalis Candèze, 1857 (MNHN).

The photos of the type specimens of $C$. porcatus (Linnaeus, 1767) (ZMUC) and C. sulcatus (Fabricius, 1777) (ZMUC) were also examined.

The data on the type material, examined or provided by other workers, are included next the catalogue of each species. To species that these data were not obtained, only the "Type locality" is included.

\section{Identification key}

The identification key for Chalcolepidius includes only 59 species; C. costatus Pjatakowa, 1941, C. fleutiauxi Pjatakowa, 1941, C. morio Candèze, 1857 and C. viriditarsus Schwarz, 1906 are not included because none specimens were obtained, except for the syntype of $C$. morio that was not in good conditions, especially its pubescence.

\section{Dissecting techniques, illustrations and descriptions}

The specimens were dissected following traditional techniques (BECKer 1956; CALDER 1996; CASARI-CHEN 1993). The aedeagus, female genitalia and genital segments of male 
and female were temporarily mounted on a slide with glycerin and drawn with the aid of a camera lucida attached to Wild M10 stereomicroscope or a Zeiss Oxioskop microscope, depending on the size of the structure. The pictures were taken with a Nikon Camera with a Micro Objective 62 or $220 \mathrm{~mm}$, under natural light.

The descriptions and redescriptions are presented in alphabetical order and the terminology follows CALDER (1996).

\section{Cladistic analysis}

The cladistic analysis includes only 59 species. The three species not examined, C. costatus Pjatakowa, C. fleutiauxi Pjatakowa and C. viriditarsus Schwarz, and C. mniszechi Candèze, were not considered in the analysis. The latter was not included because only a female syntype with destroyed abdomen was examined.

Fifty three characters are included in the analysis and a new interpretation of some of them are presented. The genera Alaus Eschscholtz, 1829, Chalcolepis Candèze, 1857 and Lacais Fleutiaux, 1942 are used as outgroups for characters polarizations.

The polarizations were made by the outgroup comparison method (Watrous \& WheEler 1981; Maddison et al. 1984; Nixon \& CARPENTER 1993), with Lacais Fleutiaux, 1942, Chalcolepis Candèze, 1857 and Alaus Eschscholtz, 1829, considered as outgroups. The analysis were performed with the computer program Hennig 86, v. 1.5 (Farris 1988) employing the $\mathrm{mh}^{*}, \mathrm{bb}^{*}$ algorithms, in its interface for Windows with Tree Gardner 2.2 (Ramos 1997). Clados, v. 1.2 (Nixon 1992) computer program was used for verifying the characters distribution. The branches nomenclature follows Amorim (1992, 1993).

\section{BIOLOGY AND HABITS}

Little is known on the habits of the adults of Chalcolepidius; they may be collected on foliage, flowers, trunks and ground. HAYEK (personal communication) has kept a female of $C$. bomplandii Guérin-Méneville, taken in Belize (Toledo District, Salamanco Camp) (16 17’N 8901W,31.iii.1982), alive in captivity, in BMNH for over nine months feeding on soft fruit such as apples and grapes. The author has kept a female of C. limbatus Eschscholtz, 1829, taken in Trinidad (July 1998), during six months feeding on syrup of honey and water.

FLeutiaux (1911) collected C. obscurus on orange tree, in wound of silk tree, Sapium aucuparium, known as "glutier des oiseleurs", and verified that this species is very common on flowers of flamboyant and on the tree trunks.

KIRK (1922) presented biological notes on Elateridae and Melasidae, assembled from his field observations, rearing, collections and notes, and from specimen labels in the collection of the Bureau of Plant Industry. He found that $C$. viridipilis (Rockville, Pennsylvania) was "collected at sour sap on oak tree in the evening" and C. smaragdinus (Tucson, Arizona) was reared from larva taken from "woodborer gallery in dead wood". According to him, the adults hibernate beneath bark, in crevices and in abandoned cells, and are sometimes attracted to light.

Some labels of the specimens examined in this work also included informations about the biology. Regarding to one female of C. aurulentus, from Moyabamba, Peru, it was found, "felled "Ajoquiru" tree called garlic tree; fresh timber of this tree has a strong odor which causes a headache to people that work this tree"; one female of C. mocquerysi from Andalucia, Colombia, "in cacao"; one female of C. rugatus from La Ceiba, Honduras, "found under bark of fallen panty decayed"; one female of C. smaragdinus, near Douglas, Arizona, "on Salix gooddingii" and a female and three males from Madera Canyon, Arizona, respectively, "on Prosopis chilensis" and "at sap ooze on mesquite"; one female of $C$. virens from Peru, Huanaco, Pozuzo, "on Ficus glabrata"; one female of $C$. viridipilis from Brazos Co., "on tanglefoot screen"; and two males of C. webbi from Yuma Co., "on Salix gooddingii Ball (willow)".

The larvae of Chalcolepidius are predaceous and usually confined to deciduous trees, feeding on woodboring larvae or termites. The author collected larvae of $C$. zonatus under the bark of decayed trunk in São Paulo state. The larvae were reared feeding on workers of termites and larvae of Tenebrionidae. Larvae of only five species were described: C. approximatus, C. corpulentus, C. erythroloma, C. viridipilis and C. zonatus.

DugÉs (1885) described, in detail, the larva of C. zonatus from Tupátaro, collected "dans le tronc pourri d'un Cazahuate". In fact, this larva belongs to C. approximatus.

Schiodte (1870) described, also in detail, the larva of $C$. erythroloma collected in Oahu "sub cortice arborum emortuarum". He also presented the illustrations of dorsal habitus, head ventral, hind leg, segments VIII-X (lateral view) and spiracle. XAMBEAU (1912) redescribed C. erythroloma.

Böving \& CRAigheAd (1931) presented the illustrations of hypostoma, nasal, mandible, head (lateral), segment IX (dorsal) and segments IX-X (lateral) of the larva of $C$. viridipilis.

BRUCH (1942) presented the descriptions and illustrations of larva, pupa and adult identified as Chalcolepidius limbatus, based on larvae collected in trunk of "palo borracho", Chorisia insignis Kth., and reared in laboratory. In this same trunk, it was also found larvae and pupae of Dryoctenes scrupulosus (Germar) (Cerambycidae) and Passalus (Passalidae), and the predator behavior was observed. Based on the picture of adult presented in that paper, it was concluded that it belongs to $C$. corpulentus.

Costa (1971) and Costa et al. (1988) redescribed the larva and pupa of $C$. zonatus.

The larvae of Chalcolepidius are characterized especially by: large size; body flattened dorsoventrally, yellow with head black and thoracic tergites and legs brown; head prognathous and strongly pigmented, with two longitudinal dorsal carinae, parallel lateral margins, bearing row of setae; mandibles without teeth; segment IX with bifid apex and many dorsal tubercles of varied sizes; segment $\mathrm{X}$ tubular and ventral bearing anal hooks.

Chalcolepidius Eschscholtz, 1829

Chalcolepidius Eschscholtz, 1829: 52; Castelnau, 1840: 237; Germar, 
1840: 276; Erichson, 1841: 77; Lacordaire, 1857: 154; Candèze, 1857: 258, 259; 1874: 160; 1886: 65; 1891: 37 (Cat.); Gemminger \& Harold, 1869: 1502 (Cat.); LeConte, 1883: 181; Champion, 1894: 272, 273; Schwarz, 1906a: 43, 44; Casey, 1907: 29; Fleutiaux, 1907: 172; Heyne-Taschenberg, 1908: 153; Blatchley 1910: 717; Schenkling, 1925: 54 (Cat.); Fleutiaux, 1926: 106 (Cat.); Blackwelder, 1944: 282 (Cat.); Casari-Chen, 1985: 394.

Type species: Chalcolepidius zonatus Eschscholtz, 1829 by subsequent designation (HysLoP 1921: 634).

Redescription. Large size (16-45 mm); usually robust and arched body. Integument clothed with very colorful metallic scale-like setae, frequently with lateral stripes on pronotum and/or elytra; first three segments of antennae of the same coloration of the general dorsal pubescence. Antennae usually serrate in both sexes, with 3rd segment triangular-elongate, shorter than 4 th. Pronotum longer than wide, usually wider at hind angles, narrowed apicad; lateral margins forming narrow an edge; hind angles usually slightly divergent, raised laterally forming edge continuous with that of lateral margins; moderately convex, convexity decreasing basad; posterior margin prominent and notched at middle; median basal tubercle usually flat and triangular-elongate. Notosternal sutures sinuate. Prosternum strongly convex, usually grooved laterally near sutures and flattened longitudinal medially. Borders of mesosternal cavity wide and horizontal at basal half or $2 / 3$ and declivous in variable degree on anterior half or $1 / 3$. Suture behind the mesosternal cavity absent or obsolete. Last visible sternite with apex rounded in male and truncate with fringe of modified (spatulate) setae in female. First three interstices usually joined and forming a flattened small tubercle at base.

Remarks. The Chalcolepidius species form a monophyletic group supported by four autapomorphies: 1) posterior margin of pronotum prominent and notched at middle, 2) notosternal sutures sinuous, 3) borders of mesosternal cavity wide and horizontal on basal $2 / 3$ or $3 / 4$ and declivous distally in variable degree, and 4) meso-metasternal suture, behind mesosternal cavity, absent or obsolete.

\section{CHECKLIST OF CHALCOLEPIDIUS SPECIES}

1. C. albisetosus sp.nov.

2. $C$. albiventris sp. nov.

3. C. angustatus Candèze, 1857

C. circumductus Candèze, 1857

4. C. apacheanus Casey, 1891

C. simulans Casey, 1907 syn. nov.

C. acuminatus Casey, 1907 syn. nov.

C. nobilis Casey, 1907 syn. nov.

5. C. approximatus Erichson, 1841

C. zonatus Dugès non Eschscholtz, 1829

C. longipennis Sturm, 1843

C. zonatus var. b Candèze, 1874

C. aztecus Casey, 1907 syn. nov.

C. sodalis Casey, 1907

C. niger Pjatakowa, 1941 syn. nov.
6. C. attenuatus Erichson, 1841

C. cuneatus Champion, 1894 syn. nov.

C. tenuis Champion, 1894 syn. nov.

7. C. aurulentus Candèze, 1874

C. porcatus var. dimidiatus Candèze, 1874

C. candezei Dohrn, 1881 syn. nov.

C. grossheimi Pjatakowa, 1941 syn. nov.

8. C. bomplandii Guérin-Méneville, 1844

C. juani Candèze, 1889

C. humboldti Candèze, 1881 syn. nov.

9. C. boucardi Candèze, 1874

10. C. chalcantheus Candèze, 1857

C. violaceous Pjatakowa, 1941 syn. nov.

11. C. copulatuvittatus sp. nov.

12. C. corpulentus Candèze, 1874

13. C. costatus Pjatakowa, 1941

14. C. cyaneus Candèze, 1881

C. scitus Candèze, 1889 syn. nov.

C. abbreviatovittatus Pjatakowa, 1941 syn. nov.

15. C. desmarestii Chevrolat, 1835

C. desmaretsii; Lacordaire, 1857 (error)

C. procerus Erichson, 1841

C. brevicollis Casey, 1907 syn. nov.

16. C. dugesi Candèze, 1886

17. C. erythroloma Candèze, 1857

C. albertsi Candèze, 1878

18. C. eschscholtzi Chevrolat, 1833

19. C. extenuatuvittatus sp. nov.

20. C. exulatus Candèze, 1874

21. C. fabricii Erichson, 1841

C. marginatus Sturm, 1843

C. fabricii var. a Candèze 1857

22. C. fasciatus sp. nov.

23. C. ferratuvittatus sp.nov.

24. C. fleutiauxi Pjatakowa, 1941

25. C. forreri Candèze, 1886

26. C. fryi Candèze, 1874

27. C. gossipiatus Guérin-Méneville, 1844

C. gossypiatus; Schenkling, 1925 (error)

C. erichsonii Guérin-Méneville, 1844 syn. nov.

C. lemoinii Candèze, 1857 syn. nov.

28. C. inops Candèze, 1886

C. murinus Champion, 1894 syn. nov.

29. C. jansoni Candèze, 1874

C. mucronatus Candèze, 1889 syn. nov.

30. C. lacordairii Candèze, 1857

C. lacordairii var. a Candèze 1857

C. lacordairei; Candèze, 1874

C. exquisitus Candèze, 1886 syn. nov.

C. monachus Candèze, 1893 syn. nov.

31. C. lafargi Chevrolat, 1835

32. C. lenzi Candèze, 1886

C. behrensi Candèze, 1886 syn. nov.

33. C. limbatus (Fabricius, 1777)

Elater striatus; Fabricius, 1801

Elater porcatus; Olivier, 1790

Elater porcatus; Herbst, 1801 
34. C. mexicanus Castelnau, 1836

35. C. mniszechi Candèze, 1881

36. C. mocquerysii Candèze, 1857

37. C. morio Candèze, 1857

38. C. obscurus Castelnau, 1836

39. C. oxydatus Candèze, 1857

C. jekeli Candèze, 1874 syn. nov.

40. C. porcatus (Linnaeus, 1767)

C. porcatus; Eschscholtz, 1829

Elater striatus Linnaeus, 1767

C. striatus; Eschscholtz, 1829

Elater maximus Sulzer, 1776

C. pulverulentus Herbst, 1786

C. guineensis Gmelin, 1788

C. peruanus Candèze, 1886 syn. nov.

C. flavostriatus Pjatakowa, 1941 syn. nov.

C. herbstii multistriatus Golbach, 1977 syn. nov.

41. C. proximus $\mathbf{s p . ~ n o v . ~}$

42. C. pruinosus Erichson, 1841

43. C. rodriguezi Candèze, 1886

44. C. rostainei Candèze, 1889

45. C. rubripennis LeConte, 1861

46. C. rugatus Candèze, 1857

C. pistorius Candèze, 1890

C. amictus Casey, 1907 syn. nov.

47. C. serricornis sp. nov.

48. C. silbermanni Chevrolat, 1835

C. aequinoctialis Castelnau, 1836

C. sericeus Erichson, 1841

49. C. smaragdinus LeConte, 1854

C. ostentus Casey, 1907 syn. nov.

C. rectus Casey, 1907 syn. nov.

50. C. spinipennis $\mathbf{s p . ~ n o v . ~}$

51. C. sulcatus (Fabricius, 1777)

C. herbstii Erichson, 1841 syn. nov.

52. C. supremus $\mathbf{s p . ~ n o v . ~}$

53. C. tartarus Fall, 1898.

C. parallelus Schwarz, 1906

54. C. truncuvittatus sp. nov.

55. C. validus Candèze, 1857 reval.

56. C. villei Candèze, 1878

57. C. virens (Fabricius, 1787)

C. perrisii Candèze, 1857 syn. nov.

58. C. virgatipennis sp. nov.

59. C. virginalis Candèze, 1857

C. championi Casey, 1907 syn. nov.

60. C. viridipilis (Say, 1825)

C. prasianus Erichson, 1841

C. debilis Casey, 1907 syn. nov.

61. C. viriditarsus Schwarz, 1906

62. C. webbi LeConte, 1854

C. substriatus Schwarz, 1906

C. snowi Casey, 1907

C. idoneus Casey, 1907

C. arizonicus Casey, 1907

C. abdominalis Casey, 1907
C. sonoricus Casey, 1907 syn. nov.

63. C. zonatus Eschscholtz, 1829

C. smaragdulus Eschscholtz, 1829

Elater porcatus Drury, 1837 non Linnaeus, 1767

Elater sulcatus Herbst, 1801 non Fabricius, 1777

C. longicollis Candèze, 1857 syn. nov.

Key for Chalcolepidius species (except C. costatus Pjatakowa, 1941, C. fleutiauxi Pjatakowa, 1941, C. morio Candèze, 1857 and C. viriditarsus Schwarz, 1906)

1. Scutellum strongly folded (Figs. 227-229, 232, 233, 235, $239,240,244,246,249,254,257,260,262,263,266$, 268-271), horizontal half subtrapezoidal and carinate anteriorly; parameres of aedeagus cleft laterodistally (Figs. 378-380, 382-385, 387-389, 391, $392,394,397,398-400,402,404,405,407,409,410$, $412,413,415-422)$

Scutellum declivous in variable degree (Figs. 225, 226, 230, 231, 234, 236-238, 241-243, 245, 247, 248, 250$253,255,256,258,259,261,264,265,267)$; parameres of aedeagus spearhead-like or cleft laterodistally (Figs. 377, 381, 386, 390, 393, 395, $396,401,403,406,408,411,414)$............................ 38

2 (1). Dorsal pubescence unicolor ......................................... 3

Dorsal pubescence bicolor . 13

3 (2). With interstices equal in width and height .................. 4 With interstices unequal in width and/or height ......... 8

4(3). Large size (28-48 mm); wide body (Figs. 44-46); pronotum rugose, wider at hind angles, narrowed apicad; antennae (Fig. 126) serrate in both sexes, $3^{\text {rd }}$ segment long; anterior and median tibiae of male bearing fringe of long cilia; general metallic pubescence blue, green, violet or brown; lateral cleft of parameres (Fig. 475) (slightly narrowed near apex, apex upwards and prominent ventrally C. lacordairii

Median size (25-34 mm); narrow body; pronotum elongate, subrectangular or subtrapezoidal; antennae of male strongly serrate, pectinate or flabellate; tibiae of male with short spines or fringe of cilia of variable length .5

5(4). Male antennae strongly serrate; pronotum subtrapezoidal

Male antennae pectinate or flabellate; pronotum subrectangular 7

6(5). Pronotum bright and smooth longitudinal medially; pubescence (Fig. 40) short, metallic brown; anterior and median tibiae of male bearing fringe of long cilia; lateral cleft of parameres (Figs. 473, 597 ) strongly narrowed dorsally giving rounded 
shape to dorsal margin, apex upwards more prominent ventrally; ovipositor short and narrow C. inops

Pronotum usually smooth; metallic pubescence (Figs. 13-16) green, blue or brown; anterior tibiae of male bearing fringe of short cilia; parameres of aedeagus (Fig. 385) wider ventrally; median lobe wider dorsally; lateral cleft of parameres (Fig. 465) widened and concave subapically; ovipositor short and wide (Figs. 584, 585) .... C. chalcantheus

7(5). Antennae of male (Fig. 105) pectinate; metallic pubescence (Fig. 12) gray, grayish-blue or greenish-blue, sometimes different color dorsally and ventrally; pronotum (Fig. 172) 1.4 times longer than wide, strongly convex with median basal tubercle indistinct; tibiae of male bearing row of spines; lateral cleft of parameres (Fig 464) parallel almost up to apex; apex prominent laterally and upwards C. boucardi

Antennae of male (Fig. 161) flabellate; metallic pubescence (Fig. 84) green-olive or bluish-green dorsally and ventrally; pronotum (Fig. 222) 1.2 times longer than wide, rectangular, moderately convex with median basal tubercle flat and triangular; anterior tibiae of male bearing fringe of short cilia; lateral cleft of parameres (Fig. 492) almost straight with upwards apex ....C. viridipilis

8(3). Interstices not forming ridges .... 9

Interstices forming ridges 10

9(8). Moderate size (22-44 $\mathrm{mm})$; interstices slightly unequal in width and height; metallic pubescence (Figs. 87-89) green, blue, brown or violet; pronotum coarsely punctuate; anterior and median tibiae of male bearing fringe of long cilia; apex of lateral cleft of parameres (Fig. 489) prominent dorsally C. virens

Large size $(42-45 \mathrm{~mm})$; wide body; interstices irregular and not well defined; metallic pubescence (Fig. 35) olive with violet reflex; male unknown .......... C. forreri

10(8). Arched body; general pubescence (Fig. 79) dull yellowish- or grayish-white; pronotum (Fig. 213) subtrapezoidal, wider at hind angles, narrowed apicad....................................................... . sulcatus

Body parallel, slightly narrower at apices of pronotum and elytra; general pubescence metallic; pronotum of variable shapes .. 11

11(10). Metallic pubescence (Fig. 65) grayish-blue, greenishblue or olive; pronotum (Fig. 204) subrectangular .. C.pruinosus Metallic pubescence olive or reddish-brown; pronotum subtrapezoidal, wider at hind angles; elytra wider at median third. 12

12(11). Pronotum (Fig. 210) wider basad, hind angles very wide; metallic pubescence (Fig. 75) olive-brown, brownish or grayish with silky and bright appearance; lateral cleft of parameres (Fig. 484) narrowed to subapical region, with apex widened and upwards; sclerotized rings of colleterial glands (Figs. 658) opened frontally

C. silbermanni

Pronotum (Fig. 200) strongly narrowed near hind angles base; hind angles divergent; pubescence (Fig. 56) brown, reddish-brown, violet-brown, violetgray or ferruginous; lateral cleft of parameres (Fig. 480) strongly narrowed near apex with apex rounded, widened laterally and upwards; sclerotized rings of colleterial glands (Fig. 650) closed. C. obscurus

13 (2). Pronotum unicolor, elytra bicolor ................................ 14

Pronotum bicolor, elytra variable 18

14(13). Elytral striae, and sometimes lower interstices, clothed with pubescence different from general coloration, but not forming lateral stripes; interstices unequal in width and, when clothed with different pubescence, also in height .................................. 15 Elytra with lateral stripes; interstices variable ............ 16

15(14). Metallic pubescence (Figs. 61-63) green, yellowishgreen, brown or violet-brown; dull pubescence ochraceus, yellow, yellowish-white or white on striae, and sometimes lower interstices; epipleura clothed with pubescence like ventral; lateral cleft of parameres (Fig. 481) wide with apex prominent laterally C. porcatus

Metallic pubescence (Figs. 7-9) grayish-blue, olivegreen, yellowish-green, green, brown, reddishbrown, brownish-wined, violet-brown, violetgreen or ferruginous; dull pubescence white, yellowish-white, ochre or ferruginous on striae, sometimes lower interstices and epipleura; lateral cleft of parameres (Fig. 462) narrowed to subapical region and strongly broadened at apex, more prominent ventrally

C. aurulentus

16(14). Lateral stripes of elytra ferruginous; interstices variable; general pubescence green or ochraceus .......... 17

Striae and lateral stripes of elytra white or yellowishwhite; interstices unequal in width; general pubescence (Figs. 19-21), including epipleura, violet-blue, greenish-blue, grayish-green or green C. cyaneus

17(16). General metallic pubescence (Fig. 30), including 
epipleura, olive-green, green or grayish-green; lateral stripes of elytra two or three interstices wide; striae sometimes clothed with ferruginous pubescence; interstices unequal in width; anterior and median tibiae of male bearing fringe of long cilia; lateral cleft of parameres (Fig. 471) slightly narrowed near apex with lateroapical sharpened angles .................................... C. fabricii

General pubescence (Figs. 37-39) ochraceus, sometimes paler ventrally; lateral stripes of elytra two or three interstices wide; sometimes striae and lateral elliptical weak stripes on pronotum clothed with ferruginous pubescence (Fig. 189); interstices unequal in width; anterior and median tibiae of male bearing fringe of long cilia; pubescence of tarsi metallic blue or green C. fryi

18(13). Pronotum with lateral stripes; elytra without lateral stripes ................................................................... 19

Pronotum and elytra with lateral stripes ..................... 22

19(18). Lateral stripes of pronotum $1 / 4$ of the pronotum width, with internal margin straight; interstices unequal in width and height

20

Pronotum with lateral stripes narrower than above or not reaching anterior margin .21

20(19). General metallic pubescence (Fig. 5) olive or olivebrown; opaque white pubescence on lateral stripes of pronotum, striae, lower interstices (except distal $2 / 3$ of $5^{\text {th }}$ ) and epipleura; anterior and median tibiae of male bearing fringe of long cilia; lateral cleft of parameres (Fig. 461) narrowed near apex, apex straight, prominent laterally and slightly upwards C. approximatus

General metallic pubescence (Fig. 67) green; reddishbrown pubescence on lateral stripes of pronotum (Fig. 206), elytra (except higher interstices) and epipleura. Male not examined C. rostainei

21(19). Large size (27-47 $\mathrm{mm})$, wide; general metallic pubescence (Fig. 83) brown or reddish-brown; lateral stripes of pronotum (Fig. 217) triangularelongate, not reaching anterior margin; white or yellowish-white pubescence on lateral stripes of pronotum and elytra (except higher interstices); epipleura variable; apex of lateral cleft of parameres (Fig. 487) strongly upwards with rounded angles C. validus

Median size (27-29 mm); general metallic pubescence (Figs. 90, 91) olive-gray; lateral stripes of pronotum (Fig. 220) narrow, widened at hind angles, sometimes reaching anterior margin; white pubescence on lateral stripes of pronotum, striae, lower interstices and epipleura (partially); lateral cleft of parameres (Fig. 491) narrowed near apex, flattened longitudinal medially, apex prominent dorsally, laterodistal angles rounded

C. virgatipennis sp. nov.

22(18). Moderately wide body, almost parallel; metallic pubescence bluish with lateral stripes on pronotum and elytra clothed with white pubescence; lateral stripes of pronotum bandlike with width variable

Wide arched body; coloration of metallic pubescence and lateral stripes of pronotum and elytra variable; stripes on pronotum of variable shape and size; pronotum wider at hind angles and gradually narrowed apicad; interstices unequal in width

23 (22). Pronotum longer than wide (1.15 times), narrowed on distal third, and slightly narrowed at hind angles base, strongly convex; lateral stripes of pronotum variable; $3^{\text {rd }}$ antennal segment long and triangular; interstices flat; striae marked only by row of coarse punctures; lateral stripes of elytra variable; lateral cleft of parameres narrowed at apex 24

Pronotum longer than wide (1.25 times), subrectangular, slightly narrowed on distal $1 / 3$ and moderately convex, lateral margins slightly sinuous; $3^{\text {rd }}$ antennal segment (Fig. 153) short and triangular; lateral stripes of pronotum (Fig. 215) approximately $1 / 4$ of the pronotum width, slightly narrowed to apex, with internal margin semi-elliptical; metallic pubescence (Fig. 81) blue; lateral stripes of elytra two interstices wide; white pubescence on lateral stripes of pronotum and elytra, epipleura, hypomera and lateral third of sternites; interstices equal, slightly convex; lateral cleft of parameres (Fig. 486) strongly constricted near apex, distal angles rounded .....

C. tartarus

24(23). General metallic pubescence (Fig. 4) violet-blue, brownish-violet or brown; lateral stripes on pronotum (Fig. 167) narrow (approximately $1 / 4$ of pronotum width) and with internal margin semielliptical; lateral stripes of elytra two interstices wide; white pubescence on lateral stripes of pronotum and elytra and epipleura; $3^{\text {rd }}$ antennal segment (Fig. 100) triangular elongate; anterior third of mesosternal cavity (Fig. 275) almost vertical forming L-shaped profile; lateral cleft of parameres (Fig. 460) narrowed at apex

C. apacheanus

General metallic pubescence (Fig. 94) blue; lateral stripes on pronotum (Fig. 223) usually wide (wider than $1 / 3$ of pronotum width) with internal margins irregular (usually sinuous); lateral stripes of elytra 
three interstices wide; white pubescence on lateral stripes of pronotum, epipleura and basal region and lateral stripes of elytra; $3^{\text {rd }}$ antennal segment (Fig. 162) triangular elongate; anterior third of mesosternal cavity (Fig. 311) strongly declivous forming inclined profile; lateral cleft of parameres (Fig. 493) strongly narrowed at apex, prominent and upwards dorsally ............. . webbi

25(22). General pubescence (Figs. 69-72) white dorsally and ferruginous ventrally; lateral stripes of pronotum (Fig. 208) and elytra ferruginous, reduced or absent; when present, lateral stripes of pronotum band-like narrowed at extremities not reaching hind angles, and lateral stripes of elytra three or four interstices wide; lateral cleft of parameres (Fig. 483) wide with apex prominent ventrally C. rugatus

Dorsal coloration of general pubescence like ventral; lateral stripes of pronotum band-like of variable width; interstices unequal in width and height

26

26(25). Median size (22-42 mm); lateral stripes of pronotum band-like; lateral stripes of elytra three or four interstices wide; interstices unequal ................. 27

Large size (29-46 mm); wide and arched body; shape and size of lateral stripes of pronotum variable; lateral stripes of elytra three or four interstices wide; interstices equal 28

27 (26). General metallic pubescence (Figs. 49, 50) olive-green, olive-gray, olive-brown, bluish or violet; lateral stripes of pronotum (Fig. 192) with internal margin semi-elliptical; lateral stripes of elytra complete, three interstices wide; white, yellowish-white or ochraceus pubescence on lateral stripes of pronotum and elytra, striae and epipleura; lateral cleft of parameres (Fig. 477) slightly narrowed apicad, apex prominent laterally and upwards C. limbatus

General metallic pubescence (Fig. 54) grayish-green or olive; stripes of pronotum (Fig. 198) $1 / 4$ of pronotum width at base and narrowed apicad with internal margin semi-elliptical; lateral stripes of elytra three interstices wide, only on anterior half; white pubescence on lateral stripes of pronotum and elytra and striae; epipleura with coloration like ventral pubescence; lateral cleft of parameres (Fig. 478) constricted near apex, apex widened forming rounded prominent angles, more prominent ventrally ......

C. mocquerysii

28(26). General metallic pubescence (Figs. 10, 11) olive, grayish-blue, grayish-green, green, bluish-green, dark-brown or violet; lateral stripes of pronotum
(Fig. 171) approximately $1 / 4$ of pronotum width basally, sometimes emarginated internally near hind angles base, and slightly narrowed apicad; lateral stripes of elytra three or four interstices wide; yellow, yellowish-white or ochraceus pubescence on lateral stripes of pronotum and elytra and striae; coloration of epipleura like ventral pubescence; lateral cleft of parameres (Fig. 463) slightly narrowed near apex, angles prominent and sharpened C. bomplandii

Dorsal general pubescence with different coloration from above; lateral stripes of pronotum reduced or rarely band-like .29

29(28). Pronotum (Fig. 166) very long, sub-rectangular, slightly narrowed on anterior half, coarsely punctuate and strongly convex; lateral stripes of pronotum narrow, sub-elliptical, not reaching base; lateral stripes of elytra three interstices wide; white pubescence (Fig. 3) on lateral stripes of pronotum and elytra; interstices unequal in width; lateral cleft of parameres (Fig. 459) with apex flattened forming two laterodistal teeth, the dorsal upwards C. angustatus

Pronotum wider at hind angles, gradually narrowed anteriad; lateral stripes of pronotum and elytra variable; interstices unequal in width and height 30

30 (29). General pubescence metallic or dull; stripes of pronotum band-like narrowed at extremities or elliptical; epipleura coloration like ventral pubescence .. 31

General pubescence metallic; lateral stripes of pronotum band-like, moderately narrow or wide; epipleura coloration white .36

31 (30). Arched body; pronotum slightly convex and rugose; epipleura coloration like ventral pubescence; lateral stripes of pronotum narrow, reddish-brown or white. 32

Almost parallel; pronotum moderately convex, finely punctuate with coarse punctures scattered on lateroanterior third; epipleura white; lateral stripes of pronotum band-like narrow or elliptical ....... 33

32(31). General metallic pubescence (Fig. 27) green or yellowish-green; lateral stripes of pronotum (Fig. 180) narrowed at extremities, not reaching basal margin; lateral stripes of elytra three interstices wide; reddish-brown pubescence on lateral stripes of pronotum and elytra; lateral cleft of parameres (Fig. 470) slightly narrowed near apex; apex straight, prominent ventrally and upwards C. eschscholtzi

General metallic pubescence olive or grayish-green; lateral stripes of pronotum narrowed at extremities 
or widened at base; lateral stripes of elytra three interstices wide; white or yellowish-white pubescence on lateral stripes of pronotum and elytra; lateral cleft of parameres almost straight with apex prominent ventrally and slightly upwards. (Figs. 47, 194, 476)

C. lafargi

33 (31). General pubescence (Figs. 31, 32) metallic olive-brown; lateral stripes of pronotum (Fig. 184) band-like, $1 / 4$ of pronotum width at base, narrowed apicad, not reaching anterior margin; lateral stripes of elytra one interstice wide; white pubescence on lateral stripes of pronotum and elytra and epipleura; lateral cleft of parameres (Fig. 472) slightly widened near middle; subapical region flatened and contricted laterally; distal margin rounded and upwards C. fasciatus sp.nov.

General pubescence metallic green or dull white; lateral stripes of pronotum elliptical and ferruginous 34

34(33). General pubescence green; lateral stripes of pronotum ferruginous, sometimes white 35

General pubescence (Figs. 25, 26) white, yellowishwhite or grayish-white; lateral stripes of pronotum (Fig. 179) narrow, not reaching extremities and distant from lateral margins; lateral stripes of elytra two or three interstices wide; ferruginous or orange pubescence on lateral stripes of pronotum and elytra; lateral cleft of parameres (Fig. 469) slightly narrowed near apex; apex slightly notched and concave longitudinally C. erythroloma

35(34). General metallic pubescence (Figs. 85, 86) green, olivegreen, yellowish-green or grayish-green; lateral stripes of pronotum (Figs. 218, 219) wide, approximately $1 / 4$ of pronotum width, not reaching hind angles (2/3 of pronotum length); lateral stripes of elytra four interstices wide; pubescence ferruginous or orange on lateral stripes of pronotum and elytra; epipleura coloration like ventral pubescence; lateral cleft of parameres (Fig. 488) slightly narrowed near apex; apex rounded, prominent ventrally and upwards C. villei

General pubescence (Figs. 92, 93) metallic grayishgreen or olive-green dorsally and dull white ventrally; lateral stripes of pronotum (Fig. 221) narrow, widened basally; lateral stripes of elytra variable in width; white pubescence on lateral stripes of pronotum and elytra, striae and sometimes lower interstices; lateral cleft of parameres (Fig. 490) short with inclined apex forming a ventrodistal tooth C. virginalis
36(30). General dorsal metallic pubescence green, olive-green, brownish-olive, bluish-gray or violet-brown; lateral stripes of pronotum band-like, $1 / 4$ of pronotum width at base and slightly narrowed apicad; lateral stripes of elytra present or absent .37

General metallic pubescence (Fig. 18) olive, wine-red, violet or green; lateral stripes of pronotum (Fig. 176) band-like, wide, $1 / 3$ of pronotum width; lateral stripes of elytra four interstices wide; yellowishwhite pubescence on lateral stripes of pronotum and elytra, striae, sometimes lower interstices and epipleura; lateral cleft of parameres (Fig. 466) narrowed at subapical region with apex prominent laterally and upwards ... C. corpulentus

37 (36). Lateral stripes of elytra two interstices wide; white pubescence (Fig. 96) on lateral stripes of pronotum (Fig. 224) and elytra, striae and sometimes lower interstices and epipleura; ventral pubescence like general dorsal; lateral cleft of parameres (Fig. 494) narrowed at subapical region with apex prominent laterally and upwards C. zonatus

Lateral stripes of elytra absent; white pubescence (Fig. 64) on lateral stripes of pronotum (Fig. 203), basal region of elytra and lower interstices; ventral pubescence white C. proximus sp. nov.

38(1). Scutellum declivous in variable degree; subapical region of parameres of aedeagus cleft .............. 39

Scutellum declivous in variable degree; subapical region of parameres of aedeagus spearhead-like

39(38). Scutellum (Figs. 236, 237) pentagonal and slightly declivous; subapical region of parameres of aedeagus cleft; pronotum (Fig. 174) more strongly convex longitudinal medially forming ridge, and with fore angles wide and rounded; fore tibiae of male abruptly dilated at apex; general pubescence (Figs. 22, 23) ferruginous or orange; sometimes higher interstices and/or not a rounded patch near middle of each elytra clothed with black pubescence; lateral cleft of parameres (Fig. 468) strongly narrowed on distal third with apex rounded and upwards C. desmarestii

Scutellum strongly declivous with anterior half almost vertical and horizontal basal area triangular .... 40

40 (39). Integument (Fig. 68) bicolor, black with wined-red elytra; general metallic pubescence green or blue, except elytra violet; antennae (Fig. 143) serrate in both sexes; pronotum (Fig. 207) strongly convex, narrowed anteriad and hind angles base; lateral 
margins of pronotum sinuous; lateral cleft of parameres (Fig. 482) narrowed apicad, apex rounded and upwards .................... C. rubripennis Integument unicolor; antennae of male serrate or not; pronotum almost rectangular. . .41

41 (40). General pubescence (Fig. 76) metallic green, yellowishor bluish-green; antennae of male (Fig. 148) flabellate; pronotum sub-rectangular narrowed on anterior fourth; lateral cleft of parameres (Fig. 485) constricted near apex, apex upwards, strongly prominent laterally forming sharpened angles ... C. smaragdinus

General metallic pubescence (Figs. 41-43) green, olive or yellowish-, grayish- or bluish-green; antennae of male (Fig. 125) serrate; pronotum (Fig. 190) with hind angles divergent; lateral cleft of parameres (Fig. 474) short, constricted subapically with apex narrow, rounded and upwards C. jansoni

42(38). Scutellum strongly declivous, folded at middle with basal half elliptical, horizontal and prominent medioposteriorly and anterior half almost vertical .... 43

Scutellum with shape and declivity different from above .47

43 (42). Horizontal elliptical area of scutellum with anterior margin forming weak ridge; dorsal pubescence (Figs. 51, 52) unicolor in male and bicolor in female; dorsal general metallic pubescence olivebrown; ventral general pubescence white or yellowish-white; when present, lateral stripes of pronotum (Fig. 195) band-like, narrower than $1 / 4$ of pronotum width, with internal margin semielliptical; lateral stripes of elytra two interstices wide; dorsal white or yellowish-white pubescence, when present, on basal region of pronotum and anterior margin of elytra of male, and lateral stripes of pronotum and elytra and striae in female; median basal tubercle of pronotum elongate and flattened .....C. mexicanus

Horizontal area of scutellum without anterior ridge; general pubescence of both sexes and both sides of the same color; unicolor or bicolor dorsally; median basal tubercle elongate or transverse

.44

44(43). Horizontal elliptical area of scutellum without concavities; integument reddish-brown (Fig. 66) clothed dorsally and ventrally with golden pubescence; median basal tubercle of pronotum (Fig. 205) elongate ..... C. rodriguezi

Scutellum variable; integument black; general dorsal pubescence unicolor; median basal tubercle of pronotum flat and transverse 45

45 (44). Pubescence (Fig. 48) grayish-green, grayish or bluishgreen; pronotum (Fig. 193) narrowed anteriorly and hind angles base; lateral margins of pronotum rounded with hind angles divergent; lateral carina of hind angles well marked; interstices flat; tibiae of male spiny ... ..C. lenzi

General dorsal pubescence bicolor; pronotum different from above; interstices unequal in width and height; general metallic pubescence green ...... 46

46(45). General metallic pubescence (Figs. 73, 74) yellowishgreen dorsally and ventrally; lateral stripes of pronotum and elytra present or absent; when present, lateral stripes of pronotum (Fig. 209) band-like and narrow, clothed with iridescent reddish pubescence; interstices unequal C. serricornis sp. nov.

General pubescence (Fig. 2) metallic green dorsally and dull yellowish-white ventrally; lateral stripes of pronotum (Fig. 165) band-like and narrower than $1 / 4$ of pronotum width (wider at base); lateral stripes of elytra two interstices wide; lateral stripes of pronotum and elytra clothed with white pubescence C. albiventris sp. nov.

47 (42). Scutellum strongly declivous, horizontal basal area elliptical.....

Scutellum moderate- or slightly declivous . .48

48 (47). Integument (Fig. 24) dark-brown with reddish-brown elytra; general pubescence brownish dorsally and white ventrally; antennae of male (Fig. 112) pectinate; posterior margin of scutellum notched at middle . C. dugesi

Integument dark-brown or black; general pubescence green; antennae of male serrate or strongly serrate; posterior margin of scutellum entire ... 49

49(48). Antennae of male (Fig. 115) serrate; general pubescence (Fig. 28) green; lateral stripes of pronotum (Fig. 181) reduced to small triangular area on hind angles, clothed with white pubescence; sclerotized rings of colleterial glands (Fig. 637) U-shaped; bursa copulatrix with wide longitudinal band with carina and spines (Fig. 590) ............................ C. extenuatuvittatus sp. nov.

Antennae of male (Fig. 116) strongly serrate; general pubescence greenish (Fig. 29) lateral stripes of pronotum (Figs. 116, 182) band-like, not reaching anterior margin; hind angles of pronotum divergent; median basal tubercle elongate; scutellum (Fig. 241) strongly declivous; horizontal area sub-elliptical, prominent medioposteriorly; female not examined 
C. exulatus

50 (47). Scutellum pentagonal and moderately declivous on anterior half; horizontal basal area wider and declivous 51 Scutellum pentagonal and slightly declivous on anterior half; horizontal basal area wider and rounded 54

51(50). General pubescence unicolor or bicolor, pronotum without lateral stripes ........................................... 52

General pubescence bicolor, lateral stripes of pronotum and elytra ferruginous ..... .53

52(51). Unicolor; general metallic pubescence (Figs. 57-60) green, blue, or violet; $3^{\text {rd }}$ antennal segment (Fig. 136) short and triangular; hind angles of pronotum (Figs. 201) divergent; interstices convex and unequal in width ..... C. oxydatus

Uni- or bicolor; general pubescence (Fig. 36) dull white, yellowish-white or ochraceus or metallic olive; lateral stripes of elytra three interstices wide; when clothed with metallic pubescence, striae and lateral stripes of elytra clothed with ochre or orange pubescence; when clothed with dull pubescence, striae and lateral stripes of elytra clothed with same color as general pubescence, only slightly denser and/or darker; antennae of male (Fig. 122) strongly serrate; interstices convex and unequal in width and height ...C. gossipiatus

53 (51). General metallic pubescence (Figs. 77, 78) green; lateral stripes of pronotum (Fig. 212) band-like, not reaching basal margin and emarginated internally near basal extremity; lateral stripes of elytra three interstices wide; ferruginous setae on lateral stripes of pronotum and elytra

C. spinipennis sp. nov.

General pubescence (Fig. 1) grayish-white; lateral stripes of pronotum (Fig. 164) narrow, elliptical, not reaching margins; ferruginous pubescence on lateral stripes of pronotum, interstice VIII and distal half of VII C. albisetosus sp.nov.

54 (50). Small size (16-29 mm) and narrow; general pubescence (Fig. 6) olive or brownish dorsally and ventrally or grayish ventrally; antennae (Fig. 102) strongly serrate in male; striae marked by row of coarse punctures; interstices equal and moderately convex C. attenuatus

Larger size $(30 \mathrm{~mm})$ and wider; unicolor or bicolor dorsally. .55

55 (54). Unicolor; general metallic pubescence (Fig. 80) olive; pronotum (Fig. 214) slightly narrowed apicad with hind angles slightly divergent; median basal tubercle flat and elongate .... C. supremus sp. nov.

Bicolor, lateral stripes of pronotum band-like or elliptical; hind angles of pronotum strongly divergent; median basal tubercle elongate ...... 56

56(55). General pubescence (Figs. 33, 34) metallic green; lateral stripes of pronotum (Fig. 185) narrow, elliptical, not reaching margins; ferruginous pubescence on lateral stripes of pronotum, interstice IX and distal half of striae VII .

C. ferratuvittatus sp. nov.

General pubescence metallic or dull; lateral stripes of pronotum band-like and white. .57

57(56). Lateral stripes of pronotum fused basally; other characters different from below ...........................58

Lateral stripes of pronotum (Fig. 216) separate basally; general pubescence (Fig. 82) metallic olive; lateral stripes of pronotum band-like, narrower than $1 / 4$ of pronotum width, curved inwards basally and not reaching hind angles apex; lateral stripes of elytra three interstices wide; white pubescence on lateral stripes of pronotum and elytra and striae; $3^{\text {rd }}$ antennal segment (Fig. 154) short and triangular C. truncuvittatus sp.nov.

58(57). Integument reddish-brown; general metallic pubescence (Fig. 17) brownish-olive; lateral stripes of pronotum (Fig. 175) band-like, approximately $1 / 4$ of pronotum width, sinuous at internal margin and fused at base; white pubescence on lateral stripes of pronotum, striae, lower interstices (partially) and epipleura; $3^{\text {rd }}$ antennal segment (Fig. 107) short and triangular C. copulatuvittatus sp.nov.

Integument black; general pubescence (Fig. 53) dull yellowish-white with metallic olive pubescence on median region of pronotum and interstices IVII; lateral stripes of pronotum (Fig. 197) bandlike with internal margin not well defined and fused basally; $3^{\text {rd }}$ antennal segment (Fig. 134) short and triangular C. mniszechi

\section{Chalcolepidius albisetosus sp. nov.}

(Figs. 1, 97, 164, 225, 272, 313, 353, 377, 676)

Type material. Holotype male: "M; Equateur Chimbo[razo] M. de Mathan 1er Semestre 1892; Chalcolepidius gossipiatus group Pto CMF von Hayek det. 1980 [under side of label:] note similarity of markings to erythroloma; Muséum Paris"(MNHN).

Holotype. Length: $35 \mathrm{~mm}$. Integument black clothed dorsally and ventrally, including legs, with grayish-white pubescence with very few metallic brownish setae dispersed among them; pronotum with two lateral brown elliptical stripes near lateral margins, not reaching extremities; brown setae clothing interstice VIII and distal half of VII; antennae clothed with very 
short black setae with reddish iridescence, except three first segments white (Fig. 1).

Frons narrow with distal third trapezoidal; small-punctuate with slightly coarser sparse punctuation; slightly concave medioanteriorly; nasal plate high, heterogeneous- and coarsely punctuate. Antennae (Fig. 97) strongly serrate, surpassing posterior margin of procoxae; $3^{\text {rd }}$ segment wider, triangular, shorter than $4^{\text {th }}$. Pronotum (Fig. 164) longer than wide, almost parallel, slightly narrowed apicad, from hind angles apex; anterior margin prominent and slightly emarginated at middle; lateral margins forming narrowed raised edge, on basal $2 / 3$; hind angles slightly divergent, wide with truncate apex, raised laterally forming an edge slightly wider than that of lateral margins; strongly convex; small-punctuate with slightly coarse punctuation sparsely and irregularly dispersed; median basal tubercle elongate, flat; posterior margin prominent and slightly notched at middle. Hypomera concave, small and densely punctuate; prosternal channel absent. Notosternal sutures slightly sinuous. Prosternum convex from sutures, flat between procoxae; small and densely punctuate, with some slightly coarser punctures near sutures. Prosternal lobe transverse, marginated laterally with angles slightly rounded; punctuation slightly coarser than that of prosternum. Scutellum (Fig. 225) strongly declivous on anterior half; horizontal area elliptical with two rounded concavities. Mesosternal cavity U-shaped with borders (Fig. 272) thick, horizontal and prominent on basal $2 / 3$ and moderately declivous on distal $1 / 3$, forming semielliptical profile. First visible sternite not prominent laterally; last visible sternite with two lateromedian rounded depressions. Tibiae of male bearing irregular row of spines internally. Striae grooved, marked by coarse punctures; interstices convex, densely small-punctuate and unequal; interstices II and III raised and fused at base, forming flattened tubercle; apices conjointly rounded with sutural spine.

Male genital segments and aedeagus. Tergite VIII wider than long, slightly narrowed apicad; anterior margin rounded; basal margin moderately notched; densely setous. Sternite VIII (Fig. 313) transverse, anterior margin strongly prominent at middle; translucent with three melanized areas. Sternite IX subelliptical, melanized on distal half except distal band. Tergite IX (Fig. 353) transverse, slightly narrowed apicad with anterior margin moderately notched at middle; densely punctuate; moderately long setae on laterodistal margins. Aedeagus (Fig. 377): three times longer than wide; apex of parameres spearheadlike; median lobe wide, 0.54 times aedeagus length, slightly constricted near middle, gradually narrowed apicad.

Female unknown.

Remarks. Chalcolepidius albisetosus sp. nov. is characterized by integument clothed with white setae; lateral stripes on pronotum (elliptical) and elytra brown; scutellum strongly declivous on anterior half and apex of parameres spearhead-like. It is similar to C. erythroloma Candèze in color but they differ especially by scutellum and aedeagus shapes. It resembles $C$. ferratuvittatus sp. nov. in shape (see remarks after the latter).
It belongs to albisetosus + group (Fig. 671).

Distribution. It is recorded from Ecuador (Chimborazo).

Etymology. The epithet is derived from the latin words albus + setosus, related to dorsal and ventral pubescence.

\section{Chalcolepidius albiventris sp. nov.}

(Figs. 2, 98, 165, 226, 273, 675)

Type material. Holotype female: "Mexico Soteapan (Veracruz) $300 \mathrm{~m}$. X.1985 T. Porion”(MZSP retained SRGI).

Holotype. Length: $39 \mathrm{~mm}$. Integument black clothed dorsally with metallic short scale-like setae green and ventrally, with longer and dull yellowish-white setae; lateral stripes of pronotum band-like, narrower than $1 / 4$ of pronotum width, reaching anterior and posterior margins, clothed with yellowish-white setae; yellowish-white setae at base and lateral stripes of elytra (two interstices wide), epipleura (partially), procoxae and trochanters; tibiae and tarsi with green setae; tibiae with small irregular areas with yellowish-white setae; antennae clothed with blue with iridescent red setae, except three first segments green (Fig. 2).

Frons trapezoidal on distal $1 / 3$, concave on anterior triangular area; small-punctuate with coarse sparse punctuation. Nasal plate high and coarsely punctuate. Antennae (Fig. 98) serrate; $3^{\text {rd }}$ segment very short with spiniform appendix. Pronotum (Fig. 165) longer than wide, slightly narrowed apicad from hind angles base, strongly narrowed frontally; anterior margin slightly prominent and sinuous at middle; anterior angles prominent; lateral margins raised laterally in small bright area forming narrow edge; inner edge widely grooved; moderately convex; small-punctuate; moderately coarse punctuation on anterior third, sparser at middle; hind angles slightly divergent, raised laterally forming an edge slightly wider than that of lateral margins; posterior margin strongly prominent and slightly notched at middle; median basal tubercle flat and elongate. Hypomera concave, small-punctuate, not forming anterior channel. Notosternal sutures slightly sinuous. Prosternum moderately convex from sutures; densely small-punctuate. Prosternal lobe with rounded angles, anterior margin slightly notched at middle; punctuation coarser and sparser than prosternum. Scutellum (Fig. 226) strongly declivous, anterior half vertical; horizontal area sub-elliptical, grooved at middle with two lateral rounded concavities, and anterior margin prominent forming two lobes. Mesosternal cavity sub-elliptical with borders (Fig. 273) thick, horizontal on anterior $2 / 3$, and moderately declivous on distal $1 / 3$ forming semi-elliptical profile. First visible sternite not prominent laterally. Tibiae spiny internally. Striae grooved formed by row of coarse punctures; interstices unequal and small-punctuate; $2^{\text {nd }}$ and $3^{\text {rd }}$ interstices fused forming flattened basal tubercle; apices conjointly rounded; lateral margins not marginated.

Male unknown.

Remarks. Chalcolepidius albiventris is characterized especially by general dorsal pubescence green with white lateral 
stripes on pronotum and elytra, ventral pubescence white and scutellum strongly declivous. The holotype is partially glabrous dorsally with antennae partially broken.

C. albiventris belongs to serricornis + group; it is the sistergroup of C. exulatus (Fig. 671).

Distribution. It is recorded from Mexico (Veracruz) (Fig. 675).

Etymology. The epithet is derived from one of the latin words for white color, albidus, related to ventral pubescence.

Chalcolepidius angustatus Candèze, 1857

(Figs.. 3, 99, 166, 227, 274, 378, 423, 459, 686)

Chalcolepidius angustatus Candèze, 1857: 290, fig. 4; Gemminger \& Harold, 1869: 1502 (Cat.); Candèze, 1874: 169; 1886: 74; 1891: 39 (Cat.); Champion, 1894: 282; Schwarz, 1906a: 46; Blackwelder, 1944: 282 (Cat.). Syntype male: "Syntype; Type; Mexico Oaxaca; B. C. A. Col. III (1). Chalcolepidius angustatus circumductus; Chalcolepidius angustatus M. Type Cdze ex coll. Lacordaire [glued underside:] C. angustatus Nob." (BMNH) (examined).

Chalcolepidius circumductus Candèze, 1857: 289; Gemminger \& Harold, 1869: 1502 (Cat.); Candèze, 1874: 169; 1886: 74; 1891: 38 (Cat.); Champion, 1894: 282 (Syn.); Schwarz, 1906a: 42. Holotype female: "Mexico; Chalcolepidius circumductus Cdz F Type ex coll. Deyrolle [Janson] circumdatus [Candèze, stuck to underside of Janson's label]; B.C.A. Coll. III (1) Chalcolepidius angustatus C. circumductus C. angustatus [Champion] (BMNH) (not examined).

CAndèze (1857) described C. circumductus, based on a female, in the next page of C. angustatus, based on two males.

Champion (1894), as first reviser, considered C. circumductus as a junior synonym of $C$. angustatus. He observed that the setae were "olive-green with luteous bands" in the former and grayish with lateral bands almost white in the latter. Besides, the alternate elytral interstices are broader and more raised in C. circumductus, but according to him, "too much importance must not be placed on this character". Probably these differences are related to the sex, since the females are larger.

SCHWARZ (1906) listed both species but expressed some doubts about the validity of these species including after $C$. angustatus " = C. circumductus Cand."

SCHENKLING (1925) had not considered the "action of the first reviser"(ICN Art. 24a) of CHAMPION (l. c.) and considering the page number of original descriptions, catalogued $C$. angustatus as junior synonym of $C$. circumductus.

BLACKWELDER (1944) followed CHAMPION (1894).

Here, the position of Champion $(l . c$.) is followed and $C$. circumductus is kept as junior synonym of $C$. angustatus.

Length: 33-35 mm. Integument black, clothed dorsally and ventrally with metallic green pubescence; lateral stripes of pronotum narrowed at extremities, not reaching posterior margin of pronotum; lateral stripes of elytra three interstices wide; yellowish-white pubescence on lateral stripes of pronotum and elytra. Ventral pubescence, including legs, olive-green (Fig. 3).

Frons not carinate, moderately concave medioanteriorly; fore angles raised and prominent; punctuation slightly coarse and sparse and heterogeneously scattered among small, weak and dense punctuation. Antennae (Fig. 99) of male serrate, third segment triangular-elongate slightly shorter than fourth, prominent laterally. Pronotum (Fig. 166) longer than wide, subrectangular, slightly narrowed on anterior half; strongly convex frontally; convexity starting at lateral external border of white lateral stripes, decreasing basad; hind angles wide, backward, raised laterally; lateral margins forming edge on basal 2/3, continuous with that of lateral edge of pronotum; punctuation small and dense, intermingled with moderately coarse and sparse on median area, density decreasing basad; median basal tubercle flat, triangular; posterior margin prominent and strongly notched at middle. Hypomera concave near lateral margins; laterointernal margins raised forming wall of anterior channel. Notosternal sutures strongly sinuous. Prosternum weakly micropunctuate, strongly convex, flattened longitudinal medially, concave near sutures. Prosternal lobe weakly micropunctuate, wide, emarginated laterally with fore angles slightly rounded. Prosternal spine flattened laterally. Scutellum (Fig. 227) strongly folded with horizontal basal area subtrapezoidal, carinate anteriorly and notched anterior- and posteriorly. Borders of mesosternal cavity (Fig. 274) wide, horizontal on basal $3 / 4$, and slightly declivous on distal $1 / 4$ forming an inclined profile. Meso- metasternal suture very weak. First visible sternite prominent laterally fits in lateral groove of elytra. Distal half of first pair of tibiae and last tarsal segment of all legs of male bearing fringe of short cilia (absent on $2^{\text {nd }}$ pair). Striae formed by row of moderately coarse punctuation; interstices weakly micropunctuate and slightly convex; unequal in width; apices conjointly rounded; flat tubercle at base of $2^{\text {nd }}$ interstice.

Aedeagus (Fig. 378): 3.8 times longer than wide; median lobe (Fig. 423) wide, half of aedeagus length, narrowed near middle, bearing 9, 9 teeth, inserted dorsally; lateral cleft of parameres (Fig. 459) with apex flattened, slightly widened forming two small laterodistal teeth, upwards dorsally.

Female not examined.

Material examined. MEXICO. Ex coll. Oberthür, ex coll. Perroud, 1 $\mathrm{M}(\mathrm{MNHN})$.

Remarks. Chalcolepidius angustatus is characterized especially by integument clothed with green pubescence with white lateral stripes on pronotum (narrowed at extremities and not reaching the base) and elytra (three interstices wide), anterior tibiae of male bearing fringe of short cilia, aedeagus with parameres cleft subapically, apex of lateral cleft with two laterodistal teeth and median lobe of aedeagus with teeth inserted dorsally.

The syntype male of $C$. angustatus, examined, is very abraded with dorsal pubescence almost all lost, except the yellowish-white narrow lateral stripes on pronotum and elytra.

It belongs to fryi* group (Fig. 671).

Distribution. It is recorded from Mexico (Oaxaca) (Fig. 686).

Chalcolepidius apacheanus Casey, 1891

(Figs. 4,100,167,228,275,314,379,424,460,495,532,580,623,693) 
Chalcolepidius apacheanus Casey, 1891: 16; Champion, 1894: 278 (= C. webbi LeConte); Champion, 1896: 552; Casey, 1907: 32; Fall \& Cokerell, 1907: 177; Leng, 1920: 167 (Cat.); Schenkling, 1925: 54 (Cat.); Blackwelder, 1944: 282 (Cat.). Syntype female: "Ariz.; Casey bequest 1925; Type USNM 48453; apacheanus; Syntype Chalcolepidius apacheanus Csy 1891 C.M.F. von Hayek 1979"(USNM) (examined).

Chalcolepidius simulans Casey, 1907: 32; Leng, 1920: 167 (Cat.). Syntype female: "Bill Wms. Fork Ariz. Aug. F. H. Snow; Casey bequest 1925; Type USNM 48448; simulans Csy; Lectotype Chalcolepidius simulans Casey CMF von Hayek 1979"(USNM) (examined). Syn. nov.

Chalcolepidius acuminatus Casey, 1907: 32; Leng, 1920:167 (Cat.). Syntype female: “Ariz.; Casey bequest 1925; apacheanus 2 paratype USNM 48453; believed to be syntype of Chalcolepidius acuminatus Casey 1907 C. M. F. von Hayek 1979"(USNM) (examined). Syn. nov.

Chalcolepidius nobilis Casey, 1907: 32; Leng, 1920:167 (Cat.). Syntype female: "Cochise Co. Ariz.; nobilis Csy; Casey bequest 1925; Type USNM 48455”(USNM) (examined). Syn. nov.

CASEY (1891) described C. apacheanus and, in 1907, presented a key including 13 new species, among them $C$. simulans, C. acuminatus and C. nobilis.

ChAmpion (1894) considered C. apacheanus synonym of C. webbi LeConte. According to him, C. apacheanus was described based on abraded specimens of $C$. webbi LeConte, 1854. In 1896, after examining large series of material he changed his mind and considered C. apacheanus as valid species. He also stated that Casey identified incorrectly the sex of the specimens he described; he supposed to be a male but it was actually a female.

BUCHANAN (1935) analyzed the material of Casey collection (see remarks after $C$. webbi) and together with the material recognized as $C$. apacheanus and $C$. acuminatus, he added, into the box, two handwritten labels, as following: "Casey evidently re-arranged the specimens of apacheanus, acuminatus, resulting in doubt as to the actual type of the latter species. It is probable that Casey's 1891 desc. of apacheanus was based on the 2 specimens here labeled type + paratype (plus at least one other $\mathrm{M}$, which was not found), that in 1907 he separated apacheanus \# 2 as the species acuminatus. Later on, this spec*imen was re-united with the type of apacheanus, but the name label "acuminatus" was attached to another specimen (the present Neotype of acuminatus)"; "The true original specimen of acuminatus is probably apacheanus 2".

HAYEK (personal communication) also analyzed this material and stated about $C$. acuminatus: "The specimen in the Casey collection with a locality label and Casey's determination label does not agree well with the description, and in my opinion cannot be part of the syntype series. Buchanan was obviously of the same opinion as he attached a "Neotype USNM 48454" label indicating that he was unable to identify the true holotype [sic] with certainty (see Buchanan 1935: 6-8). The description of acuminatus agrees well with a female labeled as "apacheanus 2; paratype USNM 48453". Some of these labels have more than one pinhole indicating that at various times the labels have been removed and replaced. I suspect that on one of these occasions, the labels have been transferred by mistake from one specimen to another and I propose that this specimen be accepted as a syntype of acuminatus Casey. Buchanan's label near the specimens supports the above theory".

SchenkLing (1925) considered $C$. webbi synonym of $C$. apacheanus.

Here, C. apacheanus and C. webbi are considered different species and C. simulans, C. acuminatus and C. nobilis as junior synonyms of the former.

Length: 32-42 mm. Wide, parallel body. Integument darkbrown and bright, clothed dorsally by short, thin, metallic scalelike setae blue, violet-blue, brownish-violet or brownish; ventral pubescence longer and denser, metallic, brownish, sometimes violet; lateral stripes of pronotum narrow, about $1 / 4$ pronotum width with internal margins semi-elliptical, not reaching lateral margins; lateral stripes of elytra two interstices wide; white pubescence on lateral stripes of pronotum and elytra, basal region of elytra and epipleura; some specimens with white lateral patches on sternites (variable size) (Fig. 4).

Frons not carinate moderately declivous. Antennae (Fig. 100) serrate in both sexes, $3^{\text {rd }}$ segment triangular-elongate, shorter than $4^{\text {th }}$. Pronotum (Fig. 167) longer than wide, subrectangular, strongly narrowed on anterior fourth and slightly narrowed at hind angles base, making lateral margins slightly sinuous; micropunctate with coarse sparse punctuation denser lateroanteriorly; strongly convex at middle; convexity decreasing anteriad and basad; anterior margin prominent at middle, slightly sinuous; lateral margins raised forming narrow edge almost reaching apex and continuous with that of hind angles; hind angles triangular, backwards, raised laterally; median basal tubercle very flat, subtriangular; posterior margin prominent and strongly notched at middle. Hypomera concave near sutures, raised in narrow band parallel sutures; laterointernal margin raised forming wall of anterior channel. Notosternal sutures strongly sinuous. Prosternum micropunctate, moderately convex, flattened longitudinal medially; slightly concave near sutures. Prosternal lobe micropunctate, wide, emarginated laterally with fore angles slightly rounded. Prosternal spine flattened laterally. Scutellum (Fig. 228) strongly folded with horizontal basal area subtrapezoidal, notched anteriorly and posteriorly, grooved longitudinal medially. Borders of mesosternal cavity (Fig. 275) wide, horizontal on basal $2 / 3$, and almost vertical on distal 1/3, forming L-shaped profile. Mesepisternum with two transverse elliptical grooves. Meso-metasternal suture very weak. First visible sternite prominent laterally, fits in lateral groove of elytra. Anterior and median tibiae and last tarsal segment of all legs of male bearing fringe of long cilia. Striae weakly marked by row of coarser punctures; interstices flat and micropunctate; $2^{\text {nd }}$ interstice projected anteriorly forming flat tubercle.

Male genital segments and aedeagus. Sternite VIII (Fig. 318) transverse, abruptly narrowed on distal third; translucent in large median area and in paired narrow lateral bands. Tergite IX densely punctuate with anterior margin rounded. Aedeagus (Fig. 379): 4.1 times longer than wide; median lobe (Fig. 424) half of aedeagus length, slightly narrowed near middle and 
bearing 9, 9 teeth; apex of lateral cleft of parameres (Fig. 460) flat and narrowed at apex, prominent dorsally.

Female genital segments and genitalia. Tergite VIII (Fig. 495) transverse, slightly prominent medioanteriorly, translucent in small subtriangular median basal area, and lateral paired bands. Sternite VIII (Fig. 532) wide- and deeply notched medioanteriorly, 0.63 spiculum gastrale length; stout and darker setae disposed in row, more concentrate near base. Female genitalia (Fig. 580): sclerotized rings of openings of colleterial glands elliptical (Fig. 623) with 38 teeth; bursa copulatrix with longitudinal median elongate area with carinae and spines and few lateral spines.

Material examined. Besides the type material, four females of Casey's collection (USNM): "Sierra Durango; Casey bequest 1925; Casey determ. apacheanus-3"; "Sierra Durango; Casey bequest 1925; Casey determ. apacheanus-4”; “Ariz.; Casey bequest, 1925; Neotype USNM 48454; acuminatus Csy; It seems probable that Casey's det. label attached in error does not agree well with descr. of acuminatus Casey C. M. F. von Hayek det. 1979.XI [stuck on underside:] Neotype designation unpublished XI.1979" "Promotorio Durango; Casey bequest 1925; Casey det. 2 acuminatus". UNITED STATES OF AMERICA. California: San Bernardino Co., Needles, $1 \mathrm{~F}$ (AMNH). New Mexico: $1 \mathrm{~F}$ (SEMC), $1 \mathrm{~F}$ (USNM); Catron Co., Mogollon Mts, 1 F (FSCA); Rte 12 2m N 180, 1 F (JEWC); Grant Co., 2 F (MZSP); Cherry Creek Camp, 13 mi N Silver City, 6900 ft., 1 F (AMNH); Santa Rita [del Cobre], 1 F (CMNH); Silver City, 1 F (AMNH). Utah: Silver Reef, 1 F (USNM); Washington Co., St George, 1 F (AMNH), 1 F (USNM). Arizona: 2 F (AMNH), 4 F (CMNH), $2 \mathrm{~F}$ (1 dissected) (MZSP), $1 \mathrm{M}$ (USNM), ex-coll. Fleutiaux, 1 F (MNHN), [identified as] Chalcolepidius substriatus Schwarz n.sp., 1 F (MNHN); Cochise Co., 2 F (FSCA), Chiricahua Mts, 3 F (FSCA), 2 F (MCZC), 1 F (USNM), $5000 \mathrm{ft}, 1 \mathrm{~F}$ (FSCA), $1 \mathrm{M}$ (MCZC), $1 \mathrm{~F}$ (USNM); Chiricahua Nat. Monument, 1 M (TAMU); Douglas, San Bernardino Ranch 1 F (MCZC); Garden Canyon, Huachuca Mts., 1 F (AMNH), Huachuca Mts. 4 M (OSUC); Ft. Huachuca, 1 F (MCZC); Portal, 1 F (FSCA), 1 F (USNM), on road to Rustler Park, 1 F (FSCA), Southwestern Research Station, nr Portal, 1 F (FSCA); 5 mi W Portal, 5400 ft., 2 F (AMNH); 5 mi N Portal, 1 F (FSCA); Sunnyside, 1 M (MZSP); Gila Co. 1 F (USNM), Globe, 1 F (USNM); Payson, 3 F (USNM); 17 mi Payson, 1 F (FSCA); Sierra Ancha, 1 F (AMNH), 1 F (USNM); Maripa Co., Phoenix, 1 F (CMNH), 3 M , 1 F (USNM); Navajo Co., Heber, 6500 ft., 1 M, 1 F (AMNH); Pima Co., Santa Catalina Mts, 1 F (USNM), Tucson, 1 F (MZSP), Pinal Co., Pinal Mts, 2 F (AMNH), 1 F (USNM); Yavapai Co., Peach Sp'g [Springs], 1 M (USNM); Cottonwood, 1 M (AMNH); Prescott, $1 \mathrm{M}, 2 \mathrm{~F}$ (AMNH), $4 \mathrm{~F}$ (CMNH), $1 \mathrm{M}, 1 \mathrm{~F}$ (MCZC), $1 \mathrm{M}, 2 \mathrm{~F}$ (NHMW); Yuma Co., Bill Williams Fork, 2 M, 2 F (MCZC), 1 M (SEMC), 2 F (USNM). Texas. Brewster Co., Big Bend Nat. Pk. 1 F (OSUC); Big Bend Ranch St. Pk. Ojito Adentro, 1 F (TAMU); Presidio Co., Presidio, 5 F (TAMU), 1 F (USNM). MEXICO. 1 F (AMNH), 2 F (MNHN), ex-coll. Fleutiaux, 3 F (MNHN). Sonora: 9 mi NNE Imuris, 1 F (SEMC). Chihuahua: Delicias, $4150 \mathrm{ft}$., 2 F (AMNH); Juarez, 1 F (USNM). Durango: $6 \mathrm{mi}$ NE El Salto, $8500 \mathrm{ft}, 8 \mathrm{~F}$ (AMNH); Palos Colorados, $8000 \mathrm{ft}$., 4 F (AMNH). Veracruz: Nogales, 1 F (USNM). Without locality: $1 \mathrm{M}$ (dissected) (MZSP).

Remarks. Chalcolepidius apacheanus is characterized especially by integument clothed with blue or violet blue setae with white lateral stripes on pronotum and elytra, scutellum folded with median carina, interstices flat and aedeagus with parameres cleft laterally.

It presents a wide range of variation in size and the females are larger and more robust than males. CASEY (1907) considered these variations as specific characters, and characterized $C$. simulans, C. acuminatus and C. nobilis especially by different proportions of some body parts. In fact, $C$. simulans presents a few larger white setae scattered on hypomera, but this feature it is not sufficient to be considered as different species.

C. apacheanus belongs to corpulentus + group; it is the sister-group of $C$. webbi (Fig. 671). It is similar to C. webbi (see remarks after the latter) its sister-group and forms, together with C. tartarus the tartarus + group, composed by blue species.

Distribution. It is recorded from United States of America (California, New Mexico, Utah, Arizona, Texas) and Mexico (Sonora, Chihuahua, Durango, Veracruz) (Fig. 693). CASEY (1907) recorded the type locality of $C$. apacheanus and C. acuminatus Casey as "Fort Apache" $\left(33^{\circ} 46^{\prime} \mathrm{N}\right.$ $109^{\circ} 59^{\prime} \mathrm{W}$, extreme south of Navajo Co), but none specimen from this locality has been found.

\section{Chalcolepidius approximatus Erichson, 1841}

(Figs. 5, 101, 168, 315, 354, 380, 425, 461, 397, 533, 624, 690)

Chalcolepidius approximatus Erichson, 1841: 82; Candèze, 1857: 275; Gemminger \& Harold, 1869: 1502 (Cat.); Candèze, 1874: 164; 1886: 71; 1891: 39 (Cat.); Champion, 1894: 274, 278, t.11, fig. 22.; Schenkling, 1925: 54 (Cat.); Fleutiaux, 1926: 107 (Cat.); Blackwelder, 1944: 282 (Cat.). Syntypes: 1 male, 3 females. All specimens: "16218; Hist.-Coll. (Coleoptera), nr 16218, Chalcolepidius approximatus Erichs., Mexico, Deppe, Zool. Mus. Berlin"; [one male bears in addition:] "approximatus Er.* Cand.* Mexico Deppe" (ZMHB) (examined).

Chalcolepidius longipennis Sturm, 1843: 67; Candèze, 1891: 39 (Syn.). Chalcolepidius zonatus, var. b, Candèze, 1874: 164; Champion, 1894: 278 (Syn.). Syntype female: "Puebla; Mexico." (BMNH) (not examined).

Chalcolepidius zonatus; Dugés (non Eschtz.) 1885 (II): 32, t. 1, f. 35 [Misidentification of larva according to Champion, 1894: 273].

Chalcolepidius aztecus Casey 1907: 33; Schenkling, 1925: 55 (Cat.); Blackwelder, 1944: 282 (Cat.). Syntype female: "Guer.; Casey bequest 1925; Type USNM 48457; aztecus Csy; Lectotype Chalcolepidius aztecus Casey C. M. F. von Hayek 1979 (not published); Chalcolepidius approximatus Erichs. C. M. F. von Hayek det.1979" (USNM) (examined). Syn. nov.

Chalcolepidius sodalis Casey, 1907: 33; Casey 1911: 253 (= C. aztecus); Schenkling, 1925: 58 (Cat.); Blackwelder, 1944: 282 (Cat.). Syntype female: "Guer.; Casey bequest 1925; Type USNM 48458; sodalis Csy; Casey determ. aztecus-2; Lectotype Chalcolepidius sodalis Casey C. M. F. von Hayek 1979 (not published); Chalcolepidius approximatus Erichs. C. M. F. von Hayek det. 1979" (USNM) (examined).

Chalcolepidius niger Pjatakowa, 1941: 43. Type locality: "Mexico, Durango". Syn. nov.

ERICHSON (1841) commented about the similarities between C. approximatus and C. zonatus, differing especially by hind angles of pronotum less strongly drawn out and the lateral white stripes on the elytra divided by carina in the former. This carina corresponds to the higher last lateral interstice and this species does not present lateral white stripes on elytra; the lower interstices are clothed with white pubescence in both species.

CANDÈze supposed that $C$. approximatus was conspecific with C. zonatus. In 1857 and 1886, he included the former in the Section II, I, A, formed by species with epipleura clothed with pubescence of the same colour as underside, but the syntypes examined have epipleura clothed with white pubescence. In 1886, he included a note: "Je soupçonne cette espèce, que je 
n'ai point vue, de n'être qu'une varieté du zonatus". This statement seems to indicate some doubts about the authenticity of the specimens he saw before and kept the supposition to be a variety of C. zonatus. In 1891, he catalogued both species and considered $C$. longipennis Sturm as conspecific with $C$. approximatus.

CHAMPION (1894) commented that $C$. approximatus is very closely to the South American $C$. zonatus Eschscholtz, but presents some small differences related to the head convexity, shape and hind angles of the prothorax and the convexity of elytral interstices.

CASEY (1907) presented a key with the new species, $C$. aztecus and C. sodalis, both females from Guerrero, sharing the item 14 of the key. In 1911, he synonymized C. sodalis under C. aztecus. After examining the material of these two species studied by Casey, it was concluded that they are conspecific with C. approximatus.

Puatakowa (1941) described C. niger from Mexico (Durango), characterized especially by yellowish-white pubescence on lateral bands of pronotum, lateral interstices and base of epipleura. Based on the original description and on studied material from the type locality, C. niger is herein considered conspecific with C. approximatus.

Length: $23-40 \mathrm{~mm}$. Integument black, clothed dorsally and ventrally, including legs, with scale-like setae brownish-olive; lateral stripes of pronotum band-like, narrower than $1 / 4$ of pronotum width, not reaching lateral margins; dull white pubescence on lateral stripes of pronotum, basal region of elytra, lower interstices except distal $2 / 3$ of $5^{\text {th }}$ and epipleura; antennae clothed with dark-brown pubescence except three first segments brownish-olive; sternites 2-5 with lateral rounded patches with white pubescence (Fig. 5).

Frons not carinate, moderately concave medioanteriorly; punctuation coarse and sparse (denser at middle), intermingled with dense and small; nasal plate high and densely punctuate. Antennae serrate in both sexes (Fig. 101), $3^{\text {rd }}$ segment triangularelongate, shorter than $4^{\text {th }}$. Pronotum (Fig. 168) longer than wide, sub-rectangular slightly narrowed anteriad, from hind angles apices; strongly convex on median anterior region; convexity decreasing basad; anterior margin prominent and sinuous at middle; hind angles backward, raised laterally forming edge continues with that of lateral margins, not reaching apex; punctuation moderately coarse and sparse, denser lateroanteriorly (distal third) intermingled with small and dense; median basal tubercle flat, triangular-elongate, continuous with very weak longitudinal medially ridge, not reaching anterior margin; posterior margin prominent and strongly notched at middle. Hypomera concave near sutures; laterointernal margin raised forming wall of anterior channel. Notosternal sutures strongly sinuous. Prosternum micropunctate with coarse and sparse punctuation near sutures, strongly convex, flattened longitudinal medially, concave near sutures. Prosternal lobe with punctuation slightly coarser than prosternum, wide, emarginated laterally with fore angles slightly rounded. Prosternal spine flattened laterally with rounded apex. Scutellum strongly folded with horizontal basal area subtrapezoidal, notched anterior- and posteriorly. Borders of mesosternal cavity wide, horizontal on basal $2 / 3$, and vertical on distal $1 / 3$, forming L-shaped profile. Mesepisternum with two transverse elliptical grooves. Meso-metasternal suture indistinct. First visible sternite prominent laterally fits in lateral groove of elytra. Anterior and median tibiae and last tarsal segment of all legs of male bearing fringe of long cilia. Interstices convex and micropunctate, unequal in width and height; striae marked by row of coarse punctures, paired; flat basal tubercle at $2^{\text {nd }}$ interstice; apices slightly rounded.

Male genital segments and aedeagus. Tergite VIII transverse, gradually narrowed apicad, strongly notched at base. Sternite VIII (Fig. 315) abruptly narrowed on distal third, translucent in subtrapezoidal median area. Tergite IX (Fig. 354) densely punctuate with tiny setae laterodistally; anterior margin rounded. Aedeagus (Fig. 380): 3.6 times longer than wide; median lobe (Fig. 425) half of aedeagus length, moderately narrowed near middle, strongly narrowed at apex, bearing 6,7 (syntype M); 4, 7; 5, 7; 9, 9; 10, 9; 10, 10 lateral teeth; lateral cleft of parameres (Fig. 461) narrowed near apex, with apex straight, prominent laterally and slightly upwards.

Female genital segments and genitalia. Tergite VIII (Fig. 497) wider than long, notched at base; median basal translucent area not reaching middle. Sternite VIII (Fig. 533) 0.58 times spiculum gastrale length, widely notched anteriorly. Female genitalia: sclerotized rings of openings of colleterial glands (Fig. 624) elliptical with 33 teeth; bursa copulatrix with longitudinal median elongate band with carinae and spines and two rounded lateral spiny areas.

Material examined. MEXICO. $1 \mathrm{~F}$ (IBSP), $2 \mathrm{~F}$ (MCZC), $4 \mathrm{~F}$ (MNHN), 2 F (USNM); [identified as] Chalc. pruinosus Eschs., ex-coll. Fleutiaux, 1 $\mathrm{M}$ (MNHN). Durango: Durango, $5 \mathrm{~F}$ (MNHN); from Durango to the Pacific, $1 \mathrm{~F}$ (MNHN). Colima: $7 \mathrm{mi}$ W Colima, $1 \mathrm{~F}$ (USNM); Tecolopa, 1 F (AMNH). Tamaulipas: Matamoros Puebla, 1 F (UNAM). Veracruz: Cuerou [= El Cuervo], 1 F (MCZC); Jalapa, 1 F (IBSP); Tierra Blanca, 1 F (FSCA); Juntos, $1 \mathrm{M}$ (ZMUC). Mexico: $1 \mathrm{~F}$ (IBSP); Ixtapan del Oro, $1850 \mathrm{~m}, 8 \mathrm{~F}$ (PCCV), $1 \mathrm{~F}$ (MZSP, retained PCCV); Tenancingo, $1 \mathrm{M}$ (dissected)(MZSP); $1450 \mathrm{~m}$ Zacazonapan env. $1 \mathrm{~F}$ (SRGI). Michoacán: Arteaga, 1 F (AMNH); Cuautla, 1 F (AMNH); El Sabino, Uruap, 2 F (SEMC); Morelia, $1 \mathrm{~F}$ (USNM). Guerrero: Cacahuãmilpa, $1080 \mathrm{~m}, 1 \mathrm{~F}$ (ZMUC); Teloloapan, $1 \mathrm{M}$ (dissected) (MZSP, retained USNM), $1 \mathrm{M}, 2$ F (USNM). Morelos: Ahuatepec, 1750 m, 1 F (MZSP retained SRGI); Cuernavaca, $1 \mathrm{~F}$ (AMNH); El Limon, $1 \mathrm{~F}$ (dissected) (MZSP, retained UNAM), 1 F (MZSP, retained USNM), 1 M, 2 F (USNM), 1 F (NHMW); $20 \mathrm{Km}$ E Cuernavaca, $1 \mathrm{~F}$ (FSCA); Jalastoc, $1 \mathrm{M}$ (IBSP), $1 \mathrm{~F}$ (USNM); Progreso, $1 \mathrm{~F}$ (USNM); Yautipec, $1300 \mathrm{~m}, 1 \mathrm{~F}$ (ZMUC). Puebla: Atlixco, $1 \mathrm{~F}$ (SEMC); Puebla, ex-coll. Fleutiaux, $1 \mathrm{M}, 2 \mathrm{~F}$ (MNHN); env. de Tehuacan, $1 \mathrm{M}$ (MNHN). Oaxaca: $10 \mathrm{mi} \mathrm{S}$. Tomellin, $1 \mathrm{~F}$ (USNM). Chiapas: 1 F (USNM). Guanajuato: Guanajuato, 1 F (USNM), ex-coll. Fleutiaux, $3 \mathrm{~F}$ (MNHN).

Remarks. Chalcolepidius approximatus is characterized especially by integument clothed with brownish-olive setae with white setae on lateral stripes of pronotum, epipleura and lower interstices (except $5^{\text {th }}$, only on anterior $1 / 3$ ), not forming lateral stripes of elytra, scutellum folded with carina and parameres of aedeagus cleft laterally.

Comparing the type material of C. aztecus and C. sodalis it 
was observed that the latter is smaller ( $=26 \mathrm{~mm} ; 33 \mathrm{~mm}$ in the former), and presents fore angles of frons more prominent and hypomera with small whitish patches; $5^{\text {th }}$ interstice white totally in the former (olive on median third in the latter). These differences are herein considered as intraspecific variations of C. approximatus. This species presents lateral white patches on sternites variable in size and in number; in some specimens they are small or formed by few setae and are present only in one or two sternites, and sometimes are even absent.

The holotype of $C$. niger was not located. The synonym was based on original description and the type locality of this species.

It is very similar to $C$. zonatus, differing, besides the geographical distribution, especially by (C. zonatus parenthesized): 1) pubescence coloration usually brownisholive dorsally and ventrally (green or olive); 2) lateral stripes of elytra absent (present); 3) $3^{\text {rd }}$ antennal segment and pronotum proportionally longer (shorter); 4) sternite VIII of male with larger darker distal area, setae in small number and apex wider in the former; 5) lateral cleft of parameres more strongly narrowed near the apex in the former; 6) spiculum of sternite VIII of female longer in the former; 7) sclerotized rings of openings of colleterial glands with 33 teeth (46), and 8) rounded spiny area of bursa copulatrix shorter in the former.

It belongs to approximatus + group (Fig. 671).

Distribution. It is recorded from Mexico (Durango, Colima, Taumalipas, Veracruz, Mexico, Michoacán, Guerrero, Morelos, Puebla, Oaxaca, Chiapas, Guanajuato) (Fig. 690).

Chalcolepidius attenuatus Erichson, 1841

(Figs.6,102,169,230,231,276,316,355,381,496,534,581,582,625,673)

Chalcolepidius attenuatus Erichson, 1841: 86; Candèze, 1857: 267; Gemminger \& Harold, 1869: 1502 (Cat.); Candèze, 1874: 162; 1886: 70; 1891: 37 (Cat.); Champion, 1894: 275, 286, t.12, f. 18; Schenkling, 1925: 55 (Cat.); Blackwelder, 1944: 282 (Cat.). Holotype male: "16207; attenuatus Er.* Cand.* Mexico, Schleid [last word illegible]; Holotype Chalcolepidius attenuatus Erichs. C M F von Hayek det. 1980" (ZMHB) (examined).

Chalcolepidius cuneatus Champion, 1894: 275, 286, t.12, f. 12; Schenkling, 1925: 55 (Cat.); Blackwelder, 1944: 202 (Cat.). Holotype male: "Type; Acapulco, Guerrero Höge; B. C. A. Col. III (1) Chalcolepidius cuneatus Ch. M type; sp. figured" (BMNH) (examined). Syn. nov.

Chalcolepidius tenuis Champion, 1894: 276, 287, t.12, f. 20; Schenkling, 1925: 57 (Cat.); Blackwelder, 1944: 283 (Cat.). Holotype female: "F; Type; Oaxaca, Mexico Höge; B. C. A. Col. III (1) Chalcolepidius tenuis Ch. F type; sp. figured; sp. n. F voisin de viridipilis Say" (BMNH) (examined). Syn. nov.

Champion (1894) described C. cuneatus from Acapulco and C. tenuis from Oaxaca, and figured a male of C. attenuatus from Oaxaca. He commented that $C$. cuneatus is "allied to $C$. attenuatus, differing by elytral interstices almost flat and coarser punctures of the striae in the former". These characters were used in the key to separate the two species. Related to $C$. tenuis he discussed the similarities of this species with $C$. viridipilis and $C$. dugesi, but did not compare it with $C$. attenuatus.
Comparing C. cuneatus and C. tenuis with C. attenuatus, it was not found appreciable differences and the two first were considered as synonyms of the latter.

Length: 16-29 mm. Narrow, parallel body. Integument black, bright, clothed dorsally and ventrally with short metallic scalelike setae brownish-olive, grayish-olive, brownish, olive or brownish-violet; sometimes grayish ventrally; antennae clothed with black setae except three first segments; in few specimens, brown (Fig. 6).

Frons not carinate, moderately declivous. Antennae (Fig. 102) long, serrate in female, strongly serrate in male; $3^{\text {rd }}$ segment transverse with spiniform appendix. Pronotum (Fig. 169) longer than wide, sub-rectangular, narrowed anteriorly and at hind angles base, making lateral margins rounded; strongly convex from lateral margins; small-punctuate, punctuation coarser lateroanteriorly; fore angles prominent; anterior margin almost straight; lateral margins with narrow smooth edge reaching apex; hind angles divergent, sharpened, strongly carinate; carina partially fused with lateral edge; median basal tubercle flat, transverse, with transverse carina near base; posterior margin moderately prominent and slightly notched at middle. Hypomera slightly convex, more raised than prosternum near sutures, small (like punctuation of pronotum) and densely punctuate; prosternal channel absent. Notosternal sutures slightly sinuous. Prosternum slightly convex from sutures; micropunctate, punctuation coarser near sutures. Prosternal lobe emarginated laterally; punctuation moderately coarse (coarser than prosternum) with fore angles rounded. Scutellum (Figs. 230, 231) moderately declivous on anterior half; posterior half horizontal and elliptical with two rounded concavities and distal margin slightly prominent at middle. Borders of mesosternal cavity (Fig. 276) wide, horizontal on basal half, and slightly declivous on distal half, forming inclined profile. Mesometasternal suture absent. First visible sternite normal, last visible sternite of male with rounded apex, bearing two lateral weak rounded impressions. Tibiae of male bearing row of long spines internally. Striae marked by row of coarse punctures; interstices equal and moderately convex; $2^{\text {nd }}$ forming flat tubercle at base; apices conjointly rounded.

Male genital segments and aedeagus. Sternite VIII (Fig. 316) subtriangular, melanized in marginal band, bilobed and clearer at base. Tergite IX (Fig. 355) transverse, densely punctuate with anterior margin slightly emarginated; fore angles rounded with moderately long setae. Aedeagus (Fig. 381): three times longer than wide; median lobe narrowed on basal third and distal half; 0.61 times aedeagus length; apex of parameres spearhead-like.

Female genital segments and genitalia Tergite VIII (Fig. 496) transverse with anterior margin rounded; translucent in small triangular basal area. Sternite VIII (Fig. 534) almost a half of spiculum length; anterior margin narrow- and deeply notched at middle. Genitalia (Figs. 581, 582): sclerotized pieces of openings of colleterial glands (Fig. 625) C-shaped with 23 small teeth; ventral half of bursa copulatrix covered internally with carinae and spines. 
Material examined. MEXICO. Sinaloa: $5 \mathrm{mi} \mathrm{N}$ Mazatlan, $1 \mathrm{M}$ (FSCA). Nayarit: Tepic, El Cora, 1 F (NHMW), 1 F (ZMHB). Jalisco: Chamela, Estación Biologia, $4 \mathrm{M}$ (AMNH), $1 \mathrm{~F}$ (FSCA), $14 \mathrm{M}, 1 \mathrm{~F}$ (UNAM); 3 M (1 dissected) (MZSP, 2 retained UNAM); Chamela vic UNAM, 6 M, 1 F (JEWC), 4 M (MZSP); 3 Km N Tomatlan, 1 M (FSCA), $1 \mathrm{M}$ (MZSP); $80 \mathrm{Km} \mathrm{S}$ El Tuito, $1 \mathrm{~F}$ (MZSP). Colima: $2.8 \mathrm{mi}$ SW Colima, 4 M (FSCA); 11.3 mi S Colima, 1 M (FSCA). Tamaulipas: Altamirano, $1 \mathrm{M}$ (AMNH). Michoacán: 10-20 mi S Capiro, $1 \mathrm{M}$ (FSCA). Guerrero: Hwy 200, $41 \mathrm{Km} \mathrm{NE} \mathrm{Ixtapa,} 1 \mathrm{~F}$ (JEWC); $43.7 \mathrm{Km} \mathrm{NW}$ Ixtapa, $1 \mathrm{~F}$ (FSCA); $51 \mathrm{Km} \mathrm{NW}$ Ixtapa, $1 \mathrm{~F}$ (FSCA). Morelos: $14 \mathrm{Km}$ Huautla-Jojutla, $1 \mathrm{~F}$ (dissected) (MZSP, retained UNAM).

Remarks. Chalcolepidius attenuatus is characterized especially by narrow and almost parallel body, pronotum with lateral margins rounded with hind angles divergent and strongly carinate, median basal tubercle of pronotum transverse and flat, prosternal channel absent, notosternal sutures slightly sinuous, scutellum moderately declivous and apex of parameres spearhead-like.

The holotype of $C$. attenuatus differs from that of $C$. tenuis, especially by pubescence coloration, greenish-brown dorsally and grayish ventrally in the former and greenish-brown in both sides in the latter, and also by the size and sex. Comparing the holotype of $C$. cuneatus with the material identified as $C$. attenuatus, the only difference found was the antennal pubescence, brown in the former and usually black in the latter. Besides, the median lobe of aedeagus is narrower and slightly constricted near apex in the former. These observed differences are considered as intraspecific variations and C. cuneatus and C. tenuis are herein considered as synonyms.

This species presents a narrow range of coloration variation; the majority of specimens present dorsal pubescence like that of ventral, but in some, the pubescence is olive or brownish dorsal- and grayish ventrally. It was found two specimens with greenish pubescence dorsally and ventrally, and two with violet setae intermingled with brownish.

C. attenuatus looks like $C$. viridipilis in shape and size, but they differ especially by presence in the former (latter parenthesized): 1) antennae of male strongly serrate (flabellate); 2) scutellum moderately declivous (folded); 3) tibia of male bearing spines (short cilia); 4) lateral margins of pronotum more rounded, hind angles more divergent and interstices more raised; 5) parameres of aedeagus with spearhead-like apex (parameres cleft); 6) sclerotized pieces of openings of colleterial glands opened, C-shaped (closed, oval-shaped); 7) bursa copulatrix totally clothed dorsally with microspines and carinae (small spiny area); 8) sternite IX of female narrower and more deeply notched at middle.

C. attenuatus is very similar to C. lenzi, differing especially by: pronotum narrower anteriad and more strongly convex at middle in the latter, making the lateral margins rounded; anterior half of scutellum moderately declivous in the former and almost perpendicular in the latter; interstices convex in the former and flattened in the latter. Besides, the median lobe of aedeagus is narrowed near base and apicad in the former and almost straight, widened near base in the latter; melanized band of sternite VIII of male entire in the former (with brighter bilobed basal area) and interrupted basally in the latter.
C. attenuatus belongs to attenuatus* group, together with C. dugesi and C. lenzi (Fig. 671).

Distribution. It is recorded from Mexico (Sinaloa, Nayarit, Jalisco, Colima, Tamaulipas, Michoacán, Guerrero, Morelos and Oaxaca) (Fig. $673)$.

\section{Chalcolepidius aurulentus Candèze, 1874}

(Figs. 7,8,9,103,170,232,277,317,382,426,462,535,626,682)

Chalcolepidius aurulentus Candèze, 1874: 163; 1886: 73; 1891: 38 (Cat.); Schwarz, 1906b: 46; Schenkling, 1925: 55 (Cat.); Fleutiaux, 1916: 16; 1926: 107 (Cat.). Syntype male: "Syntype; Type M; Upper California; Janson coll. 1903-130; aurulentus Cdz type [handwritten glued to underside of:] Chalcolepidius aurulentus Cdze, M type; = porcatus, var. locality certainly incorrect GCC"(BMNH) (examined).

Chalcolepidius porcatus var. dimidiatus Candèze 1874: 163. Syntype female: "Para [Pará]; 125; Collection Chevrolat; Chalcolepidius porcatus Cand. var. dimidiatus $\mathrm{Ch}$; Type de la var. cité par Cand. Revis. p. 163 porcatus; Collection Fleutiaux"(MNHN) (examined). Chalcolepidius candezei Dohrn, 1881: 446; Candèze, 1886: 68, 72; 1891: 38 (Cat.); Hyslop, 1916: 18; Schenkling, 1925: 55 (Cat.); Fleutiaux, 1926: 107 (Cat.); Blackwelder, 1944: 282 (Cat.). Type locality: "Brazil: Ega [=Tefe]". Syn. nov.

Chalcolepidius grossheimi Pjatakowa, 1941: 101. Type locality: "Brazil: Matto Grosso, Corumba". Syn. nov.

CANDÈZE (1874) described C. aurulentus, characterized especially by general metallic pubescence green, with striae and epipleura clothed with dull white setae. According to him this species shares the general characters with $C$. porcatus var. c', but in the former, the green pubescence present a reddishgolden reflex, and the epipleura are clothed with white setae. After examining a couple, he observed the presence of long cilia on tibiae and last tarsal segments of anterior and median legs of male. He did not refer to long cilia on last tarsal segments of posterior legs, probably because they were fallen. The type locality assigned was "Californie méridionale", later recognized as incorrect by CHAMPION (1894).

DOHRN (1881) described C. candezei characterized especially by geminate striae clothed, like epipleura, with white pubescence. He did not include the type locality of this species. Later, CANDĖzE (1886) recorded it from Ega [Tefé].

According to HAYEK (personal communication), the BMNH possesses a female of $C$. candezei from the "type locality", from the Dohrn collection, that she believes to be one of the additional specimens recorded by Dohrn after the original description.

Fleutiaux (1916) studying the Elateridae collected on the Stanford University Expedition of 1911 to Brazil, found "two very distinct varieties and one intermediate" of $C$. candezei, characterized as following. The typical form "has the strial vittae thickly beset with whitish colored scales, and prothorax and ventral surfaces with bronze purple scales"; the "var. a. elytra as in forma typica, vestiture of pronotum and ventron green"; the "var. b. vestiture of elytral striae ferrugineous yellow, pronotum and ventral vestiture green". This material, from Rondônia: Abunã (Rio Madeira), Madeira-Mamoré and Porto Velho (Rio Madeira), housed in USNM, fits perfectly in the 
range variation of $C$. aurulentus, and $C$. candezei is herein considered as synonym of the former. Fleutiaux (1926) considered $C$. porcatus Linnaeus as a variation of $C$. candezei.

PJatakowa (1941) described C. grossheimi from Brazil (Mato Grosso: Corumbá), characterized especially by general metallic pubescence green and epipleura, striae and lower interstices clothed with dull ochraceus-yellow setae, scutellum strongly folded with horizontal basal area triangular and interstices unequal. The type-material of this species was not located, but it was examined one specimen from Madeira-Mamoré (Rondônia) (USNM) and two from Corumbá (Mato Grosso) (MNHN) that answer very well with the description of $C$. grossheimi Pjatakowa. This fact let me to believe that $C$. grossheimi is conspecific with $C$. aurulentus. The specimen from Rondônia had already been examined by Hayek, who adds a label with a note: "porcatus (L) CMF von Hayek det. 1979. agrees w descr. Grossheinei Pj.”, but she did not considered the coloration of epipleura pubescence.

Length: 36-49 mm. Wide, arched body. Integument black clothed dorsally and ventrally (including legs) with thin, metallic scale-like setae, grayish-blue, olive-green, yellowish-green, green, brown, reddish-brown, violet-brown, violet-green or ferruginous; white, yellowish-white, ochre or ferruginous setae on elytral epipleura, anterior margin of elytra, striae and sometimes lower interstices (not forming lateral stripes); antennae blue, except three first segments, greenish or brownish (Fig. 7-9).

Frons not carinate, moderately declivous. Antennae (Fig. 103) serrate in both sexes, $3^{\text {rd }}$ segment triangular-elongate, slightly shorter than $4^{\text {th }}$. Pronotum (Fig. 170) longer than wide (wider in female), wider at hind angles, narrowed anteriorly and hind angles base; anterior margin sinuous; hind angles wide, slightly divergent with apex truncate, raised laterally forming narrow edge continuous with that of lateral margins on basal $3 / 4$; moderately convex; convexity stronger frontally, decreasing basad; micropunctate with punctuation coarse and sparse more concentrate on median anterior region, giving to this region rugose appearance; median basal tubercle flat, triangular, continuous with weak median ridge; posterior margin prominent and strongly notched at middle. Hypomera concave near lateral margins; micropunctate; laterointernal margin raised forming wall of anterior channel. Mesepimeron with two transverse elliptical grooves. Notosternal sutures strongly sinuous. Prosternum strongly convex, slightly concave near sutures and flattened longitudinal medially. Prosternal lobe small-punctuate, wide, emarginated laterally with rounded angles. Borders of mesosternal cavity (Fig. 277) wide and horizontal on basal $3 / 4$ and almost vertical on distal $1 / 4$, forming L-shaped profile. Prosternal spine flattened laterally. Scutellum (Fig. 232) strongly folded with horizontal basal area subtrapezoidal, notched anteriorly and posteriorly, and grooved longitudinal medially. Anterior and median tibiae and last tarsal segment of all legs of male bearing fringe of long cilia. First visible sternite prominent laterally, fits in lateral groove of elytra. Interstices convex and micropunctate, unequal in width and/or height; very flattened tubercle at base of $2^{\text {nd }}$ interstice; scutellar area slightly grooved; apices truncate with sutural spine of varied size.

Male genital segments and aedeagus. Sternite VIII (Fig. 317) transverse, strongly narrowed on distal third, translucent in trapezoidal media area and short paired lateral bands. Tergite IX transverse, densely punctuate; anterior margin straight with rounded lateral angles; tiny setae lateroanteriorly. Aedeagus (Fig. 382): 3.5 times longer than wide; median lobe (Fig. 426) wide, half of aedeagus length; slightly narrowed near middle, bearing 6,$7 ; 8,8 ; 8,9 ; 9,13 ; 11,11 ; 11,13$ small lateral teeth $(\mathrm{M}$ syntype with 13, 14 teeth); subapical region of lateral cleft of parameres (Fig. 462) narrowed; apex strongly widened, more prominent ventrally.

Female genital segments and genitalia. Tergite VIII as long as wide, notched basally; median basal translucent area Ushaped surpassing middle. Sternite VIII (Fig. 535) 0.58-0.63 times spiculum gastrale length; anterior margin slight- and widely notched. Genitalia: sclerotized rings of openings of colleterial glands (Fig. 626) with 24, 33, 34, 37 teeth; bursa copulatrix with longitudinal median elongate band with carinae and spines and two rounded lateral spiny areas.

Material examined. "NEW GRANADA". 1 F (ZMHB). COLOMBIA. Ex-coll. Fleutiaux, 1 F (MNHN). Boyacá: Muzo, 2 F (MZSP). Valle del Cauca: Cali, 1 F (FSCA). Huila: Gigante, 1 F (SRGI). Putumayo: 5 F (MNHN), 1 M (SRGI), ex-coll. Fleutiaux, 8 F (MNHN), SE, 5 F (MNHN); Caucayá, 1 F (AMNH); Florida, ex-coll. Fleutiaux, 1 F (MNHN); Nariño, Territorio Kofán $700 \mathrm{~m}$ (captura manual), $2 \mathrm{~F}$ (IAHC). Caquetá: Rio Orteguaza, Rastojo, 1 F (AMNH); Yari, 1 F (PCCV). Amazonas: PNN Amaca-yacú, Bosque Várzea, Via Palmeras jameo bordo 1 F (IAHC); PNN Amaca-yacú Várzea B. Secundario Bocas R. Amacayacu 1 F (IAHC); Lower Rio Putumayo, 2 F (AMNH); Río Tacana, 1 F (AMNH). VENEZUELA. Falcon: Cauca Valley, $1 \mathrm{~F}$ (MNHN). Amazonas: Cerro de la Neblina, base camp 140 m, 1 F (AMNH), 5 F (USNM); Mt Duida, 2 F (AMNH). GUYANA. 2 F (MNHN). SURINAME. 1 F (MNHN). FRENCH GUIANA. Cayenne: Cayenne, $1 \mathrm{~F}$ (MNHN), $3 \mathrm{~F}$ (USNM). BRAZIL. $1 \mathrm{~F}$ (AMNH). Amazonas: $7 \mathrm{~F}$ (MNHN), $2 \mathrm{~F}$ (MZSP), $1 \mathrm{~F}$ (PCCV); Bassin de l'Amazone, $3 \mathrm{~F}$ (MNHN); Benjamin Constant, $5 \mathrm{~F}$ (DZUP), $1 \mathrm{M}$ (dissected) (MZSP), $1 \mathrm{~F}$ (ZMUC), Rio Javari, $4 \mathrm{~F}$ (IBSP), $3 \mathrm{~F}$ (MCZC), $10 \mathrm{M}, 855 \mathrm{~F}$ (3 F dissected)(MZSP), 2 F (DZUP); Bocca do Teffé, 1 F (MNHN); Borba, 1 F (IBSP), Lago Acara, 1 F (DZUP), Rio Madeira, 3 F (MCZC), 1 M (dissected) (MZSP); Ega [Tefé], 1 F (NHMW); Codajaz, $1 \mathrm{~F}(\mathrm{MNHN})$; Fonteboa, $8 \mathrm{~F}(\mathrm{AMNH}), 1 \mathrm{~F}(\mathrm{MNHN})$; Itacoatiara, 4 F (MZSP); Manaus, 34 F (AMNH), ex-coll. Fleutiaux, 1 M, 5 F (MNHN), Campus do INPA, 1 F (DZUP); Manicoré, 1 F (MNHN), Rio Madeira, 2 F (AMNH); Massanary (locality not found), $1 \mathrm{~F}$ (MNHN); Maués, $1 \mathrm{~F}$ (DZUP), 1 F (USNM); Providência, 1 F (MCZC); Rio Caiary-Uaupes, 1 M, 4 F (AMNH); Rio Negro, 1 F (AMNH); Rio Juruá, 3 F (MZSP); Rio Purus, 2 F (MNHN); Rio Tiquié (Alto Rio Negro), 1 F (IBSP); São Paulo de Olivença, $12 \mathrm{~F}$ (AMNH), $1 \mathrm{~F}$ (CMNH), $1 \mathrm{~F}$ (IBSP), $12 \mathrm{~F}$ (MZSP), 2 F (SRGI), 2 F (USNM), ex-coll. Fleutiaux, 1 F (MNHN), Rio Solimões, 47 F (MZSP); Tabatinga, 1 F (MZSP); Tapuruquara, rio Negro, 2 F (MZSP); Taraquá, 1 F (MZSP); Tefé, 12 F (AMNH), 6 F (MCZC), 9 F (1 dissected)(MZSP), 1 F (USNM), ex-coll. Fleutiaux, 2 M, 14 F (MNHN); Villanova, 1 F (MNHN). Acre: Alto Purus, 2 F (MZSP); Tarauacá, Rio Tarauacá, 1 F (MZSP). Rondônia: 1 F (MZSP); Abunã, Rio Madeira, excoll. WMMann, 1954, 5 F (USNM); Ariquemes, 1 F (DZUP); 60 Km S Ariquemes, $1 \mathrm{~F}$ (FSCA); $62 \mathrm{Km} \mathrm{SW}$ Ariquemes, nr Fzda Rancho Grande, 6 F (FSCA); 62 Km S Ariquemes, Linea C20, 7 Km E B-65, Fazenda Rancho Grande, 4 F (EGRC); Forte Príncipe da Beira, 6 F (MZSP); Madeira-Mamoré, ex-coll. WMMann, 1954, 2 F (USNM); Ouro Preto d'Oeste (locality not found), 1 M, 16 F (DZUP); Pimenta Bueno, 1 F (MNMS), 2 F (DZUP); Porto Velho, 1 F (MZSP), Rio Madeira, 1 F (USNM); Posto Indígena 7 de Setembro (locality no found), 2 F (MCZC); 
Rio Madeira, ex-coll. WMMann, 1954, 6 F (USNM); Rio Urupá, 2 F (MCZC); Vilhena, 6 F (DZUP). Pará: 1 F (MNHN); Itaituba, 2 F, (MNHN), Rio Tapajós, 10 F (MZSP), 1 F (DZUP); Óbidos, 1 F (AMNH), $1 \mathrm{~F}$ (IBSP), $2 \mathrm{~F}$ (MNHN), $11 \mathrm{~F}$ (MZSP), $1 \mathrm{~F}$ (PCCV), $1 \mathrm{~F}$ (SRGI); Oriximiná, 1 F (MZSP); Rio Tapajós, 1 F (MNMS); Santarém, 1 F (MZSP), ex-coll. Fleutiaux, 2 F (MNHN); Santarém \& Óbidos, $1 \mathrm{~F}$ (PCCV); Santaremzinho, Mun. de Itaituba, Rio Tapajós, 18 F (MZSP). Piaui: Pebas, 5 F (MNHN), ex-coll. Fleutiaux, 3 F (MNHN). Ceará: Carquejo, 3 F (MZSP). Maranhão: Igarapé Gurupi-Una, Aldeia Araçu, MA, $50 \mathrm{Km}$ E de Canindé, $1 \mathrm{~F}$ (MZSP). Mato Grosso: Corumbá, 2 F (MNHN); R. Humboldt, Est. Codemat, $1 \mathrm{~F}$ (dissected) (MZSP), $1 \mathrm{~F}$ (UNAM), Margem Igarapé, $1 \mathrm{~F}$ (UNAM); Rio Verde, $1 \mathrm{~F}$ (TAMU); Rosário d'Oeste, 1 F (MZSP). Paraná: Rolândia, 1 F (MZSP). ECUADOR. Napo: 3 F (FSCA); Anzu, 4 F (IMLA); 6 Km E Atahualpa, $480 \mathrm{~m}, 1 \mathrm{~F}$ (FSCA); $24 \mathrm{Km}$ E Atahualpa, $480 \mathrm{~m}, 1 \mathrm{~F}$ (FSCA); Coca, $1 \mathrm{M}$, 4 F (PCCV), 12 F (SRGI); Esmeralda, 1 F (IMLA); Galeras Rd., 1000 m, $1 \mathrm{~F}$ (FSCA); Lago Agrio (2 Km N) (locality not found), 2 F (USNM); Limoncocha, 2 F (FSCA), 2 F (USNM); Pacayaçu, 1 F (ZMHB); Road between El Puvo \& Puerto Napo, 1 F (USNM); San Pablo, Rio Aquarico, 1 F (IMLA); Sucumbios, 215 m 1 F (TAMU). Napo-Pastaza: Rio Jatun, 17 F (AMNH). Pastaza: ex-coll. Fleutiaux, $1 \mathrm{~F}$ (MNHN); Abitagua, $1 \mathrm{~F}$ (AMNH); Puyo, $1 \mathrm{~F}$ (AMNH), $1 \mathrm{~F}$ (FSCA); Santa Clara, $1 \mathrm{~F}$ (MZSP, retained USNM), $1 \mathrm{~F}$ (USNM); Tarqui, $1 \mathrm{~F}$ (USNM); Zatzayacu, $7 \mathrm{~F}$ (AMNH), ex-coll. Lane, 2 F (USNM). Pichincha: El Partidero, $2 \mathrm{~F}$ (AMNH); Montalvo, 1 F (IMLA); Quito, 3 F (AMNH), 2 F (ZMUC). Chimborazo and Pichincha: $2 \mathrm{~F}$ (MNHN). Morona-Santiago: Macas, 1 F (ZMHB), ex-coll. Fleutiaux, 1 M, 7 F (MNHN), 1050 m, 1 F (USNM); near Macas, el Oriente, 1 F (USNM). Guayas: Guayaquil, 1 F (USNM). Loja: Loja, 2 F (MNHN), ex-coll. Fleutiaux, 14 F (MNHN). Zamora: 3 F (AMNH); Llanos, ex-coll. Fleutiaux, 1 F (MNHN); Zumbi, Santiago Zamora [illegible], $700 \mathrm{~m}, 1 \mathrm{M}, 1 \mathrm{~F}$ (AMNH); Santiago Zamora [Chinchipe Est.], $1000 \mathrm{~m}, 3 \mathrm{~F}$ (AMNH). Localities not found: Baron, 9 F (MNHN); ex-coll. Fleutiaux, $1 \mathrm{M}, 4 \mathrm{~F}$ (MNHN); Zena, $1 \mathrm{~F}$ (IMLA). PERU. $1 \mathrm{~F}$ (AMNH), $1 \mathrm{~F}$ (MCZC), 5 F (NHMW), $1 \mathrm{~F}$ (USNM), ex-coll. Fleutiaux, 4 F (MNHN), ex-coll. Sallé, 2 F (MNHN). Loreto: Achinamiza, $1 \mathrm{M}, 52 \mathrm{~F}$ (AMNH); Balsapuerto, $1 \mathrm{~F}$ (MNHN); Boquerón de Abad, 500 m, 2 F (IMLA); Estirón, Rio Ampiacu, 2 F (MZSP); Explornapo Camp on rio Sucusari, $2 \mathrm{Km}$ upstream from Rio Napo (160 Km NE Iquitos), 1 F (USNM); Explorama Lodge, $80 \mathrm{Km}$ NE Iquitos on Amazon river, $1 \mathrm{~F}$ (FSCA), 2 F (PCCV), 2 F (SRGI), 4 F (USNM); Explorama Lodge, $50 \mathrm{mi}$ NE Iquitos on Amazon river, $1 \mathrm{~F}$ (FSCA); Iquitos, $8 \mathrm{~F}$ (AMNH), $1 \mathrm{~F}$ (MNHN), 1 F (ZMUC); ex-coll. Fleutiaux, 2 F (MNHN), Rio Cachiyacu, 4 F (MNHN), ex-coll. Fleutiaux, $1 \mathrm{~F}$ (MNHN); Middle Rio Ucayali, $11 \mathrm{~F}$ (AMNH); Rio Ucayali, 6 F (AMNH); Mishuyacu, 1 M, 1 F (USNM); Mishuyacu près Iquitos, $1 \mathrm{M}$ (MNHN); Palcazu, $1 \mathrm{~F}$ (MNHN); Pucallpa, $600 \mathrm{ft}$., 2 F (AMNH), Rio Ampiacu, 1 F (MZSP); Rio Tapiche, 2 F (AMNH), Rio Ucayali, 3 F (IMLA), 1 M, 14 F (MZSP); Km 3 Tournavista Rd., $34 \mathrm{Km}$ W Puccalpa, 300 m, 1 M, 2 F (AMNH); Middle Rio Maranon, 3 F (AMNH); Upper Rio Maranon, 5 F (AMNH); Rio Maranon, 3 F (AMNH); Rio Santiago, 3 F (AMNH). Amazonas: striatus L. Fab., excoll. Fleutiaux, $1 \mathrm{~F}$ (MNHN); Juanjui, $1600 \mathrm{ft}, 1 \mathrm{~F}$ (AMNH); reg. Juanjui, 1 M, 1 F (MNHN); Pebas, 7 F (MNHN). Junín: San Ramón (de Pangoa), $40 \mathrm{Km}$ SE Satipo, 750 m, 1 F (AMNH); Satipo, 1 M, 28 F (AMNH), 2 F (FSCA), 2 F (SRGI); Soudoreni Ridges (locality not found), $900 \mathrm{~m}$, Soudoreni/Huantadriri Vall., ca $100 \mathrm{Km}$ NO Satipo, 1 F (PCCV); ca 100 $\mathrm{Km}$ SO Satipo, rio Anapate Valley ca $700 \mathrm{~m}, 1 \mathrm{~F}$ (PCCV); Rio Toro, La Merced Chanchamayo, 4 F (ZMHB). Cajamarca: Camelon, ex-coll. Fleutiaux, 1 F (MNHN); Yahuarmayo, 2 F (USNM). San Martín: Mishquiyacu, $20 \mathrm{Km}$ NE Moyabamba, 1200 m, 1 F (AMNH); Moyobamba, Hera (Jera), $860 \mathrm{~m}, 3 \mathrm{~F}$ (AMNH); felled "Ajo-quiru" tree called garlic tree. Fresh timber of this tree has a strong odor, which causes a headache to people that work this tree. $1 \mathrm{~F}(\mathrm{AMNH})$; Moyobamba region, $1 \mathrm{~F}$ (AMNH); Rikuri-cocha, $830 \mathrm{~m}, 1 \mathrm{~F}$ (AMNH). Localities not found: Atazon R. (72.74 W 4 S), 1 F (FSCA); Env. [T]Janja, 1 M, 6 F (MNHN); Chambireyacú près Yurimaguas (Huallaga), $1 \mathrm{~F}(\mathrm{MNHN})$; Tocache, $1 \mathrm{~F}$ (MNHN). Ancash: Cumbre, 5 F (MNHN), ex-coll. Fleutiaux, 1 F (MNHN); Huambo [Huamba], ex-coll. Fleutiaux, $1 \mathrm{~F}(\mathrm{MNHN})$. Huánuco: Monte Alegre, Rio Pachitea, 1 F (MNMS), 5 F (ZMHB); Monzon, Rio Huallaga, 700-900 m, 1 F (MZSP); Panguana, Rio Pachitea, 260 m, 3 F (PCCV); Pozuzo, ex-coll. Fleutiaux, 5 F (MNHN); Rio Huallaga, 4 F (AMNH), 14
F (FSCA), 4 F (PCCV), 9 F (SRGI), 1 F (SRGI), 680 m, 1 M (AMNH), 8 F (ZMHB); Upper Rio Huallaga, 1 F (AMNH); Tingo Maria, $2200 \mathrm{ft} ., 1$ M, 5 F (AMNH), 2 F (FSCA), 1 F (IMLA), 1 F (MZSP, retained SRGI), 2 F (OSUC), 2 F (SRGI), 1 F (TAMU), 1 F (UNAM), 3 F (USNM), Leoncio Prado Prov., $600 \mathrm{~m}$, Chincha vito, 1 F (FSCA), Cueva de Las Pavas, 700 m, 3 F (FSCA), Prov. Tambello Chica, 800 m, 1 F (FSCA); 8 km S Tingo Maria, $1 \mathrm{~F}$ (FSCA); Puente Chinche vito (locality not found), $\mathrm{S}$ of Tingo Maria, $1 \mathrm{~F}$ (OSUC). Cuzco: Chanchamayo, $1 \mathrm{~F}$ (MNHN), ex-coll. Fleutiaux, 2 F (MNHN); Cuzco, 1 F (ZMHB); Cosñipata, 2 F (AMNH). Madre de Dios: coll. Fleutiaux, 2 F (MNHN); Iberia, 500 m, 4 F (AMNH); Parque Manu, Pakitza, 340 m, 1 F (DZUP); Rio Tambopata Res. $30 \mathrm{Km}$ (air) SW Porto Maldonado, $290 \mathrm{~m}, 1 \mathrm{~F}$ (FSCA) Tambopata river, $2 \mathrm{~F}$ (MCZC); Vilcanota [Montain], $1 \mathrm{~F}$ (MNHN). Puno: Callanga [Callangachi], $1 \mathrm{~F}$ (MNHN); BOLIVIA. $1 \mathrm{~F}$ (MCZC), $1 \mathrm{~F}$ (USNM), 8 F (ZMUC), ex-coll. Fleutiaux, $2 \mathrm{~F}$ (MNHN). Pando \& El Beni: Cavinas, Rio Beni, 3 F (USNM). El Beni: Cachuela Esperanza, $1 \mathrm{~F}$ (USNM); Ivon $3 \mathrm{~F}$ (USNM); Puerto Velarde, $1 \mathrm{~F}$ (SRGI); Rio Itenez at mouth of Rio Baures, $1 \mathrm{~F}$ (AMNH); Rio Itenez about $4 \mathrm{Km}$ above Costa Marques (Brazil), 2 F (AMNH); Rurrenabaque, Rio Beni, 7 F (USNM); Uyapi, 1 M (MZSP, retained SRGI); Yungas Isla, Paz, 1000 m, aurulentus O. Schwarz det. 1903, ex- coll. Hauser, 3 F (ZMHB). Cochabamba: 8 F (MNHN); 2600 m, 14 F (IMLA); Chaparé, 1 F (FSCA), $1 \mathrm{~F}$ (dissected) (MZSP), $400 \mathrm{~m}, 1 \mathrm{~F}$ (PCCV), $3 \mathrm{~F}$ (DZUP), El Palmar, 1600m, $1 \mathrm{~F}$ (FSCA), Villa Tunari, $500 \mathrm{~m}, 1 \mathrm{~F}$ (IMLA), $7 \mathrm{~F}$ (MZSP); reg. Chaparé, 7 F (FSCA); Cochabamba, 2 F (MZSP), 1 Km E Villa Tunari, 1 F (FSCA), La Paz: Chuani, 1 M (USNM); Coroico, 1 F (MCZC), 6 F (NHMW), ex-coll. Fleutiaux, $1 \mathrm{~F}$ (MNHN); Ixiamas, 13 F (USNM); Rio Madidi, 221 m, 12 F (IMLA); Tumupasa, 7 F (USNM), Region La Paz, 1 F (USNM). Santa Cruz: 3 F (USNM), ex-coll. Fleutiaux, 2 F (MNHN); Buena Vista, 1 M, 7 F (FSCA), ex-coll. Fleutiaux, 9 F (MNHN), [aurulentus Cand., Fleutiaux det.], $1 \mathrm{~F}$ (MNHN); El Cidral, $1 \mathrm{~F}$ (IMLA); Ichila, $1 \mathrm{M}$ (dissected) (FSCA); Pcia. Gutierrez Nueva Maka, 1 F (MZSP); Rio Seco, 1 F (IMLA); S. Mateo, ex-coll. Fleutiaux, 1 F (MNHN); de Pucara a Marta, de la Cordillière à la Foret, $1 \mathrm{~F}(\mathrm{MNHN})$; Sara [Gutierrez], $3 \mathrm{~F}$ (ZMHB), Dept. Sta Cruz de La Sierra, 500 m, 2 F (ZMHB). Localities not found: As(g)uota, $1 \mathrm{~F}$ (USNM); Copico, ex-coll. Fleutiaux, $1 \mathrm{~F}$ (MNHN); Carinavi, 1500 m, 9 F (SRGI). PARAGUAY. Central: Asunción, 1 F (IMLA). ARGENTINA. Salta: 2 F (MCZC), ex-coll. Fleutiaux, 10 F (MNHN); San Carlos, 10 F (FSCA).

Remarks. Chalcolepidius aurulentus is characterized especially by pronotum unicolor, striae and sometimes lower interstices different from general pubescence coloration, epipleura coloration different from underside, lateral cleft of parameres narrowed to subapical region and strongly broadened at apex, more prominent ventrally, and median lobe slightly narrowed near middle. It presents a wide range of pubescence variation, and some specimens exhibit small lateral white stripes on pronotum. Four females from Bolivia (Dept. Beni; two from Rio Machupo $15 \mathrm{Km}$ SW Horquilla and two from Rio Itenez $4 \mathrm{Km}$ above Costa Marques (AMNH)), are clothed with metallic yellowish-green pubescence with lateral stripes of pronotum and elytra (except the higher interstices) clothed with ochraceus dull setae; the lateral stripes of pronotum reach the basal half in two of them and only the median third in other two. It was observed one female, from Venezuela (Mt. Duida (AMNH)), clothed with bluish-gray pubescence, with lateral stripes of pronotum (on basal 2/3), clothed with yellowish-white setae. Another female from Venezuela (Mt. Duida) presents general metallic pubescence grayish-blue, and elytra, epipleura and lateral stripes of pronotum (on basal 2/3) clothed with yellowish-white setae.

The coloration of elytra pubescence exhibits a wide range of variation especially related with the density of the whitish 
setae. Examination of the available material has shown that it increases gradually, beginning only on the striae and epipleura, like the specimen described as C. aurulentus, becoming slightly denser and denser until clothing almost whole elytra, except the higher interstices, like C. candezei and C. grossheimi. A tentative to separate a large series of unidentified material was stopped in the intermediary specimens that fitted in more than one of these species, herein recognized as C. aurulentus. Parallel to the density of whitish pubescence, it shows a gradual increasing on interstices size, beginning unequal only in width, in specimens with few whitish setae on elytra. The inequality increases until the higher point, in specimens with elytra almost totally clothed with whitish setae, with interstices unequal in width and height.

The epipleura has always different coloration from ventral general metallic setae, dull white, yellowish-white, ochre or ferruginous. In four specimens from Peru (MNHN) only a half part of epipleura is clothed with white pubescence.

Comparing the genitalia of one specimen with pubescence coloration like $C$. aurulentus with another like $C$. candezei or C. grossheimei it was found any differences except for the number of teeth of median lobe of aedeagus and of the sclerotized rings of openings of colleterial glands. The number of teeth of these structures is widely variable into this species.

C. aurulentus is very similar to $C$. porcatus, differing especially by epipleura clothed with white setae and apex of lateral cleft of parameres more strongly prominent laterally in the former.

It belongs to forreri* group (Fig. 671).

Distribution. It is very common in South America, recorded from Colombia, Venezuela, Guyana, Suriname, French Guiana, Ecuador, Brazil (Acre, Amapá, Pará, Piauí, Ceará, Rondônia, Mato Grosso, Paraná), Peru, Bolivia, Argentina and Paraguay (Fig. 682). Until 1916, it had not been recorded from other locality than "California" (type-locality), when Fleutiaux recorded it from Brazil. One specimen from South California (ZMUC) and two from Costa Rica (USNM) were examined, but not included in the material examined because these records require confirmation.

Chalcolepidius bomplandii Guérin-Méneville, 1844

(Figs.10,11,104,171,229,278,318,356,383,427,463,498,536,627,687)

Chalcolepidius bomplandii Guérin-Méneville, 1844: 17; Candèze, 1857: 262, 278, t. 6, f. 3; Gemminger \& Harold, 1869: 1502 (Cat.); Candèze, 1886: 67, 71; 1891: 39 (Cat.). Type locality: "Colombia" [the syntypes should be in MNHN, but they were not located].

Chalcolepidius bomplandi [sic]; Champion, 1894: 276, 278; Schenkling, 1925: 55 (Cat.); Blackwelder, 1944: 282.

Chalcolepidius juani Candèze, 1889: 13; 1891: 39 (Cat.); Champion, 1894: 276 (Syn.); Schwarz, 1906a: 45. Holotype female: “n. sp. juani Cdz Guatemala; Type F; Coll. E. Candèze; bonplandi var. second Champion."(ISNB)(examined).

Chalcolepidius humboldti Candèze, 1881: 22; 1886: 67, 71; 1891: 39 (Cat.); Schenkling, 1925: 56 (Cat.); Fleutiaux, 1926: 107 (Cat.); Blackwelder, 1944: 283 (Cat.). Syntype female: "Type; n.sp. humboldti Cdz; Bogota, C. Hu. Coll. R. I. Sc. N. B. Colombie Bogota ex coll. Candèze; Chalcolepidius humboldti Guér. Cand. det. E. Candèze" (ISNB) (examined). Syn. nov.

C. bomplandii was firstly characterized by dorsal pubescence yellowish-brown with yellow lateral stripes on pronotum and elytra and ventral, greenish-brown. It was originally recorded from "des régions chaudes et temperées".

CANDĖZE (1857) recorded it from "Nouvelle Grenade" and enumerated four varieties: Var.a. Prothorace antrorsum rotundatim ampliato; Var.b. Supra squamulis viridibus vel olivaceis, vittis striisque luteis; Var.c. Prothoracis elytrorumque vittis cinnabarinis; Var. d. Corpore supra, vel solum prothorace, concolore squamuloso. He also stated about the similarities of these variations with other species: the variation 'c' has same shape of C. eschscholtzi var. 'a', but in the latter, the stripes of pronotum are narrowed frontally and finish on posterior border, while in C. bomplandii they are widened posteriorly; $C$. fabricii has striae less grooved and setae of striae denser; the variation ' $d$ ' is similar to C. porcatus but always longer; the rounded shape of lateral margins of pronotum and the elytral epipleura, of the same color as metasternum, is similar to C. limbatus that is narrower than the others. In 1874, he stated that perhaps C. bomplandii occurs also in Mexico. These comparisons let me suppose that Candèze mixed other similar species.

CANDĖze (1881) described C. humboldti, from Bogotá. According to him, it presents the general shape of $C$. bomplandii with sparser pubescence and striae strongly punctuated. In his key of 1886, Candèze characterized $C$. humboldti as "presque glabre" and $C$. bomplandii and $C$. mocquerysi with body "revêtu d'écailles". I examined a syntype female of $C$. humboldti and concluded that it is conspecific with C. bomplandii. I examined also a female from Bogotá (ISNB) labeled by Candèze as "Bogota; Type; n. sp. 1892; aeruginosus, Bogota; Candèze Collection" ( nomen nudum) that also belongs to C. bomplandii.

CANDĖze (1889) described C. juani from Guatemala; CHAMPION (1894), synonymized it under C. bomplandii and commented that $C$. juani was based on abraded specimens of C. bomplandii, with marginal stripes of pronotum and elytra paler than usual; he examined also one specimen clothed dorsally with metallic violet setae. According to him, this species is common at the Atlantic slope of Guatemala and to Chontales. I examined the holotype of $C$. juani and agree with Champion.

CHAMPION (1894) treating on C. limbatus stated that: "the figure and the description of E. porcatus Drury, from the Bay of Honduras, would apply equally well to $C$. bomplandii Guér., from which the present species [C. limbatus] chiefly differs in having the epipleura clothed with elongate luteous scales and the marginal carina of the elytra more deflexed anteriorly". This supposition was not mentioned in p. 276 where he stated about C. bonplandi [sic].

SCHENkLing (1925) and Blackwelder (1944) considered $C$. juani as a variation of C. bonplandi [sic].

Length: 29-46 mm. Wide, arched body. Integument darkbrown clothed dorsally and ventrally, including elytral epipleura, with thin metallic scale-like setae, olive, grayish-blue, grayishgreen, green, bluish-green, dark-brown or violet-brown; lateral 
stripes of pronotum band-like, approximately $1 / 4$ of pronotum width, or narrower, sometimes emarginated internally near hind angles or shorter, not reaching hind angles; lateral stripes of elytra three or four interstices wide; dull yellow, yellowishwhite or ochraceus pubescence (sometimes almost ferruginous) on lateral stripes of pronotum, base of elytra, striae and lateral margins of elytra; antennae bluish except three first segments like general pubescence (Figs. 10, 11).

Frons not carinate, moderately declivous. Antennae (Fig. 104) serrate in both sexes, $3^{\text {rd }}$ segment triangular-elongate, as long as or slightly shorter than $4^{\text {th }}$. Pronotum (Fig. 171) longer than wide, wider at hind angles and narrowed apicad, from hind angles base; slightly convex, rugose; micropunctate with very coarse irregular punctuation on longitudinal median region, forming wrinkles; anterior margin sinuous at middle; lateral margins raised forming narrow smooth edge almost reaching apex; hind angles wide, slightly divergent with truncate apex; raised laterally forming edge continuous with that of lateral margins; median basal tubercle flat, triangularelongate, grooved longitudinal medially, continuous with weak longitudinal median ridge, almost reaching apex; posterior margin prominent and strongly notched posteriorly. Hypomera concave near lateral margins; micropunctate with coarse umbilicate punctuation moderately dense; laterointernal margin raised forming wall of anterior channel. Notosternal sutures strongly sinuous. Prosternum micropunctate; punctuation denser and coarser near sutures, strongly convex, flattened longitudinal medially; concave near sutures. Prosternal lobe with punctuation slightly coarser and sparser than median region of prosternum; wide; emarginated laterally with fore angles slightly rounded. Scutellum (Fig. 229) strongly folded with horizontal basal area subtrapezoidal, notched anterior- and posteriorly, slightly grooved longitudinal medially. Borders of mesosternal cavity (Fig. 278) wide, horizontal on basal $3 / 4$, and vertical on distal $1 / 4$, forming L-shaped profile. Meso-metasternal suture weak. First visible sternite prominent laterally fitting in lateral groove of elytra. Anterior and median tibiae and last tarsal segment of all legs of male bearing fringe of long cilia. Elytra: striae grooved; interstices convex and equal; $2^{\text {nd }}$ forming basal flat tubercle; apices conjointly slightly rounded.

Male genital segments and aedeagus. Sternite VIII (Fig. 318) transverse, strongly narrowed on apical third; densely setous; translucent in one median and two basal small elongate areas and two lateroanteriorly short bands. Tergite IX (Fig. 356) densely punctuate; anterior margin rounded; tiny setae lateroanteriorly. Aedeagus (Fig. 383): 3.7 times longer than wide; median lobe (Fig. 427) half of aedeagus length, moderately narrowed near middle and apicad, basal region forming small lobe continuous with basal strut; bearing 7, 7; 9, 9 teeth; lateral cleft of parameres (Fig. 463) slightly narrowed subapically; apex prominent laterally and upwards.

Female genital segments and genitalia. Tergite VIII (Fig. 498) transverse; triangular membranous basal area longer than half of tergite length. Sternite VIII (Fig. 536) 0.60 times spiculum gastrale length; anterior margin wide- and moderately notched. Genitalia: sclerotized rings of openings colleterial glands (Fig.
627) bearing 27 teeth; bursa copulatrix with longitudinal median elongate band with carinae and spines and two lateral rounded spiny areas.

Material examined. MEXICO. Ex-coll. Fleutiaux, 4 F (MNHN). Veracruz: Catemaco, 1 F (FSCA); Cosamaloapan, ex-coll. Fleutiaux, $1 \mathrm{~F}$ (MNHN); Orizaba, 4 F (MNHN); Veracruz, 7 F (MNHN). Oaxaca: Palomares, Finca San Carlos, 1 F (IBSP); Tolosa, 4 F (AMNH). Yucatan: $1 \mathrm{~F}$ (MCZC), $1 \mathrm{~F}$ (MNMS). Chiapas: Chorradero, $1 \mathrm{~F}$ (MZSP), $1 \mathrm{~F}$ (USNM); San Quintin, $1 \mathrm{M}$ (dissected) (MZSP), $1 \mathrm{~F}$ (USNM). BELIZE. Ex-coll. Fleutiaux, $1 \mathrm{~F}(\mathrm{MNHN})$, ex-coll. Oberthür, $1 \mathrm{~F}(\mathrm{MNHN})$. Toledo: 2 F (MCZC); Punta Gorda, 38 F (AMNH), 1 F (FSCA), 2 F (USNM), Columbia R. dist., 5 F (USNM); Columbia, 5 Km N San Antonio, $1 \mathrm{~F}$ (USNM). Localities not found: Benque Viejo, Father Stanton, 2 F (MCZC); M-tee Dist., 3 F (MCZC); Nim Li Punit Ruins, 1 F (MZSP). GUATEMALA. Ex-coll. Fleutiaux, 3 F (MNHN). Alta Verapaz: Coban, 1 F (USNM); Cacao, Trece Aguas, 2 F (USNM); Panzos, 3 F (NHMW), ex-coll. Fleutiaux, 14 F (MNHN); San Juan, 1 F (AMNH), 2 F (NHMW), B.C.A. Col. III (1), Chalcolepidius bomplandi Guérin, 1 F (MNHN). Baja Verapaz: San Cristobal, ex-coll. Fleutiaux, $11 \mathrm{~F}$ (MNHN). Izabal: excoll. Fleutiaux, $1 \mathrm{~F}$ (MNHN); Cayuga, $1 \mathrm{~F}$ (USNM); Livingston, $1 \mathrm{~F}$ (USNM); San Juan, 1 F (USNM). Petén: Sayaaxche, 2 F (1 dissected) (MZSP). Zacapa: La Union, $850 \mathrm{~m}, 1 \mathrm{~F}$ (SRGI); $6 \mathrm{Km} \mathrm{S}$ La Union, 4800', 2 F (MZSP). State: Senalin (locality not found), 1 F (PCCV). Pedras Negras (same name in several states), 2 F (USNM). HONDURAS. Ex-coll. Nonfried, ex-coll. Candèze, $2 \mathrm{~F}$ identified as $C$. juani (ISNB). Atlántida: Atlantida Gardin Botanica Lancetilla, 1 F (JEWC); La Ceiba, 1 F (FSCA), 13 F (USNM). Yoro: Subiranal F (MCZC). EL SALVADOR: San Salvador: San Salvador, 1 M (NHMW). NICARAGUA. 1 F (MNHN), ex-coll. Oberthür, $3 \mathrm{~F}$ (MNHN). Chontales: $1 \mathrm{~F}$ (AMNH), $1 \mathrm{~F}$ (NHMW), $1 \mathrm{~F}(\mathrm{AMNH}), 1 \mathrm{~F}(\mathrm{MCZC}), 1 \mathrm{~F}(\mathrm{MNHN})$. Río San Juan: San Carlos, $1 \mathrm{~F}$ (USNM). Zelaya: Great Corn Island, $1 \mathrm{~F}$ (AMNH). COSTA RICA. $1 \mathrm{M}$, 2 F (MZSP), 1 F (NHMW), 1 F (PCCV), 1 M, 13 F (USNM), ex-coll. Fleutiaux, $2 \mathrm{~F}$ (MNHN). Guanacaste: Bebedero, ex-coll. Oberthür, $2 \mathrm{~F}$ (MNHN), Liberia, 1 F (USNM); Tilaran, 1 F (FSCA); 2.6 mi NW Tilaran, 1400', 1 F (MZSP); Waldeck Farm, near Matina, 4 F (NHMW). Puntarenas: Wilson's Finka, San Vito, 1 F (FSCA). Alajuela: San Carlos, $1 \mathrm{~F}$ (MNHN), 3 F (MCZC), 1 F (USNM), ex-coll. Fleutiaux, 1 F (MNHN). Heredia: Finca La Selva, $1.5 \mathrm{mi}$ Puerto Viejo, $1 \mathrm{~F}$ (MZSP retained FSCA); Río Frio, Standard Fruit Co., 330 ft, 1 F (FSCA). San José: San José, excoll. Oberthür, 1 F (MNHN); Tucurrique, 1 F (MNHN). Limón: Ebene (Hamburg Farm, Reventazon), 1 F (MCZC), 1 M (MZSP, retained USNM), 1 F (USNM); 35 Km Guapiles, 1 F (FSCA); 28 Km E Siquirres, 3 F (FSCA); Hamburg Farm, 1 F (MCZC), near Siquirres, 2 F (NHMW), 1 F (PCCV); vic. La suerte, nr Cariari, 1 F (FSCA); Parismina 2 F (USNM); Ramal Parismina, Santa Clara, 6 F (USNM). Cartago: Irazu, 1 F (USNM); Reventazon Valley, 1 F (FSCA); Turrialba, 1 F (USNM), ex-coll. Fleutiaux, 1 F (MNHN); Turrialba-CATIE area, 1 F (MZSP). PANAMA. Chiriquí: $6 \mathrm{Km}$ N Fortuna Cntl. Dvd Rd., 1 F (JEWC). Bocas del Toro: 1 F (MZSP retained USNM); Rio Changena, $2 \mathrm{~F}$ (MCZC), $1 \mathrm{~F}$ (MZSP). COLOMBIA. $2 \mathrm{~F}(\mathrm{AMNH})$. Magdalena: Aracataca, $1 \mathrm{M}$ (AMNH), $2 \mathrm{~F}$ (MCZC), $1 \mathrm{~F}$ (MZSP retained MCZC), $1 \mathrm{M}$ (USNM); Onaca, $2500 \mathrm{ft}, 1 \mathrm{M}$ (dissected) (SRGI); Río Frio, 2 F (MCZC); Sta Ana, 1 F (ICNC); Sierra N. de Santa Marta, 2 F (MCZC). Caldas: Manizales, ex-coll. Oberthür, 1 M (MNHN). Cundimarca: Bogotá, 2 F (USNM). Valle: W-Cordillera, Lake Calima nr Bugo Rio Bravo Valley, 1 F (PCCV). Cauca Grande, Cueba, 500 m (locality not found), $1 \mathrm{~F}$ (AMNH). Cauca: $1 \mathrm{~F}$ (MZSP, retained MCZC). GUYANA. $1 \mathrm{~F}(\mathrm{MNHN})$.

Remarks. According to HAYEK (personal communication), GuÉRIN-MÉnEVILLE (1844) may have intended to name this species in honor of A. J. A. G. Bompland who traveled and collected in South America at the end of the eighteenth and in the early nineteenth centuries. The original spelling is $C$. bomplandii; Champion (1894), SCHENkLing (1925) and BLACKWELDER (1944) spelled "bonplandi” erroneously.

I examined the holotype of $C$. juani and two other females 
from Honduras (ex-coll. Candèze) and observed the yellow (one paler) lateral stripes on pronotum and elytra. The holotype is glabrous in the majority of areas that should be clothed with thin, metallic setae and only on small ventral areas the bluishgreen setae were seen; the other two females are clothed dorsally and ventrally with grayish-green setae. In the remainder of the examined specimens the lateral stripes of pronotum and elytra are similar to Candèze's series, and the metallic pubescence is grayish-green, grayish blue or olive. One female from Honduras (La Ceiba) and one from Belize (Punta Gorda) present lateral stripes of pronotum emarginated innerly near hind angles.

The syntype of $C$. humboldti has almost glabrous elytra. Comparing this syntype with the specimen labeled as $C$. aeruginosus, it was observed that the pubescence coloration is olive in the former and green in the latter; the lateral stripes of pronotum and elytra are ochre, darker in the latter; the pronotum is more convex and the scutellum narrower at apex in the former.

Comparing the syntype of $C$. humboldti with the material examined of $C$. bomplandii it was observed that the metallic pubescence is olive in the former and grayish or green-grayish in the latter; $3^{\text {rd }}$ antennal segment slightly shorter than $4^{\text {th }}$ in the former, and slightly shorter or equal to $4^{\text {th }}$ in the latter. These small differences are here considered as intraspecific variations.

C. bomplandii is characterized especially by wide body clothed with greenish, grayish or brownish setae with whitish lateral stripes on pronotum and elytra. It exhibits a wide range of variation in pubescence coloration and size and shape of lateral stripes of pronotum (Figs. 10,11). The aedeagus of one male from Mexico (Chiapas, San Quintino) with lateral bands of pronotum well developed (like Fig. 10) and one from Colombia (Magdalena, Onaca) with lateral bands of pronotum very small were compared, and the only difference found was the number of lateral teeth of median lobe, 9 each side in the former and 7 in the latter, considered inside of the range of intraspecific variation.

It is similar to C. mocquerysii, differing especially by more robust body, pronotum more flattened and rugose and lateral whitish stripes on pronotum sometimes emarginated innerly near hind angles in the former, and lateral whitish stripes on pronotum widened at base in latter giving to internal margin an elliptical shape; interstices equal in width in the former and unequal in the latter. In $C$. bomplandii the lateral stripes of elytra have the same width almost until the apex, and outline of the apex reaches the elytral suture; in C. mocquerysii, the lateral stripes are narrowed apicad, not reaching elytral sutures. Comparing the aedeagus of these two species, C. bomplandii presents the median lobe more strongly narrowed at middle and distal margin of lateral cleft of parameres slightly rounded, with angles slightly prominent (apex straight with distal angles sharpened and very prominent in C. mocquerysii). The number of teeth in each side of median lobe is similar in both species, 7 , 7; 9,9 in the former and 7, 8 in the latter. The sternite VIII of male of $C$. mocquerysii presents two fused small elliptical translucent areas on each side of larger median translucent area (one each side in C. bomplandii). The female genitalia is very similar in both species, only the number of teeth of sclerotized rings of openings of colleterial glands are different: 27 in C. bomplandii and 44 in C. mocquerysii.

C. bomplandii belongs to bomplandii* group (Fig. 671).

Distribution. It presents a wide geographical distribution with records from Mexico (Veracruz, Oaxaca, Yucatan, Chiapas), Belize, Guatemala, Honduras, El Salvador, Nicaragua, Costa Rica, Panama, Colombia and Guyana (Fig. 687).

Chalcolepidius boucardi Candèze, 1874

(Figs.12,105,172,233,279,319,357,384,428,464,499,537,583,628,679)

Chalcolepidius boucardi Candèze, 1874: 169; 1886: 74; 1891: 39 (Cat.); Champion, 1894: 283, t. 12, f. 12; Schenkling, 1925: 55 (Cat.); Blackwelder, 1944: 282 (Cat.). Holotype male: "Cuern[avaca] [label torn]; Chalcolepidius boucardi Lap.; Museum Paris ex coll. R. Oberthür; Holotype M Chalcolepidius boucardi Candèze 1874 CMF von Hayek det. 1979" (MNHN) (examined).

The original description is based upon a male from Cuernavaca. Up to now, the female was unknown.

Length: 24-30 mm. Narrow, parallel body. Integument black clothed dorsally and ventrally with metallic scale-like setae thin, short, metallic gray, grayish-olive, grayish-blue or greenishblue; sometimes grayish or bluish-gray ventrally; antennae blue or blue-violet, except three first segments grayish (Fig. 12).

Frons not carinate, moderately declivous. Antennae serrate in female, strongly serrate in male (Fig. 105); $3^{\text {rd }}$ segment transverse, with spiniform appendix. Pronotum (Fig. 172) very longer than wide (1.4 times width), sub-rectangular, slightly narrowed apicad; lateral margins almost straight from hind angles base, raised forming narrow smooth edge, almost reaching apex; strongly convex; convexity decreasing basad; micropunctate with coarse punctuation, more concentrate lateroanteriorly; anterior margin slightly sinuous; hind angles divergent, raised laterally forming edge continuous with that of lateral margins; median basal tubercle very flattened and triangular or indistinct; posterior margin prominent and strongly notched at middle. Hypomera concave near lateral margins; laterointernal margin raised forming wall of anterior channel. Notosternal sutures slightly sinuous. Prosternum micropunctate; punctuation coarser near sutures, strongly convex, grooved near sutures, flattened longitudinal medially. Prosternal lobe with sparse punctuation, coarser than median region of prosternum; emarginated laterally, with lateral angles rounded. Scutellum (Fig. 233) strongly folded with horizontal basal area subtrapezoidal. Borders of mesosternal cavity (Fig. 279) wide and horizontal on basal $3 / 4$ and slightly declivous on distal $1 / 4$ forming an inclined profile. First visible sternite prominent laterally fitting in lateral groove of elytra; last visible sternite with truncate apex in both sexes. Tibiae of male bearing irregular row of spines internally. Striae marked by row of coarse punctures; interstices convex, small punctuate and equal; $2^{\text {nd }}$ forming flat basal tubercle; apices conjointly rounded.

Male genital segments and genitalia. Sternite VIII (Fig. 319) 
subtriangular, translucent in triangular median area and two laterobasal bands. Tergite IX (Fig. 357) densely punctuate with anterior margin slightly emarginated bearing tiny lateroanteriorly setae. Aedeagus (Fig. 384): 4.5 times longer than wide; median lobe (Fig. 428) half of aedeagus length, slightly narrowed near middle and constricted at apex, bearing dorsally 13,$13 ; 14,14$ very small teeth; lateral cleft of parameres (Fig. 464) parallel almost until to apex; apex prominent laterally and upwards.

Female genital segments and genitalia. Tergite VIII (Fig. 499) transverse with translucent basal area triangular, longer than half of tergite length at median line. Sternite VIII (Fig. 537) very wide, 0.65 times spiculum gastrale length; anterior margin wide- and deeply notched at middle. Genitalia (Fig. 583): sclerotized rings of openings of colleterial glands (Fig. 628) with internal contour triangular, grater-like half part, bearing 36 teeth, some bi- or tricuspid; bursa copulatrix with small ventral area with carinae and spines.

Material examined. MEXICO. 1 M, 2 F (ZMHB). Jalisco: Estación Biologica UNAM, 1 F (FSCA); vic. Estación de Biologia Chamela, $1 \mathrm{M}$ (JEWC); Estación de Biologia Chamela, Arroyo Seco, 1 M (MZSP retained UNAM). Colima: 1 M (USNM); Colima, $1 \mathrm{~F}$ (dissected) (USNM). Veracruz: Presidio, 1 F (IBSP). Without locality: Museum Paris ex coll. R. Oberthür, 1 F (MNHN); Bilimek, Tlapocoyar, 1 F (NHMW). Guerrero: Presa El Caracol, $1 \mathrm{M}$ (dissected) (UNAM); Teloloapan, $1 \mathrm{M}$ (dissected) (USNM).

Remarks. Chalcolepidius boucardi is characterized especially by narrow body, antennae strongly serrate in male, pronotum longer than wide, scutellum strongly folded and parameres of aedeagus cleft laterally. The pubescence is usually gray, grayish-olive, grayish-blue or greenish-blue dorsally and ventrally. I examined one male and one female from Mexico (Jalisco, Est. Biol. UNAM) with metallic pubescence grayishblue dorsally, and grayish centrally and at a narrow stripe at base of pronotum and elytra.

It is similar to $C$. viridipilis, differing especially by presence of (C. viridipilis parenthesized): 1) antennae of male strongly serrate (flabellate); 2) pronotum 1.4 times longer than wide (1.2 times); 3) tibiae of male bearing spines on internal edge (short cilia); 4) last visible sternite of male with truncate apex (rounded apex); 5) sternite VIII of male longer in C. boucardi; 6) lateral cleft of parameres more strongly curved upwardly in the latter; 7) median lobe of aedeagus shorter, with $13-14$ very small teeth (8-9 larger); 8) spiculum gastrale of sternite VIII of female shorter and sclerotized rings of openings of colleterial glands with smaller number of teeth in C. boucardi. Both species present the base of mesosternal cavity moderately declivous, and bursa copulatrix with small ventral area with carinae and spines.

C. boucardi belongs to chalcantheus* group (Fig. 671).

Distribution. It is recorded from Mexico (Jalisco, Colima, Veracruz, Guerrero, Morelos) (Fig. 679).

Chalcolepidius chalcantheus Candèze, 1857

(Figs.13-16, 106, 173, 280, 320, 358, 385, 429, 465, 500, 538, 584, $585,629,679)$
Chalcolepidius chalcantheus Candèze, 1857: 264, 288; Gemminger \& Harold, 1869: 1502 (Cat.); Candèze, 1874: 169; 1886: 68; 1891: 38 (Cat.); Schwarz, 1906a: 46; Schenkling, 1925: 55 (Cat.); Fleutiaux, 1926: 107 (Cat.); Blackwelder, 1944: 282 (Cat.); Golbach, 1977: 155, 159. Syntype female: "Syntype; Columbia; Gundet 1848; Janson coll. 1903-130.; chalcantheus [glued underside:] Chalcolepidius chalcantheus Cdz. F Type ex coll. Deyrolle" (BMNH) (examined). Chalcolepidius violaceous Pjatakowa, 1941: 104; Golbach, 1977: 155, 159. Type locality: [Brazil]: "Corumba, Mato Grosso". Syn. nov.

CANDĖZE (1857) presented a key to Chalcolepidius species where $C$. chalcantheus is separated from C. obscurus by the pubescence coloration and elytral interstices: green, unequal in the former, black, and equal in the latter. In fact, the species positions are reverted, and the interstices are equal in the former and unequal in the latter. In 1886, CANDĖZE corrected the key and included $C$. chalcantheus in a group with "intervalles égaux".

According to the original description, C. violaceous Pjatakowa, 1941, from Corumbá, is similar to C. chalcantheus, except for the violet pubescence clothing the integument. I examined specimens with pubescence green, olive, brown-olive, brown-violet and violet, and concluded that these species are conspecific.

Length: 26-32 mm. Narrow, parallel body. Integument black, clothed dorsally and ventrally, including legs, with short metallic scale-like setae green, blue, green-olive, olive, brown-olive, brown-violet or violet; antennae clothed with blue or bluishblack, except three first segments like general coloration (Figs. 13-16).

Frons not carinate, slightly concave medioanteriorly; nasal plate high and punctuate. Antennae (Fig. 106) long, surpassing hind margins of procoxae in male; serrate in female, strongly serrate in male; $3^{\text {rd }}$ segment triangular, shorter than $4^{\text {th }}$, very prominent laterally. Pronotum (Fig. 173) longer than wide, subrectangular with hind angles prominent; slightly narrowed apicad from hind angles base; moderately convex; micropunctate with sparse coarse punctuation on anterior $3 / 4$ (sparser longitudinal medially); anterior margin slightly prominent and sinuous at middle; lateral margins forming bright and small-punctuate narrow edge on proximal $2 / 3$; hind angles wide or slightly divergent, raised laterally forming edge continuous with that of lateral margin; median basal tubercle flat and triangular; posterior margin prominent and strongly notched at middle. Hypomera concave near lateral margins; micropunctate; laterointernal margin raised forming wall of well developed anterior channel. Notosternal sutures strongly sinuous; line parallel sutures on hypomera. Prosternum micropunctate, strongly convex, flattened longitudinal medially, convex near sutures. Prosternal lobe rounded, emarginated laterally; punctuation coarser than prosternum. Prosternal spine flattened laterally, prominent at middle; subapical region straight; apex rounded. Scutellum strongly folded with horizontal basal area subtrapezoidal, anterior margin grooved at middle forming two rounded prominences (not carinate), slightly notched posteriorly. Borders of mesosternal cavity (Fig. 
280) horizontal on basal $2 / 3$ and slightly declivous on distal $1 / 3$, forming an inclined profile. Meso-metasternal suture weak. Metasternum slightly narrowed behind mesosternal cavity. Last visible sternite of male with apex rounded bearing fringe of short setae. Anterior tibiae of male bearing fringe of short cilia. First visible sternite prominent laterally, fits in lateral groove of elytra. Striae marked by row of coarse punctures; interstices equal, convex and micropunctate; very flattened tubercle at base of $2^{\text {nd }}$ interstice; apices conjointly rounded, in some specimens bearing tiny sutural spine.

Male genital segments and aedeagus. Tergite VIII wider than long, strongly notched at base, rounded anteriorly. Sternite VIII (Fig. 320) subtriangular, translucent in median triangular area and two laterobasal narrow bands. Tergite IX (Fig. 358) densely punctuate, anterior margin straight with rounded angles; tiny setae lateroanteriorly. Aedeagus (Fig. 385): 4.3 times longer than wide; parameres wider ventrally; median lobe (Fig. 429) wide, slightly narrowed at middle, strongly constricted at apex and at base of basal struts, bearing 5,$6 ; 7,9 ; 8,8 ; 8,9$; 10,$10 ; 10,12 ; 11,11$ lateral teeth; lateral cleft of parameres (Fig. 465) widened and concave subapically (spoon-like).

Female genital segments and genitalia. Tergite VIII (Fig. $500)$ very wide; median basal translucent area triangular and surpassing the middle. Sternite VIII (Fig. 538) very wide, anterior margin wide- and deeply notched, 0.80 times the spiculum length. Genitalia (Figs. 584, 585): ovipositor short and wide; sclerotized rings of openings of colleterial glands (Fig. 629) bearing 63 teeth (grater-like partially); bursa copulatrix with one moderate long and narrow spiny area.

Material examined. GUATEMALA. Retalhuleu: San Sebastian, 1 M (USNM). PANAMA. 1 M (USNM). Canal Zone: Barro Colorado, $1 \mathrm{~F}$ (MCZC); Coco Solo Hosp. 1 M (TAMU). Colón: Fort Davis, 1 M (FSCA); Ft. Espanar vic. Marg. (locality not found), 1 M (JEWC); Sta Rita Ridge, 900, 1 M (FSCA). Darién: Rio Tacarcuna, 2 M (MCZC). VENEZUELA. Ex-coll. Fleutiaux, $2 \mathrm{M}$ (MNHN). Carabobo: Valencia, $1 \mathrm{M}(\mathrm{MNHN})$. Yaracuy: RioYama, 1 M (IZAV). COLOMBIA. 1 M (MNHN). Boyacá: Minas de Muzo, 1 F (MNHN). BRAZIL. Amazonas: Benjamin Constant, $1 \mathrm{M}$ (MNRJ); Rio Juruá, ex-coll. Fleutiaux, not chalcantheus, CMF von Hayek det. 1980, 1 F (MNHN); Rio Negro, 1 M (AMNH); São Paulo [de Olivença], 1 F (MNHN). Rondônia: $62 \mathrm{Km} \mathrm{SW}$ Ariquemes, nr. Fazenda Rancho Grande, 1 M (FSCA). Pará: Aldeia Coraci, $11 \mathrm{Km}$ W Canindé, Rio Gurupí, 1 M (dissected) (MZSP); Santarém, 1 F (IBSP), 1 F (MZSP), 1 F (USNM); Tiriós, Alto Parú d'Oeste, 1 M (MZSP). Maranhão: Barra do Corda, 3 M (DZUP). Mato Grosso: Bodoquena, 1 M (MZSP); Cuiabá, $1 \mathrm{~F}(\mathrm{MNHN}), 1 \mathrm{M}$ (UFMT); Corumbá, ex-coll. Fleutiaux, $2 \mathrm{M}$ (MNHN), chalcantheus Cand. ?; coll. Fleutiaux; type locality of violet Pjatak. 1941, CMF von Hayek det. $1980=$ chalcantheus, 1 M (MNHN); Rio Brilhante, 2 M (DZUP); Rondonópolis, $1 \mathrm{~F}$ (dissected) (MZSP). Mato Grosso do Sul: Salobra (Zona da N.O.B.), 1 F (MNMS), 3 M (MZSP). Goiás: ex-coll. Fleutiaux, $1 \mathrm{~F}(\mathrm{MNHN})$; Colinas do Sul, Serra da Mesa 2 M (1 M dissected, MZSP); Mineiros, 1 F (MNHN); Niquelândia, Acamp. Bagagem, 1 M (dissected) (MZSP). Minas Gerais: Buritis, Ribeirão Confins, 2 M (MZSP). Espirito Santo: Linhares, 1 M (IMLA), Parque Sooretama, 1 M (IMLA). Paraná: Foz do Iguaçu, 4 M (MZSP, retained DZUP), 45 M (DZUP). ECUADOR. Los Ríos: Rio Palenque, 1 M (FSCA). PERU. Loreto: nr jct Rio Maranon \& Ucayali $1 \mathrm{M}$ (FSCA). ARGENTINA. Misiones: Iguazu, $1 \mathrm{M}$ (MZSP)

Remarks. Chalcolepidius chalcantheus is characterized especially by narrow and parallel body; $3^{\text {rd }}$ antennal segment shorter than $4^{\text {th }}$, very prominent laterally; anterior tibiae of male bearing fringe of short cilia; last visible sternite of male with apex rounded bearing fringe of short setae; parameres wider ventrally near apex; median lobe wide with 10-12 small teeth each side; lateral cleft of parameres widened and concave subapically (spoon-like); ovipositor, tergite and sternite VIII of female very wide; sclerotized rings of openings of colleterial glands bearing 63 teeth; bursa copulatrix with one elongate spiny area.

The females of $C$. chalcantheus are very rare in the collections. The pronotum of females, including that of syntype, is wider and more convex than male. In a few males, the hind angles of pronotum are slightly divergent. The aedeagus was observed in three specimens.

C. chalcantheus belongs to chalcantheus* group (Fig. 671).

Distribution. It is widely distributed with records in Guatemala, Panama, Venezuela, Colombia, Brazil (Amazonas, Rondônia, Pará, Maranhão, Mato Grosso, Goiás, Minas Gerais, Espírito Santo, Paraná), Ecuador, Peru and Argentina (Fig. 679).

It was observed that the pubescence is blue in the majority of examined specimens from Guatemala, olive or olive-green in those from the Panama, green from Venezuela and olive-brown from Argentina. The material from Brazil presents darker coloration: brown, brown-olive, brown-violet or violet.

\section{Chalcolepidius copulatuvittatus sp. nov.}

(Figs. 17, 107, 175, 234, 281, 321, 359, 386)

Type material. Holotype male: "Venezuela (Mocquerys); Museum Paris ex-coll. R. Oberthür; Chalcolepidius gossipiatus group CMF von Hayek det. 1980"(dissected) (MNHN).

Holotype. Length: $25 \mathrm{~mm}$. Integument reddish-brown clothed dorsally and ventrally, including legs, with metallic scale-like setae brownish-olive; frons with very narrow, irregular band on proximal and distal margins with white setae; lateral stripes of pronotum joined at base, U-shaped; white pubescence on lateral stripes of pronotum, striae and epipleura; lower interstices partially clothed with white setae (Fig. 17).

Frons narrow, distal third trapezoidal; densely smallpunctuate, slightly concave medioanteriorly; nasal plate high and coarsely punctuate. Antennae (Fig. 107) strongly serrate, surpassing posterior margin of procoxae in almost one segment; $3^{\text {rd }}$ segment short, widened apicad, very shorter than $4^{\text {th }}$. Pronotum (Fig. 175) longer than wide, slightly narrowed apicad from hind angles base; anterior margin almost straight; anterior angles very prominent; lateral margins forming narrow edge, almost reaching apex, grooved internally edge; hind angles divergent, raised laterally, forming wide edge, continuous with that of lateral margin; strongly convex from groove, densely micropunctate with moderately coarse punctuation laterally on distal third; posterior margin prominent and slightly notched at middle; median basal tubercle elongate, flat, almost indistinguishable, grooved at middle. Hypomera concave, densely small-punctuate; laterointernal margin marginated 
anteriorly, not forming channel. Notosternal sutures slightly sinuous. Prosternum moderately convex from sutures, densely small-punctuate; prosternal lobe marginated laterally with angles strongly rounded; punctuation coarser than prosternum and disposed in irregular rows giving appearance of short transverse grooves. Scutellum (Fig. 234) narrower and moderately declivous on anterior half; basal half rounded. Mesosternal cavity U-shaped with borders (Fig. 281) moderately thick and horizontal on basal half and slightly declivous on distal half, forming an inclined profile. Mesometasternal suture well marked, grooved laterally. First visible sternite not prominent laterally. Tibiae of male bearing irregular row of long spines. Striae marked by row of coarse punctures; interstices flat and densely small punctuate; unequal; apices conjointly slightly rounded; hypomera with lateral carina on anterior half.

Male genital segments and aedeagus. Tergite VIII slightly wider than long; basal margin slightly notched; lateral and anterior margins rounded; setous near lateral and anterior margins. Sternite VIII (Fig. 321) transverse, subpentagonal; anterior margin very prominent at middle; three melanized areas: two lateral bands and a small distal spot. Sternite IX elongate, melanized in narrow band on distal half. Tergite IX (Fig. 359) transverse, slightly narrowed apicad; anterior margin slightly notched; densely punctuate; moderately long setae laterodistally. Aedeagus (Fig. 386): apex of parameres spearheadlike; median lobe narrow with lateral margins slightly sinuous, narrowed apicad.

Female unknown.

Remarks. Chalcolepidius copulatuvittatus is characterized especially by integument reddish-brown clothed with pubescence brownish-olive with lateral white stripes of pronotum U-shaped; striae and epipleura clothed with white pubescence; antennae of male strongly serrate; scutellum moderately declivous on anterior half; tibiae of male bearing row of spines; apex of parameres spearhead-like.

C. copulatuvittatus is the sister-group of $C$. truncuvittatus (Fig. 671).

Distribution. It is recorded from Venezuela.

Etymology. The epithet is derived from one of the latin words for joining, copulatio, related to lateral bands of pronotum.

Chalcolepidius corpulentus Candèze, 1874

(Figs. 18, 108, 176, 322, 387, 430, 466, 501, 539, 586, 630, 692)

Chalcolepidius corpulentus Candèze, 1874: 164,165; 1886: 71; 1891: 39 (Cat.); Schwarz, 1906b: 45; Schenkling, 1925: 55 (Cat.); Fleutiaux, 1926: 107 (Cat.); Blackwelder, 1944: 282. Holotype female: "21742; Type; Bahia; Fry coll. 1905.100; corpulentus Cdz. Type F; drawer $126 "$ (BMNH)(examined).

Length: $23-43 \mathrm{~mm}$. Integument black, clothed dorsally and ventrally, including legs, with thin metallic scale-like setae, olive, wine-red, violet or green; lateral stripes of pronotum wide, 1/3 of pronotum width; lateral stripes of elytra 4 interstices wide; dull yellowish-white pubescence on lateral stripes of pronotum and elytra, lower interstices (in some specimens only striae) and epipleura; antennae with dark-blue short pubescence, except three first segments (Fig. 18).

Frons slightly concave medioanteriorly; nasal plate high, declivous and punctuate. Antennae (Fig. 108) serrate in both sexes, $3^{\text {rd }}$ triangular-elongate, shorter than $4^{\text {th }}$. Pronotum (Fig. 176) slightly longer than wide (almost as long as wide in holotype and some other females), wider at hind angles, narrower at apex (stronger in holotype and some other females) from hind angles base; strongly convex anteriorly; convexity decreasing basad; anterior margin slightly sinuous; lateral margins sinuous forming edge on basal $2 / 3$; hind angles slightly divergent with truncate apex, raised laterally, continuous with that of lateral edge; micropunctate with moderately coarse punctures lateroanteriorly (on anterior half); discal area with very weak ridges; median basal tubercle flattened, triangular, continuous with very weak longitudinal median ridge, not reaching anterior margin; posterior margin prominent and strongly notched at middle. Hypomera concave near lateral margins, micropunctate; laterointernal margin raised forming wall of well developed channel. Notosternal sutures strongly sinuous. Prosternum micropunctate with coarse sparse punctuation dispersed near notosternal sutures; strongly convex, flattened longitudinal medially, slightly concave near sutures. Prosternal lobe wide, emarginated laterally with fore angles slightly rounded; punctuation small, slightly coarser than prosternum. Prosternal spine flattened laterally with apex rounded. Scutellum strongly folded with horizontal basal area subtrapezoidal, grooved anterior- and posteriorly. Borders of mesosternal cavity wide and horizontal on basal $1 / 4$ and vertical on distal $1 / 4$, forming Lshaped profile; apex of horizontal area prominent. Mesometasternal suture absent. First visible sternite prominent laterally, fits in lateral groove of elytra. Anterior and median tibiae and last tarsal segment of all legs of male bearing fringe of long cilia. Interstices convex and micropunctate, unequal, alternate; very flat tubercle at base of $3^{\text {rd }}$ interstice; apex slightly truncate.

Male genital segments and aedeagus. Tergite VIII as long as wide with anterior margin rounded; posterior margin strongly notched, almost reaching the middle. Sternite VIII (Fig. 322) wider than long, strongly narrowed on distal third; small median elongate translucent area. Tergite IX densely punctuate; anterior margin straight with rounded angles; tiny lateroanteriorly setae. Aedeagus (Fig. 387): median lobe (Fig. 430) moderately narrowed near middle and constricted at apex, bearing 7, 8 lateral teeth; lateral cleft of parameres (Fig. 466) narrowed at subapical region with apex prominent laterally and upward.

Female genital segments and genitalia. Tergite VIII (Fig. 501) transverse, almost rectangular; translucent subtriangular basal area surpassing the middle. Sternite VIII (Fig. 539) with anterior margin slightly- widely notched, 0.55 times of spiculum gastrale length. Genitalia (Fig. 586, 587): sclerotized rings of 
openings of colleterial glands (Fig. 630) bearing 19 teeth; bursa copulatrix with an elongate longitudinal median band with carinae and spines and two lateral rounded spiny areas.

Material examined. VENEZUELA. Guárico: Hato Masaguaral (44 Km S Calabozo) 4 F (USNM). BRAZIL. Ex-coll. Fleutiaux, 1 F (MNHN). Pará: Independência, 1 F (USNM); Óbidos, 3 F (MZSP). Amazonas: Benjamin Constant, $1 \mathrm{~F}$ (MZSP), Rio Javari, $1 \mathrm{~F}$ (MZSP). Ceará: $1 \mathrm{~F}$ (MZSP), 1 M, 1 F (USNM); Carquejo, 14 M, 58 F (MZSP); Fortaleza, 1 M, 1 F (MZSP), Maranguape Mts. 1 M, 1 F (USNM). Rio Grande do Norte: Natal, 1 F (MZSP). Pernambuco: Bonito, 1 M (USNM); Garanhuns, $1 \mathrm{~F}$ (AMNH). Alagoas: Pedra, $4 \mathrm{~F}$ (AMNH). Mato Grosso: Barra do Tapirapé, $7 \mathrm{~F}$ (MZSP); Buriti, Chapada dos Guimarães, $600 \mathrm{~m}, 1 \mathrm{~F}$ (DZUP); Cáceres, 3 F (DZUP); Chapada [dos Guimarães], near Cuiabá, 5 F (USNM); Jacaré, 1 F (DZUP); Rio Verde, 400 m, 1 F (DZUP); Rosário do Oeste, 10 F (MZSP), 5 F (DZUP); Rio Xingu, 1 F (DZUP). Mato Grosso do Sul: Corumbá, Serra do Urucum, 1 F (MZSP); Salobra, 1 F (MZSP), SINOP Km 500 Estrada Cuiabá-Santarém, 1 F (MZSP). Goiás: 1 F (USNM); Goiânia, 1 F (DZUP); I. Bananal, S. Isabel, 1 F (DZUP); Jataí, ex-coll. Fleutiaux, 1M (MNHN). Bahia: 1 F (PCCV), ex-coll. Fleutiaux, $15 \mathrm{~F}$ (MNHN); Joazeiro, $1 \mathrm{M}$ (DZUP); Santo Antonio da Barra, coll. Gounelle, 3 F (MNHN); de Villa Victoria [Vitória da Conquista] a Cachimbo [Campinarana], $1 \mathrm{~F}$ (MNHN). Minas Gerais: Araxá, $1 \mathrm{M}$ (DZUP); Campos de Diamantina, Faz. do Riacho Fundo, 3 F (MNHN); Catas Altas, Serra do Caraça, $1 \mathrm{~F}$ (MNHN), ex-coll. Fleutiaux, $1 \mathrm{~F}$ (MNHN); Ibiá, 1 F (DZUP); Pedra Azul, 800 m, 1 M, 1 F (DZUP); Sertão de Diamantina, Faz. das Melancias (locality not found), $1 \mathrm{~F}$ (MNHN). São Paulo: Vale do rio Pardo, ex-coll. Gounelle, 1 F (MNHN). Paraná: Paranaguá, 1 F (NHMW). Rio Grande do Sul: Porto Alegre, 1 M (MNHN). PERU. Piura: Negritos, 1 F (USNM). BOLIVIA. Tarija: Yacuiba, 2 F (USNM). PARAGUAY. 2 F (MNHN). Boquerón: Chaco, 1 F (IBSP). ARGENTINA. 6 F (NHMW), ex-coll. Fleutiaux, 1M, 1 F (MNHN). Córdoba: Córdoba, 1 M (DZUP). Jujiuy: Ledesma, 1 F (USNM). Salta: Collera, 1 M, 2 F (USNM); General Ballivían, 1 M (USNM); Meran [Teran], 1 F (USNM); Senillosa, 1 F (USNM). Santiago del Estero: ex-coll. Fleutiaux, 3 F (MNHN); Barrancas, 4 M, 3 F (MNHN); Bords du Rio Salado, env. d'Icaño, Mistol Paso, 9 F (MNHN), La Palisia del Bracho, $25 \mathrm{Km}$. d'Icaño, 4 F (MNHN), Chaco de Santiago del Estero, 1 M, 1 F (NHMW), Rio Salado, ex-coll. Fleutiaux, 1 M, 4 F (MNHN), Rio Dulce, ex-coll. Fleutiaux, $1 \mathrm{~F}$ (MNHN). Tucumán: Horco Molle (locality not found), 1 M, 1 F (DZUP); Gran Chaco, Río Tapenago, ex-coll. Fleutiaux, 2 F (MNHN); Gran Chaco, Río Tapenago, 6 F (MNHN).

Remarks. The female holotype of Chalcolepidius corpulentus is very large (42 mm length; $15 \mathrm{~mm}$ width) justifying the specific name, but the size of examined specimens is variable (23-43 mm length). In the original description the length appears as equal $12 \mathrm{~mm}$, what is clearly a misprint.

C. corpulentus is characterized especially by wide whitish lateral stripes on pronotum, usually $1 / 3$ of pronotum length; whitish pubescence also on lateral stripes of elytra and epipleura. The metallic coloration of the pubescence is usually formed by two colorations intermingled, usually green with wine-red. Sometimes the upperside has different coloration from underside, but specimens olive present the same coloration in both sides.

C. corpulentus is very similar to $C$. zonatus, differing especially by body more parallel in the former, different coloration of metallic pubescence and different number of teeth of the sclerotized rings of openings of colleterial glands (19 in the former and 46 in the latter).

It belongs to corpulentus + group (Fig. 671).

Distribution. It is recorded from South America: Venezuela, Brazil
(Pará, Amazonas, Ceará, Rio Grande do Norte, Pernambuco, Alagoas, Mato Grosso, Mato Grosso do Sul, Goiás, Bahia, Minas Gerais, São Paulo, Paraná, Rio Grande do Sul), Peru, Bolivia, Paraguay and Argentina (Fig. 692).

Chalcolepidius costatus Pjatakowa, 1941

Chalcolepidius costatus Pjatakowa, 1941: 100. Type locality: "Patria ignota".

Original description: "Niger, capite, prothorace, scutello, corpore subtus, pedibus $1 / 2$ epipleurisque rufo-brunneo aut ferrugineo-violaceo squamulosis; elytris, prothorace lateribus fulvo vittatis; vittis antice abbreviatis, postice dilatatis. Fronte late fortiter impressa. Prothorace longitudine latitudine aequali, subtilissime, densissime, antrorsum sparsim fortiter punctato, medio longitrorsum subtiliter carinulato. Angulis posticis incrassatis, divaricatis, apice subtruncatis, declivibus. Elytris ante medium dilatatis, apice emarginatis, punctatosulcatis, interstitiis imparibus costiformibus.

Long. $42 \mathrm{~mm}$. Lat. $15 \mathrm{~mm}$. Patria ignota".

Chalcolepidius cyaneus Candèze, 1881

(Figs. 19-21, 109, 177, 323, 388, 431, 467, 540, 631, 682)

Chalcolepidius cyaneus Candèze, 1881: 21; 1886: 68, 73; 1891: 39 (Cat.); Schenkling, 1925: 55 (Cat.); Fleutiaux, 1926: 107 (Cat.); Blackwelder, 1944: 282 (Cat.). Syntype female: "Coll. R. I. Sc. N. B.; Type; ex coll. Candèze; Chalcolepidius cyaneus Cand. det. E. Candèze; n. sp. cyaneus Cdz Brasil" (ISNB) (examined).

Chalcolepidius scitus Candèze, 1889: 12; 1891: 38 (Cat.); Schenkling, 1925: 57 (Cat.), Blackwelder, 1944: 283 (Cat.). Holotype female: “ Coll. R. I. Sc. N. B. Venezuela, ex coll. Candèze n. sp. scitus Cdz Venez. St; Chalcolepidius scitus Cand., dét E Candèze" (ISNB) (examined). Syn. nov.

Chalcolepidius abbreviatovittatus Pjatakowa, 1941: 99. Syn. nov.

Candèze (1881) described C. cyaneus, from Brazil, characterized especially by integument clothed with metallic pubescence blue, with dull white setae on striae and lateral stripes of elytra, and $3^{\text {rd }}$ antennal segment shorter than $4^{\text {th }}$. He commented about the similarities of this species with $C$. porcatus, and also compared it with $C$. bomplandii, $C$. mocquerysii and C. fabricii.

CANDĖze (1889) described C. scitus, from Venezuela, characterized especially by integument clothed with metallic pubescence green with dull white setae on striae and lateral stripes of elytra, and $3^{\text {rd }}$ antennal segment equal $4^{\text {th }}$. He also compared it with C. porcatus, very similar to the former. After examining available material it is concluded that $C$. scitus is a synonym of $C$. cyaneus

PJATAKowa (1941) described C. abbreviatovitatus, from Trinidad (Caparo), characterized especially by integument clothed with metallic pubescence bluish-green with lateral stripes of pronotum (shortened anteriorly) striae and sides of epipleura clothed with dull yellowish setae, $3^{\text {rd }}$ antennal segment equal $4^{\text {th }}$ and interstices unequal in width. It was examined a series of specimens that fits very well with the description of this species and concluded that this species is conspecific with C. cyaneus. 
Length: 22-41 mm. Wide, arched body. Integument black clothed dorsally and ventrally, including legs and epipleura, with short, thin, metallic scale-like setae violet-blue, greenishblue, grayish-green or green; lateral stripes of elytra three interstices wide; dull white, yellowish-white or ochraceus setae on striae and lateral stripes of elytra. Some specimens with small lateral patches on pronotum and sides of epipleura with white setae (Fig. 19-21).

Frons not carinate, strong- or moderately concave medioanteriorly. Nasal plate high, slightly declivous. Antennae (Fig. 109) serrate in both sexes, $3^{\text {rd }}$ segment elongate, triangular, as long as or slightly shorter than $4^{\text {th }}$. Pronotum (Fig. 177) longer than wide, wider at hind angles, slightly narrowed apicad from hind angles base, narrower frontally; moderately convex longitudinal medially; convexity decreasing basad; micropunctate with coarse and sparse punctuation on anterior half or only lateroanteriorly; in some specimens forming small ridges; anterior margin sinuous (in some specimens forming two prominences near middle); lateral margins raised forming narrow edge on distal $3 / 4$; slightly concave innerly edge; hind angles wide, slightly divergent with truncate apex; raised laterally forming slightly wider edge continuous with that of lateral margins; median basal tubercle flattened, triangular, continuous with longitudinal median weak ridges; posterior margin prominent and strongly notched at middle. Hypomera concave near lateral margins; laterointernal margin raised forming wall of anterior channel. Notosternal sutures strongly sinuous. Prosternum micropunctate; coarse punctuation near sutures; strongly convex, flattened longitudinal medially, concave near sutures. Prosternal lobe wide; punctuation slightly coarser and sparser than median region of prosternum; emarginated laterally with fore angles rounded. Prosternal spine flattened laterally. Scutellum strongly folded with horizontal basal area subtrapezoidal, notched anterior- and posteriorly, grooved longitudinal medially. Borders of mesosternal cavity wide and horizontal on basal 2/3 and vertical on distal 1/3, forming L-shaped profile. Meso-metasternal suture weak. First visible sternite prominent laterally, fitting in lateral groove of elytra. Anterior and median tibiae and last tarsal segments of all legs of male bearing fringe of long cilia. Interstices convex, unequal in width; $2^{\text {nd }}$ interstice forming a rounded tubercle near base; apices conjointly rounded.

Male genital segments and aedeagus. Sternite VIII (Fig. 323) strongly narrowed on distal third, setous, translucent in subtriangular median area. Tergite IX transverse, densely punctuate; anterior margin rounded bearing tiny setae lateroanteriorly. Aedeagus (Fig. 388): median lobe (Fig. 431) 0.52 times aedeagus length, slightly narrowed apicad, more strongly narrowed near middle bearing 4,$5 ; 7,7 ; 8,8$, small lateral teeth; lateral cleft of parameres (Fig. 467) strongly constricted subapically with distal angle very prominent stronger dorsally.

Female genital segments and genitalia. Tergite VIII (Fig. 502) transverse with anterior margin rounded; densely setous; translucent median area wide, more than a half of tergite length. Sternite VIII (Fig. 540) 0.59 spiculum gastrale length; anterior margin moderate- and widely notched. Genitalia: sclerotized rings of openings of colleterial glands (Fig. 631) sub-elliptical bearing 26 teeth; bursa copulatrix with wide longitudinal median elongate band with carinae and spines and two lateral large rounded spiny areas.

Material examined. WEST INDIES. Jamaica. Ex. coll. Oberthür, 1 F (MNHN). Virgin Islands. St. Thomas, Bivoni, 2 F (USNM). Trinidad. 2 F (AMNH), 1 F (MNHN), 3 F (USNM); Arima Valley, St. Andrew Trace, $1 \mathrm{M}$ (AMNH); Biche, $1 \mathrm{~F}$ (USNM); Brasso, $1 \mathrm{~F}$ (USNM); Icacos, $1 \mathrm{M}$ (USNM); Melajo Forest Sangre Grande, $1 \mathrm{~F}$ (AMNH); St. Benedict Mt. Tunapuna, $1 \mathrm{~F}$ (SRGI); $3.3 \mathrm{mi} \mathrm{SSW}$ Talparo, $4 \mathrm{~F}$ (FSCA), $1 \mathrm{~F}$ (MZSP, retained FSCA); Tabaquite, 1 F (USNM). VENEZUELA. 2 F (MNHN), 1 F (NHMW); ex-coll. Fleutiaux, $1 \mathrm{~F}(\mathrm{MNHN})$. Barinas: Caparo, $1 \mathrm{~F}$ (SRGI); [box labeled as limbatus var. Lheirminieri], ex-coll. Fleutiaux, 1 F (MNHN). Bolivar: Agua Fria (Cr. Sta Elena), 1 F (IMLA); El Peru (nr. El Callao), 1 M (MCZC). Lara: Río Claro, 1 F (FSCA). Merida: Merida, $1 \mathrm{M}$ (dissected), $5 \mathrm{~F}$ (MNHN), $5 \mathrm{~F}$ (1 dissected) (USNM), ex-coll. Hauser, $1 \mathrm{~F}$ (ZMHB), cyaneus Cand., Fleutiaux det., $1 \mathrm{M}$ (dissected) (MNHN). Zulia: Los Angeles del Tucuco, $1 \mathrm{M}$ (dissected) (MZSP, retained USNM); Maracaibo, 1 F (USNM), 1 M, 3 F (ZMUC). GUYANA. 1 F (AMNH). East Berbice: Blairmont Plantation, $1 \mathrm{~F}$ (USNM), $1 \mathrm{~F}$ (dissected)(MZSP, retained USNM); Bloomfield Coren Tyne Berbica, $1 \mathrm{~F}$ (AMNH). SURINAME. Saramacca: Paramaribo, 4 F (ZMHB), 1 F (MZSP, retained USNM). Marowijine: Langaman Kondre, 2 F (1 dissected) (MZSP). COLOMBIA. 1 M (AMNH). Antioquia: Río Leon, Chigorodo Ant., $1 \mathrm{~F}$ (MZSP, retained USNM). Cauca: Popayan, $1 \mathrm{~F}$ (MNHN). Chocó: Río San Juan, 2 F (FSCA); El Cesar, Chimichagua, $1 \mathrm{~F}$ (ICNC). Huila: $1 \mathrm{~F}$ (ICNC); Gigante, 1 F (USNM). Santander: Pico das Armas, 1100 m, 1 F (AMNH); Nst Pebrolea, 2 F (USNM).

Remarks. Comparing the syntype of Chalcolepidius cyaneus $(40 \mathrm{~mm})$ with the holotype of $C$. scitus $(20 \mathrm{~mm})$, both females, it was observed that, besides the differences related to the pubescence coloration and size, the former is more robust with pronotum more rugose.

C. cyaneus is totally clothed with green or blue setae with striae and lateral bands of elytra clothed with white dull pubescence. Some specimens present reduced lateral stripes on pronotum and sides of epipleura with white setae. It is similar to C. porcatus but it is easily separate by presence of interstices unequal in width and dull white setae on striae and lateral stripes of elytra. Besides, in C. cyaneus the apex of lateral cleft of parameres is strongly constricted subapically with distal angles more prominent dorsally while in $C$. porcatus is less constricted, with both angles similar.

When present, the white lateral stripes of pronotum vary from a short median line near lateral margins to a wider stripe $2 / 3$ of pronotum length including the hind angles.

The length of $3^{\text {rd }}$ and $4^{\text {th }}$ antennal segments is equal or slightly unequal, independent of the coloration of pubescence. When they are unequal, the $3^{\text {rd }}$ segment is slightly shorter than $4^{\text {th }}$, that is herein considered as intraspecific variation.

I examined several specimens of this species, but none male clothed totally with metallic blue pubescence was found to permit the aedeagus analysis. I dissected one male clothed totally with green pubescence (like C. scitus) and one greenishblue dorsally and green ventrally, both with striae and lateral stripes of elytra white. The only difference between them is the additions of one tooth each side of median lobe of aedeagus and the small translucent laterobasal areas of sternite VIII of 
male, larger and double at the blue specimen.

I dissected also one male (from Guyana) and one female (from Suriname) clothed with olive-green setae, and white lateral stripes on pronotum, including the hind angles and narrowed anteriad. Comparing these specimens with others dissected, only a few differences related to the reduction of the number of teeth of male median lobe and female genitalia were observed: the median lobe of aedeagus is narrower and bears 4, 5 lateral teeth and the sclerotized rings of openings of colleterial glands bear 24 teeth. These numbers are into the range variation of this species.

\section{C. cyaneus belongs to forreri* ${ }^{*}$ group.}

Distribution. It is recorded from West Indies (Jamaica, Virgin Islands), Venezuela, Trinidad, Colombia, Guyana, Suriname and Brazil (Fig. 682).

The majority of specimens from Trinidad are clothed with metallic blue or greenish-blue setae with lateral stripes of elytra and epipleura (totally or partially) clothed with dull whitish or ochraceus setae. The specimens from Suriname and Guyana are clothed with metallic olive-green setae with white lateral stripes on pronotum, including the hind angles, and on sides of epipleura, striae and lateral bands of elytra (sometimes very narrow). I examined one female from ZMHB labeled "Mex. Merida", not included in the material examined because it is the only record of this species from Mexico; probably there is confusion with the Merida from Venezuela.

Chalcolepidius desmarestii Chevrolat, 1835

(Figs. 22, 23, 110, 174, 236, 237, 282, 324, 360, 389, 432, 468, 503, $541,588,634,677)$

Chalcolepidius desmarestii Chevrolat, 1835: 195; Candèze, 1857: 269; Gemminger \& Harold, 1869: 1502 (Cat.); Candèze, 1874: 162; 1886: 69; 1891: 37 (Cat.); Champion, 1894: 275, 284, t. 11, f. 8-9; Heyne-Taschenberg, 1908: 153, t. 25, f. 17; Schenkling, 1925: 55 (Cat.); Fleutiaux, 1926: 107 (Cat.); Blackwelder, 1944: 282 (Cat.). Syntype [abdomen destroyed]: "Type; Orizaba sous les ecources; Collection Chevrolat; desmaresti Chevr. Type Chevr. Typique Mon. Cand. Collection Fleutiaux; Syntype Another F same loc. \& collector in BMNH CMF von Hayek 12.3.79" (MNHN) (examined).

Chalcolepidius desmaretsii; Lacordaire, 1857: 155 (error).

Chalcolepidius procerus Erichson, 1841: 84; Candèze, 1857: 269 (Syn.). Syntypes: 1 male, 4 females. One female: "16208; procerus Erichs*; Desmaresti Chevr. Cand.* procerus Er.*, Mexico Coul. Stark; Syntype Chalcolepidius procerus Erichson CMF von Hayek, 1980; Chalcolepidius desmarestii CMF von Hayek det. 1980"; male and 3 females: "Mexico Coul. Stark nr 16208; Syntype Chalcolepidius procerus Erich. CMF von Hayek 1980; Chalcolepidius desmarestii Chevr. CMF von Hayek det. 1980" (ZMHB) (examined).

Chalcolepidius brevicollis Casey, 1907: 35. Holotype female: "Holotype; Purula, sp figured; Purula, Vera Paz, Champion; F; B. C. A. Col. III (1) Chalcolepidius desmaresti Chevr. F; desmaresti var.; brevicollis Casey, 1907 CMF von Hayek det 1979" (BMNH) (examined). Syn. nov.

Chevrolat (1835), stated about the type locality of $C$. desmarestii "trouvé par nos voyageurs en terre froide, à Orixaba, pendant le mois de septembre, sous une écource".

Champion (1894) observed the variations of elytral coloration (from black to bright ferrugineous) and the pubescence of the upper surface, and illustrated a typical male (Tab. XII, fig. 9) and a variety female (Tab. XII, fig. 8). CASEY (1907) named this female variety as $C$. brevicollis. Herein, after examining the available material it was concluded that $C$. brevicollis is a synonym of $C$. desmarestii.

Hayek studying the Chalcolepidius collections, labeled in 1979, five specimens (4F, 1M) from Costa Rica and one female from Colombia, as $C$. castaneus sp. n., herein recognized as $C$. desmarestii.

Length: 36-43 mm. Wide, parallel body. Integument black (in some specimens elytra totally or partially ferruginous or orange) clothed with dull scale-like setae brownish (coffee with milk) ochraceus, orange or slightly ferruginous; in some specimens variable number of interstices (usually the higher) clothed with black velvety setae; some of them with rounded black patch at middle of each elytron; antennae clothed with dark-blue setae except three first segments (Figs. 22, 23).

Frons not carinate, slightly declivous. Antennae (Fig. 110) serrate in both sexes, longer in male, $3^{\text {rd }}$ segment triangularelongate, shorter than $4^{\text {th }}$. Pronotum (Fig. 174) longer than wide, parallel, almost rectangular, raised longitudinal medially; lateral margins straight, narrowed on anterior third; anterior margin prominent forming two teeth; fore angles prominent, wide and rounded; hind angles wide, backward, raised laterally, forming a narrower edge continuous with that of lateral margins reaching the apex; median basal tubercle triangular elongate, very weak; posterior margin prominent and strongly notched at middle; punctuation small with sparse umbilicate punctuation lateroanteriorly; longitudinal median region almost smooth. Hypomera concave near lateral margins; small-punctuate with umbilicate and sparse punctuation; anterior channel absent. Notosternal sutures moderately sinuous. Prosternum micropunctate with coarser and sparse punctuation; strongly convex, grooved near sutures. Prosternal lobe wide with small and sparse punctuation; emarginated laterally; angles rounded. Scutellum (Figs. 236, 237) pentagonal and slightly declivous on anterior $1 / 3$; horizontal area subtriangular with posterior margin slightly sinuous. Borders of mesosternal cavity (Fig. 282) wide, horizontal and prominent on basal $2 / 3$ and moderately declivous on distal $1 / 3$ forming semielliptical profile. First visible sternite prominent laterally, fits in lateral groove of elytra. Anterior tibiae of male bearing short spines and abruptly dilated near apex; in female, slightly dilated near apex with very short spines. Striae grooved; interstices convex, unequal, alternate; $2^{\text {nd }}$ forming basal tubercle; apex with sutural spine.

Male genital segments and aedeagus. Sternite VIII (Fig. 324) wide, subtriangular; translucent median area narrower and opened at base. Tergite IX (Fig. 630) slightly wider than long, densely punctuate; anterior margin strongly and widely notched at middle; fore angles prominent, rounded, densely clothed with short setae. Aedeagus (Fig. 389): median lobe (Fig. 432) narrow, almost straight, 0.54 times the aedeagus length, bearing 14, 14; 14, 16 small lateral teeth; lateral cleft of parameres (Fig. 468) strongly narrowed on distal third with apex rounded and upwardly directed. 
Female genital segments and genitalia. Tergite VIII (Fig. 503) transverse with anterior margin slightly prominent at middle; translucent in small basal area and lateral well developed bands. Sternite VIII (Fig. 541) 0.63 times spiculum gastrale length; anterior margin moderate- and widely notched at middle. Genitalia (Fig. 588): sclerotized pieces of openings of colleterial glands (Fig. 634) elliptical, large with small orifice and very wide wall densely clothed with small teeth; grater-like; bursa copulatrix elongate with longitudinal narrow and long band with carinae and spines, and some lateral spines.

Material examined. MEXICO. $2 \mathrm{~F}$ (MCZC), $4 \mathrm{~F}$ (MNHN), $1 \mathrm{~F}$ (MZSP), 1 M, 3 F (NHMW); 1 M, 2 F (USNM); coll. Sallé, 2 F (MNHN). Veracruz: $1 \mathrm{~F}$ (MCZC), 3 M, 1 F (MNHN), 1 F (USNM); Coatepec, 1400 m, 1 F (SRGI); Jalapa, 1 M, 7 F (AMNH), 1 F (IBSP), 3 F (USNM); Las Minas, 1 M (JEWC); Los Tuxtlas, 2 M (JEWC); Orizaba, coll. Sallé, 1 F (MNHN); 14-16 K W Sntecompn.[Sontecomapan], 1 F (JEWC); Mirada, 2 F (NHMW). Hidalgo: $3 \mathrm{Km} \mathrm{N}$ Tlanchinol, 1470 m, 49 M (UNAM), 1 M (MZSP, retained UNAM); $3.5 \mathrm{Km} \mathrm{N}$ Tlanchinol, Bosque Mesofilo de Monta[ña], $1470 \mathrm{~m}, 4 \mathrm{M}$ (UNAM), 2 M (MZSP, retained UNAM); Tlocnuil (locality not found), $1 \mathrm{M}$ (dissected) (MZSP). Puebla: Huauchinango, ex-coll. Oberthür, 3 F (MNHN); Necaxa, 1 M (MNHN). Chiapas: Ochuc [Oxchuc], 1 F (USNM). GUATEMALA. Baja Verapaz: vic. Biotopo del Quetzal, \pm 5200, 1 F (FSCA); 6 Km E Purulha, 1 F (dissected) (MZSP); 3 Km E Purulha, 4700', 1 M (FSCA). HONDURAS. 1 F (USNM). Cortés: San Pedro Sula, 1 F (MNHN). COSTA RICA. Cartago: Irazú, 1 F (USNM). Limón: Santa Clara, Hamburg Farm, 1 F (USNM). Puntarenas: Monteverde de Puntarenas, 1 F (FSCA), 1 M, 2 F (USNM). PANAMA. Chiriquí: $6 \mathrm{Km} \mathrm{S}$ Fortuna, $1 \mathrm{M}$ (JEWC); $6 \mathrm{Km} \mathrm{N}$ Fortuna Cntl, Dvd Rd, 1 F (MZSP); 7 Km S Fortuna Dam, 1 F (JEWC). COLOMBIA. Putumayo: Mocoa, 1 F (USNM).

Remarks. Chalcolepidius desmarestii is characterized especially by general pubescence brownish, orange or ferruginous, pronotum almost rectangular with longitudinal median ridge, scutellum slightly declivous, anterior tibiae of male dilated near apex and parameres of aedeagus cleft.

The integument of $C$. desmarestii is usually black, but in some specimens the elytra are totally or partially ferruginous, in others, like the holotype of C. brevicollis, it is orange, marginated by dark-brown on distal $2 / 3$. Besides, $C$. brevicollis presents longitudinal median area of pronotum brighter, scutellum narrower, interstices less raised and basal tubercle of $3^{\text {rd }}$ interstice more flattened. The general pubescence coloration varies from brownish (coffee with milk) like to $C$. desmarestii type, to ferruginous, like C. procerus type, or orange dorsally and ventrally, like $C$. brevicollis type; sometimes the ventral pubescence is clearer than dorsal. The elytra pubescence is usually unicolor, but sometimes the higher interstices are clothed with black or dark-brown. Comparing the types, the black setae cloth totally the interstices 4, 6, 8 and partially the second in C. desmarestii and C. procerus and it is very sparse on interstices 6,8 and at distal $1 / 3$ of sutural and second of $C$. brevicollis.

Besides the differences observed in the types, two specimens from Panama (1 male and 1 female) present ventral pubescence (except hypomera, elytral epipleura and lateral margins of sternites) including legs, thinner and metallic blue; the interstices of the males are more strongly convex, and the sutural spine of elytra is variable in size. Three specimens from
Costa Rica, identified by Hayek, 1979 as " $C$. castaneus sp. nov." have a rounded spot with black setae at median region of each elytron. This species was not described (HAYEK, personal communication) and this material belongs to C. desmarestii.

C. desmarestii belongs to desmarestii+ group (Fig. 671), and it is the first species to be separated inside the group formed by second main dichotomy.

Distribution. It is recorded from Mexico (Veracruz, Hidalgo, Puebla, Chiapas), Guatemala, Honduras, Costa Rica, Panama and Colombia (Fig. 677).

\section{Chalcolepidius dugesi Candèze, 1886}

(Figs.24,111,112,178,238,283,325,361,390,504,542,589,632,673)

Chalcolepidius dugesi Candèze, 1886: 70; Champion, 1894: 275, 287, t. 12, f. 19; Schenkling, 1925: 55 (Cat.); Blackwelder, 1944: 282 (Cat.). Syntypes: 3 males, 1 female: "Coll. R. I. Sc. N. B. Mexico Guanjuato [sic] E. Dugés ex-coll. Candèze; Chalcolepidius dugesi Cd. det. E. Candèze; cf. Bull. Mus. Hist. Nat. Belg. 1886 p. 1XX. One female bears Candèze's label: "n.sp. Dugesi Cand. Guanajuato" (ISNB) (examined)

Length: 20-24 mm. Narrow, parallel body. Integument darkbrown, except elytra, reddish-brown. Dorsal pubescence dull, short and brownish (slightly olive) scale-like setae, denser on pronotum; ventral pubescence, including legs and epipleura, dull, denser, longer and white; tarsi very long with white pubescence intermingled with brownish; white pubescence at basal margins of pronotum and elytra, including scutellum (Fig. 24). Antennae clothed with dark-brown setae, except 3 first segments, brownish.

Frons not carinate, slightly concave medioanteriorly; fore angles more raised and prominent giving a U-shaped appearance to anterior margin; nasal plate high. Antennae serrate in female (Fig. 111), pectinate in male (Fig. 112); $3^{\text {rd }}$ segment transverse with spiniform appendix. Pronotum (Fig. 178) longer than wide (wider in female), subrectangular, strongly narrowed anteriorly and at hind angles base; lateral margins rounded forming small raised smooth edge; strongly convex from lateral edge; punctuation small and dense, slightly sparser near discal area; anterior margin slightly sinuous; hind angles divergent with sharpened apex, raised laterally forming edge not fused with that of lateral margin; median basal tubercle transverse, flat, with transverse carina; posterior margin prominent and slightly notched at middle. Hypomera concave near lateral margins; prosternal channel absent. Notosternal sutures almost straight. Prosternum slightly convex, from sutures. Prosternal lobe truncate. Prosternal spine compressed laterally at two distal thirds. Scutellum (Fig. 238) strongly declivous, horizontal area elliptical. Borders of mesosternal cavity (Fig. 283) wide and horizontal on basal 2/3 and slightly declivous on distal $1 / 3$, forming inclined profile. First visible sternite not prominent laterally. Tibiae of male bearing row of long spines internally, longer on anterior legs. Striae slightly grooved; interstices slightly unequal in width, moderately convex and small-punctuate; $1^{\text {st }}$ interstice raised behind scutellum; lateral margins of elytra with weak grooved formed 
by $9^{\text {th }}$ stria; apices conjointly rounded.

Male genital segments and genitalia. Sternite VIII (Fig. 325) subtriangular, translucent in median basal area and marginal band. Tergite IX (Fig. 361) transverse, narrowed apicad; densely punctuate; anterior margin moderately notched; dense lateroanteriorly moderately long setae. Aedeagus (Fig. 390): apex of parameres spearhead-like; median lobe longer than a half of aedeagus length, wider near base, slightly narrower on basal $3 / 4$, distal $1 / 3$ strongly narrowed apicad.

Female genital segments and genitalia. Tergite VIII (Fig. 504) wider than long, subtrapezoidal with anterior margin slightly notched at middle; densely setous; median basal translucent area narrower on distal half, surpassing the middle. Stenite VIII (Fig. 542) 0.61 times spiculum gastrale length, with anterior margin narrow- and deeply notched at middle. Genitalia (Fig. 589): sclerotized pieces of openings of colleterial glands (Fig. 632) C-shaped, bearing 32 teeth; bursa copulatrix with short elongate irregular spiny area; two distal spermathecae.

Material examined. MEXICO. Durango: from Durango to the Pacific, 2 F (MNHN). Nayarit: Tepic, 1 F (dissected) (ZMHB). Guanajuato: Guanajuato, ex-coll. Fleutiaux, 1 M, 2 F (MNHN); Tupataro, 1 F (ZMHB), ex-coll. Sallé, coll. Fleutiaux, 1 F (MNHN).

Remarks. According to CANDÈZE (1886), two couples form the type series, however three syntypes male and one female were examined.

Chalcolepidius dugesi is characterized especially by narrow and parallel body, integument dark-brown except elytra reddishbrown, dorsal pubescence brownish and ventral whitish, antennae serrate in female and pectinate in male, tarsi very long, scutellum strongly declivous and apex of parameres spearhead-like. It is similar to C. attenuatus differing especially by (the latter parenthesized): body longer, narrower and more parallel and integument bicolor in the former (unicolor); ventral pubescence white (same color as dorsal); antennae of male pectinate (strongly serrate); pronotum more rectangular in the former; striae marked by row of coarse punctures and interstices more raised in the latter; basal melanized area of sternite VIII of male interrupted (continuous); median lobe of aedeagus narrower, constricted near apex (wide, gradually narrowed apicad).

C. dugesi, together with C. attenuatus and C. lenzi, form the attenuatus* group.

Distribution. It is recorded from Mexico (Durango, Nayarit, Guanajuato) (Fig. 673).

Chalcolepidius erythroloma Candèze, 1857

(Figs. 25,26,113,179,239,284,326,391,433,469,505,543,633,684)

Chalcolepidius erythroloma Candèze, 1857: 263, 282, t. 6, f. 1; Gemminger \& Harold, 1869: 1502 (Cat.); Schiodte, 1870: 497, t. 5, f. 1-4 et t. 6 f.1 (Biology); Candèze, 1874: 168; 1886: 67; 1891: 39 (Cat.); Champion, 1894: 272; Fleutiaux, 1907: 172; Schenkling, 1925: 55 (Cat.); Blackwelder, 1944: 282. Syntype female: "Chile; Chalcolepidius erythroloma (Dj.) Cdze F Type ex coll. Dejean" (BMNH) (not examined).

Chalcolepidius albertisi Candèze, 1878: 9; Blackburn \& Sharp, 1885:
240 (Syn.); Candèze, 1891: 39 (Cat.); Champion, 1894: 272; Sharp, 1908: 368; Fleutiaux, 1926: 107. Holotype. Honolulu, $2000 \mathrm{ft}$. (d'Albertis) (MCSN) (not examined).

CANDÈze (1857) described C. erythroloma from Chile, with general pubescence white with lateral stripes of pronotum and elytra reddish-brown (red-brick). He also enumerated one variation: "squamulis olivaceis obductus, prothoracis elytromque vittis purpureis".

CANDĖze (1878) described C. albertisi, from Honolulu (2000 feet) and stated about the similarities with C. erythroloma, especially related with pubescence coloration. He also compared the typical arched body shape of these species with that of the American species. According to CHAMPION (1894), C. erythroloma was introduced in Sandwich Islands and latter described under a separate name, $C$. albertisi.

BLACKBURN \& SHARP (1885) synonymized C. albertisi under C. erythroloma.

Fleutiaux (1907) treating of C. erythroloma, questioned if this species really belonged to Chilean fauna. He examined the type (from Chile) and several other specimens from Ecuador, and suggested the latter locality as the "homeland" of this species. He also questioned the large distance between these two countries, and the presence of this species in Chile, which fauna offers special characters. Another surprise for him was that no record was found in the intermediary countries, Peru and Bolivia. Herein, material from Peru was studied.

Length: 25-43 mm. Wide, arched body, almost parallel. Integument black, clothed dorsally and ventrally with dense and dull like-scales setae, yellowish-white or grayish-white (slightly darker ventrally); lateral stripes of pronotum narrow sub-elliptical not reaching margins; lateral stripes of elytra 2 or 3 interstices wide (starting on $8^{\text {th }}$ ); reddish-brown (brick-brown) or orange pubescence on lateral stripes of pronotum and elytra (Fig. 25, 26). Antennae clothed with thin metallic dark-blue pubescence except three first segments, yellowish-or grayishwhite.

Frons not carinate, strongly or moderately declivous. Antennae (Fig. 113) serrate in both sexes; $3^{\text {rd }}$ triangular-elongate, shorter than $4^{\text {th }}$. Pronotum (Fig. 179) longer than wide, wider at hind angles, narrowed apicad from hind angles apices; subtrapezoidal; moderately convex; micropunctate with coarse irregular punctuation forming weak ridges; anterior margin sinuous at middle; lateral margins raised laterally forming narrow smooth edge on distal 2/3; hind angles short, wide, slightly divergent with truncate apex; raised laterally forming an edge continuous with that of lateral margins; median basal tubercle flattened, triangular, continuous with weak longitudinal median ridge, almost reaching anterior margin; posterior margin prominent and strongly notched posteriorly. Hypomera concave near lateral margins; micropunctate; laterointernal margin raised forming wall of anterior channel. Notosternal sutures strongly sinuous. Prosternum micropunctate; punctuation coarse near sutures; strongly convex, flattened longitudinal medially, concave near sutures. Prosternal lobe 
wide with punctuation sparse and slightly coarser than median region of prosternum; emarginated laterally with fore angles slightly rounded. Prosternal spine flattened laterally. Scutellum (Fig. 239) strongly folded with horizontal basal area subtrapezoidal. Borders of mesosternal cavity (Fig. 284) wide and horizontal on basal $1 / 4$ and vertical on distal $1 / 4$, forming Lshaped profile. Meso-metasternal suture absent. First visible sternite prominent laterally, fits in lateral groove of elytra. Anterior and median tibiae and last tarsal segment of all legs of male bearing fringe of long cilia. Striae grooved; interstices unequal, convex and micropunctate; interstices $2-5$ joined at base forming a very flat tubercle; elytral apex truncate with small sutural spine.

Male genital segments and aedeagus. Sternite VIII (Fig. 326) transverse, strongly narrowed apicad; subtrapezoidal, emarginated basally; translucent in a trapezoidal median area, two small basal elongate spots and two short lateral bands. Tergite IX transverse, densely punctuate, slightly narrowed distad; proximal margin emarginated; anterior margin straight with rounded angles; tiny laterodistal setae. Aedeagus (Fig. 391): median lobe (Fig. 433) 0.51 times the aedeagus length, wide at base, moderately narrowed near middle, bearing 7 teeth each side; lateral cleft of parameres (Fig. 469) slightly narrowed near apex; apex slightly notched and concave longitudinally.

Female genital segments and genitalia. Tergite VIII (Fig. 505) slightly wider than long; basal margin notched; median translucent basal area longer than a half of its length. Sternite VIII (Fig. 543) 0.59 times spiculum gastrale length; anterior margin wide- and deeply notched. Female genitalia: sclerotized rings of openings of colleterial glands (Fig. 633) bearing 39 teeth; bursa copulatrix with longitudinal median elongate band with carinae and spines and two lateral rounded spiny areas.

Material examined. HAWAIAN ISLANDS. 2M, 1 F (USNM). Oahu: 1 F (FSCA), 1 F (ZMUC); Aiea Loop, Trail, 1 F (FSCA); Honolulu, 1 F (MNHN), 1 M (dissected) (MZSP), 1 M (USNM); Fedontaines (locality not found), 1 F (MNHN); Koolau Range, 1 M, 1 F (FSCA); 1 M (USNM); 2 Km NE Makiki, Makiki Forest Trail, 1 F (MZSP, retained USNM); Manoa, ex-coll. Fleutiaux, 1 F (MNHN); Nuuanu Val., 1 M (FSCA); Pupukea, 1 F (USNM); Tantalus, 1 F (USNM); Waikane, ex-coll. Fleutiaux, $1 \mathrm{~F}$ (MNHN). ECUADOR. $2 \mathrm{~F}$ (AMNH), $1 \mathrm{~F}$ (FSCA), $1 \mathrm{~F}$ (MNHN), $1 \mathrm{~F}$ (USNM), ex-coll. Fleutiaux, 2M, $1 \mathrm{~F}(\mathrm{MNHN})$. Bolivar: Chimbó, $17 \mathrm{~F}$ (MNHN). Guayas: Arenillas, 8 F (MNHN); Balzas, 2 F (USNM); Bucay, 300m, 5 F (USNM); Bucay (Cape Noire) 300 m, 2 F (MNHN); Guayaquil, 1 F (FSCA), 7 F (USNM), 2F (ZMHB, ex-coll. G. Hauser, 1 F (ZMHB); $9 \mathrm{Km} \mathrm{N}$ Guayaquil, $1 \mathrm{~F}$ (USNM), Ingenio San Carlos, $1 \mathrm{M}$ (PCCV); La Chima, 3 F (MNHN); San Carlos, 2 F (ZMHB). Loja: Loja, 2 F (MNHN); Malacatus, $1500 \mathrm{~m}, 1 \mathrm{~F}$ (AMNH). Los Rios: Balzapamba, $650 \mathrm{~m}, 1 \mathrm{~F}$ (dissected) (MZSP), $10 \mathrm{~F}$ (USNM), $4 \mathrm{~F}$ (ZMHB), ex-coll. Fleutiaux, $2 \mathrm{~F}$ (MNHN); Catayama (locality not found), $1 \mathrm{~F}$ (USNM); Pichilingue, $1 \mathrm{~F}$ (IMLA); Playa de Montalvo, 7 F (AMNH); Quevedo, 1 F (ZMHB); Río Palenque, 1 F (FSCA); Río Palenque Station, 2 F (FSCA); vic. Quebrada (locality not found), $1 \mathrm{~F}$ (MZSP, retained USNM), $6 \mathrm{~F}$ (USNM). Manabi: Cojimíes, 1 M, 1 F (AMNH). Morona-Santiago: Macas, ex-coll. Fleutiaux, 4 F (MNHN). Pastaza: Curaray, ex-coll. Fleutiaux, 1 F (MNHN). Pichincha: Chemin entre Guanacilla et San Nicolas, 1 F (MNHN); Monts Balzar, ex-coll. Oberthür, 2 F (MNHN); Santo Domingo de los Colorados, $500 \mathrm{~m}, 1 \mathrm{~F}$ (MNMS), $1 \mathrm{~F}$ (USNM); $17 \mathrm{Km}$ E Sto Domingo de los Colorados, 1 F (FSCA). Chimborazo: Los Lanos, 2 F (ZMHB). Localities not found: Baron, $1 \mathrm{~F}$ (MNHN); Santo Domingo, $1 \mathrm{~F}$ (MNHN); Rio Cajapas, 1 F (MNHN); Alto Río Cayena, 950 m, 1 F (MNMS). CHILE. Ex-coll. Fleutiaux, $1 \mathrm{~F}$ (MNHN), ex-coll. Oberthür, $1 \mathrm{~F}$ (MNHN). PERU.
Junín: Macas, 1 F (USNM); Satipo, 1 F (FSCA). La Libertad: Pacasmayo, Pueblo Nuevo, 1 F (IMLA). Puno: Balzapata, 650 m, 4 F (USNM). Tumbes: El Caucho, vic. Tumbes, E. Pte Pizarro, 1 F (IMLA).

Remarks. Chalcolepidius erythroloma is characterized especially by general white pubescence, with lateral stripes on pronotum and elytra clothed with ferruginous setae; lateral stripes of pronotum narrow, short and elliptical. The stripes on pronotum and elytra vary in size and coloration (orange to dark reddish-brown). It was examined one specimen from Fleutiaux collection, without locality (collect. Chevrolat; erythroloma typique Cand. Mon. Collection Fleutiaux; Rev. Chil. Hist. Nat. XI 1907, p. 172 collection Fleutiaux) that presents striae two and three, and distal $2 / 3$ of first interstice, clothed with ferruginous pubescence.

C. erythroloma is similar to C. rugatus, differing especially by (the latter parenthesized): 1) ventral pubescence yellowishwhite or grayish-white (reddish-brown); 2) lateral reddish-brown stripes of pronotum short and distant from lateral margins (marginal and longer or absent); 3) $3^{\text {rd }}$ antennal segment shorter than $4^{\text {th }}$ (equal); 4) sclerotized rings of openings of colleterial glands bearing 39 teeth (34, 44 teeth); 5) apex lateral cleft of parameres slightly notched and convex longitudinally (slightly rounded).

\section{C. erythroloma belongs to fryi* group (Fig. 671).}

Distribution. It is recorded from Hawaiian Island (Oahu- not included in the map), Ecuador, Chile and Peru (Fig. 684).

Chalcolepidius eschscholtzi Chevrolat, 1833

(Figs. 27,114,180,240,327,392,434,470,506,544,591,635,685)

Chalcolepidius eschscholtzi Chevrolat, 1833: 7; Candèze, 1857: 263, 279, t. 5, f. 8; Gemminger \& Harold, 1869: 1502 (Cat.); Candèze, 1874: 167; 1886: 71; 1891: 39 (Cat.); Champion, 1894: 274, 277; Schenkling, 1925: 56 (Cat.); Fleutiaux, 1926: 107 (Cat.); Blackwelder, 1944: 282 (Cat.). Syntype female: "Mexico bacci [illegible]; Type; collection Chevrolat; Eschscholtzi Chevr. type Germ. vidit. 1843 collection Fleutiaux [stuck underside of label:] Type Chevrolat Col. Mex. 1833“ (MNHN) (examined).

According to the original description (CheVRolat 1833), "M. Lesueur a trouvé cette espèce assez abondamment sur les bois nouvellement coupés".

CANDÈze (1857) enumerated five variations to $C$. eschscholtzi: Var. a. "Squamulis viridi-aeneis, cinnabarinocircumcinctus", that included C. eschscholtzi and C. mexicanus Dej.; Var.b. "Squamulis aeneis, albido-circumcinctus", including C. lafargi; Var. c. "Squamulis fusco-aeneis, albido circumcinctus"; Var. d. "Squamulis olivaceis, purpureocircumcinctus, elytris striis albidis"; Var. e. "Squamulis aeneis, fulvo-circumcinctus, elytris striis fulvis". Some of these variations correspond to C. eschscholtzi and others to C. lafargi.

The present interpretation of $C$. eschscholtzi includes CANDĖZE's (1857) variations $a$ and $d$, and $C$. lafargi, $b$ and $c$. I did not find any specimen belonging to variation $e$ (cupreous setae, contour and striae yellow).

Length: 31-48 mm. Large, wide, arched body with convex 
elytra. Integument black clothed dorsally and ventrally with short metallic scale-like setae green or yellowish-green, in some places intermingled with golden; lateral stripes of pronotum narrowed at extremities, not reaching basal margin; lateral stripes of elytra three interstices wide; brown or reddish-brown setae on lateral stripes of pronotum and elytra (Fig. 27). Antennae clothed with blue, except three first segments, green.

Frons not carinate, moderately declivous. Antennae (Fig. 114) serrate in both sexes, $3^{\text {rd }}$ segment triangular elongate, longer than $4^{\text {th }}$. Pronotum (Fig. 180) as long as wide, wider at hind angles, narrowed apicad from hind angles apices; subtrapezoidal; convex anteriorly and flat basad; punctuation very coarse forming ridges; anterior margin slightly sinuous at middle; hind angles short, wide, backward, raised laterally forming small edge continuous with that of lateral margins, almost reaching the apex; median basal tubercle flat, triangular, grooved longitudinally and continuous with longitudinal median weak ridge; posterior margin prominent and strongly notched at middle. Hypomera convex, stronger near lateral margin; micropunctate with small sparse umbilicate punctuation; laterointernal margin raised forming wall of anterior channel. Notosternal sutures strongly sinuous. Prosternum small-punctuate with coarse punctuation near sutures; longitudinal median region with weak punctuation, almost smooth; strongly convex, flattened longitudinal medially, concave near sutures. Prosternal lobe wide, small-punctuate, in some specimens with longitudinal weak grooves; fore angles slightly rounded. Prosternal spine flattened laterally. Scutellum (Fig. 240) strongly folded, horizontal area subtrapezoidal, notched anterior and posteriorly, grooved longitudinally on anterior half. Borders of mesosternal cavity wide and horizontal on basal $3 / 4$ and vertical on distal $1 / 4$, forming L-shaped profile. Meso- metasternal suture weak, convergent at cavity base. First visible sternite prominent laterally fits in lateral groove of elytra. Anterior and median tibiae and last tarsal segments of all legs of male bearing fringe of long cilia. Striae grooved, interstices unequal and convex; $2^{\text {nd }}$ interstice flattened and prominent anteriorly forming flat tubercle; scutellar area slightly grooved.

Male genital segments and aedeagus. Sternite VIII (Fig. 327) transverse strongly narrowed on distal $1 / 3$, translucent in subtrapezoidal median area, paired basal rounded patches and lateral short bands. Sternite IX elongate, partially membranous bearing moderately long setae more concentrate near apex. Tergite IX densely punctuate, with anterior margin rounded, bearing tiny setae lateroanteriorly. Aedeagus (Fig. 392): median lobe short, approximately 0.50 times the aedeagus length; 0.53 times the parameres length; narrowed apicad, constricted near middle, bearing 6, 7 lateral teeth (Fig. 434); lateral cleft of parameres (Fig. 470) slightly narrowed near apex; apex straight, prominent ventrally and upwardly directed.

Female genital segments and genitalia. Tergite VIII (Fig. 506) transverse, setous; translucent in basal area and paired lateral narrow bands. Sternite VIII (Fig. 544) 0.56 times spiculum gastrale length, with anterior margin wide- and slightly notched; apex of spiculum gastrale rounded. Genitalia (Fig. 591): sclerotized rings of openings of colleterial glands (Fig. 635) bearing 41 teeth; bursa copulatrix with wide longitudinal median elongate band with spines and carinae and paired lateral rounded spiny areas.

Material examined. MEXICO. $1 \mathrm{~F}$ (IMLA), $8 \mathrm{~F}$ (MCZC), $3 \mathrm{~F}$ (MNHN), 1 F (MZSP), 1 F (NHMW), 3 F (USNM), ex-coll. Fleutiaux, 1 M, 3 F (MNHN). Sinaloa: Tolosa, 1 M, 48 F (AMNH). Durango: excoll. Fleutiaux, $1 \mathrm{~F}$ (MNHN); from Durango to Pacific, $7 \mathrm{M}, 1 \mathrm{~F}$ (MNHN). Veracruz: 18 F (MNHN); Balzapota (locality not found), U. M. Biol. Sta., 1 F (FSCA); Lake Catemaco, 1 M, 1 F (FSCA), 1 F (MZSP); Cordova, 5 F (USNM), BCA Col. III (1), 1 F (AMNH), 1 F (MNHN); Cotaxtla, 1 F (USNM); Dos Amantes, 3 F (IMLA), (cerca de Catemaco) 2 F (MZSP), 3 F (USNM); Est. Biol. Los Tuxtlas, Camino a Balzapote, 2 F (UNAM); Franca Vieja (locality not found), 1 F (AMNH); Fortin, 1 F (USNM); Francita, 1 F (USNM); La Buena Ventura, 1 F (AMNH); Los Tuxtlas, 7 F (UNAM), 3 F (MZSP, retained UNAM), 2 F (USNM), vic. Balzapote, 1 F (FSCA); Motzorongo, 1 F (MNHN); Orizaba, 1 F (NHMW); Reg. Orizaba, 2 M, 20 F (MNHN); Presidio, 5 F (IBSP), 1 M, 1 F (USNM); 14-16 Km W S'ntompn [Sontecomapan], 5 F (JEWC), 2 M (1 dissected) (MZSP); Santa Lucrecia, 1 M (USNM); Soteapan, 1 F (MZSP), $300 \mathrm{~m}, 1 \mathrm{M}$ (SRGI); $3 \mathrm{Km} \mathrm{S}$ Temascal, $1 \mathrm{~F}$ (FSCA); Tezonapa, $4 \mathrm{~F}$ (AMNH). Mexico: San Martin, 1 M, 1 F (PCCV); Santa Rosa, 1 F (MZSP, retained MZSP), 3 F (USNM). Morelos: Cuernavaca, 1 F (AMNH). Oaxaca: Chiltepec, 1 F (UNAM); Finca San Carlos (30 Km E Palomares), $1 \mathrm{~F}$ (dissected) (MZSP); Palomares $1 \mathrm{~F}$ (MZSP), (Finca San Carlos), $1 \mathrm{~F}$ (IBSP); Valle Nacional, 2 F (USNM); Tehuantepec, 1 F (USNM. Chiapas: ex-coll. Fleutiaux, 2 F (MNHN); San Quintin, 1 F (FSCA).

Remarks. Chalcolepidius eschscholtzi is characterized especially by wide arched body, clothed with green metallic pubescence with lateral stripes on pronotum (narrowed at extremities) and elytra clothed with brown setae, pronotum rugose, and subapical region of lateral cleft of parameres slightly narrowed with apex straight, prominent ventrally and upwardly directed.

It belongs to fryi* group (Fig. 671).

Distribution. It is restricted to Mexico (Sinaloa, Durango, Veracruz, Morelos, Mexico, Oaxaca, Chiapas) (Fig. 685).

Chalcolepidius extenuatuvittatus sp. nov.

(Figs. 28, 115, 181, 242, 285, 545, 590, 637, 674)

Type material. Holotype female. "Caracas —? Mus. Drews" (ZMUC). Paratype female. "Venezuela 1891 Meiners leg 15.11.1892" (dissected) (MZSP retained ZMUC).

Holotype. Length: $46 \mathrm{~mm}$. Integument black clothed dorsally and ventrally, including legs, with short metallic scale-like setae green; pronotum with small triangular-short patch clothed with dull white setae at hind angles base; few white setae on stria IX and lateroexternal margin of epipleura; antennae clothed with short blue setae except three first segments, green (Fig. 28).

Frons trapezoidal on distal $1 / 3$, moderately concave medioanteriorly; nasal plate high and coarsely punctuate. Antennae (Fig. 115) serrate, not reaching anterior margins of procoxae; $3^{\text {rd }}$ segment shorter than $4^{\text {th }}$, elongate with spiniform appendix. Pronotum (Fig. 181) as long as wide, wider at hind angles; narrowed apicad, from hind angles base; anterior margin slightly prominent at middle; anterior angles prominent; lateral margins forming narrow raised smooth edge, almost reaching 
apex; strongly convex and grooved internally to lateral edge; small-punctuate with moderately coarse punctuation, more concentrate on lateroanterior 2/3; hind angles divergent, raised laterally forming edge slightly wider and continuous with that of lateral margins; posterior margin downward, prominent and slightly notched at middle; median basal tubercle flat and elongate. Hypomera concave, small-punctuate; slightly swollen anteriorly, not forming anterior channel; narrow impunctuate band parallel notosternal sutures. Notosternal sutures slightly sinuous. Prosternum moderately convex from sutures, smallpunctuate. Prosternal lobe transverse with anterior angles rounded; anterior margin notched at middle; punctuation slightly coarser and sparser than that of prosternum. Scutellum (Fig. 242) strongly declivous; anterior half narrower, almost perpendicular; horizontal area sub-elliptical, grooved at middle and notched medioanteriorly. Mesosternal cavity sub-elliptical with borders (Fig. 285) thick and horizontal on basal 2/3 and moderately declivous on distal $1 / 3$, forming a semi-elliptical profile. Meso-metasternal suture well marked. First visible sternite not prominent laterally. Striae grooved, marked by row of coarse punctures; interstices strongly unequal, convex and small-punctuate; $2^{\text {nd }}$ and $3^{\text {rd }}$ interstices joined at base forming flattened forward basal tubercle; apices conjointly rounded with small sutural spine; lateral margins not marginated.

Female genital segments and genitalia (paratype, Venezuela). Tergite VIII (Fig. 507) transverse, melanized totally; anterior margin prominent at middle; basal margin notched; densely setous. Sternite VIII (Fig. 545) 0.6 times spiculum gastrale length; anterior margin narrow- and deeply notched. Genitalia (Fig. 590): sclerotized pieces of openings of colleterial glands (Fig. 637) C-shaped bearing 50 teeth; teeth disposed into two levels: lateroexternal row higher; bursa copulatrix with long longitudinal median band with carinae and spines; one spermatheca [second probably broken].

Male unknown.

Remarks. The paratype is $41 \mathrm{~mm}$ long and does not present white dull setae. The genitalia was a little damaged and it was possible to find only one spermatheca. It was observed that the bursa copulatrix is formed by slightly stronger tissue than the other parts of genitalia and it presents a reinforced area at base of laterointernal margin.

Chalcolepidius extenuatuvittatus is characterized especially scutellum strongly declivous and sclerotized pieces of the openings of colleterial glands $\mathrm{C}$-shaped with 50 teeth disposed into two levels.

It belongs to extenuatuvittatus + group (Fig. 671).

Distribution. It is recorded from Venezuela (Fig. 674).

Etymology. The epithet is derived from one of the latin words for reducing, extenuatio, related to lateral bands of pronotum.

Chalcolepidius exulatus Candèze, 1874

(Figs. 29, 116, 182, 241, 286, 393, 675)
Chalcolepidius exulatus Candèze, 1874: 161; 1886: 66, 69; 1891: 37 (Cat.); Schenkling, 1925: 56 (Cat.); Fleutiaux, 1926: 107 (Cat.); Blackwelder, 1944: 282 (Cat.). Syntype male: "Syntype; Type; Brazil; Janson coll. 1903-130; exulatus Cdz. Type [handwritten]; Chalcolepidius exulatus Cdze. Type M" (BMNH) (examined).

CANDĖZE (1874) described C. exulatus, from Brazil, based on material belonging to M. Janson's collection. He commented the similarities of this species with $C$. lemoinii, and stated that, if the type locality would be correct, this was the first species of $1^{\text {st }}$ section (scutellum declivous on anterior half) recorded from Brazil.

Length: $28 \mathrm{~mm}$. Integument black, clothed dorsally and ventrally, including legs, with greenish-gray metallic setae, partially glabrous dorsally, pubescence present only in small areas; lateral stripes of pronotum band-like (1/4 of pronotum width), narrowed anteriad, not reaching anterior margin, with internal margin sinuous; lateral stripes of elytra one interstice wide (interstice IX); white setae on lateral stripes of pronotum and elytra, striae (at least distal half) and epipleura (except triangular laterointernal area) (Fig. 29). Antennae clothed with brown setae, except 3 first segments, gray.

Frons pentagonal on distal $1 / 3$, concave medioanteriorly in triangular area; nasal plate high and punctuate. Antennae (Fig. 116) surpassing posterior margin of procoxae in one segment; strongly serrate in male; $3^{\text {rd }}$ segment short and triangular. Pronotum (Fig. 182) longer than wide, sub-rectangular, wider at hind angles, slightly narrowed apicad and slightly narrowed at hind angles base; anterior margin slightly prominent at middle; anterior angles slightly downwards, prominent and rounded; lateral margins forming narrow raised small-punctuate edge; strongly convex medioanteriorly, convexity decreasing basad; small-punctuate with slightly coarse punctuation dispersed on anterior half; lateral edge limited internally by coarse punctures and small groove; hind angles backwards, raised laterally in moderately wide edge, discontinuous from that of lateral margins; median basal tubercle flat and elongate with median elliptical concavity; posterior margin prominent and slightly notched at middle. Hypomera convex and small-punctuate, raised anteriorly, not forming anterior channel; slightly raised in narrow smooth band parallel notosternal sutures. Notosternal sutures slightly sinuous. Prosternum convex from sutures, small-punctuate; punctuation coarser and denser near sutures; two transverse short grooves anteriorly. Prosternal lobe transverse with rounded angles; marginated laterally; anterior margin notched at middle; punctuation coarser and sparser than median region of prosternum. Mesosternal cavity Vshaped with borders (Fig. 286) thick and horizontal on basal 2/ 3 and moderately declivous on distal $1 / 3$, forming an inclined profile. Tibiae of male bearing row of long spines internally. First visible sternite slightly prominent laterally fitting in small groove of elytra. Scutellum (Fig. 241) strongly declivous on anterior half; horizontal area sub-elliptical, with posterior margin prominent at middle. Striae grooved, marked by row of coarse punctures; interstices unequal, strongly convex and smallpunctuate; $2^{\text {nd }}$ and $3^{\text {th }}$ interstices fused at base forming small 
tubercle; epipleura forming small inclined carina, not reaching internal margin; apices conjointly rounded with small sutural spine.

Male genital segments and aedeagus. Sternite VIII subpentagonal with anterior margin very prominent; melanized band broken in three parts. Tergite IX transverse, densely punctuate with anterior margin rounded and marginal lateroanterior setae. Aedeagus (Fig. 393): median lobe slightly narrowed near middle; apex of parameres spearhead-like.

Female not studied.

Material examined. VENEZUELA. 1 M (MNHN). Federal District: Caracas, $1 \mathrm{M}$ (dissected, USNM). Without locality: ex-coll. Oberthür 1 $\mathrm{M}(\mathrm{MNHN})$

Remarks. Chalcolepidius exulatus is characterized especially by integument black clothed with greenish-gray pubescence with whitish setae on lateral stripes of pronotum and elytra and epipleura, antennae strongly serrate in male, scutellum strongly declivous on anterior half and apex of parameres spearhead-like. The lateral stripes of pronotum are variable in shape and size among the males examined. In the syntype, they do not reach the anterior margin of pronotum; in the specimen from "Venezuela" (MNHN), they are narrower and shorter and in the two others, a little longer than the syntype. The specimen from "Caracas", different from the others, presents the hypomera partially clothed with whitish setae.

C. exulatus is similar to C. gossipiatus, differing especially by (latter parenthesized): 1) pronotum with narrow lateral stripes (absent);2) white setae on narrow lateral stripes on elytra and epipleura (lateral bands of elytra wider, not reaching epipleura); 4) horizontal area of scutellum proportionally wider than the latter.

C. exulatus belongs to serricornis + group and it is the sister-group of C. albiventris (Fig 671).

Distribution. Besides the type locality, Brazil, it is recorded also from Venezuela (Fig.675)

Chalcolepidius fabricii Erichson, 1841

(Figs. 30, 117, 183, 328, 394, 435, 471, 508, 546, 636, 684)

Chalcolepidius fabricii Erichson, 1841: 83; Candèze, 1857: 277; Gemminger \& Harold, 1869: 1503 (Cat.); Steinheil, 1875: 110; Candèze, 1886: 68, 73; 1891: 39 (Cat.); Schenkling, 1925: 56 (Cat.); Fleutiaux, 1926: 107 (Cat.); Blackwelder, 1944: 282 (Cat.). Syntypes: 5 females. [1] "16222; Fabricii Er.* Cand.* Bogota Bug.; Syntype Chalcolepidius fabricii Erichson, C M F von Hayek, 1980"; [2-5] "Bogota, Bug. Nr. 16222; Syntype Chalcolepidius fabricii Erichson, C M F von Hayek, 1980" (ZMHB) (examined).

Chalcolepidius marginatus Sturm, 1843: 67 (Cat.) (nomen nudum); Gemminger \& Harold 1869: 1503 (Syn.)

Chalcolepidius fabricii var. a Candèze, 1857: 277.

CANDÈzE (1857) presented one variation to this species: "var. a. Elytris striis albido-squamulosis".

Length: 27-40 mm. Wide, arched body. Integument black clothed dorsally and ventrally (including epipleura) with short metallic scale-like setae green, olive or grayish-green, sometimes brownish at middle of pronotum; elytra with lateral stripes ( 2 or 3 striae wide) clothed with dull ferruginous or yellowish-white setae; in some specimens striae ferruginous (Fig. 30). Antennae (Fig. 117) clothed with black setae except 3 first segments, greenish.

Antennae (Fig. 117) serrate in both sexes; $3^{\text {rd }}$ segment triangular-elongate, slightly shorter than $4^{\text {th }}$. Frons not carinate, moderately declivous. Pronotum (Fig. 183) longer than wide, wider at hind angles, narrowed apicad from hind angles base; slightly convex, convexity decreasing basad; small-punctuate with coarse punctures more concentrate on discal area; rugose; anterior margin sinuous at middle; hind angles wide, slightly divergent, raised laterally forming narrow edge continuous with that of lateral margins, not reaching apex; median basal tubercle flat, triangular, continuous with median weak ridge; posterior margin prominent and strongly notched posteriorly. Hypomera concave near lateral margins; micropunctate; laterointernal margin raised forming wall of anterior channel. Notosternal sutures strongly sinuous. Prosternum micropunctate, strongly convex, concave near sutures, flattened longitudinal medially. Prosternal lobe small-punctuate, wide, emarginated laterally, fore angles rounded. Scutellum strongly folded with horizontal basal area subtrapezoidal, notched anterior- and posteriorly. Borders of mesosternal cavity wide and horizontal on basal $2 / 3$ and vertical at distal $1 / 3$, forming L-shaped profile. First visible sternite prominent laterally, fits on lateral channel of elytra. Anterior and median tibiae and last tarsal segment of all legs of male bearing fringe of long cilia. Striae grooved; interstices convex, unequal in width; $2^{\text {nd }}$ forming a flat tubercle at base.

Male genital segments and aedeagus. Sternite VIII (Fig. 328) transverse, gradually narrowed apicad, with anterior margin slightly notched at middle; translucent in trapezoidal median and two lateral elliptical areas, and two narrow lateral bands. Tergite IX densely punctuate with anterior margin rounded, bearing tiny lateroanterior setae. Aedeagus (Fig. 394): median lobe (Fig. 435) 0.53 times the aedeagus length, moderately narrow near middle and strongly narrowed apicad, bearing 4, 6 lateral teeth; lateral cleft of parameres (Fig. 471) slightly narrowed near apex, with lateroapical sharpened angles.

Female genital segments and genitalia. Tergite VIII (Fig. 508) transverse, setous, translucent median basal area and two lateroanterior bands. Sternite VIII (Fig. 546) 0.60 times spiculum gastrale length; anterior margin wide- and deeply notched. Genitalia: sclerotized rings of openings of colleterial glands (Fig. 636) bearing 41 teeth; bursa copulatrix with elongate longitudinal median area with carinae and spines and two lateral rounded spiny area.

Material examined. "NEW GRANADA". ex-coll. Chevrolat, excoll. Fleutiaux, $1 \mathrm{~F}$ (MNHN). VENEZUELA. $2 \mathrm{~F}$ (MCZC). COLOMBIA. $1 \mathrm{M}, 1 \mathrm{~F}(\mathrm{AMNH}), 2 \mathrm{~F}$ (MCZC), $1 \mathrm{~F}(\mathrm{MNHN}), 1 \mathrm{~F}$ (NHMW), $1 \mathrm{~F}$ (USNM), $2 \mathrm{~F}$ (ZMHB), $2 \mathrm{~F}$ (ZMUC), ex-coll. Fleutiaux, $1 \mathrm{M}, 2 \mathrm{~F}$ (MNHN). Antioquia: ex-coll. Fleutiaux, 1 F (MNHN); La Miel, Río Samana, (tronco), 1 F (ICN-MNHN); Medellín, $1 \mathrm{M}, 1 \mathrm{~F}$ (USNM); Territorio Vásquez (TV-395), 1 F (dissected) (MZSP). Boyacá: Muzo 3 F (AMNH), 2 F (ZMHB), (780 m), 1 F (USNM), (900 m), 2 F (MCZC), ex-coll. Fleutiaux, 1 F (MNHN); Pauna, Manote Bajo, La Rocheta, Alt. 
1280 mts, 1 F (ICNC). Caquetá: Yabi Caqueta, 2 F (IMLA). Chocó: Río Sucio La Balsa 50-80m $1 \mathrm{~F}$ (IAHC). Cundinamarca: Bogotá, $1 \mathrm{~F}$ (MNHN), $1 \mathrm{M}$ (NHMW), $1 \mathrm{~F}$ (SRGI), $1 \mathrm{~F}$ (ZMHB), ex-coll. Fleutiaux, 5 F (MNHN), 1 M, 9 F (USNM); env. Bogotá, $2 \mathrm{~F}$ (MNHN); Viotá $1 \mathrm{~F}$ (ICNC). Magdalena: Rio Magdalena, 2 F (MNHN), 1 F (ZMHB). Meta: Restrepo, 1 F (AMNH); Villavicencio, 1 F (MNHN). Santander: Alto Río Opon, 900 m, 1 F (AMNH); Campo Capote, Carare-Opon, 4 F (ICNC), Carare, 1 F (ICNC), Carare river, 1 F (ZMHB); Cucuta, ex-coll. Fleutiaux, 2 F (MNHN); La Lachera, 900 m, 1 F (AMNH); Pamplona, 2300 m, 1 F (MNHN); Puerto Wilches, 1 F (ZMHB). Sucre: La Mesa, A.B., $1 \mathrm{~F}$ (ICNC), 1 M, 2 F (AMNH). Tolima: Ibagué, $1 \mathrm{~F}$ (ICNC), 3 F (MNHN), 1 M (dissected) (MZSP), El Salado, 4 F (MZSP); Mine Purina (280-350 m) 2 F (ZMHB). San Juan de Cordoba (several localities with this name), $1 \mathrm{~F}$ (MNHN). ECUADOR. Manabi: Porto Viejo, $1 \mathrm{~F}$ (PCCV), ex-coll. Fleutiaux, 2 F (MNHN).

Remarks. Chalcolepidius fabricii is characterized especially by general pubescence green with ferruginous lateral bands on elytra and lateral cleft of parameres slightly narrowed near apex, with lateroapical sharpened angles. Some specimens present striae clothed with ferruginous pubescence and small sutural spine at elytral apex. I examined two specimens with yellowish-white setae on lateral bands of elytra, and also on striae in one of them, representing the CANDĖZE's (1857) variation.

It belongs to fabricii+ group (Fig. 671).

Distribution. It is restricted to north of South America with records from Venezuela, Colombia and Ecuador (Fig. 684). I examined also two specimens from Mexico (ZMHB) and one from Costa Rica (ZMUC), not included in the material examined because these records require confirmation.

Chalcolepidius fasciatus sp. nov.

(Figs. 31, 32, 118, 184, 287, 436, 472, 509, 547, 592, 638, 691)

Type material. Holotype male: "Mexico, from Durango to the Pacific; Chalcolepidius approximatus Er. CMF von Hayek det. 1980; Muséum Paris"(MNHN) [aedeagus exposed]. Paratypes: 7 females. "Mex[ico]; 556; Muséum Paris ex-coll. Fleutiaux" (MNHN); "3 mi W. S. W. Mazamitla Jal.[isco] VI.30.54; A. A. Alcorn" (SEMC); "Mexico, Sinaloa $30 \mathrm{Km}$ W. El Palmito oct. 18-21.1978 E. Giesbert coll.; Chalcolepidius sp. det. E. Giesbert" (FSCA); "Mexico, Sinaloa, Loberas Aug. 3. 1983 E. Giesbert coll.; Chalcolepidius sp. det. E. Giesbert" (MZSP, retained FSCA); "Mexico, from Durango to the Pacific; Chalcolepidius approximatus Er. CMF von Hayek det. 1980" (dissected) (MZSP retained MNHN); "Mexico, from Durango to the Pacific; Muséum Paris ex-coll. Oberthür; Muséum Paris 1952 coll. R. Oberthür"(MNHN); "Mex.[ico]: St. Michoacán, 8 mi W Naranja 19-VIII-65 D. R. Paulson" (FSCA); "4 mi W Mazamitla, Jalisco, Mex. Oct. 16, 19506800 ft. Ray F. Smith” (AMNH); “6 mi N. E. El Salto, Dgo, Mex. 8500 ft. Aug. 10. 1947” (AMNH)

Holotype. Length: $30 \mathrm{~mm}$. Integument dark-brown, clothed dorsally and ventrally with short metallic scale-like setae olivebrown; lateral stripes of pronotum narrow, 1/6 of pronotum width, narrowed apicad and not reaching anterior margin; dull white setae on lateral bands of pronotum, last striae and epipleura; antennae clothed with darker brown short setae except three first segments like general body pubescence (Figs. 31,32).

Frons narrowed lateroanteriorly making distal third trapezoidal; moderately concave medioanteriorly; nasal plate almost vertical; fore angles forwardly prominent; smallpunctuate with sparse moderately coarse punctuation. Antennae (Fig. 118) serrate, reaching posterior margin of procoxae; $3^{\text {rd }}$ segment triangular-elongate, slightly shorter than $4^{\text {th }}$. Pronotum (Fig. 184) longer than wide, wider at hind angles, slightly narrowed apicad, from hind angles apices; moderately convex; micropunctate with coarse sparse punctuation, more concentrate lateroanteriorly; anterior margin sinuous; lateral margins forming narrow raised bright and micropunctate edge almost reaching apex; hind angles backwards, raised laterally forming edge slightly wider than that of lateral margins; median basal tubercle flat, triangular, continuous with very weak ridge not reaching anterior margin; posterior margin prominent and strongly notched at middle. Hypomera concave and micropunctate with sparse moderately coarse punctuation; laterointernal anterior margin raised (not carinate) forming wall of prosternal channel; row of very coarse and heterogeneous punctures forming narrow groove parallel notosternal sutures. Notosternal sutures moderately sinuous. Prosternum strongly convex, flattened longitudinal medially and grooved near sutures, small-punctuate with slightly coarser punctures near sutures. Prosternal lobes transverse, marginated laterally with angles slightly rounded; small and sparsely punctuate. Scutellum strongly folded with horizontal basal area subtrapezoidal, carinate anteriorly and notched anterior- and posteriorly. Mesosternal cavity elliptical with borders (Fig. 287) thick and horizontal on basal $3 / 4$, and vertical on distal $1 / 4$ forming L-shaped profile. First visible sternite prominent laterally and fitted in narrow groove of elytra. Anterior and median tibiae and distal half of last tarsal segment of all legs bearing fringe of moderately long cilia. Striae grooved with row of coarse punctures; interstices unequal, convex and micropunctate; $2^{\text {nd }}$ prominent forming flattened basal tubercle; apices conjointly rounded.

Aedeagus (Fig. 436): median lobe bearing 7 teeth each side; lateral cleft of parameres (Fig. 472) slightly curved medioventrally; subapical region flattened and constricted laterally; distal margin rounded and upwards; median lobe strongly narrowed at middle, bearing 7; 7 lateral teeth.

Female genital segments and genitalia (paratype: Mexico, from Durango to the Pacific). Tergite VIII (Fig. 509) transverse with anterior margin rounded, basal margin strongly notched; densely setous; translucent in a small median basal area and a marginal band interrupted at middle. Sternite VIII (Fig. 547) 0.64 times spiculum gastrale length; anterior margin wide- and deeply notched at middle, densely setous. Female genitalia (Fig. 592): sclerotized rings of openings of colleterial glands (Fig. 638) sub-elliptical, bearing 39 teeth; bursa copulatrix rounded with longitudinal median band with carinae and spines and two rounded lateral spiny areas.

Remarks. The paratypes (all females) length vary from 28$40 \mathrm{~mm}$ and the pubescence coloration, from olive to clear-brown. In all paratypes the white pubescence is present also on laterobasal region of elytra; in the majority of them the white stripes of pronotum reaches the anterior margin and the last 
stria is more densely clothed with white pubescence; in one specimen the $8^{\text {th }}$ and in other the $3^{\text {rd }}-8^{\text {th }}$ interstices are partially clothed with white pubescence.

Chalcolepidius fasciatus is characterized especially by general pubescence olive-brown with narrow lateral stripes on pronotum and epipleura white, scutellum folded and apex of parameres cleft.

It is similar to C. approximatus, differing especially by general pubescence coloration, brownish in the former and greenish in the latter, and the white pubescence more abundant in the latter, including sternites II-V with rounded white lateral patches, wider lateral bands of pronotum and lower interstices totally or partially clothed with white setae. Besides, the lateral cleft of parameres are slightly widened near middle, subapical region flattened and constricted laterally and distal margin rounded and upwards in the former, and more constricted and with distal margin almost straight in the latter; median lobe more constricted and bearing 7 slightly larger teeth each side in the former (10 smaller teeth in the latter); sternite VIII of female with anterior margin more deeply notched at middle and black setae denser in the former; sclerotized rings of openings of colleterial glands more elliptical, bearing 39 teeth in the former and semicircular, bearing 33 teeth in the latter.

C. fasciatus belongs to fasciatus + group (Fig. 671), together with virgatipennis + virginalis.

Distribution. It is recorded from Mexico (Durango, Sinaloa, Michoacán) (Fig. 691).

Etymology. The epithet is derived from one of the latin words for presence of bands, fasciatus, related to lateral bands on pronotum and elytra.

\section{Chalcolepidius ferratuvittatus sp. nov.}

(Figs. 33, 34, 119, 185, 243, 288, 330, 362, 395, 675)

Type material. Holotype male: "Carn.[egie] Mus.[eum] Acc. 7324; Ecuador Cotopaxi La Mana Guasaganda 500 m Apr. 1995 A Barragán” (CMNH) (dissected). Paratype male: "Alto Río Opon 900 M. Alt. VI-16-48 Colombia; L. Richter coll. Frank Johnson Donor” (AMNH).

Holotype. Length: $30 \mathrm{~mm}$. Integument black clothed dorsally and ventrally with short metallic scale-like setae green, yellowish-green on elytra; pronotum with two lateral elliptical stripes near margins, clothed with ferruginous setae, intermingled with white; ferruginous setae on interstice IX and distal half of stria VIII; antennae clothed with dark-blue short setae except three first segments, green (Figs. 33, 34)

Frons narrow, anterior third trapezoidal, slightly concave medioanteriorly; nasal plate high and moderate- coarsely punctuate. Antennae (Fig. 119) strongly serrate, surpassing posterior margin of procoxae; $3^{\text {rd }}$ segment triangular and short. Pronotum (Fig. 185) longer than wide, slightly narrowed apicad from hind angles base; anterior margin prominent and slightly sinuous at middle; lateral margins forming narrow raised edge; moderately convex, small and sparsely punctuate with moderately coarse sparse punctuation longitudinal medially; hind angles strongly divergent, wide, with truncate apex, raised laterally, forming edge wider and continuous with that of lateral margins; posterior margin downwards, prominent and slightly notched at middle; median basal tubercle elongate. Hypomera concave, swollen near laterointernal margin, not forming anterior channel. Notosternal sutures slightly sinuous. Prosternum moderately convex from sutures; small-punctuate, coarser near sutures. Prosternal lobe transverse, marginated laterally, with rounded angles; punctuation sparser and slightly coarser than prosternum. Scutellum (Fig. 243) elongate, moderately declivous with posterior half wider and rounded. Mesosternal cavity U-shaped with borders (Fig. 288) thick and horizontal on basal $2 / 3$ and moderately declivous on distal 1/3, forming semi-elliptical profile. First visible sternite not prominent laterally. Tibiae of male bearing irregular row of long spines internally. Striae grooved and marked by coarse punctures; interstices convex and micropunctate, unequal (pair interstices wider and higher); $2^{\text {nd }}$ and $3^{\text {rd }}$ fused at base, forming a flattened tubercle; apices conjointly rounded with sutural spine.

Male genital segments and aedeagus. Tergite VIII slightly wider than long, slightly narrowed apicad, densely clothed with short setae; anterior margin rounded; basal margin moderately notched. Sternite VIII (Fig. 330) wider than long, subtriangular; translucent with three melanized areas: two lateral bands and one smaller distal; median basal rounded spot clearer and slightly melanized. Sternite IX sub-rectangular, with melanized band on distal half; apex translucent; short setae on distal third. Tergite IX transverse (Fig. 362), narrowed apicad; densely punctuate; anterior margin slightly notched; laterodistal margins with moderately long setae. Aedeagus (Fig. 395): apex of parameres spearhead-like; setous on distal third (tiny setae represented by punctures); median lobe slightly constricted near middle and near apex.

Female unknown.

Remarks. The paratype is $31 \mathrm{~mm}$ length and clothed totally with green pubescence with lateral stripes only on elytra; those of pronotum are lacking.

Chalcolepidius ferratuvittatus is characterized especially by the wide and parallel body with hind angles of pronotum long and wide, general pubescence green, scutellum moderately declivous, tibiae of male spiny and apex of parameres spearheadlike. It is similar in shape to C. albisetosus, but these species are easily recognized by the pubescence coloration, green in the former and white in the latter. In the former the scutellum is narrower and less declivous and in the latter the horizontal half of scutellum presents two rounded concavities and the horizontal area of mesosternal cavity more prominent. The sternite VIII of male is almost triangular and bears a basal rounded clear-brown spot in the former and present anterior margin prominent and only a darker basal line in the latter; median lobe narrower with two constrictions, making the apex narrower in the former and gradually narrowed apicad and surpassing the parameres in a shorter area in the latter.

C. ferratuvittatus belongs to serricornis + group (Fig. 671). 
Distribution. It is recorded from Colombia and Ecuador (Fig. 675).

Etymology. The epithet is derived from one of the latin words for iron, ferratus, related to the coloration of the lateral bands of pronotum and elytra.

\section{Chalcolepidius fleutiauxi Pjatakowa, 1941}

Chalcolepidius fleutiauxi Pjatakowa, 1941: 98. Type locality: Mexico (Durango).

Puatakowa (1941) described C. fleutiaxi as below.

"Niger, nitidus. Capite squamulis brunneis albidisque sparsim vestito; prothorace lateribus angustato; elytris lateribus, basi sparsim, epipleurisque dense albido squamulosis; striis, interstitiis imparibus postice brunneo squamulosis; corpore subtus brunneo, brunneo-violaceo sparsim squamuloso, pedibus antennisque nigris.

Fronte late excavata, dupliciter punctata. Prothorace glabro, subparallelo, latitudine longiore, antice rotundatim angustato, dense subtilissime, medio sparsim sat fortiter, antrorsum dupliciter punctato. Angulis posticis incrassatis. Scutello transverso, antrorsum angustato, parte antica deflexa, postica plana. Elytris subparallelis, postice rotundatim angustatis, subtruncatis, punctatosulcatis; interstitiis imparibus latioribus, elevatioribus; interstitiis 35 basi fortiter elevatis. Antennis acute serratis, articulo $2^{\circ}, 3^{\circ}$ breviore, $3^{\circ}, 4^{\circ}$ duplo minore. Long. $40 \mathrm{~mm}$., lat. $12 \mathrm{~mm}$. Mexico: Durango".

Remarks. By the original description, Chalcolepidius fleutiauxi looks-like C. mniszechi, except for the brown or brownish-violet general pubescence and antennae and legs clothed with black pubescence. Both species present lateral stripes of pronotum and elytra and epipleura clothed with white setae, antennae serrate, scutellum declivous and interstices unequal.

I strongly suspect that, when material become available for study, these two species will be found to be conspecific.

Chalcolepidius forreri Candèze, 1886

(Figs. 35, 120, 186, 244, 510, 548, 593, 594, 639, 681)

Chalcolepidius forreri Candèze, 1886: 72; Candèze, 1891: 38 (Cat.); Champion, 1894: 274, 281, t. 12, f. 5; Schenkling, 1925: 56 (Cat.); Blackwelder, 1944: 282 (Cat.). Syntypes: 2 females: "Coll. R. I. Sc. N. B. Ins. Tres Marias, ex-coll. Candèze; syntype cf. Bull. Mus. Inst. Nat. Belge 1886: lxxii". One specimen bears in addition: "Type; $n$. sp. forreri Cdz. Ins. Tres Marias F” (ISNB) (examined).

Length: 42-45 mm. Very wide, arched body. Integument black clothed dorsally and ventrally with metallic scale-like setae short, thin, dense, olive-brown with violet (purpure) reflex; antennae clothed with black setae except three first, olive (Fig. 35).

Frons not carinate, moderately declivous medioanteriorly; nasal plate high. Antennae (Fig. 120) of female serrate, $3^{\text {rd }}$ triangular-elongate, shorter than $4^{\text {th }}$. Pronotum (Fig. 186) as long as wide, slightly wider at hind angles, strongly narrowed on anterior third; moderately convex, convexity decreasing basad; micropunctate with coarse punctuation lateroanteriorly (anterior half); anterior margin strongly sinuous at middle; lateral margins raised laterally forming smooth narrow edge almost reaching apex; concave innerly edge; hind angles wide, backward, raised laterally forming wider edge, continuous with that of lateral margins; median basal tubercle very weak, triangular-elongate, continuous with very weak longitudinal median ridge; posterior margin prominent and strongly notched posteriorly. Hypomera concave near lateral margins; laterointernal margin raised forming wall of anterior channel. Notosternal sutures moderately sinuous. Prosternum micropunctate; coarse punctuation near sutures; strongly convex; flattened longitudinal medially, concave near sutures. Prosternal lobe wide, punctuation sparser and slightly coarser than median region of prosternum; emarginated laterally; fore angles slightly rounded. Prosternal spine flattened laterally. Scutellum (Fig. 244) strongly folded with horizontal basal area subtrapezoidal, strongly notched anteriorly, grooved longitudinal medially. Borders of mesosternal cavity wide and horizontal on basal $3 / 4$ and vertical on distal $1 / 4$, forming a $L$ shaped profile. Meso-metasternal suture weak. First visible sternite prominent laterally fits in lateral groove. Striae punctuate; interstices unequal irregularly convex and micropunctate; interstices 2, 4, 6 partially costiform; basal region with a flat prominence forwardly directed; apices conjointly rounded.

Female genital segments and genitalia. Tergite VIII (Fig. 510) transverse, setous, translucent in small median basal area and paired lateral bands. Sternite VIII (Fig. 548) 0.61 times spiculum gastrale length; anterior margin moderately wide- and deeply notched at middle. Genitalia: sclerotized rings of openings of colleterial glands (Fig. 639) bearing 41 teeth; bursa copulatrix (Figs. 593, 594) with longitudinal median elongate area with carinae and spines, narrowed near base, and paired lateral rounded spiny areas moderately small.

Male unknown.

Material examined. MEXICO. Nayarit: Islas Tres Marias, ex-coll. Sallé, ex-coll. Fleutiaux, $1 \mathrm{~F}$ (MNHN), ex-coll. Oberthür, $1 \mathrm{~F}$ (MNHN). Isla Maria Madre, Camp-Mariano Escobedo, $1 \mathrm{~F}$ (dissected) (UNAM).

Remarks. Chalcolepidius forreri is easily recognized by the large size, olive-brown setae, striae punctuate and interstices irregularly raised.

It belongs to forreri* ${ }^{*}$ group (Fig. 671).

Distribution. It is restricted to Mexico (Nayarit) (Fig. 681).

Chalcolepidius fryi Candèze, 1874

(Figs. 37-39, 121, 189, 289, 511, 549, 595, 640, 684)

Chalcolepidius fryi Candèze, 1874: 168; 1886: 68, 73; 1891: 39 (Cat.); Schenkling, 1925: 56 (Cat.); Fleutiaux, 1926: 107 (Cat.); Blackwelder, 1944: 282 (Cat.). Holotype female: "Type; 33877; Peru [Libertad] Lucma; Type; Fry coll. 1903.100; C. fryi type Cdz.; drawer 126" (BMNH) (examined). 
Chalcolepidius viriditarsus; Golbach, 1977: 157 (non Schwarz, 1906) [misidentification].

CANDÈze (1874) described C. fryi, from Peru, based on a female clothed with yellow dull setae with lateral stripes on pronotum (short, elliptical, not reaching margins) and elytra ferruginous, and $3^{\text {rd }}$ antennal segment shorter than $4^{\text {th }}$.

GoLBACH (1977) attributed to C. viriditarsus a male from Peru (Lambayeque), clothed dorsally with yellowish (ochraceus) setae with three last striae ferruginous, and ventrally with paler setae. The lateral stripes of pronotum were lacking, but comparing this specimen with the holotype and one female of C. fryi, it was concluded that it belongs to this species.

I suspect that $C$. viriditarsus Schwarz, 1906 is also conspecific with $C$. fryi Candèze, 1874 , but until more material becomes available for study, I consider more prudent to retain both species, especially by type-locality (San Salvador) and presence of "squamulis albidis dense vestitus" in the former.

Length: 28-38 mm. Integument black clothed dorsally and ventrally (except antennae and tarsi) with dull ochraceus-yellow, very dense scale-like setae, sometimes paler ventrally; ferruginous scale-like setae on two lateral irregular elliptical patches on pronotum (absent on male examined) and lateral stripes of elytra (2-3 interstices wide); antennae, except $1^{\text {st }}$ and part of $3^{\text {rd }}$ segment clothed with ochraceus setae, and tarsi with short metallic blue or green setae; a narrow lateral band and median region on pronotum, except male examined, glabrous (Figs. 37-39).

Frons concave medioanteriorly; nasal plate high and punctuate. Antennae (Fig. 121) very short and serrate in both sexes; $3^{\text {rd }}$ segment triangular-elongate, very prominent laterally, shorter than $4^{\text {th }}$. Pronotum (Fig. 189) slightly longer than wide (except holotype, as long as wide), wider at hind angles, narrowed apicad and at hind angles base; micropunctate with slightly coarser and sparse punctuation lateroanteriorly, denser near lateral margins; moderately convex, convexity decreasing basad; discal area with weak ridges; anterior margin prominent and sinuous at middle; fore angles upwards and rounded; hind angles slightly divergent, raised laterally, forming edge, continuous with that of lateral margins, not reaching apex; median basal tubercle weak, flat, triangular-elongate; posterior margin prominent and strongly notched at middle. Hypomera concave near lateral margins; laterointernal margin raised forming wall of well developed channel. Notosternal sutures strongly sinuous. Prosternum micropunctate, strongly convex, flattened longitudinal medially, concave near sutures. Prosternal lobe wide, with rounded angles; punctuation very dense, coarser than prosternum. Prosternal spine flattened laterally with rounded apex. Scutellum strongly folded with horizontal basal area subtrapezoidal, notched anterior and posteriorly. Borders of mesosternal cavity (Fig. 289) wide and horizontal on basal $2 / 3$ and vertical on distal $1 / 3$, forming a L-shaped profile. Meso-metasternal suture absent. First visible sternite prominent laterally fits in lateral groove of elytra. Anterior and median tibiae and last tarsal segment of all legs of male bearing fringe of long cilia; tibiae of female with moderately longer setae on internal face. Interstices convex and micropunctate, unequal in width; basal region with a flattened tubercle near $3^{\text {rd }}$ interstice base; apex slightly truncate.

Female genital segments and genitalia. Tergite VIII (Fig. 511) transverse, strongly notched at base; median basal translucent area surpassing the middle; a translucent marginal band interrupted at middle; densely setous. Sternite VIII (Fig. 549) 0.46 times the spiculum gastrale length; anterior margin wide- moderately deeply notched; apex of spiculum gastrale prominent ventrally. Genitalia (Fig. 595): sclerotized rings of openings of colleterial glands (Fig. 640) bearing 43 teeth; bursa copulatrix with longitudinal median band with carinae and spines and two lateral irregular spiny areas.

Material examined. PERU. Lambayeque: $40 \mathrm{Km}$ E Chiclayo, Río Ivancay, $1 \mathrm{M}$ (without aedeagus) (IMLA). La Libertad: Trujillo, $1 \mathrm{~F}$ (dissected, USNM).

Remarks. Only three specimens of Chalcolepidius fryi, including the holotype, were examined, but it was possible to verify the variation of the color pubescence. The male genitalia could not be studied because it had been dissected and the aedeagus was not found.

C. fryi is characterized especially by wide body clothed with ochraceus-yellow pubescence with ferruginous stripes on pronotum (lacking in male examined) and elytra, scutellum strongly folded, tibiae of male ciliate and parameres of aedeagus cleft laterally (based on GoLBACH, 1977: 160, fig. 13)

Comparing the male identified by Golbach as $C$. viriditarsus with the female holotype and the other female of $C$. fryi examined, all specimens from semiarid area of north of Peru, it was verified that: the elliptical ferruginous patches on pronotum is lacking in the former; the holotype $(38 \mathrm{~mm})$ is larger than the other specimens $(28,31 \mathrm{~mm})$ and presents pronotum more convex; the antennae and tarsi are metallic blue in the holotype and green in male, and in the other female, the antennae are blue and the tarsi bluish-green; in both females, the first and part of third antennal segment are ochraceus, while in the male only the first is ochre; the pubescence of the borders of pronotum and male dorsal is clearer (almost cream) than in female, and with lateral striae ferruginous, forming a striped band on elytron (three interstices wide).

C. fryi belongs to fryi* group (Fig. 671).

Distribution. It is restricted to Peru (Fig. 684)

Chalcolepidius gossipiatus Guérin-Méneville, 1844

(Figs. 36, 122, 188, 245, 290, 329, 363, 396, 512, 550, 642, 674)

Chalcolepidius gossipiatus Guérin-Méneville, 1844: 18; Candèze, 1857: 262, 265; Gemminger \& Harold, 1869: 1503 (Cat.); Candèze, 1874: 160; 1886: 66, 69; 1891: 37 (Cat.); Fleutiaux, 1926: 107 (Cat.). Syntypes: 1 male, 1 female. Male: "Chalcolepidius gossipiatus Guer. Rev. Zool. 1843 Colombie; ex Museo Guér.-Menév.; Muséum Paris, ex-coll. R. Oberthür; Syntype Chalcolepidius gossipiatus Guerin, CMF von Hayek, det.1980“; Female: "gossipiatus Guer. Type; Ex-Musaeo Guér-Menev.; Museum Paris, ex-coll. R. Oberthür; Syntype Chalcolepidius gossipiatus G.M. CMF von Hayek det. 1980” (MNHN) 
(examined)

Chalcolepidius gossypiatus [sic]; Schenkling, 1925: 56 (Cat.); Blackwelder, 1944: 282 (Cat.).

Chalcolepidius erichsonii Guérin-Méneville, 1844: 18; Candèze, 1857: 265. Syntypes: 1 male, 1 female. Male: "Chalcolepidius Erichsonii Guér. Rev. Zool. 1843 (type) M Colombie; ex Museo Guér. Menév.; Syntype Chalcolepidius erichsonii G. M. CMF von Hayek det.1980"; Female: "Erichsoni Guér. Nlle Grenade; Ex Musaeo A. Sallé 1897; Syntype Chalcolepidius erichsoni G. M. CMF von Hayek 1980" (MNHN) (examined). Chalcolepidius lemoinii Candèze, 1857: 262, 266, t. 5, f. 7. Syntype female: "N. Grenada; Chalcolepidius lemoinii Cdze ex coll. Candèze; Chalcolepidius lemoinii Cdz. Nlle Gren. [Candèze stuck to underside of Janson label]; Janson coll. 1903.130.” (BMNH) (not examined). Syn. nov.

Chalcolepidius lemoinii Candèze, 1857: 266. Syntype female: "Syntype; Type; Columbia; 115; Janson coll. 1903-130; Chalcolepidius Lemoinii (Reiche) Cdze Type F ex coll. de Laferté (Reiche) [glued underside:] Lemoinei Reiche; Syntype Chalcolepidius lemoinii Candèze var. a CMF von Hayek, 1979"(BMNH) (examined). Syn. nov.

Chalcolepidius lemoinei [sic]; Gemminger \& Harold, 1869: 1503 (Cat.); Candèze, 1874: 161; 1886: 66, 69; Fleutiaux, 1926: 107 (Cat.); Blackwelder, 1944: 283 (Cat.).

Chalcolepidius Le Moinei [sic]; Candèze, 1891: 37; Schenkling, 1925: 56 (Cat.).

GuÉRIn-MÉneville (1844) described C. erichsonii and $C$. gossipiatus in the same page, both from "régions temperées". The former was characterized by presence of general scale-like setae green with lateral stripes of elytra orange almost red, and striae orange-yellow. C. gossipiatus was considered similar to C. erichsonii, but the latter is clothed with scale-like setae yellowish-ochre, paler ventrally, with lateral stripes of elytra and striae orange-yellow.

CANDĖze (1857) presented two variations for C. gossipiatus, the first one I considered corresponding to C. erichsonii: "Var. a. Olivaceo-squamulosus, elytrorum striis margineque fulvosquamosis; Var.b. Olivaceo-squamulosus, prothorace fulvocinereo, elytrorum striis margineque fulvo-squamosis." In this same year, CANDÈZE described $C$. lemoinii: “...entièrement revetu d'écailles blanches, sauf les intervalles des stries des élytres, couverts d'écailles d'un beau vert..." He also described one variety: "Var.a. Prothorace, elytrorum striis margineque squamulis fulvis". He recorded it from Colombia and stated about the difficult of describing the differences between $C$. lemoinii variety and some specimens of C. gossipiatus. In 1874 he stated that sometimes the prothorax of $C$. lemoinei [sic] is clothed with green scales with a white lateral band each side.

I studied the syntypes of $C$. erichsonii, $C$. gossipiatus and $C$. lemoinii, and also the specimens presenting the colour combinations of pubescence of all varieties described for these species, and concluded that they are conspecific.

Length: 25-43 mm. Wide, parallel body. Integument from reddish-brown to dark-brown. Dorsal and ventral pubescence white, yellowish-white, ochraceus or metallic olive, or grayishgreen with striae and lateral stripes of elytra (3 interstices wide) ochraceus, ochre, orange, or at same color as general pubescence, only slightly darker and/or denser. Antennae clothed with brown or dark-brown setae except 3 first segments; legs and hypomera like ventral pubescence (Fig. 36).
Frons not carinate, slightly declivous anteriorly. Antennae (Fig. 122) serrate in female, strongly serrate in male; $3^{\text {rd }}$ segment triangular and short. Pronotum (Fig. 188) longer than wide, slightly narrowed apicad from hind angles base; slightly convex; micropunctate with sparse coarse punctuation dispersed on anterior half; lateral margins forming smooth narrow edge, grooved innerly; anterior margin prominent at middle (slightly sinuous in some specimens); hind angles wide, divergent, prominent backwards, raised laterally forming edge, wider and continuous with that of lateral margins; median basal tubercle elongate; posterior margin prominent and slightly notched at middle. Hypomera concave; raised anteriorly forming globose prominence close to prosternal channel (different from other species). Notosternal sutures slightly sinuous; prosternal channel present (different from others). Prosternum micropunctate, moderately convex. Prosternal lobe wide, emarginated laterally with fore angles slightly rounded; punctuation small, coarser than prosternum. Scutellum (Fig. 245) subtrapezoidal; anterior half narrower and strongly declivous; horizontal area sub-elliptical with two rounded concavities. Borders of mesosternal cavity (Fig. 290) wide and horizontal on basal $2 / 3$ and moderately declivous on distal 1/3, forming semi-elliptical profile. Mesepisternum with transverse irregular groove. Meso-metasternal suture weak. First visible sternite not prominent laterally. Tibiae of male bearing row of long spines internally. Interstices micropunctate and unequal in variable degree; striae marked by row of coarse punctures; $2^{\text {nd }}$ forming well developed rounded tubercle near base.

Male genital segments and aedeagus. Sternite VIII (Fig. 329) subpentagonal, translucent with three melanized areas: two lateral elongate larger and one median distal shorter. Tergite IX (Fig. 363) densely punctuate; anterior margin slightly notched with rounded angles; moderately long setae lateroanteriorly. Aedeagus (Fig. 396): median lobe wide, 0.58 times aedeagus length, slightly narrowed at middle, constricted at apex; apex of parameres spearhead-like.

Female genital segments and genitalia. Tergite VIII (Fig. 512) densely setous; median basal translucent area indistinguishable. Sternite VIII (Fig. 550) 0.60 times spiculum gastrale length; anterior margin narrow- and deeply notched at middle. Genitalia (Fig. 596): sclerotized pieces of openings of colleterial glands (Fig. 642) C-shaped, bearing 42 teeth; bursa copulatrix with wide longitudinal band with carinae and spines, narrowed basad.

Material examined. GUATEMALA. Alta Verapaz: Panzos, 1 F (MNHN). COSTA RICA. Lemoinei Cand. collection Fleutiaux, $1 \mathrm{~F}$ (MNHN). PANAMA. Chiriqui: Boquete A. Boutete, received as attenuatus Er. CMF von Hayek det. 1980, 1 M (ZMHB). "NEW GRANADA". 16205, gossipiatus Cand. gossipiatus et Erichsonii Guér. Nov. Gran. Goud., Hist. Col. (Coleoptera) Nr 16205 (1 ex.) Chalcolepidius gossypiatus Cand. Nuev. Granad. Goud.; Zool. Mus. Berlin, 1 M (ZMHB); 16205 ; Hist. Coll. (Coleoptera) nr 16205 (2ex) Chalcolepidius gossypiatus Cand. Nuev. Granad. Goud.; Zool. Mus. Berlin, 1 F (ZMHB); same data, (3 ex.), 1 F (ZMHB); N. Gran.Coll. L. W. SchaufuB, 1 M (ZMHB); N. G. [New Granada], 1 M (MCZC). Nova Grenata; collection Chevrolat; gossipiatus; gossipiatus typique Cand. Mon. collection Fleutiaux, 1 ex (abdomen destroyed) (MNHN). gossipiatus Cand. Type [handwritten]; collection Chevrolat; typique Cand. Mon. gossypiatus coll. Fleutiaux, 1 F (MNHN). 
Coll. Jekel; 39; gossypiatus (Cd., 1879); erichsoni Cand. rev. 160; jekeli det. Collection Fleutiaux, $1 \mathrm{M}$ (MNHN). Ex- Musaeo A. Sallé, ex-coll. Oberthür, $1 \mathrm{M}$ (MNHN). VENEZUELA. Ex-coll. Chevrolat, $1 \mathrm{~F}$ (MNHN), ex-coll. Oberthür, $1 \mathrm{M}(\mathrm{MNHN})$, ex- Musaeo Sallé, ex-coll. Oberthür, 1 M (MNHN), Lemoinei Cand. var.; Collection Chevrolat; Lemoinei Cand. det. mon. Collection Fleutiaux, $1 \mathrm{~F}$ (MNHN), gossipiatus Guér. Collection Fleutiaux, 1 F (MNHN). COLOMBIA. 1 F (MNHN), 1 F (ZMHB), 3 M (ZMUC), 2 M (NHMW), ex-Musaeo E. Steinheil, excoll. Oberthür, 2 F (MNHN), ex-coll. Oberthür, 1 F (MNHN); 43288; Lemoinei Cand.* Columb. Coll. Germar, 1 F (ZMHB); coll. Jekel, coll. Fleutiaux, $1 \mathrm{M}(\mathrm{MNHN})$. Caqueta: Florencia, $1 \mathrm{~F}$ (ICNC); Yabi Caqueta, 1 M (IMLA). Special District: Bogotá, gossypiatus Guér. coll. Fleutiaux, $1 \mathrm{~F}(\mathrm{MNHN})$. Huila: $1 \mathrm{M}$ (SRGI); Gigante, $1 \mathrm{~F}$ (FSCA), 2 M, $1 \mathrm{~F}$ (SRGI), 1 F (MZSP); San Agustin, Quebradillas, 3 F (ICNC). Putumayo: 1 F (SRGI). Tolima: Alvarado, $1 \mathrm{M}$ (ICNC); Armero, $2 \mathrm{M}, 1 \mathrm{~F}$ (MZSP); Ibagué, $1 \mathrm{M}$ (dissected), $2 \mathrm{~F}$ (MZSP), coll. Deharme, $1 \mathrm{M}, 1 \mathrm{~F}$ (MNHN), El Espinal, $1 \mathrm{~F}$ (dissected) (MZSP). BRAZIL. Pará: 1 M (SRGI). ECUADOR. Ex-coll. R. Oberthür, $1 \mathrm{~F}(\mathrm{MNHN})$. Bolívar: Chimbó, $1 \mathrm{M}$, $1 \mathrm{~F}$ (MNHN). Without locality: $1 \mathrm{M}$ (IMLA), Chalcolepidius gossipiatus G. M. CMF von Hayek det. 1979; comp. to erichsonii in Gen. Coll. [von Hayek] 1 M (MNHN), Lemoinei Cand. var.; coll. Chevrolat; Lemoinei Cand. det. Mon. Collection Fleutiaux, 1 F (MNHN), ex-coll. Oberthür; Chalcolepidius gossipiatus G. M. CMF von Hayek det. 1979, Gen. Coll. Paris erichsonii Chalc. comp. w/ M type, $1 \mathrm{M}(\mathrm{MNHN})$.

Remarks. Chalcolepidius gossipiatus is characterized especially by general pubescence whitish, ochraceus, olive or greenish with lateral stripes of elytra orange or of the same color of general pubescence (slightly darker and denser), antennae serrate in female and strongly serrate in male, scutellum strongly declivous and apex of parameres spearheadlike.

Examination of the available material of $C$. gossipiatus has shown a wide range of pubescence coloration. It was observed the integument clothed with dull scale-like setae ochraceusyellow with striae and lateral stripes of elytra ochre or yellowishorange, cream with striae and lateral stripes of elytra ochre, yellowish-white with lateral stripes of elytra ochraceus-yellow, totally yellowish-white, totally white with interstices glabrous and lateral margins of elytra more densely white, or metallic scale-like setae grayish-green with lateral bands of elytra ochre or orange-yellow, olive with lateral bands of elytra ochre or ferruginous, or totally grayish-green. Some specimens are dull dorsally and metallic ventrally, or sometimes, only the interstices are metallic. Besides, it was observed some sexual differences like narrower body and pronotum with lateral margins almost straight in male, and wider body with lateral margins more rounded in female. In both sexes the pronotum is as- or almost as wide as long with hind angles divergent and posterior margin as wide as elytral base. The antennae are strongly serrate in male.

C. gossipiatus belongs to extenuatuvittatus + group (Fig. 671).

Distribution. It is recorded from Central and South America: Guatemala, Costa Rica, Panama, Venezuela, Colombia, Brazil (Pará) and Ecuador (Fig. 674).

Chalcolepidius inops Candèze, 1886

(Figs.40,123,124,187,246,291,397,437,473,513,551,597,598,643,681)

Chalcolepidius inops Candèze, 1886: 73; Champion, 1894: 275, 282;
Schenkling, 1925: 56 (Cat.). Syntype female: “Coll. R. I. Sc. N. B. 1874 Koels Sierra Madre Chihuahua Mex.; n. sp. inops Cdz Chihuahua; Type; Col. E. Candèze "(ISNB) (examined).

Chalcolepidius murinus Champion, 1894: 275, 283, t. 12, f. 6; Schenkling, 1925: 57 (Cat.); Blackwelder, 1944: 283. Syntypes: 1 male, 1 female: "Syntype; Acapulco, Guerrero. Höge; B. C. A. Col. III (1) Chalcolepidius murinus" The male also bears the labels: "M; sp. figured" (BMNH) (examined). Syn. nov.

CANDÈze (1886) described C. inops from Sierra Madre de Chihuahua (Mexico) and commented that this species has the general fascies of $C$. virens, but it is easily recognized by the shape and the size of third antennal segment, very shorter than $4^{\text {th }}$ and dentate. According to him, this shape of $3^{\text {rd }}$ antennal segment is found in a small number of species.

Champion (1894) described C. murinus, from Acapulco (Mexico), based on three specimens. He commented that one of them had been examined by Candèze that considered it as unknown and attached the following remarks: "near C. inops, but differing from it in having the margins of the thorax not flattened and all the elytral striae punctured". Three lines before the description of $C$. murinus he commented that the presence of very short third antennal segment in $C$. inops brings it near C. angustatus. Probably he had not examined any material of C. inops to verify that the third antennal segment is similar to C. murinus.

After comparing the syntypes of C. murinus and C. inops, it was concluded that they are conspecific species. The differences observed by CANDĖze (1886) and CHAMPION (1894) are herein considered as intraspecific variations.

Length: 25-34 mm. Arched, almost parallel. Integument dark, clothed dorsally and ventrally with thin, short, metallic brown, brownish-olive, wine-brown or olive gray setae; antennae usually clothed with black setae, in a few specimens brown, except three first, like general body coloration (Fig. 40).

Frons not carinate, strongly declivous medioanterioriorly, consequently, nasal plate high. Antennae of male (Fig. 124) surpassing posterior margin of procoxae, pectinate; in female (Fig. 123) not reaching posterior margin and strongly serrate; $3^{\text {rd }}$ segment transverse with spiniform appendix in both sexes. Pronotum (Fig. 187) longer than wide, slightly narrowed at hind angles base, strongly narrowed near apex; anterior margin slightly sinuous at middle; fore angles prominent; moderately convex anteriorly; convexity decreasing basad, flattened longitudinal medially on basal 3/4; micropunctate with coarse sparser punctuation more concentrate near middle; lateral margins raised laterally forming bright small-punctuate narrow edge, almost reaching apex; concave innerly edge; hind angles backward, wide, raised laterally forming edge continuous with that of lateral margins; median basal tubercle triangular, very flat, almost indistinguishable, continuous with very weak longitudinal median ridge, not reaching apex; posterior margin prominent and strongly notched at middle. Hypomera concave near lateral margins; lateral margins incompletely carinate; laterointernal margin raised forming wall of anterior channel (not carinate). Notosternal sutures moderately sinuous. 
Prosternum micropunctate; punctuation coarser near sutures; strongly convex, flattened longitudinal medially, concave near sutures. Prosternal lobe transverse with rounded angles; punctuation sparse, coarser than median region of prosternum; emarginated laterally with fore angles slightly rounded. Prosternal spine flattened laterally. Scutellum (Fig. 246) strongly folded with horizontal basal area subtrapezoidal, notched anteriorly and posteriorly, grooved longitudinal medially. Mesosternal cavity narrow, U-shaped with borders (Fig. 291) thick, horizontal on basal $3 / 4$, and moderately declivous on distal $1 / 4$, forming semicircular profile. Anterior and median tibiae and last tarsal segment of all legs of male bearing fringe of long cilia. First sternite prominent laterally fits in lateral groove of elytra. Striae grooved and punctuate (a row of coarse punctures); interstices slightly convex and small-punctuate; interstices equal in width; 2-4 forming basal wide flattened tubercle; apices individually rounded.

Aedeagus (Fig. 397): median lobe (Fig. 437) wide, slightly narrowed near middle, gradually narrowed apicad; 15, 18 lateral very small teeth, dorsally directed; lateral cleft of parameres (Fig. 473) strongly narrowed dorsally giving rounded shape to dorsal margin, and apex upwards more prominent ventrally.

Female genital segments and genitalia. Tergite VIII (Fig. 513) transverse, setous, membranous in median basal triangular area, slightly shorter than half of tergite length and two bands on fore angles. Sternite VIII (Fig. 551) 0.63 times spiculum gastrale length; anterior margin slight- and widely notched at middle. Genitalia (Figs. 597, 598): sclerotized rings of openings of colleterial glands (Fig. 643) with 54 small teeth; bursa copulatrix with longitudinal median elongate area with carinae and spines; without rounded lateral spiny areas.

Material examined. MEXICO. 1 F (MNHN). Colima: Manzanillo, 1 F (MCZC). Guerrero: Cyn. del Zopilote, 2000, $1 \mathrm{~F}$ (FSCA); $51 \mathrm{Km}$ Ixtapa, 1 F (dissected) (FSCA). Jalisco: Est. Biol. Chamela, 2 F (UNAM); La Quemada, $1 \mathrm{M}$ (AMNH). Sinaloa: $5 \mathrm{mi} \mathrm{N}$ Mazatlan, 1 F (FSCA). GUATEMALA. $1 \mathrm{~F}$ (USNM). COSTA RICA. $1 \mathrm{~F}$ (MNHN).

Remarks. The syntype of Chalcolepidius inops is $25 \mathrm{~mm}$ long and clothed with brownish-olive setae with brown antennae. The syntypes of $C$. murinus are $26 \mathrm{~mm}$ long, both clothed with olive-gray setae; the antennae are clothed with black setae in male and brown in female. Comparing the syntypes with the material examined for $C$. inops, they do not present significant differences to be considered different species.

C. inops is characterized especially by pronotum micropunctate and bright longitudinal-medially with characteristic convexity, very strong frontally, decreasing basad, flattened on basal third and the lateral margins forming a wide flattened edge anteriorly. Besides, the scutellum is folded, anterior and media tibiae of male bear fringe of long cilia and lateral cleft of parameres is strongly narrowed dorsally giving a rounded shape to dorsal margin, and apex upwards more prominent ventrally.

C. inops presents a wide range of variation in size and pubescence coloration. The holotype is olive-brown, specimens with brown pubescence dorsally and ventrally and/or brown dorsally and olive-brown ventrally were examined.

C. inops belongs to forreri* group (Fig. 671).

Distribution. It is recorded from Mexico (Colima, Guerrero, Jalisco, Chihuahua and Sinaloa), Guatemala and Costa Rica (Fig. 681).

Chalcolepidius jansoni Candèze, 1874

(Figs. 41-43, 125, 190, 247, 292, 331, 364, 398, 438, 474, 514, 552, $599,600,644,677)$

Chalcolepidius jansoni Candèze, 1874: 165; 1886: 74; Champion, 1894: 275, 283, t.12, f. 7; Schenkling, 1925: 56 (Cat.); Blackwelder, 1944: 283. Syntypes: 22 females. [BMNH specimens numbered 1-19]:“1; Nicaragua/E.M.J.; Chalcolepidius jansoni Cdze. F type [Janson] jansoni [Candèze label stuck to underside]; sp. figured; Janson coll. 1903.130"; "2; Nicaragua/E.M.J.; Chalcolepidius jansoni Cdze. F [Janson]; Janson coll. 1903.130"; 3-13: "Nicaragua/E.M.J.; Chalcolepidius jansoni Cdze. F [Janson]; Janson coll. 1903.130"; "14; Nicaragua/Belt; Chalcolepidius jansoni Cdze. F [Janson]; Janson coll. 1903.130"; "15; Nicaragua; Belt; jansoni [Candèze]; Fry coll. 1905.100"; "16; Nicaragua; Belt; jansoni [Candèze]; Chalcolepidius jansoni Candèze Nicaragua Cotype [Fry]”; "17; Nicaragua; Sallé coll.; Chalcolepidius jansoni Cand. Sallé coll. 1436; B. C. A. coll. III (1) Chalcolepidius jansoni Cand. F [B. C. A. Champion]"; 18, 19: "B. C. A. Coll. III (1) Chalcolepidius jansoni Cand. F [B. C. A. Champion] (BMNH) (not examined); 1 female: “ Nicaragua; Coll. Sallé. 1 F, Coll. Sallé; jansoni”"(MNHN) (examined); 1 female: "Coll. R.I.Sc.N.B. Nicaragua ex coll. Candèze; jansoni Cdze. Nicar. [Candèze]; Chalcolepidius jansoni Cd. Det. E. Candèze (ISNB) (not examined).

Chalcolepidius mucronatus Candèze, 1889: 14. Syntype female: "Coll. R. I. Sc. N. B. Colombie ex-coll. Candèze; Type; n. sp. mucronatus Cdze. Colomb.; Chalcolepidius mucronatus Cd. det. E. Candèze" (ISNB) (examined). Syn. nov.

CANDÈZE (1874) described C. jansoni from Nicaragua, and in 1889, C. mucronatus from Colombia. According to him, both species may be confused by sutural spine at elytral apex, but the latter is narrower frontally and more attenuate behind, with deeper striae, while in the former the hind angles of pronotum are more slender and divergent.

After examining the type of $C$. mucronatus and identified specimens of $C$.jansoni from Nicaragua, Costa Rica, Panama, Colombia and Ecuador, it was concluded that these species are conspecific. The differences enumerate by CANDĖZE (1889) are herein considered as intraspecific variations.

Length: 31-37 mm. Integument black clothed dorsally and ventrally with scale-like setae, thin, short, metallic green, olive, grayish-green, yellowish-green, bluish-green, blue (iridescent) or violet; antennae brownish except three first segments, bluish (Figs. 41-43).

Frons narrow, not carinate, slightly declivous. Nasal plate high. Antennae (Fig.125) serrate in both sexes; $3^{\text {rd }}$ segment triangular-elongate, shorter than $4^{\text {th }}$. Pronotum (Fig. 190) longer than wide, narrowed apicad and at hind angles base; slightly convex longitudinal medially; anterior margin prominent at middle, forming two small teeth; lateral margins forming edge, almost reaching apex; hind angles stout, divergent with truncate apex, raised laterally forming edge continuous with that of lateral margins; median basal tubercle flat, triangular-elongate, 
continuous with longitudinal median weak ridge; posterior margin prominent and strongly notched at middle; micropunctate with sparse coarser punctures more concentrate anteriorly. Hypomera concave near lateral margins; micropunctate; convex anteriorly, but not forming wall of prosternal channel; raised in narrow band parallel notosternal sutures. Prosternal channel absent. Notosternal sutures slightly sinuous, opened frontally. Prosternum micropunctate, strongly convex, flattened longitudinal medially; concave near sutures. Prosternal spine flattened laterally. Scutellum (Figs. 247, 248) slightly declivous; horizontal area subtriangular, rounded anteriorly, slightly notched posteriorly (many times bilobed on anterior margin (Fig. 247); declivous area almost perpendicular. Borders of mesosternal cavity (Fig. 292) wide and horizontal on basal $2 / 3$ and slightly declivous on distal $1 / 3$, forming an inclined profile. First visible sternite prominent laterally, fits in lateral groove of elytra. Anterior tibiae of male and female with fringe of short cilia on distal half, longer in male. Striae punctuate; interstices equal in width, moderately convex and small punctuate; apex rounded with well developed sutural spine; $3^{\text {rd }}$ interstice forming basal rounded tubercle.

Male genital segments and aedeagus. Sternite VIII (Fig. 331) transverse, moderately narrowed apicad, slightly constricted at distal third; translucent in small median area, paired narrow lateral band, paired small elliptical laterobasal spot and small distal patch. Tergite IX (Fig. 364) densely punctuate; transverse, narrowed apicad; anterior margin narrow and strongly notched; anterior angles prominent and rounded bearing short setae. Aedeagus (Fig. 398): median lobe (Fig. 438) wide, 0.57 times aedeagus length, slightly narrowed apicad, slightly constricted near middle, bearing 6,8 lateral teeth; lateral cleft of parameres (Fig. 474) short, constricted subapically with apex narrow, rounded and upwards.

Female genital segments and genitalia. Tergite VIII (Fig. 514) transverse, almost rectangular, densely setous; translucent in triangular median basal and paired large areas at fore angles. Sternite VIII (Fig. 552) wide, 0.67 times spiculum gastrale length; spiculum gastrale bifid; anterior margin wide- and moderately notched. Female genitalia (Figs. 599, 600): sclerotized pieces of openings of colleterial glands (Fig. 644) C-shaped with many small teeth; bursa copulatrix with narrow longitudinal median band with carinae and spines and a paired lateral irregular spiny spots.

Material examined. NICARAGUA. 3 F (MNHN), 1 F (USNM), excoll. Sallé, ex-coll. Fleutiaux, 1 F (MNHN). Río San Juan: Greytown [San Juan del Norte], 1 M (USNM). COSTA RICA. 1 F (USNM). Alajuela: Río San Carlos, ex-coll. Fleutiaux, $1 \mathrm{~F}$ (MNHN). Cartago: Irazu, 18002000 m, 1 F (USNM). Limón: 35 Km N Guapiles, 1 M (FSCA); Santa Clara, Hamburg Farm, $1 \mathrm{~F}$ (dissected) (USNM); Siquirres, $550 \mathrm{~m}, 1 \mathrm{~F}$ (DZUP). PANAMA. Bocas del Toro: Bocas del Toro, vic. Chiriqui Grande, 1400, 1 M (FSCA). Panama: Cerro Campana, 1 M (EGRC); K 8-13 El Llano Carti Rd., $1 \mathrm{M}$ (JEWC), $1 \mathrm{M}$ (dissected) (MZSP); $10 \mathrm{Km} \mathrm{N}$ El Llano, 1 M, 2 F (FSCA); Cerro Jefe (locality not found), 1 F (FSCA). COLOMBIA. Chocó: Quibdo, 1 F (MZSP), 2 F (PCCV). Putumayo: $1 \mathrm{~F}$ (SRGI). Valle del_Cauca: $1 \mathrm{~F}$ (MNHN); M-Cordillera, Lake Calima/Río Bravo Valley, nr Buga, 1180-1200 m, 9 F (PCCV), 2 F (NHMW); Rio Dagua, $5 \mathrm{~F}$ (MNHN). Valle: Anchicaya, $600 \mathrm{~m}, 2 \mathrm{M}$ (AMNH). ECUADOR. Cachabé [Cachavi], $1 \mathrm{~F}$ (MNHN). PERU. Loreto: Rio Napo, $1 \mathrm{~F}$ (DZUP).
Remarks. Chalcolepidius jansoni is characterized especially by green, blue or violet pubescence coloration, hind angles of pronotum robust, divergent and prominent backwards, scutellum slightly declivous with horizontal subtriangular area and parameres of aedeagus cleft laterally.

The general pubescence of the type of $C$. mucronatus is clothed with bluish-green setae while in other specimens is olive-green, yellowish-green, green or blue; the antennae pubescence, except three first segments, are usually blue, brownish or both intermingled. It was observed also variation on thickness and density of the setae, as noted by Candèze to separate $C$. mucronatus; when the pubescence is thinner and/ or sparser the striae look-like deeper. Besides, the size of median teeth of anterior margin of pronotum, the convexity and width of anterior region of pronotum, the scutellum declivity and the size of sutural spine of elytra are also variable; in some specimens the scutellum presents two small rounded tubercles of variable sizes near anterior margin of horizontal area (Fig. 247).

C. jansoni resembles C. oxydatus but the former is narrower with hind angles of pronotum more prominent and the apices of elytra present well developed sutural spine. Besides, they differ especially by (C. oxydatus parenthesized): $3^{\text {rd }}$ antennal segment elongate (triangular); horizontal area of scutellum subtriangular (transverse, elliptical); lateral margins of pronotum almost straight (slightly sinuous); tibiae of male with very short cilia (with small teeth); parameres of the aedeagus cleft laterally (spearhead-like).

\section{C. jansoni belongs to desmarestii+ group (Fig. 671).}

Distribution. It is recorded from Nicaragua, Costa Rica, Panama, Colombia, Ecuador and Peru. I examined also one male from Paraguay (Caaguazu) (FSCA) not included in the material examined because this record requires confirmation (Fig. 677).

Chalcolepidius lacordairii Candèze, 1857

(Figs. 44-46, 126, 191, 249, 332, 399, 439, 475, 553, 603, 645, 680)

Chalcolepidius lacordairii Candèze, 1857: 263, 281, t. 5, f. 6. 2 Syntypes numbered 1 and 2: "1: Mexico; Chalcolepidius lacordaireii Cdze, ex coll. Candèze [Janson] Chalcolepidius lacordaireii Cdz. Mex [Candèze, stuck to underside of Janson's label]; Janson coll. 1903.130.2: Santa Rosa; Chalcolepidius lacordaireii Cadze, ex coll. Candèze; Janson coll. 1903.130"(BMNH) (not examined).

Chalcolepidius lacordairii var. a Candèze, 1857: 281. Syntype male: "Mexico; Chalcolepidius lacordaireii Cdze. ex coll. Candèze; Janson coll. 1903.130" (BMNH) (not examined).

Chalcolepidius lacordairei [sic]; Gemminger \& Harold, 1869: 1503 (Cat.); Candèze, 1874: 167; 1886: 68, 73; 1891: 39 (Cat.); Champion, 1894: 274, 279, t. 12, f. 1; Schenkling, 1925: 56 (Cat.); Blackwelder, 1944: 283 (Cat.)

Chalcolepidius exquisitus Candèze, 1886: 68; 1889: 13; 1891: 38 (Cat.); Champion, 1894: 274, 279, t. 11, f. 24; Schenkling, 1925: 56 (Cat.); Fleutiaux, 1926: 107 (Cat.); Blackwelder, 1944: 282 (Cat.). Syntypes: 3 females numbered 1, 2 and 3: “1: n. sp. exquisitus Cdz. Coll. Mn.[Candèze]; Coll. R. I. Sc. N. B. Panama, Chiriqui ex coll. Candèze." "2" and " 3 ", as 1 but without Candeze's manuscript label (ISNB). (not examined). [suggested to be a variety of C. lacordairii by Champion, 1894: 279] Syn. nov.

Chalcolepidius monachus Candèze, 1893: 16; Champion, 1896: 553. Syntype female: "Type F; n. sp. 1892 [sic] monachus Chihuahua Mex. Septent; Chalcolepidius monachus Cd. det. E. Candèze; Coll. R. I. Sc. N. B. Mexique ex coll. Candèze; Koels Mexico [stuck to 
curatorial label]; = lacordaireii small var." (ISNB) (examined). [suggested to be a variety of $C$. lacordairii by Champion, 1896: 553] Syn. nov.

CAndèze (1857) described C. lacordairii (from Mexico) characterized especially by general metallic pubescence greenish-blue or blue, and included one variety, clothed with indigo-blue pubescence. He considered this species as "... l'une des plus belles du genre". In the revision of the monograph (1874) he broadened the geographical distribution of this species, stating that it is common near the city of Guatemala and it is found in all Central America until "New Granada", spreading out by other side, following the littoral of Pacific until California. He discussed the variation of the pubescence coloration, blue (like the type), green, olive-green, grayishgreen, brownish-green and purple-green, characteristically, always uniform in each specimen. He stated about one specimen (San Diego, California, Coll. Janson) with different pubescence coloration, "violet-pourple" with some dorsal brown setae, visible only by golden reflex. In 1886, he presented a key with one new species, $C$. exquisitus, separate from $C$. lacordairii only by rugosity of pronotum poorly developed in the former. In the key, C. exquisitus is numbered with the same number as C. aurulentus (43), and the new species was not formally described nor included in his "Bibliographie". In 1889 he presented a description of $C$. exquisitus, comparing it with $C$. lacordairii and $C$. virens. He also recorded the type locality of C. exquisitus as Veragua (province of Panama to the east of Chiriqui), but the specimens listed above as syntypes bear the locality "Chiriqui". According to HAYEK (personal communication), these specimens agree so well with the description, especially in regard the colour, that she has no hesitation in accepting them as Candèze's original material, and the locality label is probably the result of an error made during curation. In 1891, Candèze catalogued C. exquisitus from Veragua and C. lacordairii from Guatemala, ignoring the other localities.

CANDĖze (1893) described C. monachus (from Mexico, Chihuahua) and commented the similarities with $C$. lacordairii, stating that the former is smaller, clothed with olive-brown pubescence and striae more visibly punctuate. The holotype of C. monachus is very naked and this way it is easier to see the punctuation of elytral striae considered by Candèze as specific character.

ChAmpion (1894) presented a key where C. lacordairii is separated from $C$. exquisitus by the body shape, wrinkles of pronotum and pubescence coloration. He recorded $C$. lacordairii from Mexico, Belize, Guatemala, Nicaragua and Costa Rica. He commented that this species is common in the forest-region of the Pacific slop of Guatemala, also occurring sparingly in Verapaz, and that the Candèze's record from San Diego, California, requires confirmation. Treating C. exquisitus as "species or variety" he commented that it replaces $C$. lacordairii in the southern portions of Central America, and recorded it from Nicaragua, Costa Rica and Panama. He examined a large series of specimens and verified that those from Panama are all clothed with greenish setae, and some are coarsely wrinkled in the disc, and some those from Nicaragua and Costa Rica, are bluish or violet, resembling C. lacordairii. Treating of $C$. monachus in the "Supplement", he suggested that "It is in my opinion, a small varietal form of C. lacordairii, with the longitudinal rugae of the thorax coarser than usual".

After studying a large series of material, I concluded that C. monachus Candèze, 1893 and C. exquisitus Candèze, 1886 are synonyms of $C$. lacordairii Candèze, 1857.

Length: 28-48 mm. Large, wide, arched body. Integument black, clothed dorsally and ventrally with short dense metallic scale-like setae dark-blue, blue, green, olive-green, grayishgreen, greenish-blue, brownish or brownish-olive (Figs. 4446).

Frons not carinate, strongly declivous. Antennae (Fig. 126) serrate in both sexes, $3^{\text {rd }}$ segment triangular-elongate, slightly shorter than $4^{\text {th }}$. Pronotum (Fig. 191) as long as wide or slightly longer than wide, narrowed anteriad and at hind angles base; micropunctate with very coarse and irregular punctuation forming ridges on longitudinal median region; anterior margin sinuous at middle in variable degree; lateral margins raised laterally forming narrow smooth edge almost reaching apex; concave in narrow band innerly edge; hind angles wide, slightly divergent with truncate and thick apex, raised laterally forming edge wider and continues with that of lateral margin; median basal tubercle flat, triangular-elongate, continuous with irregular longitudinal median ridge, not reaching apex; posterior margin prominent and strongly notched at middle. Hypomera concave near lateral margins; laterointernal margin raised forming wall of anterior channel. Notosternal sutures strongly sinuous. Prosternum micropunctate, apparently smooth on longitudinal median region; punctuation denser and coarser near sutures; strongly convex, flattened longitudinal medially, concave near sutures. Prosternal lobe wide with punctuation sparse, slightly coarser than median region of prosternum; in some specimens with longitudinal very weak grooves; emarginated laterally with fore angles slightly rounded. Prosternal spine flattened laterally. Scutellum (Fig. 249) strongly folded with horizontal basal area subtrapezoidal grooved and notched anteriorly and posteriorly. Borders of mesosternal cavity wide, horizontal on basal $3 / 4$, and vertical on distal $1 \frac{1}{4}$, forming L-shaped profile. Meso-metasternal suture weak. First visible sternite prominent laterally fits in lateral groove of elytra. Anterior and median tibiae and last tarsal segment of all legs of male bearing fringe of long cilia. Striae grooved; interstices convex and equal; $3^{\text {rd }}$ interstice flattened and prominent at base, forming a forward tubercle, apex truncate.

Male genital segments and aedeagus. Sternite VIII (Fig. 332) transverse, abruptly narrowed on apical third, basal margin sinuous; translucent in median larger area with two small basal patches each side and two lateral bands. Tergite IX densely punctuate; anterior margin rounded bearing lateroanteriorly tiny setae. Aedeagus (Fig. 339): median lobe (Fig. 439) 0.500.53 times aedeagus length, moderately narrowed near middle, bearing 7, 8; 8, 8 lateral teeth; lateral cleft of parameres (Fig. 
475) wide, slightly narrowed near apex with apex prominent ventrally and upwards.

Female genital segments and genitalia. Tergite VIII transverse, setous, translucent in small basal area and paired lateral bands. Sternite VIII (Fig. 553) 0.61 times spiculum gastrale length; anterior margin wide- and deeply notched. Genitalia (Fig. 603): sclerotized rings of openings of colleterial glands (Fig. 645) bearing 34 teeth; bursa copulatrix with wide longitudinal band with carinae and spines and two rounded lateral spiny areas.

Material examined. UNITED STATES OF AMERICA. California: 1 F (USNM). MEXICO. 12 F (MNHN), 1 F (MZSP), 2 F (NHMW), 1 F (UNAM), 1 F (USNM), ex-coll. Fleutiaux, 1 F (MNHN), Côte Occidental, 2 F (MNHN). Chihuahua: San Isidro, 1600 feet, 1 F (USNM). Jalisco: $15 \mathrm{Km} \mathrm{N}$ El Tuito, 2200, 1 F (FSCA). Colima: Colima, 1 F (MZSP retained USNM), 2 M, 4 F (1 M dissected, UNAM), 1 F (USNM), ex-coll. Fleutiaux, $1 \mathrm{~F}$ (MNHN); Manzanillo, $1 \mathrm{~F}$ (MCZC); Tecolopa, $1 \mathrm{~F}$ (AMNH). Veracruz: $1 \mathrm{~F}$ (MNMS), $1 \mathrm{~F}$ (ZMUC); ex-coll. Fleutiaux, $1 \mathrm{~F}$ (MNHN); Playa Escondida, 1 F (MNMS); Dos Amantes, 2 F (USNM); localities not found: Huatimac, $1 \mathrm{~F}$ (FSCA). Hidalgo: Huasca, $1 \mathrm{~F}$ (MZSP). Guerrero: Acapulco, 2 F (ZMUC). Morelos: Cuernavaca, ex-coll. Fleutiaux, 2 F (MNHN). Puebla: Tehuacan, ex-coll. Fleutiaux, 2 F (MNHN). Chiapas: La Esperanza, 4 F (USNM); Muste (locality not found), $1 \mathrm{~F}$ (MZSP); Pacific Slope, Cordilleras, 800-1000 m, $1 \mathrm{M}$ (dissected) (MZSP), $1 \mathrm{~F}$ (MZSP retained USNM), $1 \mathrm{M}, 19 \mathrm{~F}$ (USNM); Piedras Paradas (several localities with this name), $1 \mathrm{~F}$ (USNM); Rancho Sta Rosa (locality not found), $1 \mathrm{~F}$ (USNM); San Jeronimo, $680 \mathrm{~m}, 4 \mathrm{~F}$ (IMLA), $1 \mathrm{M}$ (dissected), $3 \mathrm{~F}$ (1 dissected) (MZSP), $2 \mathrm{~F}$ (PCCV); $1 \mathrm{~F}$ (SRGI), 3 F (USNM), (Tacaná), 1 M, 1 F (USNM); San Jose (1000-1500 $\mathrm{ft}$ ), 1 F (USNM); Tapachula, 1 F (USNM); Tuxtla Gutierrez, 1 F (AMNH). GUATEMALA. $2 \mathrm{~F}$ (AMNH), $4 \mathrm{~F}$ (MNHN), $1 \mathrm{~F}$ (NHMW), $1 \mathrm{~F}$ (OSUC), 3 F (USNM); 3 F (ZMUC), ex-coll. Fleutiaux, 1 M, 13 F (MNHN). Alta Verapaz: Missouri ou Coban, $1 \mathrm{M}, 1 \mathrm{~F}(\mathrm{MNHN})$. Guatemala: env. Guatemala, 8 F (MNHN). Quiché: Zacualpa, 1 F (AMNH). Retalhuleu: El Tumbador, 2500 ft., $1 \mathrm{~F}$ (MNHN); San Sebastian, 7 F (USNM). Sacatepéquez: Capetillo, 2 F (MNHN). Suchitepequez: Cuyotenango, 1 F (USNM), Finca San Rafael Olimpo, 2 F (MZSP); Moca, 1 F (AMNH); Variedades, $500 \mathrm{ft}$., $1 \mathrm{M}, 10 \mathrm{~F}$ (AMNH). Localities not found: Siboya Yopacotoá, $1 \mathrm{~F}$ (USNM). Escuintla: Cerro Zunil, $4000 \mathrm{ft}$., $2 \mathrm{~F}$ (MNHN); El Reposo, $800 \mathrm{ft}$., $1 \mathrm{~F}$ (AMNH), $1 \mathrm{~F}$ (PCCV); Escuintla, $5 \mathrm{~F}$ (NHMW), 3 F (USNM); Yepolapa, 2 F (USNM). Jutiapa: Zapote, 2 F (AMNH), 2 F (NHMW), 2 F (USNM). Zacapa: La Union, $850 \mathrm{~m}, 1 \mathrm{~F}$ (SRGI). COSTA RICA. $5 \mathrm{~F}$ (MCZC), $5 \mathrm{~F}$ (MNHN), $1 \mathrm{~F}$ (MZSP), $1 \mathrm{M}, 7 \mathrm{~F}$ (USNM). Guanacaste: Bebedero, $1 \mathrm{~F}$ (NHMW); Hda. Taboga, $2 \mathrm{M}$ (FSCA); Playa Hermosa, 1 M (FSCA). Limón: Santa Clara Pr., Hamburg Farm, $1 \mathrm{~F}$ (USNM). Puntarenas: ex-coll. Fleutiaux, $1 \mathrm{~F}$ (MNHN); Finca Las Cruces, San Vito, 1 F (FSCA); Las Cruces, nr. San Vito, 1 F (USNM); Osa Peninsula, $2.5 \mathrm{mi}$ SW Rincon, $2 \mathrm{~F}$ (FSCA), $1 \mathrm{~F}$ (USNM); $14.5 \mathrm{Km} \mathrm{N}$ Quepos, 1 F (FSCA). vic. of Rincón, 1 F (FSCA); San Vito, 1 F (FSCA) nr. San Vito de Java, 1 F (USNM), 1 F (FSCA); Surrubres, ex-coll. Fleutiaux, $1 \mathrm{~F}(\mathrm{MNHN}) ; 6 \mathrm{Km}$ N Tarcoles, $1 \mathrm{~F}$ (FSCA); Turrialba, $2 \mathrm{~F}$ (MNHN); La Conquista, ex-coll. Fleutiaux, $1 \mathrm{~F}$ (MNHN); Ponto Rieles, 7 F (AMNH). HONDURAS. $4 \mathrm{~F}$ (MNHN). Copan: $8 \mathrm{Km} \mathrm{NW}$ El Paraiso, $1 \mathrm{M}, 3 \mathrm{~F}$ (TAMU). Francisco Morazan: Zamorano, 2 F (FSCA), 1 F (USNM). Olancho: ca Catamacas, $450 \mathrm{~m}$ (degraded rainforest), $1 \mathrm{~F}$ (FSCA). NICARAGUA. 1 M, 1 F (AMNH), 1 F (USNM). Chinandega: San Marcos, $1 \mathrm{~F}$ (USNM). Managua: Managua, $1 \mathrm{~F}$ (AMNH). EL SALVADOR. Cuscatlán, 1 M (USNM); Dulce Nombre de Maria, 1 F (FSCA); San Salvador, 1 F (NHMW), 2 F (PCCV), Trop. Inst. Science, 1 F (USNM); Sta Tecla [Nueva San Salvador], 1 F (USNM). PANAMA. 1 F (AMNH), 1 F (NHMW), 3 F (USNM), ex-coll. Fleutiaux, 1 M, 7 F (MNHN). Canal Zone: $1 \mathrm{~F}$ (AMNH); Ancon, $1 \mathrm{~F}$ USNM); Barro Colorado Island, $2 \mathrm{~F}$ (AMNH), 7 F (USNM), 12 F (MCZC), 1 M (MZSP), Gatun Lake, 2 F (USNM), Las Cruces Trail, in Madden Forest, 1 F (USNM); Cano Saddle,
Gatun Lake, 3 F (USNM); Fort Kobbe, 2 F (EGRC); Ft. Clayton, 1 F (USNM); Ft. Gulick, $1 \mathrm{M}$ (OSUC); La Pita signal station rd. 29, $1 \mathrm{~F}$ (EGRC); Las Cascadas, 5 F (USNM); Madden Dam, 1 F (FSCA); Paraiso, 2 F (USNM); Tank Hill near Albrook Field, 1 F (EGRC). Chiriqui: $1 \mathrm{M}$, 5 F (MNHN), 2 F (MZSP), 4 F (USNM), 3 F (MCZC), 1 F (ZMHB), excoll. Fleutiaux, $2 \mathrm{~F}$ (MNHN), exquisitus var. collection Fleutiaux, $1 \mathrm{~F}$ (MNHN), 2-8000 ft., $1 \mathrm{~F}$ (MNHN), ex-coll. Fleutiaux, $10 \mathrm{~F}$ (MNHN); Bugaba, 800-1500 ft, $1 \mathrm{~F}$ (AMNH), $4 \mathrm{~F}$ (MCZC), $1 \mathrm{~F}$ (MZSP, retained USNM), 2 F (USNM), BCA Col. III (1), 4 F (MNHN); Volcán de Chiriqui, 2-3000 ft, $1 \mathrm{~F}$ (USNM), $2600 \mathrm{ft}$. Champion, $1 \mathrm{~F}$ (MCZC), $1 \mathrm{~F}$ (PCCV); San Félix, 1 M (USNM). Coclé: El Valle, 1 F (JEWC); Santa Clara, 1 F (AMNH). Colón: Ft. Sherman 1 F (FSCA); Porto Bello, 2 F (USNM). Darién: Camp Monsenel (locality not found), $1 \mathrm{~F}$ (AMNH); Río Tacarcuna, 1 F (USNM). Herrera: Santa Maria, El Real, 2 F (MCZC). Panama: Bayamo, $26 \mathrm{Km} \mathrm{W}$ Ipiti, $1 \mathrm{~F}$ (JEWC), $2.5 \mathrm{Km} \mathrm{W}$ Ipiti, $1 \mathrm{~F}$ (MZSP); Cabima, $1 \mathrm{~F}$ (MZSP, retained USNM), $5 \mathrm{~F}$ (USNM); Cerro Campana 2000', 1 F (MZSP), 1 F (MZSP retained EGRC), 1 F (JEWC), 850 m, 2 F (EGRC); 56 Km E Chepo, $1 \mathrm{~F}$ (JEWC); $80 \mathrm{Km} \mathrm{E} \mathrm{Chepo,} 1 \mathrm{~F}$ (JEWC), 1 F (dissected) (MZSP); El Llano, Carti Rd. 1 F (FSCA); $10 \mathrm{Km}$ $\mathrm{N}$ El Llano, 1400, 2 F (FSCA); 10-13 Km N El Llano, 1 F (FSCA); 11$15 \mathrm{Km}$ N El Llano, 350 m, 2 F (FSCA); Old Panama, 1 F (AMNH); Pearl Island, San Jose [Island], $5 \mathrm{~F}$ (USNM); San Isidro, 1 M (dissected) (MZSP), $1 \mathrm{~F}$ (USNM); Santa Rita, $1 \mathrm{~F}$ (EGRC); Taboga Island, $1 \mathrm{~F}$ (AMNH), $1 \mathrm{M}$, 1 F (USNM); Trinidad Río, 2 F (USNM).

Remarks. Chalcolepidius lacordairii is characterized especially by very wide arched body clothed with green, blue, brown or violet setae, pronotum rugose, tibiae of male bearing fringe of long cilia and lateral cleft of parameres slightly narrowed subapically with apex upwards and prominent ventrally.

After examining a large series of specimens, I could observe the wide range of variation in size, colour and rugosity of pronotum already verified by previous authors. Specimens from Mexico exhibit whole pubescence coloration occurring into this species; those from Central America are usually blue, except the smaller specimens, and green specimens are more common in Costa Rica and Panama. All specimens examined from California are green, and one from Missouri or Coban, is blue. When the male and female genitalia are compared in specimens with blue and green pubescence, the only difference observed was in the length of median lobe and the increasing of one tooth in the sclerotized rings of openings of colleterial glands.

C. lacordairii is one of the most colorful species into the genus. It is usually unicolor and presents body shape similar to C. bomplandii, C. eschscholtzi, C. lafargi, C. rugatus and C. validus: wide and almost parallel body with elytra strongly convex on anterior half. I examined one female from Guatemala (Zacapa, La Union) (SRGI) clothed with metallic bluish-green pubescence and castaneus pubescence on very narrow lateral stripes on pronotum, not reaching hind angles, and last lateral elytral striae. It is the only specimen with lateral stripes that I examined in this species.

\section{C. lacordairii belongs to forreri* group (Fig. 671).}

Distribution. It is recorded from the United States of America (California), Mexico (Chihuahua, Jalisco, Colima, Veracruz, Hidalgo, Guerrero, Morelos, Puebla, Chiapas), Guatemala, Costa Rica, Honduras, Nicaragua, El Salvador and Panama (Fig. 680). I examined specimens from Colombia, Venezuela, Ecuador, Peru and Brazil, identified as $C$. lacordairii, but this material, belongs to $C$. virens. 
Chalcolepidius lafargi Chevrolat, 1835

(Figs. 47, 127, 194, 333, 365, 400, 440, 476, 554, 641, 686)

Chalcolepidius lafargi Chevrolat, 1835: 196. Syntype female: "Ch. lafargi Ch. ...[illegible]; Type; Collection Chevrolat; lafargi Chevr. Type, Germ. Vidit 1843 Collection Fleutiaux [handwritten underside:] Type Chevrolat Col. Mex. 1835 n. 196" (MNHN) (examined).

Chalcolepidius lafargei [sic]; Candèze, 1886: 67, 71; Champion, 1894: 274, 276, t. 11 , f. 18

Chalcolepidius eschscholtzi var. lafargei Candèze, 1857: 279; Gemminger \& Harold, 1869: 1503 (Cat.); Schenkling, 1925: 56 (Cat.); Fleutiaux, 1926: 107 (Cat.); Blackwelder, 1944: 282 (Cat.)

According to the original description, C. lafargi was "trouvé par nos voyageurs, à Tuspan, en terrre chaude, sur des pieux secs, pendant le moins de mai". The type locality was not included into the labels of the syntype examined.

CANDĖze (1857) considered C. lafargei [sic] as a variation of C. eschscholtzi Chevrolat, 1833; in 1886 he listed both species separately, and related to the former stated: "N'est, pour beaucoup, qu'une variété de couleur du précedent" [C.eschscholtzi].

Champion (1894) treating of $C$. eschscholtzi stated: " $C$. lafargi is probably an extreme variety of it", but maintained both species separately.

Fleutiaux (1926) considered C. lafargei [sic] as a variety of C. eschscholtzi.

Schenkling (1925) formalized Champion's proposal considering $C$. lafargei [sic] as a variation of C. eschscholtzi. He was followed by BLACKWELDER (1944).

Here, C. lafargi is brought to its original condition.

Length: 34-48 mm. Wide, arched body. Integument black, clothed dorsally and ventrally with short, thin metallic scalelike setae olive or grayish-green; lateral stripes of pronotum band-like, approximately $1 / 6$ of pronotum width, narrowed at extremities or widened at base; lateral stripes of elytra three interstices wide; white or yellowish-white pubescence on lateral stripes of pronotum and elytra (Fig. 47).

Frons not carinate, moderately declivous. Antennae (Fig. 127) serrate in both sexes; $3^{\text {rd }}$ segment triangular-elongate, longer than $4^{\text {th }}$. Pronotum (Fig. 194) as long as wide, subtrapezoidal, wider at hind angles, narrowed anteriad from hind angles apices; flat, moderately convex, rugose; anterior margin sinuous; hind angles wide, backward with truncate apex, raised laterally forming edge continuous with that of lateral margins, almost reaching apex; median basal tubercle flat, triangular, grooved at middle, continuous with median weak ridge; posterior margin prominent and strongly notched at middle. Hypomera concave, stronger near lateral margins; micropunctate with sparse umbilicate punctuation; laterointernal margin raised forming wall of anterior channel. Notosternal sutures strongly sinuous. Prosternum smallpunctuate with coarser punctures near sutures; median region apparently smooth; strongly convex, flattened longitudinal medially, strongly concave near sutures. Prosternal lobe sparsely small-punctuate, wide, emarginated laterally with fore angles slightly rounded. Prosternal spine flattened laterally.
Scutellum strongly folded with horizontal basal area subtrapezoidal, notched anterior- and posteriorly. Borders of mesosternal cavity wide, horizontal on basal $3 / 4$, and almost vertical on distal $1 / 4$, forming L-shaped profile. Mesepisternum with two transverse elliptical grooves. Meso-metasternal suture weak and convergent at cavity base. First visible sternite prominent laterally, fits in lateral groove of elytra. Anterior and median tibiae and last tarsal segment of all legs of male bearing fringe of long setae. Striae punctuate and paired; interstices unequal, convex and slightly micropunctate.

Male genital segments and aedeagus. Tergite VIII transverse, gradually narrowed apicad; densely setous except median basal region; translucent in large median trapezoidal area, two small rounded spots near base and short lateral band. Sternite IX (Fig. 333) elongate, partially membranous bearing short setae, more concentrate near apex. Tergite IX (Fig. 365) transverse, strongly convex, densely punctuate, narrowed apicad; anterior margin rounded; tiny laterodorsal setae; three long setae on anterior margin. Aedeagus (Fig. 400): median lobe (Fig. 440) strongly constricted near middle, bearing 10, 12 teeth; lateral cleft of parameres (Fig. 476) almost straight with apex prominent ventrally and slightly upwards.

Female genital segments and genitalia. Tergite VIII transverse, translucent in triangular basal area and on lateral marginal bands. Sternite VIII (Fig. 554) 0.56 times spiculum gastrale length with anterior margin wide- and moderately notched at middle; apex of spiculum gastrale bilobed. Genitalia: sclerotized rings of openings of colleterial glands (Fig. 641) with 36 teeth; bursa copulatrix with median elongate band with carinae and spines and paired lateral rounded spiny areas.

Material examined. MEXICO. 2 F (MCZC), 4 F (NHMW), ex-coll. Fleutiaux, 1 M, 3 F (MNHN). San Luís de Potosí: Tomazunchale, 1 F (USNM). Tamaulipas: $10 \mathrm{~m}$ E Tula, 3900" $1 \mathrm{~F}$ (JEWC); Boca Toma area (locality not found), $1 \mathrm{~F}$ (JEWC); $80 \mathrm{Km} \mathrm{S}$ Ciudad Victoria, $2 \mathrm{~F}$ (FSCA); $80 \mathrm{Km} \mathrm{S} \mathrm{Cd.} \mathrm{Victoria,} \mathrm{Ruta} \mathrm{85,} \mathrm{ca} \mathrm{La} \mathrm{Gloria,} 1$ F (FSCA); Est. Biol. Los Cedros, Gomez Farias, 1 F (TAMU); La Lola [La Jola] Pto Limón (en cacao) (locality not found), 1 F (USNM). Veracruz: Jalapa, 2 F (AMNH), $1 \mathrm{~F}$ (NHMW), $1 \mathrm{~F}$ (PCCV), $2 \mathrm{~F}$ (MCZC), $1 \mathrm{~F}$ (MZSP), $1 \mathrm{~F}$ (NHMW), 1 F (USNM), BCA Col. III (1), 1 F (MNHN). Yucatan: Merida, 1 F (NHMW). Chiapas: $1 \mathrm{~F}$ (USNM); San Quintin, 2 F (USNM). COSTA RICA. Heredia: Finca La Selva, 1.5 mi S Puerto Viejo, 1 F (MZSP). WEST INDIES. $1 \mathrm{~F}$ (USNM). Without locality: $1 \mathrm{M}$ (dissected) (NHMW); Collection Chevrolat; Eschscholtzi var. typique Cand. Mon. Collection Fleutiaux; Coll. A. Sallé, $1 \mathrm{~F}(\mathrm{MNHN})$.

Remarks. Chalcolepidius lafargi is characterized especially by wide arched body clothed with green metallic pubescence with white lateral stripes on pronotum and elytra, tibiae of male bearing fringe of long cilia and apex of lateral cleft of parameres almost straight with apex prominent ventrally and slightly upwards. In some specimens, the lateral bands of pronotum do not reach the hind angles and in one specimen from Costa Rica the striae are clothed with white pubescence.

It looks-like $C$. eschscholtzi, differing especially by ( $C$. eschscholtzi parenthesized): 1) general metallic pubescence green- or grayish-olive with lateral stripes of pronotum and elytra white or yellowish-white (green or yellowish-green with stripes ferruginous (cinnamon)); 2) lateral stripes of pronotum 
longer, extending to the hind angles base in C. lafargi (not reaching hind angles base); 3 ) tergite VIII of male with one small translucent spot each side of the median larger spot (absent); 4) sternite IX of male bearing short setae (moderately long); 5) tergite IX of male bearing three long setae on anterior margin (fallen or absent); 6) median lobe of aedeagus bearing $10,12$ teeth $(6,7) ; 7)$ lateral cleft of parameres almost straight, with apex prominent ventrally, upwards in a narrow band (narrower and constricted near apex; apex prominent ventrally and more widely upwards); 8) anterior margin of sternite VIII of female more deeply notched in C. lafargi; 9) apex of spiculum gastrale bilobed (rounded); 10) sclerotized rings of openings of colleterial glands bearing 36 teeth (41).

\section{C. lafargi belongs to fryi* group (Fig. 671).}

Distribution. It is recorded from Mexico (Potosí, Tamaulipas, Veracruz, Yucatan, Chiapas), Costa Rica and West Indies (Fig. 686). I examined also one specimen from "Colombia" (AMNH) and 2 from "New Granada" (USNM), not included in the material examined this locality requires confirmation.

\section{Chalcolepidius lenzi Candèze, 1886}

(Figs.48,129,130,193,250,293,334,366,401,515,555,601,602,646,673)

Chalcolepidius lenzi Candèze, 1886: 69; 1891: 37 (Cat.); Champion, 1894: 275, 285; Schenkling, 1925: 56 (Cat.). Syntype female: "Coll. R. I. Sc. N. B. Mexique ex coll. Candèze; Sinaloa Mex; type; n. sp. lenzi Cdz. Mex. L.; Chalcolepidius lenzi dét. E. Candèze" (ISNB) (examined).

Chalcolepidius behrensi Candèze, 1886: 70; Leng, 1920: 167 (Cat.). Syntype female: "Coll. R. I. Sc. N. B. Mexique ex coll. Candèze Sinaloa Mex; n. sp. behrensi Cdz. Mex.; Lectotype Chalcolepidius behrensi Cand. M. C. Lane, 1964; Chalcolepidius behensi Cand. det. E. Candèze; Lectotype designation unpublished, CMF von Hayek det. 1979" (ISNB) (examined). Syn. nov.

CANDÈze (1886) described C. lenzi and C. behrensi, both from same locality, only published with different spelling (Mexico: respectively, Cinaloa and Sinaloa), but at the specimens labels they are written with the same spelling (Sinaloa). According to him, C. behrensi differs from C. lenzi especially by smaller size, prothorax more elongate and narrower frontally, and striae not grooved in the former. He described the pubescence as olive in the former and grayish-green in the latter.

Champion (1894) stated about $C$. lenzi: "allied to $C$. rubripennis Lec. from Lower California" and about $C$. behrensi: "near C. lenzi but smaller; the greenish scales less dense, the thorax much longer and more narrowed in front; its surface not uneven, the elytra striated but not sulcate". The different sizes, length of pronotum, depth of the striae and pubescence coloration are not considered, herein, as sufficient to justify the retention of $C$. lenzi and $C$. behrensi as separate species, and they are considered conspecific.

Length: 20-39 mm. Parallel body; integument bright. Integument dark-brown or brown clothed dorsally and ventrally with short metallic olive, grayish-green, grayish-brown, grayish or bluish-green scale-like setae (Fig. 48).
Frons not carinate, moderately declivous. Antennae (Figs. $129,130)$ serrate in female, strongly serrate in male; $3^{\text {rd }}$ segment triangular with spiniform appendix. Pronotum (Fig. 193) longer than wide, narrowed anteriorly and at hind angles base, making lateral margins rounded; strongly convex at middle; micropunctate with coarser sparse punctuation lateroanteriorly; anterior margin U-shaped; fore angles prominent; lateral margins raised forming smooth edge, grooved in narrow band innerly edge; hind angles strongly divergent, sharpened, raised laterally forming wide edge not fused with that of lateral margins; median basal tubercle flat, transverse, with transverse carina near apex; posterior margin prominent and slightly notched at middle. Hypomera slightly convex, micropunctate; emarginated posteriorly, more raised than prosternum on sutures; prosternal channel absent. Notosternal sutures slightly sinuous. Prosternum slightly convex from sutures; micropunctate; punctuation coarser near sutures. Prosternal lobe emarginated laterally; punctuation dense, coarser than prosternum with fore angles rounded. Prosternal spine flattened laterally. Scutellum (Fig. 250) strongly declivous, folded at middle with horizontal half elliptical with two rounded concavities; anterior half narrow and vertical. Borders of mesosternal cavity (Fig. 293) wide and horizontal on basal half and slightly declivous distally, forming inclined profile. Mesepisternum with transverse irregular groove as wide as sternite. Meso-metasternal suture present. First visible sternite not prominent laterally. Tibiae of male bearing row of long spines internally. Striae marked by coarse punctures; interstices equal, flat and small-punctuate; $2^{\text {nd }}$ interstice joined to $3^{\text {rd }}$ at base forming small forward tubercle more developed in male; apices conjointly rounded.

Male genital segments and aedeagus. Sternite VIII (Fig. 334) strongly narrowed on distal third; translucent with Vshaped melanized area, convergent basally. Tergite IX (Fig. 366) densely punctuate, anterior margin almost straight with rounded angles; moderately long setae lateroanteriorly. Aedeagus (Fig. 401): median lobe 0.62 times the aedeagus length, almost straight, widened at base; parameres with apices spearhead-like.

Female genital segments and genitalia. Tergite VIII (Fig. 515) transverse, setous, translucent in Y-shaped basal band. Sternite VIII (Fig. 555) 0.60 times spiculum gastrale length; anterior margin narrow- and deeply notched at middle. Genitalia: sclerotized pieces of openings of colleterial glands (Fig. 646) C-shaped bearing many small teeth; bursa copulatrix (Figs. 601, 602) membranous dorsally and totally clothed with carinae and spines ventrally.

Material examined. UNITED STATES OF AMERICA. California: Imperial Co., Calipatria, $1 \mathrm{M}(\mathrm{CMNH})$. Arizona. 1M, $2 \mathrm{~F}(1 \mathrm{M}, 1 \mathrm{~F}$ dissected, CMNH), $1 \mathrm{M}$ (dissected), $1 \mathrm{~F}$ (MZSP), 2 F (USNM); Cochise Co., Don Luis, 1 M, 8 F (AMNH); Douglas, 1 M, 1 F (USNM), San Bernardino Ranch, 3750 ft. 1 M (MCZC), 2 M (SEMC); Coconino Co. Madeira Canyon (locality not found), 1 M (OSUC); Gila Co., Globe, 1 F (USNM); Maripa Co., Mazatzal Mts, Three Bar Wildlife area, Tonto National Forest 1 M (USNM); Pima Co., Baboquivari Mts, 1 F (SEMC); Tucson, 2 F (AMNH), 1 F (FSCA), 1 F (MCZC); Santa Cruz Co.: Benson, $1 \mathrm{~F}$ (USNM); Nogales, $1 \mathrm{~F}$ (AMNH), 2 M (MZSP), 4 M (MCZC), $1 \mathrm{M}, 1$ F (USNM); Pajarito Mts. Pena Blanca (locality not found), 1 F (FSCA); 
10 mi W Patagonia, 1 F (AMNH); nr Nogales on Ruby Road, 1 F (FSCA); Yuma Co.: near Yuma, $1 \mathrm{~F}(\mathrm{CMNH})$. MEXICO. Ex-coll. Candèze, $1 \mathrm{~F}$ (ISNB). Sonora: nr Alamos, $1 \mathrm{~F}$ (USNM); $9 \mathrm{mi} \mathrm{W}$ Alamos, $1 \mathrm{M}, 1 \mathrm{~F}$ (FSCA); $10 \mathrm{Mi}$ W Alamos, $3 \mathrm{M}$ (AMNH); $13 \mathrm{mi}$ SE Alamos, $1 \mathrm{M}$ (FSCA); Immuris, 1 M (AMNH); Los Hornos, Río Yaqui, 1 M (USNM), 11.3 mi E Navajoa, 1 F (FSCA); Minas Nuevas, 1 F (AMNH); Santa Rosa Rch. N. Navojoa, 1 F (AMNH). Sinaloa: 1 F (USNM), 4.5 mi Elota, 1 M (MZSP); 5 mi N Mazatlán, $1 \mathrm{M}$ (FSCA). Nuevo Leon: Pesquería, $20 \mathrm{mi}$ NE Hermosillo, $1 \mathrm{M}$ (AMNH). Colima: Manzanillo, 1 F (MCZC). Veracruz: Jalapa, 1 F (AMNH).

Remarks. Chalcolepidius lenzi is characterized especially by antennae strongly serrate in male and serrate in female; $3^{\text {rd }}$ antennal segment transverse with spiniform appendix, shorter with more developed appendix in male; pronotum micropunctate, strongly convex with moderately wide lateral groove; hind angles of pronotum divergent; median basal tubercle transverse with carina; scutellum strongly declivous with horizontal half elliptical; tibiae of male bearing irregular row of spines; interstices flat, striae marked by row of coarser punctures; and apex of parameres spearhead-like.

Comparing the holotypes of C. behrensi and C. lenzi, both females, It was observed that the pubescence of the former is olive dorsally and grayish ventrally and that of the latter, grayish in both sides. Besides the different coloration, the type specimen of C. lenzi is really much larger than C. behrensi (40/ $30 \mathrm{~mm}$ ) and consequently it presents some differences related with the body strength: pronotum shorter and more convex, with small rugosities; interstices slightly convex near base, and prosternal lobe with deeper longitudinal grooves.

C. lenzi presents a wide range of variation in size (20-40 $\mathrm{mm}$ ) and pubescence coloration. The specimens studied from U.S.A. have green pubescence dorsally and ventrally, sometimes bluish-green dorsally and olive ventrally. The larger specimen examined ( $39 \mathrm{~mm}$, Arizona) is green in both sides and presents some weak rugosities on pronotum and deeper longitudinal grooves on prosternal lobe. Specimens from Mexico are usually clothed with pubescence brownish dorsally and grayish ventrally; three specimens from Sonora are grayish with brownish elytra while two others from Sonora are grayish dorsally and ventrally; two specimens from Sinaloa (type locality) are brownish dorsally and grayish ventrally, or grayish with brownish elytra.

C. lenzi looks-like C. smaragdinus, differing especially by (the latter parenthesized): pubescence olive, grayish-green, grayish-brown, grayish or bluish-green (green or blue); antennae strongly serrate in male, serrate in female (flabellate, pectinate); pronotum strongly convex with lateral margins rounded (moderately convex with lateral margins almost straight); hind angles of pronotum divergent (backwards); median basal tubercle transverse (indistinct or triangular); scutellum strongly declivous with horizontal half subelliptical, transverse (distal third of scutellum almost vertical and horizontal half triangular, sometimes with two tubercles).

C. lenzi is similar to C. attenuatus (see remarks after the latter). Together with C. attenuatus and C. dugesi it forms the

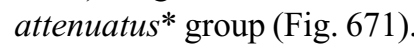

Distribution. It is recorded from United States of America (California, Arizona) and Mexico (Sonora, Sinaloa, Nuevo Leon, Colima, Veracruz) (Fig. 673)

Chalcolepidius limbatus (Fabricius, 1777)

(Figs.49, 50, 128, 192, 335, 367, 402, 441, 477, 516, 556, 647, 689)

Elater limbatus Fabricius, 1777: 234; 1781: 272

Elater striatus; Fabricius, 1801: 226; Erichson, 1841: 80 [misidentification].

Chalcolepidius limbatus; Eschscholtz, 1829: 33; Erichson, 1841: 80; Gemminger \& Harold, 1869: 1503 (Cat.); Lacordaire, 1857: 155 Candèze, 1857: 263, 272; 1886: 71; 1891: 38 (Cat.); Champion, 1894: 274, 277; Heyne \& Taschenberg, 1908: 153, t. 25, f. 16; Hyslop, 1916: 17; Schenkling, 1925: 56, 57 (Cat.); Fleutiaux, 1926: 107 (Cat.); Blackwelder, 1944: 283 (Cat.).

Elater porcatus; Olivier, 1790(31): 14, t. 7, f. 74; Drury, 1837: 70, t.47, fig. 6; Herbst, 1801: 323, t. 157, f. 3; Erichson, 1841: 80 (Syn.); Lacordaire, 1857: 155; Candèze, 1857: 272 . [Misidentification].

Chalcolepidius brullei Dejean, 1837 (nomen nudum); Erichson, 1841: 80 (Syn.).

Olivier (1790) presented a redescription of $C$. porcatus Linnaeus, where the diagnosis corresponds to C. porcatus, but the specimen illustrated presents lateral whitish stripes on pronotum. Subsequent workers considered it belonging to $C$. limbatus.

Eschscholtz (1829) presented the following diagnosis to $C$. limbatus: "ferrugineo-squamulosus; thoracis lateribus, elytrorum limbo striisque sex ausque ad apicem dissitis ochraceis. 18 lin.Bresilien”.

ERICHSON (1841) included the Olivier's interpretation of $C$. porcatus, C. striatus (Fabricius) and C. brullei (Dejean, nomen nudum) as synonyms of $C$. limbatus. LACORDAIRE (1857) and CANDĖze (1857) kept the Erichson's synonymizations including also, respectively, $C$. porcatus [treated by Herbst] and $C$. porcatus (Dejean, nomen nudum).

CANDÈzE (1857) redescribed C. limbatus and commented that this species is very common in Brazil, Guyana and Colombia, and presents numerous variations in size and coloration. He enumerated the principal variations: "var.a. squamulis viridibus, vittis striisque albidis" [correponding to Elater striatus Fab.]; "var.b. squamulis cinereis"; "var.c. squamulis fulvis, prothoracis elytrorumque vittis ochraceis"; "var.d. squamulis viridibus, vittis fulvis" [corresponding to C. brullei Dej.]. In 1886 he recorded $C$. limbatus from Mexico and Uruguay and, again, commented that it is very common in whole Brazil.

Champion (1894) recorded it from Mexico, "Bay of Honduras", Colombia, Venezuela, Guyana, Brazil and Uruguay, and considered the first two localities as dubious. In relation to the studied material from Mexico he stated: "there is an abraded male example of this species in the Janson collection, from that of Dejean, labeled as from Mexico". According to him, the figure and redescription of E. porcatus from Bay of Honduras, presented by DruRY (1837) would apply equally well to $C$. bomplandii Guérin-Méneville, which differs from $C$. limbatus in the latter having the epipleura clothed with elongate luteous setae and the marginal carina of the elytra more deflexed anteriorly. 
Heyne \& TASCHENBERG (1908) redescribed this species and presented a colored figure and, correctly, reduced the geographical distribution to Brazil, Colombia (Bogotá) and Guyana.

Length: $22-42 \mathrm{~mm}$. Wide, arched body. Integument black clothed dorsally and ventrally, including legs, with scale-like setae thin, metallic green-olive, gray-olive, brown-olive, brownviolet, bluish or violet; sometimes ventrally with different tonalities; lateral stripes of pronotum band-like, $1 / 4$ of pronotum width, narrowed anteriad, with internal margin semi-elliptical; lateral stripes of elytra complete, three interstices wide; white, yellowish-white or bright ochre dull pubescence on lateral stripes of pronotum and elytra, striae and epipleura (Figs. 49, 50). Antennae blue, except three first segments, like general pubescence.

Frons not carinate, moderately declivous. Antennae (Fig. 128) serrate in both sexes, $3^{\text {rd }}$ segment triangular-elongate, slightly shorter than $4^{\text {th }}$. Pronotum (Fig. 192) longer than wide, wider at hind angles, slightly narrowed apicad from hind angles base; anterior margin slightly prominent and sinuous at middle; micropunctate with coarse punctures more concentrate near middle, giving rugose appearance; hind angles wide, slightly divergent, with truncate apex, raised laterally forming edge continues with lateral edge except distal 1/4; median basal tubercle flat, triangular; posterior margin prominent and strongly notched at middle. Hypomera concave near lateral margins, micropunctate; laterointernal margin raised forming wall of well developed channel. Notosternal sutures strongly sinuous. Prosternum micropunctate, strongly convex, flattened longitudinal medially, slightly concave near sutures on basal $2 / 3$. Prosternal lobe micropunctate, wide, with lateral margins emarginated and fore angles slightly rounded. Prosternal spine flattened laterally. Scutellum strongly folded with horizontal basal area subpentagonal, notched anterior- and posteriorly, grooved longitudinal medially. Borders of mesosternal cavity wide, horizontal on basal $3 / 4$, and vertical on distal $1 / 4$, forming Lshaped profile. Meso-metasternal suture weak and convergent to cavity base. First visible sternite prominent laterally fits in lateral groove of elytra. Anterior and median tibiae and last tarsal segment of all legs of male bearing fringe of long cilia. Striae grooved with coarse punctures; interstices unequal in width, convex and micropunctate, almost at same high.

Male genital segments and aedeagus. Tergite VIII wider than long, slightly narrowed apicad; basal margin strongly notched; densely setous. Sternite VIII (Fig. 335) transverse, narrowed on distal third; melanized in marginal band entire or interrupted at apex; setous on distal 2/3. Sternite IX elongate, melanized in distal half, except narrow marginal band; setous laterodistally. Tergite IX (Fig. 367) transverse, densely punctuate; anterior margin rounded; two setae near lateroanteriorly margin. Aedeagus (Fig. 402): median lobe (Fig. 441) moderately narrowed near middle, bearing 4,$8 ; 8,8 ; 8,10$; 8,$11 ; 8,13 ; 9,11 ; 12,17$ lateral teeth; lateral cleft of parameres (Fig. 477) slightly narrowed apicad, apex prominent laterally and upwards.
Female genital segments and genitalia. Tergite VIII (Fig. 516) transverse; basal margin strongly notched; anterior angles rounded and anterior margin slightly prominent at middle; densely setous; translucent in median basal area surpassing middle and two lateral narrow bands. Sternite VIII (Fig. 556) 0.6 times spiculum gastrale length; anterior margin moderate- and widely notched. Genitalia: sclerotized rings of openings of colleterial glands (Fig. 647) bearing 37, 40, 44 teeth; bursa copulatrix with longitudinal median elongate band with carinae and spines and two lateral rounded spiny areas.

Material examined. WEST INDIES. Virgin Islands. St. Croix, $1 \mathrm{~F}$ (ZMUC). Trinidad. 1 F (MZSP), ex-coll. Fleutiaux, 1 F (MNHN); Caparo, ex-coll. Fleutiaux, 7 F (MNHN). VENEZUELA. 2 F (MNHN), C. limbatus var. Lherminieri Ch.; ex-coll. Fleutiaux, $2 \mathrm{~F}$ (MNHN), 2631, $1 \mathrm{~F}$ (ZMHB). Amazonas: Mt. Duida, $1 \mathrm{~F}$ (AMNH). Aragua: El Limon, $450 \mathrm{~m}, 1 \mathrm{~F}$ (IMLA). Barinas: Arismendi, $1 \mathrm{~F}(\mathrm{MNHN})$. Bolivar: $1 \mathrm{~F}$ (USNM). Federal District: Caracas, 3 F (MNHN), 1 F (USNM), ex-coll. Chevrolat, ex-coll. Fleutiaux, zonatus pars typique Cand. Mon., $1 \mathrm{~F}$ (MNHN). Guárico: Guyabal, 1 F (MNHN); La Cruz, Rivière, 2 F (MNHN); Las Adjacintas, 1 M (USNM). Lara: Bas Sarare, 2 F (MNHN). Mérida: 1 F (MNHN). Monagas: Caripito, 1 F (AMNH); Maturin, 1 F (NHMW), (Río Guarapiche), 1 F (ZMUC). Sucre: Cumaná (nr. 29.824), 1 M (MCNZ). Zulia: Maracaibo, 4 F (USNM). COLOMBIA. 2 F (MCZC), 1 M, 26 F (MNHN), 1 F (USNM), 2 F (ZMUC), ex-coll. Fleutiaux, 2 F (MNHN). Boyacá: San Luis de Gaceno, 1 F (ICNC). Special District: Bogotá, excoll. Oberthür, ex-coll. Fleutiaux, $1 \mathrm{M}$ (dissected) $4 \mathrm{~F}$ (MNHN); Oriente, Monterredondo, 4 F (IMLA); Santa Fé de Bogotá, 2 F (MNHN); Villavicencio, ex-coll. Oberthür, ex-coll. Fleutiaux, $1 \mathrm{M}(\mathrm{MNHN})$. Huila: Gigante, 1 F (ICNC). Meta: Macarena, 550 m, 1 F (ICNC); Medina, 1 M, 3 F (AMNH); Meta PNN, Tinigua CIEM R. Duda, 350 m, 1 F (IAHC); Pto Limon, Alt. $300 \mathrm{~m}, 1 \mathrm{M}$ (ICNC); Pto Lopez, Alto Menegua, Alt. 300 m, 1 F (ICNC); Restrepo, 1 M, 1 F (AMNH), 1 F (IMLA); Restrepo, Vda Alto Coney, alt. $700 \mathrm{~m}, 1 \mathrm{M}$ (ICNC); Villavicencio, $3 \mathrm{~F}$ (AMNH), 1 F (USNM), V. da Cucuy, Río Negro. H. Restrepo, 1 F (MZSP, gift ICNC). Santander: Barranca Bermeja, 1 F (AMNH). PERU. Loreto: Pucallpa, 2 F (PCCV). ECUADOR. Chinchipe: Santa Rosalia de Turim, Zamora, excoll. Fleutiaux, 1 F (MNHN). Esmeraldas: San Mateo, 1 F (IMLA). FRENCH GUIANA. Cayenne: $1 \mathrm{M}$ (MNHN), ex-coll. Fleutiaux, $1 \mathrm{~F}$ (MNHN). GUYANA. $1 \mathrm{~F}$ (ZMUC). BRAZIL. $1 \mathrm{~F}$ (AMNH), $1 \mathrm{~F}$ (FSCA), $7 \mathrm{~F}$ (MCZC), $2 \mathrm{M}, 3 \mathrm{~F}$ (USNM), $2 \mathrm{~F}$ (ZMHB), $3 \mathrm{M}, 8 \mathrm{~F}$ (ZMUC), Chalcolepidius costatus Dej. 1 F (MNHN), 16215, limbatus Esch. Er* Elater porcatus O1. Hbst Brasil, Hist. coll. (Coleoptera) nr. 16215 (1 ex) Chalcolepidius limbatus Eschs. Brasil Zool. Mus. Berlin, 1 M (ZMHB), Hist. coll. (Coleoptera) nr 16215 (2 ex.) Chalcolepidius limbatus Eschs. Brasil Zool. Mus. ZMHB, 1 F (ZMHB), (5 ex), 1 M (ZMHB), (3 ex)(4 ex)(6-10 ex) 7 F (ZMHB). Amazonas: Benjamin Constant, 1 F (MZSP); Rio Juruá, 3 F (MZSP). Roraima: Maracá (nr. 158.181), 1 F (MCNZ). Pará: Cachimbo, 1 M, 5 F (MZSP); Óbidos, 1 M, 3 F (MZSP), Canta Galo, 2 F (MZSP). Paraíba: ex-coll. Jekel, ex-coll. Fleutiaux, 1 F (MNHN). Pernambuco: Caruaru, Brejo dos Cavalos, 1 F (UFPE); Pery-Pery, 3 F (MNHN). Goiás: 1 F (MZSP); Cana Brava, 1 F (MCZC); Jataí, 13 F (MNHN); Fazenda Aceiro, 1 F (MZSP); Leopoldo Bulhões, 3 F (MZSP); Rio dos Bois, $1 \mathrm{~F}$ (MZSP); Trindade, $1 \mathrm{~F}$ (MNHN); Vianópolis, $1 \mathrm{~F}$ (MZSP), 1 F (NHMW). Mato Grosso: $1 \mathrm{~F}$ (FSCA), $10 \mathrm{~F}$ (MNHN), $1 \mathrm{~F}$ (MZSP); Barra do Tapirapé, 1 M, 1 F (MZSP); Caparó (Fazenda Pai Cué) (locality not found), 2 F (MZSP); Chapada [dos Guimarães], near Cuiabá, 2 F (USNM); Chapada Guimarães, 1 F (DZUP); Claudia (30 Km SSW) (locality not found), 1 F (MZSP); Cuiabá, 3 F (MNHN), 1 M (UFMT); Guaicurus, 5 F (MZSP); Lagoa dos Patos, Faz. Taquari, 1 M (IBSP); from Miranda to Cuiabá, 4 F (MNHN); Porto Quebracho, 1 F (MZSP); Rio Negro, 1 M (NHMW); Rio Paraná (riacho Herval), 1 M (dissected), 10 F (MZSP); Rio Verde, 400 m, 1 F (DZUP); Rondonópolis, 1 M (MZSP); Rosário d'Oeste, 3 F (PCCV), 1 M, 5 F (MZSP), 2 F (DZUP); Utiariti (Rio Papagaio), 12 F (MZSP). Mato Grosso do Sul: Corumbá, 1 F (MCZC), 1 F (NHMW), Serra do Urucum, 1 F (MZSP); Murtinho, 2 F (MZSP); Passos, 1 M (DZUP); Três Lagoas (Fazenda do Cervo), 1 M (MZSP). 
Bahia: $1 \mathrm{~F}$ (AMNH), 3 F (MCZC), 1 F (MZSP), 1 M, 3 F (ZMUC), excoll. Fleutiaux, 2 F (MNHN); Água Preta, 4 F (IBSP); Bonfim, 1 F (IBSP); Cachimbo [Campinarana], $4 \mathrm{~F}$ (MNHN); Ilhéus, $1 \mathrm{M}$ (dissected), 1 F (MZSP); Mucuri, 1 F (MZSP), BR $101 \mathrm{Km} \mathrm{295,} 1$ F (DZUP); Prado, 5 F (DZUP); Salobro, 1 M (MNHN); Uruçuca, 1 F (DZUP); Vila Victoria [Vitória da Conquista], $1 \mathrm{~F}$ (MNHN). Minas Gerais: Aimorés, $1 \mathrm{M}, 1 \mathrm{~F}$ (DZUP); Buritis, Primeira Cachoeira Rio Urucuia, $1 \mathrm{~F}$ (MZSP); Ibiá, $1 \mathrm{~F}$ (DZUP); Jampruca, 1 F (MZSP); Lagoa Santa, 4 F (ZMUC); Nova Resende, 1 M (DZUP); Organ Mt. [Serra dos Órgãos], 2 F (USNM); Passos, 3 M (DZUP); Catas Altas, Serra do Caraça, 2 F (MNHN); Sete Lagoas, 1 M, 6 F (ZMUC). Espírito Santo: 5 F (MZSP), 3 F (NHMW); Baixo Guandu, 5 M, 9 F (DZUP); Colatina, 1 F (DZUP); Conceição da Barra, 14 F (MZSP), 1 F (TAMU); 2 M, 124 F (DZUP); Córrego Itá, Barra do São Francisco,16 F (DZUP); Guarapari, 1 F (DZUP); Itapina, 1 F (DZUP); Linhares, $1 \mathrm{~F}$ (FSCA), $54 \mathrm{M}$ ( $5 \mathrm{M}$ dissected), $133 \mathrm{~F}$ (3 F dissected) (MZSP), 4 M, 68 F (DZUP), Parque Sooretama, 1 F (MZSP), 5 F (DZUP); Rio Bonito, 3 M (DZUP); Santa Leopoldina, ex-coll. Fleutiaux, 9 F (MNHN); Santa Tereza, 5 F (MZSP), 30 F (DZUP). Rio de Janeiro: $18 \mathrm{~F}$ (MNHN), $1 \mathrm{M}, 5 \mathrm{~F}$ (NHMW), 9 F (USNM, $1 \mathrm{~F}$ (ZMUC), ex-coll. Fleutiaux, 1 F (MNHN); Guapimirim, 1 M, 1 F (IBSP), $160 \mathrm{~m}$ alt., Caneca Fina- Rio Sucavao, Mun. Magé, 1 M, 2 F (USNM); Manguinhos, 1 F (MZSP); Petrópolis (nr. 158.712), 1 F (MCNZ); Rep. Rio Grande, 16 F (DZUP); Rio de Janeiro (nr. 22.190), 1 M (MCNZ), Corcovado, 1M, 1 F (MNMS), 1 M, 3 F (DZUP), [Serra dos Órgãos] Montagne des Orgues, Massif de la Tijuca, 4 F (MNHN), 1 F (NHMW). São Paulo: Araçatuba, 1 M (MZSP); Agudos, 1 F (MZSP); Batatais, $1 \mathrm{~F}$ (DZUP); Bauru, 1 F (MZSP); Boa Esperança do Sul, Fazenda Itaquerê, 1 M (MZSP); Botucatu, 2 M, 3 F (MZSP); Cassia dos Coqueiros, $1 \mathrm{~F}$ (MZSP); Corumbataí, $1 \mathrm{~F}$ (MZSP); Franca, $1 \mathrm{~F}$ (MZSP); Indiana, $3 \mathrm{~F}$ (IBSP), 3 F (MZSP); Itararé, $1 \mathrm{M}, 1 \mathrm{~F}$ (IBSP), $1 \mathrm{M}$ (MZSP); Jundiaí, $1 \mathrm{~F}$ (MZSP); Lageado, 1 F (DZUP); Marília, 2 F (MZSP); Nova Europa, Fazenda Itaquerê, 1 F (MZSP); Paranapiacaba, Alto da Serra, 1 F (MZSP); Pirajui, 1 F (IBSP); Pirassununga, 1 F (MZSP), 1 M (DZUP); Porto Cabral (Rio Paraná), 3 F (MZSP); Porto Epitácio, 1 F (MZSP); Presidente Venceslau, $1 \mathrm{~F}$ (IBSP), $1 \mathrm{~F}$ (USNM); Ribeirão Preto (Bosque Fabio Barreto), 2 F (MZSP); Rio Claro, 2 F (MZSP); Rio Piracicaba, 1 F (MNHN); Rio Preto, 1 F (MZSP); São Bernardo do Campo, Represa Rio Grande, 1 F (MZSP); São Fidelis, Sto Antonio dos Brotos, $10 \mathrm{~F}$ (MNHN); São Paulo, $2 \mathrm{~F}$ (PCCV), $1 \mathrm{~F}$ (IBSP), $2 \mathrm{~F}$ (MZSP), Ipiranga, $1 \mathrm{~F}$ (MZSP), Vila Olimpia, $1 \mathrm{~F}$ (MZSP). Paraná: Andirá (Sítio S. Roque, Águas das Antas), 1 F (IBSP); Canta Galo, 2 M, 2 F (MCZC); Caviuna, 2 M, 7 F (AMNH); Guaira, 1 F (DZUP); Foz do Iguaçu (col. MCN nr.26.722), 1 F (MCNZ), 1 F (DZUP); Heimtal [Londrina], 1 F (AMNH), 1 F (MZSP); Jundiaí do Sul (Fazenda Monte Verde), 1 F (DZUP); Maringá, 2 F (DZUP); Matelandia, 1 F (DZUP); Ponta Grossa (nr. 20.619), 1 F (MCNZ); Rolândia, 2 M, 3 F (AMNH), 17 M, 32 F (MZSP); Santa Helena (nr. 150.441), 1 F (MCNZ). Santa Catarina: Blumenau, 1 F (MCZC); Corupa, $1 \mathrm{M}$ (MZSP); Nova Teotônia [Seara], $1 \mathrm{~F}$ (AMNH), $1 \mathrm{~F}$ (MNHN), $4 \mathrm{M}$ (1 dissected), 4 F (MZSP); São Bento do Sul, Rio Vermelho, $1 \mathrm{M}, 2 \mathrm{~F}$ (MZSP). Rio Grande do Sul: 2 F (MCZC), ex-coll. Fleutiaux, 3 F (MNHN); Barão de Cotegipe, 1 F (DZUP); Iraí, (nr. 23,192), 1 F (MCNZ); Porto Alegre, Ilha das Flores, $1 \mathrm{~F}$ (MCNZ), Morro do Coco (nr. 20.617), $1 \mathrm{~F}$ (MCNZ); Pelotas, $1 \mathrm{M}$ (AMNH), $1 \mathrm{M}, 1 \mathrm{~F}$ (FSCA), $4 \mathrm{~F}$ (NHMW), $1 \mathrm{~F}$ (USNM); Porto Alegre, (nr. 158,713; 158.714; 123.232), 3 M (MCNZ); Santa Maria (Cerrito) (nr.153.504), 2 F (MCNZ); Torres, (nr. 20.620), 1 M (MCNZ). BOLIVIA. Cochabamba: Independencia, 1 F (IMLA). Santa Cruz: 1 F (FSCA), 1 F (USNM); El Cidral, 1 F (IMLA); Est. Experimental Gral. Saavedra, 1 M, 1 F (IMLA); Nueva Moka, Prov. Sara, 1 F (MZSP); Parapeti, 1 F (MZSP); Roboré, Chiquitos, 1 M (IMLA); Santa Cruz de la Sierra, 2 F (MNHN). ARGENTINA. Buenos Aires: excoll. Fleutiaux, 1 F (MNHN); Zelaya, 4 F (USNM). Chaco: 1 F (MZSP); Departamento General Guenes, Pozo la Gringa, 1 F (SRGI); Santajacino [San Jacinto], 1 M (USNM). Cordoba: Cordoba, 2 F (NHMW). Corrientes: 1 F (IMLA); San Tomé, 1 M, 1 F (IMLA). Federal District: Buenos Aires, 1 F (USNM). Entre Ríos: Concordia, 2 F (AMNH), 1 F (IMLA); Villa Hernandaria, 1 F (ZMUC). Formosa: Clorinda, 1 F (IMLA); Gran Guardia, 2 F (IMLA). Jujuy: 1 F (IMLA); Calilegua, 1 F (IMLA); Quemado, 3 F (USNM); Palpalá, 1 F (IMLA). Misiones: 1 M, 8 F (IMLA), 1 M (USNM); Azara, 1 F (MZSP); Dos de Mayo, 1 F (IMLA); Iguazu, 1 F (IMLA), 2 F (PCCV); Panambi, 1 F (IMLA); Localities not found: Mado
Puerto Magdalena, $1 \mathrm{~F}$ (AMNH). Salta: $1 \mathrm{~F}$ (IMLA); Cafayate, $1 \mathrm{~F}$ (IMLA); Orán, ruta Mac 57, Km 21, 700 m, 1 M (IMLA); Abra Grande, 1 F (IMLA); Salta, Pocitos, 1 F (MZSP); San Carlos, 800 m, 5 F (FSCA); Senillosa, 1 M (USNM); Urundel, 2 F (IMLA); Zuviria, 1 F (NHMW). Santa Fé: Villa Ana, 2 F (IMLA). Tucumán: 2 M, 4 F (IMLA); Depto Burruyaçu, La Ramada, 1 F (IMLA). PARAGUAY. 2 F (IMLA), 1 F (MCZC), 6 F (MNHN); Puerto Pte [Presidente] Franco, 3 F (MZSP); Amambay: Capitan Bado, 1 F (IMLA). Caaguazu: Itaquiri, 400 m, $1 \mathrm{~F}$ (DZUP); Paso Yobaí (locality not found), 6 F (IMLA). Caazapá: Buena Vista, $1 \mathrm{~F}$ (MCZC). Central: Assuncion, $4 \mathrm{~F}$ (IMLA), $1 \mathrm{~F}$ (MNHN), $1 \mathrm{~F}$ (SRGI). Concepción: Concepción, 3 F (AMNH), 1 F (IMLA). Cordillera: San Bernardino, 3 F (USNM). Guairá: Villarrica, 1 F (AMNH), 1 F (DZUP). Itapúa: Hohenau, 1 F (AMNH), 2 F (IMLA); Nueva Asuncion, $1 \mathrm{~F}$ (USNM). URUGUAY. Soriano: Arroyo Cololó (locality not found), 3 F (MZSP). Localities not found: Delta Arroyo - Chaná, 1 F (ILMA).

Remarks. Chalcolepidius limbatus is characterized especially by the general pubescence olive or brown with whitish setae on lateral stripes of pronotum and elytra, striae and epipleura, scutellum folded, tibiae of male bearing fringe of long cilia and lateral cleft of parameres with apex slightly prominent laterally and upwards.

I had the opportunity of dissecting several specimens of this species and observed the intraspecific variation, especially: 1) the melanized area of sternite VIII of male continuous, forming a subtrapezoidal median translucent area or interrupted on anterior margin, making the anterior band of translucent area irregular; 2) the number of teeth of median lobe of aedeagus varying from $4-17(4,8 ; 8,8 ; 8,11 ; 8,13 ; 9,11 ; 9,11 ; 12,17) ; 3)$ the number of teeth of the sclerotized rings of openings of colleterial glands with considerable variation between the right and left sides: 40, 44; 37, 43.

C. limbatus looks like $C$. bomplandii, differing especially by smaller size and elytral epipleura of the same color as lateral stripes of elytra in the former.

C. limbatus is similar to C. corpulentus and C. zonatus. It is easily separated from $C$. corpulentus by narrower lateral whitish stripes of pronotum, and from C. zonatus by the presence of separate striae, never geminate; the lateral whitish stripes of the elytra are three interstices wide in the former and two in the latter. Besides, the $3^{\text {rd }}$ antennal segment is proportionally longer in the second species, the frons more strongly declivous in the last, and the punctuation of pronotum is simple, coarser and denser in the first.

C. limbatus belongs to mocquerysii + group; it is the sistergroup of C. zonatus (Fig. 671).

Distribution. It is recorded from West Indies (Virgin Islands), Trinidad, Venezuela, Colombia, Peru, Ecuador, French Guiana, Guyana, Brazil (Amazonas, Roraima, Paraiba, Pernambuco, Goiás, Mato Grosso, Mato Grosso do Sul, Bahia, Minas Gerais, Espírito Santo, Rio de Janeiro, São Paulo, Paraná, Santa Catarina, Rio Grande do Sul), Bolivia, Argentina, Paraguay and Uruguay (Fig. 689). In the females from Trinidad (MNHN), the lateral stripes of pronotum are reduced and the epipleura partially clothed with whitish setae. The majority of them are clothed with blue or greenish-blue metallic pubescence.

Chalcolepidius mexicanus Castelnau, 1836

(Figs.51,52,131,132,195,196,251,336,368,403,517,557,607,648,672)

Chalcolepidius mexicanus Castelnau, 1836: 14; Erichson, 1841: 87; 
Candèze, 1857: 262, 268, 269; Gemminger \& Harold, 1869: 1503 (Cat.); Candèze, 1874: 162; 1886: 66, 69; 1891: 37 (Cat.); Champion, 1894: 275, 284, t. 12, f. 10-11; Schwarz, 1906a: 45; Schenkling, 1925: 57 (Cat.); Fleutiaux, 1926: 107 (Cat.); Blackwelder, 1944: 283 (Cat.). Type locality: "Mexico".

Chalcolepidius boisduvalii Dejean, 1837: 100 (nomen nudum); Champion, 1894: 284 (Syn.).

Chalcolepidius chevrolatii Dejean, 1837: 100 (nomen nudum); Champion, 1894: 284 (Syn.).

Castelnau (1836) described briefly C. mexicanus, from Mexico, probably a female, characterized especially by integument clothed with dull white pubescence except longitudinal median region of pronotum and interstices grayishgreen.

ERICHSON (1841) repeated, with the same words, Castelnau's description.

CANDĖze (1857), probably treating of one male, redescribed C. mexicanus and presented one variation: "brunneus, subtus olivaceo-squamulosus". He commented that it could be confused with $C$. attenuatus that has black integument.

CHAMPION (1894) commented that during the examination of twenty specimens of this species, he observed that all females (thirteen) had the sides of prothorax and elytra, and striae clothed with elongate white setae; the rest of upper surface was clothed with minute olive setae; the males had only the base of pronotum, scutellum and the base, and sometimes lateroanterior stripes, of elytra clothed with white setae. Ventrally, including legs, they were clothed with white with minute olive setae intermingled, except two females from Jalapa and two from Chontales, with small and olive setae. He separated $C$. mexicanus from $C$. oxydatus by the less acute sutural angles of elytra and from $C$. lemoinii by the divergent hind angles of thorax. I believe that the females from Jalapa and Chontales examined by Champion, clothed with olive setae do not belong to this species.

Length: 22-33 mm. Narrow, parallel body. Integument reddish-brown except antennae, dark-brown, clothed with scalelike metallic setae. Dorsal pubescence of male (Fig. 51) totally metallic olive-brown or with dull white or yellowish-white setae on basal region of pronotum and anterior margin of elytra; female (Fig. 52) clothed with olive-brown metallic pubescence with dull white or yellowish-white setae on frons (total- or partially), narrow lateral stripes on pronotum (narrower than $1 / 4$ of pronotum width), striae and lateral stripes of elytra (two interstices wide). Ventral pubescence, including legs and epipleura, yellowish-white in both sexes. Antennae with darkblue small metallic setae.

Frons strongly convex medioanteriorly with hind angles prominent. Antennae (Figs. 131, 132) strongly serrate in female, longer and pectinate in male; $3^{\text {rd }}$ segment transverse with spiniform appendix. Pronotum (Figs. 195, 196) longer than wide, strongly narrowed near apex and slightly at hind angles base; weakly micropunctate with very sparse moderately coarse punctuation; anterior margin slightly sinuous; lateral margin raised forming narrow edge; convexity stronger anteriorly decreasing basad, forming small groove innerly edge; hind angles backward with sharpened apex, raised laterally forming narrow edge slightly wider than that of lateral margins; median basal tubercle flattened, elongate; posterior margin prominent and slightly notched at middle. Hypomera concave, densely moderately coarsely punctuate, not forming prosternal channel. Notosternal sutures slightly sinuous. Prosternum moderately convex from sutures, micropunctate with very sparse moderately coarse punctuation, more concentrate near sutures. Prosternal lobe truncate with rounded angles, moderately coarsely punctuate. Scutellum (Fig. 251) strongly declivous, with anterior half almost vertical, horizontal basal half elliptical with anterior margin forming weak ridge. Borders of mesosternal cavity thick and horizontal on basal $3 / 4$ and vertical on distal $1 / 4$ forming L-shaped profile. First visible sternite not prominent laterally. Tibiae of male bearing irregular row of spines internally. Elytra almost parallel with apices conjointly rounded; without lateral carina; striae grooved; interstices unequal, convex, weakly micropunctate; $2^{\text {nd }}$ and $3^{\text {rd }}$ interstices forming prominent tubercle at base.

Male genital segments and aedeagus. Tergite VIII slightly wider than long, gradually narrowed apicad, densely setous at middle and near margins. Sternite VIII (Fig. 336) subpentagonal, anterior margin angular; totally yellowish, only two small irregular darker spots near base; densely setous. Tergite IX (Fig. 368) transverse, anterior margin straight with rounded angles; densely punctuate with lateroanteriorly moderately long setae. Sternite IX elongate; distal half setous laterally and melanized except narrow distal band. Aedeagus (Fig. 403): median lobe narrow, slightly narrowed near middle; apex of parameres spearhead-like.

Female genital segments and genitalia. Tergite VIII (Fig. 517) wider than long, almost rectangular with anterior margin prominent at middle; densely setous; median basal translucent area very narrow, surpassing middle. Sternite VIII (Fig. 557) densely setous with anterior margin narrow- and deeply notched; spiculum gastrale broken. Genitalia (Fig. 607): sclerotized pieces of openings of colleterial glands (Fig. 648) C-shaped, bearing 36 small teeth; bursa copulatrix with an elongate longitudinal median area with carinae and spines and spines dispersed each side; two spermathecae.

Material examined. MEXICO. $1 \mathrm{M}$ (BMNH), $1 \mathrm{M}$ (ZMHB), ex-coll. Fleutiaux, 1 M, 1 F (MNHN). Tamaulipas: Tampico, ex-coll. Oberthür, 1 F (MNHN). Veracruz: ex-coll. Sallé; B.C.A. Col. III (1), 1 F (BMNH); Miranda, $1 \mathrm{M}$ (dissected), $1 \mathrm{~F}$ (dissected) (PCCV). Without locality: $3 \mathrm{M}$, 3 F (NHMW); ex-coll. Oberthür, $1 \mathrm{M}(\mathrm{MNHN})$.

Remarks. Chalcolepidius mexicanus is characterized especially by general pubescence olive-brown dorsal and whitish ventral; females with lateral whitish stripes on pronotum; antennae strongly serrate in female and pectinate in male; scutellum strongly declivous; tibiae of male spiny internally, and apex of parameres of aedeagus spearhead-like.

The present interpretation of this species was based on study of eight specimens from Mexico. CANDĖzE (1857) described the interstices as equal, but they are equal only at base. 
C. mexicanus is similar to C. rodriguezi differing especially by (latter parenthesized): antennae of male pectinate (serrate); tergite VIII of male gradually narrowed apicad (slightly narrowed); sternite VIII of male almost unicolor (translucent with three darker spots); tergite IX of male more densely setous latero-distally and more notched on anterior margin in the latter; distal half of sternite IX of male translucent in a narrow distal band (translucent in a wide band).

C. mexicanus belongs to mexicanus* group (Fig. 671).

Distribution. It is herein recorded only from Mexico (Tamaulipas, Veracruz) (Fig. 672). CHAMPION (1894) recorded it also from Nicaragua.

\section{Chalcolepidius mniszechi Candèze, 1881}

(Figs. 53, 134, 197, 252, 253, 294)

Chalcolepidius mniszechi Candèze, 1881: 21; 1886: 69; 1891: 37 (Cat.); Champion, 1894: 275, 284; Schenkling, 1925: 57 (Cat.). Syntype female: "Coll. R. I. Sc. N. B. Mexique ex coll. Candèze; mniszechi Cdz. Mex. Coll. Mn; Chalcolepidius mniszechi Cand. det. E. Candèze; Syntype Chalcolepidius mnizechi Cand. 1882, CMF von Hayek, det. 1979" (ISNB) (examined).

Length: $30 \mathrm{~mm}$. Integument black, clothed dorsally with thin, sparse, metallic grayish-olive scale-like setae and ventrally (including legs and elytral epipleura) with dull yellowish-white; lateral stripes of pronotum band-like, approximately $1 / 4$ of pronotum width, joined basally (yellowish-white and olive pubescence are intermingled at borders becoming difficult to distinguish the limits); lateral stripes of elytra two interstices wide; yellowish-white pubescence on lateral stripes of pronotum and elytra, and striae intermingled with olive-gray at basal region of pronotum (Fig. 54). Antennae with brownish pubescence except three first segments, olive.

Fore angles of frons very prominent anteriorly; frons slightly concave medioanteriorly, making nasal plate high, almost perpendicular to labrum. Antennae (Fig. 134) serrate; $3^{\text {rd }}$ segment short and triangular. Pronotum (Fig. 197) longer than wide, almost parallel on basal $3 / 4$, strongly narrowed on anterior $1 / 4$; strongly convex; lateral margins forming edge; hind angles wide, backwardly directed, raised laterally, forming edge, wider than that of lateral margins; median basal tubercle flat, transverse; posterior margin prominent and slightly notched at middle; micropunctate (visible only at middle). Hypomera forming lateral edge; notosternal sutures slightly sinuous, with parallel line on hypomera; prosternal channel absent. Prosternum slightly grooved near sutures, flat longitudinal medially. Prosternal lobe rounded laterally with basal transverse groove, not reaching middle. Scutellum (Figs. 252, 253) moderately declivous on anterior half; horizontal half wider, elliptical with two rounded concavities. Mesosternal cavity Vshaped with borders (Fig. 294) wide and horizontal on basal half and almost vertical on anterior half, forming L-shaped profile. Meso-metasternal suture present. Striae grooved, not punctuate; interstices slightly convex, unequal in width; basal tubercle between $2^{\text {nd }}$ and $3^{\text {rd }}$ interstices; apices conjointly rounded.
Remarks. Only a syntype female of Chalcolepidius mniszechi was examined; its abdomen had been internally, totally destroyed by nuisance. This species was not included in the cladistic analysis because of the bad condition of the material.

C. mniszechi is characterized especially by general pubescence grayish-olive dorsal and whitish ventral, with whitish lateral stripes on pronotum and elytra and scutellum moderately declivous. It is similar to $C$. albiventris, but easily separated by the coloration of dorsal pubescence.

Distribution. It is recorded only from the type locality, Mexico.

Chalcolepidius mocquerysii Candèze, 1857

(Figs. 54, 133, 198, 404, 442, 478, 558, 649, 688)

Chalcolepidius mocquerysii Candèze, 1857: 262, 274; Gemminger \& Harold, 1869: 1503 (Cat.); Candèze, 1874:164; 1886: 67, 71; 1891: 39 (Cat.); Schenkling, 1925: 57 (Cat.); Fleutiaux, 1926: 108 (Cat.); Blackwelder, 1944: 283 (Cat.). Syntypes: 2 females, numbered 162: "No 1; Nov. Grenada; 105; Chalcolepidius mocquerysii Cdze F type (C. goudottii Laf.) ex coll. de Laferté [Janson] Goudolii nobis Nov. Gren [? Laferté, stuck to underside of Janson's label]; Janson coll. 1903.130"; "No 2 as no 1 but without the word 'Type' or Laferté label” (BMNH) (not examined).

CANDÈzE (1857) described C. mocquerysii, from "Nouvelle Grenade", characterized especially by pubescence metallic green with dull white setae on lateral stripes of pronotum and elytra, and paired striae. He also presented a variation: "flavosquamulosus, striis vittisque flavo-ochraceis". According to him, this species is similar to C. limbatus and C. zonatus, but the former is easily separated by the epipleura clothed with metallic setae, like underside. In his key of 1886 , he considered the epipleura coloration like underside, and put $C$. mocquerysii close to $C$. bomplandii, separated only by the presence of geminate striae in the former.

Length: 30-40 mm. Wide, arched body. Integument black, clothed with scale-like setae, metallic, thin, grayish-green or olive; lateral stripes of pronotum band-like, $1 / 4$ of pronotum width at base and narrowed apicad with internal margin semielliptical; lateral stripes of elytra three interstices wide on anterior half and narrower on distal half (one or two interstices wide), not reaching elytral apices; white dull pubescence on striae and lateral stripes of pronotum (reaching anterior margin, widened posteriorly and distant from lateral margins on anterior third) and elytra (Fig. 54). Antennae with pubescence darkblue except three first segments, green.

Antennae (Fig. 133) serrate in both sexes, $3^{\text {rd }}$ segment triangular-elongate, slightly shorter than $4^{\text {th }}$. Pronotum (Fig. 198) longer than wide, wider at hind angles, narrowed anteriad from hind angles base; lateral margins forming narrow edge; hind angles wide, slightly divergent with truncate apex, raised laterally; median basal tubercle flat and triangular, continuous with median weak ridge; posterior margin prominent and strongly notched at middle. Hypomera concave; laterointernal margin raised forming wall of anterior channel. Notosternal 
sutures strongly sinuous. Prosternum strongly convex, flattened longitudinal medially, concave near sutures. Scutellum strongly folded with horizontal basal area subtrapezoidal. Interstices unequal and convex. Borders of mesosternal cavity thick and horizontal on basal $2 / 3$ and vertical on distal $1 / 3$ forming L-shaped profile. First visible sternite prominent laterally fits in small lateral groove of elytra. Anterior and median tibiae and last tarsal segment of all legs bearing fringe of long cilia. Interstices unequal in width.

Male genital segments and aedeagus. Tergite VIII transverse, strongly notched at base and slightly narrowed apicad; densely setous. Sternite VIII transverse, moderately narrowed to apex; anterior margin straight with rounded angles; translucent in a median large subpentagonal area and two small elliptical fused areas each side, and two lateral narrow bands. Tergite IX transverse, densely punctuate with anterior margin rounded, tiny setae laterodistally. Aedeagus (Fig. 404): median lobe (Fig. 442) wide, gradually narrowed apicad, slightly narrower near middle, bearing 4,$5 ; 7,8 ; 7,9 ; 8,8 ; 9,9 ; 14,14$; lateral cleft of parameres (Fig. 478) constricted near apex, with apex widened forming prominent angles, longer ventrally.

Female genital segments and genitalia. Tergite VIII transverse, sub-rectangular, densely setous; median basal translucent area not reaching middle. Sternite VIII (Fig. 558) with anterior margin wide- and moderate- deeply notched, densely setous, 0.65 times spiculum gastrale length. Genitalia: sclerotized rings of openings of colleterial glands (Fig. 649) bearing 44 teeth; bursa copulatrix with longitudinal median area with carinae and spines and paired rounded spiny areas.

Material examined. GUATEMALA. 1 F (ZMHB). BELIZE. Stann Creek: Middlesex, $1 \mathrm{M}, 1 \mathrm{~F}$ (ZMHB) (not included in map). VENEZUELA. $1 \mathrm{~F}$ (NHMW). $1 \mathrm{~F}(\mathrm{MNHN})$. COLOMBIA. $3 \mathrm{~F}$ (MNHN), $1 \mathrm{M}$ (dissected) (MZSP, retained MCZC), ex-coll. Chevrolat, ex-coll. Fleutiaux, $1 \mathrm{~F}$ (MNHN). Antioquia: Medellin, $1 \mathrm{~F}(\mathrm{MNHN})$. Caldas: Manizales, $1 \mathrm{M}, 9$ F (MNHN). Cauca: 1 F (MCZC); Carthago, 2 M, 5 F (MNHN). Cordoba: $1 \mathrm{M}(\mathrm{MNHN})$. Special District: Bogotá, 2 F (MNHN), ex-coll. Chevrolat, ex-coll. Fleutiaux, 1 F (MNHN). Magdalena: Aracataca, 1 F (MCZC). Sucre: Aguacatal, $2 \mathrm{~F}$ (MNHN), $1 \mathrm{~F}$ (ZMHB). Tolima: Ibagué, $1 \mathrm{M}$ (MNHN); Pereira (Cauca), 2 M, 42 F (MNHN); S. Antonio, 1 F (MNHN). Valle del Cauca: ZP-076, 1 F (MZSP); Andalucia (in cacao), 1 F (USNM); Cali, 1 F (MNHN); Estacion Agricola Experimental Palmira, 1 F (dissected) (USNM); Palmyra, 1 F (MNHN); W-Cordillera, Lake Calima/ Rio Bravo Valley, 1 F (PCCV). Localities not found: Hacienda Garcia, 1 F (FSCA); Villa Elvira, 2 F (MNHN). SURINAME. 1 F (MNHN). PERU. Tumbes: [Cueva] Las Pavas, 1 ex. (ZMHB)

Remarks. Chalcolepidius mocquerysii is characterized especially by general pubescence grayish-green or olive with white stripes on pronotum and elytra, scutellum folded, tibiae of male bearing fringe of long cilia and subapical region of lateral cleft of parameres constricted with apex widened forming prominent angles. It is similar to C. limbatus and C. bomplandii, differing from the former especially by epipleura clothed with metallic pubescence, like underside. Differs from C. bomplandii by several characters discussed in the remarks of this species.

C. mocquerysii belongs to bomplandii* group and together with $C$. limbatus $+C$. zonatus form the mocquerysii+ group (Fig. 671).
Distribution. It is recorded from Guatemala, Belize, Venezuela, Colombia, Suriname and Peru (Fig. 688).

Chalcolepidius morio Candèze, 1857

(Figs. 55, 135, 199)

Chalcolepidius morio Candèze, 1857: 263, 284; Gemminger \& Harold, 1869: 1503 (Cat.); Candèze, 1874: 167; 1886: 73; 1891: 38 (Cat.); Champion, 1894: 274, 281; Schwarz, 1906a: 45; Schenkling, 1925: 57 (Cat.); Blackwelder, 1944: 283 (Cat.). Syntype male: “ ? Syntype "Mexico; M; Janson coll. 1903-130.; Chalcolepidius morio Cdze M ex coll. de Laferté" (BMNH) (examined).

Chalcolepidius atterimus Sturm in. litt.; Gemminger \& Harold, 1869: 1503 (Cat.) (Syn.).

CANDÈZE (1857) described the pubescence coloration: “... de très-petites écailles d'un gris sale, à reflet légèrement fauve, paraissant verdâtres lorsqu'on les examine à l'aide d'une forte loupe, ne masquant nullement la couleur noire du fond". It was recorded from "aux environs de Mexique".

According to CHAMPION (1894) "C. morio is very closely allied to $C$. silbermanni, from which it chiefly differs in having the alternate interstices of elytra more strongly costate". In fact, the interstices look like more raised because the pubescence is fallen.

Length: $29 \mathrm{~mm}$. Wide, arched body. Integument black and bright, totally naked dorsally and clothed with metallic green pubescence ventrally; antennae clothed with bluish pubescence except three first segments, glabrous (Fig. 55).

Frons moderately concave medioanteriorly, micropunctate with sparse moderately coarse punctuation. Nasal plate high and punctuate. Antennae (Fig. 135) serrate in male, $3^{\text {rd }}$ segment triangular-elongate, slightly shorter than $4^{\text {th }}$. Pronotum (Fig. 199) longer than wide, wider at hind angles, gradually narrowed apicad; strongly convex anteriorly, convexity decreasing basad; anterior margin prominent and sinuous at middle; lateral margins forming narrowed impunctuate edge except distal 1/4; micropunctate with sparse moderately coarser punctuation, denser laterally on anterior $1 / 3$ and near lateral edge; hind angles wide, backward, raised laterally, forming edge continuous with that of lateral margin; median basal tubercle flat, triangular elongate, continuous with longitudinal median weak edge, not reaching anterior margin; posterior margin prominent and strongly notched at middle. Hypomera concave near lateral margins, micropunctate; laterointernal margin raised forming wall of well developed channel. Notosternal sutures strongly sinuous. Prosternum micropunctate, strongly convex, flattened longitudinal medially, concave near sutures. Prosternal lobe emarginated laterally; anterior margin rounded; punctuation slightly coarser and sparser than prosternum. Prosternal spine hidden by borders of mesosternal cavity. Scutellum strongly folded with horizontal basal area subtrapezoidal, very narrow anteriorly, notched anteriorly and posteriorly. Borders of mesosternal cavity wide and horizontal on basal $3 / 4$ and vertical on distal $1 / 4$, forming L-shaped profile. Meso-metasternal suture absent. First visible sternite prominent laterally, fits in lateral groove of elytra. Anterior and median 
tibiae and last tarsal segment of all legs bearing fringe of long cilia. Striae marked by row of coarse punctures; interstices convex and micropunctate, unequal; basal region with flat tubercle near base of $2^{\text {nd }}$ and $3^{\text {rd }}$ interstices; apex slightly rounded.

Aedeagus (partially extroverted): median lobe constricted near middle and at apex, with 12 small teeth each side; lateral cleft of parameres narrowed near apex; apex slightly rounded, prominent in both sides.

Female not studied.

Remarks. The original description of Chalcolepidius morio was based on three specimens from Monsieur M. Deyrolle et de la Ferté Sénectère collection, without indication of the sex. I examined a "male syntype" that probably does not belong to the syntype series, because according to CHAMPION (1894) the male was not known by Candèze. HAYEK (personal communication) agrees with him because Candèze had not described the ciliate tibiae of male. This evidence make her to believe that the specimen examined, with an interrogation mark before syntype (? Syntype), was not the type. Another evidence also observed by her is the small size of the supposed type, 29 $\mathrm{mm}$ compared with the published length of $40 \mathrm{~mm}$.

Comparing C. morio with C. silbermanni (except the dorsal pubescence and the female genitalia), it was verified that they are very similar, differing especially by the $3^{\text {rd }}$ antennal segment narrower and shorter than the $4^{\text {th }}$; pronotum narrower and more convex in the former; lateral cleft of parameres shorter and narrower near apex, and median lobe with 12 teeth in the former and 5-8 in the latter. The differences are very small and probably these species are conspecific, but until to have more material available to study, I prefer to maintain both species.

C. morio belongs to lacordairii* group.

Distribution. It is recorded only from the type locality, Mexico. Champion (1894) presented a more precise locality "Mexico, Santo Domingo in Tehuantepec, Oaxaca"

Chalcolepidius obscurus Castelnau, 1836

(Figs.56,137,199,254,295,337,405,444,480,559,604,650,683)

Chalcolepidius obscurus Castelnau, 1836: 13; 1840: 238; Germar, 1841: 86; Erichson, 1841: 86; Lacordaire, 1857: 155; Candèze, 1857: 264, 286; Gemminger \& Harold, 1869: 1503 (Cat.); Candèze, 1886: 68, 73; Fleutiaux \& Sallé, 1889: 407; Candèze, 1891: 38 (Cat.); Fleutiaux, 1911: 247; Schenkling, 1925: 57 (Cat.); Fleutiaux, 1926: 108 (Cat.); Blackwelder, 1944: 283 (Cat.). Type locality: "Guadeloupe".

Length: 33-36 mm. Parallel, wide body. Integument black, clothed dorsally and ventrally with scale-like setae thin, short, metallic, brown, reddish-brown, violet-brown, violet-gray or ferruginous; antennae clothed with blue or black pubescence except three first segments, like general pubescence (Fig. 56).

Frons not carinate, strongly declivous. Antennae (Fig.137) serrate in both sexes, $3^{\text {rd }}$ segment triangular-elongate, shorter than $4^{\text {th }}$. Pronotum (Fig. 200) longer than wide, wider at hind angles; slightly narrowed apicad from hind angles base, narrower on distal third; moderately convex anteriorly, convexity decreasing basad; micropunctate with coarse sparse punctuation lateroanteriorly; anterior margin prominent and sinuous at middle; lateral margins raised forming narrow smooth edge except distal 1/4; concave in narrow band innerly edge; hind angles strongly divergent, short, moderately thick with truncate apex; raised laterally forming edge slightly wider than that of lateral margins; median basal tubercle flat, triangular, continuous with very weak discontinuous longitudinal median ridge; posterior margin prominent and strongly notched at middle. Hypomera concave near lateral margins; laterointernal margin raised forming wall of anterior channel. Notosternal sutures strongly sinuous. Prosternum micropunctate, punctuation denser and coarser near sutures; strongly convex, flattened longitudinal medially, concave near sutures. Prosternal lobe wide, punctuation sparser and slightly coarser than median region of prosternum; emarginated laterally; fore angles slightly rounded. Prosternal spine flattened laterally. Scutellum (Fig. 254) strongly folded, horizontal area subtrapezoidal, notched anterior- and posteriorly. Borders of mesosternal cavity (Fig. 295 ) wide and horizontal on basal $2 / 3$ and vertical on distal $1 / 3$, forming L-shaped profile. Mesepisternum with two transverse elliptical grooves. Meso-metasternal suture weak. First visible sternite prominent laterally, fits in lateral groove of elytra. Anterior and median tibiae and last tarsal segment of all legs bearing fringe of long cilia. Interstices unequal, giving costiform appearance; $2^{\text {nd }}$ forming sharpened basal tubercle forwardly directed.

Male genital segments and aedeagus. Sternite VIII (Fig. 337) transverse, strongly narrowed on distal third; translucent in median large area, paired basal smaller and two lateral bands. Tergite IX densely punctuate with anterior margin rounded and tiny setae lateroanteriorly. Aedeagus (Fig. 405): median lobe (Fig. 444) 0.58 times the aedeagus length, slightly narrowed near middle, bearing 8,9 lateral teeth; lateral cleft of parameres (Fig. 480) strongly narrowed near apex; apex widened laterally and upwards.

Female genital segments and genitalia. Tergite VIII transverse with anterior margin rounded, setous; translucent in small median basal area. Sternite VIII (Fig.559) 0.66 times spiculum gastrale length; anterior margin wide- and moderate deeply notched at middle. Genitalia (Fig. 604): sclerotized rings of openings of colleterial glands (Fig.650) with 41 teeth; bursa copulatrix with wide longitudinal median band with carinae and spines and paired lateral rounded spiny areas.

Material examined. WEST INDIES. 3 F (1 dissected) (USNM), excoll. Fleutiaux, $1 \mathrm{~F}$ (MNHN). Guadeloupe Island: $1 \mathrm{~F}$ (AMNH), $1 \mathrm{~F}$ (FSCA), 3 M, 1 F (MNHN), 4 F (ZMUC), ex-coll. Fleutiaux, 3 M, 12 F (MNHN); ; [identified as] Chalcolepidius obscurus Lap. Revue Silb. defloratus Dej., ex-Musaeo A. Sallé, 1897, 1 F (MNHN); DomaineDucos, $1 \mathrm{~F}$ (AMNH). St. Vincent Island: $2 \mathrm{~F}$ (AMNH), $1 \mathrm{~F}(\mathrm{MNHN})$. Virgin Islands: Montserrat, $1 \mathrm{M}$ (dissected) (USNM). CUBA. $1 \mathrm{~F}$ (MNHN).

Remarks. Chalcolepidius obscurus is characterized especially by general pubescence usually brown or ferruginous, but specimens with pubescence reddish-brown, violet-brown, 
violet-gray and ferruginous-brown were also studied. The pronotum is narrowed frontally and at hind angles base; scutellum folded; tibiae of male bearing fringe of long cilia; interstices strongly unequal, costiform, and parameres of aedeagus cleft.

DAJOZ (1964) presented the illustrations of the bursa copulatrix (profile and dorsal) and a detail from longitudinal median spiny area and one sclerotized ring of the openings of the colleterial glands. Comparing these illustrations with the structures of the female dissected, it was observed that in the former, the lateral rounded spiny areas of the bursa copulatrix are larger and the sclerotized rings of the openings of colleterial glands present a larger number of teeth (41, 35 in illustration).

C. obscurus is similar to C. silbermanni differing especially by (the latter parenthesized): different pubescence coloration and interstices stronger costiform in the former; pronotum almost as long as wide (longer than wide); lateral cleft of parameres strongly narrowed subapically with apex rounded, widened laterally and upwards (shorter, wider, with apex moderately widened); median lobe of aedeagus slightly narrowed near middle, bearing 8-9 lateral teeth (strongly narrowed, bearing 5, 5 lateral teeth); tergite VIII of female with median basal translucent area well delimited (not well delimited); sclerotized rings of the openings of colleterial glands closed with 41 teeth, 35 in Dajoz's illustration (slightly opened with 32 and 38 teeth ( 2 observations)).

C. obscurus belongs to forreri* ${ }^{*}$ group (Fig. 671).

Distribution. It is recorded from West Indies (Guadeloupe, St. Vicent and Virgin Islands) and Cuba (Fig. 683). One female from "Mexico" (MNHN) was examined but not included in the material examined because the locality indicated requires confirmation.

\section{Chalcolepidius oxydatus Candèze, 1857}

(Figs. 57-60, 136, 201, 255, 338, 369, 406, 560, 605, 606, 651, 672)

Chalcolepidius oxydatus Candèze, 1857: 261, 266; Gemminger \& Harold, 1869: 1503 (Cat.); Candèze, 1874: 161; 1886: 69; 1891: 37 (Cat.); Champion, 1894: 275, 286, t. 12, f. 15; Schenkling, 1925: 57 (Cat.); Blackwelder, 1944: 283 (Cat.). Holotype female: "F Type; Venezuela; Janson coll. 1903-130; Chalcolepidius oxydatus Cdze F type ex coll. Deyrolle [glued underside:] oxydatus F” (BMNH) (examined).

Chalcolepidius jekeli Candèze, 1874: 162; 1886: 70; 1891: 37 (Cat.); Champion, 1894: 275, 285, t.12, f.13; Schenkling, 1925: 56 (Cat.); Blackwelder, 1944: 283 (Cat.). Holotype female: "Collection Jekel; Type; jekelii [sic] Cand. Rev. (Cd. 1879); jekelii [sic] Type Cdz.; Jekeli Cand. Type Collection Fleutiaux"(MNHN) (examined). Syn. nov.

CANDĖze (1857) described C. oxydatus based on a female from Venezuela, clothed with green metallic pubescence. In 1874, he observed at fore legs of male, black spines equidistantly placed. In fact, the spines are present in all tibiae of male and female, more developed in the former. In the same paper he described $C$. jekeli based on a female from Colombia, with broken antennae, and stated, that he had sufficient reasons to believe that this locality is erroneous and that the specimen comes from Central America. In 1886, CANDÈZE confirmed his supposition after receiving several specimens of $C$. jekeli from
Guatemala. CHAmpion (1894) also collected this species in Guatemala.

Champion $(l . c$.) treating on $C$. oxydatus stated that the tibiae of both sexes are armed with short "teeth", longer on anterior pair and more numerous in male. He recorded this species also from Nicaragua, Costa Rica and Panama.

After examining the type material of both species, it was concluded that they are conspecific.

Length: 25-44 mm. Integument black, clothed dorsally and ventrally with thin, short metallic scale-like setae green, blue, bluish-green, grayish-blue, violet-blue, violet, olive-green, yellowish-green, or grayish-green; antennae clothed with darkbrown or blue setae, except three first segments, same color as general pubescence (Figs. 57-60).

Frons not carinate, concave and slightly declivous medioanteriorly; nasal plate punctuate, perpendicular and high. Antennae (Fig. 136) serrate in female, strongly serrate in male, $3^{\text {rd }}$ segment short, triangular. Pronotum (Fig. 201) longer than wide, very wider at hind angles; slightly narrowed anteriad, from hind angles base; moderately convex in male, strongly in female; anterior margin prominent and slightly sinuous at middle; lateral margins forming raised edge in almost all length; narrow groove innerly edge; hind angles stout, divergent, with truncate apex, raised laterally, forming edge, not continuous with that of lateral margins; micropunctate with coarse sparse punctuation; median basal tubercle flat, elongate; slightly notched at middle; posterior margin prominent and slightly notched at middle. Hypomera concave near lateral margins; small-punctuate. Notosternal sutures slightly sinuous opened frontally not making channel. Prosternum micropunctate, moderately convex from sutures. Prosternal lobe smallpunctuate with longitudinal weak grooves, emarginated laterally; fore angles rounded. Meso-metasternal suture weak, convergent near cavity base. Scutellum (Fig. 255) narrower and moderately declivous on anterior half; basal half transverse, sub-elliptical, in some specimens with one rounded concavity each side. Mesosternal cavity narrow, V-shaped, with borders (Fig. 296) wide and horizontal on basal $2 / 3$ and moderately declivous on distal $1 / 3$, forming semi-elliptical profile. First visible sternite not prominent and elytra without lateral groove. Tibiae of male with irregular row of spines internally. Interstices micropunctate, very convex, equal or unequal in width; three first interstices joined near base, forming small tubercle; scutellar area strongly grooved.

Male genital segments and aedeagus. Sternite VIII (Fig. 338) transverse, wide, pentagonal, translucent with two melanized lateral bands and a distal spot. Tergite IX (Fig. 369) densely punctuate; anterior margin almost straight with rounded angles; moderately long setae lateroanteriorly. Aedeagus (Fig. 406): median lobe 0.61 times the aedeagus length, gradually narrowed apicad; apex of parameres spearhead-like.

Female genital segments and genitalia. Tergite VIII transverse, sub-rectangular with anterior margin slightly prominent at middle; translucent in small basal triangular area. Sternite VIII (Fig. 560) wide, 0.66 times spiculum gastrale length; 
anterior margin wide- and strongly deeply notched at middle. Genitalia: sclerotized pieces of the openings of colleterial glands (Fig. 651) C-shaped, bearing 38 teeth; bursa copulatrix (Figs. $605,606)$ ventrally almost totally clothed with carinae and spines, and dorsally with few lateral disperse spines.

Material examined. MEXICO. $1 \mathrm{~F}$ (NHMW), $2 \mathrm{M}, 3 \mathrm{~F}$ (MNHN). Chiapas: Aguacero, $16 \mathrm{Km}$ W Ocozocoatla, $1 \mathrm{M}$ (FSCA); Chorreadura Canyon, 1 M (MZSP), 1 M (JEWC); Chorreadura St. Pk., 2 M (EGRC), 1 M (FSCA); Finca Violeta (locality not found), 800 m, 1 M (PCCV); La Esperanza, $1 \mathrm{M}$ (USNM); $12 \mathrm{Km} \mathrm{N}$ Mapastepec, $1 \mathrm{~F}$ (TAMU); Motozintla [de Mendoza], 1 F (FSCA); Pacific Slope Cordilleras, 800-1009 m., 1 F (USNM); Rizo de Oro, 1 F (dissected) (UNAM); San Jeronimo, 1 M, 3 F (IMLA), 1 F (USNM), Tacaná, 1 F (MZSP). Sonora: La Liberdad, 1 M, 1 F (USNM). GUATEMALA. 1 F (USNM), ex-coll. Oberthür, 4 F (MNHN). Escuintla: Palmar, Zovó, 1 M (MNHN). Guatemala: env. Guatemala, 1 M, 2 F (MNHN). Petén: Chicacao, 1 F (USNM). Retalhuleu: San Sebastian, 1 M, 2 F (USNM). Suchitepéquez: Moca, $3000 \mathrm{ft} ., 1 \mathrm{~F}$ (AMNH); Variedades, $500 \mathrm{ft}$, $5 \mathrm{~F}$ (AMNH). HONDURAS. $1 \mathrm{M}, 1 \mathrm{~F}$ (MNHN). Choluteca: Cerro Guanacaure, $10 \mathrm{Km} \mathrm{S}$ Yusquare, $510 \mathrm{~m}, 2 \mathrm{M}$ (FSCA). EL SALVADOR. Copan, 8 Km NW El Paraiso, 1 F (TAMU); San Salvador, 1 M (USNM); San Vicente, 1 M (FSCA). NICARAGUA. Managua: Managua, 1 F (AMNH). Rivas: Chacalapa, 1 F (MNMS); Corcuera, 1 F (MCZC). COSTA RICA. Cartago: Irazu, 1800-2000, $1 \mathrm{M}$ (USNM). Guanacaste: $21 \mathrm{Km} \mathrm{S}$ Canas Guanacaste, $1 \mathrm{M}$ (TAMU). Puntarenas: San Vito, $6 \mathrm{Km} \mathrm{S}$ Cerro Cruces, 5000, $1 \mathrm{M}$ (dissected) (USNM). PANAMA. 1 M (MNHN). Chiriqui: Chiriqui, 1 F (ISNB), excoll. Oberthür, $1 \mathrm{~F}$ (MNHN), ex-coll. Fleutiaux, $1 \mathrm{~F}$ (MNHN). VENEZUELA. Ex-coll. Fleutiaux, $2 \mathrm{M}$ (MNHN); ex-coll. Oberthür, 1 M, 2 F (MNHN), 16206, 1 F (ZMHB). Falcón: San Estevan près Puerto Cabello, $1 \mathrm{~F}(\mathrm{MNHN})$, ex-coll. Oberthür, $1 \mathrm{~F}$ (MNHN). Federal District: Caracas, [identified as] oxydatus Csy var., ex-coll. Oberthür, 1 F (MNHN). Miranda: El Valle, $1 \mathrm{M}$ (USNM). COLOMBIA. Ex-coll. Fleutiaux, $1 \mathrm{M}$ (MNHN). GUYANA. West Demerara: Rio Demerara, 1 M (ZMHB). BRAZIL. Amazonas: São Paulo [de Olivença], 2 F (MNHN). Without locality: ex-Musaeo Sallé; ex-coll. Oberthür, 1 F (MNHN).

Remarks. Chalcolepidius oxydatus is characterized especially by wide and almost parallel-sided body; general pubescence green, blue or violet; scutellum moderately declivous; tibiae of male spiny internally and apex of parameres spearhead-like.

The female holotype of $C$. oxydatus presents the general pubescence metallic green with last lateral stria (IX) partially clothed with yellowish-white setae. The female holotype of $C$. jekeli is clothed with blue metallic pubescence; it presents almost parallel-sided wide body, narrowed on distal third of elytra, and pronotum with coarse punctuation near middle. The pubescence of the specimens studied varies from green to violet, but only one female from Mexico (Chiapas, Rizo de Oro) and one from Venezuela, present last lateral stria (IX) partially clothed with yellowish-white pubescence, like the holotype of C. oxydatus. This female from Venezuela presents also yellowish-white setae laterally on prosternum. One large female (42 mm) without indication of locality, presents lateral bands on pronotum (not reaching anterior margin), basal third of striae and lateral bands of elytra (one interstice wide) and irregular internal band on epipleura with white pubescence. Two specimens from Costa Rica, one from Irazu and other from Puntarenas, with pubescence respectively, grayish-green and green, present sutural spine at elytral apices.

I examined also one female (ISNB) from Chiriqui, labelled by Candèze as "aeruginosus Cand., 1893, n.sp." that belongs to C. oxydatus. Comparing this female with the other specimens examined, I observed, in the latter, different coloration on general pubescence (green-olive) and on antennae (ochre).

Up to now, $C$. oxydatus and $C$. jekeli were distinguished especially by the pubescence coloration, green in the former and blue in the latter. Other variations, independent of the pubescence coloration, were observed in this species: the females are wider almost parallel-sided, narrowed on distal third of elytra and pronotum shorter than in males (almost as wide as long), and the lateral margins of pronotum (excluding the hind angles) almost straight in males, slightly rounded in females. The convexity and the punctuation of pronotum are also variable; when slightly convex presents coarser punctuation with rugose appearance. The length of the $3^{\text {rd }}$ antennal segment, declivity of anterior half of scutellum, convexity of interstices $2,4,6,8$ and size of the sutural spine of elytral apex, when present, are also variable. The differences observed in the holotype of C. oxydatus and C. jekeli are within the intraspecific variations.

C. oxydatus is similar to C. gossipiatus. Comparing both species, it was observed that they present the same scutellar shape, tibiae of male spiny internally, $3^{\text {rd }}$ antennal segment shorter than $4^{\text {th }}$ (smaller in C. oxydatus), and parameres of aedeagus with spearhead-like apex. They differ especially by the coloration of pubescence; antennae more strongly serrate in C. gossipiatus, and declivity of basal half of mesosternal cavity (almost vertical in C. oxydatus). The pronotum is longer than wide in the former and as long as wide and more convex in the latter; body wider and less convex in the former; interstices slightly unequal in the former and easily visible unequal in the latter; anterior margin of sternite VIII of female more widely notched in the latter. The bursa copulatrix of $C$. oxydatus presents, besides the longitudinal spiny area, some disperse ventral spines.

C. oxydatus is also similar to C.jansoni and C. supremus, especially by the pubescence usually green and scutellum declivous. C. jansoni, different from the others (parenthesized), present antennae serrate in both sexes (antennae strongly serrate in male), scutellum slightly declivous (moderately declivous), tibiae of male bearing short cilia (spines) and apex of parameres cleft (spearhead-like).

Comparing $C$. oxydatus with $C$. jansoni it was observed ( $C$. jansoni parenthesized): $3^{\text {rd }}$ antennal segment shorter in the former, horizontal area of scutellum elliptical (almost triangular); median basal tubercle of pronotum elongate (flat and triangular, almost indistinct); elytral apices rounded with sutural spine (truncate). Some specimens of C. oxydatus present two rounded concavities on elliptical basal half of scutellum.

C. oxydatus belongs to supremus+ group; it is the sistergroup of mexicanus* group (Fig. 671).

Distribution. It is widely distributed, recorded from Mexico (Chiapas, Sonora), Guatemala (Escuintla, Guatemala, Petén, Retalhuleu, Suchitepéquez), Honduras, El Salvador, Nicaragua, Costa Rica, Panama, Venezuela, Colombia, Guyana and Brazil (Amazonas) (Fig. 672). 
Chalcolepidius porcatus (Linnaeus, 1767)

(Figs. 61-63, 138, 202, 339, 407, 445, 481, 561, 652, 682)

Elater porcatus Linnaeus, 1767: 652; Fabricius, 1775: 211; 1787: 168; 1792: 220; 1801: 225. Syntype(s): “America” (Brünnick) (ZMUC). (Photo examined).

Chalcolepidius porcatus; Eschscholtz, 1829: 33; Castelnau, 1840: 238; Erichson, 1841: 78; Lacordaire, 1857: 155; Candèze, 1857: 265, 270; Gemminger \& Harold, 1869: 1503 (Cat.); Candèze, 1874: 163; 1881: 23; 1886: 68, 73; 1891: 38 (Cat.); Fleutiaux, 1911: 247; Schenkling, 1925: 57, 58 (Cat.); Fleutiaux, 1926: 108 (Cat.); Blackwelder, 1944: 283 (Cat.).

Elater striatus Linnaeus, 1767: 652; Fabricius, 1787: 168; Olivier, 1790: 14; Herbst, 1801: 340; Palisot de Beauvois, 1805: 212. Type locality: "Surinam".

Chalcolepidius striatus; Eschscholtz, 1829: 33; Castelnau, 1840: 237; Erichson, 1841: 79 (Syn.); Candèze, 1857: 271; 1881: 22; Schenkling, 1925: 57 (Cat.); Fleutiaux, 1926: 108 (Cat.); Blackwelder, 1944: 283 (Cat.)

Elater maximus Sulzer, 1776: 52; Olivier, 1790: 14 (= E. striatus); Fleutiaux, 1911: 248 (Syn.). Type locality: "America".

Chalcolepidius pulverulentus Herbst, 1786: 172; Schoenherr, 1817: 276 (=E. virens Fabricius); Candèze, 1891: 38 (Syn.).

Chalcolepidius guineensis Gmelin, 1788: 1914; Schoenherr, 1817: 276 (=E. virens Fabricius); Candèze, 1891: 38 (Syn.). Type locality: "Guinea".

Chalcolepidius peruanus Candèze, 1886: 72; 1891: 38 (Cat.); Schenkling, 1925: 57 (Cat.); Blackwelder, 1944: 283 (Cat.). Syntype female: "Coll. R. I. Sc. N. B. Pérou, ex coll. Candèze; n. sp. peruanus Cdz Perou" ISNB (examined). Syn. nov.

Chalcolepidius flavostriatus Pjatakowa, 1941: 102. Type locality: "Brazil, Amazonas, Mujo". Syn. nov.

Chalcolepidius herbstii multistriatus Golbach, 1977: 156, photograph 1 \& fig. 3. Paratype male: "Pará, Rio Acara E. Horvath, 1930; M; Chalcolepidius herbsti ssp multistriatus nov. ssp. R. Golbach det. 1975; Paratipo 1 M" (IMLA) (examined). Syn. nov.

OLIVIER (1790) redescribed Elater porcatus Linnaeus, 1767, recording it "dans l'Amérique méridionale, à la Baye de Honduras". The diagnosis corresponds to E. porcatus, but in the description, this species is characterized by pubescence of pronotum green-cupreous with yellowish-white lateral stripes [E. porcatus has pubescence of pronotum unicolor]; elytra sulcate, interstices raised with pubescence brownish and lateral margins yellowish-white. He included the figure (Pl. 7, fig. 74) of one specimen with pubescence of pronotum metallic green with whitish lateral stripes and elytra whitish except raised interstices, brownish, later recognized as $C$. limbatus. He also redescribed and presented a figure of $E$. striatus, a synonym of C. porcatus (Linnaeus).

FABRICIUS (1787) redescribed Elater porcatus and E. striatus, and described $E$. virens; in 1801 he redescribed these species.

Eschscholtz (1829) transferred E. porcatus and E. striatus to Chalcolepidius and, by first time, observed the presence of long cilia on male tibiae.

DruRY (1837) (new edition; old edition 1782) treating on Elater porcatus (from Bay of Honduras $[=C$. limbatus $]$ ), changed the rank of Chalcolepidius to subgenus of Elater and considered "Elater (Chalcolepidius) porcatus Fabricius" as a synonym of "Elater (Chalcolepidius) porcatus "Linnaeus. $\mathrm{He}$ also presented a figure that corresponds to C. limbatus with green pubescence. In fact, he was treating on E. limbatus, misidentified by OLIVIER (1790) as E. porcatus, and followed by other authors.

According to ERICHSON (1841), C. porcatus is very common in Brazil and Suriname, and presents several variations related to elytral sculpture and the coloration of vestiture. He enumerated these variations and considered " $E$. porcatus Fabricius", E. virens Fabricius and E. striatus Linnaeus as synonyms of $C$. porcatus (Linnaeus).

CANDĖze (1857) followed ERichson (l.c.), and stated that this species presents numerous variations, especially related with elytral sculpture and pubescence coloration. According to him, these variations could be considered as different species if the intermediary shapes were not found. He presented a table of varieties resulting from Erichson's hard work. The main problem of this table is that the pronotum of C. porcatus, herein accepted only as unicolor, may present, or not, lateral white stripes.

CANDĖze (1874) treating on C. porcatus Linnaeus, stated that the variation "virens" seems to be recorded from North up to Mexico, where it is reduced in size and it is very rare. Herein, "virens" is not considered conspecific with $C$. porcatus. According to him, a very beautiful variety of $C$. porcatus, var. $\mathrm{b}, \mathrm{c}^{\prime}$, from Pará, presents the prothorax totally brown and elytra white, except higher interstices which form black ridges. I saw this specimen in MNHN and it presents white epipleura, herein accepted as belonging to $C$. aurulentus.

CANDĖZE (1881) questioned if $C$. porcatus and C. striatus are the same species. He also described C. cyaneus, from Brazil, characterized by dark-blue metallic pubescence with striae and lateral stripes of elytra with white dull setae. According to him, this species has the general shape of C. porcatus, but the elytra are like C. striatus.

CANDĖze (1886) described C. peruanus, from Peru, characterized especially by general pubescence metallic olive with the lower interstices white. According to him, this species belongs to "porcatus" group, and it is separate especially by geminate and white striae and epipleura coloration like underside. He commented that ERICHSON (1841) put together, under the name of $C$. porcatus, several forms of this species, showing that there is not a well-established limit among them. CANDĖZE (l.c.) preferred to attribute specific names to specimens easily recognizable, and based on this principle, $C$. virens, was considered as a valid species. The principal problem of this attitude is to consider the specimens of the extremities of the range of variations as distinct species; probably the intermediary shapes were not found.

CANDÈze (1891) synonymized $C$. guineensis Gmelin and $C$. pulverulentus Herbst under $C$. porcatus. These species had been considered as synonyms of $C$. virens. The type locality "Guinea" attributed to Elater guineensis Gmelin is puzzling, as Chalcolepidius species do not occur in Africa.

Fleutiaux (1911) included, besides E. striatus Linnaeus, $E$. guineensis Gmelin and E. pulverulentus Herbst, also E. maximus Sulzer as synonyms of $C$. porcatus; $E$. virens was considered as a variety. He was followed by SCHENKLING (1925) and BLACKWELDER (1944). 
Puatakowa (1941) described briefly C. flavostriatus, from Brazil (Amazonas: Mujo), characterized especially by general metallic pubescence bluish-green, with ochraceus striae; striae not geminate and epipleura like ventral coloration. The description of this species fits very well with $C$. porcatus.

GolbaCH (1977) described $C$. herbstii multistriatus, from Brazil (Amazonas: Manaus; Pará: Rio Acara). According to him, this subspecies differs from the typical species especially by presence of striae and interstices distinct from base until apex; interstices unequal; general metallic pubescence brown, greenish and violet mixed or only brown; striae clothed with row of yellowish setae.

Based on the analysis of the photo of the type of C. porcatus and available material of the other species, including some types, it was concluded that C. peruanus, C. flavostriatus and C. herbstii multistriatus are conspecific with C. porcatus, and the differences among them are into the range of variation of coloration showed by this species.

Length: $25-46 \mathrm{~mm}$. Wide, arched body. Integument black clothed dorsally and ventrally with dense metallic green, yellowish-green, brown or violet-brown pubescence; dull setae ochraceus, yellow, yellowish-white or white on striae and sometimes lower interstices; pubescence of epipleura like ventral; antennae clothed with dark-blue short setae except three first segments, similar general coloration (Figs. 61-63).

Antennae (Fig. 138) serrate in both sexes, $3^{\text {rd }}$ segment triangular-elongate, shorter than $4^{\text {th }}$. Pronotum (Fig. 202) longer than wide, subtrapezoidal, wider at hind angles, slightly narrowed apicad; strongly convex medioanteriorly, convexity decreasing basad; small-punctuate with coarse and sparse punctuation on anterior half, more concentrate laterally; in some specimens rugose near middle; anterior margin sinuous and prominent at middle; lateral margins forming narrow raised edge, almost reaching apex; hind angles backward, wide with truncate apex, raised laterally, forming edge wider than that of lateral margins; posterior margin prominent and strongly notched at middle; median basal tubercle flat, triangular, continuous with weak median ridge, not reaching apex. Hypomera concave; internal margin raised forming wall of prosternal channel; raised narrow band parallel sutures. Notosternal sutures strongly sinuous. Prosternum strongly convex, flattened longitudinal medially and concave near sutures; small-punctuate with coarse punctuation near sutures. Prosternal lobe transverse with fore angles rounded; punctuation like prosternum. Scutellum strongly folded with horizontal basal area subtrapezoidal notched anterior- and posteriorly. Mesosternal cavity U-shaped with borders thick and horizontal on basal $3 / 4$ and almost vertical on distal $1 / 4$ forming L-shaped profile. First visible sternite prominent laterally, fits in small groove of elytra. Anterior and median tibiae and last tarsal segment of all legs of male bearing fringe long cilia. Interstices convex and unequal; flat tubercle at base of $2^{\text {nd }}$; apex truncate with tiny sutural spine.

Male genital segments and aedeagus. Sternite VIII (Fig. 339) transverse, narrowed on distal third, translucent in median large area, paired small elliptical patch near base and two lateral narrow bands. Tergite IX transverse, densely punctuate with anterior margin rounded; tiny lateroanterior setae. Aedeagus (Fig. 407): median lobe wide (Fig. 445), slightly narrowed near middle, bearing 7, 7; 9,10;10, 10 lateral teeth $(14,14$ in C. herbsti multistriatus holotype); lateral cleft of parameres (Fig. 481) wide with apex slightly prominent laterally.

Female genital segments and genitalia. Tergite VIII transverse with anterior margin rounded; translucent basal area almost reaching middle. Sternite VIII (Fig. 561) 0.70 times spiculum gastrale length; anterior margin wide- and deeply notched. Genitalia: sclerotized rings of openings of colleterial glands (Fig. 652) bearing, 36, 36, 53 teeth; bursa copulatrix with longitudinal elongate median band with carinae and spines and paired rounded lateral spiny areas.

Material examined. WEST INDIES. Guadeloupe: ex-coll. Fleutiaux, 1 F (MNHN). VENEZUELA. Bolivar: Acopan-tepuí, 1 F (AMNH); Agua Fria, Cr. Sta Elena (several localities with this name), 1 F (IMLA); St. Helena, $1 \mathrm{~F}$ (AMNH). COLOMBIA. Tibu, $1 \mathrm{~F}$ (FSCA). GUYANA. 3 F (MNHN), 1 F (MZSP), ex-coll. Jekel, ex-coll. Fleutiaux, 1 F (MNHN). East Demerara: Georgetown, 2 F (AMNH), 2 F (USNM). East Berbice: Mallali, 1 M, 2 F (MNHN). Mazaruni Potaro: Bartica Dist., 3 F (AMNH), Kartabo, 3 F (AMNH), Penal Settlement, 3 F (AMNH), Kalacoon, 1 F (AMNH); Kamakuwa, 1 M, 4 F (AMNH); Rockstone, 3 F (USNM); Tukeit [Falls], 6 F (AMNH); Tumatumari, 1 F (AMNH); Upper Mazaruni R., 1 F (AMNH). West Demerara: ex-coll. Sallé, 1 F (MNHN); Rio Demerara, 2 F (USNM), 2 F (ZMHB). SURINAME. 1 F (MCZC). Suriname: Paramaribo, $1 \mathrm{~F}$ (ZMHB). Brokopondo: Brownsberg, $1 \mathrm{~F}$ (FSCA). Marowijne: Christian Kondre, $1 \mathrm{~F}$ (MZSP); Langaman Kondre, $1 \mathrm{~F}$ (MZSP). FRENCH GUIANA. $35 \mathrm{~F}$ (MNHN), ex-coll. Fleutiaux, $2 \mathrm{M}$, $40 \mathrm{~F}(\mathrm{MNHN})$. Cayenne: Cayenne, $2 \mathrm{~F}$ (MNHN), $3 \mathrm{~F}$ (USNM), $4 \mathrm{~F}$ (ZMUC), ex-coll. Fleutiaux, $4 \mathrm{~F}$ (MNHN), ex-coll. Gounelle, $3 \mathrm{~F}$ (MNHN), ex-coll. Sallé, coll. Fleutiaux, 1 M, 6 F (MNHN), Madeleine, 1 F (SRGI); env. Cayenne, ex-coll. Fleutiaux, 12 F (MNHN), Bas Mahury, 2 F (MNHN), Bas Mahury, Paco, 5 F (MNHN); La Chaumière, 2 F (SRGI); Comte [rivière], 3 F (SRGI); Gourdonville, 2 F (MNHN), excoll. Le Moult, ex-coll. Fleutiaux, 4 F (MNHN); Ilet la Mère, 1 F (MNHN); Pk-33, Rte à Kaw, 2 F (FSCA), 1 F (MZSP); Kourou, 7 F (MNHN), 1 F (SRGI), 2 F (USNM), Montagne des Signes, 2 M, 19 F (SRGI); Maroni river, 7 F (USNM); Mountsinéry, 1 F (SRGI); Paracou, 1 F (SRGI); Passoura, ex-coll. Le Moult, ex-coll. Fletiaux, 2 F (MNHN); Rémire, 1 F (SRGI); Rochambeau, 1 F (SRGI); St. Laurent de Maroni, 15 F (MNHN), ex-coll. Fletiaux, 9 F (MNHN); St. Jean, 3 F (USNM); St. Jean Maroni [Saint Laurent du Maroni], ex-coll. Fleutiaux, 5 F (MNHN). Inini: Entre le Hana et le Maroni, Massif de l'Acarouani, 2 F (MNHN); Bas Maroni, Charvein, ex-coll. Fletiaux, 5 F (MNHN); Chantier Forestier de Charvein, Afluent Maroni, 4 F (MNHN); Charvein, 2 F (MNHN); Maroni, ex-coll. Fletiaux, $16 \mathrm{~F}$ (MNHN), $20 \mathrm{Km}$ aval. Sant. Hermina, $2 \mathrm{~F}$ (MNHN); Nouveau Chantier, Bas- Maroni, ex-coll. Fleutiaux, 9 F (MNHN); Pariacabo, $5 \mathrm{~F}(\mathrm{MNHN})$, rivière Kourou, ex-coll. Le Moult, ex-coll. Fleutiaux, 4 F (MNHN); Rt D5, 4 Km SE Tonnegrande Jct., 1 F (FSCA), 1 F (JEWC); Saül, 7 F (SRGI); Ferme Vidal (locality not found), 1 F (SRGI); BRAZIL. 1 F (AMNH), 1 F (USNM), 2 F (NHMW), 1 F (ZMUC), ex-coll. Gounelle, 3 F (MNHN), 16209, Hist. Coll. (Coleoptera) nr 16209 (2 ex.) Chalcolepidius porcatus Linn., Brasil Zool. Mus. ZMHB, 1 M (ZMHB), (1 ex.), (3 ex.), (4 ex.), (5 ex.), 4 F (ZMHB). Amapá: Macapá (Rio Tracajatuba), 1 F (MZSP); Oiapoque, 2 F (MNMS); Serra do Navio, 6 F (IBSP), 5 F (1 F dissected, MZSP); Serra do Navio, IgarapéSucurijú, 2 F (1 dissected) (MZSP). Amazonas: 1 F (MNHN), 2 F (PCCV); Altamira, 2 F (MZSP); Benjamin Constant (Rio Javari), 8 F (MZSP); Borba, 1 F (IBSP); Camela, ex-coll. Fleutiaux, 3 F (MNHN); Itacoatiara, ex-coll. Dirings, 1 M 2 F (1M, 1 F dissected, MZSP); Manaus, 1 F $(\mathrm{AMNH})$, Vale do Sol, Aleixo, $1 \mathrm{~F}$ (DZUP); Tefé (Ega), 1 F (MNHN), 1 F (MZSP), ex-coll. Fleutiaux, 1 F (MNHN); Vila Nova [Rio], 1 F (MNHN). Acre: $4 \mathrm{~F}$ (MZSP). Rondônia: $60 \mathrm{Km} \mathrm{S}$ Ariquemes, $1 \mathrm{~F}$ (FSCA); $60 \mathrm{Km}$ SW Ariquemes, nr Fzda Rancho Grande, 1 F (FSCA); Forte Príncipe da 
Beira, 7 F (MZSP); Pimenta Bueno, 1 F (MZSP); Posto Indígena 7 de Setembro (locality not found), 2 F (MZSP); Porto Velho, 1 F (MZSP); Rio Urupá, 2 F (MZSP). Roraima: Mt. Roraima, 4000 m, 1 F (AMNH); Vilhena, $1 \mathrm{~F}$ (MZSP). Pará: $1 \mathrm{~F}$ (MCZC), $2 \mathrm{~F}$ (SRGI), $1 \mathrm{~F}$ (USNM), $1 \mathrm{~F}$ (ZMHB), ex-coll. Fleutiaux, 1 M, 5 F (MNHN); Barreirinha, Rio Tapajós, 2 F (MZSP); Belém, 2 F (MZSP); Benevides, ex-coll. Gounelle, 7 F (MNHN); Bragance [Bragança], ex-coll. Fleutiaux, 7 F (MNHN); Canindé, Rio Gurupi, 2 F (MZSP); Colonia Rio Branco, Caipos, 1 F (DZUP); Igarapé Uruaim, $40 \mathrm{Km}$ Rio Gurupi, $2 \mathrm{~F}$ (MZSP), ex-coll. Fleutiaux, $1 \mathrm{~F}$ (MNHN); Ilha de Mosqueiro, 2 F (SRGI); Itaituba, 2 F (AMNH), Rio Tapajós, 12 F (MZSP), 1 F (DZUP), Santaremsinho, ex-coll. Dirings, 22 F, (MZSP), ex-coll. Dirings, 1 F (MZSP); Mocajuba, Mangabeira, 2 F (DZUP); Óbidos, 1 F (AMNH); 9 F (MNHN), 2 F (MZSP), 1 F (PCCV), $1 \mathrm{~F}$ (SRGI), 8 F (DZUP), 2 F (ZMHB), ex-coll. Dirings, 1 M, 125 F (1M, $1 \mathrm{~F}$ dissected, MZSP), ex-coll. Fleutiaux, $4 \mathrm{~F}$ (MNHN), Canta Galo, $19 \mathrm{~F}$ (MZSP), Traíra, 18 F (MZSP); Oriximiná, 1 F (MZSP); Rio Água Azul (locality not found), 1 F (DZUP); Rio Tapajós, 3 F (MZSP), Taperinha, Santarém, 2 F (MNHN); Santarém, 3 F (IBSP), 5 F (MNHN), 5 F (MZSP), 6 F (USNM), Faz. Taperinha, 3 F (NHMW), 3 F (MZSP); Santo Antonio do Tauá, ex-coll. Fleutiaux, 3 F (MNHN); Tiriós, Alto Parú d'Oeste, 2 F (MZSP). Mato Grosso: Chapada [dos Guimarães], near Cuiabá, $1 \mathrm{~F}$ (USNM); Estação Codemat (locality not found), $1 \mathrm{~F}$ (dissected) (INPA); Rosário [Oeste], 1 F (MZSP). ECUADOR. Oriente: Hacienda "Ila" (locality not found), $1 \mathrm{~F}$ (AMNH). Napo: Canelos, $1 \mathrm{~F}$ (MNHN). Loja: Loja, $1 \mathrm{~F}$ (MNHN); Suñag (locality not found), $1 \mathrm{~F}$ (SRGI). PERU. $1 \mathrm{~F}$ (MNHN), $1 \mathrm{~F}$ (ZMHB). Amazonas: Pebas, $1 \mathrm{~F}$ (MNHN). Cuzco: Urubamba, 5 F (MNHN). Huánaco: Pozuzo, 1 F (MNHN); Tingo Maria, $1 \mathrm{~F}$ (AMNH), 680 m, 1 F (ZMHB). Lima: Santa Rosa, Rio Chinchipe, 1600 m, 2 F (IMLA). Yacucho: Jojen, 700 m, 1 M (IMLA).

Remarks. As presented by historical review, in the past there were several misidentifications related to the specimens similar to Chalcolepidius porcatus, or species occurring in the same area. This situation is a consequence of the very wide range of variations showed by this species, especially regarding to the pubescence coloration and the height and distance among the elytral interstices. The general pubescence coloration presents different shades of grayish-green, yellowish-green, green, greenish-blue, olive-brown, olive, wine-brown, brown or bluish-gray. The dull setae are yellowish, yellowish-white, yellow, ochraceus, ochre or white, and beset the striae and sometimes the interstices, especially the lower and narrower. The epipleura is always clothed with pubescence of the same color as that of the underside. When a large series is examined, it is possible to see the gradual increasing of the areas clothed with pale setae and the differences among the interstices. There are specimens with interstices almost equal and only the striae clothed with whitish setae, forming or not narrow lateral stripes, like the syntype of $C$. porcatus; specimens with interstices strongly unequal and lower interstices totally or partially beset with dull pubescence, like those described as $C$. peruanus; and intermediary forms, with interstices unequal and interstices clothed with white setae in variable degree.

C. porcatus presents similar pubescence coloration and geographical distribution to $C$. aurulentus, but they differ especially by epipleura coloration, of the same color of ventral pubescence in the former and white in the latter. I dissected two males and two females of $C$. porcatus and observed that the genitalia presents a great deal of variations, and it is not useful to separate these species. Only the median lobe of aedeagus is more constricted behind the lateral teeth in all males dissected (slightly constricted in C. aurulentus). The median lobe present 7,$7 ; 10,10 ; 14,14$ lateral teeth $(6,7 ; 8,8 ; 8$, $9 ; 9,13 ; 11,11 ; 11,13$ in C. aurulentus); the sclerotized rings of openings of colleterial glands, 34,$36 ; 36,37$ teeth $(24 ; 33 ; 34 ; 37$ in C. aurulentus).

C. porcatus belongs to forreri* group (Fig. 671).

Distribution. It is recorded from West Indies (Guadeloupe), Venezuela, Colombia, Guyana, Suriname, French Guiana, Brazil (Amapá, Amazonas, Acre, Rondônia, Roraima, Pará, Mato Grosso), Ecuador and Peru (Fig. 682).

The majority of the specimens from French Guiana are clothed with metallic pubescence olive-green, brownish-green or violet-brown with interstices slightly unequal, clothed with yellowish-white or ochre dull setae. The specimens from Brazil are basically divided into two groups: those from Acre, Amazonas and Pará are predominantly green or yellowish-green with striae yellow or ochraceus, and the interstices are unequal but not clothed with dull setae; those from Amapá (Serra do Navio) are predominantly violet, reddish-brown, violet-brown or brown with striae yellowish or ochraceus. I examined a series of five specimens from Brazil (ZMHB) where one male and one female ("1 ex.", "2 ex.") were clothed with olive-brown metallic setae with striae not geminate, clothed with ochraceus dull setae in male and yellowish in female; three other females, one with wine-green and two with wine-brown metallic setae and geminate striae clothed with ochre dull setae, and in one female the lower interstices were almost beset by ochre setae. The specimens from Peru are grayish-green or green, with striae geminate or not and white, and the interstices are unequal clothed or not with white or yellowish-white setae. I examined one specimen from Peru (Jojen, 700 m - IMLA) clothed dorsally with metallic blue setae with white dull striae, and ventrally with green pubescence.

\section{Chalcolepidius proximus sp. nov.}

(Figs. 64, 139, 203, 687)

Type material. Holotype female: "40 Mi S. Culiacan, Sinaloa, Mex. July 22, 1954; M. Cazier W. Gertsch Bradts Collectors” (AMNH).

Holotype. Length: $20 \mathrm{~mm}$. Integument black, clothed dorsally by metallic scale-like setae brownish-olive and ventrally, including legs (except tibiae and tarsi), by dull white pubescence; lateral stripes of pronotum band-like, approximately $1 / 4$ of pronotum width; dull white pubescence on basal region of frons, lateral stripes of pronotum, basal region of elytra and lower interstices (Fig. 64).

Frons narrower anteriorly; nasal plate high, declivous and punctuate. Antennae (Fig. 139) serrate; $3^{\text {rd }}$ segment triangularelongate slightly shorter than $4^{\text {th }}$. Pronotum (Fig. 203) longer than wide, slightly narrowed anteriad, from hind angles apices; stronger narrowed on anterior $1 / 4$; strongly convex (stronger longitudinal medially), densely micropunctate with sparse coarser punctures; anterior margin slightly prominent and sinuous at middle; hind angles wide, backward, raised laterally forming edge, widened and continuous with that of lateral 
margins until anterior $1 / 4$; median basal tubercle triangular or indistinct; posterior margin prominent and strongly notched at middle. Hypomera concave; internal margin raised laterally forming wall of prosternal channel. Notosternal sutures moderately sinuous. Prosternum strongly convex, flattened longitudinal medially, grooved laterally; weakly micropunctate with denser and coarser punctuation near sutures. Scutellum strongly folded; horizontal area subtrapezoidal notched anterior- and posteriorly. Borders of mesosternal cavity thick and horizontal on basal $3 / 4$ and vertical on distal $1 / 4$ forming Lshaped profile. First visible sternite prominent laterally. Elytra strongly convex; narrowed on distal half with apex conjointly rounded; interstices unequal. Sternite VIII of female with anterior margin wide- and deeply notched at middle.

Male unknown.

Remarks. Chalcolepidius proximus is characterized especially by general dorsal pubescence brownish-olive and ventral white, white pubescence on lateral stripes of pronotum, basal region of elytra and lower interstices, and scutellum folded. It looks-like $C$. virginalis.

C. proximus belongs to bomplandii* group (Fig. 671).

Distribution. It is recorded from Mexico (Sinaloa) (Fig. 687).

Etymology. The epithet is derived from one of the latin words for close, proximus, related to similarity to other species (C. validus).

Chalcolepidius pruinosus Erichson, 1841

(Figs. 65, 140, 204, 518, 562, 608, 653)

Chalcolepidius pruinosus Erichson, 1841: 84; Candèze, 1857: 263, 276; Gemminger \& Harold, 1869: 1503 (Cat.); Candèze, 1874: 165; 1886: 68, 72; 1891: 38 (Cat.); Champion, 1894: 274, 281; Schenkling, 1925: 57 (Cat.); Blackwelder, 1944: 283 (Cat.). Syntypes: 2 females: "Mexico Deppe Nr 16221; Syntype Chalcolepidius pruinosus Erichs. CMF von Hayek det. 1980" and “16221; pruinosus Er.* Cand.* Mexico Deppe; Syntype Chalcolepidius pruinosus Erichs. CMF von Hayek det. 1980"(ZMHB) (examined).

ERICHSON (1841) described C. pruinosus, from Mexico, clothed with metallic greenish pubescence and interstices raised, alternate, costiform.

CANDĖZE (1857) commented that the coloration of this species is different from all others, resembling $C$. virens, but with different sculpture of elytra. He considered it very similar to $C$. silbermanni, from which it differs, especially by silky appearance, olive pubescence and body less linear.

According to CHAMPION (1894) this species "is very closely allied to, and perhaps only a variety of, $C$. silbermanni, from which it differs in its slaty-blue or greenish scales and more parallel shape. The male characters are similar".

Length: 31-38 mm. Wide, parallel body. Integument black clothed dorsally and ventrally, including legs, with short metallic scale-like setae, grayish-blue, greenish-blue or olive, sometimes intermingled with violet; antennae clothed with black or dark- blue setae, except three first segments (Fig. 65).

Antennae (Fig. 140) very short, not reaching middle of lateral margins of pronotum, serrate; $3{ }^{\text {rd }}$ segment triangular-elongate, slightly shorter than $4^{\text {th }}$. Pronotum (Fig. 204) very longer than wide, wider on hind angles, slightly narrowed anteriad, narrower on $1 / 4$ proximal; strongly convex; micropunctate with coarse sparse punctuation, in some specimens forming small ridges; anterior margin slightly sinuous; fore angles downwards and rounded; lateral margins forming narrow edge on $3 / 4$ basal; hind angles backwards, raised laterally, forming edge, continuous with that of lateral margins; median basal tubercle flattened, triangular-elongate, continuous with small ridge, not reaching anterior margin; posterior margin prominent and strongly notched at middle. Hypomera concave, laterointernal margin raised forming wall of anterior channel, not marginated. Notosternal sutures strongly sinuous. Prosternum micropunctate, strongly convex, flattened longitudinal medially; grooved near sutures. Prosternal lobe transverse with rounded angles; punctuation small (coarser than prosternum). Scutellum strongly folded with horizontal basal area subtrapezoidal, notched anterior- and posteriorly. Borders of mesosternal cavity thick and horizontal on basal $2 / 3$ and moderately declivous on distal $1 / 3$, forming semi-elliptical profile. First visible sternite prominent laterally, fits in small groove of elytra. Anterior and median tibiae and last tarsal segments of all legs of male bearing fringe of long cilia. Interstices unequal and costiform; micropunctate; striae grooved and marked by coarse punctures; apex conjointly rounded.

Female genital segments and genitalia. Tergite VIII (Fig. 518) transverse, strongly notched at base with anterior margin rounded; densely setous; median basal translucent area small and subquadrate. Sternite VIII (Fig. 562) with anterior margin wide- and deeply notched and spiculum gastrale widened near base. Female genitalia (Fig. 608): sclerotized rings of openings of colleterial glands (Fig. 653) bearing 38 teeth including 8 bior tricuspid; bursa copulatrix with elongate longitudinal median area with carinae and spines, and small lateral paired spiny areas.

Material examined. MEXICO. $1 \mathrm{~F}$ (dissected) (USNM), $1 \mathrm{~F}$ (ZMHB), ex-coll. Chevrolat, $1 \mathrm{~F}$ (MNHN), ex-coll. Jekel, $1 \mathrm{~F}$ (MNHN). Hidalgo: Parada, ex-coll. Sallé, 1 F (MNHN). Oaxaca: ex-coll. A. Sallé, 2 M (MNHN); Yolotepec, 1 F (ZMHB). Without locality: 1 F (NHMW).

Remarks. Chalcolepidius pruinosus is characterized especially by general pubescence grayish- or greenish-blue, scutellum folded, tibiae of male bearing fringe of long cilia and interstices unequal, costiform.

It is similar to C. silbermanni, differing especially by more parallel body and pronotum in the former and the pubescence coloration, with blue or olive shade in the former and brown or gray in the latter. Besides, the sclerotized rings of the openings of colleterial glands are totally closed with 38 teeth ( 8 bi- or tricuspid) in the former and opened with 32,33 teeth in the latter (two females dissected), with respectively one and four bi- or tricuspid teeth in the latter; the spiny lateral areas of bursa copulatrix are smaller in the former, formed only by 
dispersed spines. Comparing the female genital segments, the median translucent area of tergite VIII is smaller and the spiculum gastrale of sternite VIII is widened near apex in the former. The male genitalia of the former were not studied.

C. pruinosus belongs to forreri* ${ }^{*}$ group (Fig. 671). 683).

Distribution. It is recorded from Mexico (Hidalgo, Oaxaca) (Fig.

Chalcolepidius rodriguezi Candèze, 1886

(Figs. 66, 141, 205, 256, 340, 370, 408)

Chalcolepidius rodriguezi Candèze, 1886: 66, 70; 1891: 37 (Cat.); Champion, 1894: 275, 286, t.12, f.16-17; Blackwelder, 1944: 283 (Cat.); Schenkling, 1925: 57 (Cat.). Holotype male: "Type; n. sp. rodriguezi Cdz Guatemala; Chalcolepidius rodriguezi Cand. det. E. Candèze; Coll. R. i. Sc. N. B. Guatemala ex- coll. Candèze" (ISNB) (examined)

CANDÈze (1886) described C. rodriguezi based on a male from Guatemala, and characterized it as "vestiture fauve" in the key and "olivaceo-fulvescentibus obductus" with antennae strongly serrate and interstices equal in the diagnosis.

Length: $27 \mathrm{~mm}$. Narrow, parallel body. Integument reddishbrown, clothed dorsally and ventrally with very short scalelike golden pubescence, denser dorsally; longer pale (cream) setae on two lateral striae; antennae with brown pubescence, except three first segments, pale (cream) (Fig. 66).

Frons not carinate, slightly concave medioanteriorly; nasal plate high. Antennae of male (Fig. 141) strongly serrate (partially broken); $3^{\text {rd }}$ segment short and triangular. Pronotum (Fig. 205) longer than wide, wider at hind angles, slightly narrowed apicad from hind angles apices; micropunctate with coarse punctuation more concentrate near middle; anterior margin slightly sinuous; lateral margins raised laterally forming smooth narrow edge almost reaching apex; grooved innerly edge; hind angles wide, backwardly directed, raised laterally forming edge, continuous with that of lateral margin; median basal tubercle elongate and flat, posterior margin prominent and slightly notched at middle. Hypomera slightly concave. Notosternal sutures slightly sinuous. Prosternal channel absent. Prosternum moderately convex, from sutures. Prosternal lobe wide, emarginated laterally with rounded angle. Scutellum (Fig. 256) strongly declivous and narrower on anterior half; basal half horizontal and elliptical. Borders of mesosternal cavity vertical, wide and horizontal on basal 2/3 and vertical on distal 1/3, forming L-shaped profile. Tibiae of male bearing row of long spines internally. Striae weakly punctuate; interstices slightly convex and micropunctate, unequal especially on apical half; $2^{\text {nd }}$ and $3^{\text {rd }}$ forming prominent flat tubercle at base; apices conjointly rounded.

Genital segments of male and aedeagus. Tergite VIII slightly wider than long, slightly narrowed apicad with anterior margin rounded; basal margin strongly notched; clothed by short setae. Sternite VIII (Fig. 340) transverse, narrowed to apex on distal half, becoming pentagonal; melanized in two large lateral bands and median anterior small spot. Sternite IX elongate; melanized area reduced to transversal band on distal half; apex translucent. Tergite IX (Fig. 370) densely punctuate, transverse, narrowed apicad; anterior margin moderately notched; moderately long setae lateroanteriorly. Aedeagus (Fig. 408): median lobe narrowed on basal third and subapical region; apex of parameres spearhead-like.

The female was not studied.

Remarks. According to CHAMPION (1894) the female of Chalcolepidius rodriguezi differs from male "in having a large admixture of elongate white scales on both the upper and under surfaces". He believes that this difference is apparently sexual, as in $C$. mexicanus. I did not study the female.

C. rodriguezi is characterized especially by narrow body with integument reddish-brown clothed with golden pubescence, antennae of male strongly serrate, median basal tubercle of pronotum elongate, scutellum strongly declivous, tibiae of male bearing irregular row of spines and apex of parameres spearhead-like.

It is similar to C. mexicanus (see remarks above the latter).

C. rodriguezi belongs to mexicanus* group (Fig. 671).

Distribution. It is recorded only from type locality, Guatemala.

Chalcolepidius rostainei Candèze, 1889

(Figs. 67, 142, 206, 257, 519, 563, 654, 690)

Chalcolepidius rostainei Candèze, 1889: 12; 1891: 38 (Cat.); Schenkling, 1925: 57 (Cat); Blackwelder, 1944: 283 (Cat.). Type locality: "Nouvelle Grenade".

CANDÈze (1889) described C. rostainei, based on one specimen from "Nouvelle Grenade" collected by M. St. Amand Rostaine, belonging to Reiche collection where it was named as "equatorius". It was clothed with metallic green pubescence with lateral stripes on pronotum and elytra and epipleura clothed with reddish-brown setae, and interstices unequal. He commented the similarities of this species with C. limbatus, $C$. bomplandii and C. fabricii.

Length: 37-39 mm. Wide, arched body. Integument black clothed dorsally and ventrally with short metallic green scalelike pubescence (including legs and tarsi); lateral stripes of pronotum band-like, approximately $1 / 4$ of pronotum width; dull reddish-brown setae on lateral bands of pronotum, elytra (except higher interstices) and epipleura; antennae clothed with short dark-blue setae, except three first segments, green (Fig. 67).

Frons not carinate, strongly declivous. Nasal plate declivous. Antennae of female (Fig. 142) serrate, $3^{\text {rd }}$ segment triangular-elongate, slightly shorter than $4^{\text {th }}$. Pronotum (Fig. 206) longer than wide, wider at hind angles, slightly narrowed apicad from hind angles apex, narrower on anterior third; strongly convex, coarsely punctuated; lateral margins forming raised bright edge almost reaching apex; anterior margin sinuous; hind angles backwards, raised laterally; median basal tubercle flat, triangular-elongate continuous with longitudinal 
median weak ridge; posterior margin prominent and strongly notched at middle. Hypomera concave, with narrow raised band parallel notosternal sutures; laterointernal margin raised forming wall of anterior channel. Notosternal sutures strongly sinuous, opened frontally forming deep channel. Prosternum strongly convex, strongly grooved near sutures, flattened longitudinal medially; prosternal lobe truncate with rounded angles. Scutellum (Fig. 257) strongly folded with horizontal basal area subtrapezoidal notched anterior- and posteriorly. Borders of mesosternal cavity wide and horizontal on basal $2 / 3$ and vertical at apex, forming to anterior third L-shaped profile. First visible sternite prominent laterally, fits in small groove of elytra. Anterior and median tibiae and last tarsal segment of all legs of male bearing fringe of long cilia. Interstices unequal, convex and micropunctate; apices slightly rounded (almost truncate) with tiny sutural spine.

Female genital segments and genitalia. Tergite VIII (Fig. 519) transverse with anterior margin slightly rounded and notched at base; densely setous; translucent in large median basal triangular area and lateroanterior narrow band (interrupted at middle). Sternite VIII (Fig. 563) 0.63 times spiculum gastrale length, anterior margin wide- and deeply notched. Genitalia: sclerotized rings of openings of colleterial glands (Fig. 654) wide basally, bearing 34 teeth; bursa copulatrix elongate with longitudinal median band with carinae and spines and paired lateral rounded spiny areas.

The male was not studied.

Material examined. BRAZIL. Pará: Óbidos, 1 F (dissected) (MZSP).

Remarks. Chalcolepidius rostainei is characterized especially by general pubescence green with lateral stripes of pronotum, epipleura and lower interstices reddish-brown, and scutellum folded. It is similar to C. zonatus differing especially by (the latter parenthesized): only lateral stripes of pronotum distinct (lateral stripes on pronotum and elytra); lateral stripes of pronotum reddish-brown (yellowish-white); sclerotized rings of openings of colleterial glands bearing 34 teeth (46).

C. rostainei is the sister-group of C. validus (Fig. 671).

Distribution. It is recorded, besides the type locality ("Nouvelle Grenade"), also from Brazil (Pará) (Fig.690).

Chalcolepidius rubripennis LeConte, 1861

(Figs. 68, 143, 207, 258, 259, 297, 341, 409, 446, 482, 520, 564, $609,610,655,677)$

Chalcolepidius rubripennis LeConte, 1861: 336; 1863: 45 (Cat.); Gemminger \& Harold, 1869: 1503 (Cat.); Candèze, 1886: 66, 69; 1891: 37 (Cat.); Schwarz, 1906a: t. 2, f. 7; Casey, 1907: 34; Leng, 1920: 167 (Cat.); Fleutiaux, 1926: 108 (Cat.); Schenkling, 1925: 57 (Cat.); Blackwelder, 1944: 283 (Cat.).

Length: $25-46 \mathrm{~mm}$. Moderately wide body, parallel. General integument black with wine-red or orange elytra; general metallic pubescence, except elytra, scale-like setae, short, thin, green or blue or both mixed; elytral pubescence violet, shorter and sparser than pronotum; antennae with navy pubescence except three first segments, blue or green (Fig. 68).

Frons not carinate, moderately declivous. Antennae serrate in female, strongly serrate in male (Fig. 143); $3^{\text {rd }}$ segment triangular-short. Pronotum (Fig. 207) longer than wide, narrowed anteriorly and at hind angles base, making lateral margins rounded; strongly convex at middle; micropunctate with coarser punctuation variable in thickness and density; in some specimens slightly rugose lateroanteriorly; anterior margin prominent and rounded at middle; lateral margins rounded, raised laterally forming narrow edge almost reaching apex; hind angles divergent, sharpened, raised laterally in moderately wide edge, continuous with that of lateral margin, slightly narrower; median basal tubercle flat, elongate, posterior margin moderately notched at middle. Hypomera concave near lateral margins, raised in narrow band near sutures; laterointernal margin raised forming wall of anterior channel. Notosternal sutures strongly sinuous. Prosternum micropunctate, strongly convex, flattened longitudinal medially, concave near sutures. Prosternal lobe with punctuation coarser than prosternum; in some specimens with weak longitudinal grooves; wide, emarginated laterally with fore angles slightly rounded. Prosternal spine flattened laterally. Scutellum (Figs. 258, 259) with anterior half strongly declivous; horizontal area subtriangular, notched anterior- and posteriorly, grooved longitudinal medially or with two rounded concavities. Borders of mesosternal cavity (Fig. 297) wide and horizontal on basal $1 / 2$ and slightly declivous on distal $1 / 2$, forming inclined profile. Meso-metasternal suture weak. First visible sternite prominent laterally, fits in lateral groove of elytra. Anterior tibiae of male bearing fringe short cilia. Striae marked by coarse punctures; interstices equal, convex and smallpunctuate; apices conjointly rounded.

Male genital segments and aedeagus. Sternite VIII (Fig. 341) transverse, narrowed apicad, with constriction on distal third; setous; translucent in median area. Tergite IX densely punctuate; transverse, with anterior margin straight with rounded angles; tiny setae near lateroanterior and anterior margins. Aedeagus (Fig. 409): median lobe (Fig. 446) wide, slightly narrowed near middle, 0.52 times the aedeagus length, bearing 10,$10 ; 14,14$ small lateral teeth; lateral cleft of parameres (Fig. 482) narrowed apicad; apex rounded and upwards.

Female genital segments and genitalia. Tergite VIII (Fig. 520) transverse, setous; anterior margin prominent at middle; translucent in median basal triangular area and paired lateral band. Sternite VIII (Fig. 564) 0.61 times spiculum gastrale length; anterior margin wide- and deeply notched. Genitalia: sclerotized rings of openings of colleterial glands (Fig. 655) bearing 48 teeth; bursa copulatrix (Figs. 609, 610) with median elongate moderately wide band with carinae and spines; without lateral paired spiny areas.

Material examined. UNITED STATES OF AMERICA. Tropic of Cancer, $10 \mathrm{mi} \mathrm{N}$ Hwy.1, $1 \mathrm{~F}$ (USNM). California: $5 \mathrm{~F}$ (CMNH), $5 \mathrm{~F}$ (MCZC), 1 M (dissected), 1 F (MZSP), 2 F (USNM); Sonoma Co. MEXICO. $1 \mathrm{~F}(\mathrm{MNHN}), 1 \mathrm{~F}$ (NHMW). Baja California: $1 \mathrm{~F}(\mathrm{AMNH})$, 7 M, 4 F (MCZC), 1 M, 5 F (MNHN), 1 F (MZSP), 3 F (USNM), 1 M, 23 F (MNHN), ex-coll. Fleutiaux, 1 M, 1 F (MNHN); Cape San Lucas, 2 F (AMNH), 1 M, 1 F (MCZC), 1 M (MNHN); El Taste, 1 M, 1 F (USNM); 
Santa Rosa, 2 F (AMNH), 2 F, 1 M (CMNH), 1 F (FSCA), 3 F, 1 M (MCZC), 1M (MZSP), 1 F (SEMC), 4 M, 15 F (USNM); San Felipe, 1 M, $1 \mathrm{~F}$ (OSUC), 1 M, 2 F (USNM); Santiago, 1 F (IBSP). Baja California Sur: $23 \mathrm{Km} \mathrm{W} \mathrm{La} \mathrm{Paz,} 1$ F (FSCA), 2 F (USNM); Canyon-Stream, 5-7 1/ $2 \mathrm{Km}$ E La Burrera, 580-640 m, 1 F (FSCA); Bahia Concepcion, Playa El Coyote, $1 \mathrm{M}$ (FSCA); $4 \mathrm{Km} \mathrm{N}$ Los Barriles, $1 \mathrm{M}$ (FSCA); $8.7 \mathrm{mi} \mathrm{S}$ Mulege, $1 \mathrm{M}$ (TAMU); El Pescadero, $1 \mathrm{M}$ (TAMU14.1 mi W on Ramal a Los Naranjos, 1 M (MZSP retained TAMU), 1 M, 3 F (TAMU); 16.4 mi W on Ramal a Los Naranjos, 1 M, 2 F (TAMU); S. Rosalia, 1 F (MZSP retained USNM); San Jose del Cabo, 1 M (AMNH), 1 F (MZSP), 1 F (NHMW), 1 M, 3 F (USNM); Betw. San Jose del Cabo and Triunfo, 2 M, 2 F (AMNH); 1.5 mi W San Pedro, 1 F (FSCA); 1.5 mi S San Pedro, Km 163, 1 M (FSCA); 32 Km E Todos Santos, 1 F (USNM); 9-13 mi E hwy 19, E of Todos Santos, 1 M (TAMU); Isla San Jose, Punta NW Golfo California, $2 \mathrm{~F}$ (UNAM). Localities not found: $5 \mathrm{mi}$ E La Burrera, Sierra de la Victoria Mts, $1800 \mathrm{ft}, 1 \mathrm{M}$ (OSUC); $2 \mathrm{mi} \mathrm{N}$ Las Cuevas $1 \mathrm{~F}$ (FSCA), $9.6 \mathrm{mi} \mathrm{W}$ hwy 1 on Ramal Sn Antonio de la Sierra, 1 F (TAMU). Durango: 3 mi SE San Bartolo, 1 F (MCZC), 1 M (MZSP). Yucatan: Isla del Carmen, Puerto Batlandra, 1 F (dissected) (MSZP, retained UNAM), Puerto la Lancha, $2 \mathrm{M}, 1 \mathrm{~F}$ (UNAM), $1 \mathrm{M}$ (MZSP, retained UNAM).Through C. V. Riley, 1 M (USNM).

Remarks. Chalcolepidius rubripennis is easily recognized by wine-red or orange coloration of elytral integument, antennae of male strongly serrate, lateral margins of pronotum rounded, scutellum strongly declivous, anterior tibiae of male bearing short cilia and parameres of aedeagus cleft laterally.

It is the sister group of chalcantheus * (Fig. 671).

Distribution. It is recorded from United States of America (California) and Mexico (Baja California, Baja California Sur, Durango, Yucatan) (Fig. 677)

Chalcolepidius rugatus Candèze, 1857

(Figs. 69-72, 144, 208, 260, 298, 342, 371, 410, 447, 483, 521, 565, $611,656,685)$

Chalcolepidius rugatus Candèze, 1857: 263, 280; Gemminger \& Harold, 1869: 1503 (Cat.); Candèze, 1874: 167; 1886: 72; 1891: 39 (Cat.); Champion, 1894: 274, 276, t.11, f. 20; Schenkling, 1925: 57 (Cat.); Blackwelder, 1944: 283 (Cat.). Type locality: "Mexico".

Chalcolepidius pistorius Candèze, 1890: 184; 1891: 39 (Cat.); Champion, 1894: 276, 277 (Syn.). Syntypes: 4 females: "Coll. I. R. Sc. N. B., Honduras, ex Candèze; Chalcolepidius pistorius Cand. dét. E. Candèze; Sec. S. Schenkling, Col. Cat. Junk, xi.1925-1927 p. 58, Chalcolepidius rugatus v. pistorius Cand.; syntype". One specimen also bears : "n. sp. 1890 pistoreus Cdz. Honduras". In the smallest specimen was added: "to small to be part of syntype series; C.M.F.von Hayek det. 1979. Published length $40 \mathrm{~mm} "$ (ISNB) (examined).

Chalcolepidius amictus Casey, 1907: 33; Schenkling, 1925: 54 (Cat.); Blackwelder, 1944: 282 (Cat.). Syntype female: "Hond.; Casey bequest 1925; Type USNM 48459; amictus Csy” (USNM) (examined). Syn. nov.

CANDÈze (1857) described C. rugatus (from Mexico) and commented that, at first sight, this species looks like a variation of C. eschscholtzi, but it is easily separated by the pubescence coloration. According to the original description, this species is clothed, dorsally with white pubescence, with the sides of pronotum and elytra marginated by yellow, and ventrally, with brown pubescence.

The type of C. rugatus should be in the BMNH collection but, according to HAYEK (personal communication), it was not possible to identify it with any degree of certainty. She observed that the female in BMNH bearing Janson's label with the word "Type", has the margins of the prothorax and elytra dark redbrown, whereas CANDĖze (l.c.) stated that they are yellow ("jaune"); another female, with yellow bands bearing Candèze's determination label has Verapaz [Guatemala] as locality. These data let her to suppose that Candèze made a mistake concerning the locality because in the revision of the monograph (1874) he recorded the localities "Chiapas, Tabasco [both Mexico] and Guatemala" and in the Catalogue (1891), only "Guatemala".

CANDĖZE (1890) described C. pistorius (from Honduras) and commented that this species is similar to C. rugatus, differing only by uniform dorsal white pubescence coloration.

CHAMPION (1894) considered C. pistorius as a variation of C. rugatus. He commented that in a long series of specimens it is not possible to separate C. pistorius from C. rugatus. According to him, in freshly emerged specimens the whole of the upper surface is clothed with white setae. He observed specimens like the typical $C$. rugatus, with marginal stripe fulvous or luteous, and specimens with marginal stripes tawnybrown; ventrally all specimens were clothed with chocolatebrown pubescence. I agree with CHAMPION (l.c.); after studying a large series of specimens, I observed lateral stripes of pronotum and elytra of varied sizes and clothed with pubescence varying from yellowish to ferruginous.

CASEY (1907) described C. amictus (from Honduras), clothed dorsally with uniform white and ventrally with brown pubescence. He commented, "amictus is related to pistorius, being very much more narrowly oval”. I studied one syntype female of this species and concluded that $C$. amictus is conspecific with $C$. rugatus and that the differences observed by Casey are into the range intraspecific variations of $C$. rugatus.

Length: 36-42 mm. Wide, elliptical, arched body. Integument black, clothed with scale-like setae, white dorsally and ferruginous ventrally; several specimens with lateral stripes of pronotum, of varied size (never reaching hind angles, 2/3 anterior not reaching lateral margins) and lateral stripes of elytra 3 or 4 interstices wide (not including elytral epipleura), clothed with pubescence from yellowish to ferruginous (Figs. 69-72).

Frons pentagonal, not carinate, strongly concave medioanteriorly; fore angles raised. Antennae (Fig. 144) serrate in both sexes; $3^{\text {rd }}$ segment triangular-elongate, as long as $4^{\text {th }}$ (shorter in syntype of C. amictus). Pronotum (Fig. 208) longer than wide, wider at hind angles, narrowed anteriad from hind angles base; slightly convex and flat; rugose; micropunctate with very coarse and irregular punctuation forming wrinkles; anterior margin slightly sinuous at middle; lateral margins raised, forming moderately wide smooth edge on basal 2/3; grooved innerly edge; hind angles wide, slightly divergent with truncate apex, raised laterally forming edge continuous with that of lateral margins; median basal tubercle indistinct or very flattened, triangular, continuous with longitudinal median ridge, not reaching anterior margin; posterior margin prominent and strongly notched at middle. Hypomera concave near lateral margins; micropunctate with moderate coarse and sparse 
umbilicate punctuation; laterointernal margin raised forming wall of anterior channel. Notosternal sutures strongly sinuous. Prosternum micropunctate, punctuation denser near sutures; longitudinal median region almost smooth; strongly convex, flattened longitudinal medially, concave near sutures. Prosternal lobe sparsely micropunctate, wide, emarginated laterally with fore angles slightly rounded. Prosternal spine flattened laterally. Scutellum (Fig. 260) strongly folded with horizontal basal area subtrapezoidal, notched anterior- and posteriorly, grooved longitudinal medially. Borders of mesosternal cavity (Fig. 298) wide and horizontal on basal $2 / 3$ and vertical on distal $1 / 3$, forming L-shaped profile. Meso-metasternal suture weak. First visible sternite prominent laterally, fits in lateral groove of elytra. Anterior and median tibiae and last tarsal segment of all legs bearing fringe of long cilia. Elytra strongly convex at middle; striae grooved; interstices convex and unequal, especially near apex; $2^{\text {nd }}$ interstice forming basal flattened and prominent tubercle; apex truncate.

Male genital segments and aedeagus. Sternite VIII (Fig. 342) transverse, narrowed apicad, narrower on distal fourth; translucent in large median area and paired small rounded basal spots and narrow short lateral bands. Tergite IX (Fig. 371) transverse, densely punctuate, narrowed apicad, with anterior margin rounded; one lateral moderately long seta and many laterodistal tiny setae. Aedeagus (Fig. 410): median lobe (Fig. 447 ) wide, gradually narrowed to toothed area, $0.51-0.53$ times the aedeagus length, bearing 7-8 lateral small teeth; lateral cleft of parameres (Fig. 483) wide with apex prominent ventrally.

Female genital segments and genitalia. Tergite VIII (Fig. 521) transverse with anterior margin rounded; strongly notched at base; translucent in transverse basal band and paired lateroanterior bands. Sternite VIII (Fig. 565) 0.55-0.59 times spiculum gastrale length; anterior margin wide- and moderately deep at middle. Genitalia: sclerotized rings of openings of colleterial glands (Fig. 656) bearing 7; 8; 34; 44 teeth; bursa copulatrix (Fig. 611) with wide longitudinal median band with carinae and spines and paired large lateral rounded spiny areas.

Material examined. MEXICO. 2 F (USNM). Veracruz: Catemaco, 1 M, 17 F (FSCA). Michoacán: La Piedad, 1 F (USNM). Oaxaca: Oaxaca, ex-coll. Fleutiaux, $1 \mathrm{~F}$ (MNHN). Tabasco: Teapa, $1 \mathrm{~F}$ (AMNH), $1 \mathrm{~F}$ (USNM). Yucatan: $2 \mathrm{~F}$ (MNHN), $1 \mathrm{~F}$ (USNM); ex-coll. Fleutiaux, $1 \mathrm{~F}$ (MNHN); 3 Km E Chitzen Itza, 1 F (FSCA); Colonia Yucatan, 13 F (AMNH); Nuevo X-Can, 1 F (PCCV), 2 F (SRGI), 1 F (USNM); Pisté, 1 F (MZSP); Temax, 1 F (NHMW), 1 F (USNM); X-Can, 2 F (MZSP), 2 F (PCCV), 1 M (USNM). Quintana Roo: 2 M, 4 F (IMLA); Cancun [Punta], 1 F (FSCA); Carrillo, Puerto, 1 F (AMNH); 18 Km N Carrillo Puerto, 1 F (FSCA); Hwy 295, $11 \mathrm{Km} \mathrm{N}$ Carrillo Puerto, $1 \mathrm{~F}$ (USNM); $17 \mathrm{Km} \mathrm{N}$ Felipe Carrillo Puerto, 2 F (FSCA), 1 F (MZSP); $10 \mathrm{Km}$ N Cobá, 1 F (JEWC); Solferino, $1 \mathrm{~F}$ (dissected) (MZSP), $1 \mathrm{~F}$ (USNM); Tumbes (locality not found), 4 F (AMNH). Chiapas: 1 F (IMLA), 2 F (MNHN); Bachajón, 1 F (SRGI); Chorreaduro, 2 F (USNM); La Revancha, 1 F (PCCV); Oxchuc, 1 F (USNM); Ruins at Palenque, 4 F (AMNH); San Quintin, 1 F (MZSP retained USNM), 12 F (USNM); San Jeronimo, 1 F (IMLA). BELIZE. 2 F (AMNH), 1 M, 1 F (MNHN), 2 F (NHMW); ex-coll. Fleutiaux, $1 \mathrm{~F}$ (MNHN); M-tee Dist. (locality not found) $1 \mathrm{~F}$ (MCZC). Toledo: Nim Li Punit Ruins (locality not found), 1 F (MZSP retained USNM); Punta Gorda, 1 F (AMNH); Rio Hondo, 1 F (AMNH). GUATEMALA. $5 \mathrm{~F}$ (MNHN), $1 \mathrm{M}$ (dissected), $1 \mathrm{~F}$ (USNM), ex-coll. Fleutiaux, 4 F (MNHN). Alta Verapaz: Panzos, ex-coll. Fleutiaux, 2 F
(MNHN); Polochic River, 3 F (USNM). Copán: Quiriguá [River], $1 \mathrm{~F}$ (USNM). Guatemala: env. Guatemala, 2 F (MNHN); Piedras Negras, 2 F (USNM). Petén: Sayaaxche, 1 M (dissected), 1 F (MZSP); Tikál NP, 1 F (FSCA); Uaxactún, 1 F (USNM). Izabal: Cayuga, 1 M, 1 F (USNM). HONDURAS. 1 F (MCZC), 1 F (NHMW), 2 F (USNM), ex-coll. Sallé, ex-coll. Fleutiaux, 2 M, 4 F (MNHN) [identified as] Ch. rugatus Cnd. St., 1 F (ZMHB), 67158 Coll. Nonfried, Hist. Coll. nr 67158 (1ex) Chalcolepidius Honduras $1 \mathrm{~F}$ (ZMHB), amictus Casey Canad. Ent. 1907 p. 33, 1 F (ZMHB), ex-coll. Nonfried, 3 F (ZMHB). Atlántida: La Ceiba (found under bark of fallen painty decayed), $1 \mathrm{~F}$ (USNM); La Ceiba, $1 \mathrm{M}$ (AMNH), 2 F (USNM); 12 Km SW La Ceiba, 1 F (FSCA); Tela (Lancetilla), Jardin Botanico, $1 \mathrm{~F}$ (FSCA). Cortés: S. Pedro Sula, $5 \mathrm{~F}$ (MNHN), $1 \mathrm{~F}$ (MZSP), ex-coll. Fleutiaux, $1 \mathrm{M}, 7 \mathrm{~F}$ (MNHN), C. strigatus Lec. 30, 1 F (ZMHB), ex-coll. G. Hauser, 1 F (ZMHB), ex-coll. Fruhstorfer, Chalcolepidius strigatus, 2 F (MNHN). Francisco Morazán: Zamorano, 1 F (MZSP). Olancho: Pq. Nac. La Muralla, 1 F (FSCA), 2 F (1 dissected) (MZSP), 4 F (JEWC). Santa Bárbara: Lago Yojoa-iskov, 1 M (ZMUC); Vic. L. Yojoa, Pena Blanca, 1 F (FSCA). Yoro: Olanchito Mon. 1 F (MNMS). NEW GRANADA: $1 \mathrm{~F}$ (USNM). Zacapa: La Union, $\pm 850 \mathrm{~m}$, $1 \mathrm{~F}$ (SRGI).

Remarks. Chalcolepidius rugatus is characterized especially by wide and arched body, clothed with white pubescence dorsally and ferruginous ventrally, scutellum folded, tibiae of male bearing fringe of long cilia and parameres of aedeagus cleft laterally. It presents a wide range of variation on dorsal pubescence coloration, observed only when a large series is examined. In one extremity are the specimens totally white, that according to CHAMPION (1894) are freshly emerged, and at other, specimens with lateral stripes on pronotum and elytra, ferruginous. The intermediary shapes starts with lateral stripes of pronotum very narrow, weak and yellowish, followed by specimens with stripes gradually larger and darker until becoming ferruginous, as ventrally. Dirty or naked specimens can be confused with $C$. bomplandii, but the ventral pubescence is ferruginous in C. rugatus.

Comparing the syntype of $C$. amictus with other specimens clothed with white pubescence, it was verified that it presents narrower and more parallel body, $3^{\text {rd }}$ antennal segment shorter, pronotum longer with longitudinal rugosities poorly developed and hind angles of pronotum very wide with truncate apices and distal elliptical grooves.

Comparing the genitalia of the specimens of the extremities of the coloration range (white totally/white with ferruginous stripes) it was verified that in those specimens with brown stripes: the median lobe of aedeagus is narrower behind lateral teeth, the subapical region of lateral cleft of parameres is more strongly constricted and the sternite VIII of female has longer darker setae and slightly shorter spiculum gastrale. The number of teeth of the median lobe of aedeagus and those of sclerotized rings of openings of colleterial glands are respectively, 8,8 and 44 in totally white and 7, 7 and 34 in striped specimens. The genitalia of specimens into the intermediary range of pubescence coloration were not analyzed.

\section{C. rugatus belongs to fryi* group (Fig. 671).}

Distribution. It is recorded from Mexico (Veracruz, Michoacán, Oaxaca, Tabasco, Yucatan, Quintana Roo, Chiapas) Belize, Guatemala and Honduras (Fig. 685). I examined also one specimen from Puerto Rico (MCZC) and one from Colombia (MNHN) not included in the material examined because these localities require confirmation. 


\section{Chalcolepidius serricornis sp. nov.}

(Figs.73,145,209,261,299,343,372,411,522,566,613,614,657,675)

Type material. Holotype male: "Mexico Veracruz Los Tuxtlas 22-III86 C. Mayoiga; Colección del Instituto de Biologia UNAM. México, D. F."(UNAM). Paratypes: 2 males, 3 females. Males: "Mexico: State of Veracruz, Catemaco, 5-VIII-1977 P. Hubbel Collection" (FSCA); "Mexico. Veracruz Los Tuxtlas 6-IV-87 C. Mayoiga; Colleción del Instituto de Biologia UNAM. México, D.F.“ (dissected) (MZSP, retained UNAM). Females: "F; Valle Nacional Oaxaca 1200 m Mexique- Octobre 1987 Thierry Porion leg; collectio Dr. P. Cate"(PCCV); "Mexico. Soteapan (Veracruz) $500 \mathrm{~m}$ aout $1989 \mathrm{~T}$. Porion cedit" (dissected) (MZSP retained SRGI).

Holotype. Length: $35 \mathrm{~mm}$. Integument black clothed dorsally and ventrally with metallic scale-like setae yellowish-green; lateral margins of pronotum and elytra iridescent of red; setae more concentrate laterally on pronotum forming band-like of same color; antennae clothed with short metallic blue setae except three first segments, green; tarsi green (Fig. 73).

Frons trapezoidal on anterior third, small-punctuate with slightly coarse punctuation, moderately dense, concave medioanteriorly in triangular area; nasal plate slightly declivous, dense- and coarsely punctuate with lateral angles prominent. Antennae (Fig. 145) long, strongly serrate, surpassing hind margin of procoxae in one segment; $3^{\text {rd }}$ segment transverse with spiniform appendix. Pronotum (Fig. 209) longer than wide, subrectangular, narrowed apicad from hind angles apex; anterior angles prominent and rounded; lateral margins forming raised narrow bright and small punctuate edge, almost reaching apex; longitudinal groove parallel edge; convexity moderate starting internally groove and decreasing basad; small-punctuate with slightly coarser moderately dense punctuation, sparser near disc; hind angles backward with sharpened apex, raised laterally, forming edge continuous with that of lateral margins; median basal tubercle flat, elongate, concave at middle; posterior margin prominent and slightly notched at middle. Hypomera concave with lateral carina from pronotal edge; narrow raised band parallel notosternal sutures; anterior channel absent. Notosternal sutures slightly sinuous. Prosternum moderately convex from sutures, flattened near procoxae; small-punctuate with slightly coarse punctures, more concentrate near sutures. Prosternal lobe transverse with rounded angles; slightly notched at middle; punctuation small, coarser and denser than prosternum. Scutellum (Fig. 261) strongly declivous, anterior half narrow and vertical; horizontal half wider, elliptical, notched anteriorly bearing two rounded impressions; anterior margin of horizontal area prominent, not carinate. Mesosternal cavity sub-elliptical with borders (Fig. 299) thick on basal 2/3 and moderately declivous on distal $1 / 3$, forming semicircular profile. First visible sternite normal, not prominent. Tibiae of male bearing irregular row of spines. Striae grooved, marked by coarser punctures; interstices unequal, micropunctate; $2^{\text {nd }}$ and $3^{\text {rd }}$ raised forming tubercle near base; apices conjointly rounded.

Male genital segments and aedeagus (paratype, Mexico, Veracruz Los Tuxtlas). Tergite VIII slightly wider than long, slightly narrowed apicad; densely setous; anterior margin rounded; basal margin notched. Sternite VIII (Fig. 343) transverse, prominent medioanteriorly; translucent with four melanized areas: two lateral bands and one spot apical, and one irregular, basal. Sternite IX melanized at distal half; melanized area setous. Tergite IX (Fig. 372) wider than long, slightly narrowed apicad; densely punctuate; anterior margin moderately notched; moderately long setae lateroanteriorly. Aedeagus (Fig. 411): apex of parameres spearhead-like; median lobe slightly narrowed apicad, constricted near apex.

Female genital segments and genitalia (paratype, Mexico, Soteapan, Veracruz, $500 \mathrm{~m}$ ). Tergite VIII (Fig. 522) transverse; anterior margin slightly prominent at middle and slightly rounded; basal margin strongly notched; translucent in median basal area (constricted at middle) and marginal narrow band (interrupted at base and at middle). Sternite VIII (Fig. 566) 0.58 times spiculum gastrale length; anterior margin narrow- and deeply notched; lateral melanized areas clearer on external third. Genitalia (Fig. 613): sclerotized pieces of openings of colleterial glands (Fig. 657) C-shaped with small teeth; bursa copulatrix (Figs. 613,614) with longitudinal median band with carinae and spines dispersed in both sides; two spermathecae.

Remarks. The male paratypes of Chalcolepidius serricornis have 29 and $35 \mathrm{~mm}$. The smaller is from the same locality of holotype, clothed with yellowish-green setae with weak red iridescence only at base and in a sutural band of elytron and hypomeron. The larger specimen is partially glabrous, clothed with bluish-green setae dorsally and yellowish-green with red iridescence in a few areas ventrally.

The female paratypes are larger, $38-43 \mathrm{~mm}$ long. That from the same locality of the holotype is clothed with green pubescence in both sides, dorsally with weak bright yellowish iridescent setae, more concentrate laterally on pronotum forming a lateral band-like; elytra with interstices VIII and IX clothed with dull yellowish-white setae. The other two are partially glabrous dorsally, with yellowish-green setae dorsally and ventrally, lateral stripes of pronotum yellowish-white, not reaching anterior and posterior margins, and interstices VII-IX or only VII and IX clothed with yellowish-white setae.

The females are more robust and present shorter and serrate antennae; the tibial spines are also shorter.

C. serricornis is characterized especially by the general pubescence green, usually without lateral stripes, antennae of male strongly serrate, scutellum strongly declivous, tibiae of male spiny and apex of parameres spearhead-like.

C. serricornis belongs to serricornis++ group; it forms, together with $C$. ferratuvittatus, C. albiventris and C. exulatus, the serricornis + group (Fig. 671).

Distribution. It is recorded from Mexico (Federal District, Oaxaca, Veracruz) (Fig. 675).

Etymology. The epithet is derived from one of the latin words for saw serra, related to antennal shape of male.

Chalcolepidius silbermanni Chevrolat, 1835

(Figs. 75, 145, 210, 262, 300, 344, 373, 412, 448, 484, 523, 567, $612,658,683)$ 
Chalcolepidius silbermanni Chevrolat, 1835: 197; Erichson, 1841: 86; Candèze, 1857: 275; Gemminger \& Harold, 1869: 1503 (Cat.); Candèze, 1886: 72; 1891: 38 (Cat.); Champion, 1894: 274, 280; 1897: 282; Schenkling, 1925: 57 (Cat.); Fleutiaux, 1926: 108 (Cat.); Blackwelder, 1944: 283 (Cat.). Syntypes: 2 females: “Type; Collection Chevrolat; silbermanni type Chevrolat col. Mex. 1835 no 97 collection Fleutiaux"; "Collection Fleutiaux; silbermanni Chevr. Type Germ. vidit. 1948 typique Cand. Mon. collection Fleutiaux" (MNHN) (examined).

Chalcolepidius aequinoctialis Castelnau, 1836: 13; Gemminger, 1869: 1502 (Cat.); Candèze, 1874: 164, 165 (Syn.); Schenkling, 1925: 58 (Cat.); Fleutiaux, 1926: 108 (Cat.); Blackwelder, 1944: 283 (Cat.). Type locality: "Mexico \& Columbia".

Chalcolepidius sericeus Erichson, 1841: 83; Candèze, 1857: 275 (Syn.); Schenkling, 1925: 57 (Cat.); Fleutiaux, 1926: 108 (Cat.); Blackwelder, 1944: 283 (Cat.). Syntypes: 6 males, 5 females. Males: "16220; Silbermanni Chevr. Cand.* sericeus Er.* Columb Otto; Hist. coll. (Coleoptera) nr 16220 (1 ex) Chalc. silbermanni Chev. Columb., Mexico. Zool. Mus. ZMHB; Syntype Chalcolepidius sericeus Erich. C. M. F. von Hayek, 1980". Females: “16220; Hist. coll. (Coleoptera) nr 16220 (2 ex) [each specimen with a number from 2-6] Chalcolepidius silbermanni Chevr. Columb. Mexico. Zool. Mus. Berlin; Syntype Chalcolepidius sericeus Erich. CMF von Hayek 1980 (ZMHB) (examined).

Chalcolepidius sulciger Dejean, 1837: 100 (Cat.) (nomen nudum); Champion, 1894: 280 (Syn.)

According to CANDĖze (1857), C. silbermanni is close to $C$. porcatus var. virens by body shape, but it is distinguished by silkish aspect of the coloration, hind angles of pronotum not divergent and interstices unequal. He studied one specimen of C. sericeus Erichson, from Museum of Berlin, and one of $C$. silbermanni Chevrolat, and concluded that these two species are conspecific. Treating of C. gossipiatus, CANDEZÉ (1857) stated "Le C. aequinoctialis de M. Laporte de Castelnau (Rev. de Silberm. 1836, IV, p. 13) n'est probablement autre que cette...". In 1874 he changed his mind and considered $C$. aequinoctialis as a synonym of $C$. silbermanni.

Champion (1894) considered, besides $C$. sericeus, also $C$. sulciger Dejean (nomen nudum) as synonym of C. silbermanni. According to him this is the commonest species in Central America, extending northwards to Durango and reaching an altitude of 8000 feet in some parts of Mexico. He verified that in one specimen from Juquila the setae on the upper and under surfaces are violet.

Length: 27-39 mm. Wide, arched body. Integument black, clothed dorsally and ventrally with dense, short, metallic scalelike setae, olive-brown, brownish or sometimes grayish with silky and bright appearance; antennae clothed with bluish except three first segments of same colour as general pubescence (Fig. 75).

Frons not carinate, moderately declivous. Antennae (Fig. 146) serrate in both sexes; $3^{\text {rd }}$ segment triangular-elongate, shorter than $4^{\text {th }}$. Pronotum (Fig. 210) longer than wide, wider at hind angles, gradually narrowed anteriad from hind angles apex; moderately convex anteriorly, flat, wrinkled at middle; micropunctate with coarse irregular punctuation giving rugose appearance to median region; anterior margin sinuous at middle; lateral margins raised laterally forming narrow smooth edge almost reaching apex; hind angles wide, backward, raised laterally forming edge continuous with that of lateral margins; median basal tubercle flat, triangular, continuous with weak longitudinal median ridge, not reaching anterior margin; posterior margin prominent and strongly notched at middle. Hypomera concave near lateral margins; laterointernal margin raised forming wall of anterior channel. Notosternal sutures strongly sinuous. Prosternum micropunctate, punctuation coarser and denser near sutures; longitudinal median region almost smooth, strongly convex, flattened longitudinal medially, concave near sutures. Prosternal lobe wide, punctuation small and sparse; emarginated laterally with fore angles slightly rounded. Prosternal spine flattened laterally. Scutellum (Fig. 262) strongly folded with horizontal basal area subtrapezoidal, notched anteriorly and posteriorly, grooved on anterior half. Borders of mesosternal cavity (Fig. 300) wide and horizontal on basal $3 / 4$ and vertical on distal $1 / 4$, forming L-shaped profile. Meso-metasternal suture indistinct. First visible sternite prominent laterally, fits in lateral groove of elytra. Anterior and median tibiae and last tarsal segment of all legs of male bearing fringe of long cilia. Striae marked by coarse and sparse punctures; interstices convex, unequal and costiform; $2^{\text {nd }}$ interstice more raised and prominent at base.

Male genital segments and aedeagus. Sternite VIII (Fig. 344) transverse, narrowed apicad, strongly narrowed on distal third; translucent in median large area, laterally, almost reaching base, and paired very small basal spots and narrow lateral bands. Tergite IX (Fig. 373) densely punctuate, transverse, narrowed anteriad with anterior margin rounded; tiny laterodistal setae. Aedeagus (Fig. 412): median lobe (Fig. 448) 0.48 times the aedeagus length, strongly narrowed at middle, bearing 5,5 ; 7, 8 lateral teeth; lateral cleft of parameres (Fig. 484) narrowed to subapical region with apex widened and upwards.

Female genital segments and genitalia. Tergite VIII (Fig. 523) transverse with anterior margin rounded; translucent in large triangular basal area. Sternite VIII (Fig. 567) 0.63 times spiculum gastrale length; anterior margin moderately wide and deeply notched. Genitalia: sclerotized rings of openings of colleterial glands (Fig. 658) opened frontally, bearing 32, 33 teeth with respectively one and four teeth bi- or tricuspid; bursa copulatrix (Fig. 612) with elongate longitudinal median band with carinae and spines and paired lateral rounded spiny areas.

Material examined. MEXICO. 2 M, 12 F (NHMW), 2 F (ZMUC), ex-coll. Sallé, ex-coll. Fleutiaux, 3 F (MNHN), Hark, Hist. coll. nr 16220, 1 F (ZMHB); Côte Occidental, 1 M, 15 F (MNHN). Sinaloa: 1 F (FSCA), 2 F (USNM); Tres Reyes, 1 F (USNM). Durango: Durango, ex-coll. Fleutiaux, $1 \mathrm{~F}(\mathrm{MNHN})$; from Durango to Pacific, $1 \mathrm{~F}$ (MNHN). Nayarit: vic. [vicinity] Compostela, $1 \mathrm{~F}$ (FSCA). Jalisco: $20 \mathrm{Km}$ El Tuito, $2 \mathrm{~F}$ (JEWC); Est. De Biologia Chamela, 1 F (MZSP, retained UNAM). San Luis de Potosi: "El Albano", 1 F (UNAM); San Judas, 6 F (AMNH); Tolosa (locality not found), $28 \mathrm{~F}$ (AMNH). Tamaulipas: Bocatoma WS, 7 Km SSE Gomes Farias, 3 F (FSCA), 5 F (EGRC); Boca Toma area 2 F (JEWC); $55 \mathrm{Km} \mathrm{S}$ Ciudad Victoria, $1 \mathrm{~F}$ (FSCA); $80 \mathrm{Km} \mathrm{S}$ Ciudad Victoria, Ruta 85, ca La Gloria, 2 F (FSCA); Est. Biol. Los Cedros, Gomez Farias, 300 m, 1 F (TAMU). Veracruz: 3 F (MNHN); Almolonga, 1 F (USNM); Atoayc, 1 F (USNM); Catemaco Lake, Road, 1 F (FSCA), 2 F (SRGI), Coyame, $1 \mathrm{~F}$ (USNM), Dos Amantes, $1 \mathrm{~F}$ (AMNH), $1 \mathrm{~F}$ (MNMS), $1 \mathrm{~F}$ (USNM); Chinameca, 1 F (FSCA); Córdoba, 3 F (AMNH), 4 F (NHMW), 1 F (USNM), Hoege, BCA Col. III (1), 1 F (MNHN); Reg. Cordoba, 1 F 
(MNHN); Cotaxtla, 1 M (USNM); Laguna Montebello, 1 F (FSCA); Pajapan, 1 F (SRGI); Rég. d'Orizaba, 1 M, 2 F (MNHN); Palo Gacho, 1 F (USNM); Presidio, 3 F (IBSP); Los Tuxtlas, 1 M (MZSP, retained UNAM), 1 F (MZSP), 1 F (UNAM), vic. Balzapote, $1 \mathrm{~F}$ (FSCA), Montepio, 1 F (UNAM); Est. Biol. Los Tuxtlas, 1 F (UNAM); Pacific Slope Cordilleras, 800-1000 m, 1 F (USNM); Pl. [Playa] Escondida (locality not found), $1 \mathrm{M}$ (USNM); Veracruz, $1 \mathrm{~F}$ (UNAM). Michoacán: Aquila, $1 \mathrm{~F}$ (MZSP). Guerrero: $43.7 \mathrm{Km}$ NW Ixtapa, $2 \mathrm{~F}$ (FSCA); $51 \mathrm{Km}$ NW Ixtapa, 1 F (FSCA). Oaxaca: 6 F (MNHN); Juquila, ex-coll. Sallé, ex-coll. Fleutiaux, 2 F (MNHN); Palomares (Finca San Carlos), 1 F (IBSP); Portillo del Ravo (locality not found), 1 F (UNAM); Temascal, $1 \mathrm{~F}$ (USNM). Tabasco: Jalapa, $6 \mathrm{~F}$ (AMNH), $1 \mathrm{~F}$ (NHMW). Yucatan: Colonia, $19 \mathrm{~F}$ (AMNH); $3 \mathrm{Km} \mathrm{E}$. Xcalacoop (locality not found), $1 \mathrm{M}$ (FSCA), 4 Km SW Espita, 1 F (MZSP), 1 F (FSCA); Mérida, 1 F (IBSP), $2 \mathrm{~F}$ (NHMW); Temax, $1 \mathrm{~F}$ (MNHN), $1 \mathrm{~F}$ (USNM); Nuevo X-Can, $1 \mathrm{~F}$ (PCCV); X-Can, 2 F, 1M (dissected, MZSP), 4 F (PCCV), 2 F (USNM). Quintana Roo: $3 \mathrm{~F}$ (IMLA); $17 \mathrm{Km} \mathrm{N}$ Felipe Carrillo Puerto, $1 \mathrm{M}, 9 \mathrm{~F}$ (FSCA); 10.9 Km S Playa del Carmen, 1 M, 1 F (FSCA); Km 146 Chetumal, $1 \mathrm{~F}$ (UNAM). Chiapas: $2 \mathrm{~F}$ (MNHN), ex-coll. Fleutiaux, $2 \mathrm{~F}$ (MNHN); Chorreadura [Cerro], 1 F (USNM); San Jeronimo, 3 F (1 dissected, MZSP), 1 F (USNM); San Quintin, 2 F (FSCA), 5 F (USNM). BELIZE. 1 F (AMNH). Toledo: Punta Gorda, 7 F (AMNH), 1 F (USNM). GUATEMALA. 2 F (ZMUC), ex-coll. Fleutiaux, 7 F (MNHN). Alta Verapaz: Chacón, 1 F (MNHN), 1 F (NHMW), 2 F (USNM); Panzos, 3 F (MNHN). Guatemala: env. de Guatemala, 3 F (MNHN). El Peten: Sayaaxche, 2 F (MZSP); localities not found: Secanquim, 1 M (USNM); Xepo Capa, 1 F (USNM). Retalhuleu: El Reposo, 800 ft., BCA Col. III (1), 1 F (MNHN); San Sebastian, 1 F (USNM); El Cantro (locality not found), $1 \mathrm{~F}$ (AMNH). HONDURAS. $1 \mathrm{M}$ (MNHN), $1 \mathrm{~F}$ (USNM). Atlántida: La Ceiba, 2 F (FSCA), 3 F (USNM). Cortés: San Pedro Sula, 1 F (NHMW), ex-coll. Fleutiaux, 2 F (MNHN). Francisco Morazán: El Espinito 3250', 1 F (FSCA). NICARAGUA. 2 F (AMNH), ex-coll. Sallé, ex-coll. Fleutiaux, $1 \mathrm{~F}$ (MNHN). Managua: Managua, 1 F (USNM). EL SALVADOR. San Salvador, 1 F (NHMW); Bath St Thos., 2 F (USNM). COSTA RICA. 4 F (USNM); Piedras Negras, ex-coll. Fleutiaux, $1 \mathrm{~F}$ (MNHN); Chitaria, $1 \mathrm{~F}$ (USNM). Cartago: Turrialba, $1 \mathrm{M}$ (MNHN). Guanacaste: 6 mi W Cañas, Taboga, 1 F (USNM). Limón: Guápiles, 250300 m, 1 F (USNM); Samara, 1 F (PCCV). Puntarenas: San Mateo, 1 F (MZSP retained USNM), $3 \mathrm{~F}$ (USNM), ex-coll. Fleutiaux, $1 \mathrm{~F}$ (MNHN). San Jose: San Jose, $1 \mathrm{M}$ (AMNH). PANAMA. Ex-coll. Fleutiaux, $1 \mathrm{~F}$ (MNHN). Canal Zone: Ancon, 1 M, 2 F (USNM); Bohio, 1 F (USNM); Fort Kobbe, $1 \mathrm{~F}$ (TAMU); Gamboa, $1 \mathrm{~F}$ (USNM); $5 \mathrm{mi} \mathrm{W}$ Paraiso, $1 \mathrm{~F}$ (EGRC); Tabernilla, $1 \mathrm{~F}$ (USNM). Chiriqui: $1 \mathrm{M}$ (MZSP); vic. [vicinity] Caldera, 1 F (JEWC); vic. [vicinity] Hornito, 1 F (FSCA); Pto Armuelles, 1 F (FSCA). Coclé: Altos de Campana, 1 F (FSCA). Colón: $4.5 \mathrm{Km} \mathrm{E}$ Palenque, 1 F (JEWC). Panama: Cerro Campana, 1000', 1 F (FSCA); 11 Km N El Llano, 350 m., 2 M, 1 F (FSCA); $2.5 \mathrm{Km} \mathrm{W}$ Ipeti, $3 \mathrm{M}, 2 \mathrm{~F}$ (FSCA), 1 F (MZSP); Cerro Campana road 1930', 1 M, 1 F (FSCA); Panama, 2 F (USNM); Taboga, 1 F (ZMUC), 1 F (USNM); vic El Llano, $1 \mathrm{~F}$ (MZSP); Bayano Dist., 2,5 Km W Ipeti, 2 M, 2 F (MZSP), 1 M, 6 F (JEWC), 2 Km E Ipeti, $1 \mathrm{~F}$ (FSCA), $55 \mathrm{Km} \mathrm{E}$ Chepo, $1 \mathrm{~F}$ (FSCA), $46 \mathrm{Km}$ E Chepo, $1 \mathrm{~F}$ (FSCA); La Campana, $1 \mathrm{M}$ (MZSP retained USNM), $3 \mathrm{M}$, $8 \mathrm{~F}$ (USNM); El Cermeno, $1 \mathrm{~F}$ (USNM). Veraguas: Hist. coll. nr 16220, $1 \mathrm{~F}$ (ZMHB). TRINIDAD. $1 \mathrm{~F}$ (USNM). VENEZUELA. $1 \mathrm{M}$ (AMNH), $5 \mathrm{~F}$ (NHMW), $1 \mathrm{~F}$ (ZMUC), Stark, ex-coll. Jekel, $1 \mathrm{~F}$ (MNHN). Distrito Federal: Caracas, ex-coll. Fleutiaux, 2 F (MNHN); Macuto, 1 M (MZSP). Yaracuy: La Hoya, $1 \mathrm{M}$ (IMLA). Zulia: $17 \mathrm{Km}$ NE Carrasquero, $1 \mathrm{~F}$ (USNM); Maracaibo, 11M, 14 F (USNM); San Julian, 1 M, 2 F (USNM). COLOMBIA. 8 F (AMNH), 1 F (MNHN). Columbia, Hist. coll. nr 16220, 6 F (ZMHB); Columbia, coll. Jekel, coll. Fleutiaux, 1 F (MNHN). Atlántico: Barranquilla, $1 \mathrm{M}, 3 \mathrm{~F}$ (MNHN). Bolívar: Zambrano, Hda Monterrey, $1 \mathrm{~F}$ (IAHC). Boyacá: Muzo, $1 \mathrm{~F}$ (AMNH), 1 M, 3 F (MNHN). Cauca: Santa Rosa entre S. Francisco e Carthago, 6 F (MNHN). Special District: Bogota, 1 F (AMNH). Huila: Gigante, 2 F (SRGI). Magdalena: Rio Frio, $1 \mathrm{~F}$ (USNM). Santander: Barrancabermeja, $1 \mathrm{~F}$ (MZSP, gift from ICNC), 2 F (USNM); Ocaña, 1 M (MNHN). Valle del Cauca: Agua Clara, $1 \mathrm{~F}$ (ICNC); Andalucia (in cacao), $1 \mathrm{~F}$ (USNM). PERU-BRAZIL frontier, $1 \mathrm{~F}$ (AMNH). HAITI. La Vallee, Tortue Isl., $1 \mathrm{~F}$ (USNM); Pt. Prince, $1 \mathrm{M}$ (MNHN), $1 \mathrm{~F}$ (USNM), ex-coll. Fleutiaux, $2 \mathrm{~F}$ (MNHN); San Michel, $1 \mathrm{~F}$ (IMLA), $1 \mathrm{~F}$ (USNM). DOMINICAN REPUBLIC. Barahona:
4.5 Km S Barahona, 2 F (FSCA); $11 \mathrm{Km} \mathrm{S}$ Barahona, $1 \mathrm{M}$ (MZSP), $1 \mathrm{M}$, 3 F (FSCA). La Altagracia: Nisibón "Papa Lalo", 1 F (FSCA). La Romana: Higueral, 1 F (FSCA). Pedernales: Pq. Nac. Jaragua, 1 F (JEWC). PUERTO RICO. $1 \mathrm{~F}$ (USNM); Bayamon, $1 \mathrm{~F}$ (USNM). Caribbean N. F., Catalina Field Off, 1 F (FSCA); Ponce, 1 M (USNM); Playa de Salinas, $1 \mathrm{~F}$ (MZSP); San Juan, 1 F (USNM). WEST INDIES. Guadeloupe: Baines Jaunes, B.T., 1 F (FSCA). Jamaica: ex-coll. Fleutiaux, 1 F (MNHN); 2 mi Ferry, St. Andrew Par., 1 F (OSUC); Dornoch River, Trelawny, 1 F (AMNH). Jackson Town, 1 M (AMNH); Falmouth, 2 F (AMNH).

Remarks. Chalcolepidius silbermanni is characterized especially by general pubescence unicolor, metallic, olivebrown, brownish or grayish with silky and bright appearance, scutellum folded, tibiae of male bearing fringe of long cilia and interstices unequal and costiform. The sclerotized rings of the openings of the colleterial glands are broken frontally in a narrow area, in both dissected female. Some specimens present rugose pronotum; one female from Panama (Prima Prv. vic El Llano) presents dorsal and ventral pubescence green and one from Mexico (Oaxaca, Portillo del Ravo), ventral pubescence violet.

According to the original description, C. silbermanni was "trouvé par nos voyageurs, à Tuspan, et plus rarement à la Véra-Cruz, en terrre chaude, sur le bois mort. Il resemble beaucoup au Sulciger de Dejean; mais, dans ce dernier, le corselet est moins long at plus large". The label of the syntype examined includes only "Mex.".

The type locality of $C$. sericeus Erichson, 1841, is "La Guayra" [Venezuela]. I studied five females of ZMHB, labeled as "Hist.-Coll. (Coleoptera), nr 16220 (5 ex.) Chalcolepidius silbermanni Chevr., Columb., Mexico" and another female presenting also a manuscript label "silbermanni Chevr. Cand.*, sericeus Er.*, Columb. Otto" that were recognized by von Hayek as syntypes of $C$. sericeus. The type locality was not included in these labels.

C. silbermanni is similar to C. obscurus and C. pruinosus (see remarks after the two last). It belongs to forreri* group (Fig. 671).

Distribution. It is recorded from Mexico (Sinaloa, Durango, Nayarit, Jalisco, San Luis de Potosi, Tamaulipas, Veracruz, Michoacán, Guerrero, Oaxaca, Tabasco, Yucatan, Quintana Roo, Chiapas), Belize, Guatemala, Honduras, Nicaragua, El Salvador, Costa Rica, Panama, Colombia, Trinidad, Venezuela, Haiti, Dominican Republic, Puerto Rico and West Indies (Guadeloupe, Jamaica) (Fig. 683).

Chalcolepidius smaragdinus LeConte, 1854

(Figs. 76, 147, 148, 211, 263, 301, 345, 374, 413, 449, 485, 524, $568,615,678)$

Chalcolepidius smaragdinus LeConte, 1854: 223; Candèze, 1857: 292; Gemminger \& Harold, 1869: 1504 (Cat.); Candèze, 1886: 69, 74; Casey, 1907: 35; Leng, 1920: 167 (Cat.); Kirk, 1922: 238 (biology); Schenkling, 1925: 57 (Cat.); Fleutiaux, 1926: 108 (Cat.); Blackwelder, 1944: 283 (Cat.). Type locality: "San Diego trip".

Chalcolepidius ostentus Casey, 1907: 34; Leng, 1920: 167 (Cat.). Syntypes: 1 male, 1 female. Male: "Congress Jc. Ariz. July F. H. Snow; Casey bequest 1925; ostentus-2 paratype USNM 48461; = smaragdinus LeConte CMF von Hayek det. 1980". Female: "Bill. Wms. Fork Ariz. Aug. F.H. Snow; Casey bequest 1925; Type USNM 48461; ostentus Csy; = smaragdinus CMF von Hayek det. 1980"(USNM) (examined). Syn. nov. 
Chalcolepidius rectus Casey, 1907: 34; Leng, 1920: 167 (Cat.). Syntypes: 4 males, 3 females. One female: "San Bernardino Ranch Cochise Co. Ariz. 3750 ft. Aug. F. H. Snow; Casey bequest 1925; type USNM 48460; rectus Csy; C. smaragdinus". Three males and 3 females: same data by collection label respectively "rectus-2", "rectus-6", "rectus-3", "rectus-4", "rectus-5", "rectus-7" plus "paratype USNM 48450" (USNM)(examined). Syn. nov.

CASEY (1907) presented an identification key for the Chalcolepidius species from Arizona and Mexico, with lateral stripes on pronotum densely clothed with white or whitish setae, including two new species, $C$. rectus and $C$. ostentus, close to $C$. smaragdinus. These three species were separated by very small differences, like width and convexity of prosternum, shape of elytra, sculpture of elytral striae, shape of last ventral segment of female and density and coloration of pubescence.

$C$. rectus and $C$. ostentus are, here, considered conspecific with C. smaragdinus and the differences enumerated by Casey, are considered as intraspecific variation.

Length: 20-37 mm. Narrow, parallel. Dark-brown clothed dorsally and ventrally with thin short scale-like setae metallic green, yellowish-green, bluish-green, greenish-blue, brownishgreen; legs and antennae violet or/and blue (Fig. 76).

Frons not carinate, strongly declivous. Antennae flabellate in male (Fig. 148), pectinate in female (Fig. 147). Pronotum (Fig. 211) very longer than wide, almost rectangular, narrowed at apex; lateral margins parallel forming small edge, almost reaching apex; strongly convex from edge; small-punctuate with coarse sparse punctuation, denser lateroanteriorly; anterior margin prominent at middle, slightly sinuous; hind angles wide, backward, raised laterally forming edge, wider and continuous with that of lateral margin; median basal tubercle very weak and triangular or indistinct; posterior margin prominent and strongly notched at middle. Hypomera concave near lateral margins; laterointernal margin slightly raised forming wall of wide anterior channel. Notosternal sutures slightly sinuous. Prosternum micropunctate, with small punctuation or both; moderately convex, flattened longitudinal medially, slightly concave near sutures. Prosternal lobe micropunctate with anterior margin rounded; emarginated laterally. Prosternal spine flattened laterally. Scutellum (Fig. 263) narrower and strongly declivous, almost vertical on anterior half; horizontal half subtrapezoidal with posterior margin notched and sometimes with two anterior tubercles. Borders of mesosternal cavity (Fig. 301) moderately wide and horizontal on basal $2 / 3$ and slightly declivous on distal $1 / 3$, forming an inclined profile. Mesepisternum with two transverse elliptical grooves. Mesometasternal suture weak and convergent at cavity base. First visible sternite prominent laterally; prominence stay on a small lateral groove of elytra (not fitted). Tibiae of male bearing irregular row of spines internally. Striae very weakly marked by slightly coarser punctures; interstices flat and small punctuate.

Male genital segments and aedeagus. Sternite VIII (Fig. 345) transverse, slightly narrowed apicad, narrower on distal half; translucent in median area and paired lateral bands. Tergite
IX (Fig. 374) with anterior margin slightly notched and angles wide and rounded; short setae lateroanteriorly. Aedeagus (Fig. 413): median lobe (Fig. 449) narrow, 0.56 times aedeagus length, slightly narrowed near middle, bearing 6,$6 ; 11,9$ lateral teeth; the syntype of $C$. rectus bears 13, 14 teeth; lateral cleft of parameres (Fig. 485) constricted near apex; apex upwards, strongly prominent laterally forming sharpened angles.

Female genital segments and genitalia. Tergite VIII (Fig. 524) transverse, translucent in median basal triangular area, longer than half of tergite length, and marginal band except on medioanteriorly region. Sternite VIII (Fig. 568) very wide, 0.65 times spiculum gastrale length; anterior margin wide- and moderately notched at middle. Genitalia (Fig. 615): ovipositor wide; sclerotized rings of openings of colleterial glands (Fig. 659) bearing 79 teeth; bursa copulatrix with few dorsal spines.

Material examined. UNITED STATES OF AMERICA. Arizona: $1 \mathrm{~F}$ (CMNH), 4 F (MNHN), 4 F (USNM), 3 M (ZMHB); Cochise Co., $15 \mathrm{mi}$ E Douglas, 6 F (FSCA), 28 mi Douglas, 1 F (USNM); Douglas, 2 M, 1 F (AMNH), $1 \mathrm{~F}, 1 \mathrm{M}$ (dissected) (CMNH), $1 \mathrm{~F}$ (PCCV), $1 \mathrm{M}, 1 \mathrm{~F}$ (MCZC), 1 M (SEMC), 1 M, 2 F (USNM); Douglas, San Bernardino Ranch, 3750 ft., $1 \mathrm{~F}$ (AMNH), $1 \mathrm{M}, 1 \mathrm{~F}$ (MCZC), $1 \mathrm{~F}$ (OSUC), $1 \mathrm{M}$ (SEMC), $2 \mathrm{M}, 4$ F (USNM), (on Salix gooddingii) 1 F (dissected, MZSP); 2 mi NE Willcox, 1 F (AMNH); Gila Co., Globe, 2 M, 1 F (AMNH), 1 M (SEMC), 2 M (USNM); Maripa Co., Phoenix, 3 M, 3 F (AMNH), 1 F (MCZC), 1 F (MZSP), 5 M, 9 F (USNM); Pima Co., Altar Valley, 1 F (FSCA); Baboquivari Mts, 1 F (SEMC), 1 F (USNM); Catalina Mts, 1 F (FSCA); Continental, $1 \mathrm{~F}$ (AMNH), 4 M (JEWC), 1 M (MZSP); 1 M, 1 F (USNM); $6 \mathrm{mi}$ SE Continental $1 \mathrm{M}$ (dissected, MZSP); 8-10 mi E Continental, $1 \mathrm{~F}$ (MZSP); Florence, 1 F (USNM); Florida Cn., 1 F (USNM); Lower Madera Cyn., 1 F (FSCA); Madeira Canyon., 5 M, 2 F (FSCA), 2M (JEWC), 1 M (MZSP), 1 M, 2 F (USNM), 2 F (TAMU); Santa Rita Mts., Madera Canyon, 2 M, 4 F (AMNH), 1 F (IMLA), 1 M (SEMC), 4 M, 2 F (USNM), (on Prosopis chilensis) $1 \mathrm{~F}$ (MZSP); $2 \mathrm{mi} \mathrm{N}$ Madera Canyon, $2 \mathrm{M}, 1 \mathrm{~F}$ (PCCV), (at sap ooze on mesquite), $3 \mathrm{M}$ (TAMU) ; $10 \mathrm{mi} \mathrm{N}$ Madera Canyon, 1 M, 2 F (PCCV); McCleary's Cmp., 1 F (USNM); Kits Peak Rincon, Baboquivari Mts., about 4050 ft., 1 F (AMNH); Sabino Cyn., Sta Catalina Mts., 2600-3500 ft., 1 M (AMNH); St Rita Range, 5 M, 1 F (MZSP; 2 M retained USNM), 28 M (USNM); Sabino Canyon, $1 \mathrm{M}, 1 \mathrm{~F}$ (USNM); Vail, 1 F (SEMC); Cuter (locality not found), $1 \mathrm{M}, 1 \mathrm{~F}$ (AMNH); Santa Cruz Co., Nogales, 1 F (FSCA); Sta Cruz Valley, 1 F (AMNH); Sonoita Creek, 1 F (AMNH); Tumacacori, 1 M, 3 F (PCCV); Tucson, 1 M , 3 F (USNM); Yavapai Co., 1 F (CMNH); Yuma Co., Congress Junction, 1 M (MCZC), 2 M, 1 F (SEMC); Redington (Cat's claw), 1 F (USNM); Coyote Mts., about $3500 \mathrm{ft}$ (31o 53'N 111o 29'W), 1 F (AMNH). New Mexico: $1 \mathrm{M}$ (CMNH). MEXICO. Sonora: Magdalena, $1 \mathrm{~F}(\mathrm{AMNH})$; Nacozari [de Gracia], 2700', 1 F (AMNH); Navojoa, 1 F (OSUC), 1 M (USNM).

Remarks. Chalcolepidius smaragdinus is easily recognized by the green pubescence with yellow, blue or violet reflex, antennae flabellate in male and pectinate in female, scutellum strongly declivous, tibiae of male spiny internally and parameres of the aedeagus cleft laterally. It is variable in size and pubescence coloration; some specimens are predominantly green and others predominantly blue. The male syntype of $C$. ostentus is bluish-green dorsally and ventrally, and the female is yellowish-green dorsal- and bluish-green ventrally, both with violet-blue legs. The syntypes of $C$. rectus are smaller and yellowish-green dorsally and ventrally, with bluish-green legs. One syntype (rectus-5) had been already dissected and the median lobe of aedeagus presents 13, 14 small lateral teeth. 
It is similar to $C$. viridipilis differing especially by pubescence coloration (green-olive in $C$. viridipilis, green in C. smaragdinus); pronotum strongly convex, elytral interstices flatter and fore angles of frons more prominent in $C$. smaragdinus. Besides, C. viridipilis is smaller in size. One male from Congress has blue setae dorsally and blue intermingled by violet, ventrally. A comparison with $C$. lenzi is presented after the latter.

C. smaragdinus belongs to chalcantheus* group (Fig. 671).

Distribution. It is recorded from United States of America (Arizona and New Mexico) and Mexico (Sonora) (Fig. 678)

\section{Chalcolepidius spinipennis sp. nov.}

(Figs. 77,78, 149, 150,212,264,302,346,375,414,525,566,616,660,676)

Type material. Holotype male: "Mex[ico] Veracruz 14-16 Km S'ntcompn [Sontecomapan] 4,6-V-94 JEWappes"(MZSP retained JEWC) (Fig. 77). Paratypes: 5 males, 4 females. Males: "Rancho Santa Rosa San Antonio Buena Vista Chiapas Mexique X.85; collectio Dr. P. Cate"(NHMW retained PCCV); "Mexico: Veracruz Los Tuxtlas area "Las Cabanas"3-15 May, 1981 C. M. \& O.S. Flint, Jr.; "Los Tuxtlas" Biological Station, $31 \mathrm{Km}$ NE of Catemaco"(dissected) (USNM); "Mexico Veracruz Soteapan 300 m X.1985 T. Porion" (MZSP retained SRGI); "Mexico Veracruz Coatepec 1500 X.1985 T. Porion L." (BMNH retained SRGI); "P. Bleuzen dos Amates Veracruz Catamaco Mexique Sept. 1979" (SRGI) (Fig. 78). Females: "Mex. Veracruz 14-16 Km S'ntcmpn June-94 P \& A.Garcia" (JEWC); "F; Chalcolepidius eschscholtzi Presidio V. C. Mexico" (USNM); "Mexico Soteapan (Veracruz) $500 \mathrm{~m}$ Aout 1989 T. Pourion Cedit" (dissected)(MZSP retained SRGI); "Mexico: State of Chiapas San Quintin, 12.IX.1977 P. Hubbell collection" (FSCA).

Holotype. Length: $40 \mathrm{~mm}$. Integument black clothed dorsally and ventrally, including legs and epipleura, with short metallic scale-like setae green; pronotum with band-like irregular stripes, $1 / 6$ of pronotum width, narrowed internally near base, not reaching margins, clothed with ferruginous setae; elytra with lateral ferruginous bands (three interstices wide); antennae clothed with short black setae iridescent of brown (Fig. 77).

Frons narrow; anterior third trapezoidal; strongly concave medioanteriorly in triangular area; nasal plate high and grooved transversally. Setae of labrum surpassing mandibles. Antennae strongly serrate (Fig. 150), surpassing hind margin of procoxae in almost one segment; $3^{\text {rd }}$ segment triangular and short. Pronotum (Fig. 212) slightly longer than wide, wider at hind angles, narrowed anteriad from hind angles base; anterior margin prominent and slightly sinuous at middle; fore angles very prominent; lateral margins forming moderately wide raised edge almost reaching apex; moderately convex from edge, convexity decreasing basad; small-punctuate with moderate coarse punctuation more concentrate laterally; hind angles divergent, narrowed at apex, raised laterally forming edge, wider and continuous with that of lateral margins; posterior margin prominent and slightly notched at middle; median basal tubercle elongate and flattened; two divergent elongate impressions starting at apex of basal tubercle. Hypomera concave and grooved near lateral margins; lateral margins forming edge; densely small-punctuate; anterior margin slightly swollen, not forming anterior channel. Notosternal sutures slightly sinuous.
Prosternum moderately convex from sutures; flattened longitudinal medially; small-punctuate; punctuation denser and coarser near sutures. Prosternal lobe transverse, marginated laterally with rounded angles; punctuation sparser and coarser than prosternum, heterogeneous, giving rugose appearance. Scutellum (Fig. 264) moderately declivous and narrower at anterior half; posterior half almost horizontal, sub-elliptical and grooved at middle. Mesosternal cavity U-shaped with borders (Fig. 302) thick and horizontal on basal 2/3 and moderately declivous on distal $1 / 3$, forming semi-elliptical profile. Mesometasternal suture very weak. First visible sternite not prominent laterally. Tibiae of male bearing irregular row of spines internally. Striae grooved, interstices convex, unequal and smallpunctuate; $2^{\text {nd }}$ interstice raised at base forming tubercle; apices prominent at suture, bearing well developed sutural spine; not marginated laterally; epipleura grooved longitudinal medially.

Male genital segments and aedeagus (paratype: Mexico, Veracruz, Los Tuxtlas, area "Las Cabanas" "Los Tuxtlas" Biological Station, $31 \mathrm{Km} \mathrm{NE}$ of Catemaco). Tergite VIII slightly wider than long, lateral and anterior margins rounded; basal margin slightly notched; densely setous near margins. Sternite VIII (Fig. 346) transverse, subpentagonal, anterior margin very prominent at middle; three melanized areas: two lateral bands and one distal spot; median basal rounded spot slightly melanized. Sternite IX elongate, membranous on basal half and narrow apical band. Tergite IX (Fig. 375) transverse, slightly narrowed apicad; anterior margin slightly notched; densely punctuate with moderately long setae more concentrate laterodistally. Aedeagus (Fig. 414): apex of parameres spearheadlike; median lobe gradually narrowed apicad; apex constricted.

Female genital segments and genitalia (paratype: Mexico, Veracruz, Soteapan). Tergite VIII (Fig. 525) slightly wider than long; anterior margin slightly prominent; translucent in basal narrow band and small area near middle. Sternite VIII (Fig. 569) 0.57 times spiculum gastrale length; anterior margin narrowand deeply notched. Genitalia (Figs. 616, 617): sclerotized pieces of openings of colleterial glands (Fig. 660) C-shaped bearing many teeth; bursa copulatrix with carinae and spines in almost completely ventral area; with some ventral dispersed spines.

Remarks. The paratypes of Chalcolepidius spinipennis varies from $33-45 \mathrm{~mm}$. The females have the antennae shorter, less strongly serrate (Fig. 149) and $3^{\text {rd }}$ segment proportionally longer; they also present small spines at tibiae.

Besides the type material, I examined also a very damaged male (Mexico dos Amates 9.I.1980 E.C.Wellington(SRGI)), not included in the type series.

C. spinipennis is characterized especially by general pubescence green with lateral stripes on pronotum and elytra ferruginous, antennae strongly serrate in male, scutellum moderately declivous, elytra with sutural spine and apex of parameres spearhead-like.

The lateral stripes of pronotum varies in size, reaching or not the margins of pronotum; in one male from Chiapas, San Quintin, the setae of lateral stripes of pronotum are very sparse and the band is visible only under microscope. The lateral 
stripes of pronotum and elytra are usually ferruginous or brown; in three males (Soteapan, Coatepec, dos Amates) they are ochraceus.

C. spinipennis forms with $C$. copulatuvittatus and $C$. truncuvittatus the spinipennis + group (Fig. 671).

Distribution. It is recorded from Mexico (Veracruz, Chiapas) (Fig. 676).

Etymology. The epithet is derived from one of the latin words for spine, spina, related to elytral apex.

Chalcolepidius sulcatus (Fabricius, 1777)

Figs. 79, 151, 213, 303, 526, 570, 661, 680

Elater sulcatus Fabricius, 1777: 234; 1781: 266; 1787: 172; Olivier, 1790: 13 (pars); Fabricius, 1792: 220; 1801: 226; Herbst, 1801: 321, t. 157, f. 6. Two Syntypes "America boreali Dom. Spengler" (ZMUC) ( Photo examined).

Chalcolepidius sulcatus; Eschscholtz, 1829: 32; Erichson, 1841: 42; Lacordaire, 1857: 155; Candèze, 1857: 263, 282 (pars); Gemminger \& Harold, 1869: 1504 (Cat.); Candèze, 1874: 167; 1886: 68, 72; 1891: 38 (Cat.); Schwarz, 1906a: 46; Schenkling, 1925: 57 (Cat.); Fleutiaux, 1926: 108 (Cat.); Blackwelder, 1944: 283.

Chalcolepidius herbstii Erichson, 1841: 82; Lacordaire, 1857: 155; Candèze, 1857: 287; Gemminger \& Harold, 1869: 1503 (Cat.); Candèze, 1886: 68, 73; 1891: 38 (Cat.); Schwarz, 1906a: 46; Schenkling, 1925: 56 (Cat.); Fleutiaux, 1926: 107 (Cat.); Blackwelder, 1944: 283 (Cat.). Syntypes: 1 male, 1 female. Male: "M; 16230; Herbsti Er.* Cand.* Elat. sulcatus Hbst.* Am. mer.; syntype Chalcolepidius herbstii Erichson C.M.F. von Hayek, 1980". Female: "Americ. merid. nr. 16230; Syntype Chalcolepidius herbstii Erichson C.M.F. von Hayek 1980" (ZMHB) (examined). Syn. nov.

The original description of Elater sulcatus was repeated, with the same words, in the FABRICIUS subsequent papers (1781, $1787,1792,1801)$. According to the original description, the pubescence is "albidus", but examining the photos of the syntypes (ZMUC), it looks like yellowish or ochre, effect probably resulting of the dirtiness of the pubescence.

OLIVIER (1790) started the confusion about the C. sulcatus identity and geographical distribution. He presented the following diagnosis "T. noir; couvert d'un duvet blanchâtre; elytres avec trois stries elevées, glabres", followed by a redescription identical of Fabricius's description. He also presented illustrations of the dorsal and ventral habitus (Pl. 2, fig. $10 \mathrm{a}, \mathrm{b}$ ) of one specimen that does not fit well with its diagnosis; it corresponds, however, to the present interpretation of $C$. validus Candèze, 1857. It has the pronotum clothed with brown-violet pubescence with white lateral stripes, narrowed apicad, and the elytra clothed with white pubescence, except the higher interstices, brown-violet.

FABRICIUS (1801) also included "Elater sulcatus Oliv. Ins. 2. 31. Tab. 2. fig. 10", but this illustration does not correspond to the description.

EschschOLTz (1829) redescribed C. sulcatus and recorded it from Guyana, an erroneous locality.

Castelnau (1840) and Erichson (1841) redescribed the pronotum of C. sulcatus as bicolor, assuming the Olivier's 1790 illustration as belonging to this species.
CANDĖze (1857) mixed both species, presenting a key where C. sulcatus was included in the Section II, $2^{\text {nd }}$ subdivision: "Prothorax unicolore, sans bandes laterales", but redescribed it as "revêtu de petites écailles très-serées, d'un châtain, les côtés du prothorax en arrière et les élytres couverts d'écailles un peu plus allongées que les premières d'un blanc pur, soyeux". This description is based on Olivier's illustration of C. sulcatus, that in fact corresponds to $C$. validus, described by CANDĖZE (l.c.) in the following page. In 1874, CANDĖze supposed that $C$. validus should be a more robust form of $C$. sulcatus, but only FleUtiaux (1911) synonymized both species.

ERICHSON (1841) described C. herbstii and included Elater sulcatus, as synonym. This position has been carried on by several subsequent authors (LACORDAIRE 1857; CANDĖze 1857, 1891; Schwarz 1906a; Schenkling 1925; Blackwelder 1944).

Based on photos of the two syntypes of $C$. sulcatus (Fabricius) (ZMUC) and on the study of two syntypes of $C$. herbstii Erichson, 1841 (ZMHB) and identified and unidentified material of both species, I concluded that these species are conspecific.

The misled on the geographical distribution is due to the misidentification of some specimens. The type locality of Elater sulcatus Fabricius is "America Boreali" and no further data was included in subsequent references to this locality; FABRICIUS $(1781,1792,1801)$ referred to "America Meridionale"; OLIVIER (1790) recorded it from Cayenne, which illustration is herein accepted as of $C$. validus. Following this misidentification, HERBST (1801) also recorded it from Cayenne and his illustration is based on a specimen that resembles the present interpretation of $C$. zonatus or C. limbatus, which, unlike C. sulcatus, occur in South America. ERICHSON (1841) recorded C. sulcatus from Guyana and CASTELnAU (1840) from Brazil, both localities considered herein as incorrect. The first record from "Antilles" appears to be that of CANDÈZE (1857), and fifty years later FLEUTIAUX (1911) recorded it from Martinique and Guadeloupe.

ERICHSON (1841) gives the locality of C. herbstii as "Sudamerica", and no further references to the locality of this species was given until GoLBACH $(1977: 155)$ recorded a male from Brazil (HNHM). According to him, with this data is possible to know a more exact locality of this species. He also described C. herbstii multistriatus based in four specimens from Brazil. I had the opportunity of examining one of these paratypes (Brazil, Pará, Rio Acara) and concluded that it belongs to C. porcatus.

Length: 25-35 mm. Wide, arched body. Integument black clothed dorsally and ventrally with dense dull, yellowish-white or grayish-white scale-like setae (in two specimens almost white); higher interstices, prosternum, and median region of mesosternum, metasternum and sternites 1-4, glabrous (Fig. 79).

Frons not carinate, strongly declivous. Antennae (Fig.151) serrate in both sexes; $3^{\text {rd }}$ segment triangular-elongate, shorter than $4^{\text {th }}$. Pronotum (Fig. 213) slightly longer than wide, wider at hind angles, slightly narrowed apicad from hind angles base, strongly narrowed on distal third; anterior margin prominent 
and sinuous at middle; lateral margins raised laterally forming edge on basal $3 / 4$; moderately convex; convexity decreasing basad; small-punctuate with sparse umbilicate punctuation, more concentrate medioanteriorly; hind angles slightly divergent with truncate apex, raised laterally forming edge narrower and continuous with that of lateral margins until distal 1/4; median basal tubercle flattened, triangular; posterior margin prominent and strongly notched at middle. Hypomera smallpunctuate, concave near lateral margins; laterointernal margin raised forming wall of anterior channel. Prosternal spine flattened laterally. Notosternal sutures strongly sinuous. Prosternal lobe micropunctate, wide, emarginated laterally with angles rounded. Prosternum micropunctate, strongly convex, grooved laterally, flattened longitudinal medially. Scutellum strongly folded with horizontal basal area subtrapezoidal, strongly notched anteriorly and slightly posteriorly. Borders of mesosternal cavity (Fig. 303) wide and horizontal on basal $2 / 3$ and vertical near apex, forming L-shaped profile. Mesometasternal suture weak, convergent on mesosternal cavity base. First visible sternite prominent laterally, fits in lateral groove of elytra. Anterior and median tibiae and last tarsal segment of all legs of male bearing fringe of long ciliae. Interstices convex, unequal; scutellar area moderately grooved; rounded prominent tubercle at base of $2^{\text {nd }}$ interstice.

Female genital segments and genitalia. Tergite VIII (Fig. 526) transverse, almost rectangular with anterior margin rounded, translucent in median basal subtriangular area and paired band on fore angles. Sternite VIII (Fig. 570) 0.59 times spiculum gastrale length; anterior margin wide and moderatedeeply notched at middle. Genitalia: sclerotized rings of openings of colleterial glands (Fig. 661) bearing 35 teeth; internal margin and space between teeth bearing micro teeth; bursa copulatrix with longitudinal median dorsal band, narrowed near base, with carinae and spines, and paired lateral spiny rounded areas.

Male genital segments and aedeagus not studied.

Material examined. MEXICO. Sonora: Copete Mine 30 E of Carbó, $2 \mathrm{~F}(\mathrm{AMNH})$; Pesquera, $20 \mathrm{mi}$ NE Hermosillo, $1 \mathrm{~F}$ (AMNH). WEST INDIES. Virgin Islands: Saint Croix, $1 \mathrm{~F}$ (dissected) (MZSP), 2 F (USNM), 1 M, 2 F (ZMUC); Christiantead, 3 F (USNM); nr Wheelof (?), Forttune (several localities with same name), $1 \mathrm{~F}$ (USNM). Ins. [Insulae] America, 5 F (ZMUC).

Remarks. Chalcolepidius sulcatus is characterized especially by the general whitish pubescence in both sides, scutellum folded, tibiae of male with long fringe of long cilia.

It belongs to forreri* ${ }^{*}$ group (Fig. 671).

Distribution. It is recorded from Mexico (Sonora) and West Indies (Virgin Islands) (Fig. 680), but I consider that the former locality requires confirmation.

Chalcolepidius supremus sp. nov.

(Figs. 80, 152, 214, 265, 304, 672)

Type material. Holotype male: "M; Caracas Venz; Chittenden coll.; Chalcolepidius mexicanus Castelanau CMF von Hayek det. 1980" (USNM).
Holotype. Length: $30 \mathrm{~mm}$. Integument black totally clothed with short, metallic scale-like grayish-olive setae; antennae clothed with brown setae except three first segments, grayisholive (Fig. 80).

Frons trapezoidal on distal third; strongly concave medioanteriorly in triangular area; nasal plate punctuate and high. Labral setae surpassing mandibles. Antennae (Fig. 152) strongly serrate (partially broken); $3^{\text {rd }}$ segment very short, prominent distad. Pronotum (Fig. 214) slightly longer than wide, slightly narrowed apicad from hind angles base; anterior margin slightly prominent at middle; anterior angles very prominent; lateral margins raised laterally forming bright edge, almost reaching apex; weak narrow groove internally edge; strongly convex from groove, convexity decreasing basad; smallpunctuate; coarse sparse punctuation laterally on anterior half; hind angles divergent, narrow at apex, raised laterally forming edge discontinuous with that of lateral margins; median basal tubercle very flat and elongate; posterior margin strongly prominent and slightly notched at middle. Hypomera concave, slightly raised in narrow bright sparsely small-punctuate band, parallel notosternal sutures, not reaching apex; apex slightly swollen and not marginated; prosternal channel absent. Notosternal sutures slightly sinuous. Prosternum moderately convex from sutures; densely small-punctuate; coarser punctuation near sutures. Prosternal lobe transverse with rounded angles and notched medioanteriorly; punctuation coarser than prosternum. Scutellum (Fig. 265) narrower and moderately declivous on anterior half; basal half transverse with lateral margins rounded and distal margin prominent. Mesosternal cavity V-shaped with borders (Fig. 304) thick and horizontal on basal $2 / 3$ and moderately declivous on distal $1 / 3$, forming semi-elliptical profile. Meso-metasternal suture well visible. First visible sternite not prominent laterally. Tibiae of male bearing irregular row of spines internally. Interstices convex, unequal and small-punctuate; apices conjointly rounded, slightly prominent at suture; $2^{\text {nd }}$ and $3^{\text {rd }}$ interstices raised at base.

Male genitalia not studied; holotype not dissected.

Female unknown.

Remarks. Chalcolepidius supremus is characterized especially by general pubescence olive, antennae of male strongly serrate, scutellum moderately declivous and tibiae of male spiny internally. It is similar to $C$. jansoni and $C$. oxydatus (see remarks after the latter).

It belongs to supremus ${ }^{+}$group (Fig. 671).

Distribution. It is recorded from Venezuela (Fig. 672).

Etymology. The epithet is derived from one of the latin words for higher, supremus, related to the importance of this specimen.

Chalcolepidius tartarus Fall, 1898

(Figs.81,153,215,266,305,347,376,415,450,486,571,618,662,693)

Chalcolepidius tartarus Fall, 1898: 238; Leng, 1920: 167 (Cat.); 
Schenkling, 1925: 59 (Cat.). Holotype male: "Yuma, Cal." (MCZC) (examined).

Chalcolepidius parallelus Schwarz, 1906a: 98; Casey, 1907: 29, 33 (Syn.); Becker, 1961: 163 (Syn.). Syntype male: "Arizona; coll. Schwarz; Typus; parallelus Schw.; Dtsch. Entomol. Institut Berlin”(DEIC) (not examined).

Length: 21-36 mm. Parallel, moderately narrow body. Integument dark-brown or black clothed with short metallic scale-like setae blue, bluish-green, turquoise-blue or violetblue; antennae clothed with violet setae except three first segments, blue or greenish; lateral stripes of pronotum approximately $1 / 4$ of pronotum width, slightly narrowed to apex, with internal margin semi-elliptical; lateral stripes of elytra two interstices wide; dull white pubescence on anterior region of frons, lateral stripes of pronotum and elytra, basal region of elytra, epipleura, hypomera and lateral bands of sternites (Fig. 81).

Frons not carinate, slightly or moderately declivous. Antennae (Fig. 153) strongly serrate in male, serrate in female, $3^{\text {rd }}$ segment short and triangular. Pronotum (Fig. 215) very longer than wide, slightly narrowed apicad from hind angles apices; moderately convex longitudinal medially, convexity decreasing basad; micropunctate with sparse umbilicate coarser punctuation, denser lateroanteriorly; anterior margin slightly sinuous at middle; lateral margins raised laterally forming small edge almost reaching apex; hind angles backward, wide with truncate apex, raised laterally forming edge, narrower and continuous with that of lateral margins; median basal tubercle triangular very weak or indistinct; posterior margin prominent and strongly notched at middle. Hypomera concave near lateral margins; laterointernal margin raised forming wall of anterior channel. Notosternal sutures moderately sinuous. Prosternum micropunctate, moderately convex; flattened longitudinal medially; slightly concave near sutures. Prosternal lobe micropunctate, wide, emarginated laterally with fore angles rounded. Prosternal spine flat laterally. Scutellum (Fig. 266) strongly folded with horizontal basal area subtrapezoidal, grooved longitudinally and notched anterior and posteriorly. Borders of mesosternal cavity (Fig. 305) wide and horizontal on basal $2 / 3$ and slightly declivous on distal $1 / 3$, forming subelliptical profile. Meso-metasternal suture indistinct. First visible sternite prominent laterally; prominence fits in lateral groove of elytra. Anterior and median tibiae and last tarsal segment of all legs of male bearing fringe of short cilia. Striae marked by row of coarse punctures; interstices equal in width and height, slightly convex and small-punctuate. Male with elytra longer than abdomen.

Male genital segments and aedeagus. Sternite VIII (Fig. 347) wider than long, slightly narrowed apicad, with anterior margin rounded; translucent in median triangular area and paired lateral narrow bands. Tergite IX (Fig. 376) densely punctuate with anterior margin slightly notched; short setae lateroanteriorly. Aedeagus (Fig. 415): median lobe (Fig. 450) 0.53 times aedeagus length, slightly narrowed at middle, strongly at apex, bearing 10,10; 15, 15 teeth; lateral cleft of parameres (Fig. 486) constricted near apex, distal angles rounded.

Female genital segments and genitalia. Tergite VIII transverse, setous, translucent in median basal triangular area and marginal band. Sternite VIII (Fig. 571) 0.70 times spiculum gastrale length; anterior margin wide- and deeply notched. Genitalia: sclerotized rings of openings of colleterial glands (Fig. 662) partially grater-like, bearing many small teeth; bursa copulatrix (Fig. 618) with small dorsal area with carinae and spines.

Material examined. UNITED STATES OF AMERICA. California: Imperial Co., Laguna Lake, $1 \mathrm{~F}$ (dissected) (MZSP); Riverside Co., Blythe, $1 \mathrm{~F}(\mathrm{AMNH})$. Arizona: $1 \mathrm{M}, 1 \mathrm{~F}$ (AMNH), $1 \mathrm{~F}$ (PCCV), $1 \mathrm{~F}$ (MZSP), 17 M, 4 F (USNM), ex-coll. Fleutiaux, 2 F (MNHN); Cochise Co., Huachuca Mts., 1 F (USNM), Miller Cyn., 1 F (FSCA), 1 M (dissected), 1 F (JEWC), $1 \mathrm{M}$ (dissected) (MZSP); Texas Canyon (locality not found), 1 M,1 F (FSCA); Texas Pass, Dragon Mts., 1 F (FSCA); Maripa Co., Glendale, $1 \mathrm{M}$ (TAMU); Phoenix, $6 \mathrm{M}, 5 \mathrm{~F}$ (AMNH), $1 \mathrm{~F}$ (CMNH), $2 \mathrm{M}$, $1 \mathrm{~F}$ (OSUC), $1 \mathrm{~F}$ (SEMC), $6 \mathrm{M}, 8 \mathrm{~F}$ (USNM), ex-coll. Fleutiaux, $1 \mathrm{~F}$ (MNHN); Tempe, 1 F (USNM); Pima Co., 1 M (AMNH); Baboquivaria Mts., 1 M (SEMC); Madera Canyon, 1 F (PCCV); Tucson, 1 F (AMNH), 1 M (FSCA), 5 M (USNM); Santa Cruz Co., Tumacacori, 1 F(PCCV); Yuma Co., Yuma, $1 \mathrm{M}$ (dissected) (MZSP). New Mexico: ex-coll. Fleutiaux, 2 M (MNHN).

Remarks. Chalcolepidius tartarus is characterized especially by moderately narrow body, general pubescence blue, bluish-green, turquoise-blue or violet-blue, with white lateral stripes on pronotum and elytra, epipleura, hypomera and lateral bands of sternites (in some specimens also the femora with white patches), antennae strongly serrate in male, scutellum folded, tibiae of male with fringe of short cilia and parameres of aedeagus cleft laterally. It is similar to $C$. apacheanus and $C$. webbi in coloration but it differs especially by presence of: 1) white pubescence on hypomera and sides of sternites; 2) $3^{\text {rd }}$ antennal segment short and triangular; 3 ) male tibiae bearing fringe of short cilia (longer cilia in other two); 4) pronotum almost parallel; 5) interstices convex (flat in other two); 6) sclerotized rings of openings of colleterial glands bearing larger number of teeth; 7) bursa copulatrix without lateral rounded spiny areas and with shorter elongate dorsal area with carinae and spines.

C. tartarus forms, together with C. apacheanus $+C$. webbi, the tartarus + group (Fig. 671).

Distribution. It is recorded from Southwest of the United States of America (California, Arizona, New Mexico) (Fig. 693).

\section{Chalcolepidius truncuvittatus sp. nov.}

(Figs. 82, 154, 216, 269, 306)

Type material. Holotype female: "Mex. Tamaulipas Bocotoma Area 7 Km SSE Gomez Farias June 1-4 1982 J. E. Wappes; Chalcolepidius eschscholtzi Chevr. det. E. C. Becker 1988"(MZSP retained JEWC) (Fig. 82).

Holotype. Length: $29 \mathrm{~mm}$. Integument black clothed dorsally and ventrally (including legs and epipleura) with short metallic scale-like setae olive; lateral stripes of pronotum band-like, narrow, 1/6 of pronotum width, not reaching anterior and hind 
angles, convergent at base; dull white setae on lateral stripes of pronotum, striae and lateral stripes of elytra (three interstices wide); antennae clothed with blue short metallic setae intermingled with brown, except three first segments, olive (Fig. 82).

Frons trapezoidal at distal third, concave medioanteriorly; nasal plate punctuate and high. Antennae (Fig. 154) serrate, reaching anterior margin of procoxae; $3^{\text {rd }}$ segment very short and widened distad. Pronotum (Fig. 216) longer than wide, slightly narrowed anteriad from hind angles base; anterior margin almost straight; anterior angles prominent; lateral margins forming narrow raised edge, almost reaching apex; narrow groove innerly edge; strongly convex from groove, convexity decreasing basad; densely small-punctuate with slightly coarser punctuation on anterior third; hind angles divergent, strongly raised laterally forming edge wider and continuous with that of lateral margins; posterior margin downwards, moderately prominent and slightly notched at middle; median basal tubercle transverse and flattened. Hypomera concave, not forming anterior channel. Notosternal sutures slightly sinuous. Prosternum moderately convex from sutures; densely small-punctuate; punctuation coarser and denser near sutures. Prosternal lobe transverse with rounded angles; punctuation sparser and coarser than prosternum. Mesosternal cavity V-shaped with borders (Fig. 306) thick, prominent and horizontal on basal $2 / 3$ and slightly declivous on distal third, forming inclined profile. Meso-metasternal suture well marked. First visible sternite not prominent laterally. Scutellum (Fig. 267) narrower and moderately declivous on anterior half; horizontal half elliptical with two deep rounded concavities. Striae marked by row of coarse punctures; interstices slightly convex, almost flat and unequal in width; small-punctuate; $2^{\text {nd }}$ and third joined at base, forming small flattened forward tubercle; lateral margins of elytra not marginated; epipleura grooved longitudinal medially; apices conjointly rounded.

Male unknown.

Remarks. Chalcolepidius truncuvittatus is characterized especially by general pubescence olive, with white on lateral stripes of pronotum (not reaching hind angles and convergent at base) and elytra, and scutellum moderately declivous.

It is the sister-group of C. copulatuvittatus (Fig. 671).

Distribution. It is recorded from Mexico (Taumalipas) (Fig. 676).

Etymology. The epithet is derived from one of the latin words for cutting, truncus, related to lateral bands of pronotum.

Chalcolepidius validus Candèze, 1857 reval.

(Figs. 83, 155, 217, 268, 348, 416, 451, 487, 527, 572, 663, 690)

Chalcolepidius validus Candèze, 1857: 263, 283; Gemminger \& Harold, 1869: 1504 (Cat.); Candèze, 1874: 167; 1886: 68, 72; 1891: 38 (Cat.); Fleutiaux, 1911:247 (Syn.); 1947: 108; Schenkling, 1925: 59; Fleutiaux, 1926: 108 (Cat.); Blackwelder, 1944: 283 (Cat.). Syntype female: “Antilles; Chalcolepidius validus F type Cdze. ex coll. Deyrolle; validus; Janson coll. 1903.100” (BMNH) (not examined).

Elater sulcatus; Olivier, 1790: t.2, f.10 (non Fabricius, 1777) (misidentification).

Chalcolepidius sulcatus; Castelnau, 1840: 238; Erichson, 1841: 81, 82; Candèze, 1857: 263, 282; 1874: 167; 1886: 72; 1891: 38.

The identified material of $C$. sulcatus (Fabricius) and $C$. validus Candèze are messed because the redescriptions of these species are contradictories. This problem started, before the description of C. validus, when OLIVIER (1790), treating of C. sulcatus, presented the redescription of this species and an illustration of one specimen, with pronotum bicolor (that does not correspond to C. sulcatus, which has pronotum unicolor). From this time, C. sulcatus was interpreted as having the pronotum bicolor, like $C$. validus Candèze, 1857, later described. Consequently, these two species have been considered as the same, but here, they are treated as distinct species.

CANDÈze (1857) gave continuation to the confusion and described C. validus, including it in the key before C. sulcatus, in a subdivision with pronotum unicolor, without lateral bands, separated from the latter only by hind angles of pronotum more divergent. He described/redescribed both species as having pronotum bicolor, with lateral whitish stripes narrowed apicad. He stated that both species are very similar, differing especially by larger body and the bands of pronotum yellowish-white in C. validus, and white in C. sulcatus. In fact, he was treating of the OLIVIER's (1790) illustration of C. sulcatus that corresponds to $C$. validus, described in the following page, and both "species" treated by him correspond to $C$. validus.

Fleutiaux (1911) did not note the previous misleading and synonymized C. validus Candèze, 1857 under C. sulcatus (Fabricius, 1777), which is revalidated and redescribed. He recorded this species from Martinique and Guadeloupe, but considered the last locality as doubtful. I studied several specimens of Fleutiaux collection, identified by him as $C$. sulcatus that really belong to $C$. validus.

Length: $27-47 \mathrm{~mm}$. Wide, parallel, arched body. Integument black; frons, pronotum, scutellum and ventral region, including legs, clothed with metallic brown or reddish-brown scale-like setae; lateral stripes on pronotum triangular-elongate, not reaching anterior margin; yellowish-white or white pubescence on lateral stripes of pronotum and elytra; higher interstices naked; epipleura clothed with brown or white totally, or anterior region brown and posterior white; antennae clothed with darkbrown pubescence except three first segments with sparse brown or reddish-brown setae (Fig. 83).

Frons not carinate, strongly declivous at middle; fore angles raised. Antennae (Fig. 155) serrate in both sexes; $3^{\text {rd }}$ triangular elongate, shorter than $4^{\text {th }}$. Pronotum (Fig. 217) as long as wide, wider at hind angles, slightly narrowed apicad from hind angles apices, strongly narrower on anterior $1 / 4$; moderately convex longitudinal medially, convexity decreasing basad; micropunctate with coarse umbilicate and sparse punctuation of variable thickness on median anterior region, in some specimens forming small ridges; anterior margin sinuous in 
variable degree; lateral margins raised laterally forming smooth, moderately wide edge reaching apex; concave in moderately wide band innerly edge; concave band wider basad; hind angles wide, slightly divergent with truncate and thickened apex; raised laterally forming edge wider and continuous with that of lateral margins; median basal tubercle flat, triangular, continuous with weak longitudinal median ridge, not reaching anterior margin; posterior margin prominent and strongly notched at middle. Hypomera concave near lateral margins; micropunctate with sparse umbilicate moderately coarse punctures anteriorly; laterointernal margin raised forming wall of anterior channel. Notosternal sutures strongly sinuous. Prosternum micropunctate; punctuation coarse near notosternal sutures; longitudinal median region apparently smooth; strongly convex, flattened longitudinal medially, concave near sutures. Prosternal lobe wide, punctuation sparser and coarser than longitudinal median region of prosternum; emarginated laterally; fore angles slightly rounded. Prosternal spine flattened laterally. Scutellum (Fig. 268) strongly folded with horizontal basal area subtrapezoidal, notched on anterior and posterior margins, grooved or not on median anterior region. Borders of mesosternal cavity wide and horizontal on basal $3 / 4$ and vertical on distal $1 / 4$, forming L-shaped profile. Meso-metasternal suture absent. First visible sternite prominent laterally, fits in lateral groove of elytra. Anterior and median tibiae and last tarsal segment of all legs of male bearing fringe of long cilia. Interstices convex and micropunctate; unequal; $2^{\text {nd }}$ forming basal tubercle; apex truncate, in some specimens with tiny sutural spine.

Male genital segments and aedeagus. Sternite VIII (Fig. 348) transverse, gradually narrowed apicad; translucent in median large area and paired lateral bands. Tergite IX densely punctuate; anterior margin almost straight, with rounded angles; tiny setae lateroanteriorly. Aedeagus (Fig. 416): median lobe (Fig. 451) 0.53 times the aedeagus length, wide and slightly narrowed at middle, bearing 9, 11 lateral teeth; lateral cleft of parameres (Fig. 487) with apex strongly upwards.

Female genital segments and genitalia. Tergite VIII (Fig. 527) transverse, sub-rectangular with, anterior margin slightly rounded and slightly notched at middle; translucent basal triangular area reaching middle, and a paired anterior bands. Sternite VIII (Fig. 572) 0.66 times spiculum gastrale length; anterior margin wide- and deeply notched at middle. Genitalia: sclerotized rings of openings of colleterial glands (Fig. 663) higher proximally, bearing 43 teeth; bursa copulatrix with longitudinal median band with carinae and spines and paired lateral rounded spiny areas.

Material examined. WEST INDIES. 16229 [Erichson material], $1 \mathrm{~F}$ (ZMHB). Martinique: $1 \mathrm{~F}$ (FSCA), $5 \mathrm{~F}$ (MNHN), ex-coll. Fleutiaux, $6 \mathrm{~F}$ (MNHN), ex-coll. Hauser, $1 \mathrm{~F}$ (ZMHB); Chaffarjou, $2 \mathrm{M}$ (MNHN); Fort de France, $1 \mathrm{M}$ (AMNH), $1 \mathrm{M}, 1 \mathrm{~F}$ (MNHN); Fournissis, 1880, $1 \mathrm{~F}$ (MNHN); Montagne Peleé, 1 F (MNHN), 1826, Museum Paris, 1 M, 1 F (MNHN); Pornain, 74, 1 F (MNHN); San Domingo, 1 F (MCZC); Tivoli, $1 \mathrm{~F}$ (USNM), near river Martinique, $1 \mathrm{~F}$ (USNM). Guadeloupe: ex-coll. Fleutiaux, 2 F (MNHN). Dominica: 1 M (dissected, FSCA), 1 F $(\mathrm{MNHN})$; Laiou, Chalcolepidius validus Cand. = sulcatus Fabr. var., coll. Fleutiaux, $1 \mathrm{~F}$ (MNHN); Long Dilton, $1 \mathrm{M}, 1 \mathrm{~F}(\mathrm{AMNH})$; River, above Macoucheri State, 1 F (FSCA); St. John Parish, Cabrits NP, 1 M (TAMU);
St. Joseph Parish el 500', 1 Km E Morne Raquette, 1 F (TAMU). Saint Lucia: 1850, 4 F (MNHN).

Remarks. Chalcolepidius validus is characterized especially by wide body clothed with brown or reddish-brown pubescence with elytra and lateral stripes of pronotum (short, triangular) with whitish setae, scutellum folded, tibiae of male bearing fringe of long cilia and parameres of aedeagus cleft laterally. It presents a range of variation especially related with pubescence coloration: general pubescence usually brown or reddish-brown (one specimen with olive pubescence) with lateral stripes of pronotum and elytra white, yellowish-white or ochraceus and epipleura brown, white or brown and white together.

C. validus is the sister-group of C. rostainei (Fig. 671).

Distribution. It is recorded from West Indies (Martinique, Guadeloupe, Dominica, Saint Lucia) (Fig. 690). I examined one specimen from Mexico (MCZC), one from French Guiana (MNHN) and three from Brazil (MNHN, USNM) that were not included in the list of material examined because these localities require confirmation.

\section{Chalcolepidius villei Candèze, 1878}

(Figs.85,86,156,218,219,307,349,417,452,488,528,573,622,664,685)

Chalcolepidius villei Candèze, 1878: 9; 1886: 67, 71; Schenkling, 1925: 57 (Cat.); Fleutiaux, 1926: 109 (Cat.); Blackwelder, 1944: 283 (Cat.). Syntypes: 2 females: "Coll. I. R. Sc. N. B. Equateux ex coll. Candèze; Chalcolepidius villei $\mathrm{Cd}$. det. E. Candèze. One specimen bears Candèze's label: villei Cdze Ecuador" (ISNB) (not examined).

The male is described by first time.

Length: 29-48 mm. Arched, wide body. Integument black, clothed dorsally and ventrally (including legs and epipleura) with short, metallic and dense scale-like setae green, greenolive, yellowish-green or grayish-green; lateral stripes of pronotum wide, elliptical, of varied sizes, not reaching hind angles; denser pubescence brown, ferruginous or orange on lateral stripes of pronotum and elytra, at maximum, four interstices wide. Antennae clothed with black pubescence except three first segments, greenish (Figs. 85, 86, 218, 219).

Frons not carinate, moderately declivous. Antennae (Fig. 156) serrate in both sexes, $3^{\text {rd }}$ segment triangular-elongate, slightly shorter than $4^{\text {th }}$. Nasal plate declivous. Pronotum (Figs. $218,219)$ longer than wide, wider at hind angles, narrowed apicad from hind angles apex; lateral margins forming small raised edge almost reaching apex; moderately convex, convexity decreasing basad; micropunctate with coarse irregular punctuation forming rugosities; anterior margin sinuous; hind angles slightly divergent, with truncate apex and raised laterally, forming edge continuous with that of lateral margins; median basal tubercle triangular elongate, flat, continuous with longitudinal median ridge not reaching anterior margin; posterior margin prominent and strongly notched at middle. Hypomera concave near lateral margins, with narrow raised band parallel notosternal sutures; micropunctate with slightly coarser umbilicate punctuation, more concentrate laterally; laterointernal margin raised forming wall of anterior channel. 
Notosternal sutures moderately sinuous. Prosternum micropunctate; longitudinal median region apparently smooth, strongly convex, and flat longitudinal medially; concave near sutures. Prosternal lobe micropunctate, wide, emarginated laterally with fore angles slightly rounded. Prosternal spine flattened laterally. Scutellum strongly folded with horizontal basal area subtrapezoidal, notched anterior and posterior. Borders of mesosternal cavity (Fig. 307) wide and horizontal on basal $3 / 4$ and almost vertical on distal $1 / 4$, forming L-shaped profile. Mesepimeron with two transverse elliptical grooves. Meso-metasternal suture weak, convergent at cavity base. First visible sternite prominent laterally, fits in lateral groove of elytra. Anterior and median tibiae and last tarsal segment of all legs of male bearing fringe of long cilia. Striae grooved; interstices micropunctate and convex, unequal; $3^{\text {rd }}$ forming flat basal tubercle forwards; apices truncate with small sutural spine, densely setous internally.

Male genital segments and aedeagus. Tergite VIII transverse, strongly notched laterobasally, slightly narrowed apicad with anterior margin rounded. Sternite VIII (Fig. 349) transverse, gradually narrowed apicad, subtrapezoidal, translucent in median large area and two lateral smaller opened areas near base. Tergite IX densely punctuate; anterior margin rounded, with tiny lateroanterior setae. Aedeagus (Fig. 417): median lobe (Fig. 452) 0.54 times aedeagus length, with 7-8; 8, 9 , lateral teeth, constricted near struts base and slightly narrowed near middle; lateral cleft of parameres (Fig. 488) slightly narrowed near apex; apex rounded, very prominent ventrally and strongly upwards.

Female genital segments and genitalia. Tergite VIII (Fig. 528) transverse, strongly notched at base; anterior margin rounded and slightly prominent at middle; translucent basal area short and wide. Sternite VIII (Fig. 573) 0.67 times spiculum gastrale length; anterior margin wide- and moderately notched at middle. Genitalia (Fig. 622): sclerotized rings of openings of colleterial glands (Fig. 664) bearing 38 teeth; bursa copulatrix with longitudinal median band with carinae and spines and paired rounded lateral spiny areas; some sclerotized plates with spines dispersed around the elongate band.

Material examined. COLOMBIA. Ex-coll. Fleutiaux, $2 \mathrm{~F}$ (MNHN). Antioquia: Medellín, 2 F (MNHN), 1 F (NHMW). Cauca: 1 F (MNHN); Valle Buenaventura, Qbda [Quebrada] Guaipare, Guandal, 1 F (ICNC). Chocó: Quibdó, 1 M, 1 F (PCCV ), 1 F (MZSP). Santander: Quebrada La Cristalina, $1 \mathrm{~F}$ (MZSP). Valle del Cauca: $5 \mathrm{~F}$ (MNHN); Cali, $1 \mathrm{~F}$ (ZMHB); Cordillera, Lake Calima, Río Bravo Valley, nr Bugo, 1180-1200 m, 1 M (dissected), $1 \mathrm{~F}$ (MZSP retained PCCV), $11 \mathrm{~F}$ (PCCV ), $2 \mathrm{~F}$ (NHMW); Medio Calima, 4 F (1 F dissected, MZSP); Río Dagua, 6 F (MNHN);Valle Restrepo, V. do Río Bravo, Alt. $900 \mathrm{~m}, 1 \mathrm{~F}$ (ICNC). ECUADOR. $1 \mathrm{~F}$ (NHMW). Esmeraldas: 2 M (1 M dissected), 8 F (IMLA), 3 F (DZUP); Malimpias, Rio Esmeraldas, 1 F (MNMS); La Tola, 1 F (MNMS); San Martin, 2 F (IMLA). Guayas: Guayaquil, 1 F (MNHN). Napo: Coca, $1 \mathrm{~F}$ (PCCV ). Pichincha: Puerto Quito, $1 \mathrm{~F}$ (PCCV). Imbabura: Paramba, 4 F (MNHN). BOLIVIA. La Paz: Rio Madidi, Iturralde, 1 F (IMLA).

Remarks. Chalcolepidius villei is characterized especially by general pubescence green with lateral stripes of pronotum (elliptical) and elytra from brown to orange, scutellum folded, tibiae of male bearing fringe of long cilia and parameres of aedeagus cleft laterally. It is variable in size and also in pubescence coloration. It was observed specimens with general pubescence green, olive-green, yellowish-green or grayishgreen; sometimes the upperside is slightly different from underside. The antennae are usually clothed with black pubescence; in some specimens they are black on $1^{\text {st }}$ and $3^{\text {rd }}$ segments becoming brown apicad. The lateral stripes of pronotum are variable in coloration, size and shape: it is brown, ferruginous or slightly orange, and the size varying from $2 / 3$ to $3 / 4$ of pronotum length, but never reaching the hind angles base; in the majority of the specimens examined they reach the anterior and lateral margins and are narrowed apicad, but in a few, they are narrower and distant from the margins. The specimens from Ecuador and Bolivia present the lateral stripes of pronotum and elytra very narrow, incomplete, or even absent. According to the original description, in the holotype, the lateral stripes of pronotum do not reach the fore nor the hind angles. I dissected one male from Ecuador (Esmeralda) clothed with olive-green pubescence with ferruginous setae in two very narrow elongate stripes on pronotum and two lateral striae on each elytron, and verified that the genital segments and the aedeagus are very similar to that from Colombia with wider ferruginous bands on pronotum and elytra; the only difference is an additional tooth on each side of median lobe, and the apex of lateral cleft of parameres are identical.

C. villei is similar to $C$. fabricii differing especially by ( $C$. fabricii parenthesized): 1) pronotum with lateral ferruginous stripes (stripes absent); 2) hind angles of pronotum with truncate apex; 3) tergite VIII of male with lateroanterior margins rounded (narrowed apicad); 4) sternite VIII of male narrow with lateral translucent area opened (lateral translucent area closed); 5) median lobe bearing 7-8 teeth (4-6); 6) median lobe constricted near struts base (not constricted); 7) sclerotized rings of the openings of colleterial glands bearing 38 teeth (41).

C. villei belongs to fryi* group (Fig. 671).

Distribution. It is recorded from Colombia, Ecuador and Bolivia (Fig. 685).

Chalcolepidius virens (Fabricius, 1787)

(Figs. 87-89, 157, 308, 418, 453, 489, 530, 574, 665, 680)

Elater virens Fabricius, 1787: 172; Olivier, 1790: 15, pl.2, fig.19, pl. 5, fig. 55; Fabricius, 1792: 220; 1801: 226; Palisot de Beauvois, 1805: 213 , t. 9, f. 2. Syntype female: “America insularis"(HMUG) (not examined).

Chalcolepidius virens; Castelnau, 1840: 238; Erichson, 1841: 79 (= C. porcatus) (error); Candèze, 1881: 22; 1886: 68, 73; 1891: 38 (Cat.); Champion, 1894: 274, 280; 1897: 282; Schwarz, 1906a: 46.

Chalcolepidius porcatus var. virens; Erichson, 1841: 79; Lacordaire, 1857: 155; Candèze, 1857: 271; 1874: 163; Fleutiaux, 1911: 248; Schenkling, 1925: 57 (Cat.); Fleutiaux, 1926: 108 (Cat.); Blackwelder, 1944: 283 (Cat.).

Chalcolepidius perrisii Candèze, 1857: 285; Gemminger \& Harold, 1869: 1503 (Cat.); Candèze, 1886: 68, 73; Schenkling, 1925: 57 (Cat.); Fleutiaux, 1926: 108 (Cat.); Blackwelder, 1944: 283. Holotype female: "Type; 389; perrisii; collection Chevrolat; Type; Perrisi Candèze type Collection Fleutiaux; Chalcolepidius type Perrisii Cand. Mon. p. 289-24 fulvomarginatus Chev. olim. Amer. aequin Dr Dupont H; Collection Chevrolat; Collection E. Fleutiaux; rubbled specimen 
A Chalcolepidius porcatus (L.) CMF von Hayek, 1979" (MNHN)(examined). Syn. nov.

FABRICIUS (1787) described Elater virens, clothed with green pubescence, immaculate, and redescribed it in 1792 and 1801. Later, some coloration variations, as well some misidentifications, were observed by other authors.

OLIVIER (1790) presented illustrations of one specimen with blue pubescence and other green, and commented the similarities of this species with Elater striatus Linnaeus.

Castelnau (1840) redescribed this species as "entièrement couvert d'écailles couleur lie du vin, legérément dorées en dessous; le fond des élytres avec une rangée étroite, peu manquée de poils grisâtres". At this point Castelnau must have mixed $C$. virens with $C$. porcatus.

ERICHSON (1841) following Castelnau's concept considered Elater virens Fabricius "1801" as a variation of C. porcatus.

LACORDAIRE (1857) and CANDĖZE (1857) kept $C$. virens as a variation of $C$. porcatus. CANDÈzE (1874) treating of $C$. porcatus stated that this species is distributed by all "Amérique Méridional" until near $30^{\text {th }}$ degree and the variation virens seems to be on north until to Mexico, but it is very reduced in size and very rare. Later, CANDĖZE (1881) considered $C$. virens as a distinct species, and commented about the stability of the unicolorous pubescence, that varies from olive-green to blue, without bands or lines. This idea was followed in 1886 and 1891.

In the CHAMPION's (1894) key, $C$. virens is separate from $C$. exquisitus only by the body shape. In fact, besides the body shape, they differ especially by shape of the apex of lateral cleft of parameres and by geographical distribution. Champion commented about the different Candèze's positions and recorded C. virens from Mexico, Panama (Chiriqui) and Brazil. In 1897 he included the locality "Grenade-Balthazar (windward side)" and stated: "A Tropical-American insect extending to as far north as Mexico".

The more recente workers like FLEUTIAUX (1911, foot note) and Cataloguers, like SCHENkLING (1925) and BlACKWELDER (1944), have listed $C$. virens as a variety of $C$. porcatus Linnaeus. Examination of the available material has shown that they occur in the same regions, but they are herein, considered as distinct species.

CANDÈze (1857) described $C$. perrisii based on a totally black female, bright and glabrous, characterized especially by red band on integument of lateral margins of elytra.

HAYEK (personal communication) examining the holotype of $C$. perrisii, verified that the red margin of the elytra and some irregular red patches and scratches on the epipleura and thoracic sternites are due the abrasion of the surface of the cuticle. She took one specimen of $C$. porcatus, and with the aid of a paper handkerchief and a small stiff brush, removed the setae. She used a small sharp scalpel to scrape the lateral margins of the elytra until the red colour appeared. This treatment produced a pattern of scratches closely resembling those on the type of C. perrisii. According to her, considerable pressure is required to remove the setae and to abrade the surface of cuticle, and these results argue against the theory that the appearance of the specimen is the result of a series of natural events during the beetles lifetime. Similar effects were produced by treating specimens of $C$. limbatus and $C$. zonatus.

I examined the holotype of $C$. perrisii and also the specimen treated by Hayek and the presence, in the former, of green setae at base of elytra and no trace of white setae on pronotum let me consider it as a synonym of C.virens.

Length: 24-44 mm. Integument black clothed dorsally and ventrally with dense metallic scale-like setae green, grayishgreen, yellowish-green, bluish-green, blue, reddish-brown, violet-brown or violet (Figs. 87-89).

Frons trapezoidal, concave medioanteriorly; nasal plate high. Antennae (Fig. 157) serrate in both sexes, $3^{\text {rd }}$ segment triangular-elongate, slightly shorter than $4^{\text {th }}$. Pronotum longer than wide, wider at hind angles, slightly narrowed apicad, stronger narrowed in some females; convexity variable; micropunctate, intermingled with coarse punctuation moderately dense, giving rugose appearance in many specimens; hind angles wide, backwardly directed with truncate apex, raised laterally forming edge continuous with narrow lateral edge of pronotum; median basal tubercle flat, elongate, triangular, continuous with longitudinal median ridge, almost reaching anterior margin; posterior margin prominent and strongly notched at middle. Hypomera concave; laterointernal margin raised forming wall of anterior channel. Notosternal sutures strongly sinuous. Prosternum strongly convex, concave near sutures. Prosternal lobe transverse, fore angles slightly rounded. Scutellum strongly folded with horizontal basal area subtrapezoidal, concave longitudinal medially, notched anterior- and posteriorly. Borders of mesosternal cavity (Fig. 308) wide and horizontal on basal $3 / 4$ and vertical on distal $1 / 3$, forming L-shaped profile. First visible sternite prominent laterally, fits in small groove of elytra. Anterior and median tibiae and last tarsal segment of all legs of male bearing fringe of long cilia. Interstices slightly unequal; $2^{\text {nd }}$ forming flat tubercle near base; apex truncate with lateral angles rounded; few specimens bearing tiny sutural spine.

Male genital segments and aedeagus. Tergite VIII wider than long, gradually narrowed apicad on distal half; basal margin strongly notched; densely setous. Sternite VIII transverse, gradually narrowed apicad, stronger on distal $1 / 3$; densely setous, except median basal area; translucent in large median area with small spot each side and two short lateral bands. Sternite IX translucent in lateral band on distal third; setous at apex. Tergite IX densely punctuate; transverse with lateral margins rounded; anterior margin straight; tiny setae laterally on distal third. Aedeagus (Fig. 418): median lobe (Fig. 453) slightly narrowed near middle bearing 4-13; 10, 13 lateral teeth; lateral cleft of parameres (Fig. 489) with apex prominent dorsally.

Female genital segments and genitalia. Tergite VIII (Fig. 530) transverse, subrectangular; anterior angles slightly rounded; basal margin strongly notched; translucent area surpassing middle. Sternite VIII (Fig. 574) 0.65 times spiculum gastrale length; anterior margin wide- and deeply notched. Female genitalia: sclerotized rings of openings of colleterial 
glands (Fig. 665) bearing 43 teeth; bursa copulatrix with longitudinal median wide band with carinae and spines and two lateral rounded spiny areas.

Material examined. WEST INDIES. Barbados. Par. St. Andrew, Mirabeau Agr. School, 2 F (FSCA); Par. St. Andrew Paradise, 1 F (FSCA). Grenada. 1 F (FSCA); Cacao Stammer (locality not found), 1 M, 2 F (ZMUC); Par. St. Patrick Mt. Rose, 1 F (MZSP, retained FSCA); St. Georges, $1 \mathrm{M}$ (MCZC), $1 \mathrm{~F}$ (MNHN). Trinidad. $1 \mathrm{M}(\mathrm{AMNH}), 2 \mathrm{~F}$ (MNHN), 3 F (USNM), 1 F (ZMUC); Arima Valley, 6 F (AMNH); St. George Co., Arima Ward, Morne Bleu Rd. Relay Sta., 1 F (FSCA); Maraval, 4 F (USNM); Maraval Valley, 1 F (USNM); Mount Hope, 1 M (MZSP, retained JEWC); Port of Spain, $1 \mathrm{~F}$ (AMNH), $13 \mathrm{M}, 15 \mathrm{~F}$ (FSCA), $3 \mathrm{M}$ (2 $\mathrm{M}$ dissected), $1 \mathrm{~F}$ (MZSP, retained FSCA), $1 \mathrm{~F}$ (MZSP), $1 \mathrm{~F}$ (ZMHB); Sangre Grande, 1 F (USNM); St. Benedict Mt., Tunapuna, 1 F (SRGI). TOBAGO. $1 \mathrm{~F}$ (MZSP, retained USNM), $3 \mathrm{~F}$ (USNM); Friendship, $1 \mathrm{~F}$ (USNM); Scarborough, $1 \mathrm{~F}$ (USNM); St. John Prov., Charlotteville, $1 \mathrm{~F}$ (USNM). VENEZUELA. $1 \mathrm{~F}$ (AMNH), $3 \mathrm{~F}$ (MCZC), $7 \mathrm{~F}$ (MNHN), $8 \mathrm{~F}$ (NHMW), 3 F (PCCV), 3 F (ZMUC), ex-coll. Fry 1905-100, left hand side $=$ "perrisii"Cand. made by Hayek, CMF von Hayek det. 1979, 1 F (MNHN), ex-coll. Fleutiaux, 2 F (MNHN); ex-coll. Le Moult, $1 \mathrm{~F}$ (MNHN). Aragua: Rancho Grande, nr Maracay, 6 F (AMNH), 1 F (FSCA); Maracay Bay, 5 F (FSCA). Bolívar: Borbón, 1 F (SRGI); Caura Dam, 1 F (AMNH). Isla Margarita, $1 \mathrm{~F}$ (ZMUC). Carabobo: Urama, $1 \mathrm{~F}$ (USNM). Falcón: La Guaira, 1 F (USNM); San Esteban, 1 M, 1 F (MNHN); San Esteban près du Puerto Cabello, 2 F (MNHN); Esteban Valley, ex-coll. Oberthür, ex-coll. Fleutiaux, $3 \mathrm{~F}$ (MNHN). Federal District: Caracas, 1 $\mathrm{F}$ (MZSP, retained ZMUC), $1 \mathrm{~F}$ (USNM), $1 \mathrm{M}, 8 \mathrm{~F}$ (ZMUC), ex-coll. Sallé, ex-coll. Fleutiaux, 2 F (MNHN). Miranda: Caucagua, 1 F (MNHN). Lara: Cumaragua, 1 F (MZSP, retained USNM), 3 F (USNM). Monagas: Caripito, 6 F (AMNH). Sucre: Cunamá, 1 F (USNM); Los Camales, $1 \mathrm{~F}$ (USNM). Yaracuy: Yumare, 1 M (IMLA). Zulia: Maracaibo, 2 F (USNM); San Julian, 1 M, 4 F (USNM). COLOMBIA. 4 F (MNHN), ex-coll. Fleutiaux, 1 F (MNHN). Valle de Cauca: ex-coll. Fleutiaux, 1 F (MNHN). GUYANA. 4 F (ZMUC). West Berbice: Blaimont Plantation, 1 F (USNM). SURINAME. $2 \mathrm{~F}$ (MCZC), $6 \mathrm{~F}$ (MNHN), $1 \mathrm{~F}$ (ZMUC). Brokopondo: Brownsberg Natuurpark, Mazaroni Plateau, 400-500 m, 1 F (USNM). BRAZIL. 1 F (MZSP, retained USNM), 2 F (NHMW), 3 F (USNM). Amapá: Serra do Navio, 1 F (IBSP). [Amazonas or Para:] Santa Rosa, ex-coll. Fleutiaux, 6 F (MNHN). Amazonas: Benjamin Constant, 5 F (MZSP); Itacoatiara, $16 \mathrm{~F}$ (1 F dissected) (MZSP); Itapiranga, $1 \mathrm{~F}$ (MCZC); Jari to Vila Nova, 1 F (IBSP); Manaus, 3 F (AMNH), 1 F (MNHN), $3 \mathrm{~F}$ (MNRJ), $3 \mathrm{~F}$ (MZSP, retained DZUP), $2 \mathrm{~F}$ (MZSP), $26 \mathrm{~F}$ (DZUP); Providência, 1 F (MZSP retained NHMW), 1 F (NHMW); Reserva Biológica do Cuieiras, $50 \mathrm{Km}$ N Manaus, $1 \mathrm{M}$ (dissected) (MNHN); Reserva Ducke, 2 F (MZSP); Rio Uatumã, 5 F (AMNH). ECUADOR. 1 $\mathrm{F}(\mathrm{AMNH}), 1 \mathrm{~F}(\mathrm{MNHN}), 1 \mathrm{~F}$ (USNM). Bolívar: Balzapampa, $1 \mathrm{~F}(\mathrm{MNHN})$. Esmeraldas: Río Verde, 2 F (MNMS); San Mateo, 1 F (MNMS). MoronaSantiago: Macas, 4 F (IMLA), 6 F (MNHN). Napo: Canelos, 1 F (MNHN). Pastaza: Río Bobonaza, $1 \mathrm{~F}$ (USNM); Cuisimi, on Río Cuisimi, $150 \mathrm{Km}$ SE Puyo, 350 m, 1 F (AMNH); Montalvo, 2 F (IMLA); Río Pindo Yaçu, Oriente, 1 F (MNMS); Tena, 1 F (IMLA). Pichincha: Quito, 1 F (AMNH); Santo Domingo [de los Colorados], 1 F (AMNH); Llamas (locality not found), $2 \mathrm{~F}$ (MNHN). PERU. $6 \mathrm{~F}$ (MNHN), $1 \mathrm{~F}$ (NHMW), $2 \mathrm{~F}$ (USNM), $1 \mathrm{~F}$ (ZMHB), $1 \mathrm{~F}$ (ZMUC), ex-coll. Sallé, ex-coll. Fleutiaux, $1 \mathrm{M}$ (MNHN). Ayacucho: La Mar, Santa Rosa, 640 m, 1 F (USNM); Rio Toro, 1 F (ZMHB). Cuzco: Quiroz, Rio Paucartambo, 1 F (FSCA); Urubamba, 10 F (MNHN). Huánaco: Pozuzo, 3 F (MNHN); Shapajilla, jungle $630 \mathrm{~m}$, on Ficus glabrata, $1 \mathrm{~F}$ (USNM). Junín: Central région du Pérené, 2 F (MNHN); Chanchamayo, 11 F (AMNH), 22 F (MNHN), 2 $\mathrm{F}$ (NHMW), $4 \mathrm{~F}$ (ZMHB), $1 \mathrm{~F}$ (ZMUC), ex-coll. Fleutiaux, 13 F (MNHN), $1300 \mathrm{~m}, 1 \mathrm{M}$ (dissected), $5 \mathrm{~F}$ (IMLA); La Merced, $6 \mathrm{~F}$ (AMNH), $1 \mathrm{~F}$ (MNHN); Piches \& Perene Vs., 2000 a 3000 ft., 1 F (USNM); Satipo, 1 M (FSCA); La Palma, 1500 m, 1 F (USNM). Lima: Environs Lima, 4 F (AMNH); 3 F (MNHN). Loreto: Iquitos, 2 F (ZMUC). Madre de Dios: Iberia, $500 \mathrm{ft}$., $1 \mathrm{~F}$ (AMNH). Piura: Río Santiago, 1 F (AMNH); Río Singo, 1 F (MNHN). BOLIVIA. 2 F (USNM), 1 F (ZMUC). Cochabamba: Cochabamba, 2600 m, 4 F (IMLA). El Beni: Chaparé, San Frans del Chipirili, 1 M, 2 F (IMLA). La Paz: Coroico, 1 F (MCZC), 3 F (MNHN),
1 F (NHMW); Prov. Lasicaje, Maipiri, Cerro Paititi (locality not found), 2 F (IMLA); Uyapi, 2 F (MZSP, retained SRGI), 7 F (SRGI).

Remarks. Chalcolepidius virens is characterized especially by uniform coloration, scutellum folded, tibiae of male bearing fringe of long cilia and parameres of aedeagus cleft laterally with apex prominent dorsally. It is commonly confused with $C$. lacordairii, especially the larger and green specimens, but $C$. virens is recorded from West Indies and South America and presents narrower and smaller body, pronotum weakly rugose and different shape of apex of lateral cleft of parameres.

It is variable in pubescence coloration, and specimens green, grayish-green, yellowish-green, bluish-green, blue, reddishbrown, violet-brown or violet were examined.

The specimens from Brazil are usually brown, violet-brown or violet; those from other countries of South America, green or olive-green with a few specimens bluish; specimens from Trinidad are predominantly blue and some are bluish-green.

The aedeagus of six males from different localities and with different pubescence coloration were examined and it was observed variation only on the number of lateral teeth of median lobe. It was found from 4 to 13 teeth: one green male from Trinidad (Port of Spain) presented 4, 5 teeth; three blue males from same locality, 5, 6; 5, 8; 10,10; one green male from Peru (Valle Chanchamayo), 10, 11; and one violet-brown from Brazil (Amazonas) 7, 8 teeth. The largest number of teeth, 12, 13, was found in one blue specimen from Grenade. The apex of the lateral cleft of parameres is prominent dorsally in all aedeagus examined, being stronger in one specimen from Amazonas. The males dissected showed genital segments similar in all specimens.

\section{C. virens belongs to forreri* group (Fig. 671).}

Distribution. It is recorded from West Indies (Barbados, Grenade), Trinidad, Tobago, Venezuela, Colombia, Guyana, Suriname, Brazil (Amapá, Amazonas), Ecuador, Peru and Bolivia (Fig. 672).

\section{Chalcolepidius virgatipennis sp. nov.}

(Figs. 90, 91, 158, 220, 309, 529, 575, 620, 666, 691)

Type material. Holotype male: "Durango Mex[ico]; Chalcolepidius approximatus CMF von Hayek det. 1980; Muséum Paris coll. E. Fleutiaux “ [aedeagus extroverted] (MNHN) (Fig. 90).Paratypes: 2 females: "Coll. Schwarz; Sr.[Sierra] Durango Mexico Coll. Speyer; M[??] Berlin Dahlem Fleutiaux; coll. F1. 62; Chalcolepidius approximatus Er. CMF von Hayek det. 1980; Muséum Paris coll. E. Fleutiaux "(MNHN) (Fig. 91); "Mex[ico]; Muséum Paris coll. E. Fleutiaux" (dissected) (MZSP retained MNHN).

Holotype. Length: $27 \mathrm{~mm}$. Integument dark-brown clothed dorsally and ventrally with metallic scale-like setae grayisholive (glabrous on longitudinal median region of pronotum and higher interstices); lateral stripes of pronotum narrow, widened at base, parallel lateral margins, reaching $2 / 3$ of pronotum length; dull white setae on lateral stripes of pronotum, median region of epipleura, striae and lower interstices (except small basal area); distal third of pronotum, laterally with sparse white setae, not forming band; antennae clothed with dark-brown short 
setae intermingled with reddish-brown (Fig. 90).

Frons narrower distally making anterior half trapezoidal; slightly concave medioanteriorly; small-punctuate with sparse slightly coarse punctuation; nasal plate very high, slightly declivous and coarsely punctuate. Antennae (Fig. 158) serrate, not reaching posterior margin of procoxae; $3^{\text {rd }}$ segment triangular-elongate, slightly shorter than $4^{\text {th }}$. Pronotum (Fig. 220) longer than wide, slightly narrowed apicad from hind angles base; strongly convex; convexity decreasing basad; smallpunctuate with sparse coarser punctuation more concentrate on lateroanterior half; lateral margins forming narrow edge on $2 / 3$ basal; anterior margin sinuous, prominent at middle; hind angles moderately wide, slightly divergent, raised laterally forming edge continuous with that of lateral margins; posterior margin prominent and strongly notched at middle; median basal tubercle flattened, triangular-elongate, concave at middle, continuous with weak longitudinal median ridge, not reaching anterior margin. Hypomera concave and small-punctuate with slightly coarse sparse punctuation; internal margin raised and not carinate anteriorly forming wall of prosternal channel; narrow slightly raised band parallel notosternal sutures. Notosternal sutures strongly sinuous. Prosternum strongly convex, grooved near sutures; small-punctuate with coarse sparse punctuation near sutures. Prosternal lobe transverse, marginated laterally with rounded angles; punctuation small, slightly coarser and sparser than prosternum. Scutellum strongly folded with horizontal basal area subtrapezoidal, notched anterior- and posteriorly. Mesosternal cavity narrow, elliptical, with borders (Fig. 309) thick and horizontal on basal $2 / 3$ and moderately declivous on distal $1 / 3$, forming semielliptical profile. First visible sternite prominent laterally, fits in small groove of elytra. Anterior and median tibiae and last tarsal segment of all legs of male bearing fringe of long cilia. Striae grooved, marked by coarse punctures; interstices unequal and micropunctate; lower interstices flat, convex only on basal fourth; apices conjointly rounded; lateral margins of elytra not carinate.

Aedeagus: median lobe (Fig. 454) constricted near middle bearing 7, 8 lateral teeth; lateral cleft of parameres (Fig. 491) constricted near apex, flattened longitudinal medially; apex prominent dorsally, with rounded laterodistal angles.

Female genital segments and genitalia (Paratype: Mexico). Tergite VIII (Fig. 529) transverse, subrectangular, strongly notched basally; densely setous, translucent in median basal area, surpassing middle and marginal band interrupted at middle; densely setous. Sternite VIII (Fig. 575) 0.63 times spiculum gastrale length, wide- and strongly notched at middle. Genitalia: sclerotized rings of openings of colleterial glands (Fig. 666) elliptical bearing 31 teeth; bursa copulatrix (Fig. 620) with longitudinal median band with carinae and spines and two lateral rounded spiny areas.

Remarks. The females paratypes are $28-29 \mathrm{~mm}$ long. The olive pubescence is denser than that of holotype and the paratype from Durango presents the lateral white stripes of pronotum reaching the anterior margin (very narrow on distal third).

Chalcolepidius virgatipennis is characterized especially by general pubescence olive with white setae on lateral stripes of pronotum, median region of epipleura, striae and lower interstices, lateral white stripes of pronotum narrow, short (2/3 basal of pronotum) and widened at base, scutellum folded, tibiae of male bearing fringe of long cilia and parameres of aedeagus cleft laterally. It is similar to C. approximatus, differing especially by white lateral stripes of pronotum, shorter and narrowed apicad in the former and longer, wider and almost parallel in the latter, and epipleura totally clothed with white setae in the latter. Besides, the median lobe of aedeagus is more constricted with larger teeth in the former, but the number of lateral teeth of the median lobe is almost the same, 7, 8 in the former and 10, 10 in the latter. The apices of lateral cleft of parameres present rounded angles in the former and sharpened angles in the latter. The female genital segments and genitalia are similar in both species, only the sclerotized rings of the openings of colleterial glands are more elongate, bearing 31 teeth in the former and 33 in the latter. 671).

C. virgatipennis is the sister-group of $C$. virginalis (Fig.

Distribution. It is recorded from Mexico (Durango) (Fig. 691).

Etymology. The epithet is derived from one of the latin words for striped, virgatus, related to elytra.

Chalcolepidius virginalis Candèze, 1857

(Figs. 92, 93, 159, 221, 350, 419, 455, 492, 531, 576, 667, 691)

Chalcolepidius virginalis Candèze, 1857: 264, 288; Gemminger \& Harold, 1869: 1504 (Cat.); Candèze, 1874: 168; 1886: 72; 1891: 38 (Cat.); Champion, 1894: 274, 281, 282, t. 12, f. 2, 3; Schenkling, 1925: 57 (Cat.); Blackwelder, 1944: 283 (Cat.). Holotype male: "Type; Merida, Yucatan; Collection Chevrolat; virginalis Cand. Type; Collection Fleutiaux" (MNHN) (examined).

Chalcolepidius virginalis var. Champion, 1894: 274, 282, t. 12, f. 3; Casey, 1907: 35 (= C. championi)

Chalcolepidius championi Casey, 1907: 35 ; Schenkling, 1925: 55 (Cat.). Syntype female: "Type; Tehuantepec, Sumichrast; F; B. C. A. Col. III (1) Chalcolepidius virginalis, var. F Cand.; sp. figured; Syntype of Chalcolepidius championi Casey CMF von Hayek 1978"(BMNH) (examined). Syn. nov.

The original description of $C$. virginalis was based on a male, from Merida (Mexico), with median region of pronotum and higher interstices naked. It was described as black, clothed with white setae, and according to CANDÈzE (1857) "Il est probable que les individus fraichement métamorphosés sont entièrement blancs à l'exception des antennes et des tarses"; he observed long cilia only on first pair of tibiae and last tarsal segment of all legs of male. In fact, the median region of pronotum and interstices are clothed with metallic green setae.

CANDĖZE (1886) kept an idea that this species was totally clothed with white setae, and characterized $C$. virginalis as "unicolore, blanchâtre".

Champion (1894) put C. virginalis close to C. angustatus separate especially by shape of lateral stripes of pronotum and 
the coloration of setae of the under surface. He also included a variation: "the marginal band of white scales much narrower, the rest of the thorax and elytra, the base of the latter excepted, clothed with minute greenish or cinereous scales". He observed long cilia at apex of anterior tibiae and the last tarsal segments of all legs. After examining a good series, he concluded that the upper and under surfaces of this species are clothed with white setae and the elytral interstices and a wide median band on the pronotum are sparsely clothed with minute brassy setae. He illustrated a typical male and a variety female.

CASEY (1907) considered the Champion's variety a new species and stated: "In like manner the species published on plate 12 of Vol. III, part I, fig. 3, of "Biologia", appears to be more than a variety of virginalis, and it may take the name of championi (n. sp.)".

I studied the male holotype of $C$. virginalis and the female syntype of $C$. championi and concluded that they are conspecific.

Length: 24-38 mm. Integument black, clothed dorsally with grayish-green or olive-green pubescence and ventrally, including legs, with white scale-like setae; lateral stripes of pronotum band-like, narrow (1/8 pronotum width) widened basally and sometimes near middle; white pubescence on irregular band of frons, lateral stripes of pronotum and base and lateral bands of elytra (2-3 interstices wide) and sometimes, lower interstices (Figs. 92, 93). Antennae clothed with short dark-blue or dark-brown setae.

Frons strongly convex at middle; fore angles prominent; punctuation small and dense intermingled with coarse and sparse. Antennae of male (Fig. 159) strongly serrate; third antennal segment triangular-short. Pronotum (Fig. 221) very longer than wide, slightly narrowed apicad from hind angles apex, narrower at apex; lateral margins forming narrow lateral edge on basal 2/3; punctuation small and dense intermingled with coarse and sparse; anterior margin slightly sinuous; hind angles wide, backwardly directed, raised laterally forming edge continuous with that of lateral margins; median basal tubercle very weak and triangular or indistinct; posterior margin prominent and strongly notched at middle. Hypomera concave and small-punctuate; anterior internal margin raised forming wall of prosternal channel. Notosternal sutures moderately sinuous. Prosternum strongly convex and concave near sutures, flattened and glabrous longitudinal medially. Prosternal lobe wide with hind angles slightly rounded; punctuation small and dense. Scutellum strongly folded with horizontal basal area subtrapezoidal notched anterior- and posteriorly, grooved longitudinal medially, stronger anteriorly, forming two dentiform prominences at anterior margin. Borders of mesosternal cavity wide and horizontal on basal $2 / 3$ and moderately declivous on distal $1 / 4$, forming semi-elliptical profile. First visible sternite prominent laterally fits in small groove of elytra. Anterior tibiae and last tarsal segment of all legs bearing fringe of long cilia. Striae marked by rows of coarse punctures; interstices convex and small punctuate, unequal; a flat basal tubercle near second interstice.
Male genital segments and aedeagus. Tergite VIII wider than long, gradually narrow apicad; strongly notched basally; densely clothed with setae. Sternite VIII (Fig. 350) wider than long, slightly narrowed apicad; translucent at middle and at two narrow lateral bands; setae more concentrate near margins and longitudinal median on $2 / 3$ distal. Tergite IX wider than long, densely punctuate; anterior margin almost straight. Sternite IX partially translucent with short setae near apex. Aedeagus (Fig. 419): median lobe (Fig. 455) wide, slightly narrowed near middle, forming rounded prominence near base of struts, bearing 10, 10 lateral teeth; lateral cleft of parameres (Fig. 490) short dorsally, more developed ventrally, with apex inclined forming small ventral tooth.

Female genital segments and genitalia. Tergite VIII (Fig. 531) transverse, strongly notched on basal margin; translucent at median basal triangular area surpassing middle and at marginal band, interrupted at middle; densely setous. Sternite VIII (Fig. 576) 0.57 times spiculum gastrale length; anterior margin moderately wide and deeply notched. Genitalia: sclerotized rings of openings of colleterial glands (Fig. 667) bearing 32 teeth; bursa copulatrix with longitudinal median area with carinae and spines and two lateral small rounded spiny areas.

Material examined. MEXICO. $1 \mathrm{~F}$ (MNHN), $1 \mathrm{~F}$ (ZMHB), ex-coll. Fleutiaux, $1 \mathrm{~F}$ (MNHN). Sonora: $5 \mathrm{Km}$ E Alamos, $1 \mathrm{~F}$ (FSCA); Guaymas, Golf of California, 1 F (dissected) (MCZC); Huizar, 1 F (ZMHB). Oaxaca: Tehuatepec, $1 \mathrm{M}$ (dissected) (FSCA).

Remarks. Chalcolepidius virginalis is characterized especially by general pubescence greenish dorsal and white ventral, white lateral stripes on pronotum and elytra, lateral stripes of pronotum band-like and narrow, widened basally, scutellum folded, anterior tibiae of male bearing fringe of long cilia and parameres of aedeagus cleft laterally.

This species is variable in pubescence coloration. The male holotype of $C$. virginalis is clothed with white setae with median region of pronotum and interstices, especially the higher, totally or partially naked. It is possible to observe only a few greenish setae near lateral margins of pronotum and several on interstices. The female syntype of $C$. championi examined is clothed with grayish-green setae dorsally with white pubescence at narrow lateral stripes of pronotum and base and lateral bands of elytra (2-3 interstices wide); the last interstice is clothed with grayishgreen pubescence. The different coloration of the setae of the two types is not related with the sex because CHAMPION (1894) examined three females, which he called "typical form of this species", that corresponds to $C$. virginalis male holotype coloration. I examined a female (ZMHB) similar to the syntype of $C$. championi, but the lateral white stripes of elytra are irregular and the white pubescence is present on basal third of striae 5-6 and interstice 8, and almost totally on striae 8 and 9. The male dissected is from the type locality of $C$. championi (FSCA), and it was almost totally naked dorsally and white ventrally, including legs. It was possible to observe white setae near hind angles of pronotum and a few greenish near median basal tubercle area. This male presents fringe of long cilia on anterior tibiae and last tarsal segment of all legs. The median 
lobe of aedeagus presents larger number of teeth (10 each side) in relation to holotype, which aedeagus was partially extroverted ( 6 teeth in one side and 5 in other). One of the examined females is clothed with olive setae on median region of pronotum and higher interstices and the lateral bands of pronotum are widened near middle.

The lateral white bands of pronotum are variable in width: in specimens predominantly greenish dorsally, they are narrow and widened near hind angles; in specimens with lower interstices white, they are wider and sometimes, widened near middle.

C. virginalis is the sister-group of C. virgatipennis (Fig. 671).

Distribution. It is restricted to Mexico (Sonora, Oaxaca, Yucatan) (Fig. 691)

Chalcolepidius viridipilis (Say, 1825)

(Figs.84,160,161,222,269,310,351,420,456,492,577,619,668,678)

Elater viridipilis Say, 1825: 257. Syntype(s): “America" (believed lost, see Hayek, 1973: 280).

Chalcolepidius viridipilis; LeConte, 1853: 495; Lacordaire, 1857: 155; Candèze, 1857: 264, 290, 291, t.6, f.1; Gemminger \& Harold, 1869: 1504 (Cat.); Candèze, 1874: 169; 1886: 69, 74; 1891: 40 (Cat.); Casey, 1907: 34; Blatchley, 1910: 717; Kirk, 1922: 238 (biology); Schenkling, 1925: 57 (Cat.); Fleutiaux, 1926: 108 (Cat.); Blackwelder, 1944: 283 (Cat.)

Chalcolepidius prasianus Erichson, 1841: 85; Candèze, 1857: 291 (Syn.). Holotype female: "16231; viridipilis Lec., Cand.*, Elat. viridip. Say prasianus Er.* Am. Sept.; holotype F Chalcolepidius prasianus Erichson, 1841 CMF von Hayek, 1980 = viridipilis Say 1825" (ZMHB) (examined).

Chalcolepidius debilis Casey, 1907: 34; Leng, 1920: 167 (Cat.); Schenkling, 1925: 55 (Cat Syntypes: 2 males, 1 female. Males: "DC; Casey bequest 1925; debilis-2 paratype USNM 48456"; same data + "debilis-3". Female: "NC; Casey bequest 1925; Type USNM 48456; debilis" (USNM) (examined). Syn. nov.

ERICHSON (1841) described C. prasianus from Brazil, later considered as an erroneous type locality.

LeConte (1853) transferred Elater viridipilis to Chalcolepidius and supposed that this species could be the same as $C$. prasianus Erichson, 1841. He was the first to give more precise locality than "America" recording $C$. viridipilis from "Middle and Southern States"

CANDĖZE (1857) examined the female described by Erichson and commented that the type locality given for $C$. prasianus, Brazil, is erroneous. He was surprised with Erichson's position including $C$. viridipilis in the same section as $C$. attenuatus because these species have different scutellum shape.

I examined the Erichson's material of $C$. prasianus (ZMHB) and observed that, by the label of the female holotype, "Amer. Sept.", this species is recorded from North America, and by label of another male, "Bras. Richt" identified as "ramicornis N", it is recorded from Brazil. This data confirm the Candèze's supposition that it does not occur in Brazil.

CASEY (1907) presented a key including C. debilis, a new species, in the item 17, shared with $C$. viridipilis. These two species were separated by (C. viridipilis in parenthesis): elytra little more than twice as long as wide (2 $1 / 2$ times); striae sulcate, very coarsely punctuate or foveate (striae punctuate; punctures moderately coarse and well separate); and hind angles of pronotum more obtuse, abruptly and feebly averted (gradually and feebly averted). According to him, C. debilis is smaller in size (20-22 $\mathrm{mm}$ ) than $C$. viridipilis $(24 \mathrm{~mm})$. After examining the material studied by Casey I concluded that $C$. debilis is conspecific with $C$. viridipilis and that the differences presented by CASEY (l.c.) represent intraspecific variations.

Length: 18-26 mm. Narrow, parallel body. Integument darkbrown or brown, clothed with scale-like short, metallic setae green-olive or bluish-green dorsally and ventrally; in some specimens both color are intermingled (Fig. 84).

Frons not carinate, strongly declivous. Antennae long, surpassing hind angles and flabellate in male (Fig. 161), pectinate in female (Fig. 160); $3^{\text {rd }}$ segment transverse with spiniform appendix in male and elongate and triangular in female. Pronotum (Fig. 222) very longer than wide (1.2 times longer than wide) subrectangular, sides almost parallel, narrowed only frontally or also slightly narrowed at hind angles base; moderately convex from lateral edges; convexity decreasing basad; micropunctate with moderately coarse and sparser punctuation lateroanteriorly; anterior margin slightly sinuous at middle; lateral margins raised forming narrow smooth edge; hind angles wide, backwards, with rounded apex, raised laterally forming edge wider and continuous with that of lateral margins; median basal tubercle flat, triangular; posterior margin prominent and strongly notched at middle. Hypomera concave, small and densely punctuate, internal margin raised anteriorly forming wall of anterior channel. Notosternal sutures slightly sinuous. Prosternum with small and sparse punctuation; punctuation coarse and dense near sutures; moderately convex, flattened longitudinal medially; slightly concave near sutures. Prosternal lobe with punctuation moderately coarse and sparse; emarginated laterally; anterior margin rounded. Scutellum (Fig. 269) strongly folded with horizontal basal area subtrapezoidal, grooved longitudinal medially. Borders of mesosternal cavity (Fig. 310) wide and horizontal on basal $2 / 3$ and slightly declivous on distal $1 / 3$, forming inclined profile. Meso-metasternal suture weak. First visible sternite not prominent laterally. Anterior and median tibiae of male bearing fringe of short cilia. Striae marked by coarse punctures; interstices equal, convex and small punctuate; base of interstices 2-4 flat and forwardly directed forming weak tubercle.

Male genital segments and aedeagus. Sternite VIII (Fig. 351) transverse, narrowed apicad, subtrapezoidal, translucent at middle and at two lateral and basal bands. Tergite IX transverse, densely punctuate; fore angles widely rounded; anterior margin slightly notched at middle. Aedeagus (Fig. 420): median lobe (Fig. 456) 0.55 times the aedeagus length, wide, slightly narrowed near middle and apex, bearing 8,$9 ; 8,11$ very small lateral teeth; lateral cleft of parameres (Fig. 492) almost straight with upwards apex.

Female genital segments and genitalia. Tergite VIII transverse, almost rectangular with fore angles rounded; translucent at median basal triangular area and at marginal band, 
interrupted basally and at middle. Sternite VIII (Fig. 577) 0.57 times spiculum gastrale length; anterior margin wide- and deeply notched. Genitalia (Fig. 619): sclerotized rings of openings of colleterial glands (Fig. 668) grater-like near base; bursa copulatrix with small ventral area with carinae and spines.

Material examined. Besides the holotype, I examined also $1 \mathrm{M}$ and 1 F of C. prasianus from Hist. coll. of ZMHB: M: "16231; Bras. Richt; ramicornis N; Chalcolepidius viridipilis Say CMF von Hayek 1980"; F: "16232; [same data as male]". North America: 2 F (ZMHB). UNITED STATES OF AMERICA. California: $1 \mathrm{M}$ (MNHN). Texas: $3 \mathrm{M}$ (USNM); Dallas Co., Dallas, 1 F (ZMHB); localities not found: Hanston, 1 F (USNM), Through C.V. Riley, 1 M (USNM). Bexar Co., Stone Oak S'bait, 2 M, 1 F (JEWC), 1 M, 1 F (MZSP); Brazos Co., College Station (on tanglefoot screen), $1 \mathrm{~F}$ (TAMU); $10 \mathrm{mi} \mathrm{S}$ College Station, $1 \mathrm{~F}$ (FSCA); Burleson Co, 1 M (MZSP, retained TAMU); Comal Co., $1 \mathrm{M}$ (AMNH); Crockett Co., 2 mi w. jct. 29 \& 163, 1 F (TAMU); Galveston Co., Galveston, 1 M (CMNH); Kendall Co., New Branfels, 2 F (USNM); Kern Co., Kernville, 1 M (TAMU); McLennan Co., 1 F (TAMU); Nelson Co., 2 F (MZSP; 1 F retained USNM); Gonzales Co., Welder Wildlife Refuge, 1 F (TAMU); Tarrant Co., Fort Worth Nat. Ctr., 1 F (PCCV). New Jersey: Burlington Co., Palmyra, 1 F (USNM); Mercer Co., Trenton, $1 \mathrm{~F}$ (USNM)._Pennsylvania: $1 \mathrm{~F}(\mathrm{AMNH}), 1 \mathrm{~F}(\mathrm{CMNH}), 2 \mathrm{~F}$ (1 dissected) (MZSP), 1 M (SEMC), 1 F (USNM); Allegheny Co., Pittsburgh, 2 F (CMNH); Delaware Co., 1 F (AMNH), 1 F (OSUC); Lester, 1 F (USNM); Philadelphia Co., Philadelphia, 1 F (OSUC), 4 F (USNM); Schuylkill Co, Frackville, 1 F (OSUC); Westmoreland Co., Jeannette, 1 M (dissected) (MZSP). Missouri: Vernon Co., In Nevada area, 1 F (FSCA). Oklahoma: Payne Co., Stillwater, 1 M (USNM). Arkansas: Buffalo St. Pk, 1 F (TAMU). Maryland: 3 F (CMNH); Baltimore Co., Baltimore, $1 \mathrm{M}, 1 \mathrm{~F}$ (USNM); Catonsville, 1 F (USNM); Dorchester Co., Breton Bay, Potomac, $1 \mathrm{M}$ (MZSP retained USNM); Cambridge, 1 F (FSCA); Prince Georges Co., College Park, 1 M (USNM); near Plummer Md (locality not found), $1 \mathrm{~F}$ (USNM). District of Columbia: $2 \mathrm{M}$ (CMNH), $1 \mathrm{M}$ (MZSP); Washington, 1 F (FSCA), 1 F (PCCV), 14 M, 22 F (USNM), Park near USNM, 1 M, 2 F, 1 couple in copula (USNM); Rock Creek (locality not found), $1 \mathrm{M}, 4 \mathrm{~F}$ (USNM). Virginia: $1 \mathrm{~F}$ (CMNH), $4 \mathrm{~F}$ (USNM); Alex Co., 1 M (USNM); Arlington Co., Arlington, 1 F (AMNH), $1 \mathrm{~F}$ (CMNH), 4 F (USNM); Fairfax Co., Falls Church, 1M, 3F (USNM); Henrico Co., Glenallen, 1 M (USNM); Nelson Co., Norfolk, 1 F (USNM); Spotsylvania Co., Fredericksburg, 1 M (USNM). North Carolina: Wake Co., Raleigh, 1 F (USNM). South Carolina: Pickens Co., Pickens, 1 F (USNM). Alabama: Mobile Co., Mobile, 1 F (USNM). Georgia: Chatham Co., Tybée Island, 1 M (OSUC). Louisiana: New Orleans, 1 F (MNHN); St Tammany Parish, Covington, 1 F (USNM); Slidell, 1 M (AMNH). Florida: Alachua Co., Gainesville, 1 F (FSCA); Nassau Co., Amelia Island, 1 F (FSCA); St Nicholas (locality not found), 1 M (USNM); Dade Co., Miami, 1 F (USNM). MEXICO. Guerrero: Altamirano, 1 M (AMNH); 41-43 Km N Chilpancingo, $1 \mathrm{~F}$ (FSCA); $4 \mathrm{mi}$ Taxco [de Alarcón], $1 \mathrm{~F}$ (SEMC). Bras., nr 16 232, identified as "ramicornis N", 1 M (ZMHB).

Remarks. Chalcolepidius viridipilis is characterized especially by the general pubescence metallic unicolor, usually olive, bluish-green or both intermingled, pronotum very long, subrectangular, scutellum folded, anterior tibiae of male bearing fringe of short cilia, parameres of aedeagus cleft laterally and median lobe of aedeagus bearing very small spines. In some specimens, the median basal tubercle of pronotum is continuous with a longitudinal median impunctate weak ridge, not reaching anterior margin and the scutellum presents a very weak longitudinal groove or anterior margin notched.

It is similar to C. attenuatus especially by the size and body shape, but they are easily separated (see Remarks after $C$. attenuatus).

C. viridipilis belongs to chalcantheus* group (Fig. 671).
Distribution. It is recorded from United States of America (California, Texas, New Jersey, Pennsylvania, Missouri, Oklahoma, Arkansas, Maryland, District of Columbia, Virginia, North Carolina, South Carolina, Alabama, Georgia, Louisiana, Florida,) and Mexico (Guerrero) (Fig. 678).

\section{Chalcolepidius viriditarsus Schwarz, 1906}

Chalcolepidius viriditarsus Schwarz, 1906b: 97; Schenkling, 1925: 59 (Cat.); Blackwelder, 1944: 283 (Cat.). Syntype female: "San Salvador; Coll. Schwarz; viriditarsus Schw" (DEIC) (not examined).

SCHWARZ (1906) described C. viriditarsus, from San Salvador, characterized especially by body clothed dorsally and ventrally with yellowish scale-like setae, elytra with brownish-yellow lateral stripes and tarsi clothed with metallic green setae. Although this species was not examined, I suspect that it is conspecific with $C$. fryi, but I consider more prudent retain both species, until some material become available for study. Based on the original description, $C$. viriditarsus not differs significantly from $C$. fryi, except for the paler pubescence and by the absence of ferruginous narrow band on each side of pronotum.

\section{Chalcolepidius webbi LeConte, 1854}

(Figs. 94, 95, 162, 223, 270, 311, 421, 457, 493, 578, 670, 693)

Chalcolepidius webbi LeConte, 1854: 223; Candèze, 1857: 292; LeConte, 1863: 45 (Cat.); Gemminger \& Harold, 1869: 1504; Candèze, 1886: 74; Casey, 1907: 31; Leng, 1920: 167 (Cat.); Schenkling, 1925: 57 (Cat.). Type localities: “Journey from San Diego to El Paso"and "San Diego trip".

Chalcolepidius substriatus Schwarz, 1906b: 46, t. 2, f. 8; Casey, 1907: 29 (Syn.); Becker, 1961: 163 (Syn. confirmed). Lectotype male (designated by Becker l. c.): "Arizona; coll. Schwarz; Typus; substriatus Schw.; Dtsch. Entomol. Institut Berlin” (DEIC) (not examined).

Chalcolepidius snowi Casey, 1907: 31; Leng, 1920: 167 (Syn.). Syntypes: 3 males: "Bill Wms Fork Ariz. Aug. F. H. Snow; Casey bequest 1925; Casey determ. arizonicus 2, 7, 8; Syntype Chalcolepidius snowi Casey 1907 C. M. F. von Hayek 1980; C. webbi LeConte CMF von Hayek 1980" (USNM) (examined).

Chalcolepidius idoneus Casey, 1907: 31; Casey, 1911: 253 (= C. snowi Casey, 1907). Syntype female: "Bill Wms Fork Ariz. Aug. F. H. Snow; Casey bequest 1925; Casey determ. arizonicus-5; May be original type of idoneus; Syntype of Chalcolepidius idoneus Casey C. M. F. von Hayek 1980; C. webbi LeConte C.M.F. von Hayek det. 1980" (USNM) (examined).

Chalcolepidius arizonicus Casey, 1907: 31; Casey, 1911: 253 (=C. snowi Casey, 1907). Syntype male: "Bill Wms Fork Ariz. Aug. F. H. Snow [label is damaged]; Casey bequest, 1925; Type USNM 48450; Ariz. Csy; Syntype Chalcolepidius arizonicus Casey C.M.F. von Hayek det. 1980; C. webbi Casey C. M. F. von Hayek det. 1980"(USNM)(examined).

Chalcolepidius abdominalis Casey, 1907: 32; 1911: 253 (= C. snowi Casey, 1907). Syntypes: 1 male, 1 female. Male: "Bill Wms Fork Ariz. Aug. F. H. Snow; Casey bequest 1925; Type USNM 48452; abdominalis Csy; Casey determ. arizonicus-10; Syntype Chalcolepidius abdominalis Casey C.M.F. von Hayek 1980; C. webbi LeConte C.M.F. von Hayek det 1980". Female: " Bill Wms Fork Ariz. Aug. F. H. Snow; Casey bequest 1925; Casey determ. arizonicus4; Syntype Chalcolepidius abdominalis Casey C.M.F. von Hayek 1980; C. webbi LeConte C. M. F. von Hayek det. 1980" (USNM) (examined).

Chalcolepidius sonoricus Casey, 1907: 35. Name proposed by Casey for a Champion's illustration of $C$. webbi (P1. XI, fig. 23). Syn. nov.

CASEY (1907) presented a key to species with lateral whitish 
stripes on pronotum, including 13 new species, among them were $C$. snowi, $C$. idoneus, $C$. arizonicus and $C$. abdominalis. He also synonymized C. substriatus Schwarz under C. webbi and proposed a new name, C. sonoricus, to CHAMPION's (1894) illustration of C. webbi (plate XI, fig. 23). In 1911 he synonymyzed $C$. idoneus, $C$. arizonicus and $C$. abdominalis under $C$. snowi.

BeCKer (1961) designated the lectotype of C. substriatus Schwarz and confirmed the synonymy of this species with $C$. webbi.

Here, $C$. sonoricus is considered a new synonym of $C$. webbi.

Length: 25-33 mm. Parallel body. Integument dark-brown clothed dorsally and ventrally with short and sparse scale-like setae metallic blue (sometimes partially clothed or intermingled with brownish pubescence ventrally); lateral stripes of pronotum wide, usually wider than $1 / 3$ of pronotum width, sinuous at internal margins; lateral stripes of elytra three interstices wide; white or yellowish-white pubescence on lateral stripes of pronotum and elytra, base of elytra and epipleura (Figs. 93, 94).

Frons not carinate, moderately declivous. Antennae (Fig. 162) serrate in both sexes; $3^{\text {rd }}$ segment triangular-elongate, shorter than $4^{\text {th }}$. Pronotum (Fig. 223) longer than wide, slightly narrowed anteriad and at hind angles base; strongly convex at middle, convexity decreasing anteriad and basad; micropunctate with slightly coarser punctuation, denser lateroanteriorly; anterior margin prominent and slightly sinuous at middle; lateral margins slightly sinuous, raised laterally, forming narrow edge, almost reaching apex; hind angles narrow, slightly divergent, raised laterally forming edge continuous with that of lateral margins; median basal tubercle very weak and triangular or indistinct; posterior margin prominent and strongly notched at middle. Hypomera concave near lateral margins; laterointernal margin raised forming wall of anterior channel. Notosternal sutures moderately sinuous. Prosternum micropunctate, moderately convex, flattened longitudinal medially, slightly concave near sutures. Prosternal lobe micropunctate, wide, emarginated laterally with fore angles slightly rounded. Scutellum (Fig. 270) strongly folded with horizontal basal area subtrapezoidal, notched anterior- and posteriorly. Borders of mesosternal cavity (Fig. 311) wide and horizontal on basal 2/3 and moderately declivous on distal $1 / 3$, forming semielliptical profile. Meso-metasternal suture weak, convergent at cavity base. First visible sternite prominent laterally, fits in lateral groove of elytra. Anterior and median tibiae and last tarsal segment of all legs bearing fringe of long cilia. Striae weakly marked by row of coarse punctures; interstices flat and micropunctate; $2^{\text {nd }}$ interstice prominent anteriorly forming flat basal tubercle.

Male genital segments and aedeagus. Sternite VIII transverse, narrowed apicad, strongly narrowed on distal third; basal margin trilobed; translucent in a median area (with distal border indistinct) and two lateral bands. Tergite IX transverse, densely punctuate; anterior margin rounded; lateroanterior tiny setae. Aedeagus (Fig. 421): median lobe (Fig. 457) 0.49 times the aedeagus length, strongly narrowed near middle, and bearing 7, 9; 10, 10 small lateral teeth; lateral cleft of parameres (Fig. 493) strongly narrowed apicad, prominent dorsally.

Female genital segments and genitalia. Tergite VIII transverse with anterior margin slightly prominent at middle; translucent in basal median area (almost reaching middle) and marginal band interrupted at middle. Sternite VIII (Fig. 578) very wide- and deeply notched at middle, 0.68 times spiculum gastrale length. Genitalia (Fig. 621): sclerotized rings of openings of colleterial glands (Fig. 670) bearing 37 teeth; bursa copulatrix with longitudinal band with carinae and spines and two lateral small rounded sparsely spiny areas.

Material examined. Besides the syntypes of $C$. snowi, $C$. idoneus, $C$. arizonicus and C. abdominalis, I studied also $1 \mathrm{M}$ and $2 \mathrm{~F}$ of Casey's collection; M: "Bill Wms Fork Ariz. Aug. F. H. Snow; Casey bequest 1925; Casey determ. arizonicus-6; v. near Casey descr. of snowi but is F, $27 \mathrm{~mm}$, white margin of pr. straight internally, ? later addition C. M. F. von Hayek det. 198-; C. webbi LeConte C. M. F. von Hayek det. 1980"; F: "Bill Wms Fork Ariz. Aug. F. H. Snow; Casey bequest 1925; Casey determ. arizonicus-3; v. near Casey descr. of snowi but white margin of pronotum straight internally, ? later addition C. M. F. von Hayek 198-; C. webbi LeConte C. M. F. von Hayek det. 1980"; F, "Bill Wms Fork Ariz. Aug. F. H. Snow; Casey bequest 1925; Neotype USNM 48451 [red label]; idoneus Csy [handwritten]; not part of original series of idoneus Casey, = webbi LeConte C. M. F. von Hayek det. 1980".

UNITED STATES OF AMERICA. California: $2 \mathrm{~F}$ (OSUC), $1 \mathrm{M}$ (dissected) (MZSP), 3 M, 4 F (USNM); Imperial Co., Calexico, 2 F (SEMC); Winterhaven, 1 M, 1 F (AMNH); Los Angeles Co., Los Angeles, 1 F (USNM); Riverside Co., Blythe, 1 M (FSCA) 2 M (IMLA); 6 m N Blythe, $1 \mathrm{M}$ (MZSP), $1 \mathrm{M}$ (JEWC); Colorado River Blyth Calif., $1 \mathrm{M}, 1$ F (AMNH); San Bernardino Co., Earpp, 1 F (FSCA); 13 mi NE Earp, 2 M, 1 F (USNM); Needles, 4 M, 1 F (MCZC), 3 M, 2 F (USNM); San Diego Co., San Diego, $1 \mathrm{M}(\mathrm{CMNH})$; Imperial Co., Calipatria, $1 \mathrm{M}$ (AMNH), $1 \mathrm{M}(\mathrm{CMNH}), 1 \mathrm{M}, 1 \mathrm{~F}$ (SEMC); Holtville, $1 \mathrm{M}, 2 \mathrm{~F}$ (AMNH), $1 \mathrm{M}$ (FSCA), $2 \mathrm{M}$ (1 dissected) (MZSP), $6 \mathrm{M}, 3 \mathrm{~F}$ (USNM); Bardscp (locality not found), $1 \mathrm{~F}$ (USNM)). Arizona: $1 \mathrm{M}, 1 \mathrm{~F}$ (AMNH), 1M, $2 \mathrm{~F}$, (OSUC), $1 \mathrm{~F}$ (MZSP), $16 \mathrm{M}, 13 \mathrm{~F}$ (USNM), ex-coll. Fleutiaux, $1 \mathrm{M}, 2 \mathrm{~F}$ (MNHN); Gila Co., Globe, 3 M (USNM); Maripa Co., Phoenix, 2 M, 8 F (AMNH), $2 \mathrm{M}(\mathrm{CMNH}), 3 \mathrm{M}, 1 \mathrm{~F}$ (FSCA), $3 \mathrm{M}, 1 \mathrm{~F}$ (MCZC), $2 \mathrm{M}, 2 \mathrm{~F}$ (MZSP retained USNM), $1 \mathrm{~F}$ (PCCV), $16 \mathrm{M}, 21 \mathrm{~F}$ (USNM), $2 \mathrm{M}$ (ZMUC); Tempe, 1 M (USNM); Pinal Co., Florence, 1 F (CMNH); Coconino Co., Bill Williams Fork, $1 \mathrm{~F}$ (AMNH), $1 \mathrm{M}(\mathrm{CMNH}), 1 \mathrm{M}, 1 \mathrm{~F}$ (MCZC), $1 \mathrm{~F}$ (dissected)(MZSP) 1 M, 1 F (USNM); Glendale, 1 F (TAMU); Yavapai Co., Prescott, 1 F (AMNH), 1 M (PCCV), 1 F (USNM); Yuma Co., (Salix gooddingii Ball) (willow), $2 \mathrm{M}$ (PCCV); Morelos Dam (locality not found), $1 \mathrm{M}$ (AMNH), $1 \mathrm{~F}$ (FSCA); Yuma, $2 \mathrm{M}, 1 \mathrm{~F}$ (AMNH), 7 M, 7 F (MCZC), $1 \mathrm{~F}$ (OSUC), $1 \mathrm{M}$ (PCCV), $4 \mathrm{M}, 10 \mathrm{~F}$ (USNM). New Mexico: $1 \mathrm{M}$ (CMNH. MEXICO. Sonora: 1 F (USNM). Durango: Durango, $1 \mathrm{~F}$ (MNMS).

Remarks. Enclosed with the loaned material of Casey collection (USNM), there was a "Notice" with the conditions for loan of specimens and also an advise "that in a series, the specimens bearing red labels with the word "Type" and a USNM type-number are not valid holotypes. Mr. Buchanan added the red labels when Casey's collection was received at U.S. National Museum. Although Mr. Buchanan tried to indicate \& label the specimen he thought was the one Casey used for his description (following a verbal statement by Casey this was the first in his pinned series \& bearing a name label), Casey did not label his specimens with holotype labels nor call them holotypes in his publications. Therefore, until a lectotype is designated and 
published by a specialist, all specimens of taxa with more than one specimen in the Casey Collection are Syntypes".

Buchanan also added, into the boxes, information with his conclusions about the type-material. Related to $C$. snowi, $C$. idoneus, C. arizonicus and C. abdominalis he noticed: "Casey evidently restudied his material in Chalcolepidius, did some radical shifting of specimens + name labels in the case of snowi, idoneus, arizonicus, abdominalis. In the Casey box, snowi was represented by one unlabeled $\mathrm{F}$, which is certainly not one of the original set but is doubtless a specimen selected by Casey later on to represent this species. All the other specimens were grouped with arizonicus, idoneus, abdominalis being indicated as synonyms. The specimen labeled abdominalis seems to be one of the original set of that species without question, + is here labeled TYPE, but the specimen of idoneus (only $25 \mathrm{~mm}$ long) is, like snowi, clearly a later substitution. Keeping in mind the published data for snowi, idoneus, arizonicus, + abdominalis it is possible to reconstruct Casey's original series of these 4 species with reasonable certainty as follows: I) $-\underline{\text { snowi }}=$

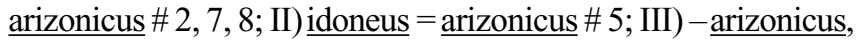
1 specimen, TYPE; IV) abdominalis $=$ arizonicus $\# 4,10$. The neotype of snowi, arizonicus \# 3, 6, 9 (neotype of idoneus) disagree, in one point as another, with the published requirements for the 4 species in question, + were probably added later by Casey".

When Hayek studied this material, she added labels with notes pinned to the specimens. In her drafts she stated about the hard work on Casey's material: "the identification of the syntype material of these species has not been easy. The difficulties encountered are, without doubt, due to the fact that when, four years after describing idoneus, arizonicus and abdominalis Casey (1911:253) examined additional material and decided that they did not differ from snowi, and then reorganized his collection to reflect his new interpretation of the species. The decisions regarding the syntype material were influenced by Buchanan's note in Casey the collection".

Chalcolepidius webbi is characterized especially by general pubescence metallic blue with white pubescence on wide lateral stripes of pronotum, lateral stripes of elytra and epipleura, scutellum folded, tibiae of male bearing fringe of long cilia and parameres of aedeagus cleft laterally.

C. webbi is similar to C. apachenus, by general appearance, differing especially by different coloration of metallic setae, blue or blue intermingled with brownish in C. webbi and blueviolet, brownish or brownish-violet in C. apacheanus, and by presence of the following in $C$. webbi: metallic pubescence longer and denser, clothing the integument, white lateral bands of pronotum and elytra wider, that of pronotum usually sinuous at internal margins, pronotum longer and more convex, giving to lateral margins more rounded appearance, scutellum longer, and borders of mesosternal cavity strongly declivous. Besides, in $C$. webbi the median lobe is narrower near the middle which present 7, 9 lateral teeth (9, 9 in C. apacheanus); sternite VIII of female with more widely notched anterior margin and shorter spiculum gastrale; sclerotized rings of the openings of the colleterial glands with 37 teeth (38 in C. apacheanus), and bursa copulatrix with paired lateral spiny area (few dispersed spines in C. apacheanus)

Some variations on pubescence coloration was observed: one female from Yuma, Cal. (MCZC), has elytra almost totally clothed with white pubescence; two males from the same locality have the pronotum almost totally clothed with white pubescence.

C. webbi is the sister-group of C. apacheanus (Fig. 671).

Distribution. It is recorded from United States of America (California, Arizona, New Mexico) and Mexico (Sonora, Durango) (Fig. 693).

Chalcolepidius zonatus Eschscholtz, 1829

(Figs. 96, 163, 224, 271, 312, 352, 422, 458, 494, 579, 669, 688)

Chalcolepidius zonatus Eschscholtz, 1829: 32; Erichson, 1841: 81; Lacordaire, 1857: 155; Candèze, 1857: 262, 273; Gemminger \& Harold, 1869: 1504; Candèze, 1874: 164; 1886: 67, 71; 1891: 39 (Cat.); Schwarz, 1906a: 45; Heyne-Taschenberg, 1908: 153, t. 25, f. 12; Schenkling, 1925: 57 (Cat.); Fleutiaux, 1926: 109 (Cat.); Blackwelder, 1944: 283. Type locality: "Brazil".

Chalcolepidius smaragdulus Eschscholtz, 1829: 32; Erichson, 1841: 81 (Syn.). Type locality: "Brazil".

Elater sulcatus Fabricius, 1777: 234; Herbst, 1801: 326, pl. 157, fig. 6. [Misidentification].

Chalcolepidius longicollis Candèze, 1857: 284; Gemminger \& Harold, 1869: 1503 (Cat.); Candèze, 1886: 67, 71; Schenkling, 1925: 57 (Cat.); Fleutiaux, 1926: 107 (Cat.); Blackwelder, 1944: 283 (Cat.). Holotype male: "Columbia; 113; Janson coll. 1903-130; Chalcolepidius longicollis Cdze. M type ex coll.; Laferté; longicollis [glued to underside of anterior label]; drawer 126" (BMNH) (examined). Syn. nov.

Eschscholtz (1829) described briefly C. zonatus and $C$. smaragdulus, both from Brazil, and later considered as conspecific.

CANDÈze (1857) redescribed C. zonatus, keeping $C$. smaragdulus as synonym, and presented one variation, var. a: squamulis violaceis, vittis striisque albidis. According to him, C. zonatus like C. limbatus, is found in Brazil, Guyana and Colombia and it is similar to the greenish variety of the latter, but it is easily distinguished by white lateral stripes of pronotum narrowed and deflected from lateral border frontally and elytral interstices unequal.

CANDĖzE (1874) included other variation, var. b: squamulis brunneis, vittis striisque albidis. In 1886, he recorded it from Mexico, probably misidentification with $C$. approximatus. He also stated about the pubescence coloration of the specimens from Brazil, especially around Rio, where they are green with white lateral stripes, changing to violet in Mexico.

Heyne \& Taschenberg (1908) redescribed C. zonatus, including a colored illustration.

Piza (1968) in "Insetos de Piracicaba", redescribed briefly C. zonatus and presented a picture, fig. 21.

CANDÈze (1857) described C. longicollis, from Colombia, based on a male of Laferté collection already named as $C$. longicollis Reiche. He considered the underside clothed with yellowish-white pubescence, but according to HAYEK (personal communication), after cleaning, the majority of setae of underside are brassy with very small patches of white setae 
laterally on $2^{\text {nd }}, 3^{\text {rd }}$ and $4^{\text {th }}$ sternites. I examined this holotype and concluded that $C$. longicollis is conspecific with $C$. zonatus.

Length: 22-43 mm. Wide, arched body. Integument black clothed dorsally and ventrally, including legs, with thin metallic scale-like setae green, olive, blackish-gray, bluish-gray, brownish-olive or brownish-violet; lateral stripes of pronotum band-like, approximately $1 / 4$ of pronotum width, narrowed anteriad; dull white setae on lateral stripes of pronotum (parallel lateral margins), base of elytra, striae, lateral stripes of elytra (two interstices wide, VIII-IX) and epipleura; antennae clothed with dark-blue except three first segments, green (Fig. 96).

Frons not carinate, strongly declivous. Antennae (Fig. 163) serrate in both sexes, $3^{\text {rd }}$ segment elongate, triangular, shorter than $4^{\text {th }}$. Pronotum (Fig. 224) longer than wide, wider at hind angles, slightly narrowed anteriad from hind angles apex, strongly narrowed on anterior $1 / 4$; anterior margin prominent and sinuous at middle; hind angles wide, slightly divergent, with truncate apex, raised laterally forming edge continuous with that of lateral margin until distal $1 / 4$; median basal tubercle triangular-elongate and very weak or indistinct; posterior margin prominent and strongly notched at middle; convexity moderate; densely micropunctate with sparse umbilicate punctures more concentrate lateroanteriorly. Hypomera concave near lateral margins; micropunctate; laterointernal margin raised forming wall of well-developed channel. Notosternal sutures strongly sinuous. Prosternum micropunctate, strongly convex, flattened longitudinal medially, slightly concave near sutures on basal $2 / 3$. Prosternal lobe micropunctate, wide, emarginated laterally with fore angles slightly rounded. Prosternal spine flattened laterally. Scutellum (Fig. 271) strongly folded with horizontal basal area triangular, notched anterior- and posteriorly, grooved longitudinal medially on anterior half. Borders of mesosternal cavity (Fig. 312) wide and horizontal on basal $3 / 4$ and vertical on distal $1 / 4$, forming Lshaped profile. Mesepisternum with two transverse elliptical grooves. Meso-metasternal suture weak, convergent at cavity base. First visible sternite prominent laterally, fits in lateral groove of elytra. Anterior and median tibiae and last tarsal segment of all legs of male bearing fringe of long cilia. Interstices convex and micropunctate, unequal (pairs narrower and less raised), striae paired; scutellar area slightly concave; very flat tubercle at base of $3^{\text {rd }}$ interstice; apex truncate with tiny sutural spine.

Male genital segments and aedeagus. Tergite VIII slightly wider than long, strongly notched basally, slightly narrowed apicad, clothed with short setae. Sternite VIII (Fig. 352) transverse, narrowed apicad, subtrapezoidal, basal margin trilobed (median lobe wider) translucent at median region and two small spots at each side. Tergite IX densely punctuate, anterior margin rounded. Aedeagus (Fig. 422): median lobe (Fig. 458) slightly narrowed near middle, constricted at apex; bearing 9, 10; 10, 10 lateral teeth; lateral cleft of parameres (Fig. 494) slightly narrowed near apex; apex upwards.

Female genital segments and genitalia. Tergite VIII transverse, almost rectangular; translucent basal area almost reaching middle. Sternite VIII (Fig. 579) 0.74 times spiculum gastrale length; anterior margin moderately wide and deeply notched at middle. Genitalia: sclerotized rings of openings of colleterial glands (Fig. 669) bearing 46 teeth; bursa copulatrix with longitudinal elongate band with carinae and spines and two lateral rounded spiny areas.

Material examined. FRENCH GUIANA. Cayenne: Saint Laurent du Maroni, ex-coll. Fleutiaux, 8 F (MNHN) COLOMBIA. Caquetá: Santa Rita, Vicnada, $1 \mathrm{~F}$ (ICNC). ECUADOR. $1 \mathrm{~F}$ (FSCA). BRAZIL. $1 \mathrm{~F}$ (AMNH), $2 \mathrm{~F}$ (MCZC), $5 \mathrm{~F}$ (MNHN); $1 \mathrm{M}, 4 \mathrm{~F}$ (NHMW), $8 \mathrm{~F}$ (USNM), $1 \mathrm{~F}$ (ZMUC), ex-coll. Fleutiaux, $1 \mathrm{~F}$ (MNHN). Pará: Santarém, $1 \mathrm{~F}$ (MZSP). Goiás: 2 F (MZSP); Goiânia, 3 F (FSCA); Muquém, 1 F (MZSP). Pernambuco: Bonito, 1 F (USNM); Recife, Campos UFPE, 1 M (UFPE). Mato Grosso: Barra do Tapirapé, 1 F (MZSP); Cuiabá, 1 F (UFMT), Chapada [dos Guimarães], 1F (USNM); Jacaré, Xingu 1 F (MZSP); Rio Negro, $1 \mathrm{~F}$ (MNHN); Roncador, 1 F (MZSP). Minas_Gerais: $1 \mathrm{~F}$ (MCZC); Lambari, 3 F (USNM); Lavras, 3 F (MZSP); Mar de Hespanha, ex-coll. Fleutiaux, 1 F (MNHN); Mariana, 2 F (MZSP); Passa Quatro, 2 F (MCZC); env. de Passa Quatro, Bord du Rio das Pedras (1000 m), 1 F (MNHN); Plateau da Mantiqueira entre Queluz et Lafayete (1200-2000 m), 1 F (MNHN); Rio Matipó, 1 F (MZSP); Rio São Pedro, 1 F (MCZC); Catas Altas, Serra do Caraça, 3 F (MNHN), 1 F (MZSP); São José das Ilhas, Faz. Palmeiras, 2 F (MZSP); Viçosa, $10 \mathrm{~F}$ (MZSP), 1 F (USNM). Rio de Janeiro: $2 \mathrm{~F}$ (MCZC), 2 F (MNHN), 2 F (MZSP); Angra dos Reis, $2 \mathrm{~F}$ (MZSP); Bocaina, $1 \mathrm{~F}$ (MZSP); Itatiaia, $1 \mathrm{~F}$ (IBSP), 6 F (MZSP); Mendes, $1 \mathrm{~F}$ (MZSP), $92 \mathrm{Km}$ from Rio de Janeiro, $1 \mathrm{~F}$ (USNM), ex-coll. Fleutiaux, 7 F (MNHN); Petrópolis, $1 \mathrm{~F}$ (MZSP), $1 \mathrm{~F}$ (DZUP); Rio de Janeiro, $1 \mathrm{~F}$ (USM), 1 F (DZUP); Serra dos Órgãos, 1 F (MZSP); Teresópolis, 1 F (MNHN), 1 F (MZSP), 7 F (DZUP). Espírito Santo: 1 F (MZSP), 3 F (NHMW), ex-coll. Fleutiaux, $10 \mathrm{~F}$ (MNHN); Colatina, $1 \mathrm{~F}$ (DZUP); Fundão, 1 F (DZUP); Rio Bonito, 1 F (FSCA); Santa Leopoldina, excoll. Fleutiaux, 3 F (MNHN); Santa Teresa, $1 \mathrm{~F}$ (IBSP), $17 \mathrm{~F}$ (1 dissected) (MZSP), $1 \mathrm{M}, 220 \mathrm{~F}$ (DZUP). São Paulo: $1 \mathrm{M}$ (USNM), ex-coll. Fleutiaux, 2 F (MNHN); Anhembi, 1 F (MZSP); Barueri, 1 F (MZSP); Botucatu, 2 F (MZSP); Campinas, 1 F (MZSP); Casa Grande, 1 F (IBSP), $2 \mathrm{~F}$ (DZUP), $1 \mathrm{~F}$ (USNM); Cubatão, $2 \mathrm{~F}$ (USNM); Estac. R.d.S.E.S.P., 1 F (IBSP); Guarujá, 1 F (MZSP), Iporanga, 1 F (MZSP); Ilha dos Búzios, 3 F (1 dissected) (MZSP); Ilha Santo Amaro, Praia Pernambuco, $1 \mathrm{~F}$ (IBSP); Ilha de São Sebastião, 2 F (IBSP), 3 F (MZSP); Ipeúna, 1 F (MZSP); Itararé, $1 \mathrm{~F}$ (IBSP), $3 \mathrm{M}$ (1 dissected)(MZSP); Itatiba, $1 \mathrm{~F}$ (MZSP); Itu, Faz. Pau d'Alho, 1 M, 7 F (MZSP); Jundiaí, 2 F (MZSP); Manoel da Nóbrega, 1 F (MZSP); Pai Mathias, 1 F (MZSP), 1 M, 6 F (USNM); Passa Quatro, Bordo do Rio das Pedras; Peruíbe, $1 \mathrm{~F}$ (IBSP, $1 \mathrm{~F}$ (USNM), Estrada do Grajau, 1 F (dissected) (MZSP); São Bernardo, 1 F (IBSP); 2 F (NHMW); Piracicaba, 1 M, 4 F (IBSP), 2 F (MZSP); Pirassununga, $1 \mathrm{~F}$ (MZSP); Rio Mombuca, $3 \mathrm{~F}$ (MZSP). Sabaúna, $1 \mathrm{~F}$ (NHMW); Santos, 2 F (MZSP), raia Grande, 1 F (MZSP), Cidade da Criança, 2 F (MZSP), Praia do Itaguaré, $1 \mathrm{~F}$ (dissected)(MZSP); São Manuel, 1 F (MZSP); São Paulo, 2 F (FSCA), 1 M, 6 F (IBSP), 5 F (MZSP), $1 \mathrm{~F}$ (NHMW), $1 \mathrm{~F}$ (USNM), Booklin, $1 \mathrm{M}$ (MZSP), Cantareira, 2 F (USNM), Horto Florestal, 3 F (MZSP), Ipiranga, 1 M, 3 F (MZSP), Santo Amaro, 2 F (IBSP), Tremembé, 1 M (USNM); Ubatuba, 1 F (MZSP); Serra da Mantiqueira, $1 \mathrm{~F}$ (NHMW); Vale do Rio Pardo, $1 \mathrm{~F}$ (MNHN). Paraná: 1 F (NHMW); Alexandra, 1 F (DZUP); Antonina, 2 F (DZUP); Curitiba, $1 \mathrm{~F}$ (MNHN), $4 \mathrm{~F}$ (MZSP), 2 F (DZUP), 1 F (USNM); Jaguariaiva, 1 F (MZSP); Maringá, 1 F (DZUP); Matinhos 1 F (MZSP); Morretes, 975 m, 1 F (DZUP); Paranaguá, 1 F (MZSP); Piraquara, Águas Claras, 2 F (DZUP); Ponta Grossa, 14 F (MZSP), 2 F (DZUP); Porto Cabral, 1 F, (MZSP); São José dos Pinhais, 3 F (DZUP); Tijucas do Sul, Vossoroca, 3 F (DZUP). Santa Catarina: $1 \mathrm{~F}$ (MCZC), 1 F (MZSP), 3 F (PCCV), $1 \mathrm{~F}$ (NHMW), ex-coll. Fleutiaux, 3 F (MNHN); Blumenau, 1 F (MCZC), excoll. Fleutiaux, 3 F (MNHN); Corupa (Hansa Humboldti), 28 F (AMNH), $1 \mathrm{M}, 5 \mathrm{~F}$ (FSCA), $1 \mathrm{~F}$ (PCCV), $2 \mathrm{~F}$ (DZUP), 2 F (USNM); Joinville, $12 \mathrm{~F}$ (MZSP), 6 F (NHMW), 1 F (DZUP), Rio Bracinho, 1 F (MZSP); Neu Bremen (locality not found), 2 F (MZSP); Rio Natal, 1 M, 3 F (MZSP); São Bento do Sul, 1 F (DZUP), 12 F (MZSP), Rio Vermelho, 1 F (AMNH), 43 F (MZSP), 1 F (SRGI); São Francisco, 3 F (AMNH); Timbó, ex-coll. 
Dirings, 4 M, 29 F, (MZSP). Rio Grande do Sul: 1 M (MCZC), $1 \mathrm{~F}$ (NHMW), ex-coll. Fleutiaux, 2 F (MNHN); Pinhal, 1 F (AMNH); Pelotas, 1 M (USNM); Porto Alegre, 2 F (NHMW); Vila Oliva, 1 M (MZSP). BOLIVIA. Santa Cruz de la Sierra, 1 F (MNHN). ARGENTINA. Missiones: Oberá, 1 F (SRGI); Posados, 1 F (SRGI).

Remarks. The holotype of Chalcolepidius longicollis is naked, without any trace of setae, especially on median area of pronotum and higher interstices. It is possible to see some yellowish-white dull setae on lateral stripes of pronotum (not reaching lateral margins), epipleura, basal region of elytra, striae (partially), lateral stripes of elytra (two interstices wide) and some patches on sternites, and some metallic brownish-olive setae on lateral margins of pronotum, distal area of some interstices, hypomera, lateral bands on prosternum, meso- and metasternum, legs and lateral bands on visible sternites. On the right protibia remains the fringe of long cilia. The white patches on sternites are also found in C. approximatus, and the differences between these two species are discussed into the remarks of the latter.

C. zonatus is characterized especially by general pubescence green or grayish, with whitish setae on lateral stripes of pronotum and elytra, striae and epipleura, scutellum strongly folded, tibiae of male bearing fringe of long cilia, interstices unequal and parameres of aedeagus cleft laterally.

C. corpulentus, C. limbatus and C. zonatus are very similar including the apex of lateral cleft of parameres, not prominent dorsally in C. zonatus, moderately prominent in C. corpulentus and strongly in C. limbatus. $C$. corpulentus has the pronotum strongly convex (especially in females) with wider lateral stripes, almost $1 / 3$ of pronotum width, striae paired and lower interstices clothed with dull setae. C. limbatus and C. zonatus have narrower lateral stripes of pronotum and interstices unequal, paired in the latter. C. corpulentus presents the smaller number of teeth at the sclerotized rings of the openings of colleterial glands, 19 , while $C$. limbatus has 37-44 and C. zonatus, 46 . The number of teeth of median lobe of aedeagus varies from 7-8 in the first, 47 in the second and 9-10 in the third.

Comparing C. zonatus with C. limbatus it was verified that besides the different coloration of pubescence, in the former the pronotum is longer and less convex, the prosternal suture more sinuous and the sclerotized rings of the openings of colleterial glands have more teeth, and in the latter, the pronotal stripes are wider, $3^{\text {rd }}$ antennal segment shorter and the spiculum of sternite VIII of female is longer. C. zonatus also looks like $C$. rostainei (see Remarks after the two latter).

C. zonatus belongs to mocquerysii + group (Fig. 671); it is the sister-group of $C$. limbatus.

Distribution. It is recorded from French Guiana, Colombia, Ecuador, Brazil (Pará, Goiás, Pernambuco, Mato Grosso, Minas Gerais, Rio de Janeiro, Espírito Santo, São Paulo, Paraná, Santa Catarina, Rio Grande do Sul), Bolivia and Argentina (Fig. 688)

\section{CLADISTIC ANALYSIS}

Sexual Dimorphism. CHAMPION (1894) drew attention to the fact that in C. mexicanus, the females have the sides of the pronotum clothed with elongate white setae, and the males, clothed almost totally with olive pubescence. Examination of available material has shown that this characteristic appears to be variable, some males being partially or entirely clothed with white setae. The opposite condition, in which the females have very few or no white, gray or yellow setae was not observed. According to Champion (l.c.) the female pubescence of $C$. rodriguezi, different from male, golden dorsally and ventrally, has large admixture of white setae on both the upper and under surfaces. During the present work only males were examined.

The females bodies in Chalcolepidius species, are usually larger and more robust; the shape and size of antennae may be different in both sexes. In the majority of species, the antennae are serrate in both sexes and longer in male, but in some species, they are serrate in female and strongly serrate or pectinate in male, or pectinate in female and flabellate in male.

Although in a number of species only one sex is known, it is probable that all Chalcolepidius species display the last visible sternite with rounded apex in male and truncate with fringe of modified setae (spatulate) in female. In addition, the males of the majority of species have a distinct fringe of cilia, which may be relatively short or long, on the ventral surface of anterior tibiae. In some species, the middle tibiae and the fifth tarsal segments of all legs bear a fringe of long cilia. In the males of $C$. desmarestii the anterior tibiae is swollen ventrally at the apex. The swelling bears a dense brush of cilia. In other species the males present a developed irregular row of spines on the ventral surface of anterior tibiae; the other legs may also present these spines, but smaller.

Body Shape. The body of Lacais is wide and arched; that of Alaus and Chalcolepis are slightly narrower and almost parallel. The body of the majority of Chalcolepidius is robust, wide and arched, while in some species it is wide and almost parallel, and in a few it is narrow and parallel. Narrow and parallel body is considered the apomorphic condition (C1) and appears independently in group attenuatus * and group chalcantheus * (with group forreri* reversed to plesiomorphic condition).

1) Body shape (no) $(\mathrm{ci}=50, \mathrm{ri}=83)$

0 ) wide and arched or almost parallel;

1) narrow and parallel.

Pubescence. The majority of Hemirhipini is clothed with very colorful scale-like setae, with same color on upper- and underside. Many times the dorsal pubescence forms typical patterns for each genus. In Lacais (except L. suturalis) and several Alaus species, the pubescence is bicolor dorsally and white ventrally, and in Chalcolepis it is unicolor in both sides. The dorsal pubescence of Lacais is variable, not exhibiting a generic pattern, but in Alaus presents typical eye-like spots of velvety pubescence on the pronotum. In the last genus, the pubescence is similar in male and female. The pubescence coloration of epipleura is like the underside in these three

\section{CHARACTERS}


genera.

The Chalcolepidius, like the majority of the Hemirhipini, are clothed with scale-like setae, usually metallic and very colorful, and similar in male and in female. Different coloration in male and female $(\mathrm{C} 2)$ is considered the apomorphic condition and appears independently in $C$. mexicanus and $C$. rodriguezi. The Chalcolepidius pubescence is uni- or bicolor, in many species showing a typical pattern, forming laterodorsal stripes on pronotum and/or elytra, of varied shapes, colors and sizes. Dorsal pubescence bicolor, forming laterodorsal stripes is considered the apormophic condition (C3) and appears independently in group gossipiatus + and group fabricii + .

The pubescence coloration of the Chalcolepidius is widely variable, but it was possible to recognize four patterns, herein considered as apomorphic (C4): general pubescence variable (4.2) ("variable" includes species that present intraspecific variation, not exhibiting a typical coloration pattern) appears independently in group gossipiatus + and group fabricii + ; general pubescence white with brown stripes on pronotum and elytra (4.3) appears independently in C. albisetosus (from group gossipiatus + ) and C. erythroloma and C. rugatus (from group fabricii ${ }^{+}$); general pubescence green with white lateral bands on pronotum and elytra and striped elytra (4.4), represents an autapomorphy to group mocquerysii+; and general pubescence blue with white lateral stripes on pronotum and elytra (4.1) appears in group tartarus ${ }^{+}$.

The presence of lateral stripes on pronotum is considered the apomorphic condition (C5), and appears independently in C. albiventris $+C$. exulatus, group albisetosus + and group fryi*. The lateral stripes of pronotum (C6) are band-like, elliptical or triangular. Band-like (6.1) appears independently in group serricornis ++ and group fryi*; lateral bands elliptical (6.2) appear independently in C. ferratuvittatus and C. albisetosus (group serricornis ++ ) and C. fryi + C. erythroloma + C. villei (group fryi*); in C. validus the lateral stripes are triangular (6.3). The elliptical stripes (C7) brown (7.1) appear independently in C. ferratuvittatus, C. albisetosus and C. erythroloma, and orange (7.2) in C. fryi and C. villei (groupfryi*).

The lateral stripes band-like present variable shapes and sizes (C8), considered as apomorphies: lateral bands fused (8.2) appear in C. copulatuvittatus; narrowed at extremities (8.3) is an autapomorphy to group fryi* (with C. fryi, C. erythroloma and $C$. villei reversed to plesiomorphic condition); moderately wide (8.4) appear independently in C. albiventris $+C$. exulatus, C. lafargi and group bomplandii + (with C. validus reversed to plesiomorphic condition, group fasciatus + with narrow band and $C$. corpulentus, wide (1)); narrow stripes (8.5) appear independentlty in group spinipennis ${ }^{+}$and group fasciatus ${ }^{+}$.

The general pubescence of elytra is usually of the same color of pronotum, considered as plesiomorphic condition (C9). In some species, different pubescence coloration clothes the striae or lower interstices, independent of the presence of lateral stripes, while in others, only the lateral stripes or whole the elytra are clothed with different pubescence coloration. Pubescence of elytra with striae clothed with different pubescence coloration forming stripes, independent of the presence or absence of lateral bands (9.1) appear independently in group extenuatuvittatus + (except group serricornis + and C. spinipennis, with lateral bands and without stripes (9.2) and $C$. albiventris reversed to plesiomorphic condition), $C$. aurulentus, C. cyaneus and C. porcatus; elytra with lateral bands but not striped (9.2), appears in group fabricii + (except group bomplandii + reversed to striae with different coloration) and group corpulentus + ; and elytra unicolor with coloration different from that of pronotum (9.3) is an autapomorphy to $C$. rostaine $+C$. validus.

The characters 4-9 were coded as missing for $C$. morio.

The epipleura coloration is equal or different from the underside, independent of the presence or absence of the lateral stripes on pronotum and/or elytra; in some species are partially different. Pubescence coloration of the epipleura different or partially different from underside is considered the apomorphic condition (C10): (10.1) pubescence of epipleura different from underside and without lateral stripes dorsally, is an autapomorphy to C. aurulentus; (10.2) pubescence of epipleura different from underside and with lateral stripes on pronotum, appears independently in C. copulatuvittatus and group approximatus $+;$ (10.3) pubescence of epipleura different from underside and with lateral stripes on pronotum and elytra, appears independently in C. limbatus $+C$. zonatus and group fasciatus ++ (with C. virgatipennis with pubescence of epipleura partially different from underside (10.4), and $C$. virginalis reversed to plesiomorphic condition).

Usually the pubescence coloration of underside is homogeneous (C11); in C. approximatus, C. tartarus and $C$. apacheanus the sternites present lateral white patches of variable size, considered as apomorphic condition.

2) Pubescence of male and female (no) $(\mathrm{ci}=50, \mathrm{ri}=0)$ 0) similar;

1) different.

3) Dorsal pubescence coloration (no) $(\mathrm{ci}=50, \mathrm{ri}=96)$

0 ) unicolor or different in each sex;

1) bicolor forming dorsolateral stripes.

4) Pattern of dorsal pubescence (no) $(\mathrm{ci}=57, \mathrm{ri}=89)$

0) unicolor;

1) blue with lateral white stripes;

2) variable;

3) white-brown;

4) green with bands on pronotum and striped elytra.

5) Pubescence of pronotum (no) $(\mathrm{ci}=33, \mathrm{ri}=92)$

0) unicolor;

1) forming lateral stripes or bands.

6) Lateral stripes of pronotum (no) $(\mathrm{ci}=37, \mathrm{ri}=81)$

0) absent;

1) band-like;

2) elliptical;

3) triangular. 
7) Elliptical stripes on pronotum (no) $(\mathrm{ci}=40, \mathrm{ri}=0)$

0) absent;

1) brown;

2) orange.

8) Stripes on pronotum band-like (no) $(\mathrm{ci}=45, \mathrm{ri}=66)$
0) absent;
1) wide;
2) fused;
3) narrowed at extremities;
4) moderately wide;
5) narrow.

9) Elytral pubescence (no) $(\mathrm{ci}=27, \mathrm{ri}=75)$

0) unicolor, like pronotum;

1) striped with or without lateral bands;

2) with lateral bands;

3) unicolor different from pronotum.

10) Epipleura coloration (no) $(\mathrm{ci}=44, \mathrm{ri}=58)$

0) similar to underside;

1) different from underside, without lateral stripes dorsally;

2) different from underside, with lateral stripes on pronotum;

3) different from underside, with lateral stripes on pronotum and elytra;

4) partially different from underside.

11) Pubescence of sternites (no) $(\mathrm{ci}=33, \mathrm{ri}=0)$

0) unicolor;

1) with white patches.

Antennae. The antennae of Lacais species are 11- or 12segmented in both sexes or 11-segmented in female and 12segmented in male; serrate in female and pectinate in male or pectinate in female and flabellate in male. In Alaus (except $A$. nobilis, A. patricius and A. tricolor) the antennae are 11segmented and serrate in both sexes, with $3^{\text {rd }}$ segment triangular elongate, equal, shorter or longer than $4^{\text {th }}$. In Chalcolepis they are 11-segmented and serrate in both sexes, with $3^{\text {rd }}$ segment almost equal or shorter than $4^{\text {th }}$.

The antennae of Chalcolepidius species are short and 11segmented in both sexes, usually not reaching posterior margin of pronotum. They are usually serrate in both sexes; in some species they are serrate in female and strongly serrate or pectinate in male, or pectinate in female and flabellate in male. Antennae of male serrate are considered the plesiomorphic condition (C12). The state (12.1), strongly serrate appears in group supremus + (except $C$. mexicanus and $C$. dugesi with antennae pectinate (12.2)), group rubripennis + (except $C$. smaragdinus and $C$. viridipilis with antennae flabellate (12.3), group forreri* reversed to plesiomorphic condition and $C$. inops with antennae pectinate(12.2)), C. virginalis and C. tartarus.

The examination of available material has shown that the size and shape of $3^{\text {rd }}$ antennal segment varies both inter- as intraspecific, but three patterns could be established in Chalcolepidius. The third antennal segment is usually triangular-elongate, slightly shorter than $4^{\text {th }}(0.70-0.93$ times length of $\left.4^{\text {th }}\right)$ or triangular-short (0.40-0.65 times the $4^{\text {th }}$ length) in antennae serrate or strongly serrate, and transverse with spiniform appendix in antennae pectinate or flabellate. Third antennal segment of male triangular-elongate is considered plesiomorphic condition (C13). The state (13.1), short and triangular, appears independently in group supremus + (except C. mexicanus, group attenuatus* and C. serricornis with $3^{\text {rd }}$ antennal segment transverse (13.2)), group rubripennis + (except $C$. smaragdinus, $C$. boucardi, $C$. viridipilis and $C$. inops, transverse (13.2) and group forreri* reversed to plesiomorphic condition), C. virginalis and C. tartarus.

The characters 12 and 13 were coded as missing for $C$. extenuatuvittatus, C. albiventris, C. truncuvittatus, C. forreri, C. proximus and C. rostainei.

12) Antennal shape of male (o) $(\mathrm{ci}=25, \mathrm{ri}=65)$

0) serrate;

1) strongly serrate;

2) pectinate;

3) flabellate.

13) $3^{\text {rd }}$ antennal segment of male (no) $(\mathrm{ci}=20, \mathrm{ri}=60)$

0) triangular-elongate;

1) triangular-short;

2) transverse.

Pronotum. The pronotum of Chalcolepidius usually presents a typical shape: elongate, slightly narrowed apicad with hind angles wide and truncate, moderately convex anteriorly, decreasing basad, herein named as subtrapezoidal. There are species also with pronotum subquadrangular or subrectangular, with lateral margins almost straight, sinuous or rounded, and convexity variable. However, the shape, degree of convexity, punctuation and sculpture of the prothorax appear to vary intraspecific. It is possible to recognize one condition really apomorphic, related with the shape of lateral margins (C14), rounded in group attenuatus* and C. rubripennis. Related with the convexity, it was established three apomorphic patterns (C15): pronotum stronger convex at middle (15.1) giving to pronotum a rounded convexity, appear in group attenuatus*, C. copulatuvittatus, C. rubripennis, C. smaragdinus and $C$. boucardi; convexity of pronotum very strong medioanteriorly (15.2), decreasing basad, is an autapomorphy to C. inops; and convexity of pronotum stronger longitudinal medially (15.3), forming like a ridge, autapomorphy to $C$. desmarestii.

The median basal tubercle of pronotum is transverse and semi-elliptical in Lacais, Alaus and Chalcolepis. In the Chalcolepidius species it is usually triangular-elongate and very flat, sometimes indistinct or continuous with a weak ridge, not reaching anterior margin. In some species it is elongate or transverse, in the last case, bearing a transverse carina. Median basal tubercle transverse, without carina was considered plesiomorphic condition (C16). It was postulated a series 
considered nonadditive, for the apomorphic conditions: median basal tubercle elongate (16.2), appears in the group supremus ${ }^{+}$ (with group attenuatus* and $C$. truncuvittatus, reversed to transverse with carina (16.1)); triangular-elongate (16.3) is an autapomorphy to group desmarestii ${ }^{+}$(with $C$. rubripennis reversed to elongate (16.2)).

The posterior margin of pronotum is slightly rounded and prominent at middle in Lacais, slightly notched in Alaus and slight- or moderately notched in Chalcolepis. In all Chalcolepidius species, the posterior margin of pronotum is prominent and notched at middle, representing an autapomorphy to the genus (C17). The majority of Chalcolepidius species present posterior margin of pronotum moderate- or strongly notched at middle, but many times, it is very difficult to separate the conditions that are herein considered together. The posterior margin of pronotum slightly rounded is considered the plesiomorphic condition and it was postulated a series, considered nonadditive, for the apomorphic conditions (C18): posterior margin slightly notched (18.1) appear in whole genus with reversals to strongly notched (18.2) in the group desmarestii+.

14) Lateral margins of pronotum (no) ( $\mathrm{ci}=50, \mathrm{ri}=66)$

0) straight or sinous;

1) rounded.

15) Convexity of pronotum (no) $(\mathrm{ci}=42, \mathrm{ri}=33)$

0) slight or moderate;

1) stronger at middle;

2) stronger medioanteriorly;

3) forming longitudinal median ridge.

16) Median basal tubercle (no) $(\mathrm{ci}=60, \mathrm{ri}=87)$

0) transverse;

1) transverse with carina;

2) elongate;

3) triangular-elongate or indistinct.

17) Posterior margin of pronotum (no) $(\mathrm{ci}=100, \mathrm{ri}=100)$

0 ) rounded at middle;

1) notched at middle.

18) Median region of posterior margin of pronotum (o) (ci= $100, r i=100$ )

0) slightly rounded;

1) slightly notched;

2) strongly notched.

Prosternum. In Lacais, Alaus and Chalcolepis, the prosternum is slight- or moderately convex, from notosternal sutures; the notosternal sutures are straight and the prosternal channel is absent. In Chalcolepidius species the prosternum is usually strong- or moderately convex, flattened longitudinal medially and grooved near sutures, making the notosternal sutures sinuous. Prosternum strongly convex, flat longitudinal medially and grooved laterally is considered the apomorphic condition (C19), representing an autapomorphy to group desmarestii+. Notosternal sutures sinuous (C20) are the apomorphic condition, representing an autapomorphy to Chalcolepidius. The degree of sinuosity of notosternal sutures many times varies intraspecific and it is very difficult to separate moderate- from strongly sinuous, and these two conditions are herein considered together. It was postulated a nonadditive series for the apomorphic conditions of notosternal sutures (C21): slightly sinuous (21.1) appears in whole genus except $C$. desmarestii and group forreri*, moderate- or strongly sinuous (21.2). In the majority of Chalcolepidius species the notosternal sutures are opened frontally and the laterointernal margin of hypomera is raised forming the wall of prosternal channel. The presence of prosternal channel (C22) is considered apomorphic condition and represents an autapomorphy to group rubripennis + . In C. gossipiatus the hypomera are raised anteriorly forming a globose prominence near the apex.

19) Prosternum (no) $(\mathrm{ci}=100, \mathrm{ri}=100)$

0 ) slight or moderately convex from sutures;

1) strongly convex, flat longitudinally and grooved laterally.

20) Notosternal suture (no) $(\mathrm{ci}=100, \mathrm{ri}=100)$

0) straight;

1) sinuous.

21) Notosternal suture (no) $(\mathrm{ci}=66, \mathrm{ri}=95)$

0) straight;

1) slightly sinuous;

2) moderate to strongly sinuous.

22) Prosternal channel (no) $(\mathrm{ci}=100, \mathrm{ri}=100)$

0) absent;

1) present.

Mesosternal Cavity. The mesosternal cavity of Chalcolepidius, different from any other Hemirhipini, is U- or V-shaped with borders wide and horizontal on basal $2 / 3$ or $3 / 4$, and declivous on distal $1 / 3$ or $1 / 4$, representing an autapomorphy for the genus (C23). In some species the horizontal area of mesosternal cavity is slightly prominent apicad. The distal part of mesosternal cavity is slight-, moderate or strongly declivous, taking semielliptical or inclined profile in the two first and L-shaped in the last. Borders of mesosternal cavity (C24) moderately declivous taking an inclined profile (24.2) appears in group supremus + (except C. mexicanus and C. rodriguezi, almost vertical (24.3) and group attenuatus*, copulatuvittatus + truncuvittatus reversed to slightly declivous (24.1)) and C. desmarestii; slightly declivous (24.1) taking semielliptical or inclined profile appears in group jansoni ${ }^{+}$, except forre $i^{*}$; strongly declivous, almost vertical (24.3), taking L-shaped profile, in group forreri* (except $C$. inops, C. pruinosus, C. virgatipennis $+C$. virginalis and group tartarus + (except $C$. tartarus reversed to slightly declivous (24.1) and C. apacheanus, strongly declivous, almost vertical 
(24.3)) and C. angustatus reversed to slightly declivous (24.1)).

In all Chalcolepidius species the suture behind the mesosternal cavity is obsolete or absent, condition considered apomorphic, representing an autapomorphy to Chalcolepidius (C25).

23) Borders of mesosternal cavity (no) $(\mathrm{ci}=100, \mathrm{ri}=100)$

0) narrow, almost horizontal;

1) wide, prominent, horizontal on basal $2 / 3$ or $3 / 4$ and declivous on distal $1 / 3$ or $1 / 4$.

24) Declivity of distal $1 / 3$ or $1 / 4$ of mesosternal cavity (no) ( $\mathrm{ci}=23, \mathrm{ri}=62)$

0 ) almost horizontal;

1) slightly declivous (inclined profile);

2) moderate declivous (inclined profile);

3) almost vertical (L-shaped profile).

25) Meso-metasternal suture (no) $(\mathrm{ci}=100, \mathrm{ri}=100)$

$0)$ present;

1) absent or obsolete

Scutellum. The scutellum is subhexagonal-elongate with posterior margin notched in Lacais and subpentagonal or elongate in Alaus and Chalcolepis. In these three genera the scutellum is straight kept in a declivous forward position.

In Chalcolepidius species the scutellum is pentagonal or elongate and narrower and declivous at variable degree on anterior half. The majority of species presents the basal and more visible half of scutellum horizontal, subtrapezoidal, narrowed anteriad with anterior carina, and the anterior half narrow, folded under the carina taking an almost vertical position. Usually, the anterior and posterior margins of horizontal half are notched at middle. Due to the shape of the horizontal half, this kind of scutellum was defined as "triangular" by previous authors, and it is herein considered as folded, representing the fully apomorphic condition of declivous scutellum. In some species the anterior half of scutellum is slight-, moderate or strongly declivous, but never folded or forming transverse carina at anterior margin of horizontal half, and the horizontal half present variable shapes, but never subtrapezoidal.

It was postulated a series, considered additive, for the scutellar shape of Chalcolepidius species (C26): scutellum subpentagonal and slightly declivous (26.1) appears in $C$. desmarestii and $C$. jansoni; moderately declivous (26.2), $C$. supremus and C. oxydatus; strongly declivous (26.3), in group mexicanus + (with C. attenuatus, C. ferratuvittatus and group spinipennis + , reversed to moderately declivous (26.2)) and $C$. rubripennis; and folded with anterior carina (26.4), representing an autapomorphy to group chalchanteus* (with $C$. smaragdinus reversed to strongly declivous (26.3)).

The presence of carina at anterior margin of horizontal half of scutellum is considered apomorphic condition (C27) representing an autapomorphy to group chalcantheus* (with C. smaragdinus reversed to plesiomorphic condition).
Each type of scutellum shows such a wide range variation in its appearance, especially in the relative length and width of the horizontal portion, but the shape of this area is kept. The shape of horizontal half of scutellum presents a series of apomorphic conditions, considered as nonadditive (C28): subpentagonal (28.1) appears independently in C. supremus and $C$. desmarestii; elliptical (28.2) is an autapomorphy to group oxydatus + (except C. mexicanus, C. serricornis and $C$. albiventris, elliptical with anterior margin bilobed (28.3) and group ferratuvittatus + and $C$. copulatuvittatus reversed to subpentagonal (28.1)); triangular (28.4) appears independently in C. jansoni and C. rubripennis; and subtrapezoidal (28.5), represents an autapomorphy to group chalcantheus* (with $C$. smaragdinus, reversed to triangular (28.4)).

26) Scutellum (o) $(\mathrm{ci}=40, \mathrm{ri}=81)$

0) subhexagonal and declivous;

1) subpentagonal and slightly declivous;

2) moderately declivous;

3) strongly declivous;

4) folded.

27) Median region of scutellum (no) $(\mathrm{ci}=50, \mathrm{ri}=95)$

0) almost horizontal;

1) angular with carina.

28) Horizontal area of scutellum (no) $(\mathrm{ci}=50, \mathrm{ri}=70)$

0) hexagonal;

1) subpentagonal;

2) elliptical;

3) elliptical with anterior margin bilobed;

4) triangular;

5) subtrapezoidal.

Elytra. The elytral interstices are moderately convex in Lacais and Chalcolepis and flat or slightly convex in Alaus. In Chalcolepidius the elytral striae are usually concave, marked by row of coarse punctures, and the interstices are equal or unequal in width and convex in variable degree. The width and degree of convexity of the elytral interstices vary both interand intraspecific. These are the classic characters that have been used up to the present, either singly or in combination with one another to distinguish the species. Examination of the available material has shown that in almost every case they are too variable, except when the striae are alternate, irregularly convex or flat, considered as the apomorphic conditions of this character (C29): in C. obscurus, C. pruinosus and $C$. silbermanni (group forreri*) the striae are alternate (29.1); in C. forreri, irregularly convex (29.2) forming small and irregular ridges; in C. lenzi, C. smaragdinus and C. apacheanus $+C$. webbi, the interstices are flat.

The apices of elytra are rounded in Lacais, Chalcolepis and the majority of Alaus and Chalcolepidius species. The presence of sutural spines at elytral apices of $C$. oxydatus, $C$. extenuatuvittatus, C. ferratuvittatus, C. albisetosus, $C$. spinipennis, $C$. desmarestii and $C$. jansoni is considered 
apomorphic condition (C30) of this character.

29) Interstices (no) $(\mathrm{ci}=60, \mathrm{ri}=60)$

0) convex;

1) alternate;

2) irregular;

3) flat.

30) Apex of elytra (no) $(\mathrm{ci}=14 ; \mathrm{ri}=0)$

0) without sutural spine;

1) bearing sutural spine.

First Visible Sternite. In Lacais, Chalcolepis and the majority of Chalcolepidius species, the lateral margins of the first visible sternite is prominent and rounded laterally, and when in resting, fits in a marginal groove of elytra. In a few species of Chalcolepidius, like in Alaus, the lateral margins are not prominent, ending at the level of tergites. This condition is considered apomorphic (C31) and appears in group supremus ${ }^{+}$ and $C$. viridipilis.

The character 31 was coded as missing for $C$. rodriguezi.

31) First visible sternite (no) $(\mathrm{ci}=50, \mathrm{ri}=93)$

0 ) prominent laterally;

1) not prominent laterally.

Male Tibiae. In several Chalcolepidius species, different from any other Hemirhipini, the tibiae of male present internally, a fringe of cilia or an irregular row of spines. The fringe of cilia is present also under the last tarsal segment of all legs. Depending on the species, the cilia are short or long, and present only beneath of anterior, or anterior and median pairs of tibiae. In $C$. desmarestii the apex of anterior tibiae male is dilated.

The presence of the fringe of cilia or row of spines on the male tibiae is considered the apomorphic condition. Among the Chalcolepidius species, different apomorfic states can be distinguished, in a series considered nonadditive. The anterior tibiae of male (C32) bearing spines (32.1) represents an autapomorphy to group supremus ${ }^{+}$; fringe of short cilia (32.2) appears in C. jansoni, C. rubripennis and group chalcantheus* (with $C$. smaragdinus and $C$. boucardi reversed to plesiomorphic condition); fringe of long cilia (32.3) represents an autapomorphy to group forreri* (with C. angustatus and $C$. tartarus reversed to fringe of short cilia (32.2)). The median tibiae of male $(\mathrm{C} 33)$ bearing spines (33.1) represents an autapomorphy to group supremus ${ }^{+}$, and fringe of long cilia (33.2), autapomorphy to group forreri* (with C. angustatus reversed to plesiomorphic condition).

The characters 32 and 33 were coded as missing for $C$. extenuatuvittatus, C. albiventris, C. truncuvittatus, C. forreri and $C$. proximus.

32) Anterior tibiae of male (no) $(\mathrm{ci}=42, \mathrm{ri}=80)$

0 ) without ornamentations or with stout setae;

1) bearing spines;
2) bearing fringe of short cilia;

3) bearing fringe of long cilia.

33) Median tibiae of male (no) $(\mathrm{ci}=66, \mathrm{ri}=95)$

0 ) without ornamentations or with stout setae;

1) bearing spines;

2) bearing fringe of long cilia.

Sternite VIII and Tergite IX of Male. The sternite VIII of male in Lacais is triangular, subtrapezoidal or semi-elliptical, translucent with melanized marginal lateroanterior band and two small patches comma-like near base; in Alaus it presents variable shapes and melanized areas; in Chalcolepis it is subtrapezoidal with melanized lateroanterior band, in some species broken medioanteriorly.

In the majority of Chalcolepidius species the sternite VIII of male is subtrapezoidal (C34), considered the plesiomorphic condition. Sternite subpentagonal with anterior margin strongly prominent (34.1) represents an autapomorphy to group oxydatus $^{+}$and semielliptical, with anterior margin rounded (34.2), appears independently in C. boucardi and C. tartarus.

The different shapes of the marginal melanized band of sternite VIII of male in Chalcolepidius are considered as apomorphic condition (C35). It is postulated a series nonadditive for the shapes of melanized band: entire (35.1) appears in jansoni+ (except C. boucardi and C. inops, entire with narrow laterobasal transverse band (35.2)); divided into three parts (35.4), is an autapomorphy to group supremus + (with $C$. ferratuvittatus and C. spinipennis reversed to (35.3), divided into three parts with mediobasal clearer spot); entire with narrow laterobasal transverse band (35.2), in boucardi + viridipilis and $C$. silbermanni; broken basally with mediobasal clearer spot (35.5), is an autapomorphy to group attenuatus* (with $C$. dugesi and $C$. lenzi broken basally (35.7)); broken basally, almost fused (35.6), independently in C. exulatus and $C$. desmarestii; and sternite totally brownish and melanized band absent (35.8), autapomorphy to C. mexicanus.

The tergite IX of male is transverse and densely punctuate in Lacais, Alaus, Chalcolepis and Chalcolepidius. The anterior margin is moderately notched at middle with moderately long lateroanterior setae in Lacais and the majority of Alaus and Chalcolepis species. In Chalcolepidius it is slight-, moderateor strongly notched or rounded at middle. Median region moderately notched at middle with moderately long lateroanteriorly setae is considered the plesiomorphic condition (C36). It is postulated a series nonadditive of apomorphic conditions: moderately notched at middle without or with very tinny lateroanterior setae (36.1) appears in C. rubripennis and group chalcantheus* (with C. smaragdinus reversed to plesiomorphic condition); anterior margin rounded (36.2), in group forreri* (with C. lacordairii, C. virens, C. porcatus and group rostaine + reversed to moderately notched at middle without or with very tinny lateroanterior setae (36.1)) and $C$. apacheanus; and strongly notched at middle (36.3), in $C$. desmarestii and C. jansoni.

The characters 34-36 were coded as missing for C. supremus, 
C. extenuatuvittatus, $C$. albiventris, $C$. tuncuvittatus, and $C$. forreri, C. sulcatus, C. pruinosus, C. fryi, C. angustatus, $C$. proximus and $C$. rostainei, and the characters 35 and 36 , for $C$. inops, C. morio, C. angustatus, C. fasciatus and $C$. virgatipennis.

34) Shape of sternite VIII of male (no) $(\mathrm{ci}=50, \mathrm{ri}=83)$

$0)$ triangular or subtrapezoidal;

1) subpentagonal with anterior margin strongly prominent at middle;

2) semielliptical .

35) Melanized area of sternite VIII of male (no) $(\mathrm{ci}=66$, $\mathrm{ri}=$ 60)

0) U-shaped;

1) entire;

2) entire, base narrow;

3) divided into three parts, spot at base;

4) divided into three parts;

5) broken basally with basal spot;

6) broken basally, almost fused;

7) broken basally;

8) absent.

36) Anterior margin of tergite IX of male (no) $(\mathrm{ci}=30, \mathrm{ri}=72)$

0 ) moderately notched with lateral setae;

1) moderately notched with or without tiny setae;

2) rounded;

3) strongly notched.

Aedeagus. The aedeagus of Lacais presents subapical lateral region of parameres slightly prominent, almost straight or with a very small tooth, and median lobe gradually narrowed apicad with lateral margins straight or slightly sinuous. In Chalcolepis the subapical region of parameres presents a dorsal tooth and the median lobe is wide, narrowed near middle and gradually narrowed apicad, with lateral margins sinuous. In Alaus the aedeagus is variable, with laterodistal region of parameres with laterodistal tooth, rounded, unciform or forming a dorsal uncus. The basal piece is located above the parameres base in all species of these three genera except in Alaus nobilis, A. patricius and A. tricolor.

The Chalcolepidius species present two shapes of aedeagus. The first one is long and narrow (length $=3.0-4.6$ width) with median lobe short (0.46-0.56 aedeagus length), toothed laterally and parameres cleft laterally near apex; the basal piece presents a large membrane joining it with the parameres base. When dried material is dissected, the position of the basal piece is variable, and it is related with the fixation, but in all specimens it was possible to move the basal piece dorsally, reaching the basal fourth of parameres. The shapes of the median lobe and the apex of the lateral cleft of parameres are useful to recognize the species, but they are so variable that many times it is impossible to be polarized. The second kind is shorter and wider (length $=2.7-3.31$ width) with median lobe longer (0.53-0.63 aedeagus length), without teeth, and subapical region of parameres spearhead-like, and basal piece always located above the parameres base, independent of the fixation. This aedeagus shape is found in species with scutellum declivous in variable degree, but never in folded ones.

Aedeagus with subapical region of parameres spearheadlike is considered plesiomorphic. Parameres of aedeagus cleft laterally is considered the apomorphic condition (C37) representing an autapomorphy to group desmarestii+. It was postulated a series nonadditive for the length of lateral cleft of parameres (C38): moderately long (38.1) represents an autapomorphy to group desmarestii+, with $C$. boucardi reversed to short (38.2). Apex of lateral cleft of parameres (C39) truncate (39.1) appears in group chalcantheus* (with $C$. erythroloma and $C$. virgatipennis with apex excavate (39.3) and $C$. virginalis and $C$. webbi with apex rounded ventrally and one teeth dorsally (39.4)); apex rounded (39.2) appears in C. desmarestii, C. jansoni, C. rubripennis and C. chalcantheus.

The subapical region of lateral cleft of parameres is variable in shape but it was possible to recognize six patterns (C40): narrow with apex rounded (40.2) appears in $C$. desmarestii, $C$. jansoni and C. rubripennis; wide (40.6), is an autapomorphy to group chalcantheus*, except $C$. chalcantheus with apex spoon-like (40.4), C. inops and apacheanus + webbi reversed to narrow with apex truncate (40.1), and C. erythroloma and $C$. virgatipennis reversed to flattened and concave (40.3).

The basal piece located dorsally, on basal fourth of aedeagus is considered apomorphic condition (C41) and represents an autapomorphy to group desmarestii+.

Median lobe constricted near middle (C42) is considered apomorphic condition and represents an autapomorphy to group mexicanus*, with group ferratuvittatus,$+ C$. copulatuvittatus and probably $C$. truncuvittatus, reversed to apomorphic condition.

The median lobe toothed laterally (C43) is considered the apomorphic condition and represents an autapomorphy to group desmarestii + , with C. boucardi reversed to (43.2), bearing very small and dorsal teeth. It was postulate a series nonadditive for the number of teeth of median lobe (C44): less than 20 teeth (44.1) is an autapomorphy to group desmarestii+, except $C$. jansoni and $C$. viridipilis with more than 30 (44.2).

The width of base of median lobe/parameres also indicated a nonadditive series of apomorphic condition (C45): 0.45-0.50 (45.1) appears in C. oxydatus; 0.51-0.60 (45.2) is an autapomorphy to group mexicanus ${ }^{*}$ with group serricornis + reversed to $0.45-0.50$ (1).

The characters 37-45 were coded as missing for C. supremus, C.extenuatuvittatus, C. albiventris, $C$. tuncuvittatus, and $C$. forreri, C. sulcatus, C. pruinosus, C. fryi, C. proximus and $C$. rostainei and the characters 44 and 45 , for $C$. virgatipennis.

37) Subapical region of parameres of aedeagus (no) (ci= $100, \mathrm{ri}=100)$

0) spearhead-like;

1) cleft laterally. 
38) Lateral cleft of parameres (no) $(\mathrm{ci}=100, \mathrm{ri}=100)$
0) absent;
1) moderately long;
2) short.

39) Lateral cleft of parameres (no) $(\mathrm{ci}=57, \mathrm{ri}=83)$
0) absent;
1) with truncate apex;
2) with rounded apex;
3) with apex excavate;
4) rounded in one angle.

40) Subapical region of lateral cleft of parameres (no) (ci = $75, \mathrm{ri}=88$ )

0) absent;

1) narrow with apex truncate;

2) narrow with apex rounded;

3) flattened and concave;

4) apex spoon-like;

5) short with dorsal uncus;

6) wide.

41) Position of basal piece of aedeagus (no) $(\mathrm{ci}=100$, $\mathrm{ri}=100$ )

0) above the parameres base;

1) dorsally, on basal fourth of parameres.

42) Median lobe (no) $(\mathrm{ci}=33, \mathrm{ri}=77)$

0 ) gradually narrowed apicad;

1) constricted near middle.

43) Median lobe (no) $(\mathrm{ci}=100, \mathrm{ri}=100)$

0 ) without lateral teeth;

1) with lateral teeth;

2) with dorsal small teeth.

44) Number of teeth of median lobe (no) $(\mathrm{ci}=66, \mathrm{ri}=92)$

$0)$ without teeth;

1) under 20;

2) above 30 .

45) Width of median lobe base/parameres (no) (ci=66, $\mathrm{ri}=90)$

0) $0.35-0.44$;

1) $0.45-0.50$

2) $0.51-0.60$.

Tergite VIII of Female. The tergite VIII of female is wide with melanized patches relatively small with anterior margin wide and deeply notched in Lacais; narrower with anterior margin rounded or slightly notched at middle in Chalcolepis, and variable, presenting several shapes in Alaus. The spiculum gastrale varies from 1.50 to 1.65 times the tergite length in Lacais, 1.33 to 1.53 in Alaus and 1.35 to 1.70 in Chalcolepis.

The tergite VIII of female of Chalcolepidius is transverse and translucent with two melanized elliptical large patches, usually fused at middle; the anterior margin is notched at middle in variable degree and the spiculum gastrale varies from 1.45 to 1.70 times the tergite length. The tergite is clothed with fine, clear and moderately long setae with a band of darker, erect and stout setae bordering the internal margin of dark spots. Anterior margin of tergite VIII of female narrow and deeply notched at middle (C46) is considered the apomorphic condition and represents an autapomorphy to group mexicanus*. In the majority of species, the tergite width is inside of a pattern of size, except C. chalcantheus and C. smaragdinus (C47), with sternite is very wide.

46) Anterior margin of tergite VIII of female (no) ( $\mathrm{ci}=100$, $\mathrm{ri}=100)$

0 ) wide and slightly or moderately deeply notched at middle;

1) narrow and deeply notched at middle.

47) Width of tergite VIII of female (no) $(\mathrm{ci}=50$, ri $=0)$

0) inside pattern;

1) wider than pattern.

Ovipositor. In Lacais, Alaus, Chalcolepis and the majority of Chalcolepidius, the width of the ovipositor is from 3 to 4.5 times the length, condition considered as plesiomorphic, and treated as "normal" because it is inside the pattern of size of this group. C. chalcantheus and C. smaragdinus present ovipositor short and wide (C48), from 2 to 2.5 times the ovipositor length.

48) Ovipositor (no) $(\mathrm{ci}=50, \mathrm{ri}=0)$

0) "normal";

1) short and wide.

Sclerotized Pieces of the Openings of the Colleterial Glands. In Lacais the sclerotized pieces of the openings of the colleterial glands are C-shaped without teeth or L-shaped with teeth; in Alaus, C-shaped and toothed, with one arm approximately two times longer; and in Chalcolepis, C-shaped with or without teeth.

In Chalcolepidius they are C- or ring-shaped and always toothed. The sclerotized pieces of the openings of the colleterial glands ring-shaped is considered the apomorphic condition (C49) and appear in C. desmarestii and group rubripennis + (with C. silbermanni reversed to plesiomorphic condition). It was postulated a series nonadditive of apomorphic conditions for the distribution of teeth on the rings (C50): with one row of teeth (50.1) appears in C. rubripennis (Fig. 655) and as reversal in group forreri* (Figs. 626, 631, 639, 645, 650, 653, 661, 665); with some basal rows (50.2), appear independently in $C$. porcatus (Fig. 652) and C. rostainei (Fig. 654); with several rows (50.3) represents an autapomorphy to group chalcantheus* (Figs. 628, 629, 659, 668), with C. smaragdinus and $C$. viridipilis bearing many rows in approximately $1 / 2$ of the ring diameter (50.4), and groupforreri* reversed to (50.1), with one row of teeth (except $C$. inops (Fig. 643) and C. tartarus 
(Fig. 662), bearing many rows in approximately $1 / 2$ of the ring diameter (50.4)); and grater-like (50.5) is an autapomorphy to $C$. desmarestii (Fig. 634).

49) Sclerotized pieces of the openings of the colleterial glands (no) $(\mathrm{ci}=66, \mathrm{ri}=90)$

0 ) opened;

1) closed.

50) Sclerotized rings of the openings of the colleterial glands (no) $(\mathrm{ci}=50, \mathrm{ri}=68)$

0) without teeth;

1) with one row of teeth;

2) with some rows of teeth at base;

3 ) with several rows of teeth in $1 / 3$;

4) with many rows of teeth in $1 / 2$ of diameter;

5) grater-like.

Bursa Copulatrix. In Lacais, Alaus and Chalcolepis, the bursa copulatrix is elongate with wide spiny area; in Chalcolepidius it is elongate or rounded, many times taking a triangular shape, with variable spiny areas. Bursa copulatrix rounded is considered the apomorphic condition (C51) representing an autapomorphy in the group rubripennis + (Figs. $580,581,584-587,591-595,597,598,603,604,608-612,615,618-$ 622).

The spiny areas of bursa copulatrix are variable in Chalcolepidius species; when totally spiny ventrally is considered the plesiomorphic condition (C52). Different apomorfic states can be distinguished in the spiny areas of the bursa copulatrix in a series considered nonadditive: dorsal band short and wide (52.1) appears in C. dugesi (Fig. 589); dorsal area reduced (52.2) in group chalcantheus* (Figs. 583, 584, $585,615,619)$; and with longitudinal wide band (52.3) in $C$. rubripennis and group forreri* (with C. tartarus (Fig. 618) reversed to (52.2), dorsal area reduced) (Figs. 580, 591, 592-597, $598,603,604,608,611,612,620-622)$.

The female of several species was not studied and, consequently, the characters 46-53 were coded as missing for C. rodriguezi, C. supremus, C. albisetosus, C.ferratuvittatus, $C$. albiventris, $C$. exulatus, $C$. copulatuvittatus, $C$. truncuvittatus, C. morio, C. angustatus and C. proximus.

51) Bursa copulatrix (no) $(\mathrm{ci}=100, \mathrm{ri}=100)$

0) elongate;

1) rounded.

52) Areas of bursa copulatrix with spines and carinae internally (no) $(\mathrm{ci}=75, \mathrm{ri}=92)$

0) totally spiny ventrally;

1)dorsal band short and wide;

2) dorsal area reduced;

3) longitudinal wide band.

Spermathecae. The majority of Chalcolepidius species present bursa copulatrix rounded with one spermatheca near middle, at dorsal folder of bursa copulatrix. The remainder species present bursa copulatrix elongate and like Lacais, Alaus and Chalcolepis species, present two spermathecae, usually distal. The presence of only one spermatheca (C53) is considered the apomorphic condition and represents an autapomorphy to group rubripennis + .

53) Number of spermathecae (no) $(\mathrm{ci}=100, \mathrm{ri}=100)$

0) two distal;

1) one dorsal median.

\section{RESULTS}

The analysis of the interrelationships of Chalcolepidius species includes 59 taxa and 53 characters. The outgroups comprise Lacais Fleutiaux, 1942, Chalcolepis Candèze, 1857 and Alaus Eschscholtz, 1829. All characters were equally weighted and were unordered (no) except for characters 12 (antennal shape of male), 18 (median region of posterior margin of pronotum) and 26 (scutellum shape), that presented evidence of the character evolution. The data matrix is represented by Table 1 . The analysis resulted in 2,636 more parcimonious trees, and the consensus tree (Fig. 671) is 256 length, $\mathrm{CI}=46$ and RI $=81$. When all characters were considered "unordered", the results did not change. In parentheses format it is the following: (supremus (oxydatus (mexicanus, rodriguezi (attenuatus, dugesi, lenzi) (extenuatuvittatus (gossipiatus ((serricornis (ferratuvittatus (albiventris, exulatus))) (albisetosus (spinipennis (copulatuvittatus, truncuvittatus $)))))))$ )) (desmarestii (jansoni (rubripennis (chalcantheus, smaragdinus, boucardi, viridipilis (forreri, inops, lacoradairii, sulcatus, virens, aurulentus, cyaneus, morio, porcatus, obscurus, pruinosus, silbermanni (fabricii (fryi, erythroloma, villei, angustatus, eschscholtzi, lafargi, rugatus (bomplandii, proximus (mocquerysii (limbatus, zonatus)) (approximatus ((rostainei, validus) ((fasciatus (virgatipennis, virginalis)) (corpulentus (tartarus (apacheanus, webbi)))))))).

The monophyly of Chalcolepidius is well supported by following autapomorphies: posterior margin of pronotum prominent and notched at middle (17.1); notosternal sutures sinuous (20.1); borders of mesosternal cavity wide and horizontal on basal $2 / 3$ or $3 / 4$ and declivous distally in variable degree (23.1); meso-metasternal suture, behind mesosternal cavity, absent or obsolete (25.1). The analysis results, divide the Chalcolepidius into two well corroborated monophyletic groups of species, each one with several groupings. The first monophyletic group, supremus ${ }^{+}$, formed by 17 species, is supported by three autapomorphies, the anterior tibiae of male bearing spines (32.1), median tibiae of male bearing spines (33.1) and melanized area of sternite VIII of male divided into three parts (35.4), and the homoplasies, antennae of male strongly serrate (12.1), $3^{\text {rd }}$ antennal segment short and triangular (13.1), borders of mesosternal cavity moderately declivous distally (24.2), scutellum moderately declivous (26.2) and first sternite visible not prominent laterally (31.1). The second monophyletic group, desmarestii + , formed by 42 species, is supported by 9 
Table 1. Data matrix for Chalcolepidius species, except C. costatus, C. fleutiauxi, C. mniszechi and C. viriditarsus. (0) plesiomorphic state; 1, 2, 3, $4,5,6,7,8$, apomorphic states; (?) missing data.

\begin{tabular}{|c|c|c|c|c|c|c|}
\hline & 1 & 10 & 20 & 30 & 40 & 50 \\
\hline Outgroup & 0000000000 & 0000000000 & 0000000000 & 0000000000 & 0000000000 & 000 \\
\hline C. supremus & 0000000000 & 0110021101 & 1012120100 & $111 ? ? ? ? ? ? ?$ & ?????????? & ?? ? \\
\hline C. oxydatus & 0000000000 & 0110021101 & 1012120201 & 1111400000 & 0000100000 & 000 \\
\hline C. mexicanus & 0100000000 & 0220021101 & 1013130300 & 1111800000 & 0100210000 & 000 \\
\hline C. rodriguezi & 0100000000 & 0110021101 & 1013130200 & $? 111400000$ & 01002 ????? & ?? ? \\
\hline C. attenuatus & 1000000000 & 0121111101 & 1011120200 & 1111500000 & 0100210000 & 000 \\
\hline C. dugesi & 1000000000 & 0221111101 & 1011130200 & 1111700000 & 0100210000 & 010 \\
\hline C. lenzi & 1000000000 & 0121111101 & 1011130230 & 1111700000 & 0100210000 & 000 \\
\hline C. extenuatuvittatus & 0000000014 & $0 ? ? 0021101$ & 1012130201 & 1????????? & ????? 10000 & 000 \\
\hline C. gossipiatus & 0012000010 & 0110021101 & 1012130200 & 1111400000 & 0100210000 & 000 \\
\hline C. serricornis & 0012010020 & 0120021101 & 1012130300 & 1111400000 & 0100110000 & 000 \\
\hline C. ferratuvittatus & 0012021020 & 0110021101 & 1012120101 & 1111300000 & $00001 ? ? ? ? ?$ & ?? ? \\
\hline C. albiventris & 0012110414 & $0 ? ? 0021101$ & 1012130300 & $1 ? ? ? ? ? ? ? ? ?$ & ?????????? & ?? ? \\
\hline C. exulatus & 0012110424 & 0110021101 & 1012130100 & 1110600000 & $00001 ? ? ? ? ?$ & ?? ? \\
\hline C. albisetosus & 0013121010 & 0110021101 & 1012130201 & 1111400000 & 01002 ????? & ?? ? \\
\hline C. spinipennis & 0012110520 & 0110021101 & 1012120201 & 1111300000 & 0100210000 & 000 \\
\hline C. copulatuvittatus & 0012110212 & 0110121101 & 1011120100 & 1111400000 & $000002 ? ? ? ? ?$ & ?? ? \\
\hline C. truncuvittatus & 0012110510 & $0 ? ? 0011101$ & 1011120200 & $1 ? ? ? ? ? ? ? ? ?$ & ?????????? & ?? ? \\
\hline C. desmaresti & 0000000000 & 0000331211 & 2012110101 & 0000631122 & 1011000015 & 000 \\
\hline C. jansoni & 0000000000 & 0000031211 & 1011110401 & 0200131122 & 1012000000 & 000 \\
\hline C. rubripennis & 0000000000 & 0111121211 & 1211130400 & 0200111122 & 1011000011 & 131 \\
\hline C. chalcantheus & 1000000000 & 0110031211 & 1211141500 & 0200111124 & 1011001113 & 121 \\
\hline C. smaragdinus & 1000000000 & 0320131211 & 1211130430 & 0000101116 & 1011001114 & 121 \\
\hline C. boucardi & 1000000000 & 0120131211 & 1211141500 & 0002211216 & 1021000013 & 121 \\
\hline C. viridipilis & 1000000000 & 0320031211 & 1211141500 & 1200211116 & 1012000014 & 121 \\
\hline C. forreri & 0000000000 & $0 ? ? 0031211$ & 2213141520 & 0????????? & ?????000011 & 131 \\
\hline C. inops & 0000000000 & 0220231211 & 2212141500 & $0320 ? ? 1111$ & 1011000014 & 131 \\
\hline C. lacordairii & 0000000000 & 0000031211 & 2213141500 & 0320111116 & 1011000011 & 131 \\
\hline C. sulcatus & 0000000000 & 0000031211 & 2213141500 & 032 ??????? & ?????000011 & 131 \\
\hline C. virens & 0000000000 & 0000031211 & 2213141500 & 0320111116 & 1011000011 & 131 \\
\hline C. aurulentus & 0000000011 & 0000031211 & 2213141500 & 0320121116 & 1011000011 & 131 \\
\hline C. cyaneus & 0000000010 & 0000031211 & 2213141500 & 0320121116 & 1011000011 & 131 \\
\hline C. morio & $000 ? ? ? ? ? ? 0$ & 0000031211 & 2213141500 & $0320 ? ? 1116$ & $1 ? 1 ? 0 ? ? ? ? ?$ & ?? ? \\
\hline C. porcatus & 0000000010 & 0000031211 & 2213141500 & 0320111116 & 1011000012 & 131 \\
\hline C. obscurus & 0000000000 & 0000031211 & 2213141510 & 0320121116 & 1011000011 & 131 \\
\hline C. pruinosus & 0000000000 & 0000031211 & 2212141510 & 032 ??????? & ?????000011 & 131 \\
\hline C. silbermanni & 0000000000 & 0000031211 & 2213141510 & 0320221116 & 1011000022 & 131 \\
\hline C. fabricii & 0012000020 & 0000031211 & 2213141500 & $03201 ? 1116$ & 1011000011 & 131 \\
\hline C. fryi & 0012122020 & 0000031211 & 2213141500 & 032 ??????? & ?????000011 & 131 \\
\hline C. erythroloma & 0013121020 & 0000031211 & 2213141500 & 0320121133 & 1011000011 & 131 \\
\hline C. villei & 0012122020 & 0000031211 & 2213141500 & 0320121116 & 1011000011 & 131 \\
\hline C. angustatus & 0012110320 & 0000031211 & 2211141500 & $020 ? ? ? 1116$ & $1 ? 110 ? ? ? ? ?$ & ?? ? \\
\hline C. eschscholtzi & 0012110320 & 0000031211 & 2213141500 & 0320121116 & 1011000011 & 131 \\
\hline C. lafargi & 0012110420 & 0000031211 & 2213141500 & 0320121116 & 1011000011 & 131 \\
\hline C. rugatus & 0013110320 & 0000031211 & 2213141500 & 0320121116 & 1011000011 & 131 \\
\hline C. bomplandii & 0012110410 & 0000031211 & 2213141500 & 0320121116 & 1011000011 & 131 \\
\hline C. proximus & 0012110410 & $0 ? ? 0031211$ & 2213141500 & 0????????? & ?????????? & ??? \\
\hline C. mocquerysii & 0014110410 & 0000031211 & 2213141500 & 0320121116 & 1011000011 & 131 \\
\hline C. limbatus & 0014110413 & 0000031211 & 2213141500 & 0320121116 & 1011000011 & 131 \\
\hline C. zonatus & 0014110413 & 0000031211 & 2213141500 & 0320121116 & 1011000011 & 131 \\
\hline C. approximates & 0012110412 & 1000031211 & 2213141500 & 0320121116 & 1011000011 & 131 \\
\hline C. rostainei & 0012110432 & $0 ? ? 0031211$ & 2213141500 & 032 ??????? & ?????00012 & 131 \\
\hline C. validus & 0012130032 & 0000031211 & 2213141500 & 0320111116 & 1011000011 & 131 \\
\hline C. fasciatus & 0012110513 & 0000031211 & 2213141500 & $032 ? ? ? 1116$ & 1011000011 & 131 \\
\hline C. virgatipennis & 0012110514 & 0000031211 & 2212141500 & $032 ? ? ? 1133$ & $101 ? ? 00011$ & 131 \\
\hline C. virginalis & 0012110510 & 0110031211 & 2212141500 & 0320111145 & 1011000011 & 131 \\
\hline C. corpulentus & 0012110123 & 0000031211 & 2213141500 & 0320111116 & 1011000011 & 131 \\
\hline C. tartarus & 0011110423 & 1110031211 & 2211141500 & 0222101116 & 1011000014 & 121 \\
\hline C. apacheanus & 0011110423 & 1000031211 & 2213141530 & 0320121111 & 1011000011 & 131 \\
\hline C. webbi & 0011110423 & 0000031211 & 2212141530 & 0320111141 & 1011000011 & 131 \\
\hline
\end{tabular}


autapomorphies, median basal tubercle of pronotum triangularelongate or indistinct (16.3), median region of posterior margin of pronotum strongly notched (18.2), prosternum strongly convex, flat longitudinally and grooved laterally (19.1), subapical region of parameres of aedeagus cleft laterally (37.1), lateral cleft of parameres moderately long (38.1), subapical region of lateral cleft of parameres narrow with apex rounded (40.2), basal piece of aedeagus located dorsally, on basal fourth of parameres (41.1), median lobe of aedeagus with lateral teeth (43.1) and median lobe with less than 20 teeth (44.1), and the homoplasies, anterior margin of tergite IX of male moderately notched with or without tiny setae (36.1) and lateral cleft of parameres with rounded apex (39.2).

Inside the group supremus + , the group oxydatus + is supported by two autapomorphies, horizontal area of scutellum elliptical (28.2) and sternite VIII of male subpentagonal with anterior margin strongly prominent at middle (34.1), and one homoplasy, median lobe $0.45-0.50$ of parameres width (45.1); the group mexicanus*, by three autapomorphies, median lobe constricted near middle (42.1), median lobe $0.51-0.60$ parameres width (45.2) and anterior margin of tergite VIII of female narrow and deeply notched at middle (46.1), and the homoplasy, scutellum strongly declivous (26.3). The relationships among the species of group mexicanus* (mexicanus, rodriguezi (attenuatus, dugesi, lenzi)) are unclear. The group attenuatus* is supported by one autapomorphy, melanized area of sternite VIII of male broken basally and with basal spot (35.5) and the homoplasies, body narrow and parallel (1.1), $3^{\text {rd }}$ antennal segment of male transverse (13.2), lateral margins of pronotum rounded (14.1) and pronotum stronger convex at middle (15.1), and by reversals, median basal tubercle of pronotum transverse with carina (16.1) and mesosternal cavity sligthy declivous distally (24.1). The following groups are supported only by homoplasies, except when indicated: extenuatuvittus + , elytral pubescence striped with or without lateral bands (9.1); gossipiatus + , dorsal pubescence bicolor forming lateral stripes (3.1) and pattern of dorsal pubescence variable (4.2); serricornis ++ , lateral stripes of pronotum band-like (6.1); serricornis + , elytra with lateral bands (9.2), and the reversal, median lobe from 0.45 to 0.50 of parameres width (45.1); ferratuvittaus + , by reversals, horizontal area of scutellum subpentagonal (28.1) and median lobe of aedeagus gradually narrowed apicad (42.0); albiventris + exulatus, pubescence of pronotum forming lateral stripes or bands (5.1), stripes of pronotum band-like, moderately wide (8.4) and epipleura coloration partially different from underside (10.4), and by reversal, sternite VIII of male triangular or subtrapezoidal (34.0); albisetosus ${ }^{+}$, pubescence of pronotum forming lateral stripes or bands (5.1) and elytra striped with or without lateral bands (9.1). The group spinipennis + is supported by one autapomorphy, lateral bands of pronotum fused (8.2) and the reversal, scutellum moderately declivous (26.2); copulatuvittatus + truncuvittatus, by reversals, borders of mesosternal cavity slightly declivous distally (24.1) and median lobe of aedeagus gradually narrowed apicad (42.0).

Inside the group desmarestii+, the group jansoni+ is supported by homoplasies, horizontal area of scutellum triangular (28.4) and anterior tibiae of male bearing fringe of short cilia (32.2); group rubripennis ${ }^{+}$, by autapomorphies, prosternal channel present (22.1), bursa copulatrix rounded (51.1) and one dorsal median spermatheca (53.1), and the homoplasies, antennae of male strongly serrate $(12.1), 3^{\text {rd }}$ antennal segment of male short and triangular (13.1), scutellum strongly declivous (26.3), sclerotized pieces of the openings of colleterial glands ring-shaped (49.1), sclerotized rings of the openings of colleterial glands with one row of teeth (50.1) and bursa copulatrix with dorsal area with carinae and spines reduced (52.2); group chalcantheus*, by autapomorphies, scutellum folded (26.4), median region of scutellum angular with carina (27.1), horizontal area of scutellum subtrapezoidal (28.5), subapical region of lateral cleft of parameres wide (40.6) and sclerotized rings of openings of colleterial glands bearing several rows of teeth (50.3), and the homoplasy, body narrow and parallel (1.1), and the reversal, lateral cleft of parameres truncate at apex (39.1); group forreri* ${ }^{*}$, by autapomorphies, anterior tibiae of male bearing fringe of long cilia (32.3) and median tibiae of male bearing fringe of long cilia (33.2), and the homoplasies, notosternal sutures moderate- or strongly declivous (21.2), borders of mesosternal cavity almost vertical distally (24.3), anterior margin of tergite IX of male rounded (36.2) and bursa copulatrix with longitudinal wide band with spines and carinae (52.3), and by reversals, body wide and arched or almost parallel (1.0), antennae of male serrate (12.0), $3^{\text {rd }}$ antennal segment triangular-elongate (13.0) and sclerotized rings of the openings of colleterial glands with one row of teeth (50.1); group fabricii+, by homoplasies, dorsal pubescence bicolor forming dorsolateral stripes (3.1), pattern of dorsal pubescence variable (4.2) and elytral pubescence forming lateral stripes (9.2); group fryi* by autapomorphy, stripes on pronotum band-like narrowed at extremities (8.3), and by homoplasies, pubescence of pronotum forming lateral stripes or bands (5.1) and lateral stripes of pronotum band-like (6.1); group bomplandii + , by homoplasy, stripes of pronotum band-like, moderately wide (8.4) and the reversal, elytral pubescence striped with or without lateral bands (9.1); group mocquerysii+, by autapomorphy, dorsal pubescence green with band on pronotum and striped elytra (4.4); limbatus + zonatus, by homoplasy, epipleura coloration different from underside and pronotum and elytra with lateral stripes (10.3); group approximatus + : by homoplasy, epipleura coloration different from underside, pronotum with lateral stripes (10.2); group rostainei++, by reversal, anterior margin of tergite IX of male moderately notched (36.1); rostainei + validus, by autapomorphy, elytral pubescence unicolor, different from pronotum (9.3); group fasciatus ++ , by homoplasy, epipleura coloration different from underside, pronotum and elytra with lateral sripes (10.3); group fasciatus + : by homoplasy, stripes on pronotum band-like narrow (8.5); virgatipennis + virginalis, by reversals, borders of mesosternal cavity moderately declivous distally (24.2) and subapical region of lateral cleft of parameres short with dorsal uncus (40.5), and the homoplasy, lateral cleft of parameres with apex excavate (39.3); group 
corpulentus + , by homoplasy, elytral pubescence with lateral bands (9.2); group tartarus + , by reversals, dorsal pubescence blue with white stripes (4.1) and borders of mesosternal cavity moderately declivous distally (24.2); and apacheanus + webbi, by homoplasy, interstices flat (29.3) and reversal, subapical region of lateral cleft of parameres narrow with apex truncate (40.1). The relationships among the species of the groups chalcantheus ${ }^{*}$, forreri $^{*}$, fryi* ${ }^{*}$ and bomplandii* remains unclear.

\section{GEOGRAPHICALDISTRIBUTION}

The Chalcolepidius species are widely distributed throughout the North, Central and South America (Figs. 672693). Three species, C. bomplandii (Fig. 687), C. desmarestii (Fig. 677) and C. oxydatus (Fig. 672), are distributed in these three continents, with records from Mexico to northeast of South America. The majority of the species occurs in North America: C. apacheanus (Fig. 693), C. lenzi (Fig. 673), C. rubripennis (Fig. 677), C. smaragdinus (Fig. 678), C. viridipilis (Fig. 678) and C. webbi (Fig. 693), are recorded from southwest of United States (except $C$. viridipilis, in southeast) and Mexico, and C. albiventris (Fig. 675), C. angustatus (Fig. 686), C. approximatus (Fig. 690), C. attenuatus (Fig. 673), C. boucardi (Fig. 679), C. dugesi (Fig. 673), C. eschscholtzi (Fig. 685), C. fasciatus (Fig. 691), C. forreri (Fig. 681), C. mexicanus (Fig. 672), C. morio, C. proximus (Fig. 687), C. pruinosus (Fig. 683), C. serricornis (Fig. 675), C. spinipennis (Fig. 676), C. sulcatus (Fig. 680), C. truncuvittatus, C. virgatipennis (Fig. 691) and $C$. virginalis (Fig. 691) from Mexico (C. sulcatus also from West Indies). In South America also occurs a large number of species: C. aurulentus (Fig. 682), C. corpulentus (Fig. 692), C. limbatus (Fig. 689), C. porcatus (Fig. 682) and C. zonatus (Fig. 688), occur in almost whole South America; C. virens (Fig. 680) is widely distributed on the east side; C. extenuatuvittatus (Fig. 674), C. exulatus (Fig. 675) and C. supremus (Fig. 672) are restricted to Venezuela and C. rostainei (Fig. 690), to Brazil (Pará); the remainder species, C. albisetosus, C. cyaneus (Fig. 682), C. copulatuvittatus, C. erythroloma (Fig. 684), C. fabricii (Fig. 684), C.ferratuvittatus (Fig. 675), C. fryi (Fig. 684) and C. villei (Fig. 685) are distributed by northeastern countries $(C$. cyaneus, C. limbatus, C. porcatus and C. virens also from West Indies and C. erythroloma from Hawaii). C. inops (Fig. 681), C. lacordairii (Fig. 680), C. lafargi (Fig. 686), C. rugatus (Fig. 685 ) and C. silbermanni (Fig. 683) are recorded from North and Central America (C. lafargi and C. silbermanni also from West Indies); C. chalcantheus (Fig. 679), C. gossipiatus (Fig. 674), C. jansoni (Fig. 677) and C. mocquerysii (Fig. 688) from Central and northeast of Souh America (except C. chalcantheus, in almost whole South America); C. obscurus (Fig. 683) and C. validus (Fig. 690) from West Indies. C. tartarus (Fig. 693) is recorded only from North America (United States) and $C$. rodriguezi only from Central America (Guatemala).

Acknowledgements. I would like to thank the Curators and Institutions listed on "Material", by assistance and loaning of the material; CMF von Hayek (BMNH) for sending me her drafts with the studies on Chalcolepidius, from which I took several important date included in the present revision as "personal communication", and also for arrangements of the loans of the type material; Dr L. Herman (AMNH) for the arrangements and sponsorship of the Collection Study Grant from American Museum of Natural History, and, also S. Lodhi, for valuable help, providing facilities in the collection, and for hospitality during my permanence in AMNH; Dr. C. Girard (MNHN) for the use of the museum's facilities and the Elateridae collection, and also for loaning material; Ole Martin (ZMUC), for sending the photos of the types of Chalcolepidius porcatus and $C$. sulcatus and for the information about the type of $C$. virens; and Dr. E. Becker (CNCI) for informations about literature and the Casey's type material. Special thanks to Dr. Ricardo Pinto da Rocha, (Instituto de Biociências, Universidade de São Paulo IBUSP) by encouragement and incentive in the initial phase of the present work and during the arrangements of my trip to NY, and also by help and hints on specimens pictures; Dr. Sergio Ide (Instituto Biológico, São Paulo) by incentive, valuable suggestions and help on Clados computer software and the text edition; Dr. Sergio A. Vanin (IBUSP), by suggestions on some characters polarizations; Dr. Luiz Ricardo L. de Simone (MZSP) by helping on instalation of Treegardner computer software; and Christiana Klingenberg (MZSP) by maps production and cladogram design. Special thanks also to Dr. Ubirajara R. Martins (MZSP), Dr. Albino M. Sakakibara (DZUP) and again to Dr. Sergio A. Vanin (IBUSP) by patience in reading and correcting in detail the manuscript of this paper. Researcher funds were provided by Fundação de Amparo à Pesquisa do Estado de São Paulo (FAPESP - proc. 97/09154-6; 00/4664-0; 01/11034-6) and Conselho de Desenvolvimento Científico e Tecnológico (CNPq- proc. 303303-87). 

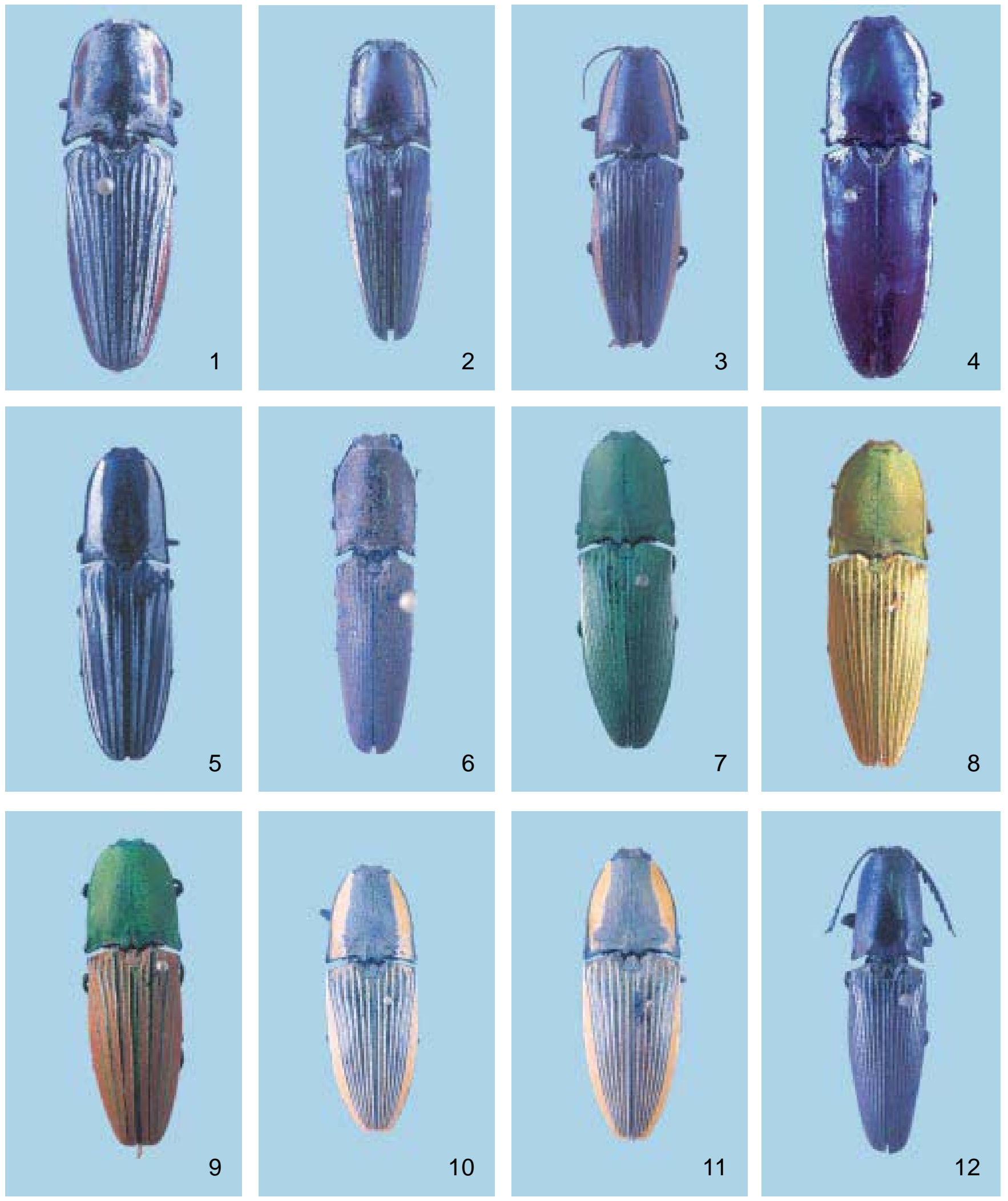

Figs. 1-12. Habitus: 1, C. albisetosus sp. nov. (M, Holotype) (35 mm); 2, C. albiventris sp. nov. (F, Holotype) (39 mm); 3, C. angustatus Candèze, 1857 (M, Mexico, MNHN) (32 mm); 4, C. apacheanus Casey, 1891 (F, Arizona, Sierra Durango, "apacheanus 4", Casey collection, USNM); 5, C. approximatus Erichson, 1841 (F, Cuernavaca, USNM) (28 mm); 6, C. attenuatus Erichson, 1841 (F, Chamela, vic. UNAM, JEWC) (23 mm); 7-9, C. aurulentus Candèze, 1874 (F, Cochabamba, Vila Tunari, MZSP) (30 mm), (F, Óbidos, Traíra, MZSP) (44 mm), (F, Pimenta Bueno, DZUP) (33 mm); 10-11, C. bomplandii Guérin-Méneville, 1844 (F, Turrialba-CATIE area, MZSP) (42 mm), (F, Parismina Fluss, Salvadora Farm, MZSP) (45 $\mathrm{mm}) ; 12$, C. boucardi Candèze, 1874 (M, Teloloapan, USNM) (28 mm). 

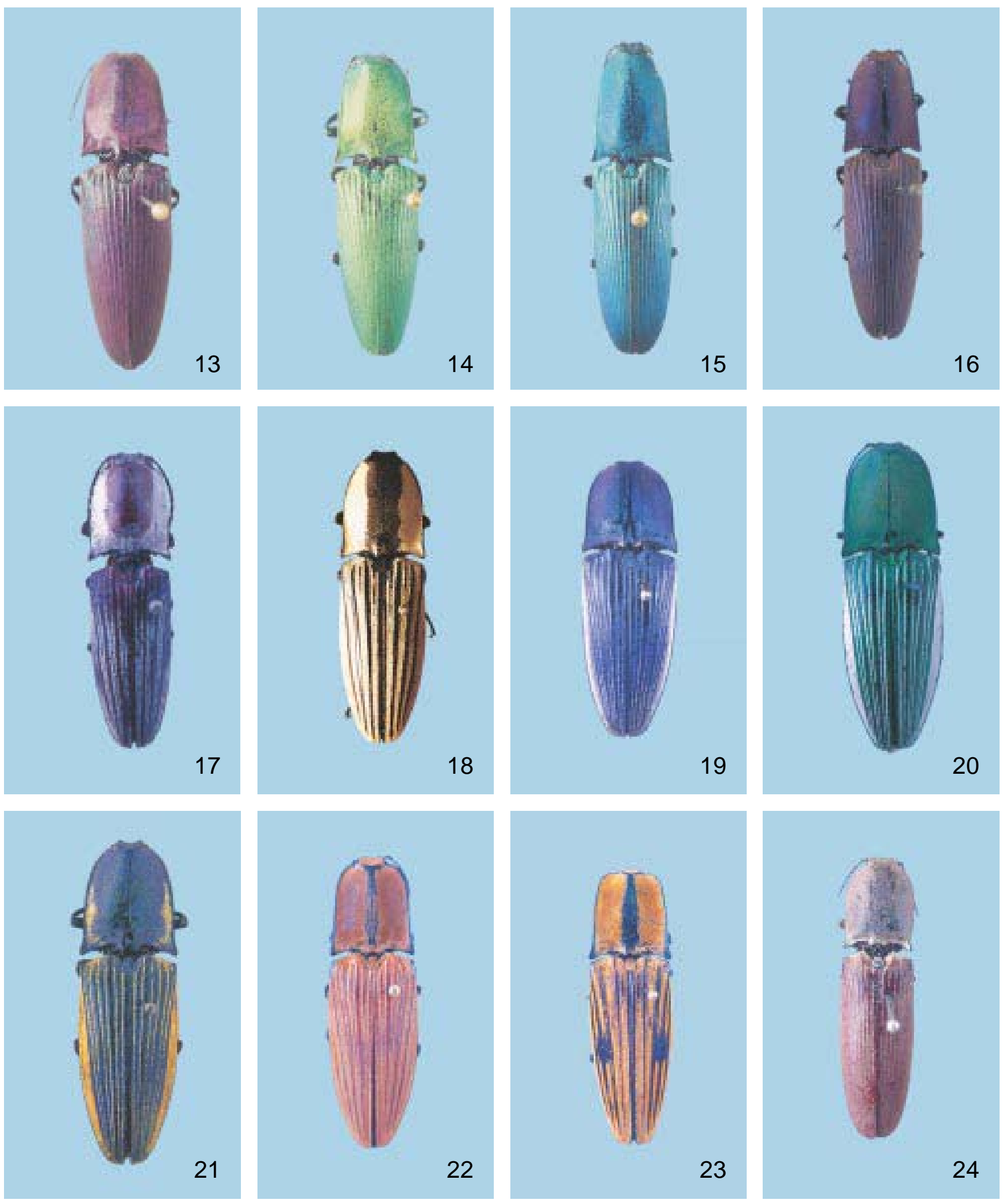

Figs. 13-24. Habitus: 13-16, C. chalcantheus Candèze, 1857 (M, Cuiabá, UFMT) (26 mm), (M, Yacury-Yumaré, IZAV) (26 mm), (M, Sebastian Retalhuleu, USNM) (31 mm), (M, Foz do Iguaçu, UFPR) (38 mm); 17, C. copulatuvittatus sp. nov. (M, Holotype) (25 mm); 18, C. corpulentus Candèze, 1874 (F, Carquejo, MZSP) (36 mm); 19-21, C. cyaneus Candèze, 1881 (F, Syntype) (40 mm), (F, Merida, USNM) (37 mm), (F, Tabaquite, USNM) (34 mm); 22-23, C. desmarestii Chevrolat, 1835 (M, Los Tuxtlas, UNAM, USNM) (42 mm), (F, Monteverde area, USNM) (38 mm); 24 , C. dugesi Candèze, 1886 (Tupataro, ZMHB) $(27 \mathrm{~mm})$. 

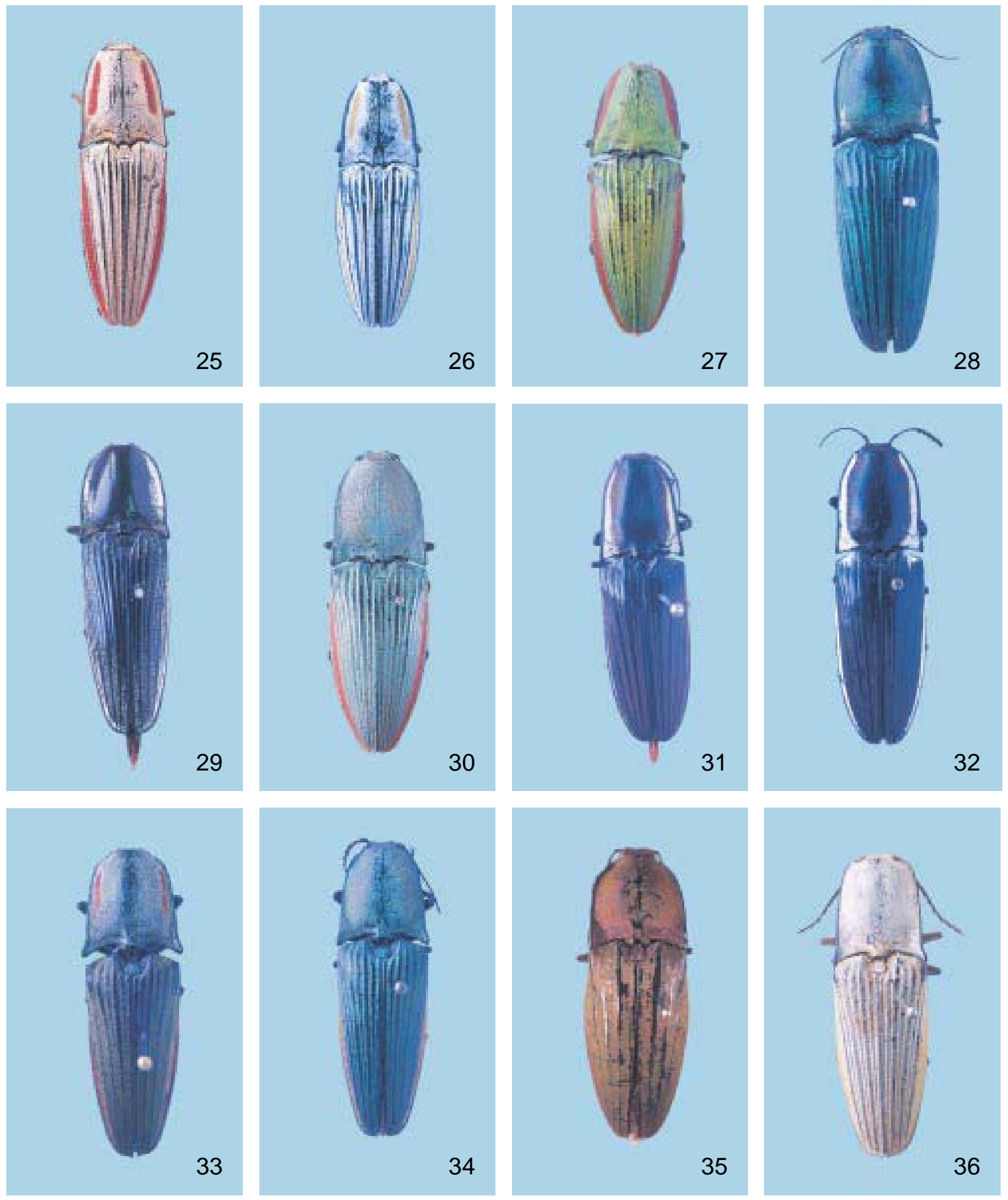

Figs. 25-36. Habitus: 25-26, C. erythroloma Candèze, 1857 (F, Los Rios, Vic. Quebrada, MZSP) (35 mm), (F, Hawaiian Isl., USNM) (38 mm); 27, C. eschscholtzi Chevrolat, 1833 (F, Santa Rosa, MZSP) (45 mm); 28, C. extenuatuvittatus sp. nov. (F, Holotype) (46 mm); 29, C. exulatus Candèze, 1874 (M, Syntype) (29 mm); 30, C. fabricii Erichson, 1841 (F, Columbien Carare, ZMHB) (39 mm); 31-32, C. fasciatus sp. nov. (M, Holotype) (30 mm), (F, Paratype, 6 mi NE El Salto, AMNH) $(37 \mathrm{~mm})$;33-34, C. ferratuvittatus sp. nov. (M, Holotype) (30 mm), (M, Paratype) $(31 \mathrm{~mm}) ; 35, C$. forreri Candèze, 1886 (F, Syntype) (43 mm); 36, C. gossipiatus Guérin-Méneville, 1844 (M, N. Granade, nr16205, ZMHB) (32 mm). 

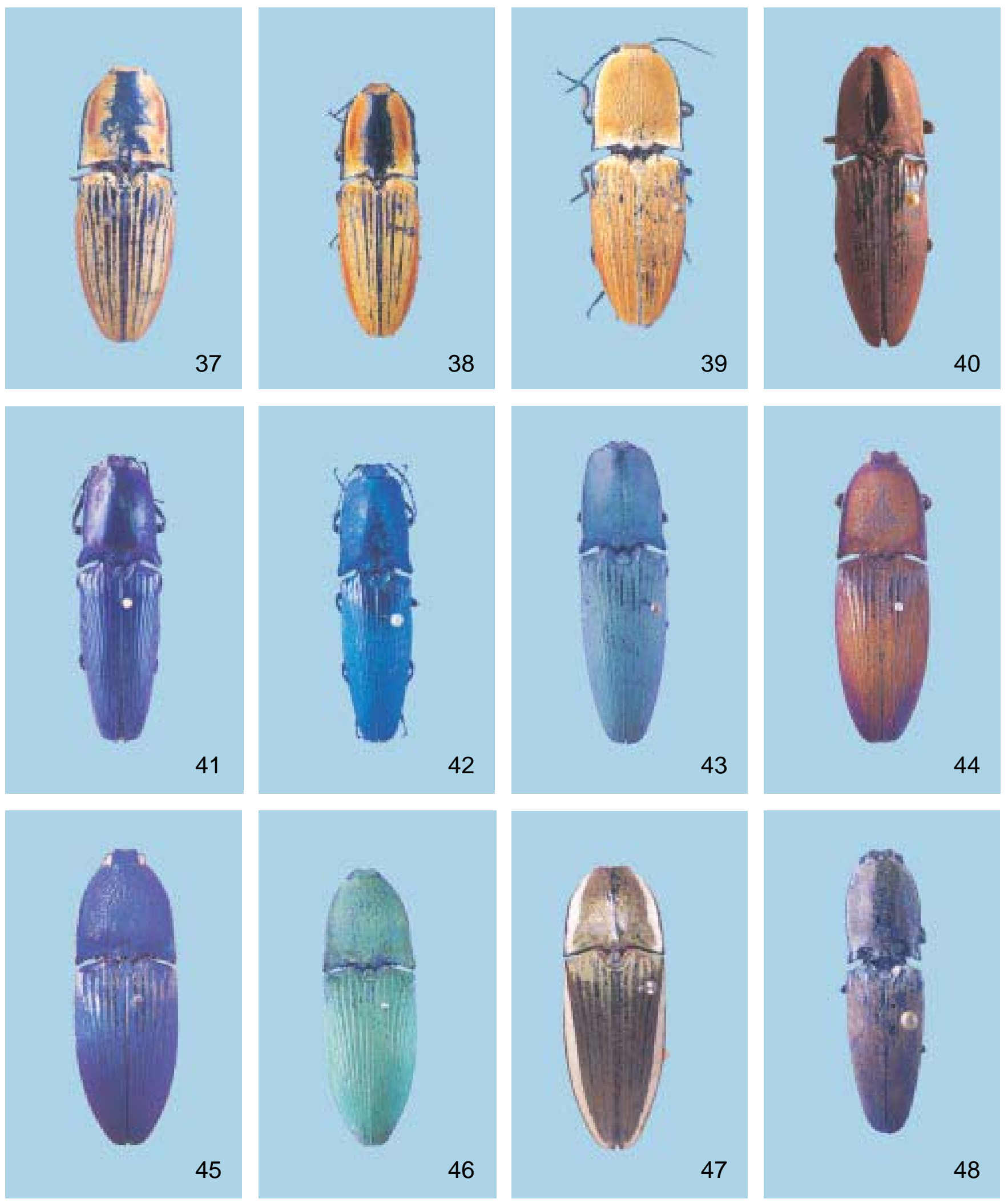

Figs. 37-48. Habitus: 37-39, C. fryi Candèze, 1874 (F, Holotype) (38 mm), (F, Trujillo, USNM) (31 mm), (M, Lambayeque, IMLA) (28 mm); 40, C. inops Candèze, 1886 (F, Guerrero, $51 \mathrm{Km}$ Ixtapa, FSCA) $(28 \mathrm{~mm}) ; 4$ 41-43, C. jansoni Candèze, 1874 (F, Quibdo-Choco, PCCV) (41 mm), (F, Lake Colima, PCCV) (28 mm), (F, $10 \mathrm{Km} \mathrm{N}$ El Llano, FSCA) (37 mm); 44-46, C. lacordairii Candèze, 1857 (F, Colima, USNM) (43 mm), (F, Chiapas, Piedras Paradas, USNM) (48 mm), (F, Chiriqui, MZSP) (46 mm); 47, C. lafargi Chevrolat, 1835 (F, Syntype); 48, C. lenzi Candèze, 1886 (M, Sinaloa, $4.5 \mathrm{mi}$ Elota, MZSP) $(26 \mathrm{~mm})$. 

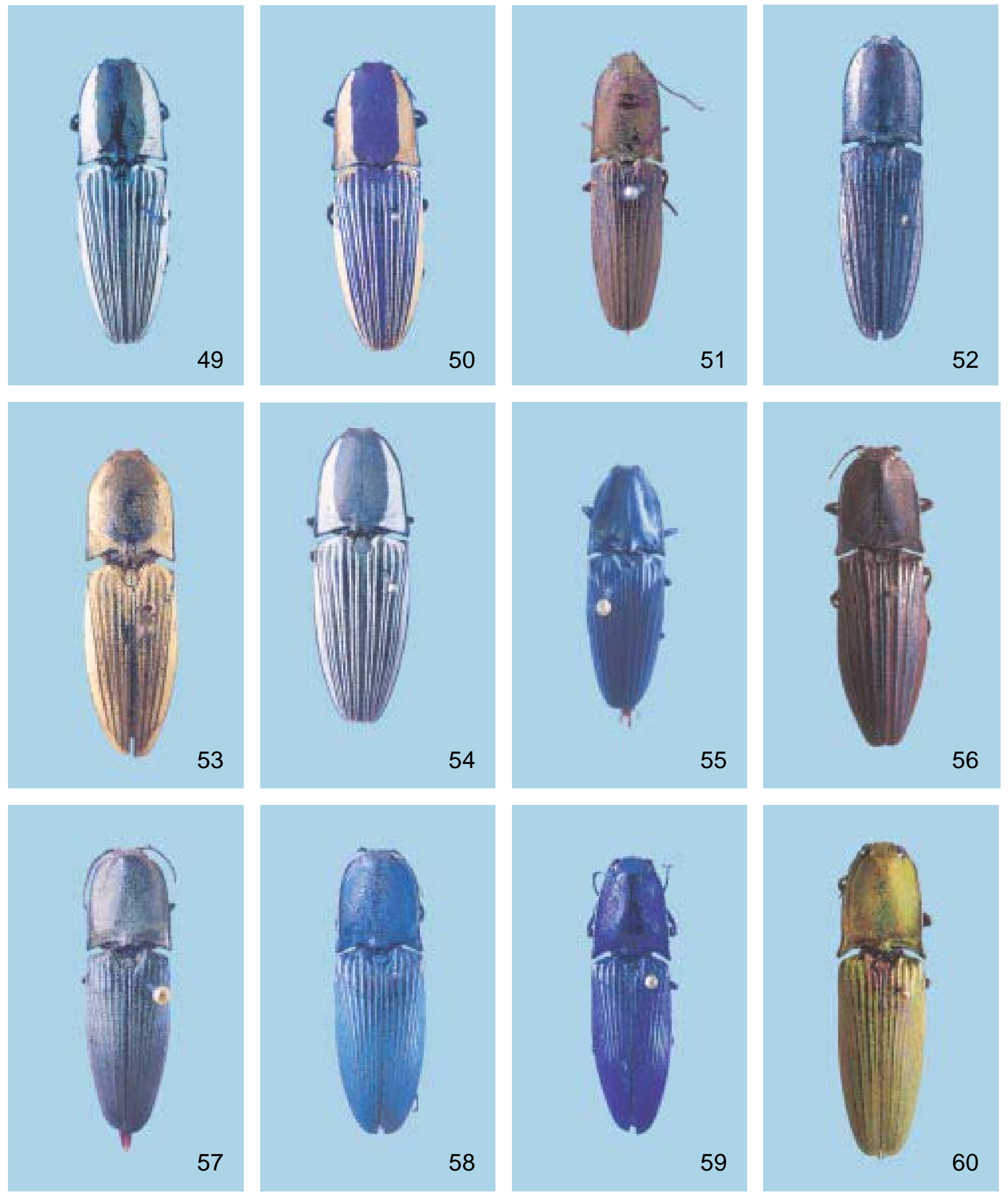

Figs. 49-60. Habitus: 49-50, C. limbatus (Fabricius, 1777) (F, Puerto Pto Franco, MZSP) (36 mm), (F, Conceição da Barra, MZSP) (38 mm); 5152, C. mexicanus Castelnau, 1836 (M, Mexico, ZMHB), (F, Mexico, MNHN) $(27 \mathrm{~mm})$; 53, C. mniszechi Candèze, 1881 (F, Syntype) (30 mm); 54, C. mocquerysii Candèze, 1857 (Las Pavas, ZMHB) (38 mm); 55, C. morio Candèze, 1857 (M Syntype) (29 mm); 56, C. obscurus Castelnau, 1836 (F, Antilles, USNM) (33 mm); 57-60, C. oxydatus Candèze, 1857 (M, Rio Demerara, ZMHB) (27 mm), (F, Chiapas, Pacific Slope Codillera, USNM) (43 mm), (M, Chorradero, MZSP) (33 mm) (M, S. Vito, $6 \mathrm{Km}$ C. Cruces, USNM) (39 mm). 

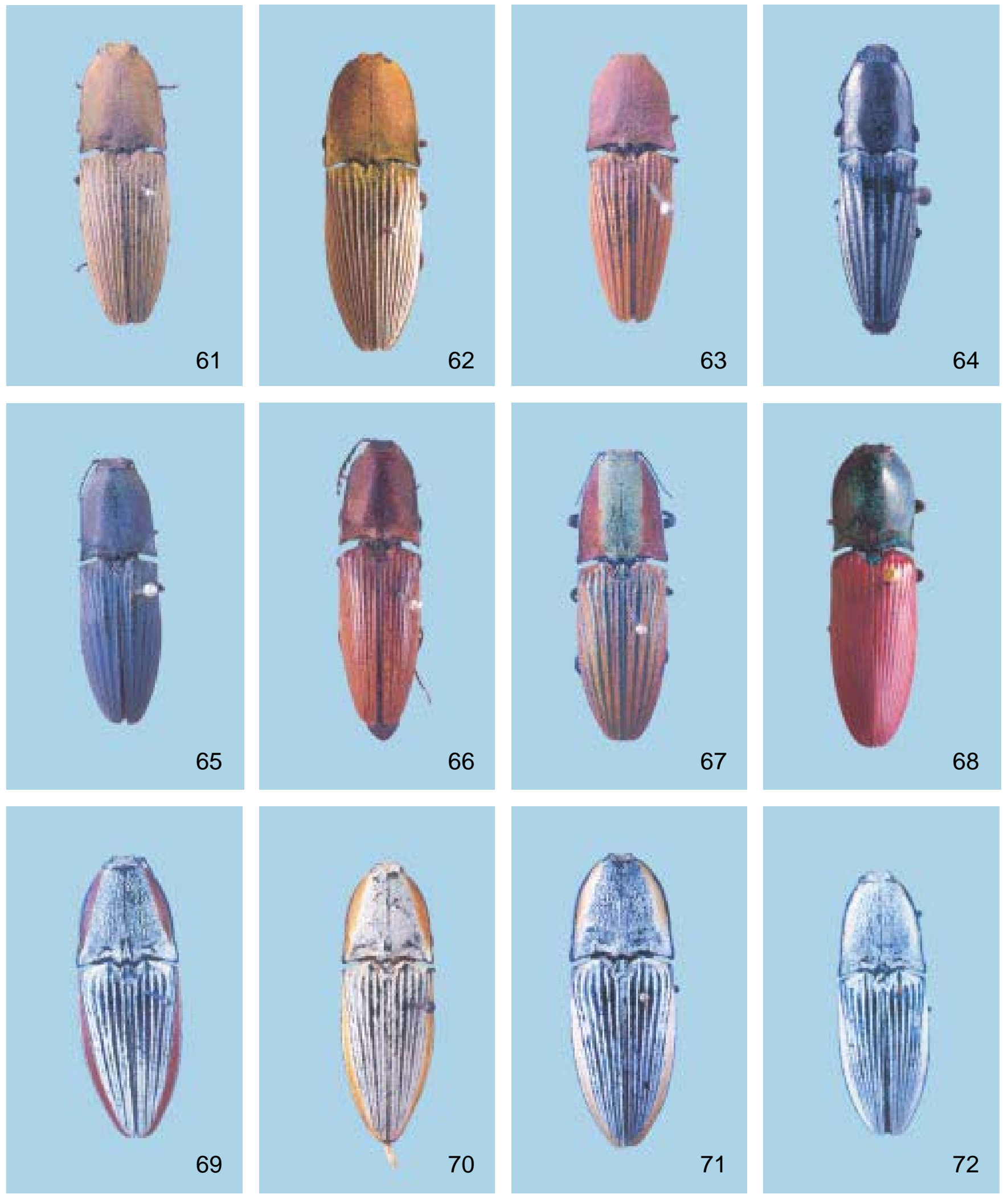

Figs. 61-72. Habitus: 61-63, C. porcatus (Linnaeus, 1767) (F, Brasil, ZMHN) (40mm), (F, Benjamin Constant, MZSP) (41 mm), (F, Brasil, nr 16209, ZMHB) $(23 \mathrm{~mm}) ; \mathbf{6 4}$, C. proximus sp. nov. (F, Holotype) $(20 \mathrm{~mm}) ; \mathbf{6 5}$, C. pruinosus Erichson, 1841 (F, Syntype) $(33 \mathrm{~mm}) ; 66$, C. rodriguezi Candèze, 1886 (M, Holotype) $(26$ mm); 67, C. rostainei Candèze, 1889 (F, Óbidos, MZSP) (39 mm); 68, C. rubripennis LeConte, 1861 (F, Lower California, FSCA) (37 mm); 69-72, C. rugatus Candèze, 1857 (F, Tabasco, Teapan, USNM) (39 mm), (F, El Peten, USNM) (32 mm), (F, Q. Roo, Hwy 295, $11 \mathrm{Km}$ N Puerto Carrillo, FSCA) (45 mm), (F, Quiriaga, USNM) (43 mm). 

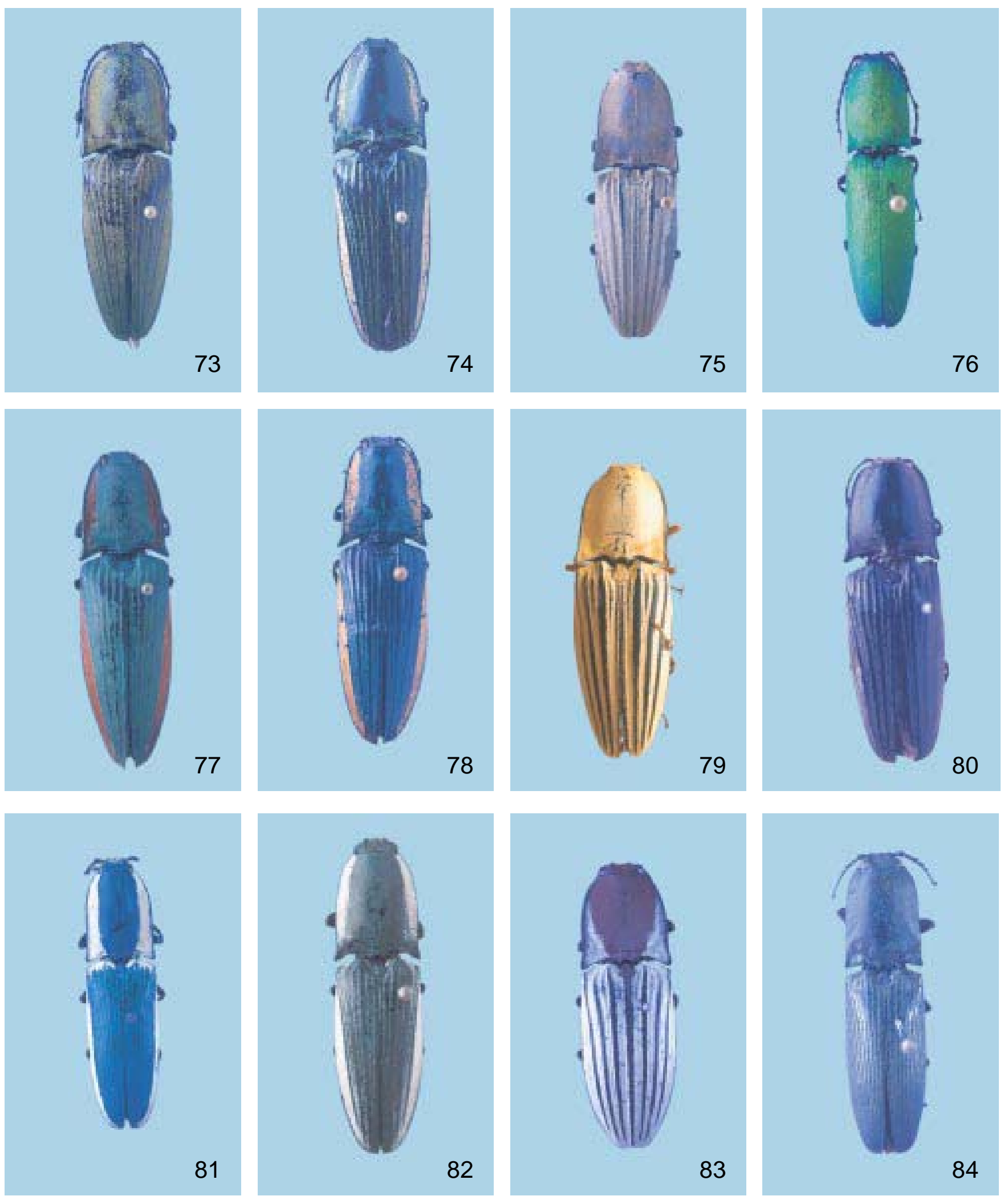

Figs. 73-84. Habitus: 73-74, C. serricornis sp. nov. (M, Holotype) ( $35 \mathrm{~mm}$ ), (F, Paratype, Vale Nacional, PCCV) ( $35 \mathrm{~mm}) ; 75$, C. silbermanni Chevrolat, 1835 (F, $2.5 \mathrm{Km}$ W Ipeti, MZSP) (28 mm); 76, C. smaragdinus LeConte, 1854 (M, St Rita Range, MZSP)(26 mm); 77-78, C. spinipennis sp. nov. (M, Holotype) (40 mm), (M, Paratype, Dos Amates, SRGI) (32 mm); 79, C. sulcatus (Fabricius, 1777) (F, St Croix, USNM) (35 mm); 80, C. supremus sp. nov. (M, Holotype) $(30 \mathrm{~mm}) ; 81$, C. tartarus Fall, 1898 (F, Arizona, MZSP) (29 mm); 82, C. truncuvittatus sp. nov. (F, Holotype) (29 mm); 83, C. validus Candèze, 1857 (F, Martinica, FSCA) (42 mm); 84, C. viridipilis (Say, 1825) (F, Dist. of Columbia, USNM) (24 mm). 

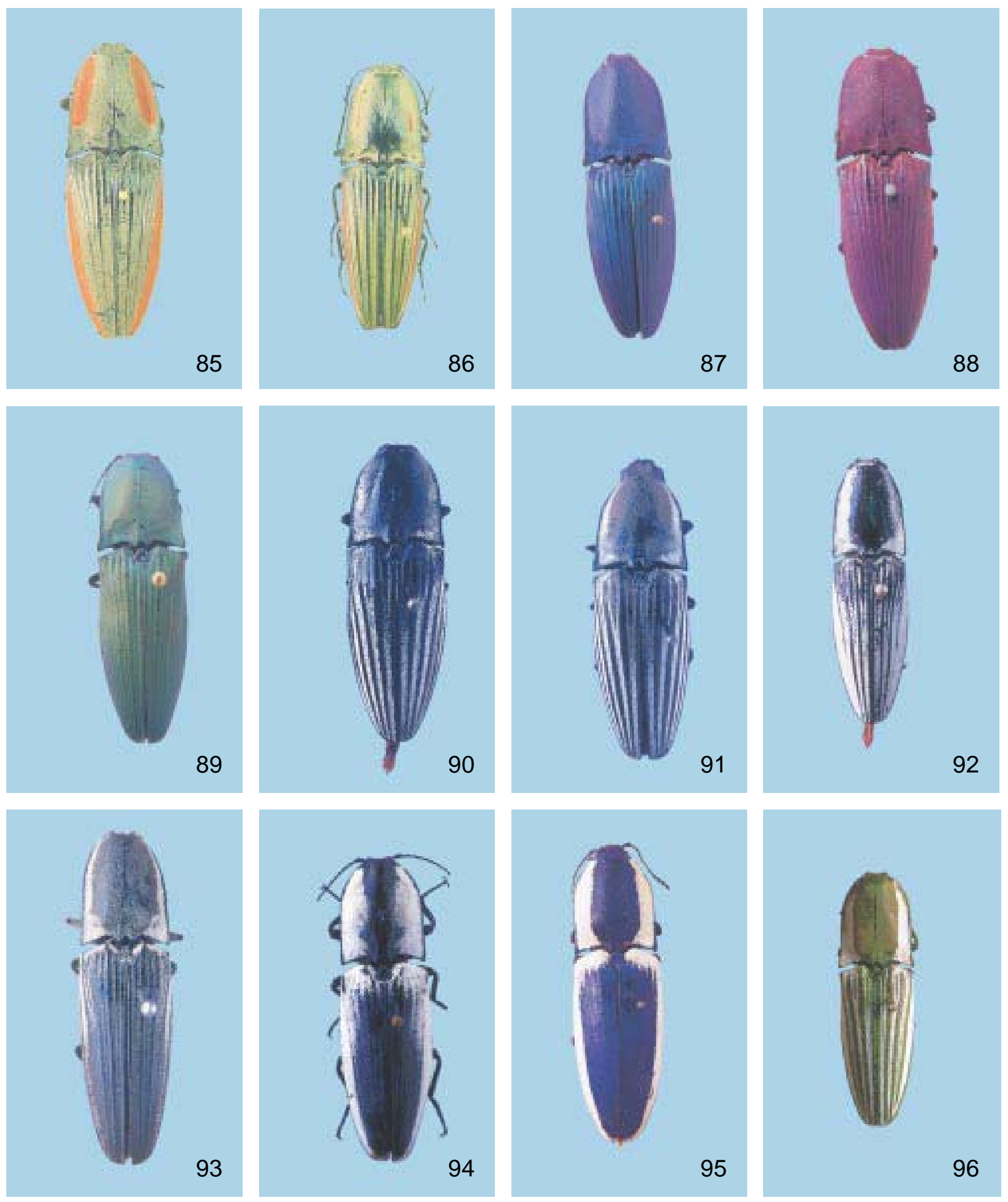

Figs. 85-96. Habitus: 85-86, C. villei Candèze, 1878 (F, Quibdo-Choco, PCCV) (43 mm), (F, Pichincha, PCCV) (32 mm); 87-89, C. virens (Fabricius, 1787) (F, Port of Spain, FSCA) (33 mm), (F, Benjamin Constant, MZSP) $(37 \mathrm{~mm})$, (F, Par- St Andrew Mirabe Agr. School, FSCA) (33 mm); 90-91, C. virgatipennis sp. nov. (M, Holotype) $(27 \mathrm{~mm})$, (F, Paratype, Sierra Durango, MNHN) $(30 \mathrm{~mm})$; 92-93, C. virginalis Candèze, 1857 (M, Holotype) (24 mm), (F, Mexico, ZMHB) (29 mm); 94-95, C. webbi LeConte, 1854 (F, Yuma, FSCA) (38 mm), (F, Phoenix, MZSP) (36 mm); 96, C. zonatus Eschscholtz, 1829 (F, Santa Tereza, MZSP) (31 mm). 

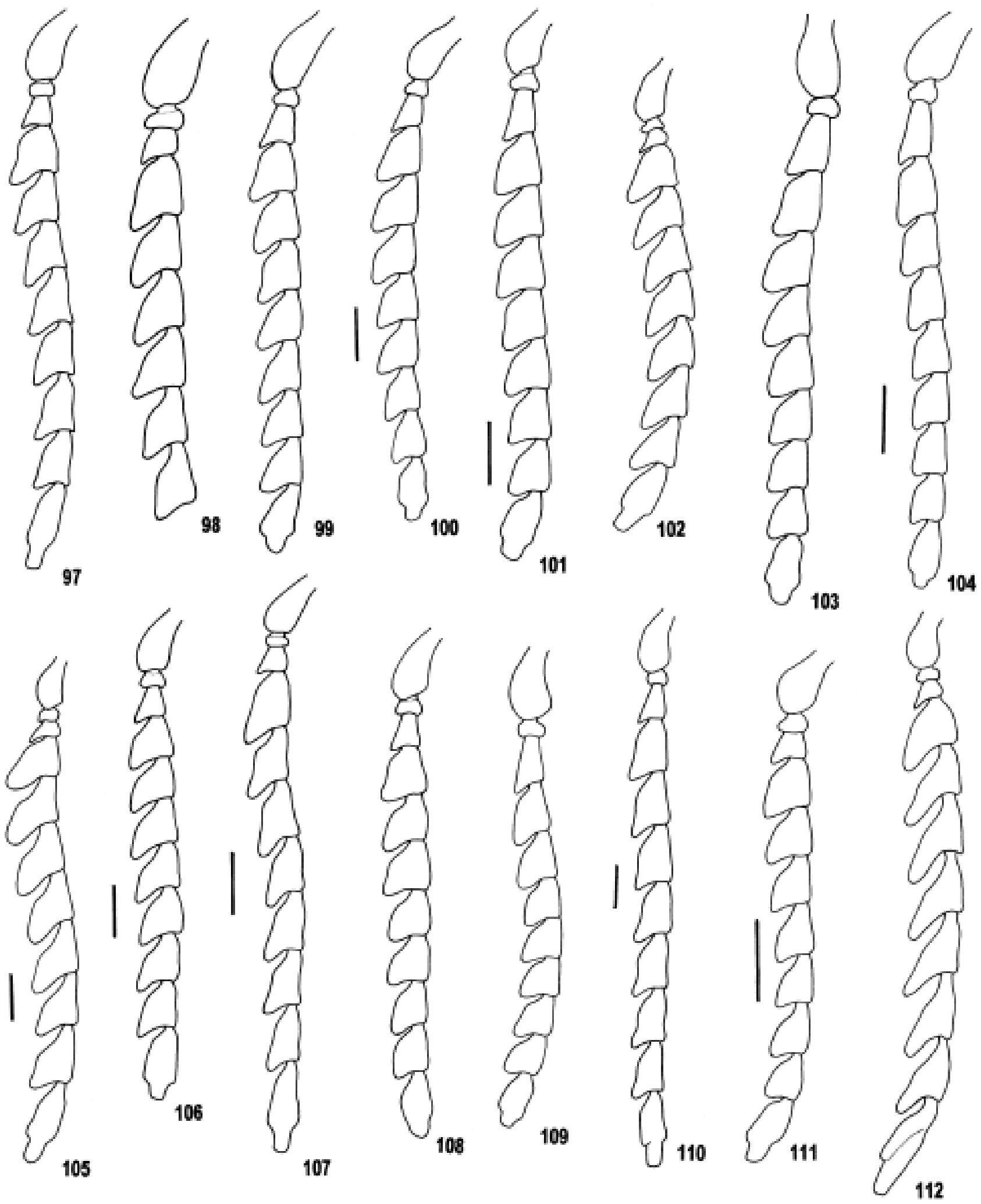

Figs. 97-112. Antenna: 97, C. albisetosus sp. nov. (M, Holotype); 98, C. albiventris sp. nov. (F, Holotype); 99, C. angustatus (M, Mexico, MNHN); 100, C. apacheanus (M, Phoenix, USNM); 101, C. approximatus (M, Tenancingo, MZSP); 102, C. attenuatus (M, Est.Biol. Chamela, MZSP); 103, C. aurulentus (M, Ichila, FSCA); 104, C. bomplandii (M, San Quintin, MZSP); 105, C. boucardi (M, Presa El Caracol, UNAM); 106, C. chalcantheus (M, Niquelândia, MZSP); 107, C. copulatuvittatus sp. nov. (M, Holotype); 108, C. corpulentus (M, Carquejo, MZSP); 109, C. cyaneus (F, Syntype); 110, C. desmarestii (M, 3 Km N Tlanchinol, UNAM); 111, 112, C. dugesi (F, M, Syntypes). Bars = 1 mm. Figs 97, 99, 100; 98, 104; $101,102,108 ; 103,111,112 ; 106,109$, respectively to the same scale. 

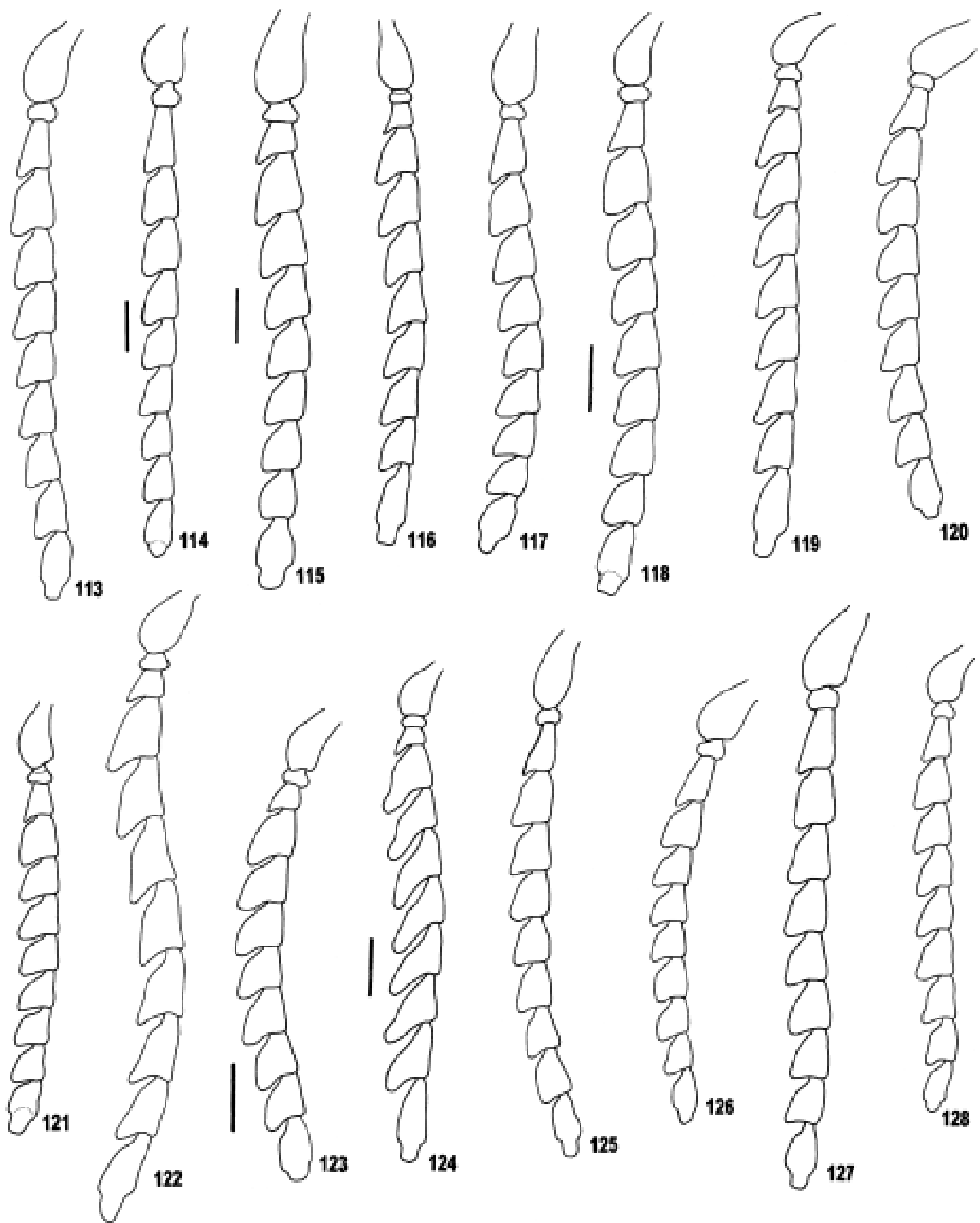

Figs. 113-128. Antenna: 113, C. erythroloma (M, Honolulu, MZSP); 114, C. eschscholtzi (F, Lake Catemaco, MZSP); 115, C. extenuatuvittatus sp. nov. (F, Holotype); 116, C. exulatus (M, Syntype); 117, C. fabricii; 118, C. fasciatus sp. nov. (M, Holotype); 119, C. ferratuvittatus sp. nov. (M, Holotype); 120, C. forreri (F, Syntype); 121, C. fryi (M, Chiclayo, IMLA); 122, C. gossipiatus (M, Nouvelle Grenade, ZMHB); 123, 124, C. inops (F, Syntype, C. inops), (M, Syntype of C. murinus); 125, C. jansoni (M, K8-13 El Llano-Carti Rd., JEWC); 126, C. lacordairii (F, San Jeronimo, IMLA); 127, C. lafargi (F, Boca Toma area, JEWC); 128, C. limbatus (M, Linhares, MZSP). Bars = $1 \mathrm{~mm}$. Figs 113, 115-117, 121, 126; 114, 119, $120,122,128 ; 118,125 ; 123,127$, respectively, to the same scale. 

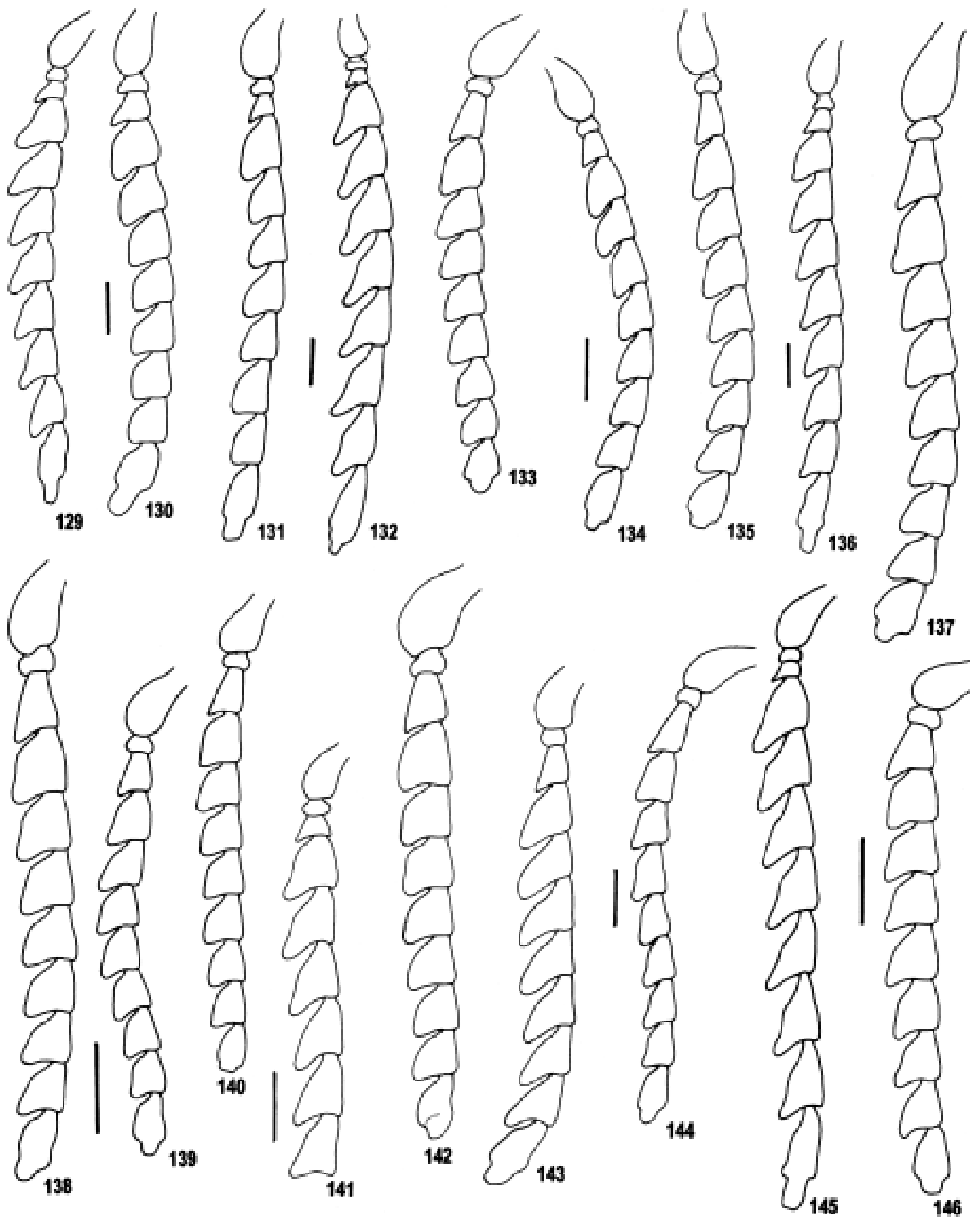

Figs. 129-146. Antenna: 129, 130, C. lenzi (M, F, Arizona, CMNH); 131, 132, C. mexicanus $(\mathrm{F}, \mathrm{M}$, Miranda, PCCV); 133, C. mocquerysii (F, Rio Bravo Valley, PCCV); 134, C. mniszechi (F, Syntype); 135, C. morio (M, Syntype); 136, C. oxydatus (M, Chorreadura Canyon, MZSP); 137, C. obscurus (M, Montserrat, USNM); 138, C. porcatus; 139, C. proximus sp. nov. (F, Holotype); 140, C. pruinosus (F, Mexico, USNM); 141, C. rodriguezi (M, Holotype); 142, C. rostainei (F, Óbidos, MZSP); 143, C. rubripennis (M, Santa Rosa, CMNH); 144, C. rugatus (M, Sayaaxche, MZSP); 145, C. serricornis sp. nov. (M, Holotype); 146, C. silbermanni (X-Can, MZSP). Bars = 1 mm. Figs 129, 130, 143; 131, 133-135, 137; 138, $146 ; 140-142 ; 144,145$, respectively to the same scale. 


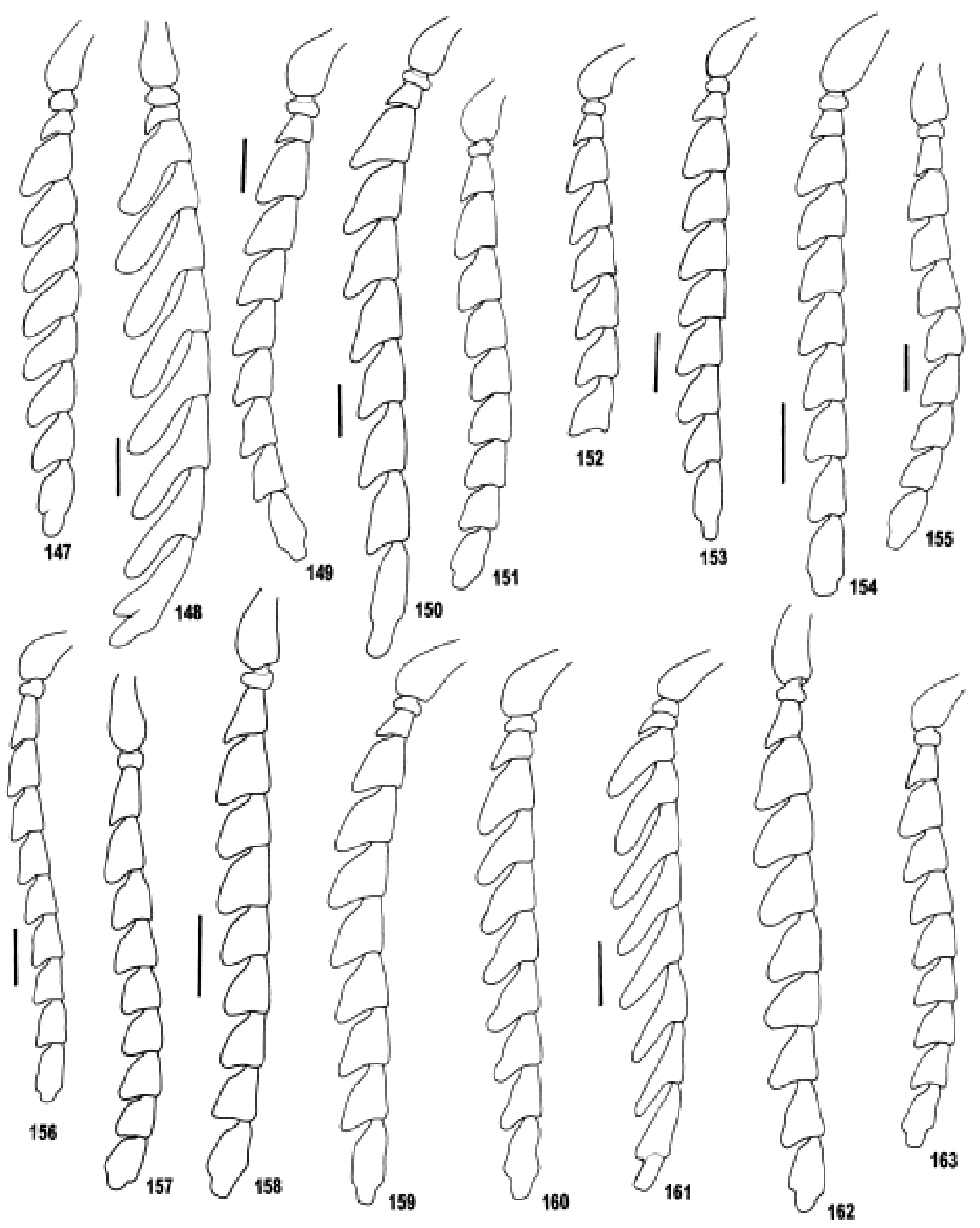

Figs. 147-163. Antenna: 147-148, C. smaragdinus (F, 15 mi E Douglas, MZSP), (M, 6 mi Continental, MZSP); 149-150, C. spinipennis sp. nov. (F, Paratype Soteapan, MZSP), (M, Holotype); 151, C. sulcatus (F, Saint Croix, MZSP); 152, C. supremus sp. nov. (M, Holotype); 153, C. tartarus (F, Laguna Lake, MZSP); 154, C. truncuvittatus sp. nov. (F, Holotype); 155, C. validus (M, Martinica); 156, C. villei (F, Medio Calima, MZSP); 157, C. virens (F, Itacoatiara, MZSP); 158, C. virgatipennis sp. nov. (M, Holotype); 159, C. virginalis (M, Tehuatepec, FSCA); 160-161, C. viridipilis (F, Pennsylvania, MZSP), (M, Jeannette, MZSP); 162, C. webbi (M, Calipatria, CMNH); 163, C. zonatus (M, Itararé, MZSP). Bars = $1 \mathrm{~mm}$. Figs 147, $148 ; 150,152,163 ; 151,154 ; 157-159 ; 161,162$, respectively to the same scale. 

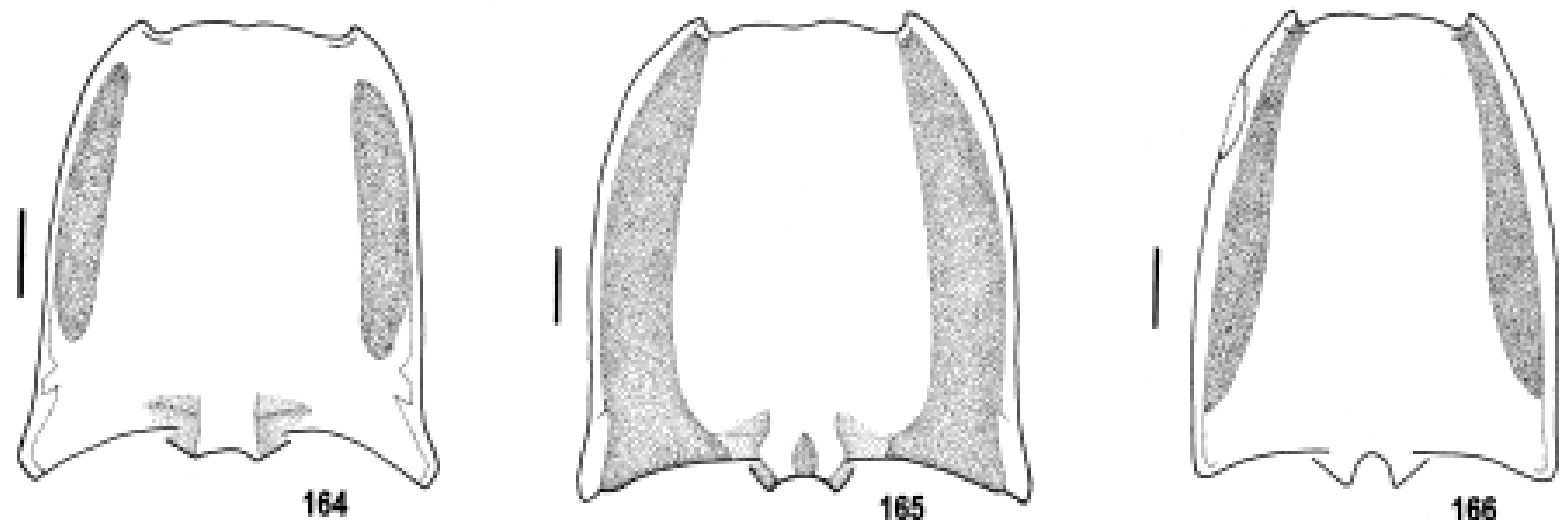

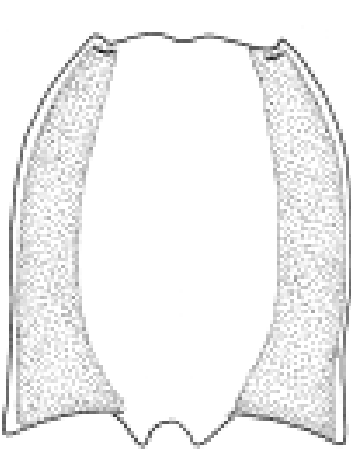

167

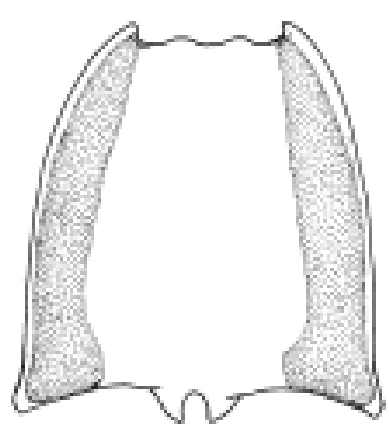

171

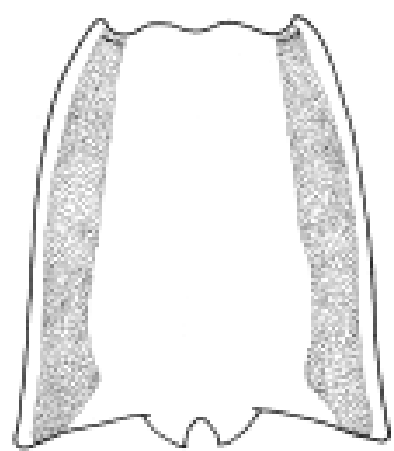

168

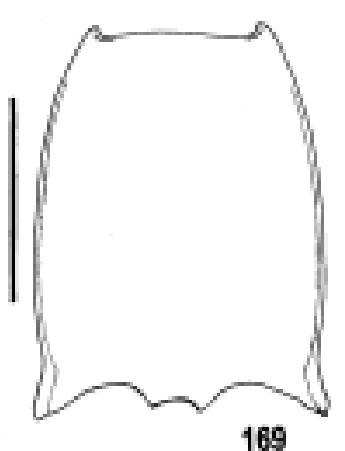

169

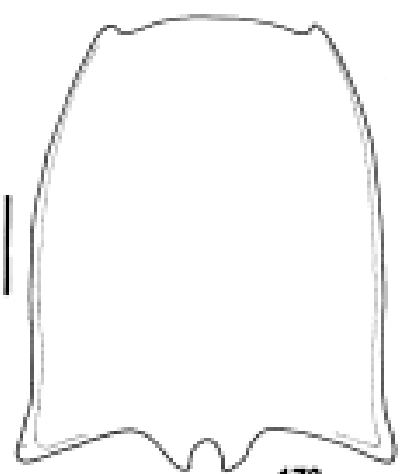

173

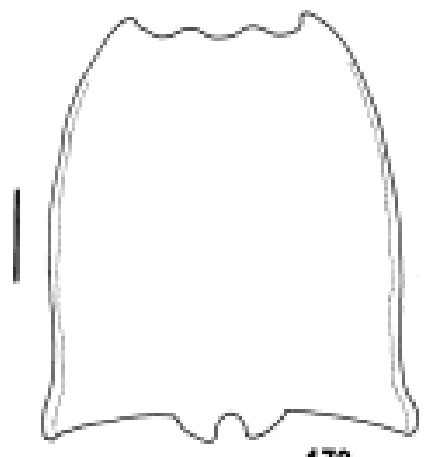

170

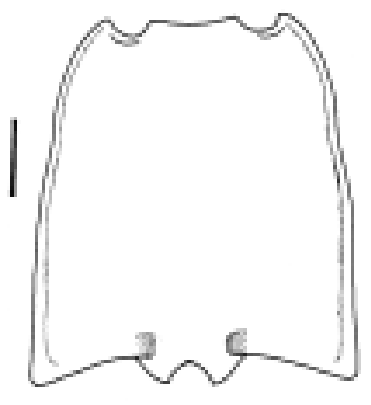

174
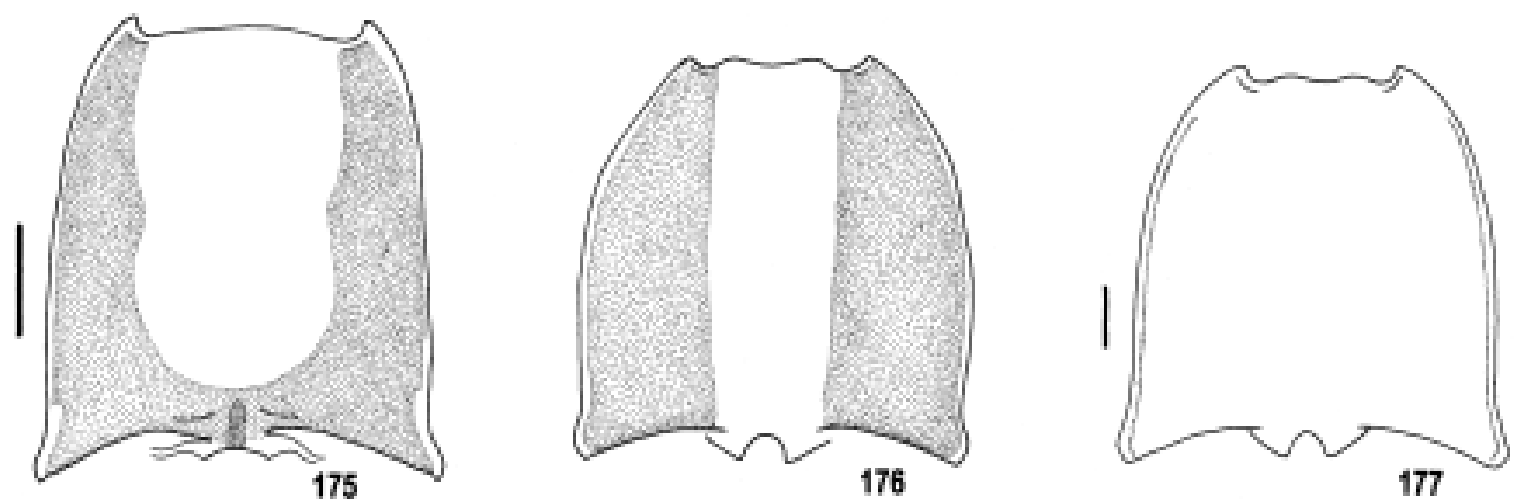

Figs. 164-177. Pronotum: 164, C. albisetosus sp. nov. (M, Holotype); 165, C. albiventris sp. nov. (F, Holotype); 166, C. angustatus (M, Syntype); 167, C. apacheanus (M, Phoenix, USNM); 168, C. approximatus (M, Tenancingo, MZSP); 169, C. attenuatus (M, Est.Biol. Chamela, MZSP); 170, C. aurulentus (M, Ichila, FSCA); 171, C. bomplandii (M, San Quintin, MZSP); 172, C. boucardi (M, Presa El Caracol, UNAM); 173, C. chalcantheus (M, Niquelândia, MZSP); 174, C. desmarestii (M, 3 Km N Tlanchinol, UNAM); 175, C. copulatuvittatus sp. nov. (M, Holotype); 176, C. corpulentus (M, Carquejo, MZSP); 177, C. cyaneus (F, Syntype). Bars = $2 \mathrm{~mm}$. Figs 164, 167, 168, 172; 165, 171; 176, 177, respectively to the same scale. 


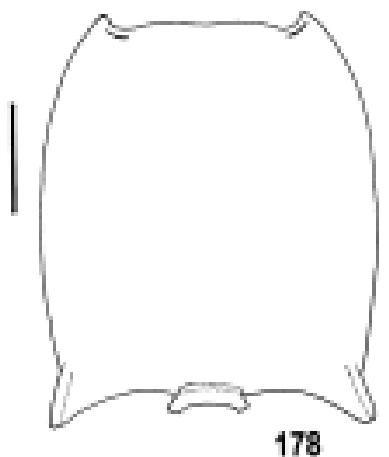

178
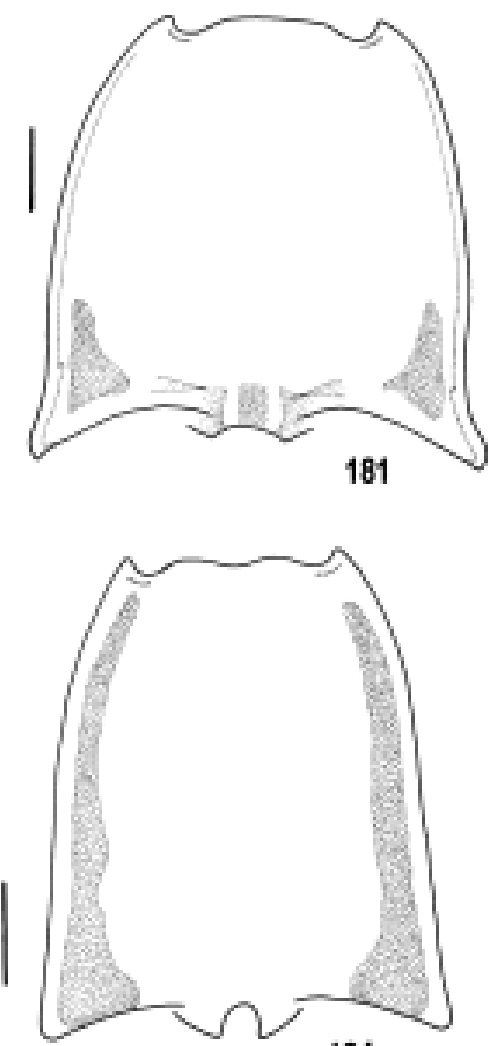

184

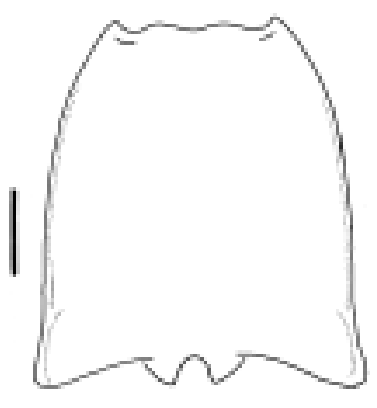

187

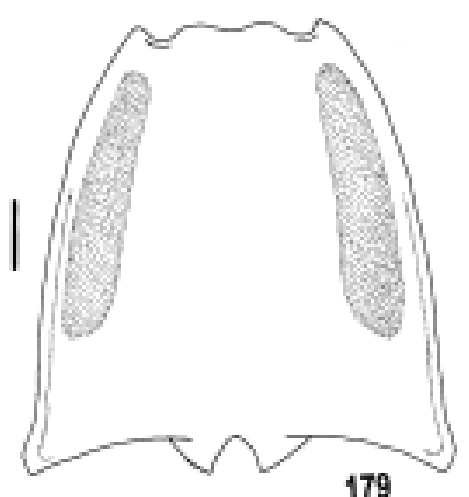

179
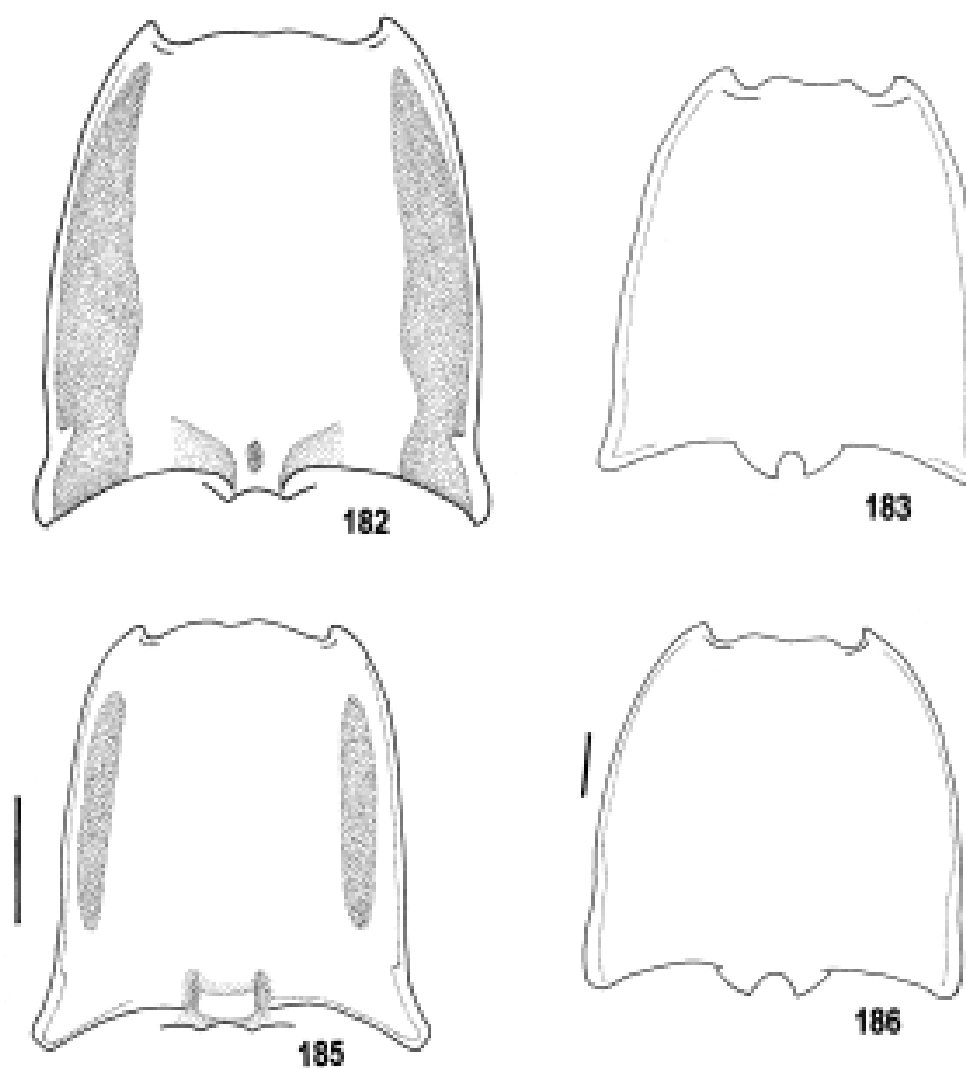

186

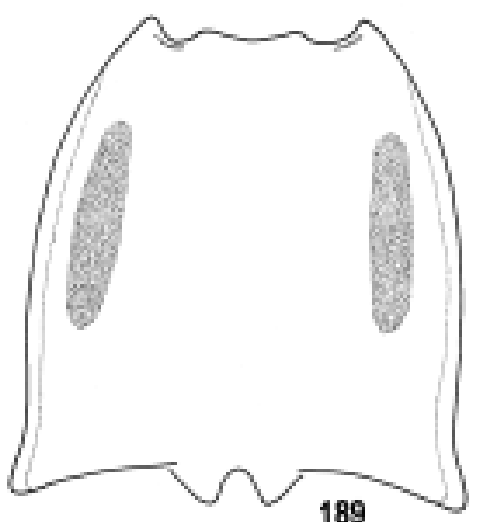

Figs. 178-189. Pronotum: 178, C. dugesi (M, Syntype); 179, C. erythroloma (M, Honolulu, MZSP); 180, C. eschscholtzi (F, Lake Catemaco, MZSP); 181, C. extenuatuvittatus sp. nov. (F, Holotype); 182, C. exulatus (M, Syntype); 183, C. fabricii; 184, C. fasciatus sp. nov. (M, Holotype); 185, C. ferratuvittatus sp. nov. (M, Holotype); 186, C. forreri (F, Syntype); 187, C. inops (F, Syntype); 188, C. gossipiatus (M, Nouvelle Grenade, ZMHB); 189, C. fryi (F, Trujillo, USNM). Bars = 2 mm. Figs 180, 183, 188; 182, 184; 187, 189, respectively to the same scale. 


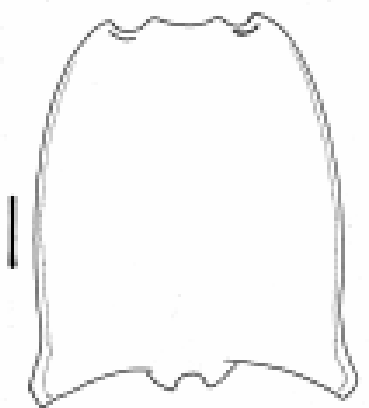

190

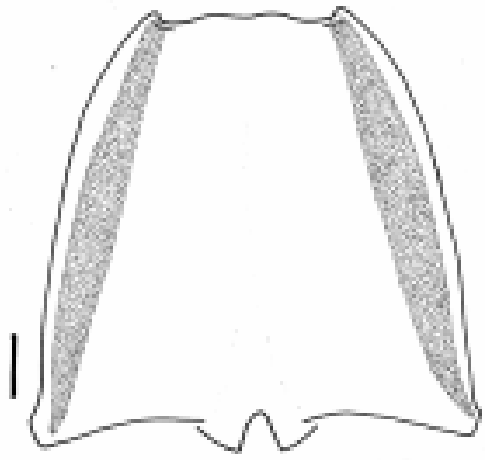

194

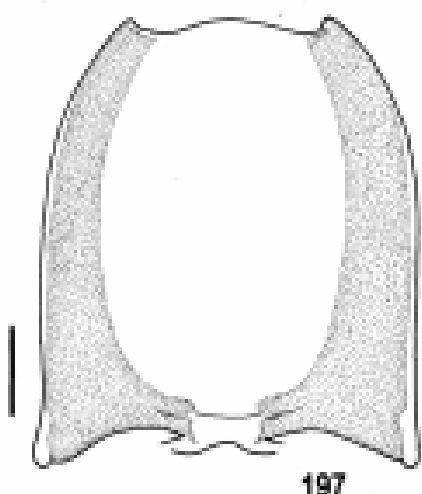

197

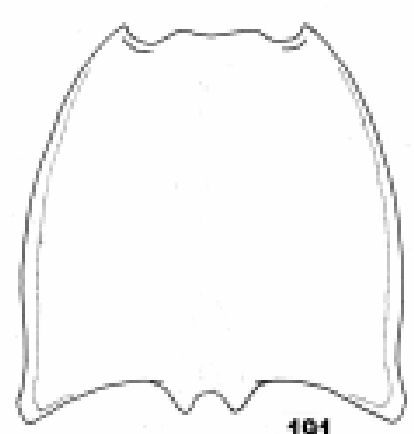

191

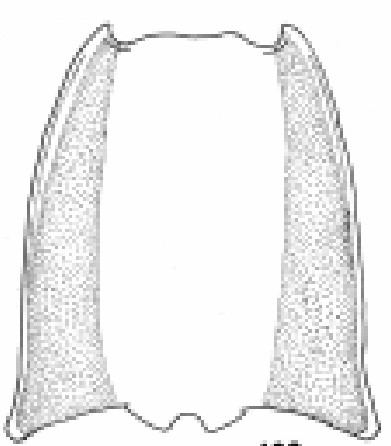

192

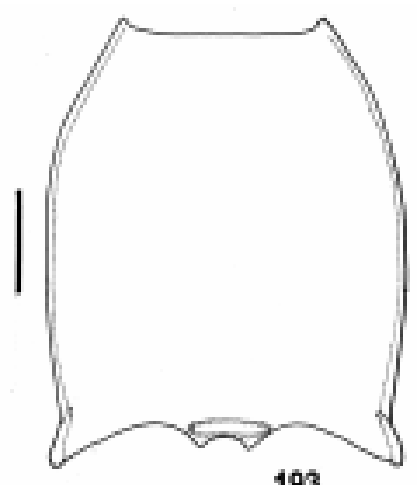

193

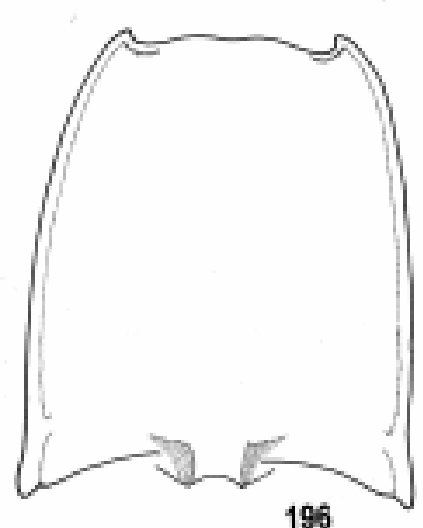

195

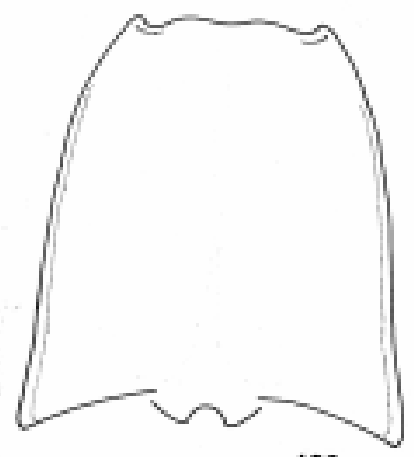

199

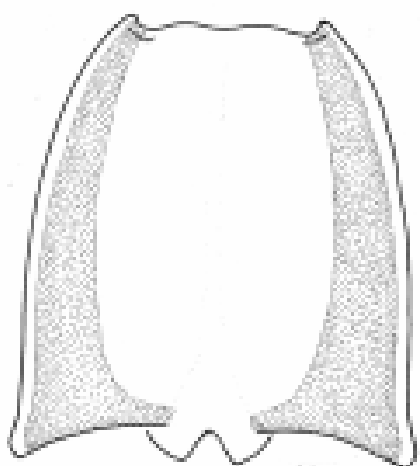

198
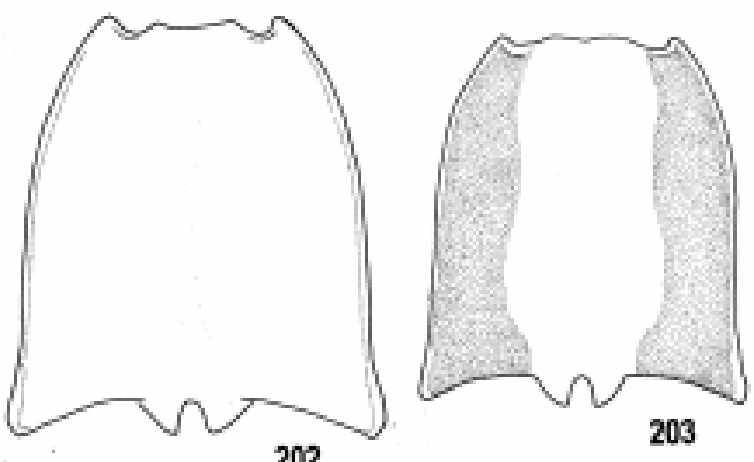

203

Figs. 190-203. Pronotum: 190, C. jansoni (M, K8-13 El Llano-Carti Rd., JEWC); 191, C. lacordairii (F, San Jeronimo, IMLA); 192, C. limbatus (M, Linhares, MZSP); 193, C. lenzi (M, Arizona, CMNH); 194, C. lafargi (M, without locality, NHMW); 195, 196, C. mexicanus (F, M, Miranda, PCCV); 197, C. mniszechi (F, Syntype); 198, C. mocquerysii (M, Colombia, MZSP); 199, C. morio (M, Syntype); 200, C. obscurus (M, Montserrat, USNM); 201, C. oxydatus (M, San Sebastian, USNM); 202, C. porcatus (F, Estação Codemat, INPA); 203, C. proximus sp. nov. (F, Holotype). Bars $=2 \mathrm{~mm}$. Figs 190,$191 ; 192,196-198 ; 193,199 ; 195,203 ; 200-202$, respectively to the same scale. 


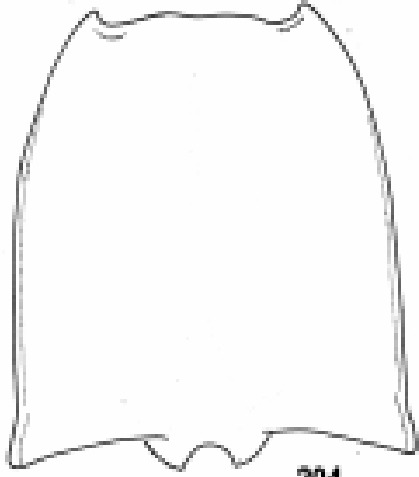

204

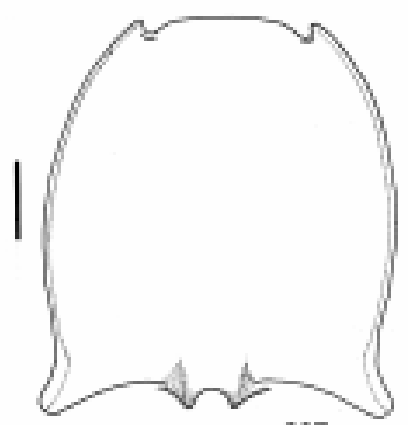

207

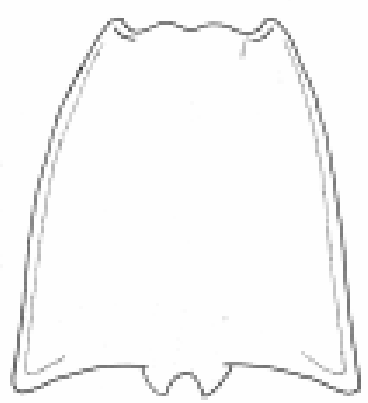

210

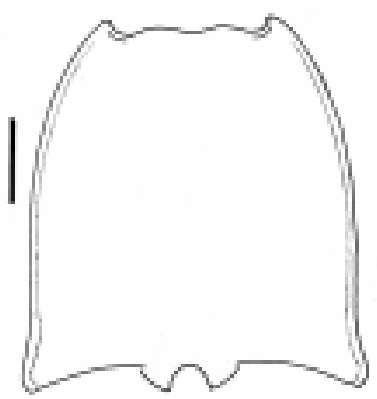

213

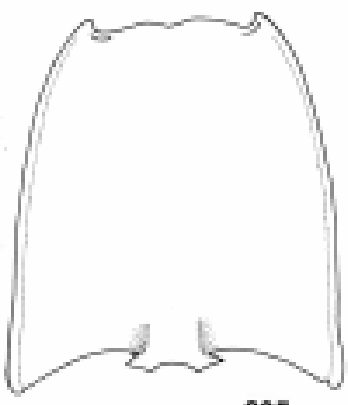

205

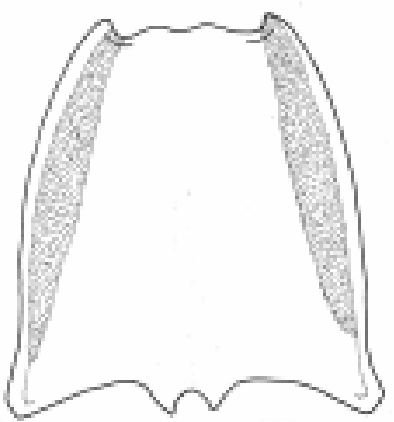

208

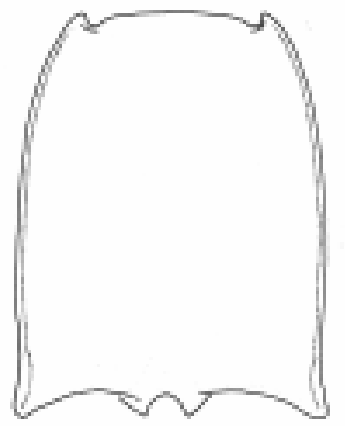

211

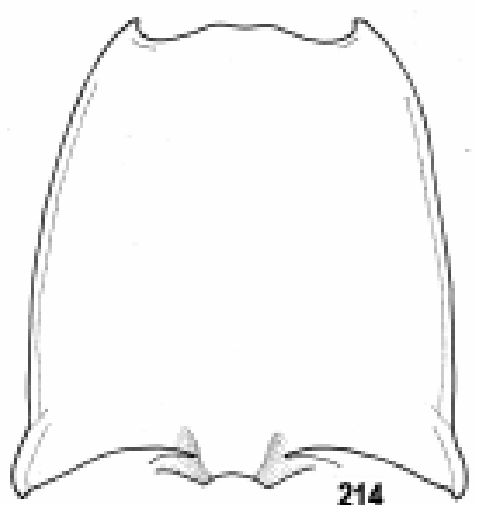

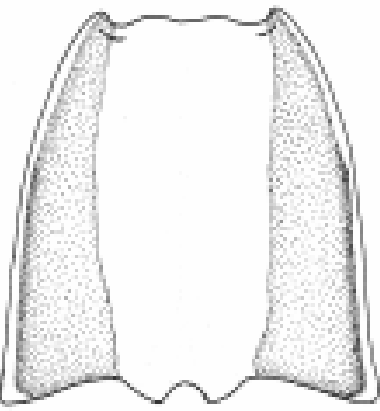

206

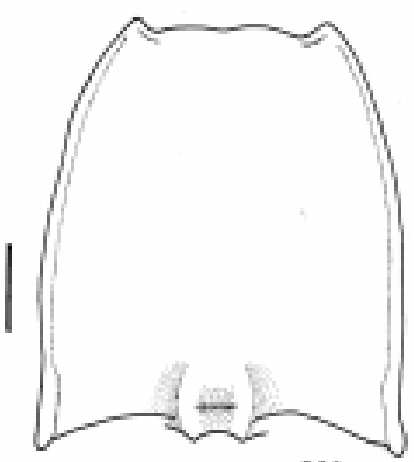

209
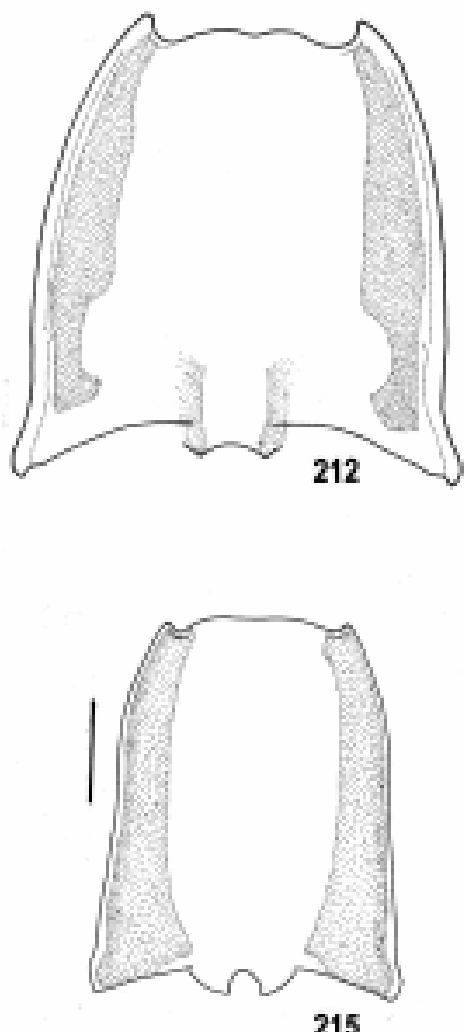

Figs. 204-215. Pronotum: 204, C. pruinosus (F, Mexico, USNM); 205, C. rodriguezi (M, Holotype); 206, C. rostainei (F, Óbidos, MZSP); 207, C. rubripennis (M, California, CMNH); 208, C. rugatus (M, Sayaaxche, MZSP); 209, C. serricornis sp. nov. (M, Holotype); 210, C. silbermanni (XCan, MZSP); 211, C. smaragdinus (M, 6 mi Continental, MZSP); 212, C. spinipennis sp. nov. (M, Holotype); 213, C. sulcatus (F, Saint Croix, MZSP); 214, C. supremus sp. nov. (M, Holotype); 215, C. tartarus (M, Holotype). Bars = 2 mm. Figs 204, 213, 214; 205, 209, 211, 212; 206-208, 210 , respectively to the same scale. 


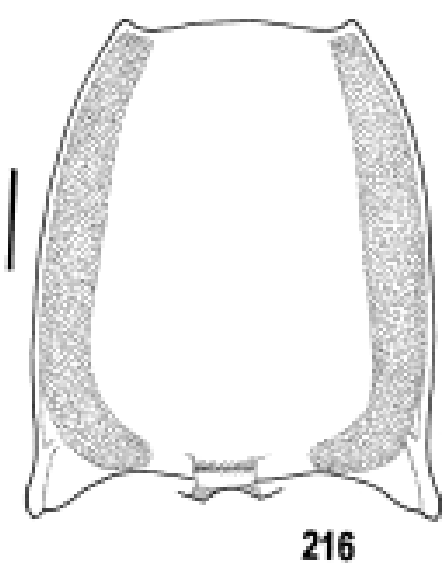

216

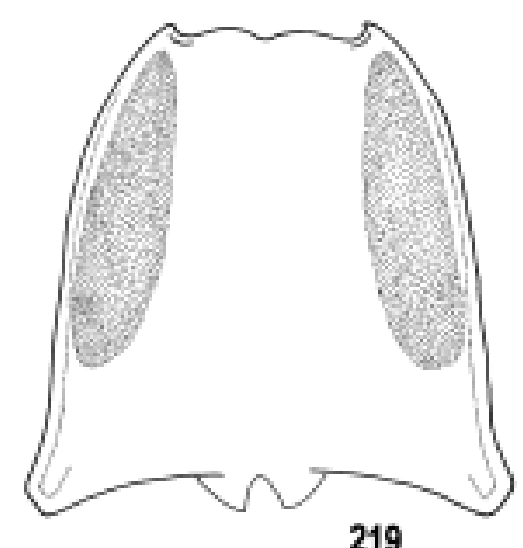

219

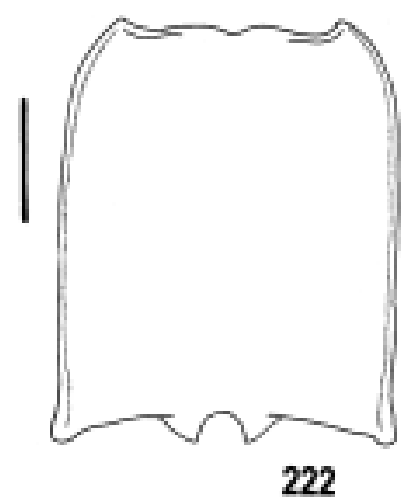

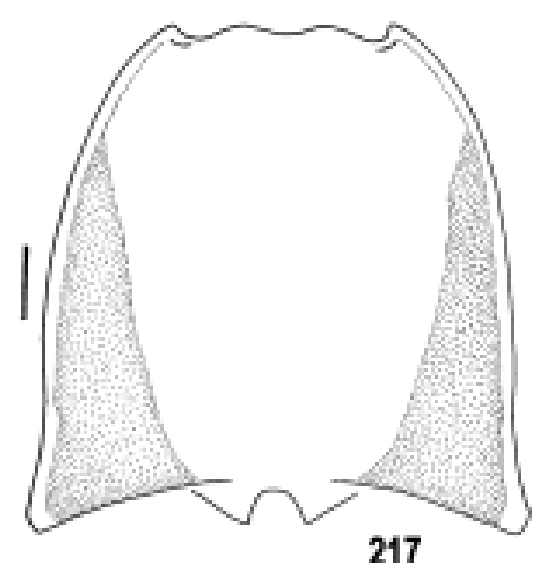

217

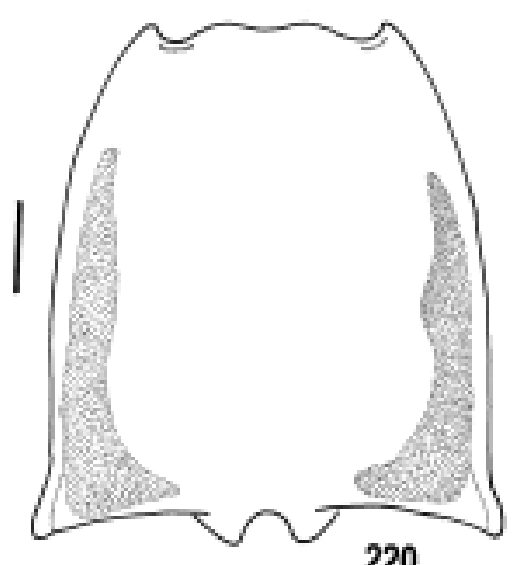

220

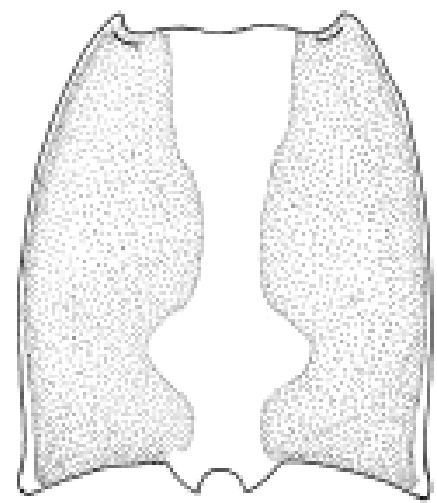

223
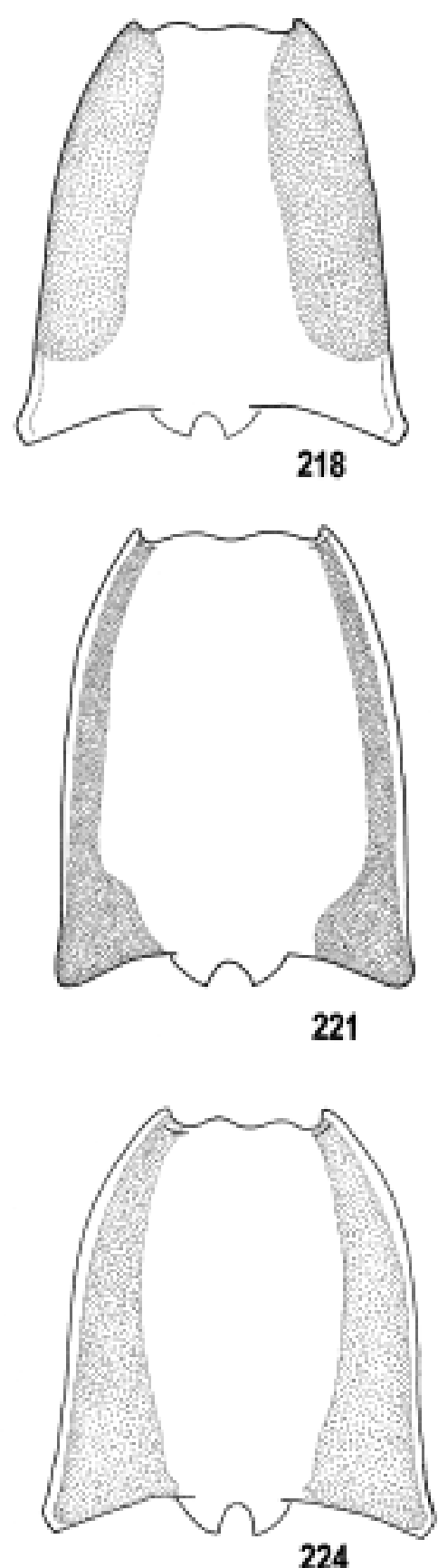

Figs. 216-224. Pronotum: 216, C. truncuvittatus sp. nov. (F, Holotype); 217, C. validus (M, Martinica); 218, 219, C. villei (M, Rio Bravo, MZSP), (F, Medio Calima, MZSP); 220, C. virgatipennis sp. nov. (M, Holotype); 221, C. virginalis (F, Mexico, ZMHB); 222, C. viridipilis (M, Jeannette, MZSP); 223, C. webbi (M, Calipatria, CMNH); 224, C. zonatus (M, Itararé, MZSP). Bars = 2 mm. Figs 216, 218, 219, 221, 223; 220, 224, respectively to the same scale. 


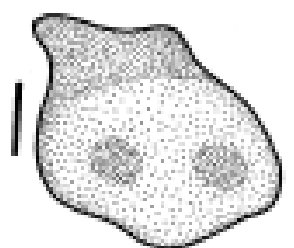

225

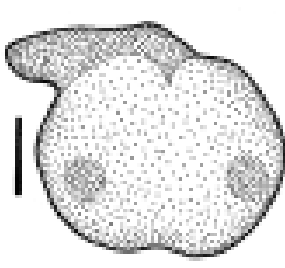

226

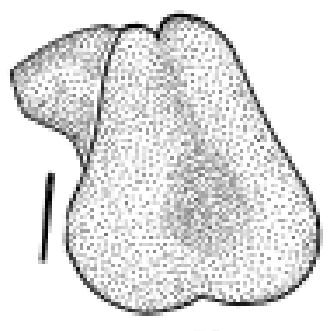

227

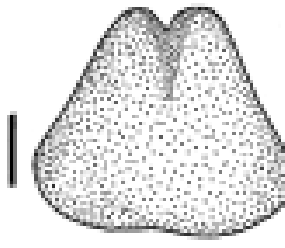

228

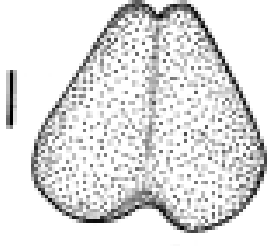

229

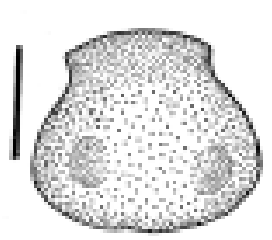

230

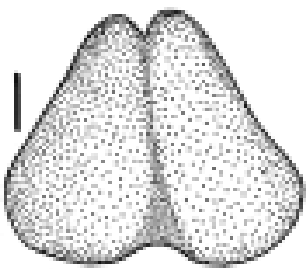

235

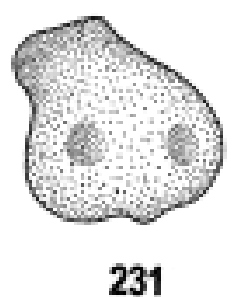

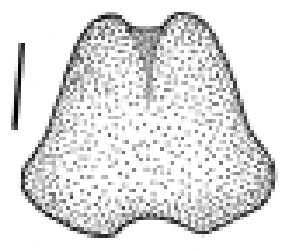

232

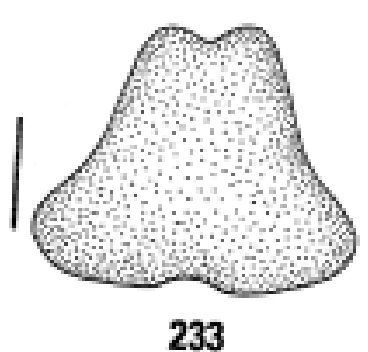

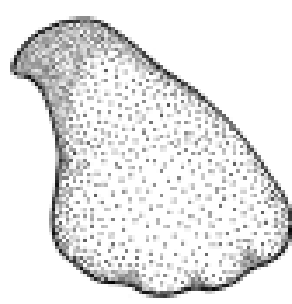

236
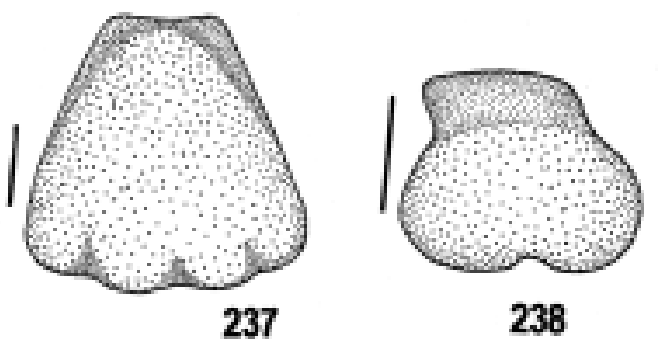

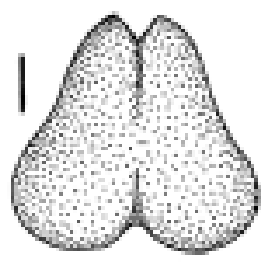

240

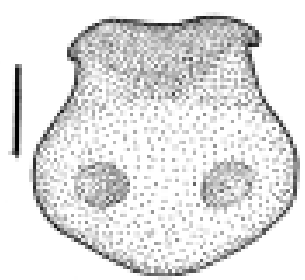

245

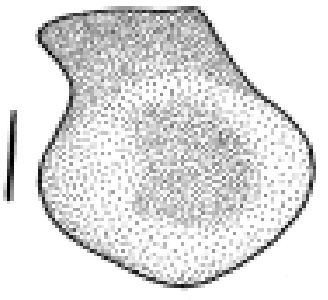

241

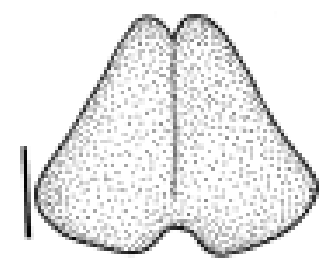

246
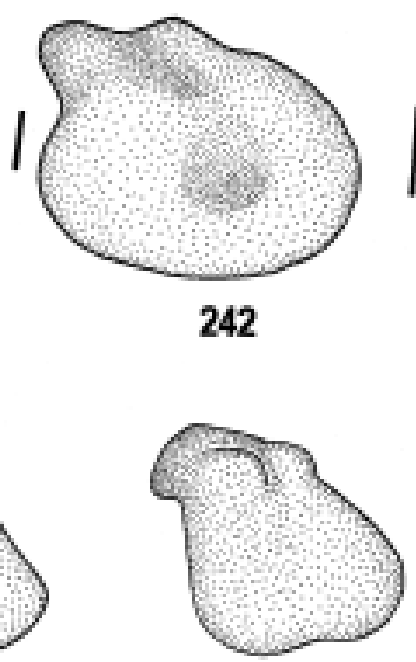

247
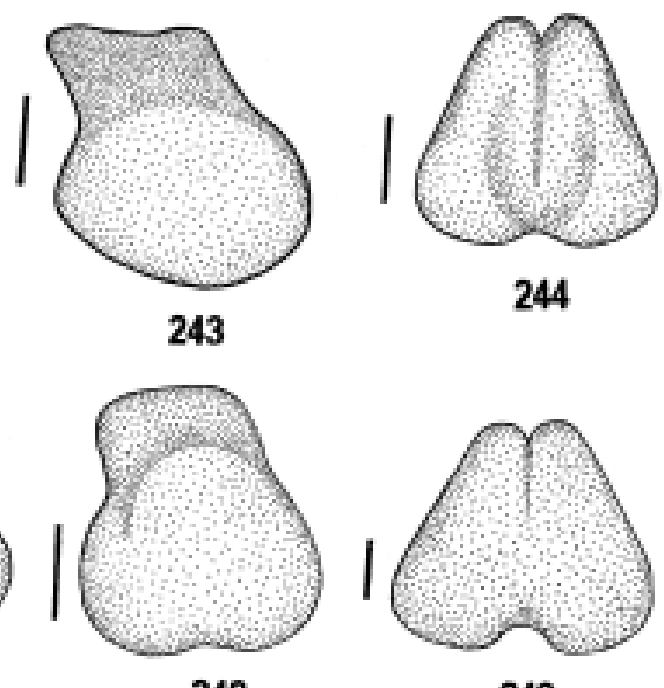

248

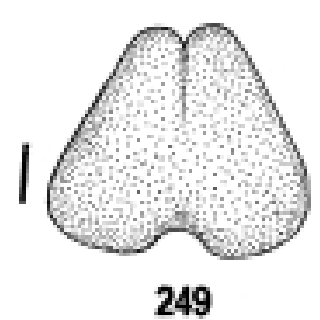

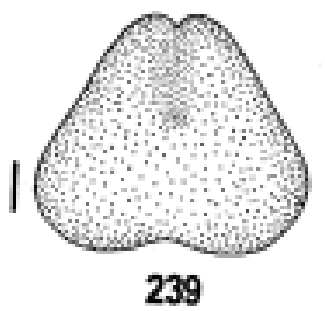

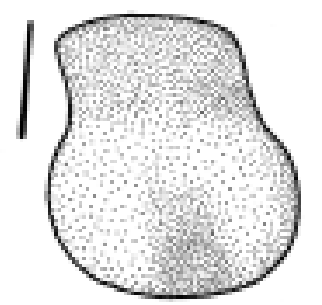

234

Figs. 225-249. Scutellum: 225, C. albisetosus sp. nov. (M, Holotype); 226, C. albiventris sp. nov. (F, Holotype); 227, C. angustatus (M, Syntype); 228, C. apacheanus (M, Phoenix, USNM); 229, C. bomplandii (M, San Quintin, MZSP); 230, 231, C. attenuatus (Est.Biol. Chamela, MZSP); 232, C. aurulentus (M, Ichila, FSCA); 233, C. boucardi (M, Presa El Caracol, UNAM); 234, C. copulatuvittatus sp. nov. (M, Holotype); 235, C. cyaneus (F, Syntype); 236, 237, C. desmarestii (M, 3 Km N Tlanchinol, UNAM); 238, C. dugesi (M, Syntype); 239, C. erythroloma (M, Honolulu, MZSP); 240, C. eschscholtzi (F, Lake Catemaco, MZSP); 241, C. exulatus (M, Syntype); 242, C. extenuatuvittatus sp. nov. (F, Holotype); 243, C. ferratuvittatus sp. nov. (M, Holotype); 244, C. forreri (F, Syntype); 245, C. gossipiatus (M, Ibagué, MZSP); 246, C. inops (M, Syntype of $C$. murinus); 247, 248, C. jansoni (F, Cerro Jefe, FSCA), (M, K8-13 El Llano-Carti Rd., JEWC); 249, C. lacordairii (F, San Jeronimo, IMLA). Bars = $0.5 \mathrm{~mm}$. Figs. 231,$232 ; 247,248$, respectively to the same scale. 

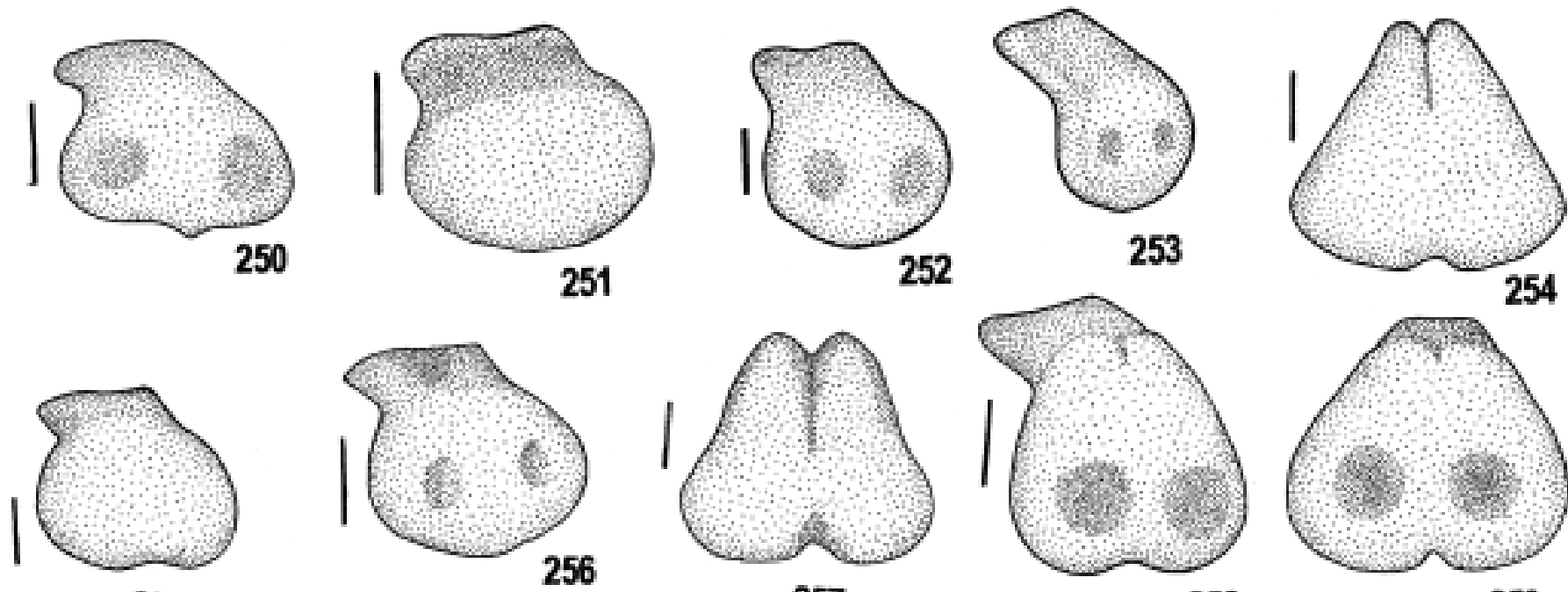

254

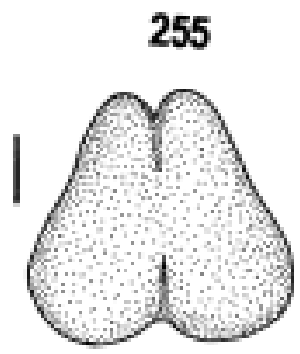

260
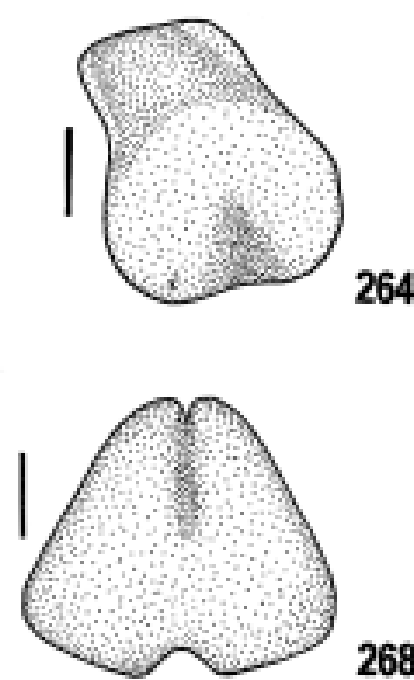

264

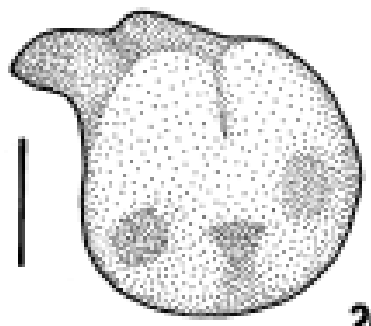

261

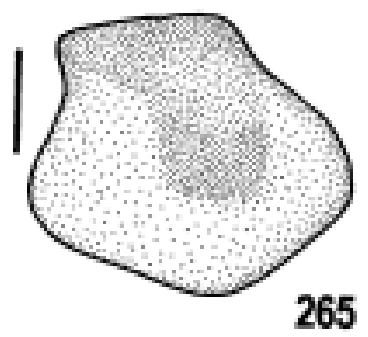

269

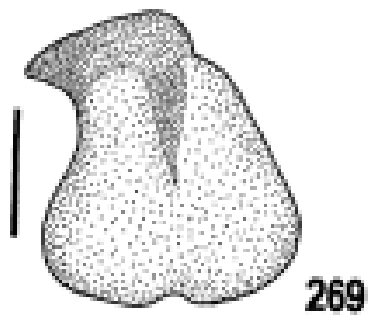

268

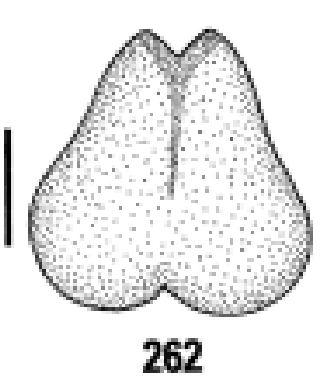

258

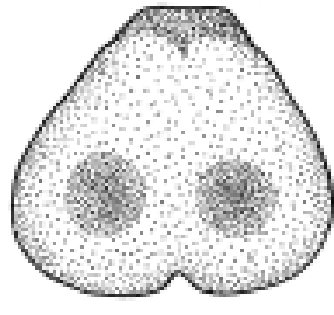

257
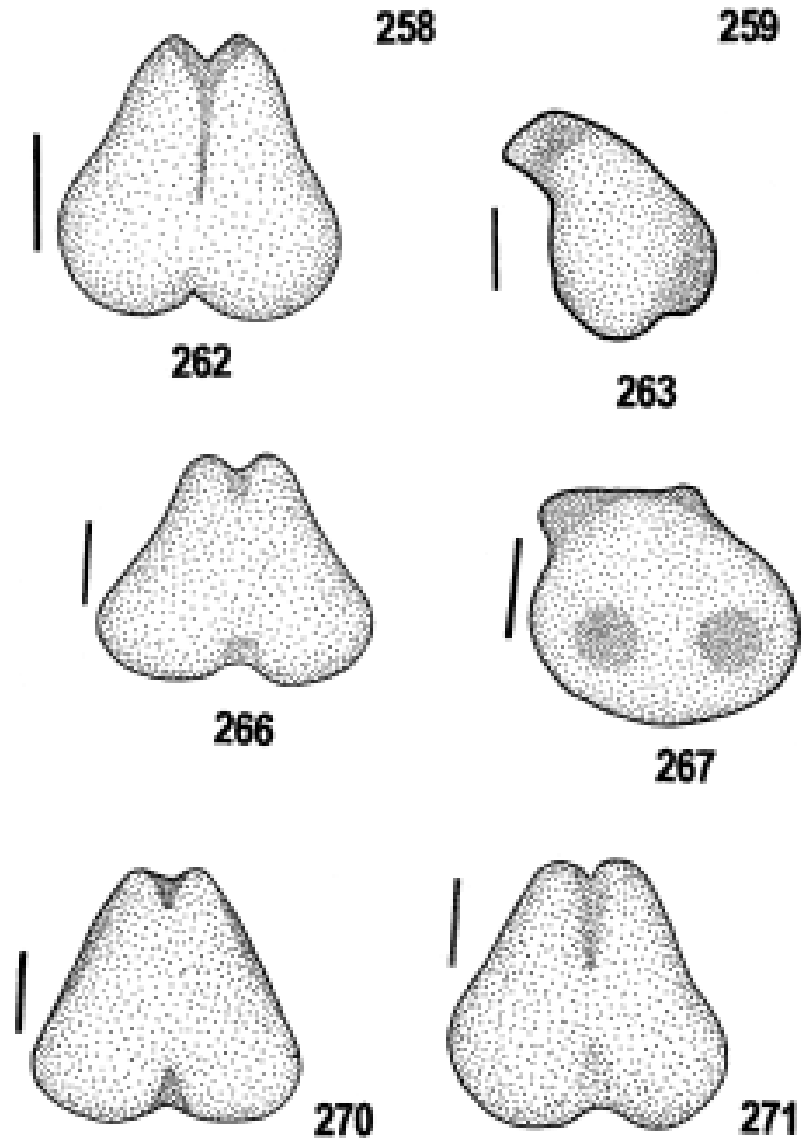

Figs. 250-271. Scutellum: 250, C. lenzi (M, Arizona, CMNH); 251, C. mexicanus (M, Miranda, PCCV); 252, 253, C. mniszechi (F, Syntype); 254, C. obscurus (F, Antilles, USNM); 255, C. oxydatus (M, Chorreadura Canyon, MZSP); 256, C. rodriguezi (M, Holotype); 257, C. rostainei (F, Óbidos, MZSP); 258, 259, C. rubripennis (M, Santa Rosa, CMNH); 260, C. rugatus (M, Sayaaxche, MZSP); 261, C. serricornis sp. nov. (M, Holotype); 262, C. silbermanni (X-Can, MZSP); 263, C. smaragdinus (M, 6 mi Continental, MZSP); 264, C. spinipennis sp. nov. (M, Holotype); 265, C. supremus sp. nov. (M, Holotype); 266, C. tartarus (F, Laguna Lake, MZSP); 267, C. truncuvittatus sp. nov. (F, Holotype); 268, C. validus (M, Dominica, FSCA); 269, C. viridipilis (M, Jeannette, MZSP); 270, C. webbi (M, Calipatria, CMNH); 271, C. zonatus (M, Itararé, MZSP). Bars $=0.5 \mathrm{~mm}$. Figs 252,$253 ; 258,259$, respectively to the same scale. 


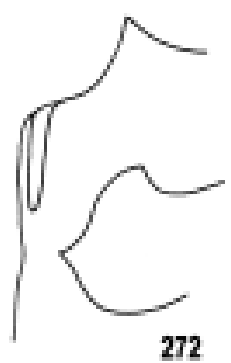

272

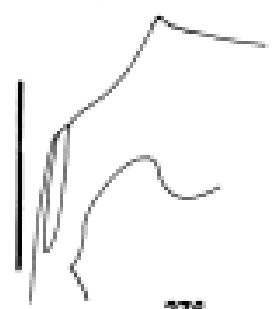

276

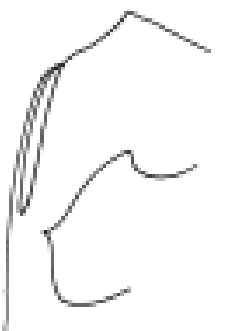

260

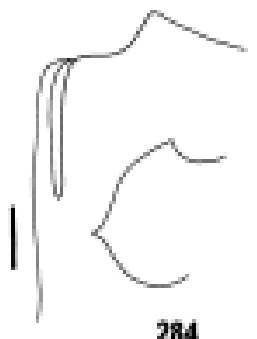

284

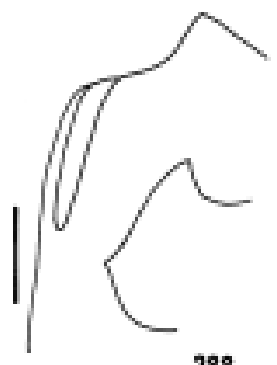

288

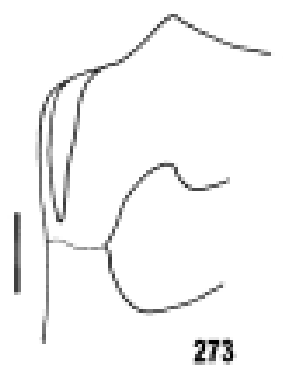

273

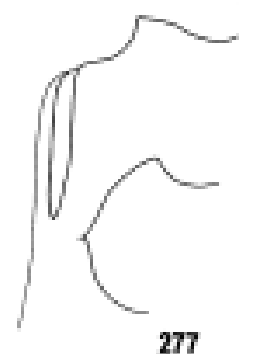

277
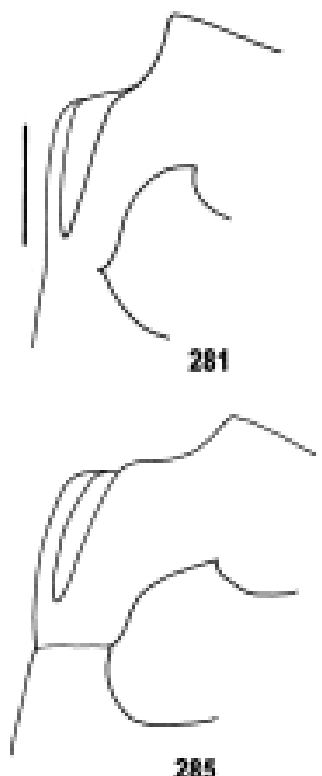

285

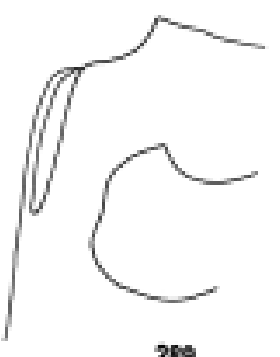

289
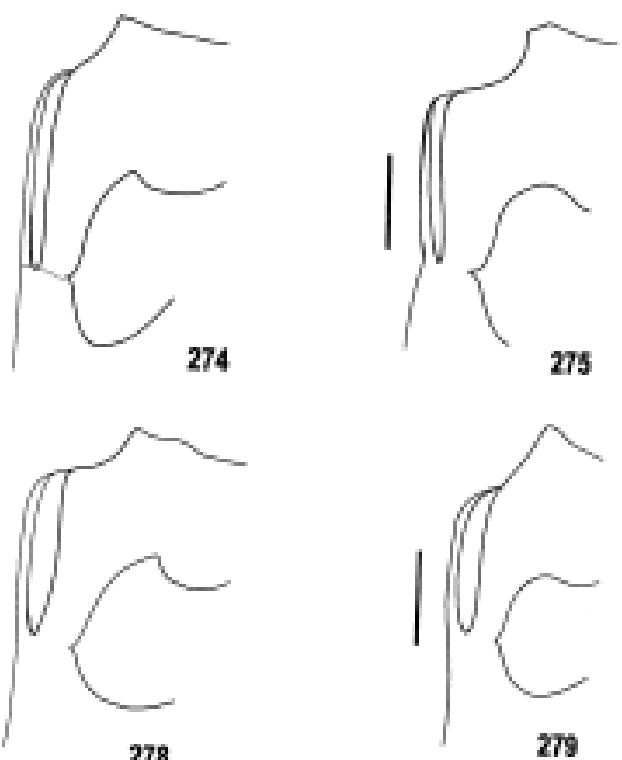

278

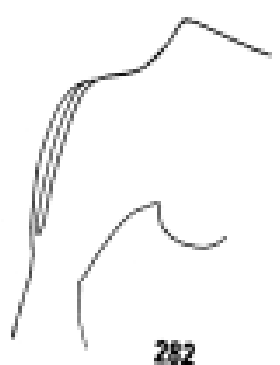

282

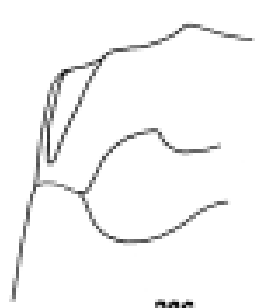

286

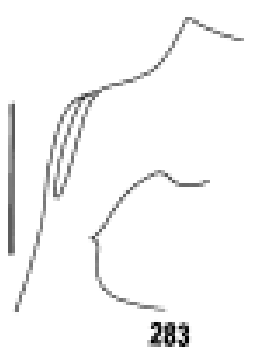

283

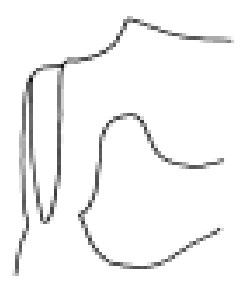

287

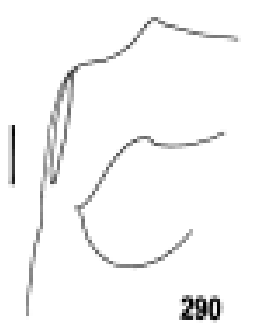

Figs. 272-287. Mesosternal cavity (lateral): 272, C. albisetosus sp. nov. (M, Holotype); 273, C. albiventris sp. nov. (F, Holotype); 274, C. angustatus (M, Syntype); 275, C. apacheanus (M, Phoenix, USNM); 276, C. attenuatus (Est.Biol. Chamela, MZSP); 277, C. aurulentus (M, Ichila, FSCA); 278, C. bomplandii (M, San Quintin, MZSP); 279, C. boucardi (M, Presa El Caracol, UNAM); 280, C. chalcantheus (M, Niquelândia, MZSP); 281, C. copulatuvittatus sp. nov. (M, Holotype); 282, C. desmarestii (M, 3 Km N Tlanchinol, UNAM); 283, C. dugesi (M, Syntype); 284, C. erythroloma (M, Honolulu, MZSP); 285, C. extenuatuvittatus sp. nov. (F, Holotype); 286, C. exulatus (M, Syntype); 287, C. fasciatus sp. nov. (M, Holotype); 288, C. ferratuvittatus sp. nov. (M, Holotype); 289, C. fryi (M, Chiclayo, IMLA); 290, C. gossipiatus (M, Armero, MZSP); 291, C. inops (M, Syntype of $C$. murinus). Bars = 1 mm. Figs 272, 273, 278, 286, 287; 274, 275, 277, 282; 279, 280; 284, 285; 288, 289, 291 respectively to the same scale. 


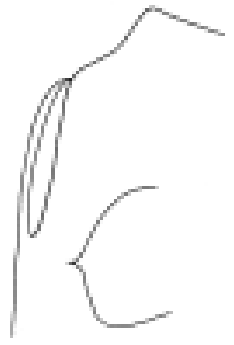

292

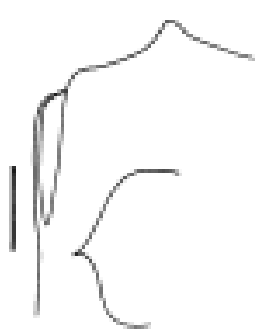

296

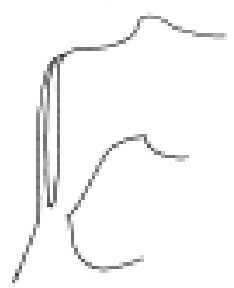

300
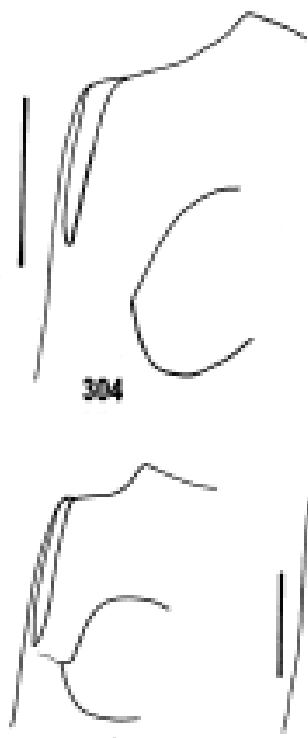

308

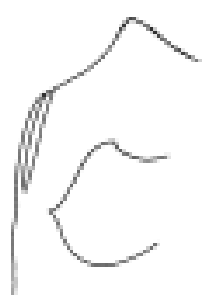

293

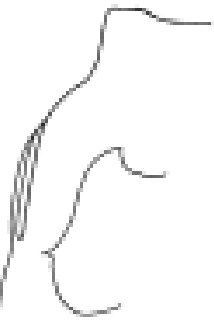

297

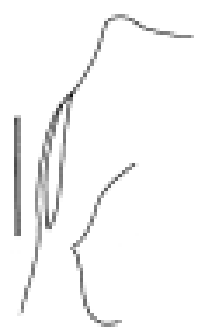

301

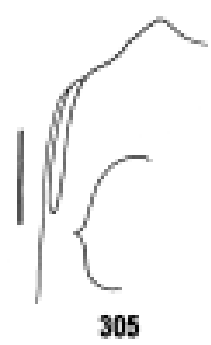

305

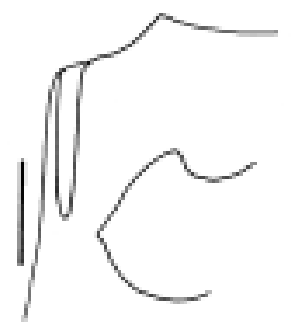

309

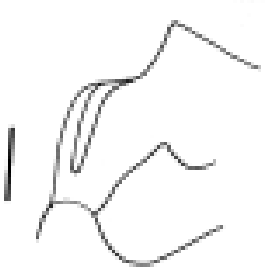

294

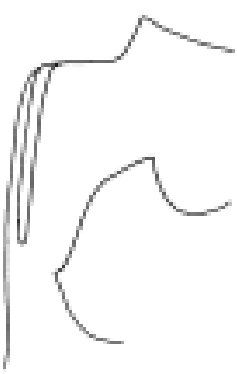

298

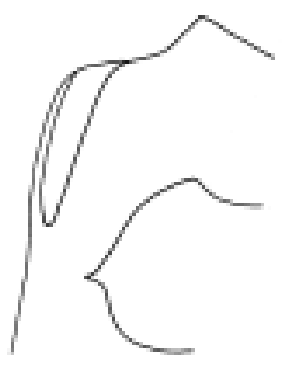

302

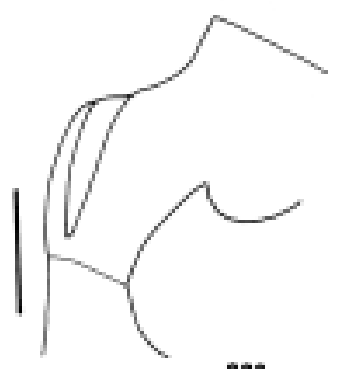

306

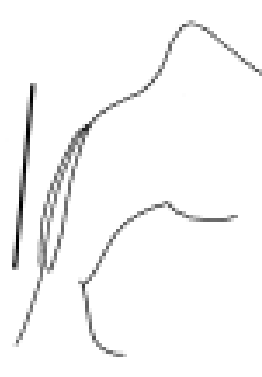

310

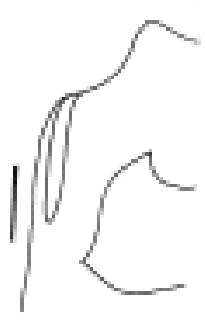

311

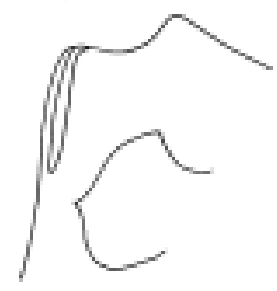

295

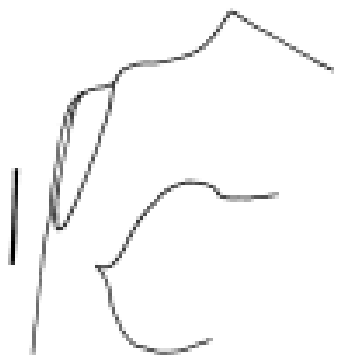

299

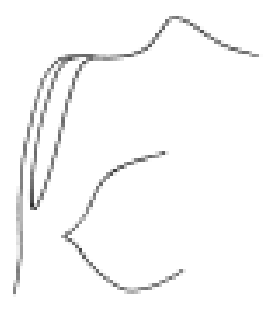

300

Figs. 292-312. Mesosternal cavity (lateral): 292, C. jansoni (M, K8-13 El Llano-Carti Rd., JEWC); 293, C. lenzi (M, Arizona, CMNH); 294, C. mniszechi (F, Syntype); 295, C. obscurus (F, Antilles, USNM); 296 C. oxydatus (M, San Sebastian, USNM); 297, C. rubripennis (M, Santa Rosa, $\mathrm{CMNH}$ ); 298, C. rugatus (M, Sayaaxche, MZSP); 299, C. serricornis sp. nov. (M, Holotype); 300, C. silbermanni (X-Can, MZSP); 301, C. smaragdinus (M, 6 mi Continental, MZSP); 302, C. spinipennis sp. nov. (M, Holotype); 303, C. sulcatus (F, Saint Croix, MZSP). 304, C. supremus sp. nov. (M, Holotype); 305, C. tartarus (F, Laguna Lake, MZSP); 306, C. truncuvittatus sp. nov. (F, Holotype); 307, C. villei (F, Quibdó, PCCV); 308, C. virens (F, Itacoatiara, MZSP); 309, C. virgatipennis sp. nov. (M, Holotype); 310, C. viridipilis (M, Jeannette, MZSP); 311, C. webbi (M, Calipatria, CMNH); 312, C. zonatus (M, Itararé, MZSP). Bars = 1 mm. Figs. 292, 293, 298, 303; 294, 295; 296, 297, 300, 302; 305, 308 to the same scale. 

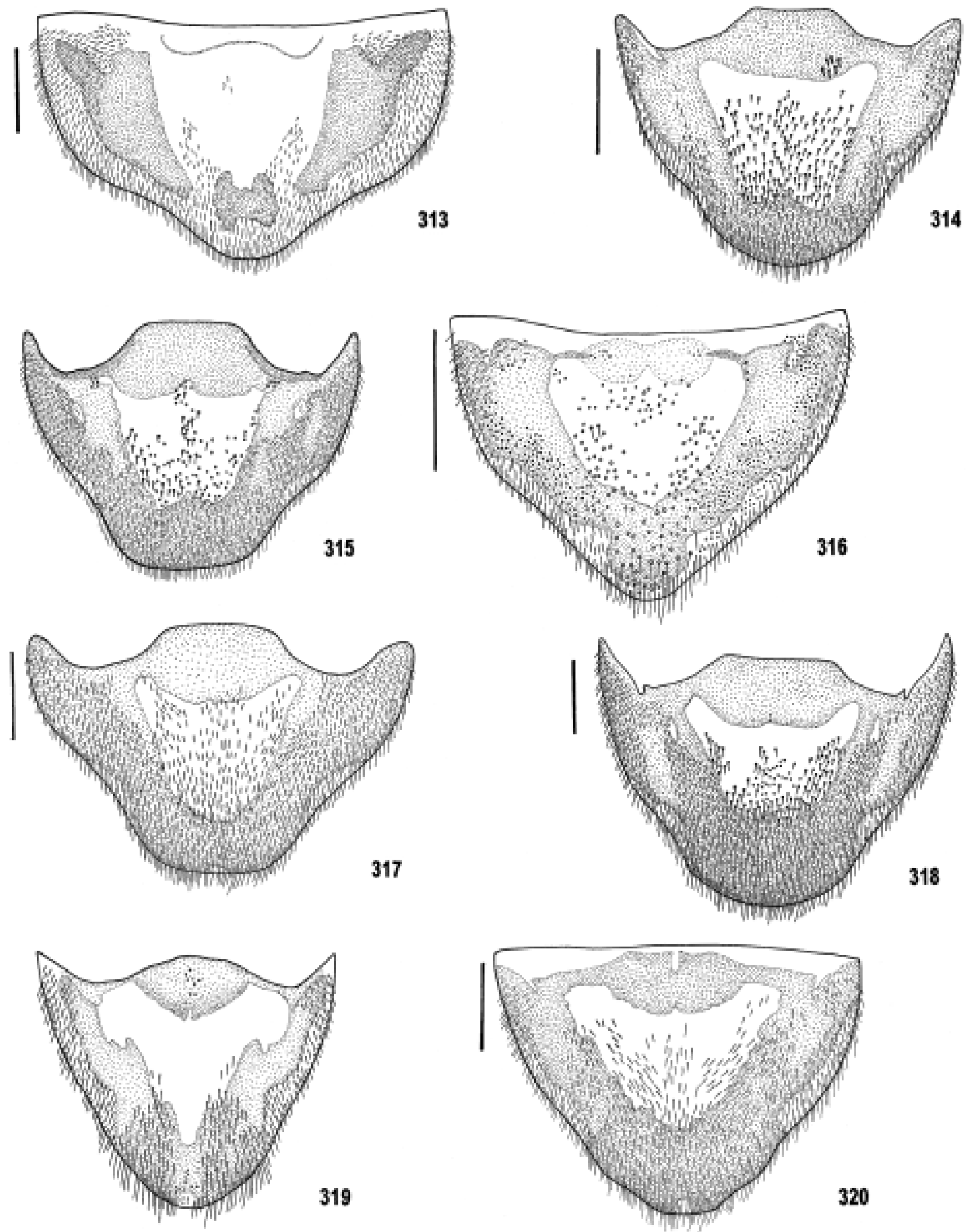

Figs. 313-320. Sternite VIII of male: 313, C. albisetosus sp. nov. (Holotype); 314, C. apacheanus (without locality, MZSP); 315, C. approximatus (Tenancingo, MZSP); 316, C. attenuatus (Est. Biol. Chamela, MZSP); 317, C. aurulentus (Ichila, FSCA); 318, C. bomplandii (San Quintin, MZSP); 319, C. boucardi (Presa El Caracol, UNAM); 320, C. chalcantheus (Niquelândia, MZSP). Bars $=1 \mathrm{~mm}$. Figs 313, 315; 319, 320, respectively to the same scale. 

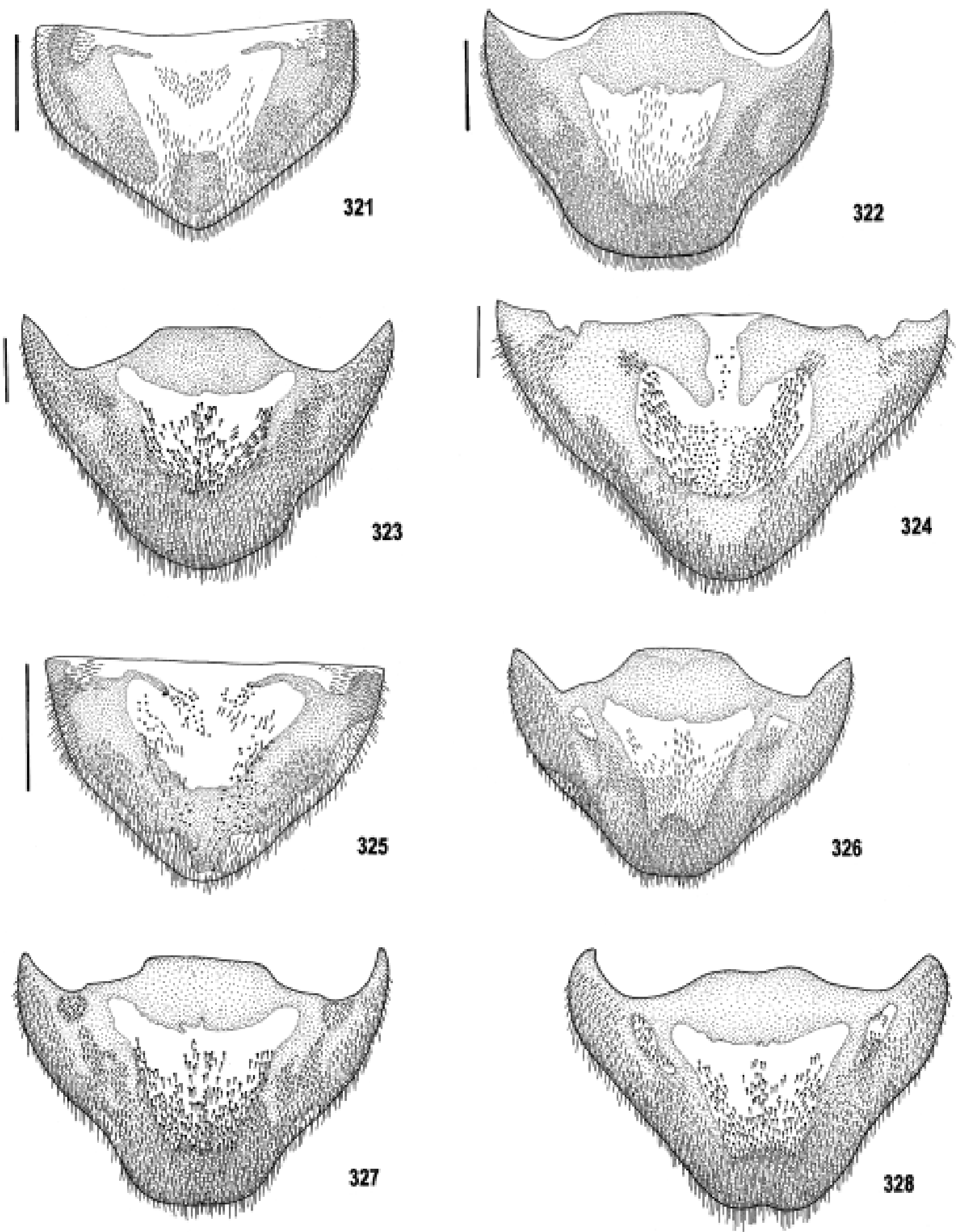

Figs. 321-328. Sternite VIII of male: 321, C. copulatuvittatus sp. nov. (Holotype); 322, C. corpulentus (Carquejo, MZSP); 323, C. cyaneus (Los Angeles Tucuco, MZSP); 324, C. desmarestii (Tlocnuil, MZSP); 325, C. dugesi (Syntype); 326, C. erythroloma (Honolulu, MZSP); 327, C. eschscholtzi (14-16 Km W S'ntompn, JEWC); 328, C. fabricii (Ibagué, MZSP). Bars = $1 \mathrm{~mm}$. Figs 324, 328; 322, 326, 327, respectively to the same scale. 

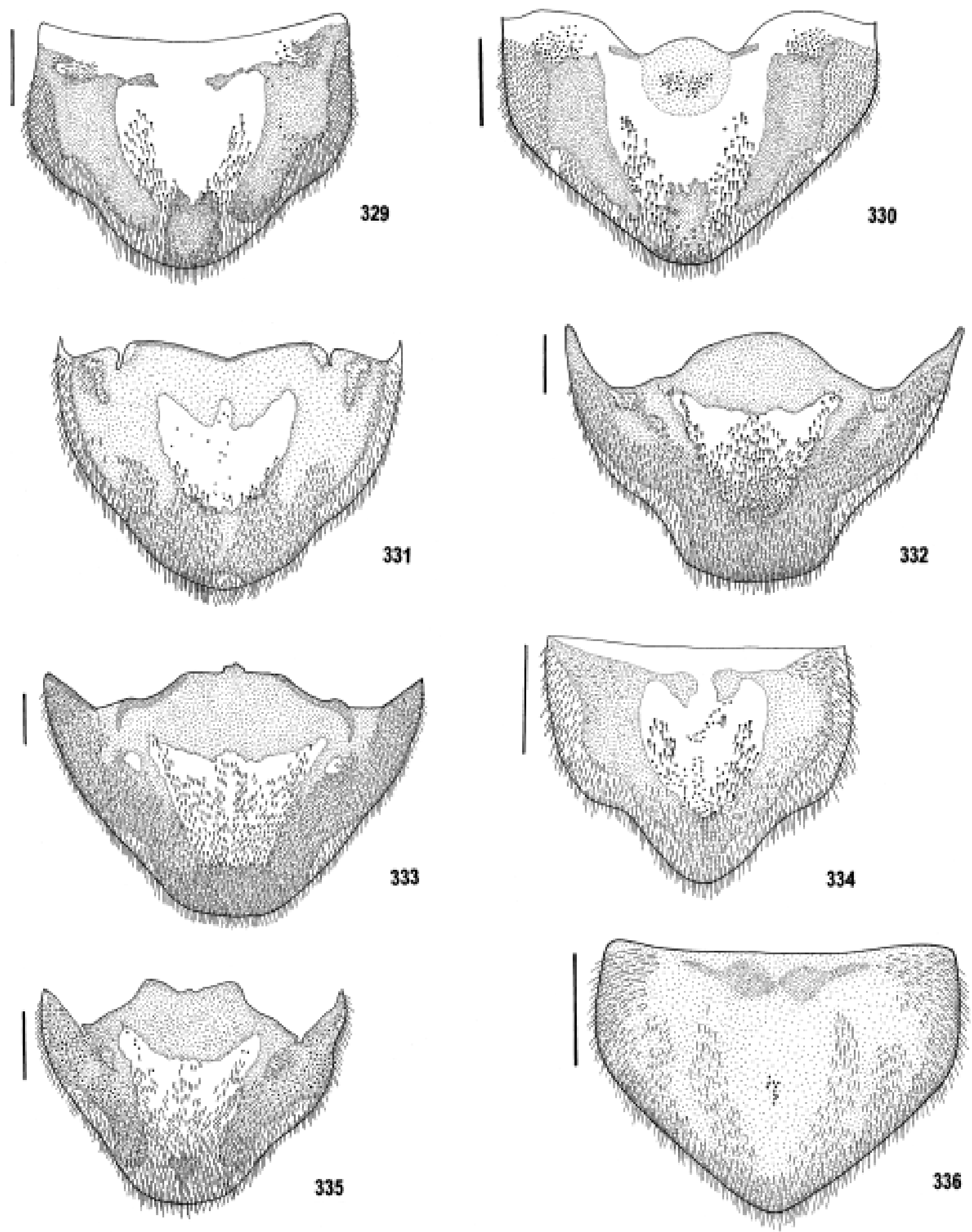

Figs. 329-336. Sternite VIII of male: 329, C. gossipiatus (Ibagué, MZSP); 330, C. ferratuvittatus sp. nov. (Holotype); 331, C. jansoni (K8-13 El Llano-Carti Rd., JEWC); 332, C. lacordairii (Colima, UNAM); 333, C. lafargi (M, without locality, NHMW); 334, C. lenzi (M, Arizona, CMNH); 335, C. limbatus (Linhares, MZSP); 336, C. mexicanus (Miranda, PCCV). Bars $=1 \mathrm{~mm}$. Figs 330, 331, to the same scale. 

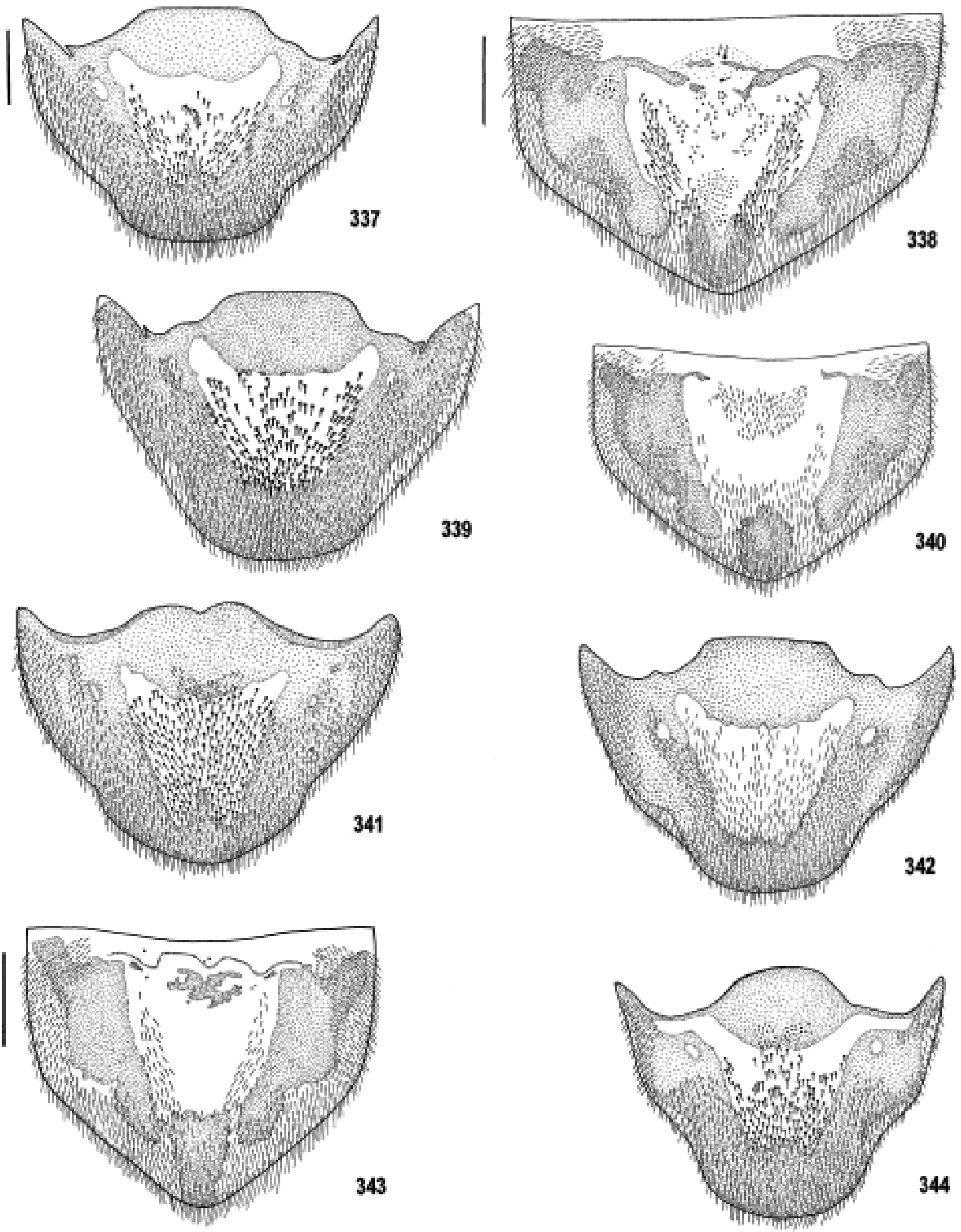

Figs. 337-344. Sternite VIII of male: 337, C. obscurus (Montserrat, USNM); 338, C. oxydatus (San Vito, USNM); 339, C. porcatus (Itacoatiara, MZSP); 340, C. rodriguezi (Holotype); 341, C. rubripennis (California, CMNH); 342, C. rugatus (Sayaaxche, MZSP); 343, C. serricornis sp. nov. (Paratype); 344, C. silbermanni (X-Can, MZSP). Bars $=1 \mathrm{~mm}$. Figs 337, 339, 342, 344; 338, 340, 341, respectively to the same scale. 

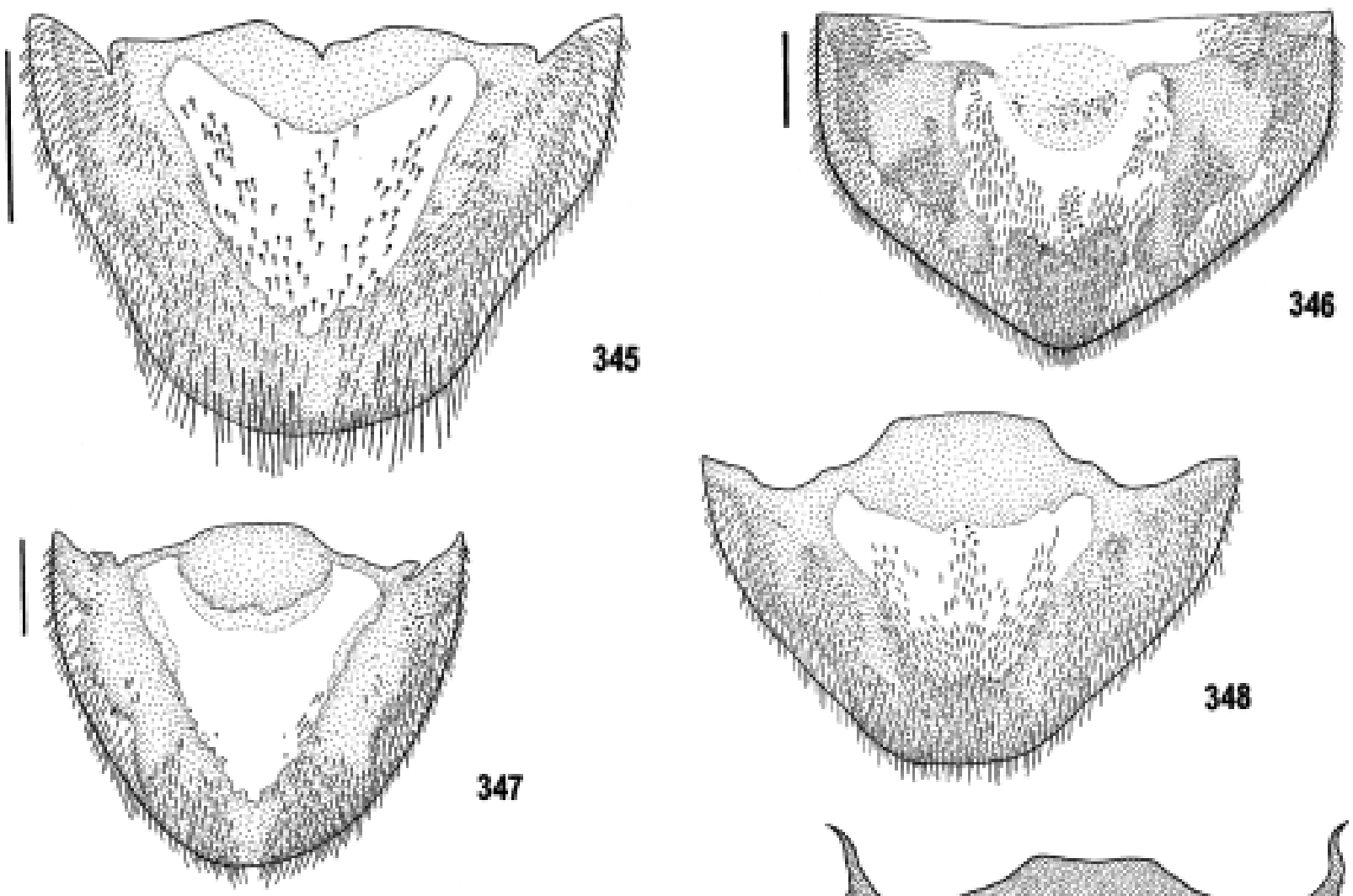

347
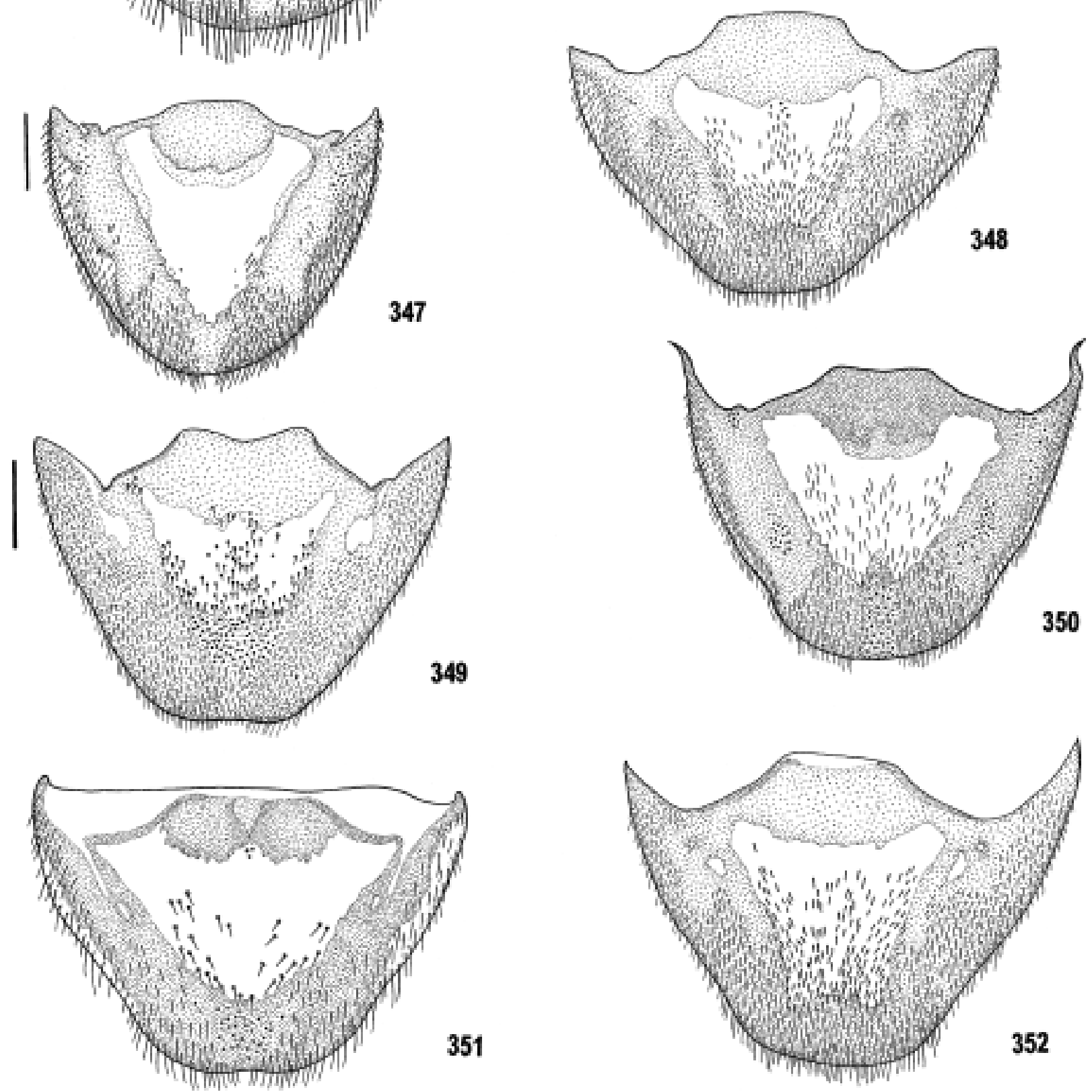

Figs. 345-352. Sternite VIII of male: 345, C. smaragdinus (Douglas, CMNH); 346, C. spinipennis sp. nov. (Paratype); 347, C. tartarus (Yuma, MZSP); 348, C. validus (Dominica, FSCA); 349, C. villei (Rio Bravo Valley, MZSP); 350, C. virginalis (Tehuatepec, FSCA); 351, C. viridipilis (Jeannette, MZSP); 352, C. zonatus (Itararé, MZSP). Bars = $1 \mathrm{~mm}$. Figs 345, 351; 346, 348; 349, 350, 352, respectively to the same scale. 

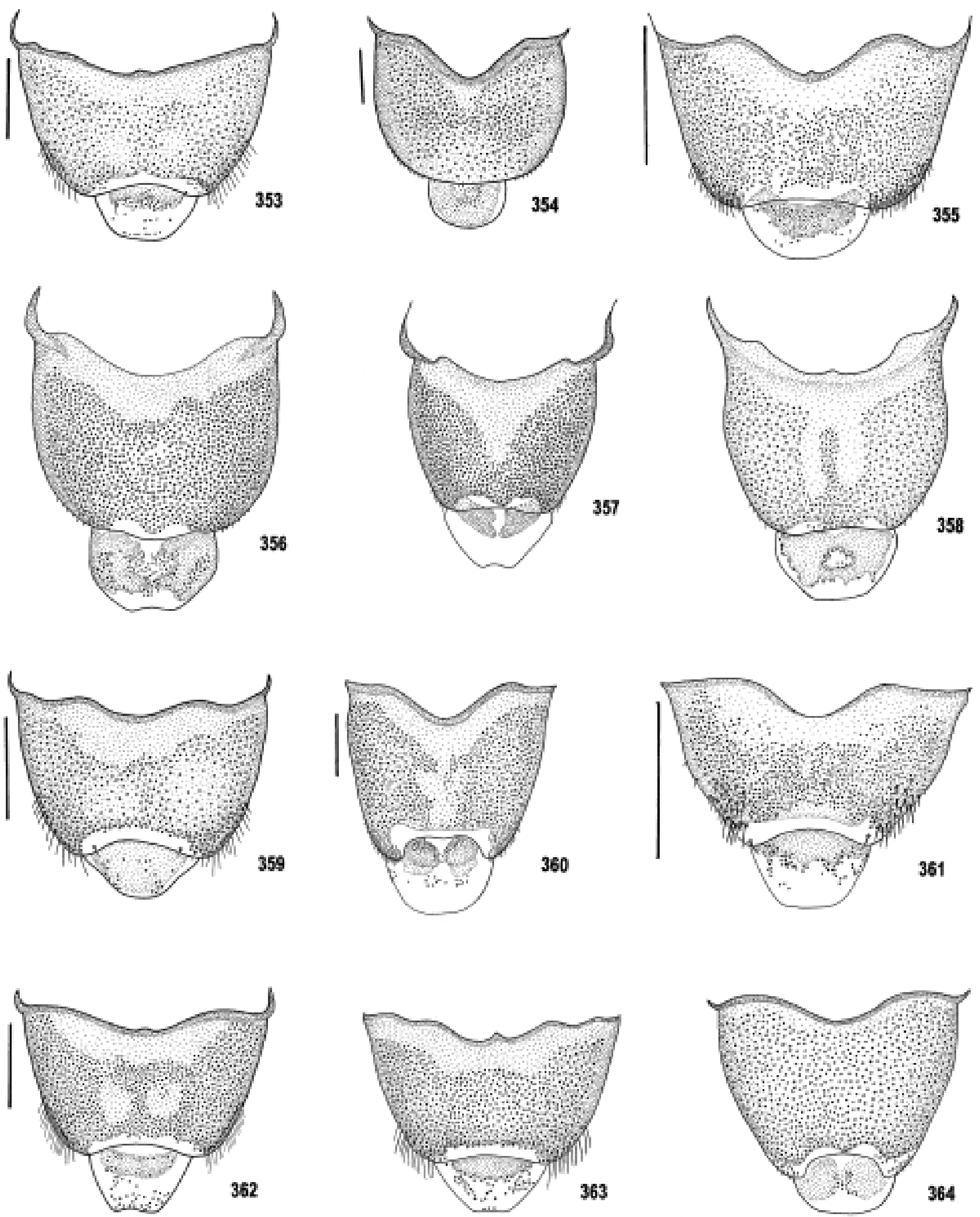

Figs. 353-364. Tergites IX-X of male: 353, C. albisetosus sp. nov. (Holotype); 354, C. approximatus (Tenancingo, MZSP); 355, C. attenuatus (Est.Biol. Chamela, MZSP); 356, C. bomplandii (San Quintin, MZSP); 357, C. boucardi (Presa El Caracol, UNAM); 358, C. chalcantheus (Niquelândia, MZSP); 359, C. copulatuvittatus sp. nov. (Holotype); 360, C. desmarestii (Tlocnuil, MZSP); 361, C. dugesi (Syntype); 362, C. ferratuvittatus sp. nov. (Holotype); 363, C. gossipiatus (Ibagué, MZSP); 364, C. jansoni (K8-13 El Llano-Carti Rd., JEWC). Bars = 1 mm. Figs 353, $356,357,358,363,364$, to the same scale. 

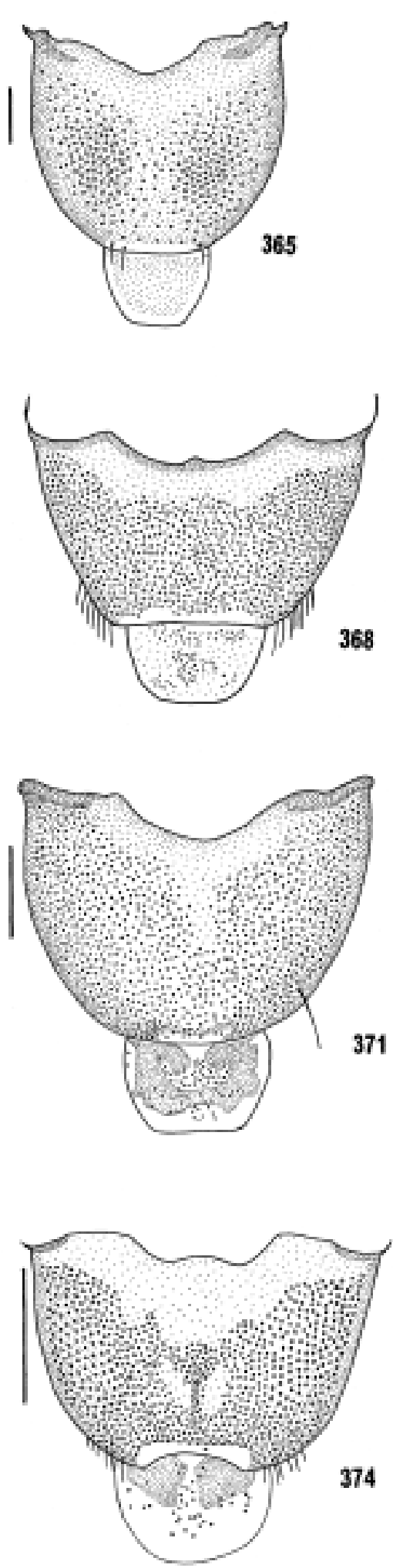
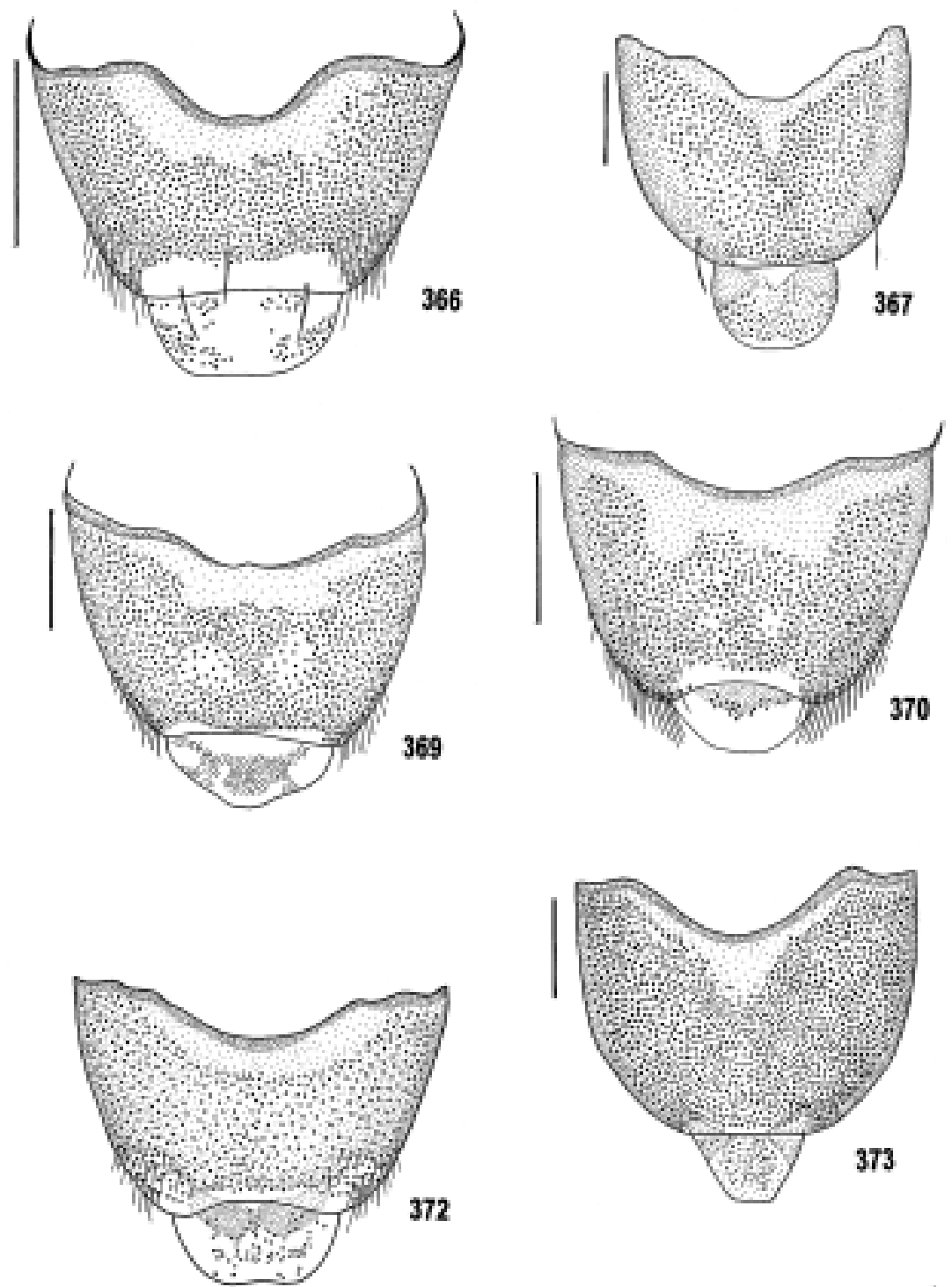

372
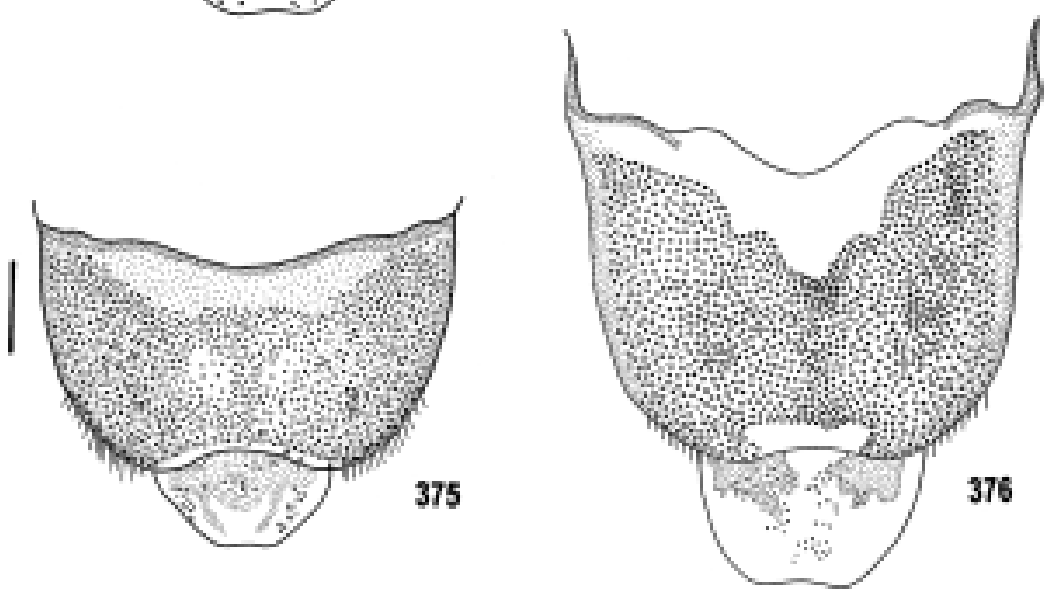

Figs. 365-376. Tergites IX-X of male: 365, C. lafargi (without locality, NHMW); 366, C. lenzi (Arizona, CMNH); 367, C. limbatus (Linhares, MZSP); 368, C. mexicanus (Miranda, PCCV); 369, C. oxydatus (San Vito, USNM); 370, C. rodriguezi (Holotype); 371, C. rugatus (Sayaaxche, MZSP); 372, C. serricornis sp. nov. (Paratype); 373, C. silbermanni (X-Can, MZSP); 374, C. smaragdinus (Douglas, CMNH); 375, C. spinipennis sp. nov. (Paratype); 376, C. tartarus (Yuma, MZSP). Bars $=1 \mathrm{~mm}$. Figs 368, 370, 372; 269, 376, respectively, to the same scale. 

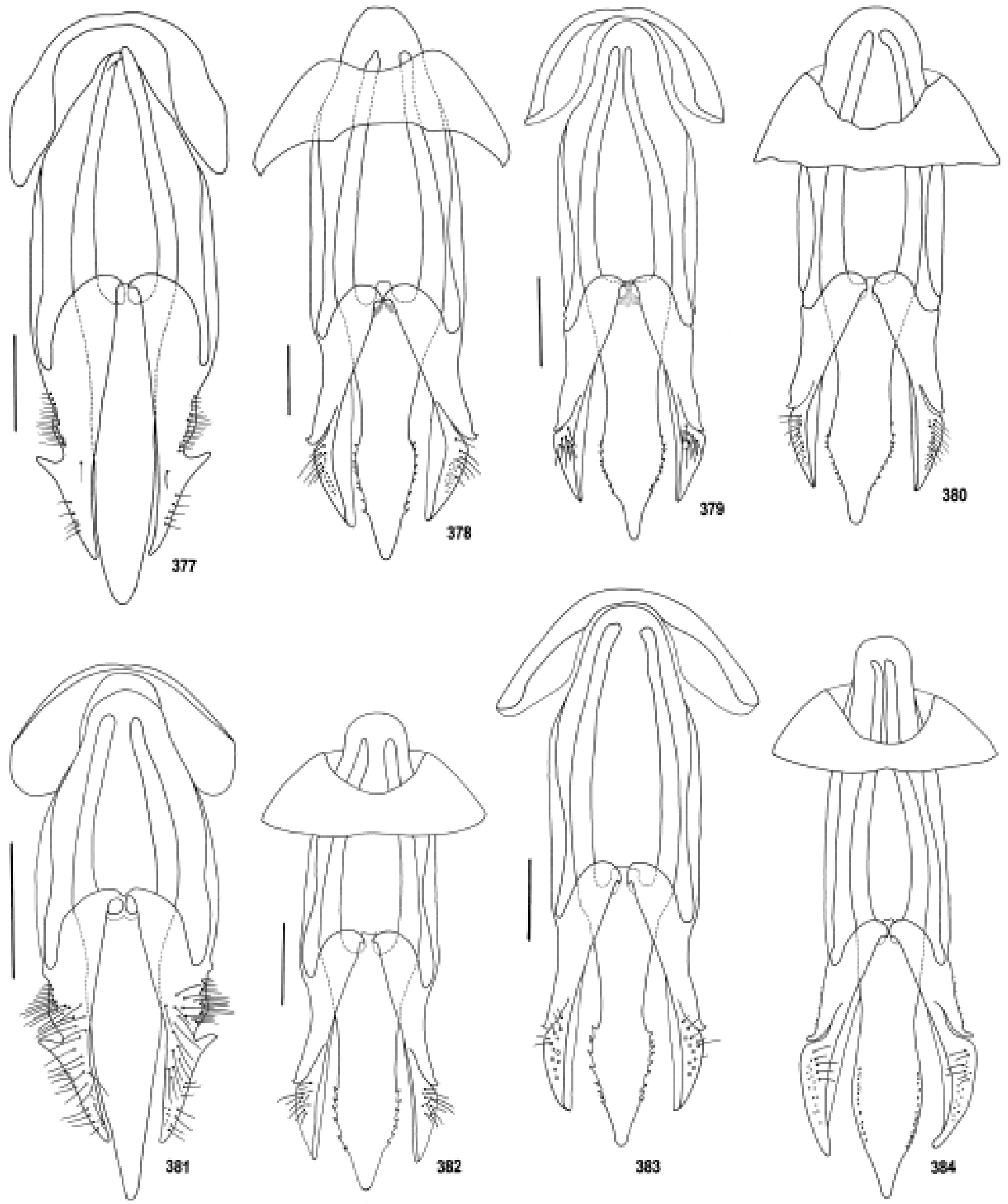

Figs. 377-384. Aedeagus (dorsal): 377, C. albisetosus sp. nov. (Holotype); 378, C. angustatus (Syntype); 379, C. apacheanus (without locality, MZSP); 380, C. approximatus (Tenancingo, MZSP); 381, C. attenuatus (Est.Biol. Chamela, MZSP); 382, C. aurulentus (Ichila, FSCA); 383, C. bomplandii (San Quintin, MZSP); 384, C. boucardi (Presa El Caracol, UNAM). Bars = 1 mm. Figs 379, 384; 380, 383, respectively, to the same scale. 


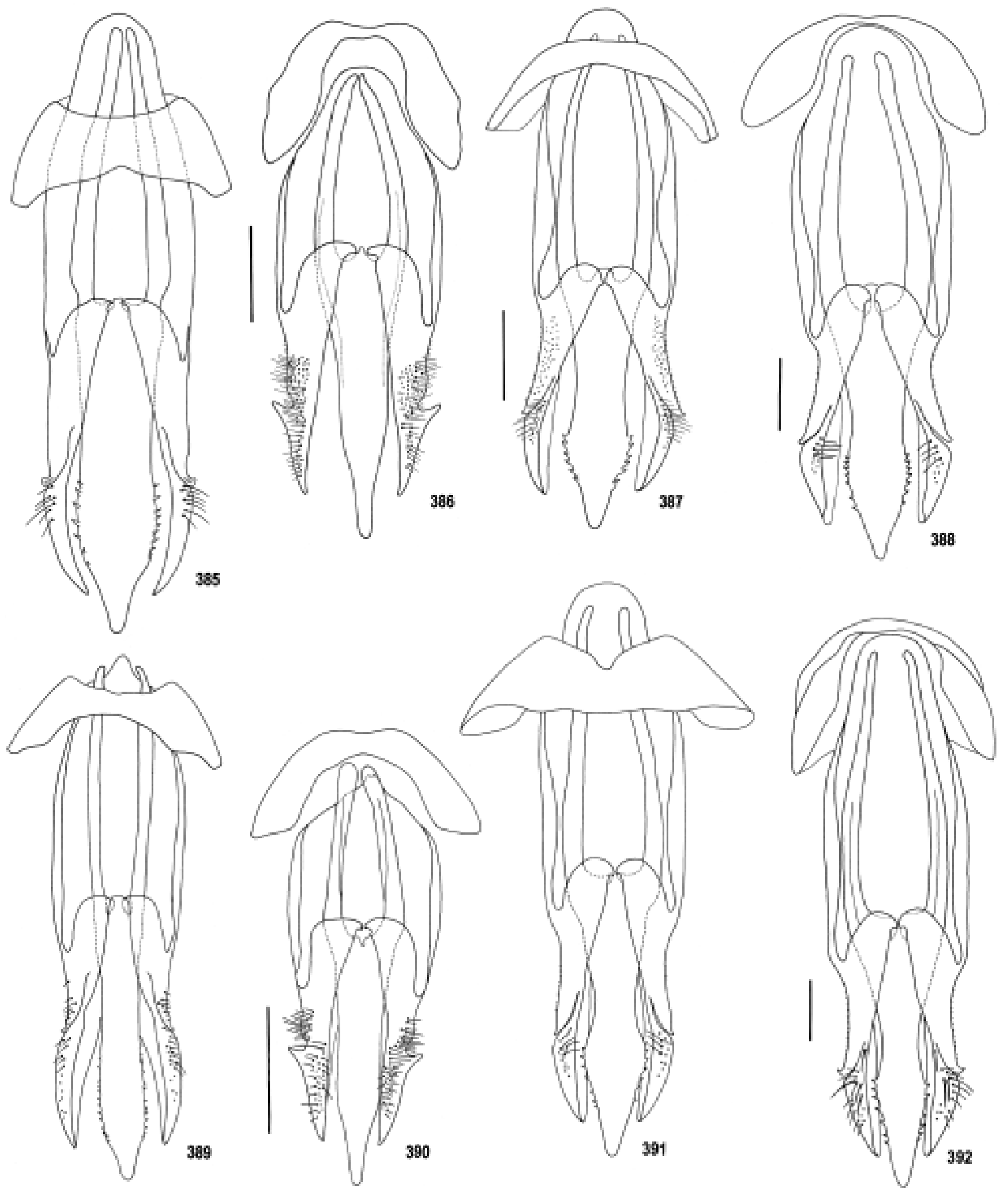

Figs. 385-392. Aedeagus (dorsal): 385, C. chalcantheus (Niquelândia, MZSP); 386, C. copulatuvittatus sp. nov. (Holotype); 387, C. corpulentus (Carquejo, MZSP); 388, C. cyaneus (Los Angeles Tucuco, MZSP); 389, C. desmarestii (Tlocnuil, MZSP); 390, C. dugesi (Syntype); 391, C. erythroloma (Honolulu, MZSP); 392, C. eschscholtzi (14-16 Km W S'ntompn, JEWC). Bars = 1 mm. Figs 385, 386; 388, 391; 389, 392, respectively, to the same scale. 

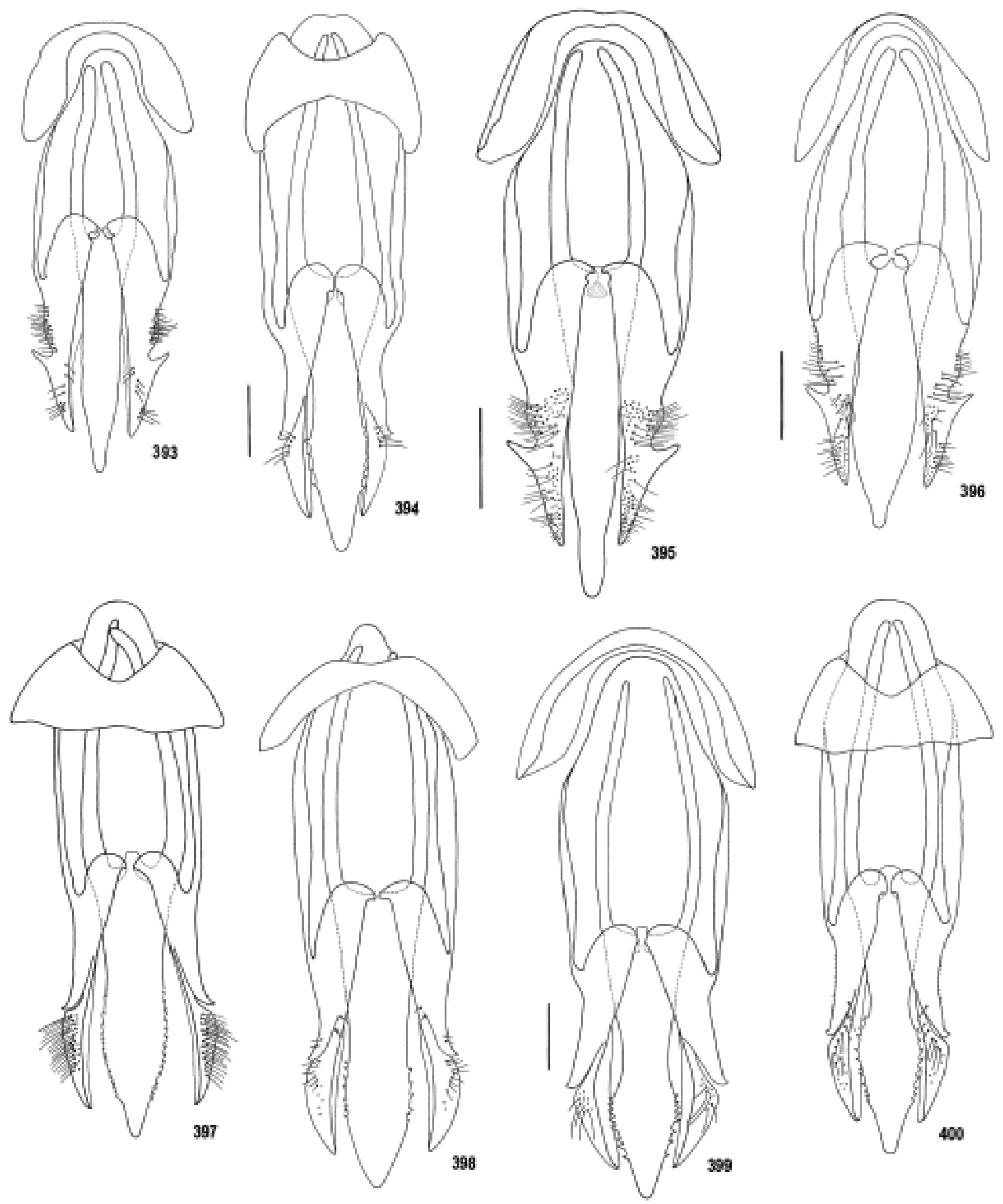

Figs. 393-400. Aedeagus (dorsal): 393, C. exulatus (Caracas, USNM); 394, C. fabricii (Ibagué, MZSP); 395, C. ferratuvittatus sp. nov. (Holotype); 396, C. gossipiatus (Ibagué, MZSP); 397, C. inops (Syntype of C. murinus); 398, C. jansoni (K8-13 El Llano-Carti Rd., JEWC); 399, C. lacordairii (Colima, UNAM); 400, C. lafargi (without locality, NHMW). Bars = 1 mm. Figs 393, 394; 395, 397, 398; 399, 400, respectively, to the same scale. 

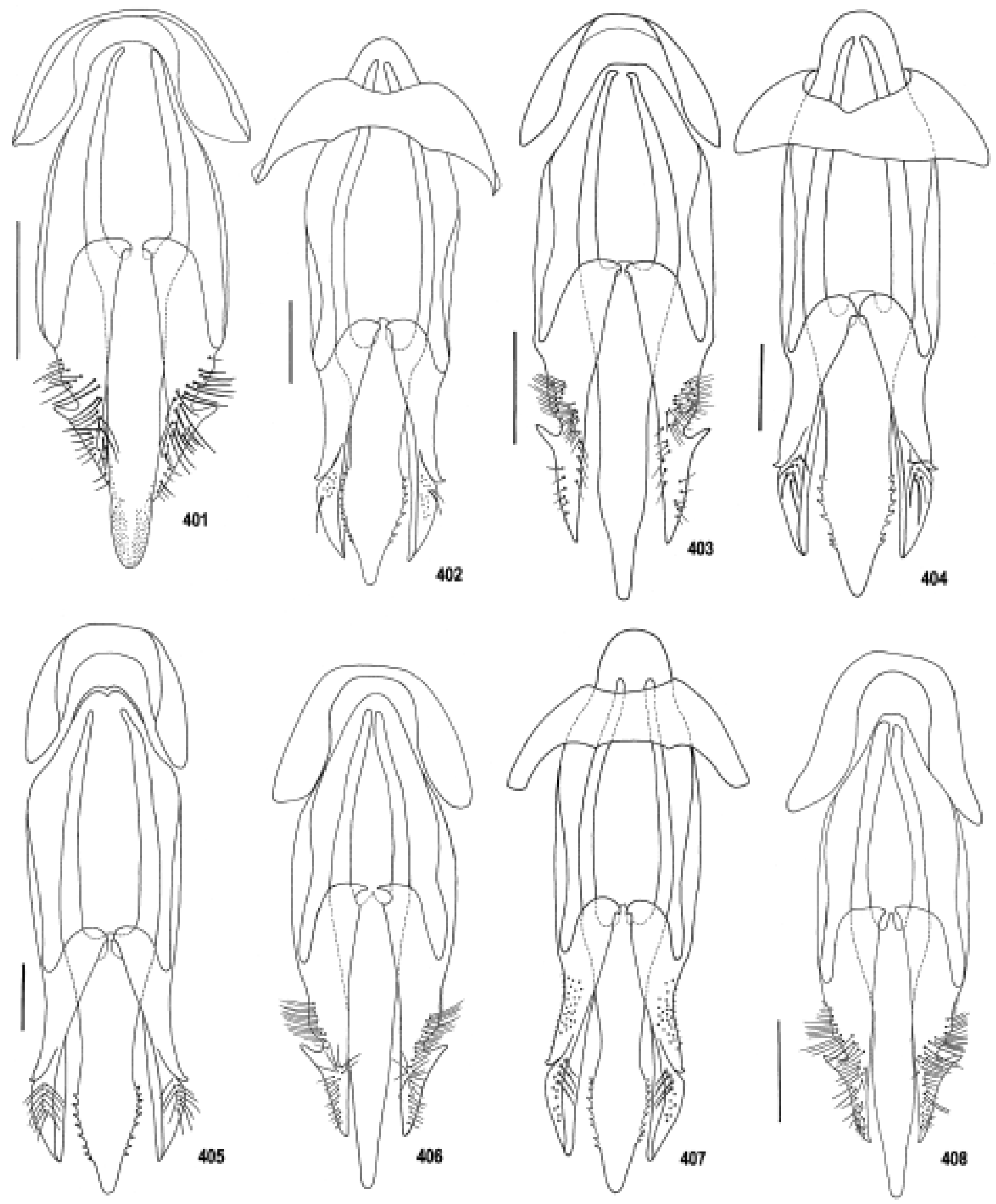

Figs. 401-408. Aedeagus (dorsal): 401, C. lenzi (Arizona, CMNH); 402, C. limbatus (Linhares, MZSP); 403, C. mexicanus (Miranda, PCCV); 404, C. mocquerysii (Colombia, MZSP); 405, C. obscurus (Montserrat, USNM); 406, C. oxydatus (San Vito, USNM); 407, C. porcatus (Itacoatiara, MZSP); 408, C. rodriguezi (Holotype). Bars $=1 \mathrm{~mm}$. Figs 402, 406, 407, to the same scale. 

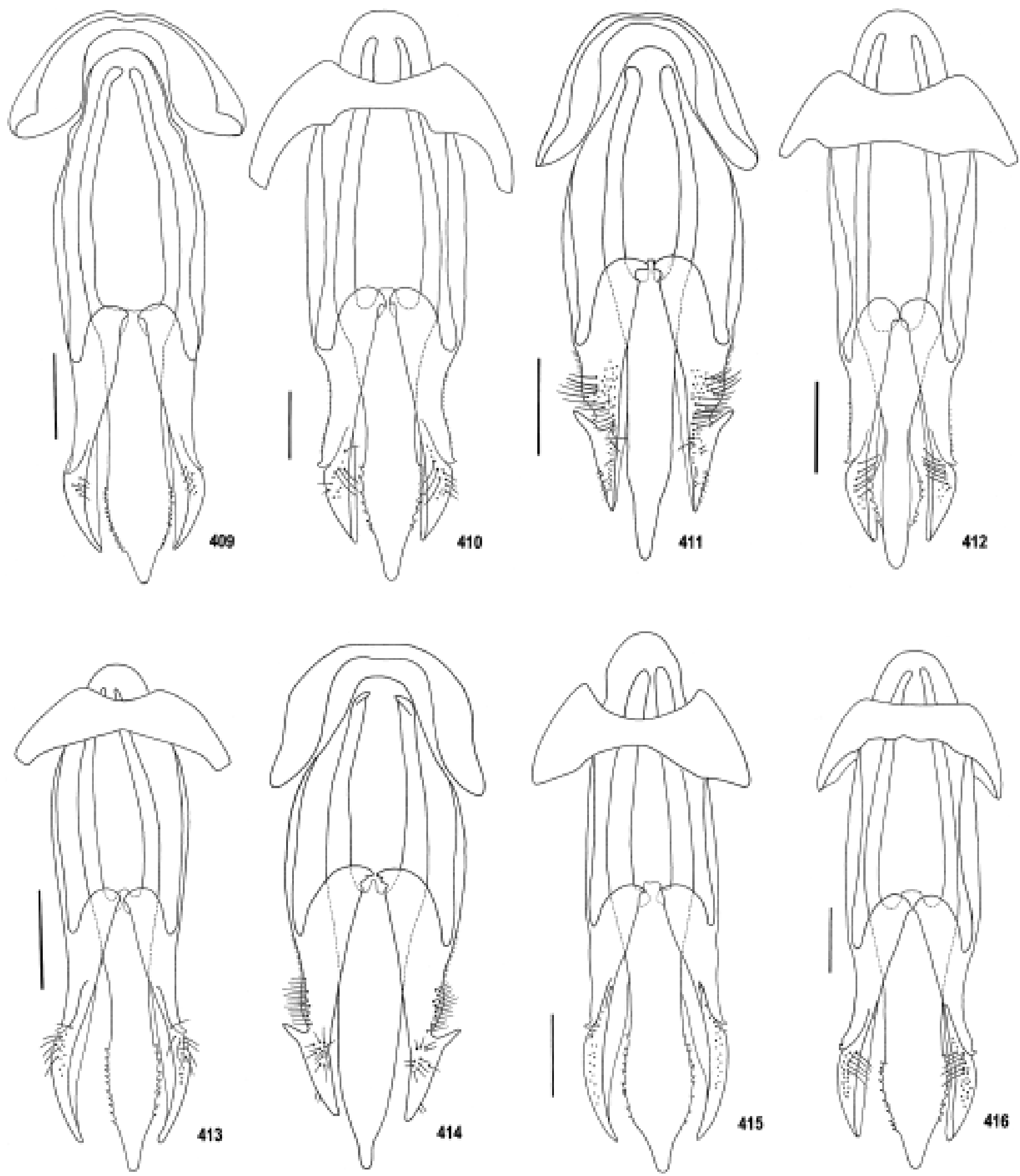

Figs. 409-416. Aedeagus (dorsal): 409, C. rubripennis (California, CMNH); 410, C. rugatus (Sayaaxche, MZSP); 411, C. serricornis sp. nov. (Paratype); 412, C. silbermanni (X-Can, MZSP); 413, C. smaragdinus (Douglas, CMNH); 414, C. spinipennis sp. nov. (Paratype); 415, C. tartarus (Yuma, MZSP); 416, C. validus (Dominica, FSCA). Bars = $1 \mathrm{~mm}$. Figs 413,414 , to the same scale. 

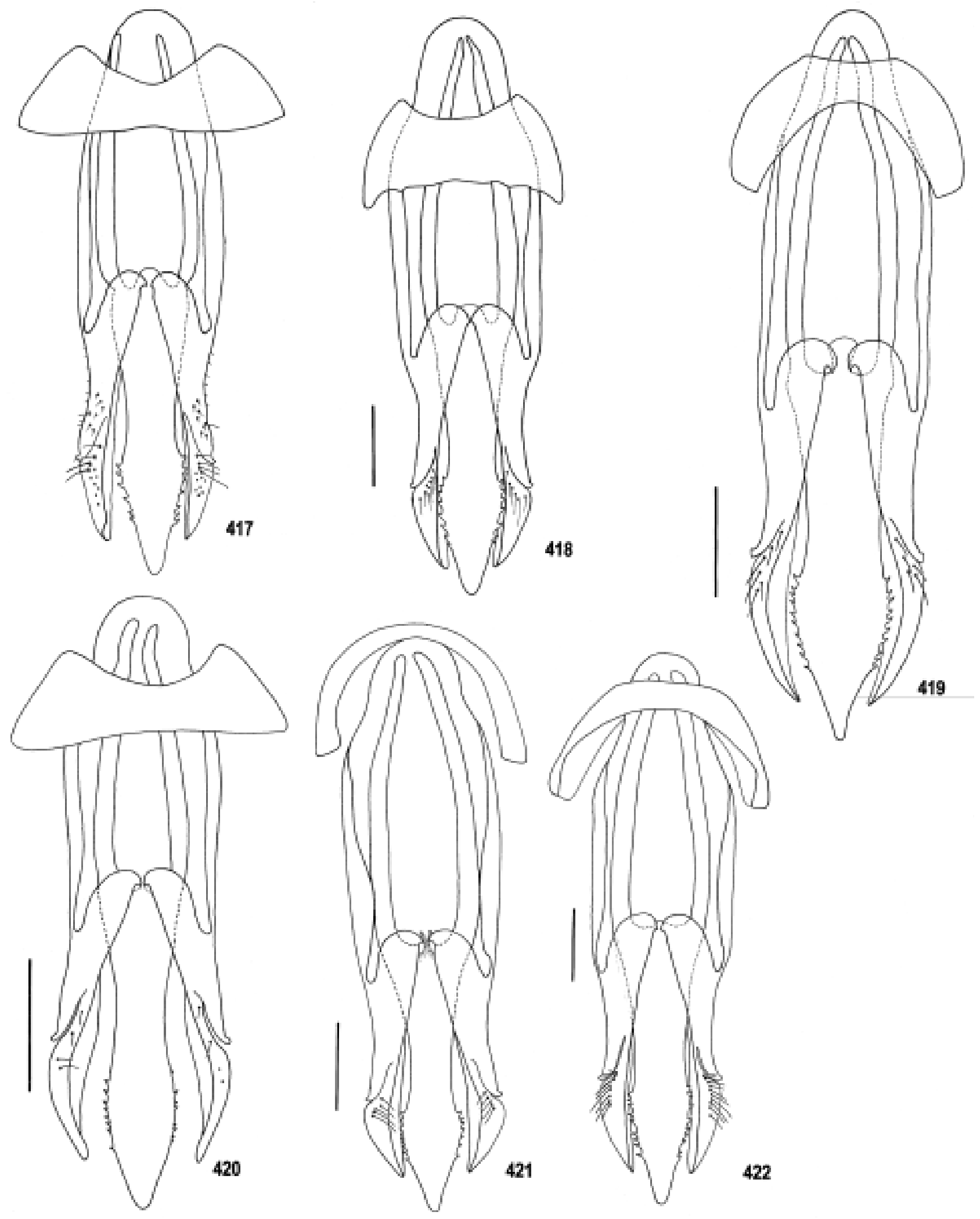

Figs. 417-422. Aedeagus (dorsal): 417, C. villei (Rio Bravo Valley, MZSP); 418, C. virens (Reserva Biológica de Cuieiras, MNHN); 419, C. virginalis (Tehuatepec, FSCA); 420, C. viridipilis (Jeannette, MZSP); 421, C. webbi (California, MZSP); 422, C. zonatus (Itararé, MZSP). Bars $=1 \mathrm{~mm}$. Figs 417,418 , to the same scale. 


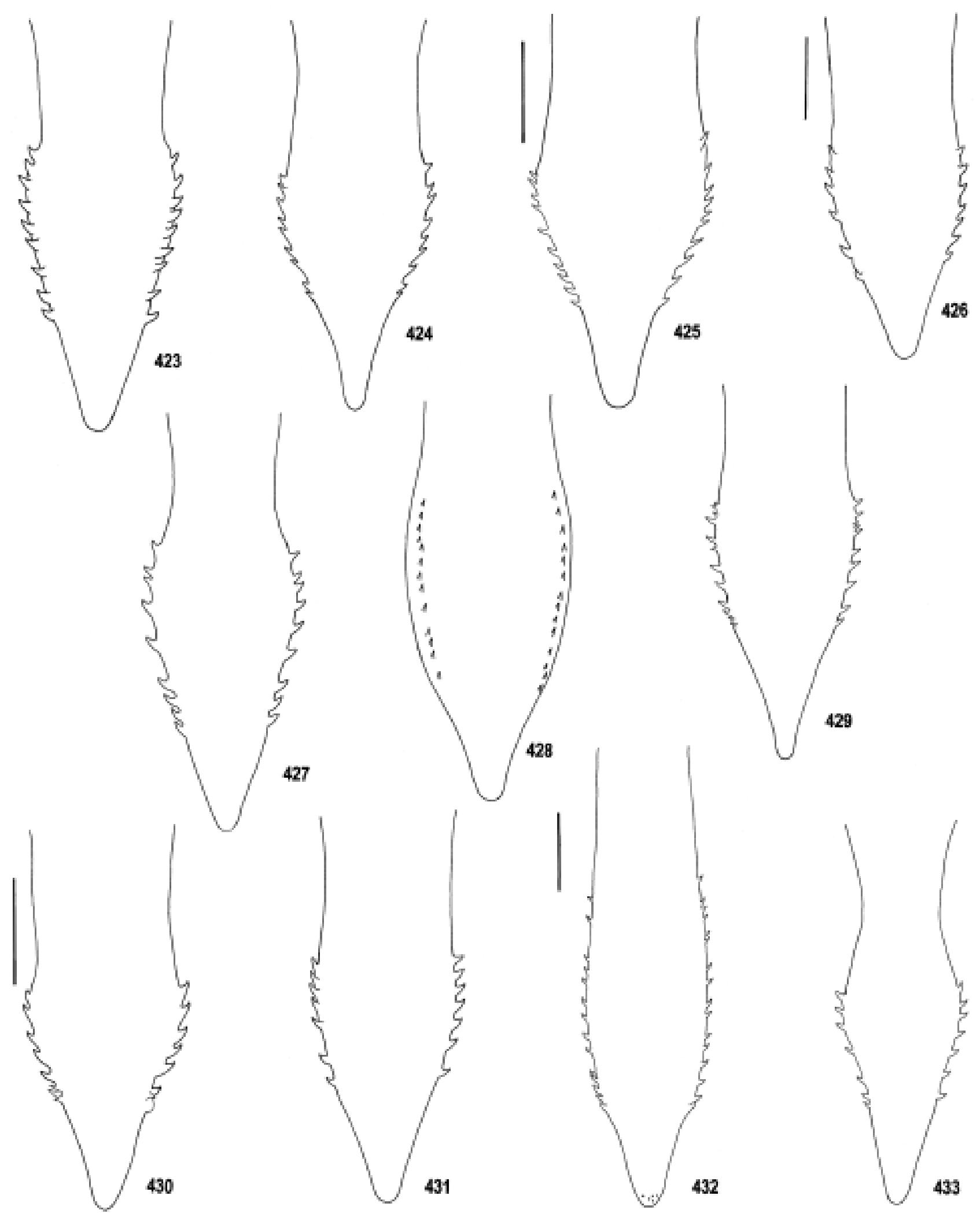

Figs. 423-433. Apex of median lobe: 423, C. angustatus (Syntype); 424, C. apacheanus (without locality, MZSP); 425, C. approximatus (Tenancingo, MZSP); 426, C. aurulentus (Ichila, FSCA); 427, C. bomplandii (San Quintin, MZSP); 428, C. boucardi (Presa El Caracol, UNAM); 429, C. chalcantheus (Niquelândia, MZSP); 430, C. corpulentus (Carquejo, MZSP); 431, C. cyaneus (Los Angeles Tucuco, MZSP); 432, C. desmarestii (Tlocnuil, MZSP); 433, C. erythroloma (Honolulu, MZSP). Bars $=0.5$ mm. Figs 424, 425, 427, 428; 423, 426, 429, 431; 432, 433, respectively, to the same scale. 

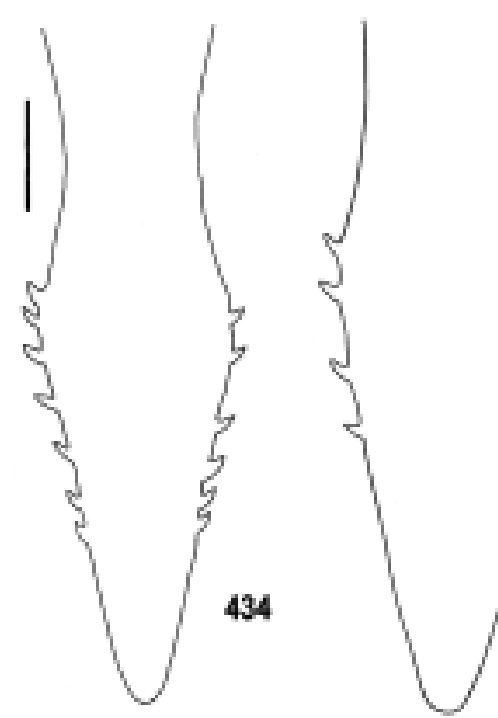

435
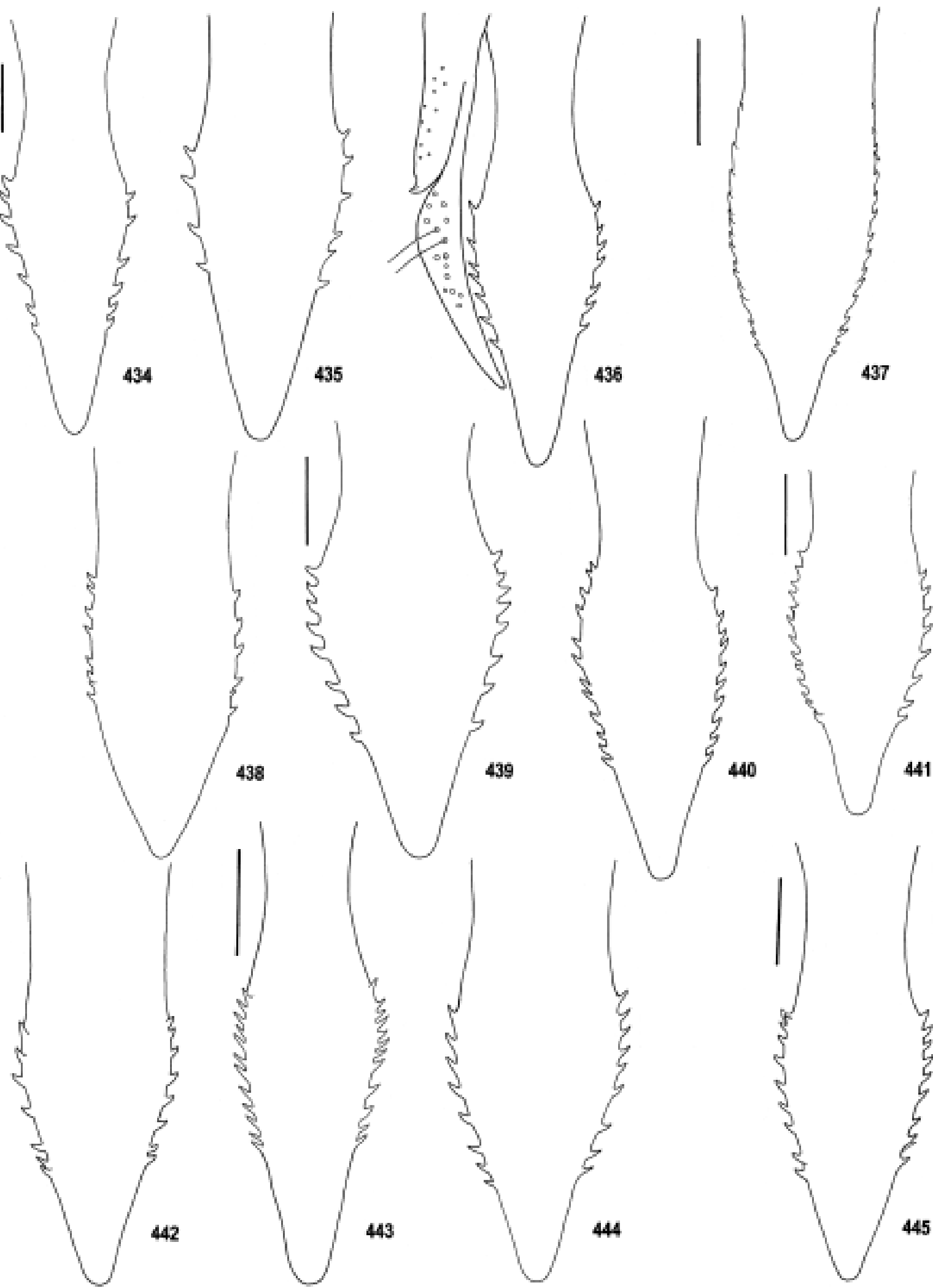

438

439
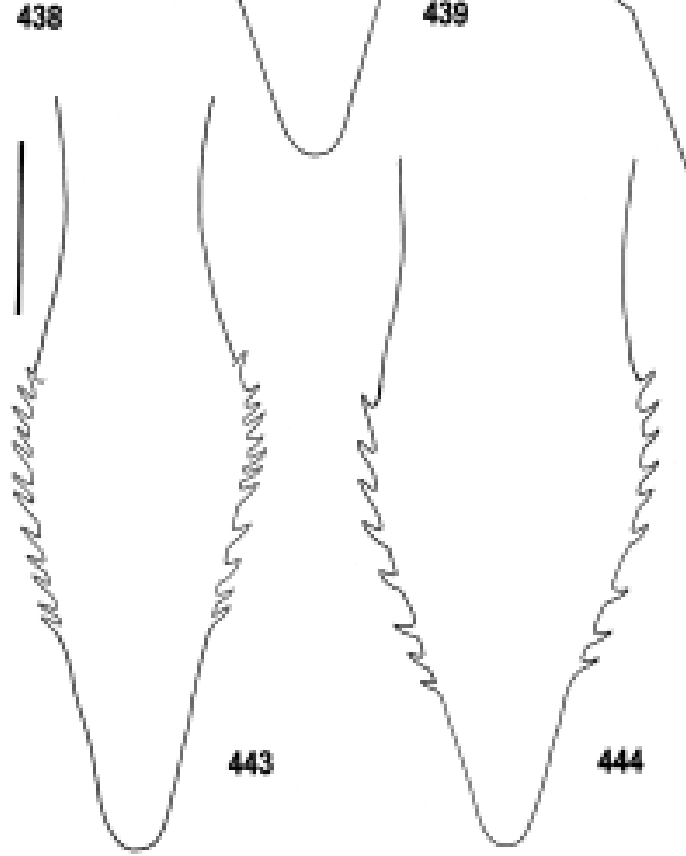

441

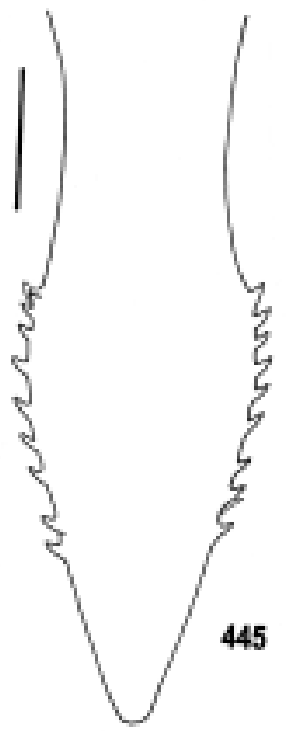

Figs. 434-445. Apex of median lobe: 434, C. eschscholtzi (14-16 Km W S'ntompn, JEWC); 435, C. fabricii (Ibagué, MZSP); 436, C. fasciatus sp. nov. (Holotype); 437, C. inops (Syntype of C. murinus); 438, C. jansoni (K8-13 El Llano-Carti Rd., JEWC); 439, C. lacordairii (Colima, UNAM); 440, C. lafargi (without locality, NHMW); 441, C. limbatus (Linhares, MZSP); 442, C. mocquerysii (Colombia, MZSP); 443, C. morio (Syntype); 444, C. obscurus (Montserrat, USNM); 445, C. porcatus (Itacoatiara, MZSP). Bars $=0.5$ mm. Figs 435, 442, 444, 445; 436, 437, 440; 438, 443, respectively, to the same scale. 


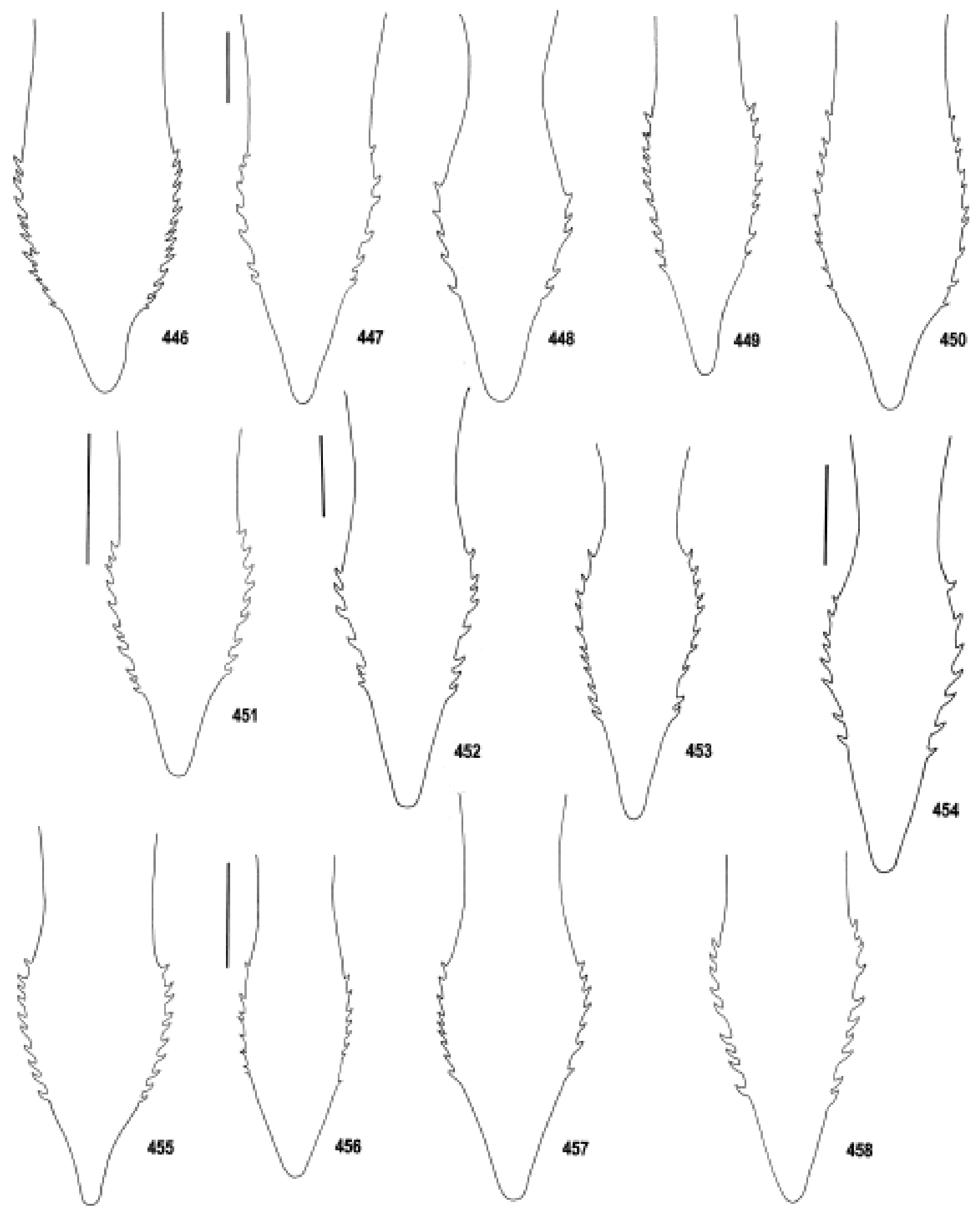

Figs. 446-458. Apex of median lobe: 446, C. rubripennis (California, CMNH); 447, C. rugatus (Sayaaxche, MZSP); 448, C. silbermanni (X-Can, MZSP); 449, C. smaragdinus (Douglas, CMNH); 450, C. tartarus (Yuma, MZSP); 451, C. validus (Dominica, FSCA); 452, C. villei (Rio Bravo Valley, MZSP); 453, C. virens (Reserva Biológica de Cuieiras, MNHN); 454, C. virgatipennis sp. nov. (Holotype); 455, C. virginalis (Tehuatepec, FSCA); 456, C. viridipilis (Jeannette, MZSP); 457, C. webbi (California, MZSP); 458, C. zonatus (Itararé, MZSP). Bars $=0.5$ mm. Figs 446, 456, 457; 448, $449,454,457 ; 450,452,453,455,458$, respectively, to the same scale. 

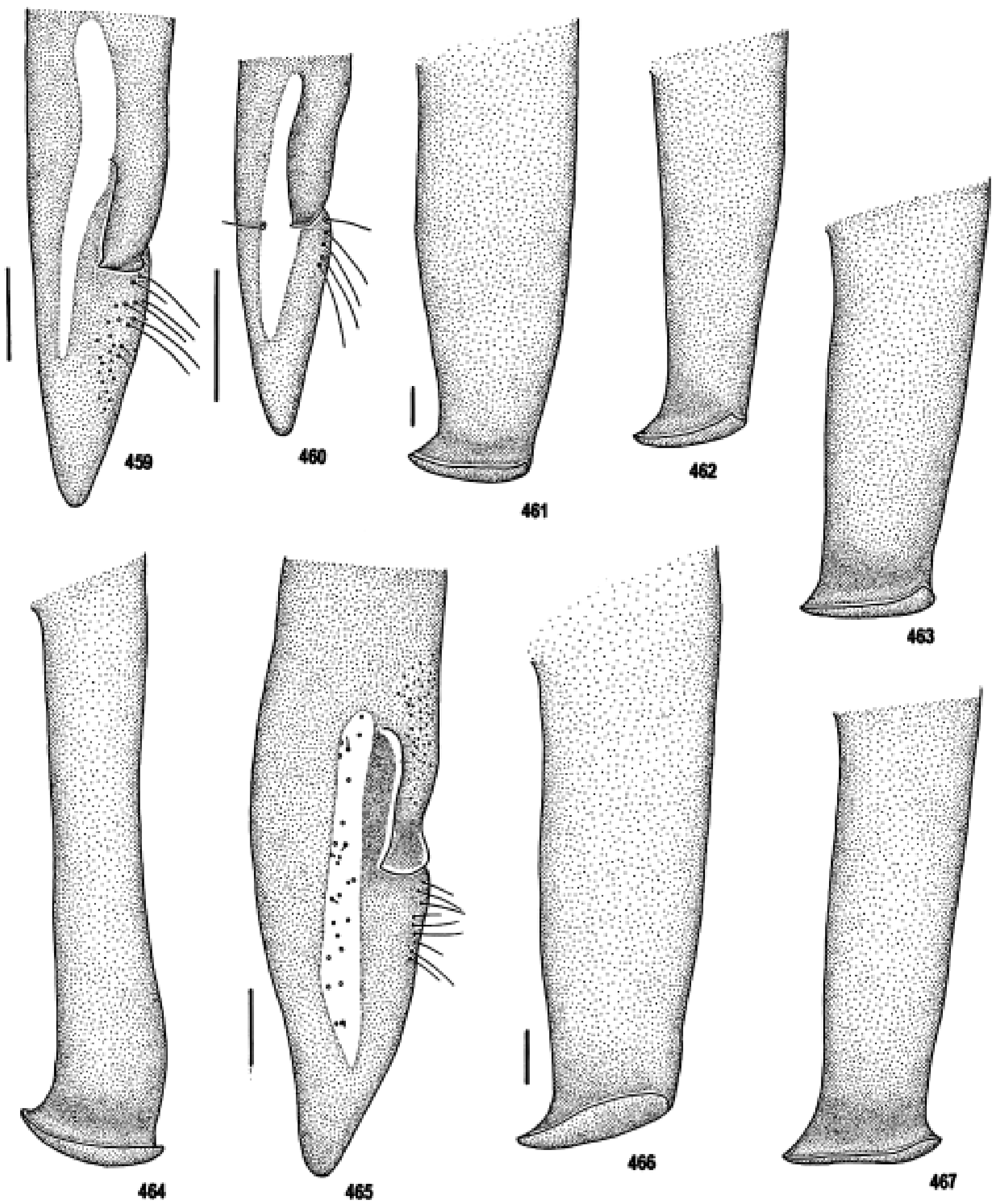

Figs. 459-467. Apex of lateral cleft of parameres: 459, C. angustatus (Syntype); 460, C. apacheanus (without locality, MZSP); 461, C. approximatus (Tenancingo, MZSP); 462, C. aurulentus (Ichila, FSCA); 463, C. bomplandii (San Quintin, MZSP); 464, C. boucardi (Presa El Caracol, UNAM); 465, C. chalcantheus (Niquelândia, MZSP); 466, C. corpulentus (Carquejo, MZSP); 467, C. cyaneus (Los Angeles Tucuco, MZSP). Bars $=0.05 \mathrm{~mm}$, except Figs. 459, 460, $465=0.25$ mm. Figs. 461-463, 467; 464, 466, respectively, to the same scale. 

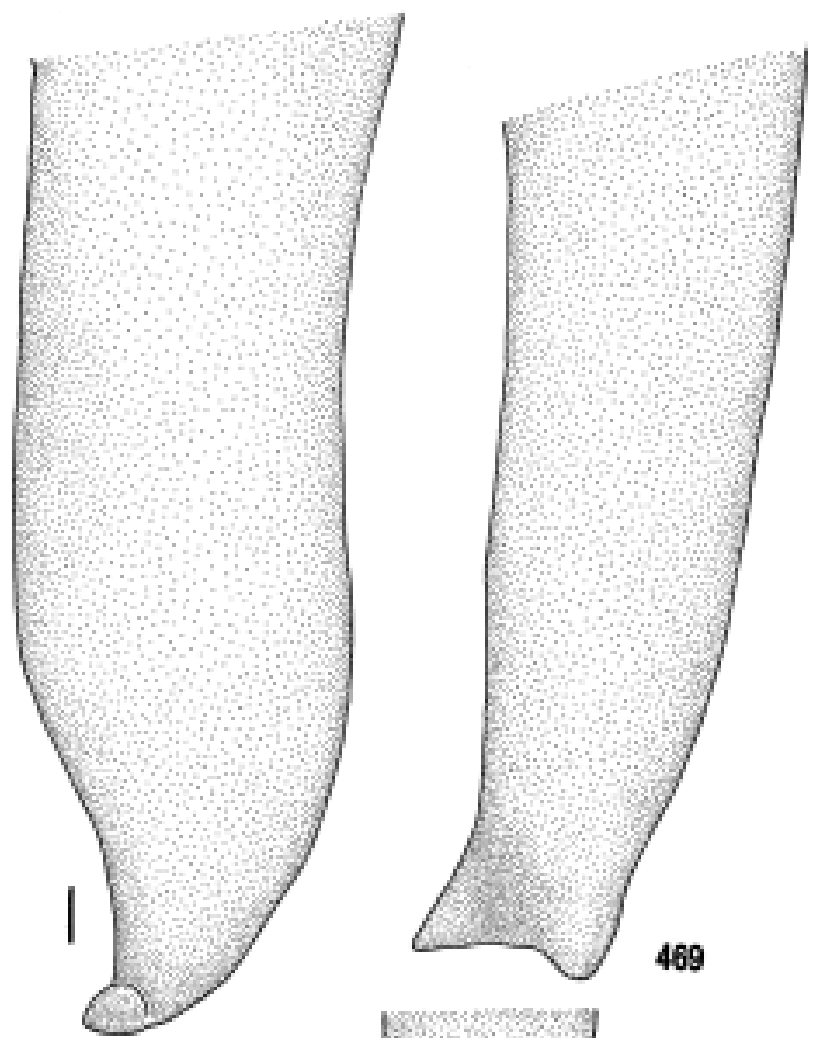

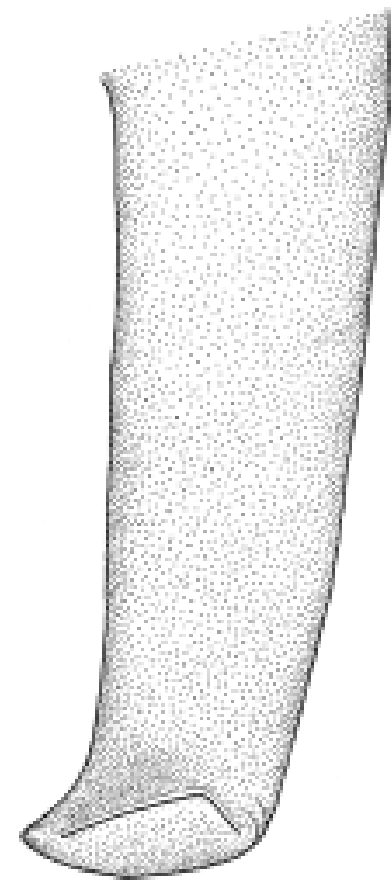

470

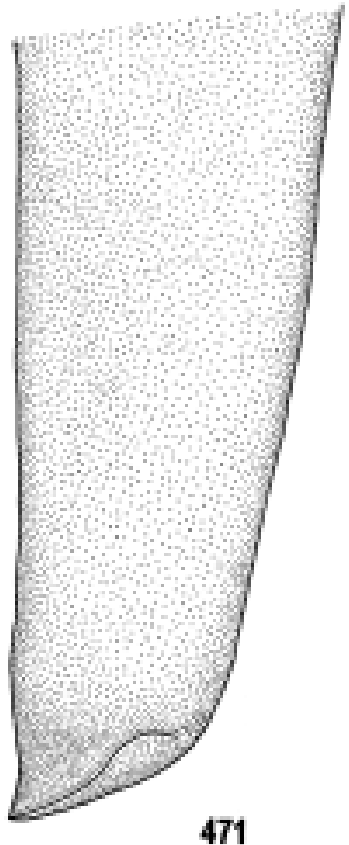

471
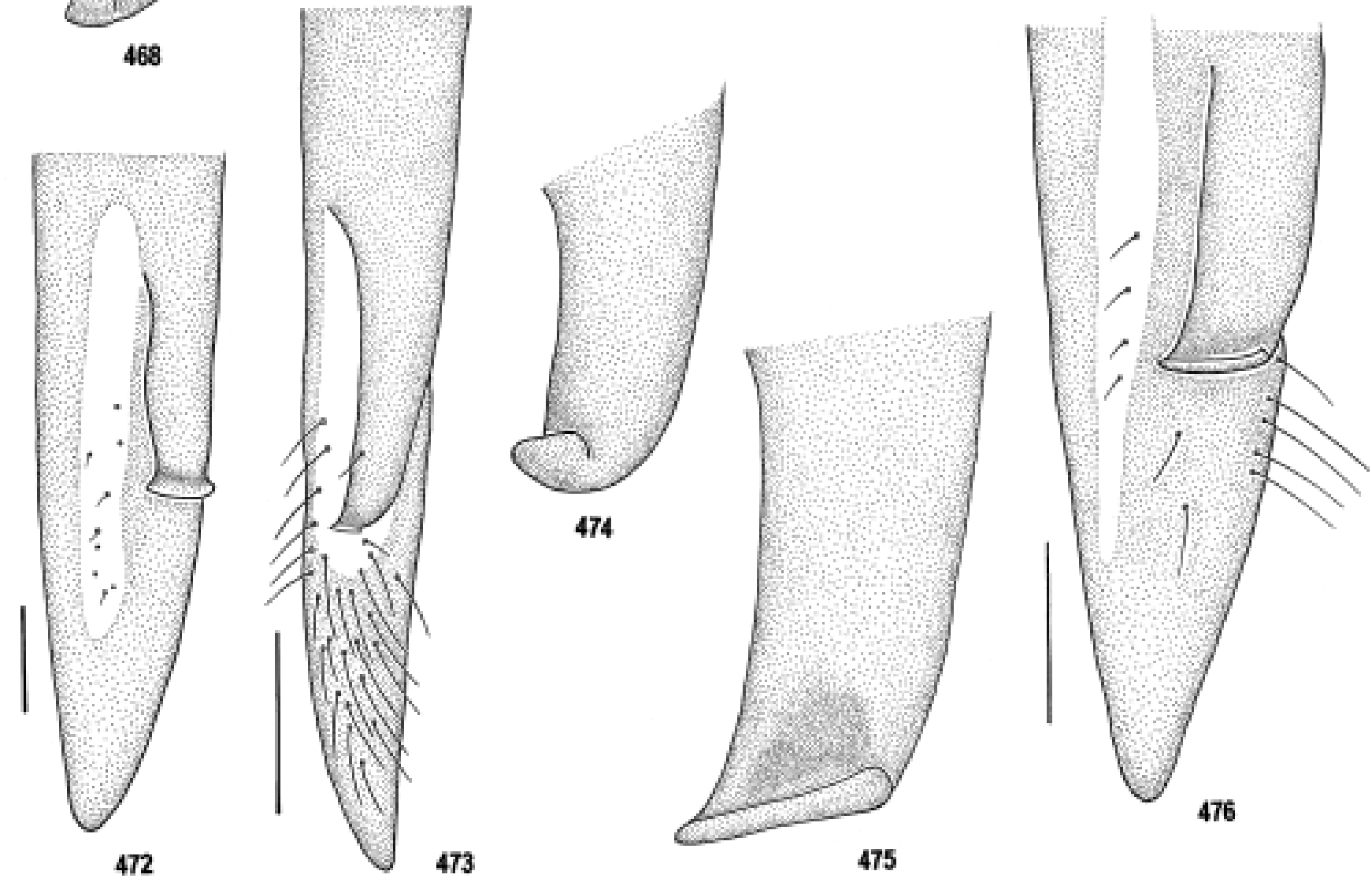

Figs. 468-476. Apex of lateral cleft of parameres: 468, C. desmarestii (Tlocnuil, MZSP); 469, C. erythroloma (Honolulu, MZSP); 470, C. eschscholtzi (14-16 Km W S'ntompn, JEWC); 471, C. fabricii (Ibagué, MZSP); 472, C. fasciatus sp. nov. (Holotype); 473, C. inops (Syntype of $C$. murinus); 474, C. jansoni (K8-13 El Llano-Carti Rd., JEWC); 475, C. lacordairii (Colima, UNAM); 476, $C$. lafargi (without locality, NHMW). Bars $=0.05 \mathrm{~mm}$, except Figs. 472, 473, $476=0.25 \mathrm{~mm}$. Figs. 468- 471, 474, 475, to the same scale. 


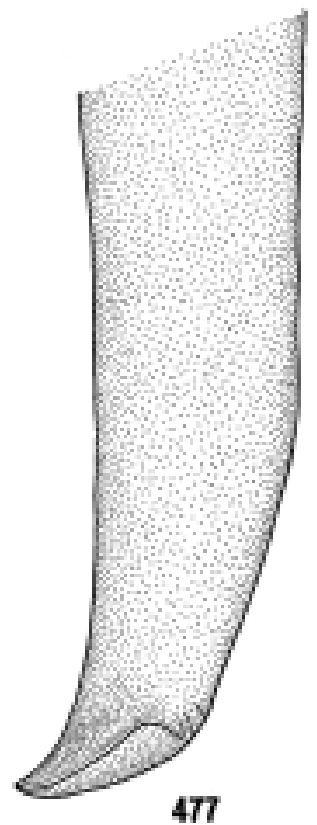

477

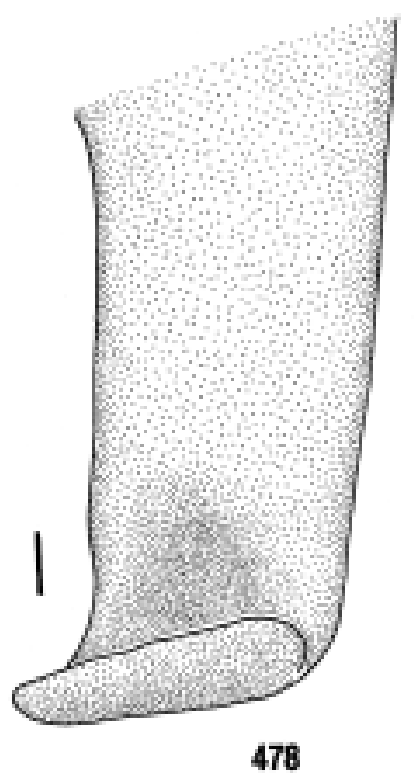

478

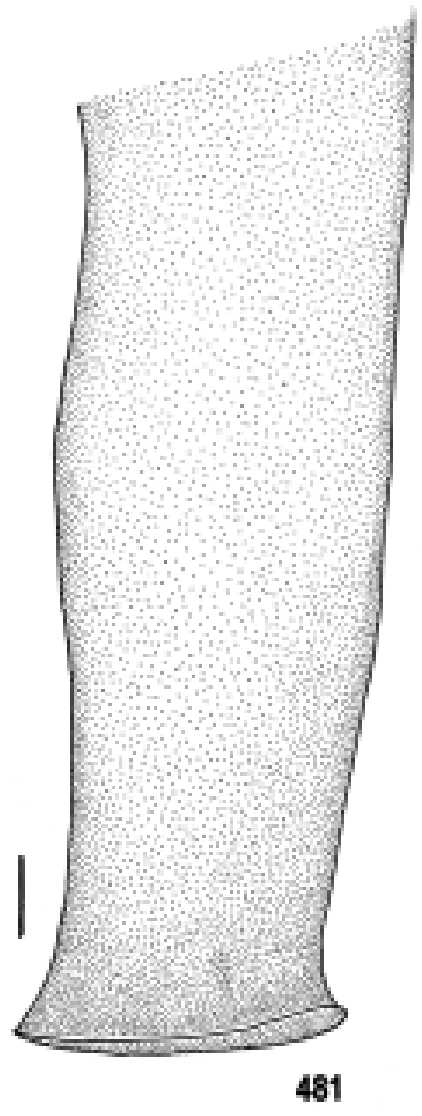

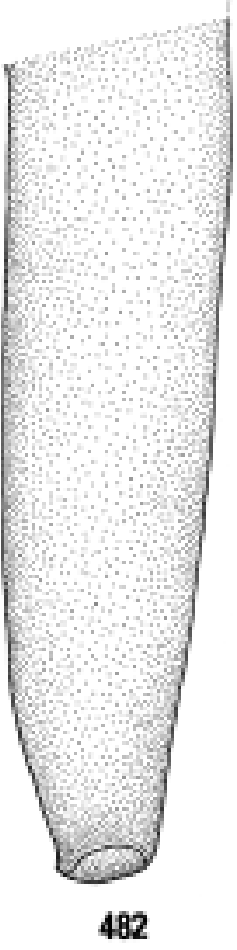

483

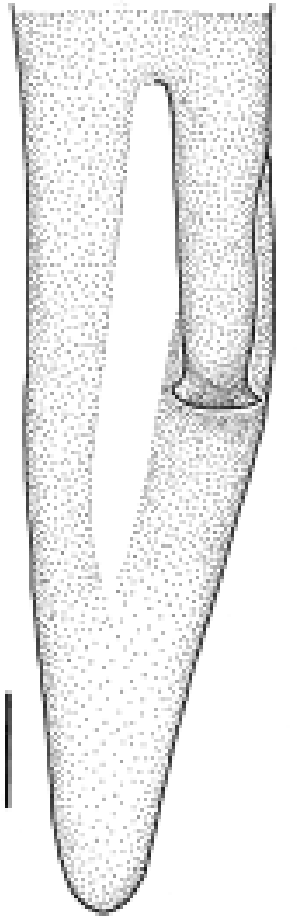

479
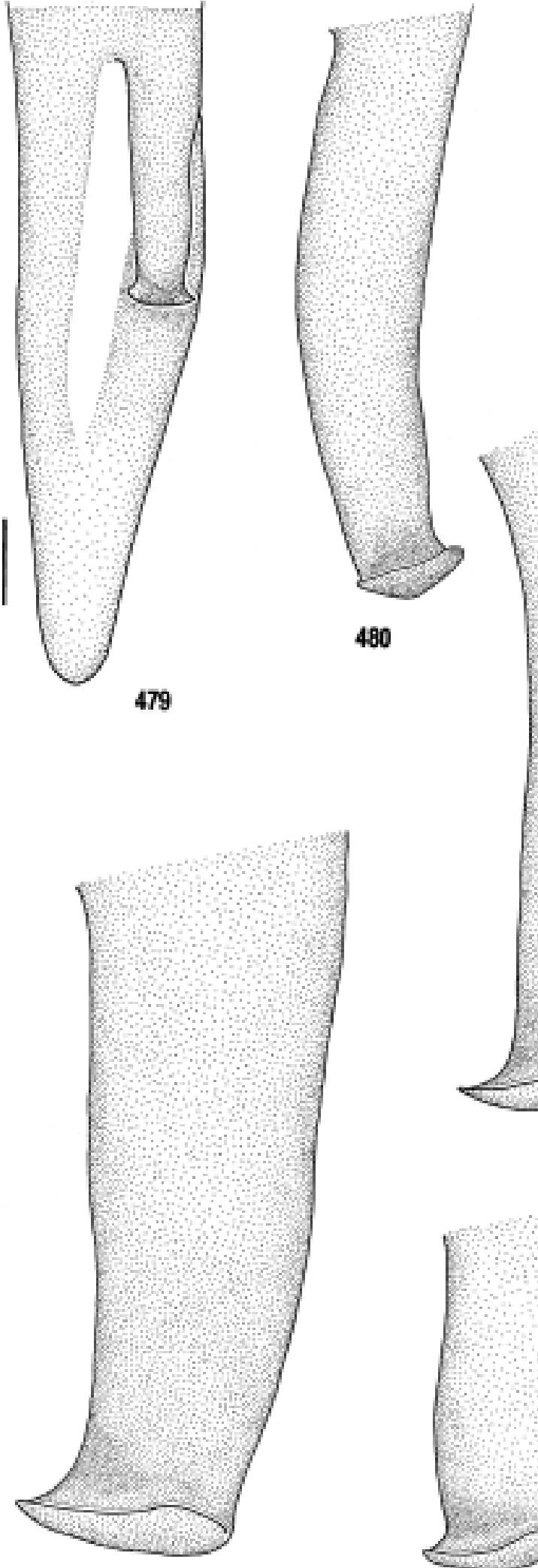

Figs. 477-485. Apex of lateral cleft of parameres: 477, C. limbatus (Linhares, MZSP); 478, C. mocquerysii (Colombia, MZSP); 479, C. morio (Syntype); 480, C. obscurus (Montserrat, USNM); 481, C. porcatus (Itacoatiara, MZSP); 482, C. rubripennis (California, CMNH); 483, C. rugatus (Sayaaxche, MZSP); 484, C. silbermanni (X-Can, MZSP); 485, C. smaragdinus (Douglas, CMNH). Bars $=0.05 \mathrm{~mm}$, except Fig. $479=0.25 \mathrm{~mm}$. Figs. $477,478,480,484 ; 481-483,485$, respectively, to the same scale. 

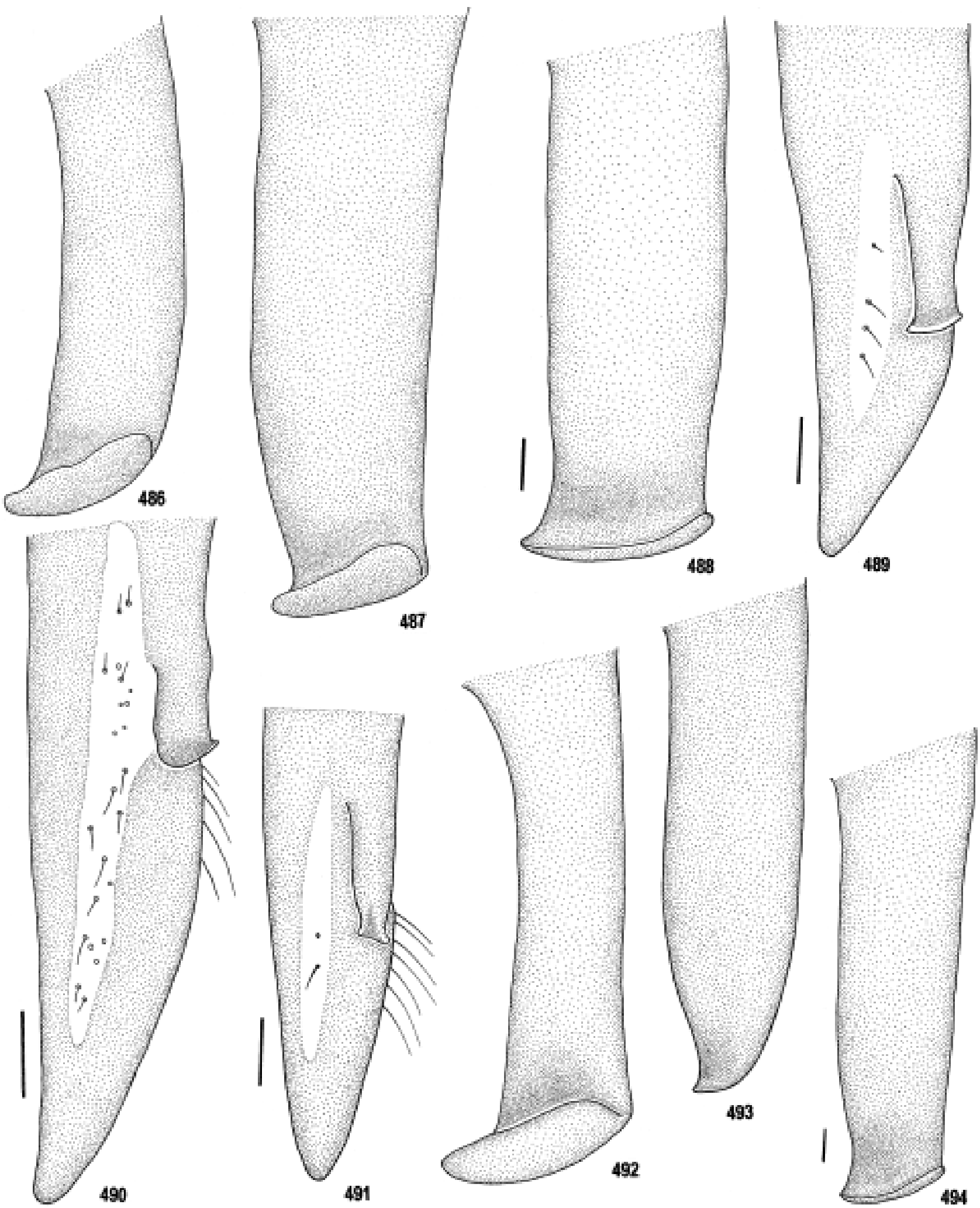

487
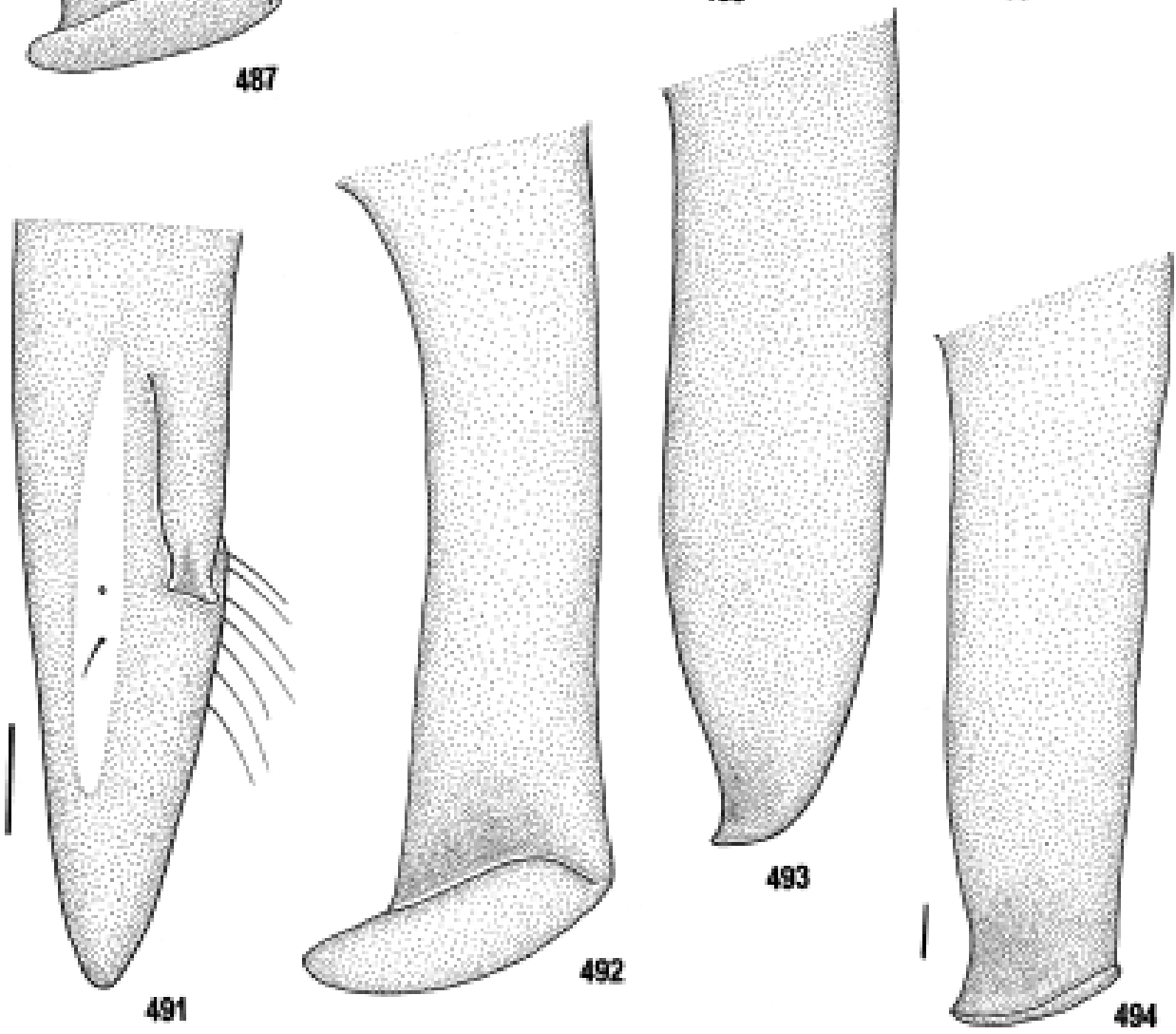

Figs. 486-494. Apex of lateral cleft of parameres: 486, C. tartarus (Yuma, MZSP); 487, C. validus (Dominica, FSCA); 488, C. villei (Rio Bravo Valley, MZSP); 489, C. virens (Reserva Biológica de Cuieiras, MNHN); 490, C. virginalis (Tehuatepec, FSCA); 491, C. virgatipennis sp. nov. (Holotype); 492, C. viridipilis (Jeannette, MZSP); 493, C. webbi (California, MZSP); 494, C. zonatus (Itararé, MZSP). Bars $=0.05 \mathrm{~mm}$, except Figs. $489-491=0.25 \mathrm{~mm}$. Figs. 486, 487, 488, 492; 493, 494, respectively, to the same scale. 

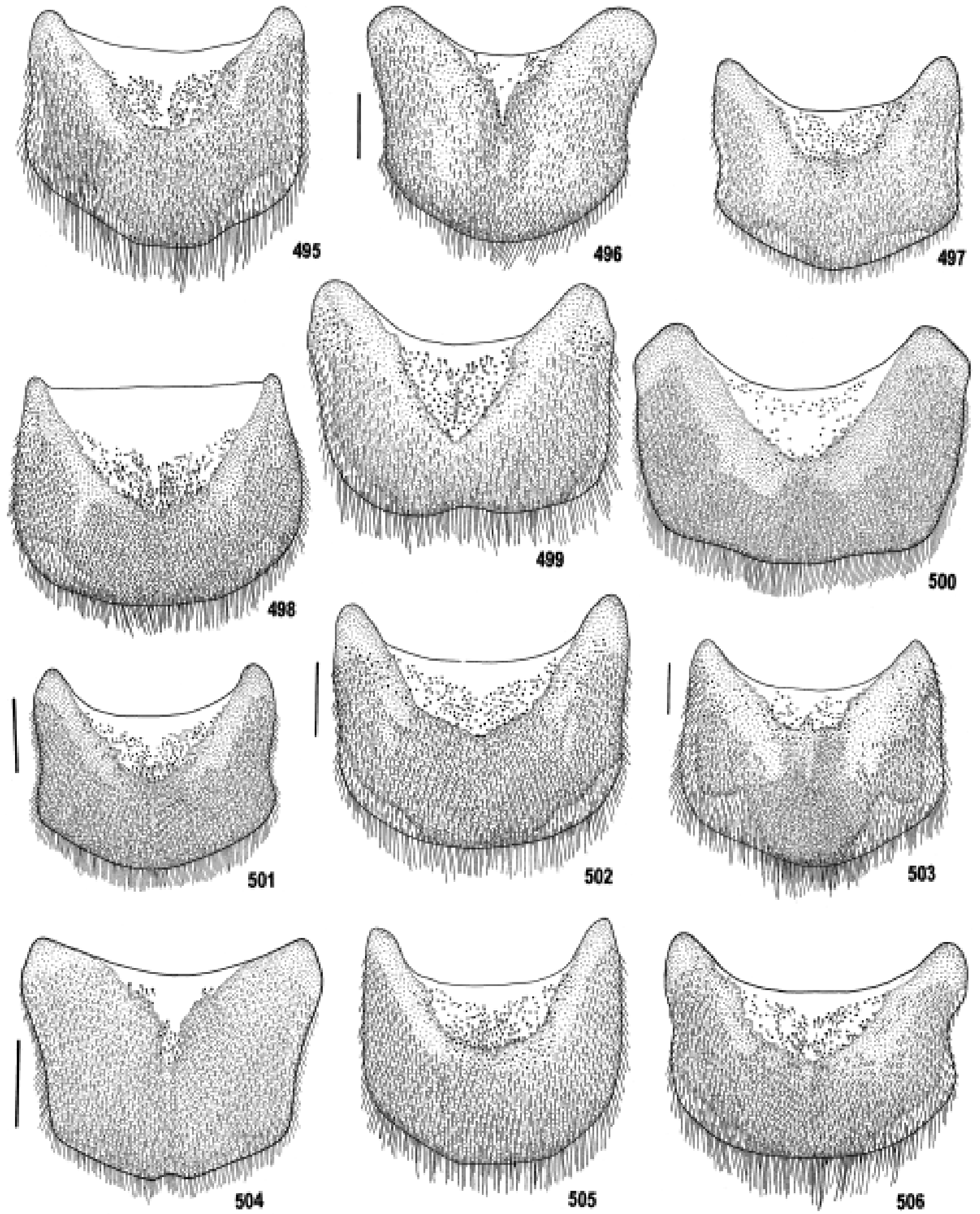

Figs. 495-506. Tergite VIII of female: 495, C. apacheanus (Arizona, CMNH); 496, C. attenuatus (14 Km Huautla-Jojutla, MZSP); 497, C. approximatus (El Limon, MZSP); 498, C. bomplandii (Sayaaxche, MZSP); 499, C. boucardi (Presa El Caracol, UNAM); 500, C. chalcantheus (Rondonópolis, MZSP); 501, C. corpulentus (Carquejo, MZSP); 502, C. cyaneus (Merida, USNM); 503, C. desmarestii (6 Km E Purulha, MZSP); 504, C. dugesi (Tepic, ZMHB); 505, C. erythroloma (Balzapampa, MZSP); 506, C. eschscholtzi (Finca San Carlos, MZSP). Bars $=1 \mathrm{~mm}$. Figs. 495$497,499,500 ; 489,503,505,506$, respectively, to the same scale. 

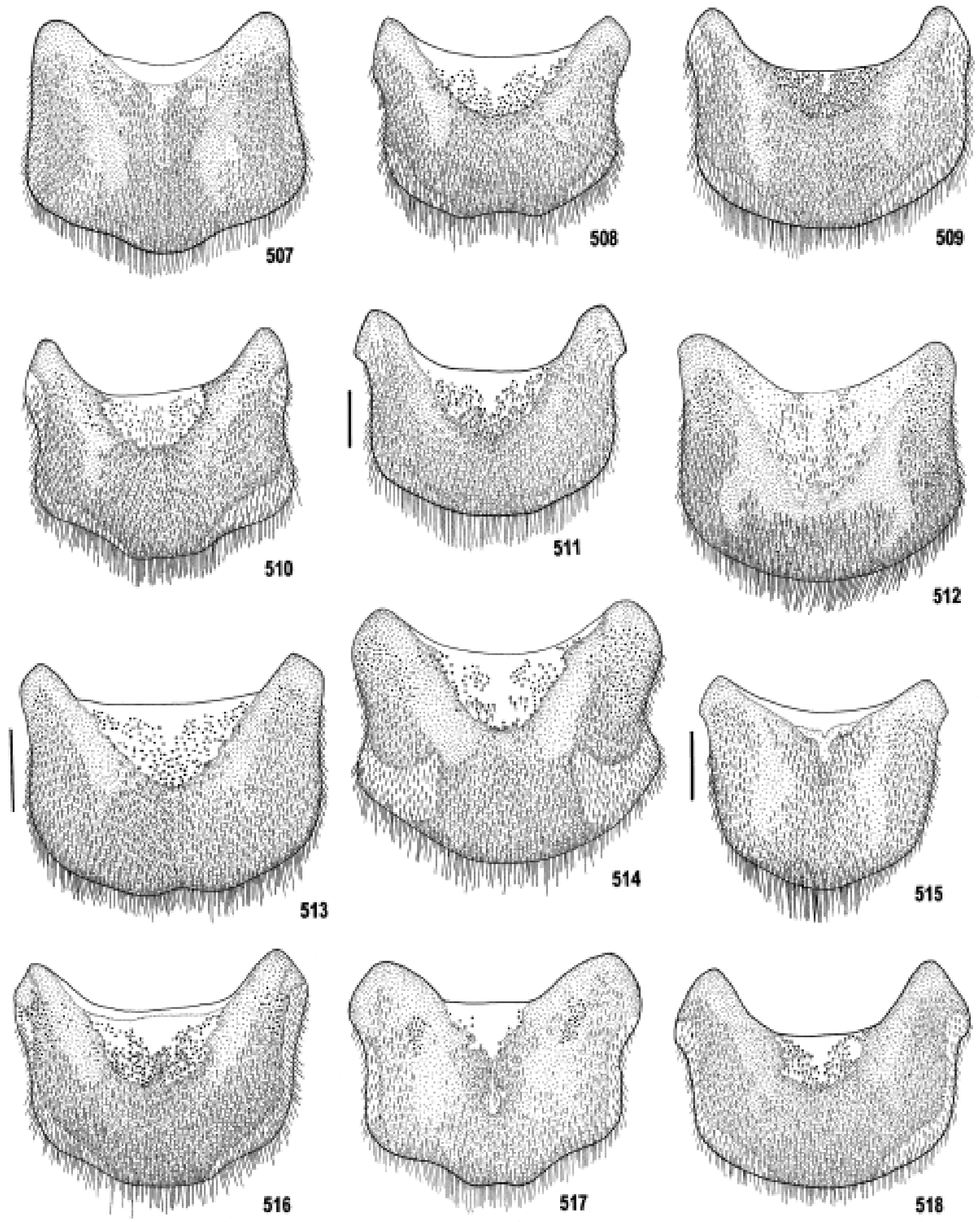

Figs. 507-518. Tergite VIII of female: 507, C. extenuatuvittatus sp. nov. (Paratype); 508, C. fabricii (Território Vásquez, MZSP); 509, C. fasciatus sp. nov. (Paratype); 510, C. forreri (Isla Maria Madre, UNAM); 511, C. fryi (Trujillo, USNM); 512, C. gossipiatus (El Espinal, MZSP); 513, C. inops (51 Km Ixtapa, FSCA); 514, C. jansoni (Hamburg Farm, USNM); 515, C. lenzi (Arizona, CMNH); 516, C. limbatus (Linhares, MZSP); 517, C. mexicanus (Miranda, PCCV); 518, C. pruinosus (Mexico, USNM). Bars $=1 \mathrm{~mm}$. Figs 507, 508, 510-512, 518; 509, 514-517, respectively, to the same scale. 

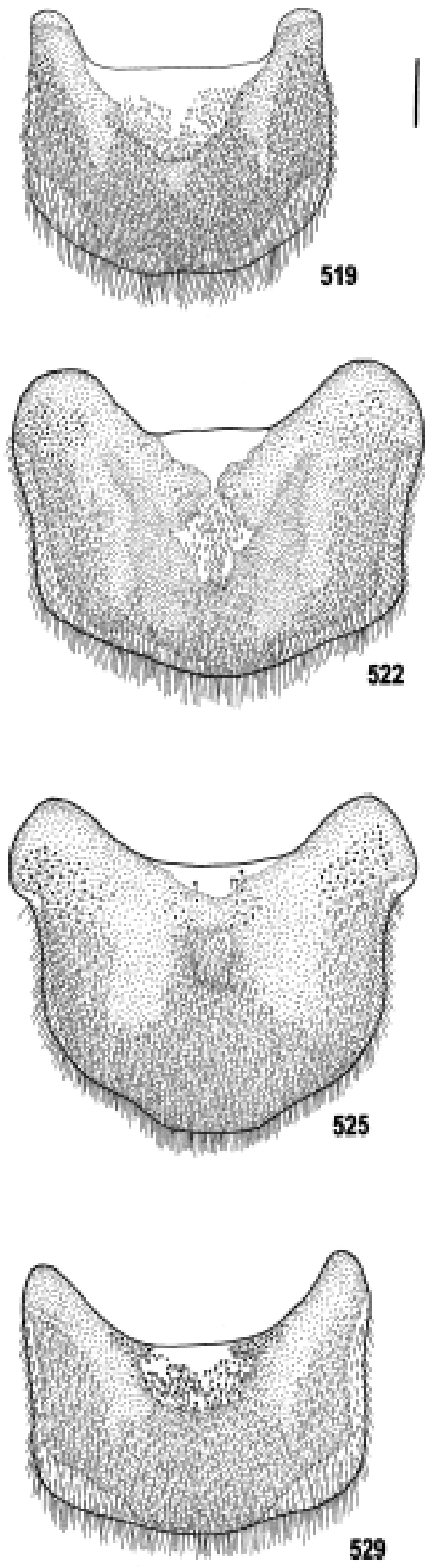

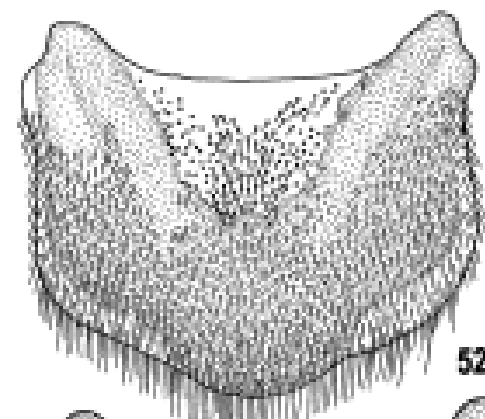

520
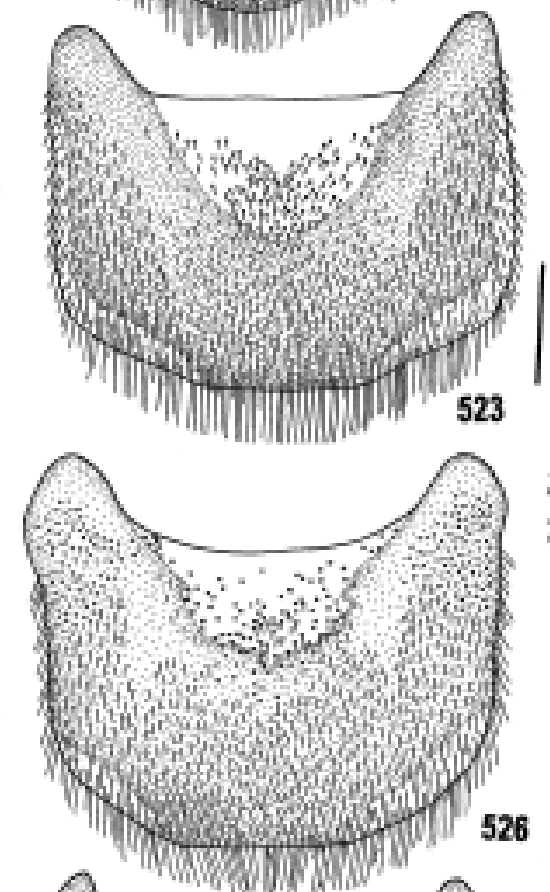

526

528

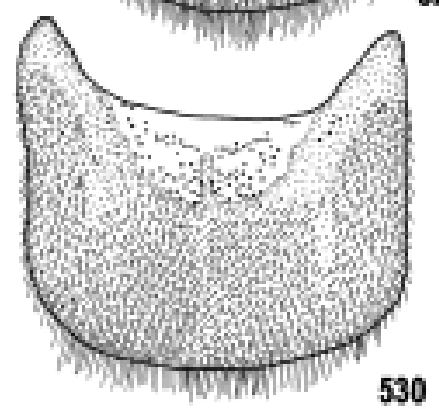

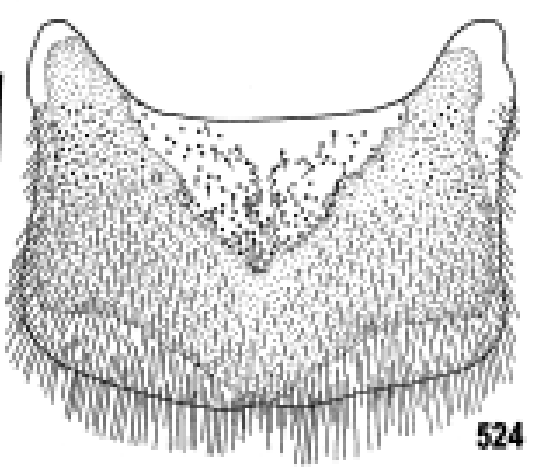
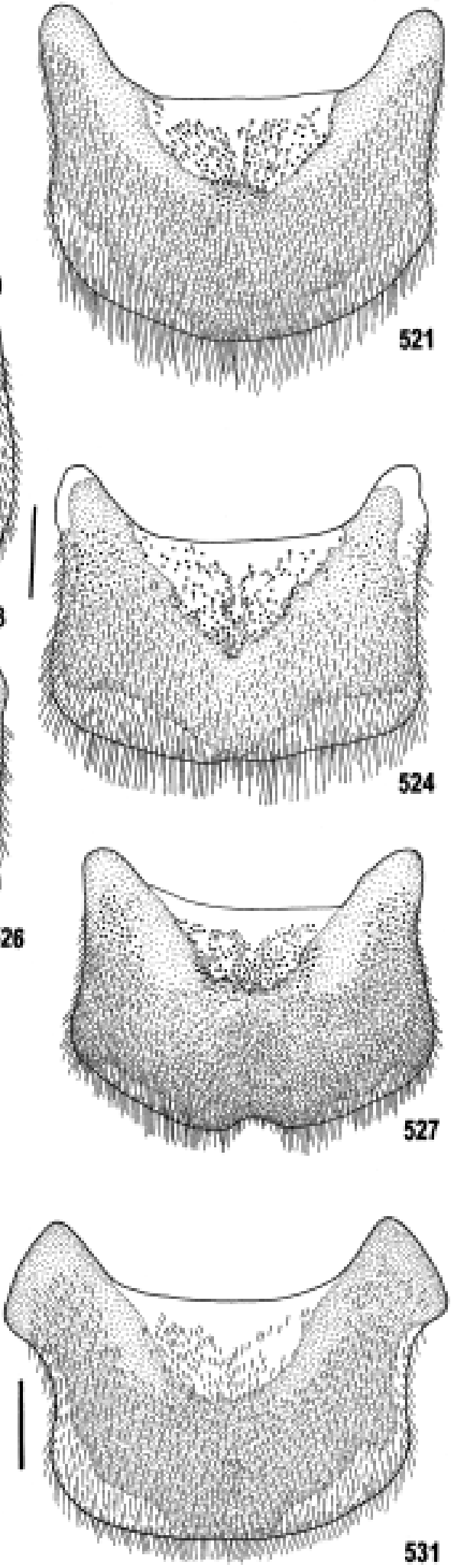

Figs. 519-531. Tergite VIII of female: 519, C. rostainei (Óbidos, MZSP); 520, C. rubripennis (Puerto Batlandra, MZSP); 521, C. rugatus (Solferino, MZSP); 522, C. serricornis sp. nov. (Paratype); 523, C. silbermanni (Sayaaxche, MZSP); 524, C. smaragdinus (Douglas, CMNH); 525, C. spinipennis sp. nov. (Paratype); 526, C. sulcatus (Saint Croix, MZSP); 527, C. validus; 528, C. villei (Medio Calima, MZSP); 529, C. virgatipennis sp. nov. (Paratype); 530, C. virens (Itacoatiara, MZSP); 531, C. virginalis (Guaymas, MCZC). Bars = 1 mm. Figs 519, 520, 522, 525, 527, 528; 521, $529,530,531 ; 523,524,526$, respectively, to the same scale. 

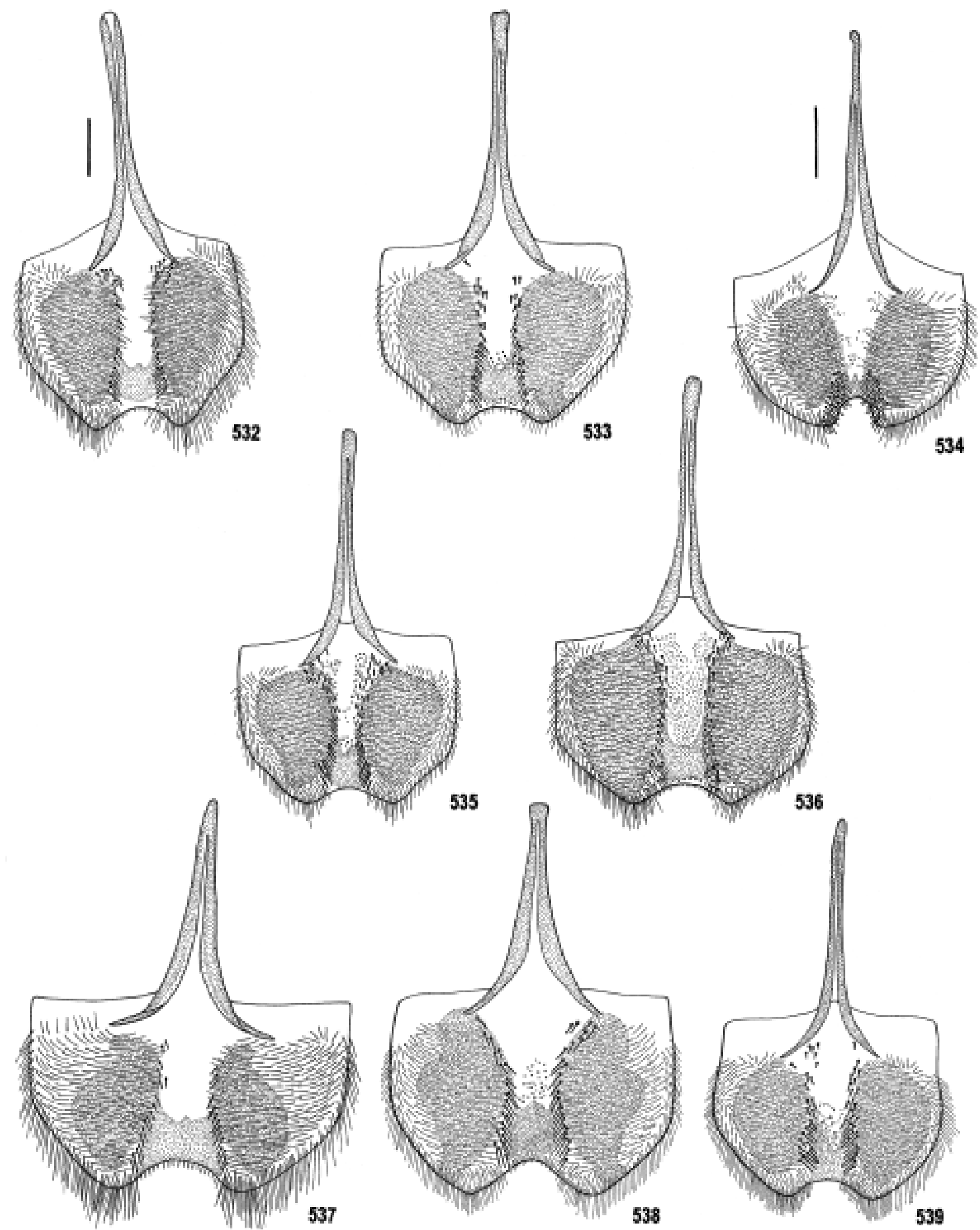

Figs. 532-539. Tergite VIII of female: 532, C. apacheanus (Arizona, CMNH); 533, C. approximatus (El Limon, MZSP); 534, C. attenuatus (14 Km Huautla-Jojutla, MZSP); 535, C. aurulentus (Chaparé, MZSP); 536, C. bomplandii (Sayaaxche, MZSP); 537, C. boucardi (Colima, USNM); 538, C. chalcantheus (Rondonópolis, MZSP); 539, C. corpulentus (Carquejo, MZSP). Bars = 1 mm. Figs 532, 535, 536; 533, 534, 537-539, respectively, to the same scale. 


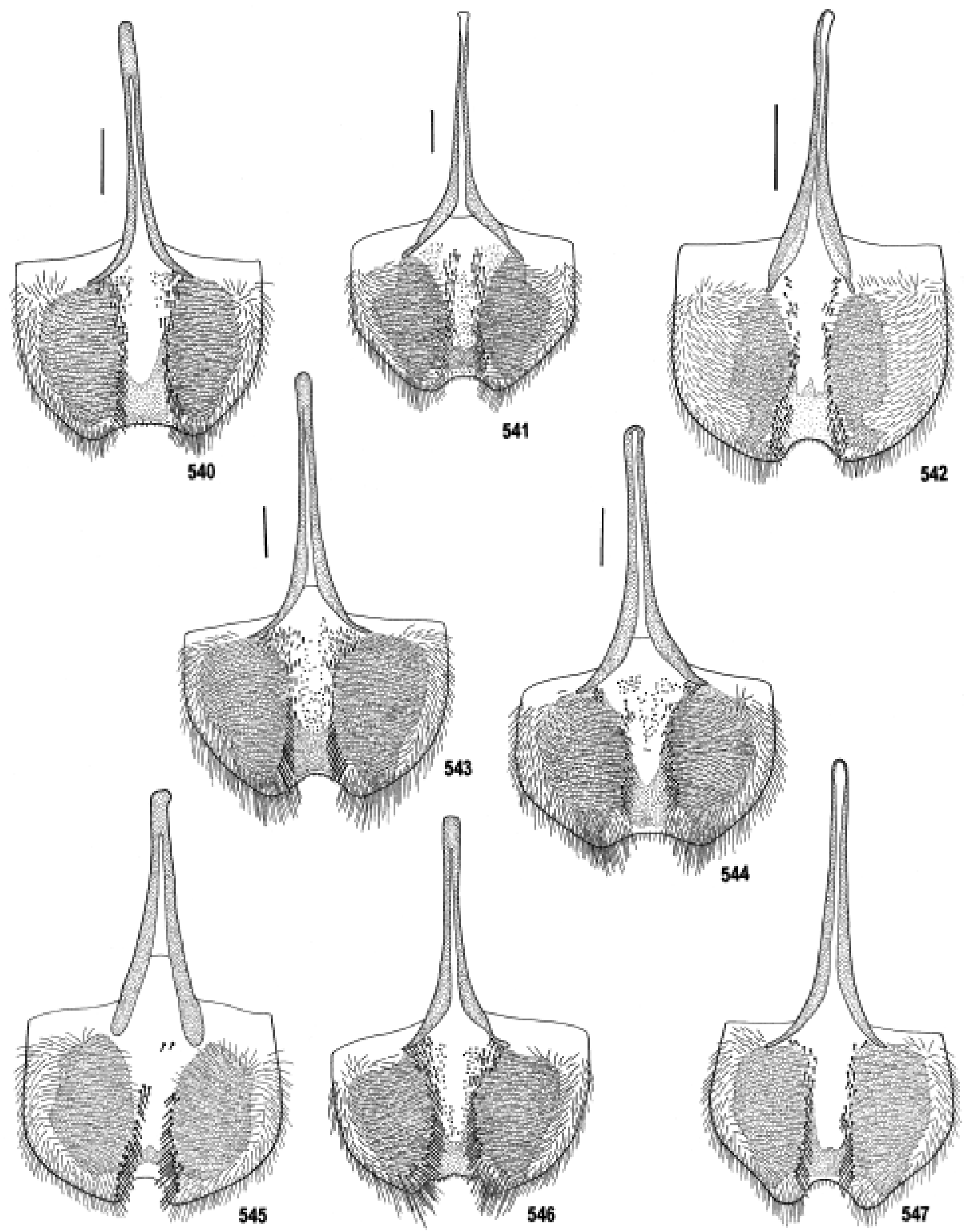

Figs. 540-547. Tergite VIII of female: 540, C. cyaneus (Merida, USNM); 541, C. desmarestii (6 Km E Purulha, MZSP); 542, C. dugesi (Tepic, ZMHB); 543, C. erythroloma (Balzapampa, MZSP); 544, C. eschscholtzi (Finca San Carlos, MZSP); 545, C. extenuatuvittatus sp. nov. (Paratype); 546, C. fabricii (Território Vásquez, MZSP); 547, C. fasciatus sp. nov. (Paratype). Bars = 1 mm. Figs 540, 547; 543, 545, 546, respectively, to the same scale. 


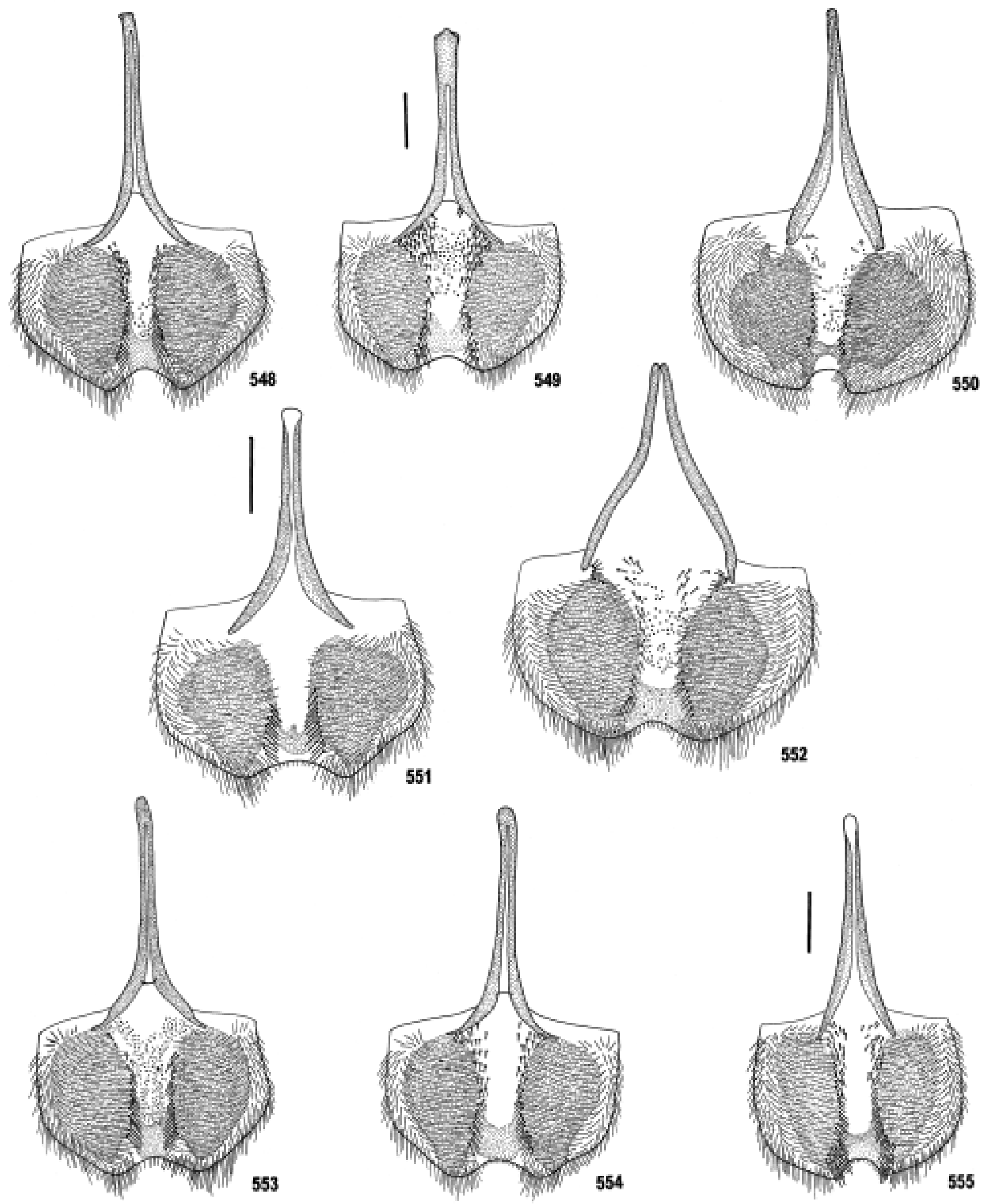

Figs. 548-555. Tergite VIII of female: 548, . forreri (Isla Maria Madre, UNAM); 549, C. fryi (Trujillo, USNM); 550, C. gossipiatus (El Espinal, MZSP); 551, C. inops (51 Km Ixtapa, FSCA); 552, C. jansoni (Hamburg Farm, USNM); 553, C. lacordairii (San Jeronimo, MZSP); 554, C. lafargi; 555, C. lenzi (Arizona, CMNH). Bars $=1 \mathrm{~mm}$. Figs 548-550, 553, 554; 552, 555, respectively, to the same scale. 


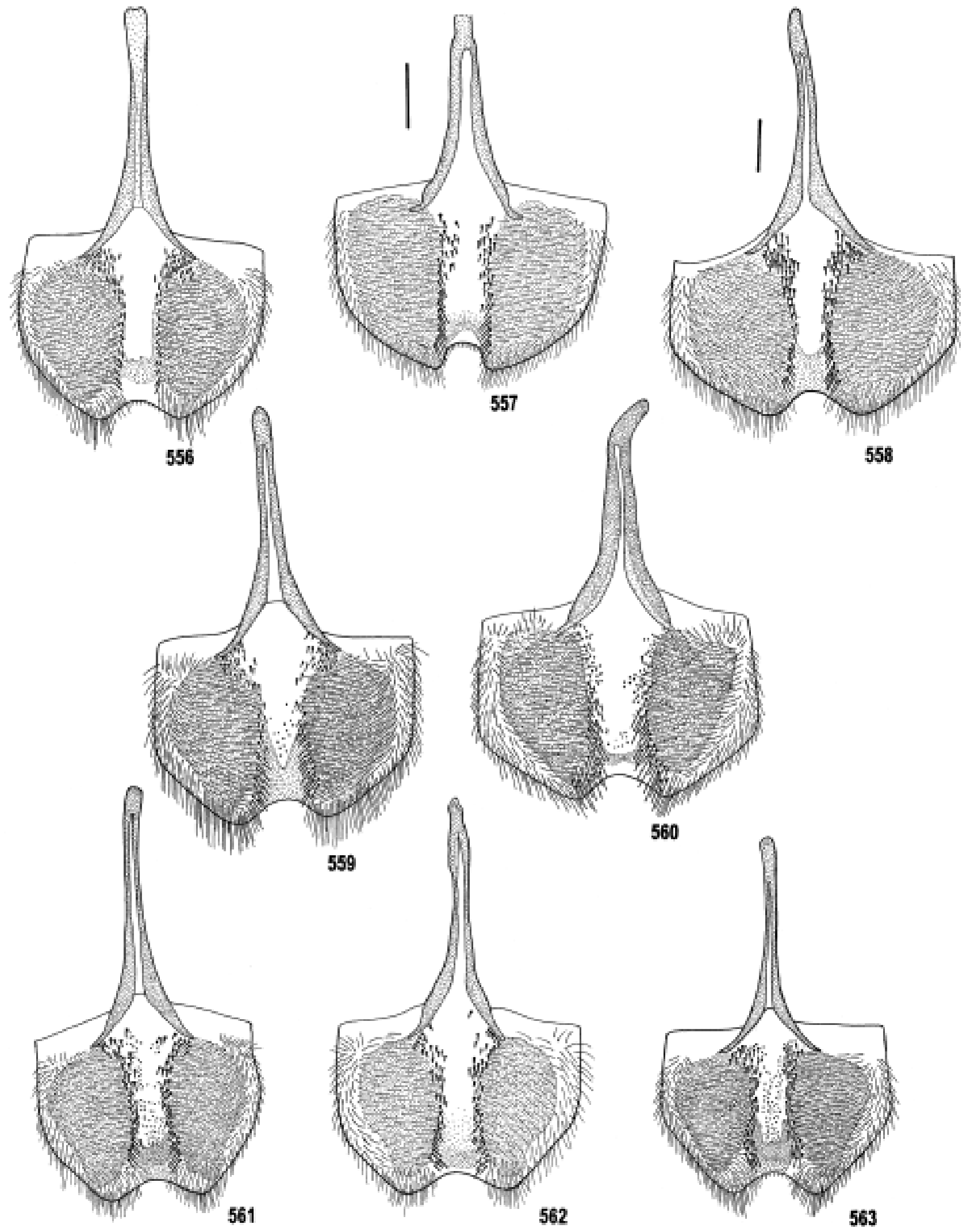

Figs. 556-563. Tergite VIII of female: 556, C. limbatus (Linhares, MZSP); 557, C. mexicanus (Miranda, PCCV); 558, C. mocquerysii (Estacion Agricola Experimental Palmira, USNM); 559, C. obscurus (Antilles, USNM); 560, C. oxydatus (Rizo de Oro, UNAM); 561, C. porcatus (Estação Codemat, INPA); 562, C. pruinosus (Mexico, USNM); 563, C. rostainei (Óbidos, MZSP). Bars = $1 \mathrm{~mm}$. Figs 556, 557, 559, 560; 558, 561-563, respectively, to the same scale. 


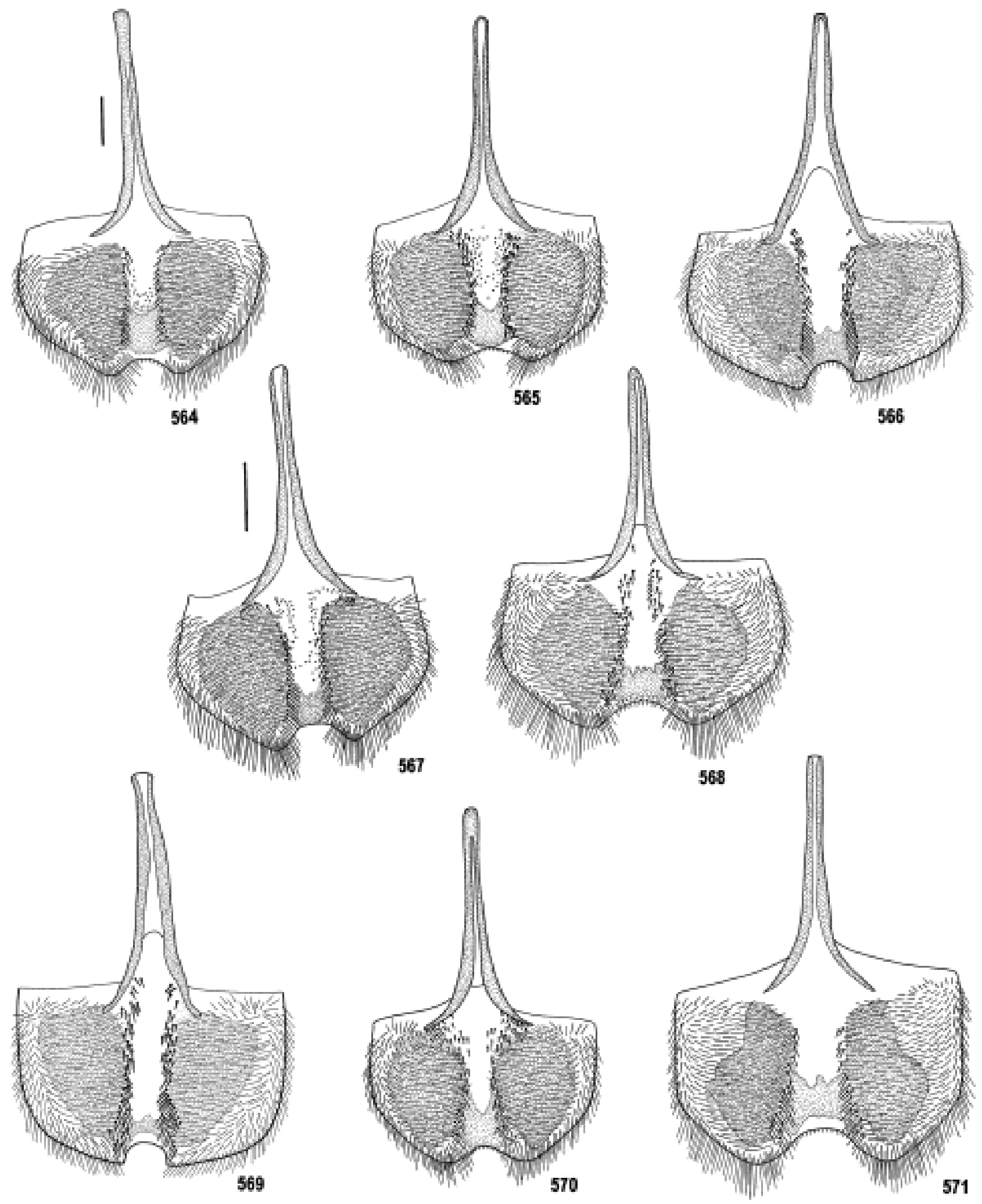

Figs. 564-571. Tergite VIII of female: 564, C. rubripennis (Puerto Batlandra, MZSP); 565, C. rugatus (Solferino, MZSP); 566, C. serricornis sp. nov. (Paratype); 567, C. silbermanni (Sayaaxche, MZSP); 568, C. smaragdinus (Douglas, CMNH); 569, C. spinipennis sp. nov. (Paratype); 570, C. sulcatus (Saint Croix, MZSP); 571, C. tartarus (F, Laguna Lake, MZSP). Bars = $1 \mathrm{~mm}$. Figs 564-566, 569; 567, 568, 570, 571, respectively, to the same scale. 

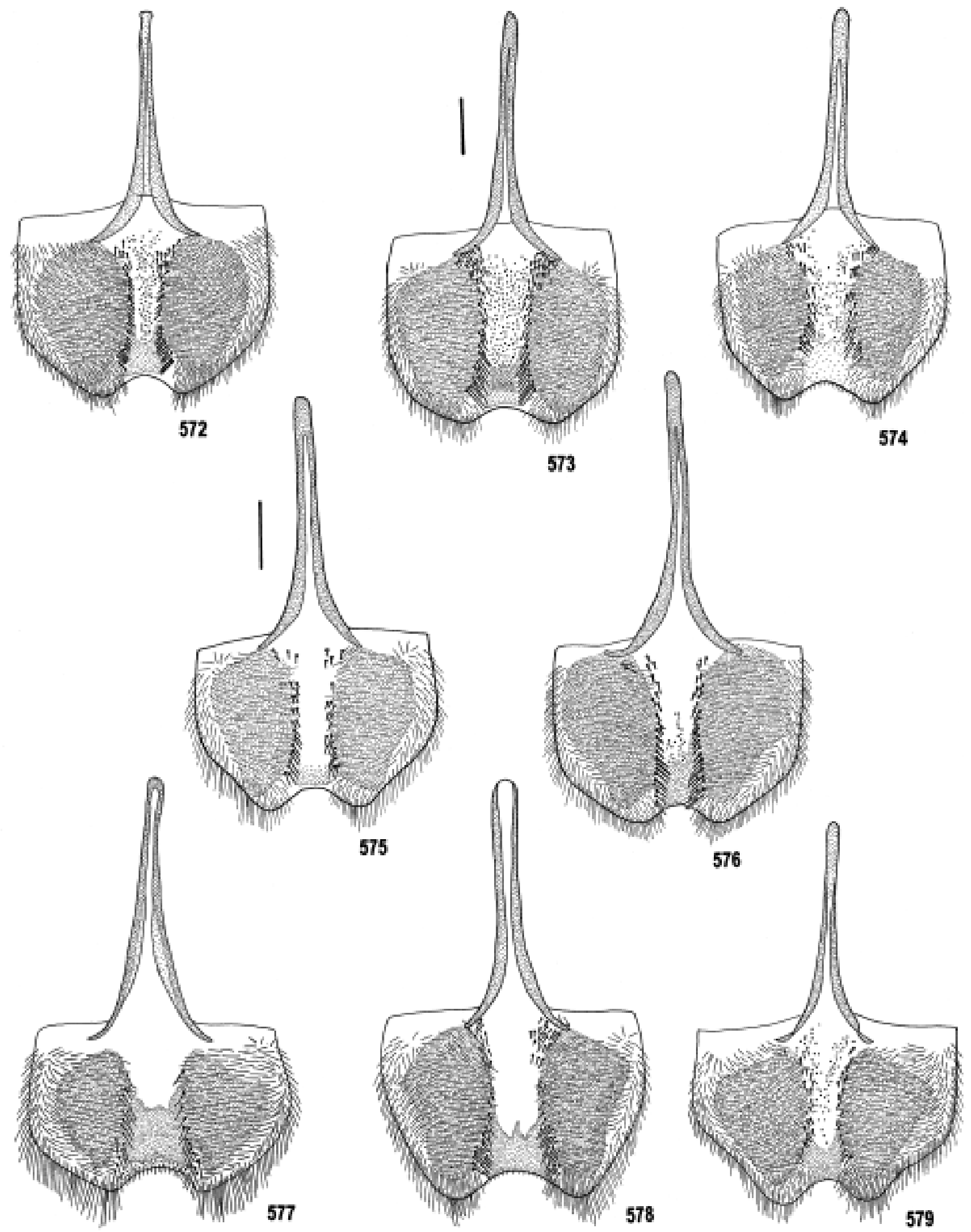

Figs. 572-579. Tergite VIII of female: 572, C. validus; 573, C. villei (Medio Calima, MZSP); 574, C. virens (Itacoatiara, MZSP); 575, C. virgatipennis sp. nov. (Paratype); 576, C. virginalis (Guaymas, MCZC); 577, C. viridipilis (Pennsylvania, MZSP); 578, C. webbi (Bill Williams Fork, MZSP); 579, C. zonatus (Ilha de Buzios, MZSP). Bars $=1 \mathrm{~mm}$. Figs 572, 573, 576, 578, 579; 574, 575, 577, respectively, to the same scale. 

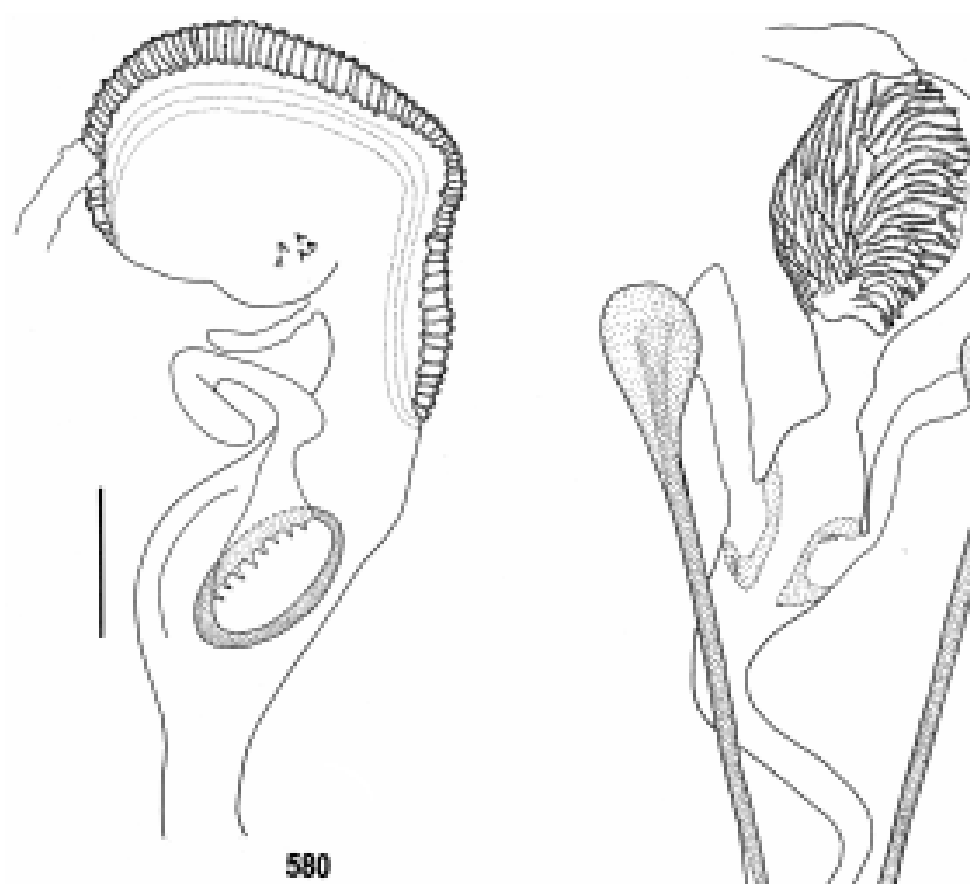

580
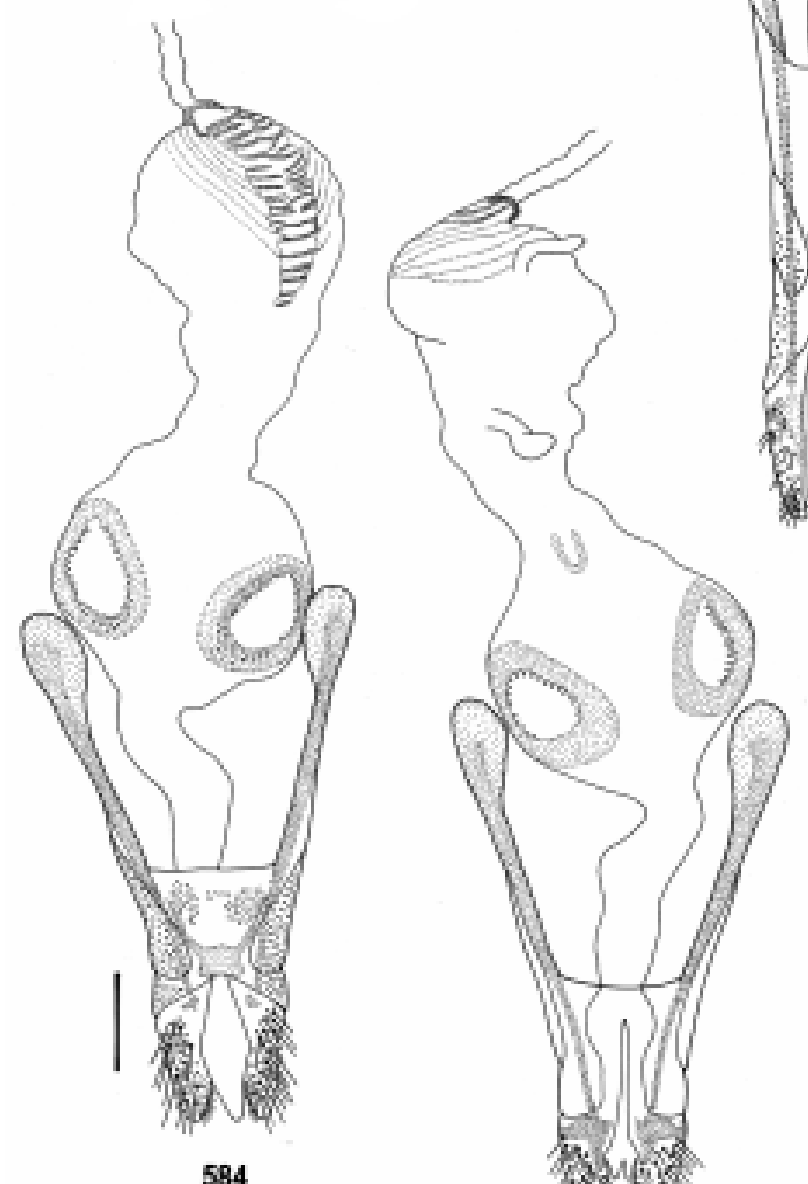

584

Figs. 580-587. Female genitalia: 580, C. apacheanus (lateral) (Arizona, CMNH); 581, 582, C. attenuatus (ventral, dorsal) (14 Km Huautla-Jojutla, MZSP); 583, C. boucardi (ventral) (Colima, USNM); 584, 585, C. chalcantheus (ventral, dorsal) (Rondonópolis, MZSP); 586, 587, C. corpulentus (ventral, dorsal) (Carquejo, MZSP). Bars $=1 \mathrm{~mm}$. Figs 580, 581; 583-585; 586, 587, respectively, to the same scale. 

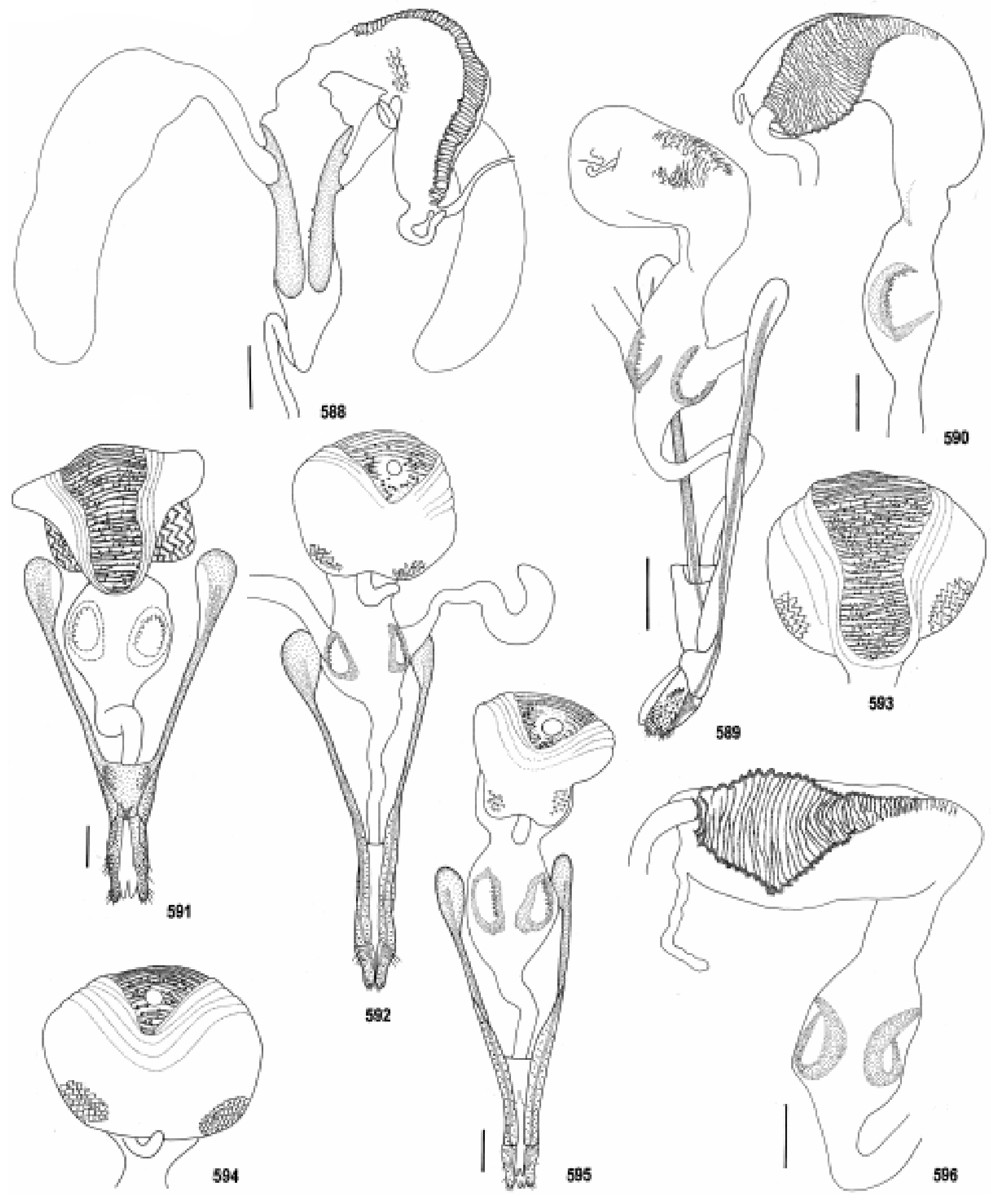

Figs. 588-596. Female genitalia: 588, $C$. desmarestii (dorsal) (6 Km E Purulha, MZSP); 589, C. dugesi (lateral) (Tepic, ZMHB); 590, C. extenuatuvittatus sp. nov. (lateral) (Paratype); 591, C. eschscholtzi (ventral) (Finca San Carlos, MZSP); 592, C. fasciatus sp. nov. (dorsal) (Paratype); 593-594, C. forreri (ventral, dorsal) (Isla Maria Madre, UNAM); 595, C. fryi (dorsal) (Trujillo, USNM); 596, C. gossipiatus (dorsal) (El Espinal, MZSP). Bars $=1 \mathrm{~mm}$. Figs 591, 592; 594, 595, respectively, to the same scale. 


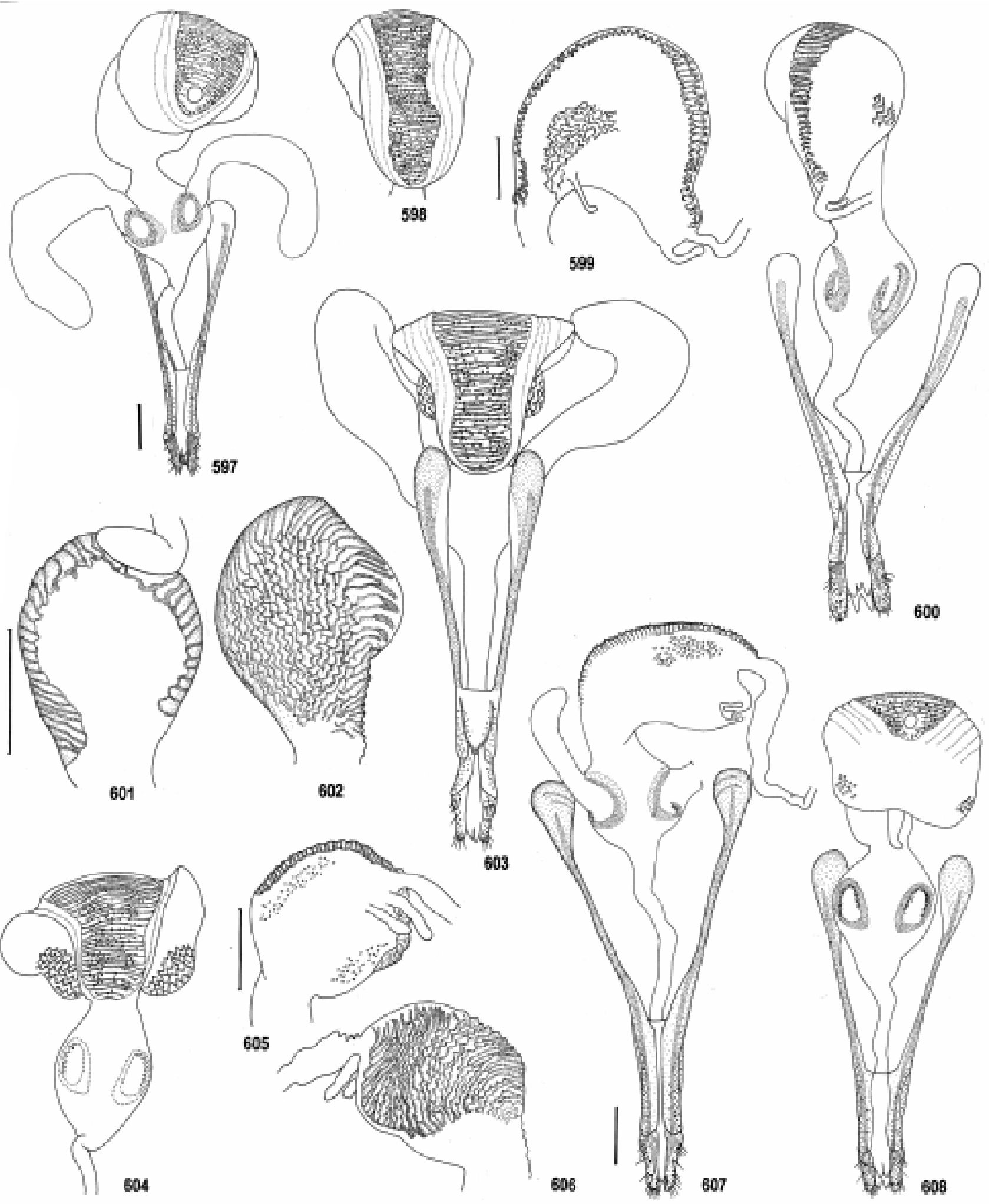

Figs. 597-608. Female genitalia: 597-598, C. inops (dorsal, ventral) (51 Km Ixtapa, FSCA); 599-600, C. jansoni (lateral, dorsal) (Hamburg Farm, USNM); 601-602, C. lenzi (dorsal, ventral) (F, Arizona, CMNH); 603, C. lacordairii (ventral) (San Jeronimo, MZSP); 604, C. obscurus (ventral) (Antilles, USNM); 605-606, C. oxydatus (dorsal, ventral) (Rizo de Oro, UNAM); 607, C. mexicanus (dorsal) (Miranda, PCCV); 608, C. pruinosus (dorsal) (Mexico, USNM). Bars $=1 \mathrm{~mm}$. Figs 597, 598, 603, 604, 608; 600, 607; 605, 606, respectively, to the same scale. 

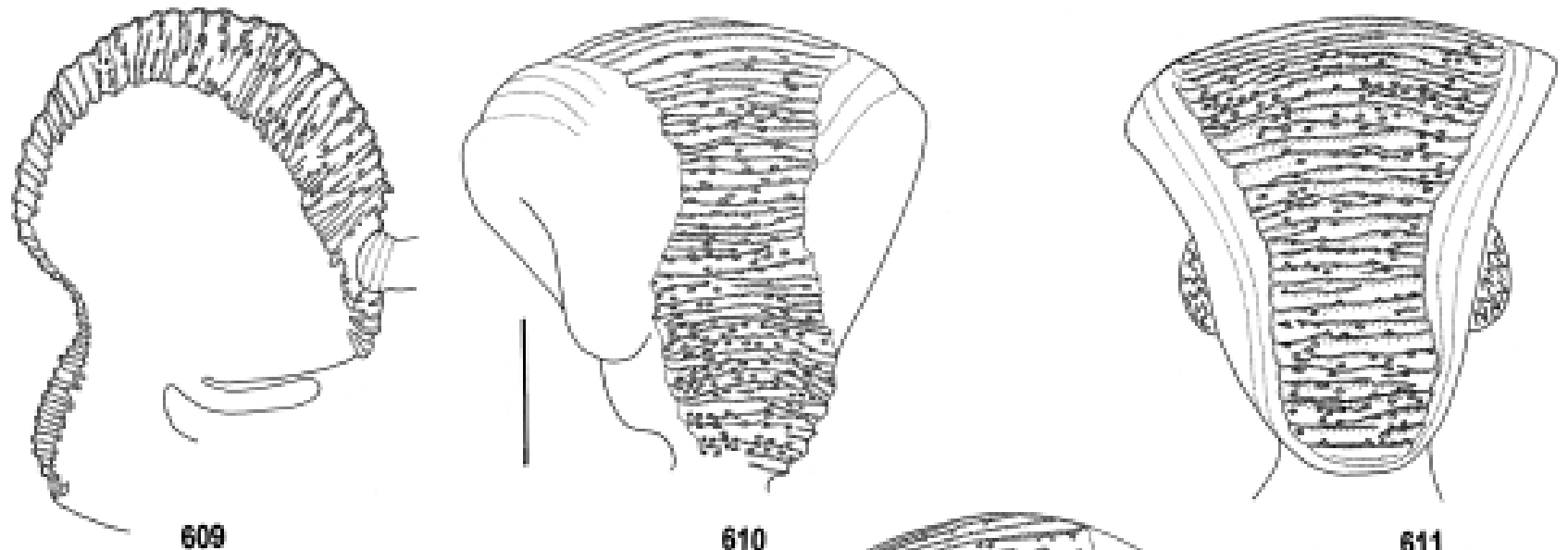

609
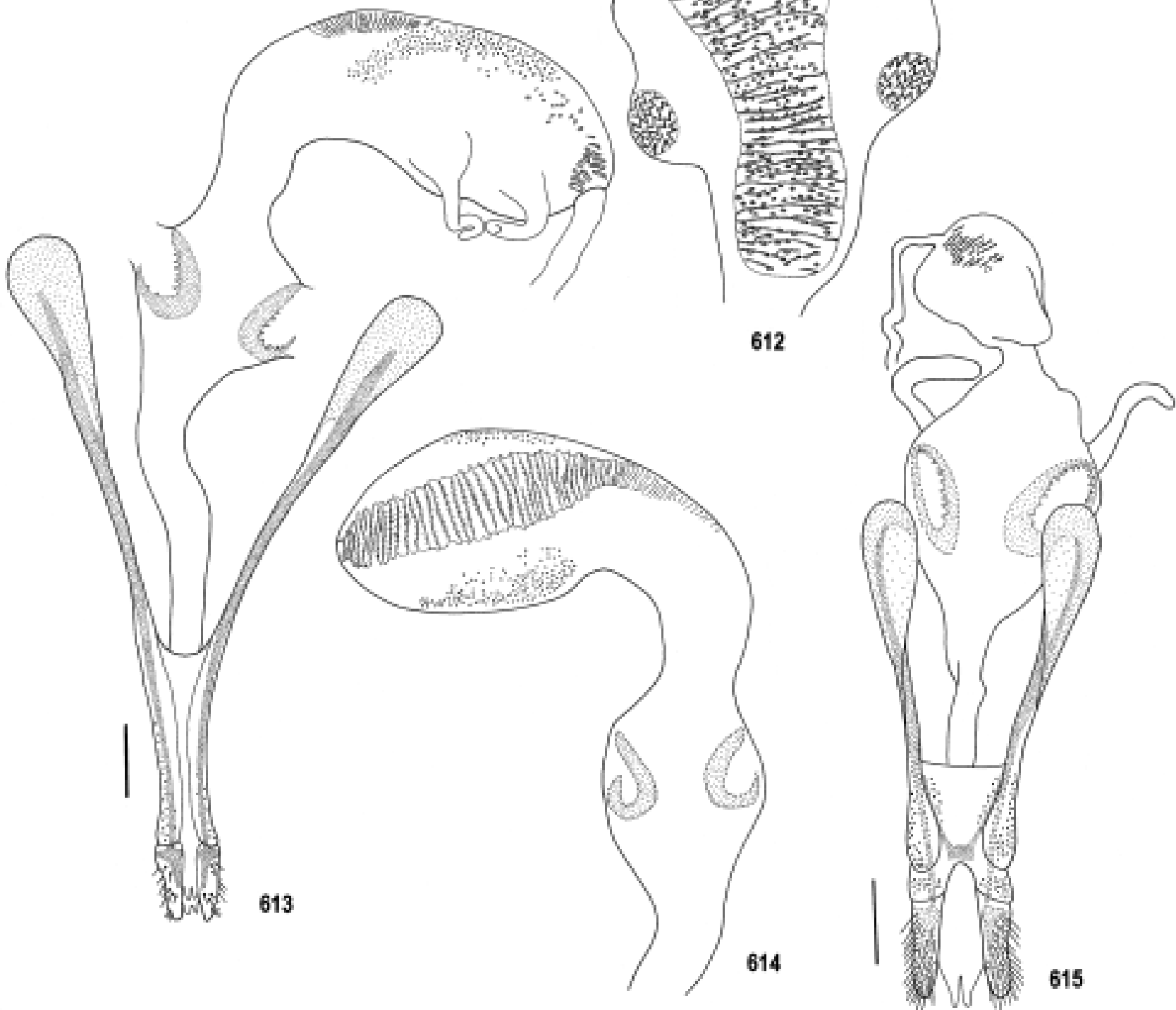

Figs. 609-615. Female genitalia: 609-610, C. rubripennis (lateral, ventral) (Puerto Batlandra, MZSP); 611, C. rugatus (ventral) (Solferino, MZSP); 612, C. silbermanni (ventral) (Sayaaxche, MZSP); 613-614, C. serricornis sp. nov. (dorsal, lateral) (Paratype); 615, C. smaragdinus (ventral) (15 mi E Douglas, MZSP). Bars $=1 \mathrm{~mm}$. Figs 609-612; 613, 614, respectively, to the same scale. 

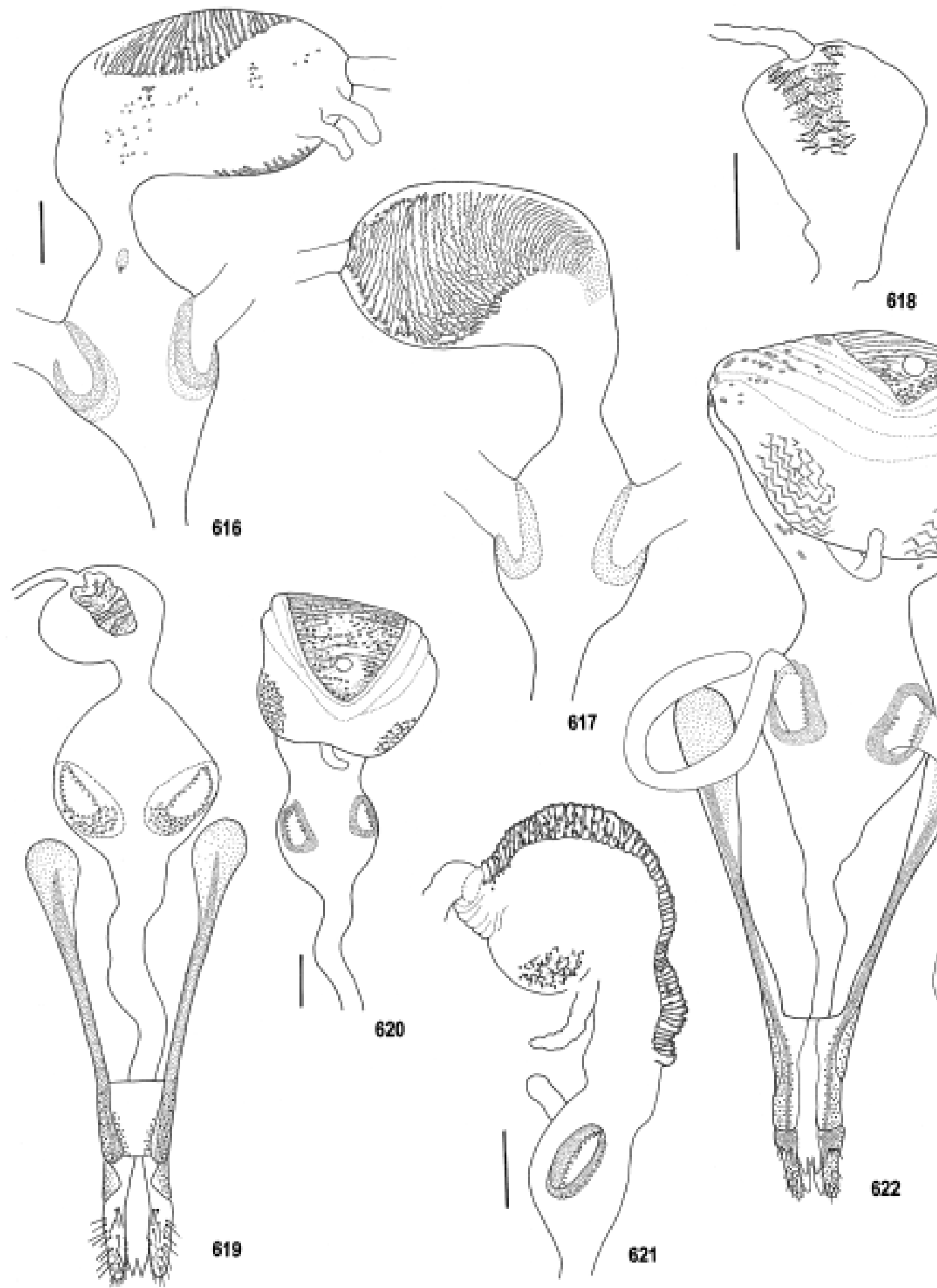

618

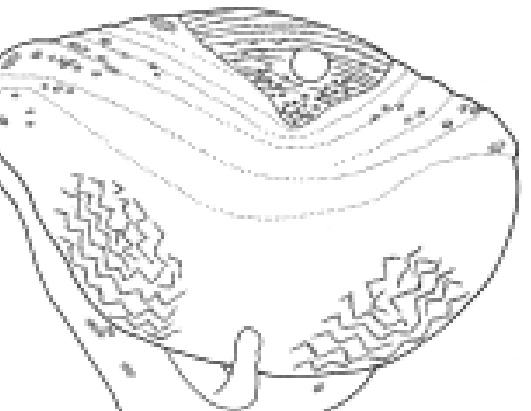

620 

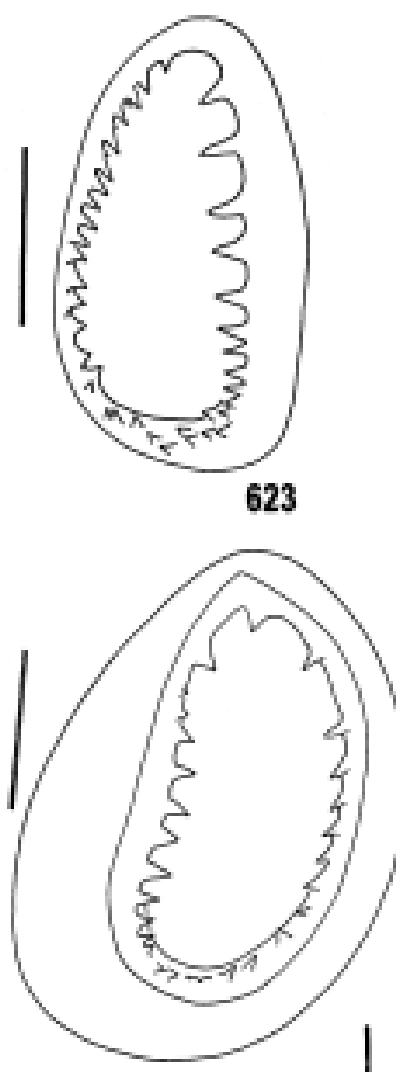

627

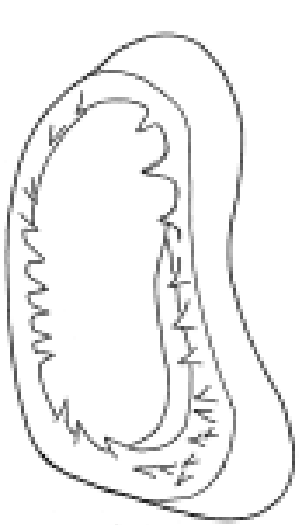

631
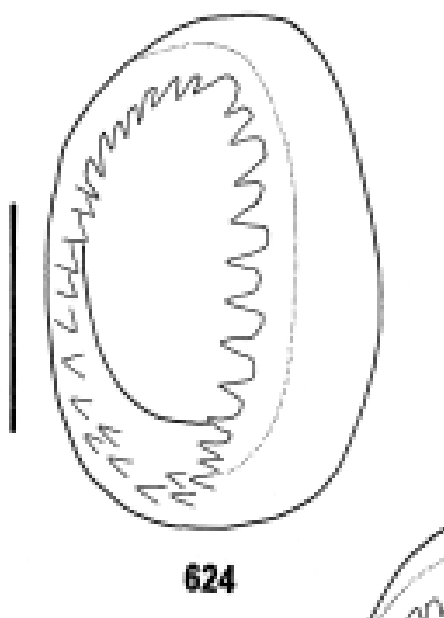

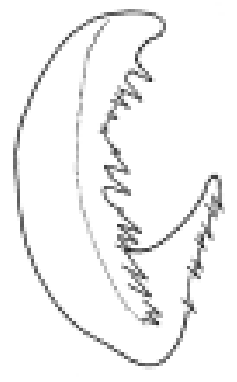

625

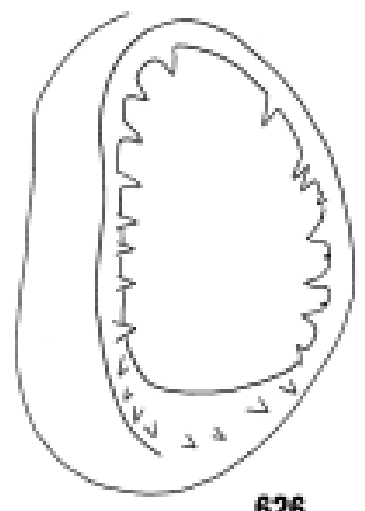

626

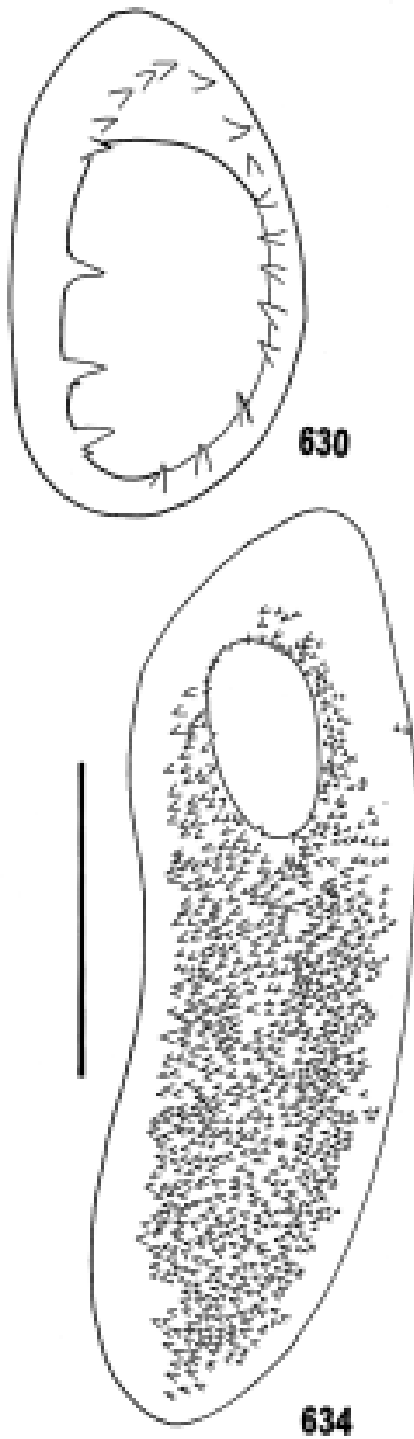

632

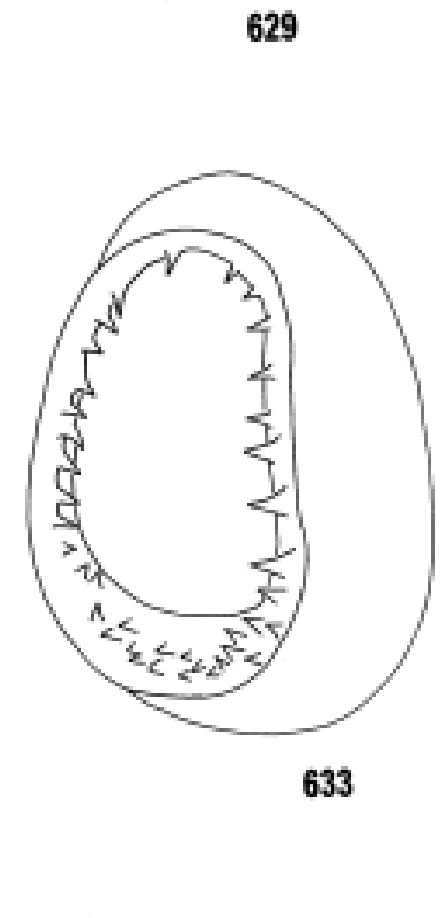

629

634

Figs. 623-634. Sclerotized piece of colleterial gland: 623, C. apacheanus (Arizona, CMNH); 624, C. approximatus (El Limon, MZSP); 625, C. attenuatus (14 Km Huautla-Jojutla, MZSP); 626, C. aurulentus (Chaparé, MZSP); 627, C. bomplandii (Sayaaxche, MZSP); 628, C. boucardi (Colima, USNM); 629, C. chalcantheus (Rondonópolis, MZSP); 630, C. corpulentus (Carquejo, MZSP); 631, C. cyaneus (Merida, USNM); 632, C. dugesi (Tepic, ZMHB); 633, C. erythroloma (Balzapampa, MZSP); 634, C. desmarestii (6 Km E Purulha, MZSP). Bars $=0.5 \mathrm{~mm}$. Figs 623, 626, 631,$633 ; 624,625 ; 629,630,632$, respectively, to the same scale. 

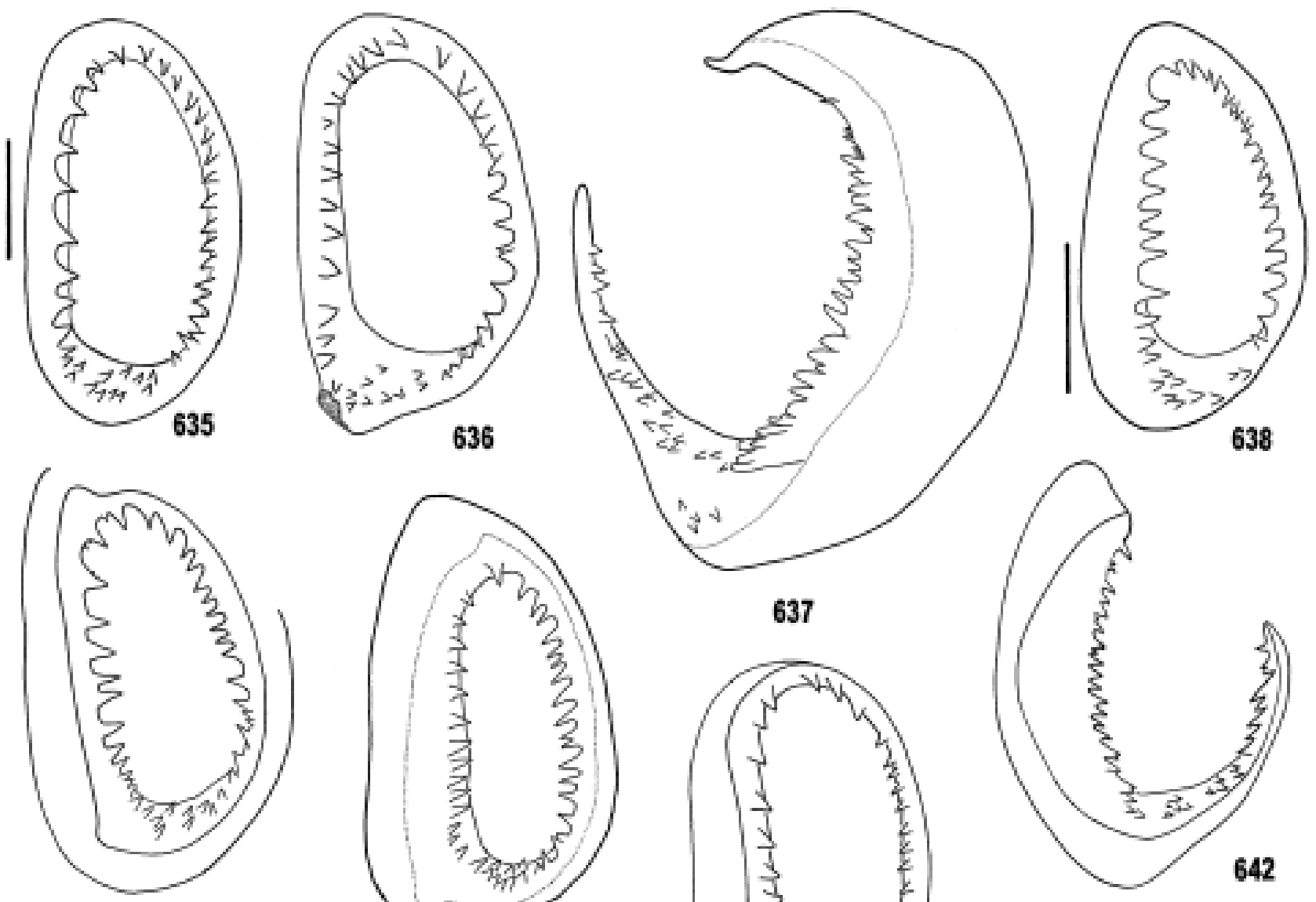

639

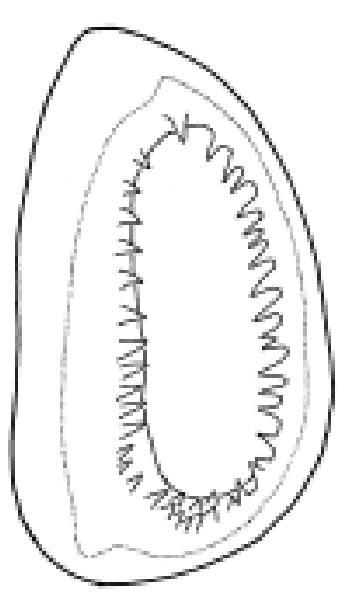

640

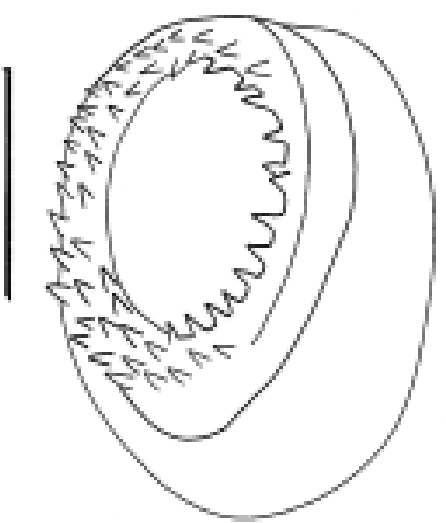

643
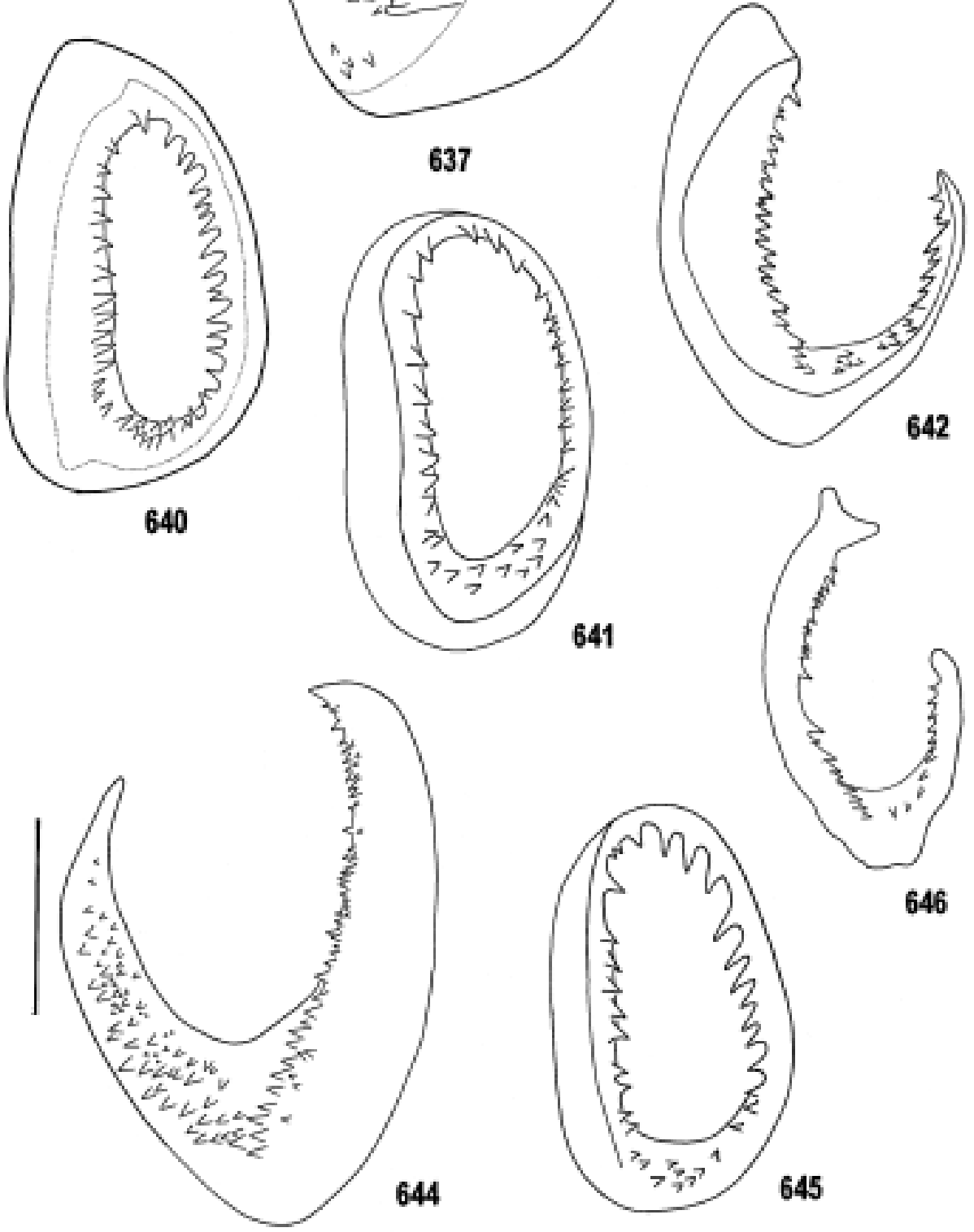

Figs. 635-646. Sclerotized piece of colleterial gland: 635, C. eschscholtzi (Finca San Carlos, MZSP); 636, C. fabricii (Território Vásquez, MZSP); 637, C. extenuatuvittatus sp. nov. (Paratype); 638, C. fasciatus sp. nov. (Paratype); 639, C. forreri (Isla Maria Madre, UNAM); 640, C. fryi (Trujillo, USNM); 641, C. lafargi; 642, C. gossipiatus (El Espinal, MZSP); 643, C. inops (51 Km Ixtapa, FSCA); 644, C. jansoni (Hamburg Farm, USNM); 645, C. lacordairii (San Jeronimo, MZSP), 646, C. lenzi (Arizona, CMNH). Bars = 0.5 mm. Figs 635, 639-642, 645; 636, 638; 637, 643; 644, 646, respectively, to the same scale. 

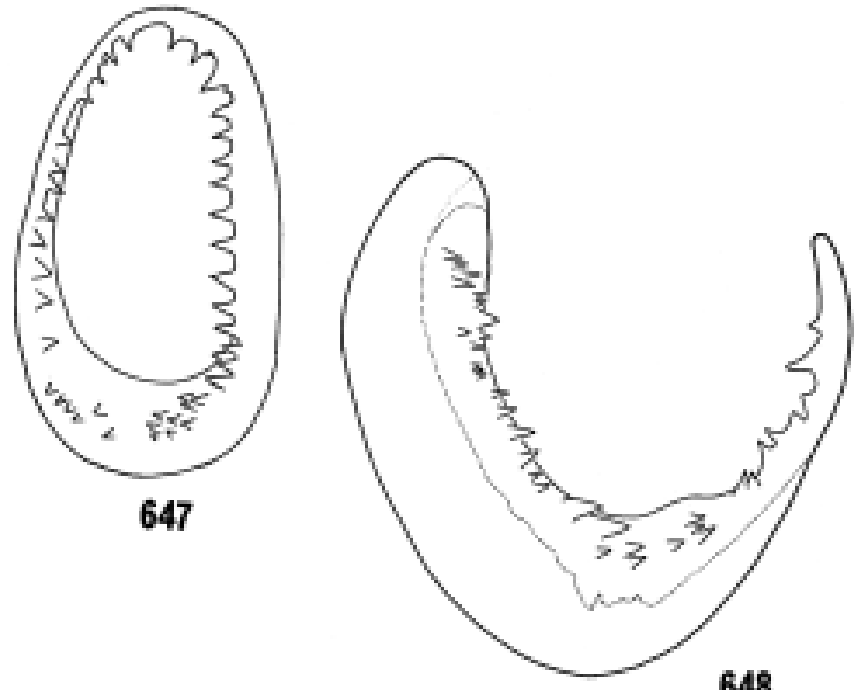

648

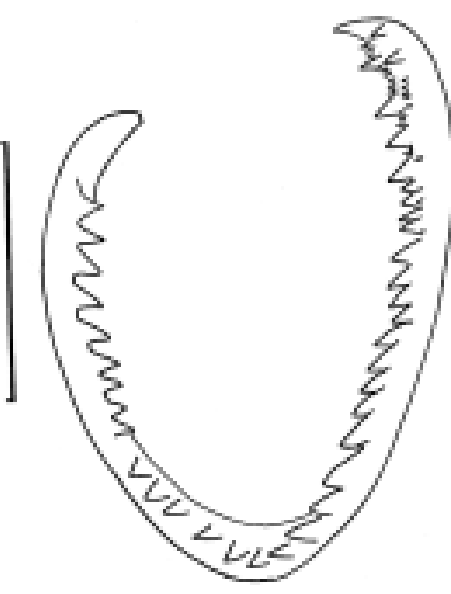

651
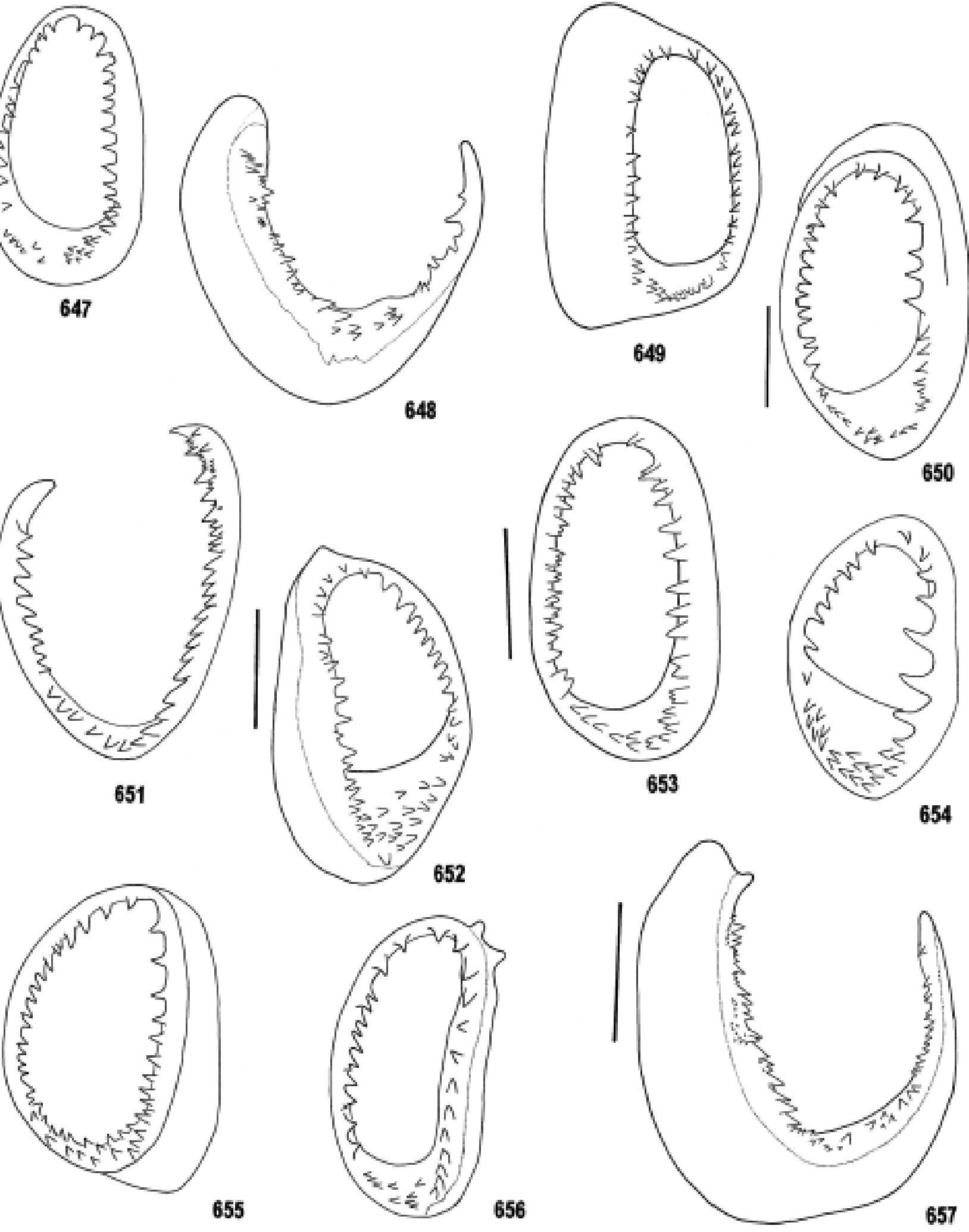

Figs. 647-657. Sclerotized piece of colleterial gland: 647, C. limbatus (Linhares, MZSP); 648, C. mexicanus (Miranda, PCCV); 649, C. mocquerysii (Estacion Agricola Experimental Palmira, USNM); 650, C. obscurus (Antilles, USNM); 651, C. oxydatus (Rizo de Oro, UNAM); 652, C. porcatus (Estação Codemat, INPA); 653, C. pruinosus (Mexico, USNM); 654, C. rostainei (Óbidos, MZSP); 655, C. rubripennis (Puerto Batlandra, MZSP); 656, C. rugatus (Solferino, MZSP); 657, C. serricornis sp. nov. (Paratype). Bars $=0.5 \mathrm{~mm}$. Figs 647, 649, 650, 659; 648, 657; 652, 654, 655, respectively, to the same scale. 


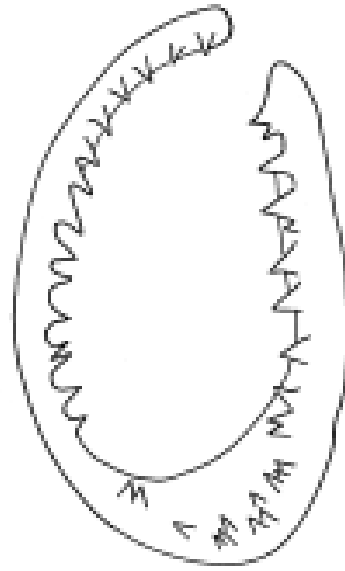

658
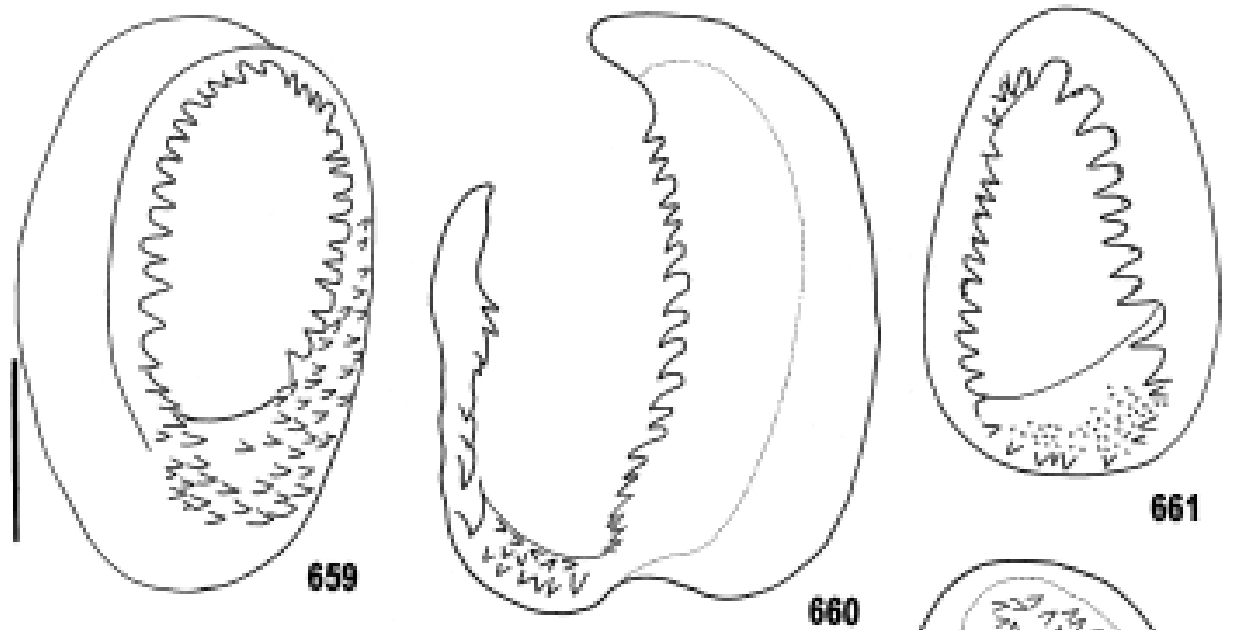

659
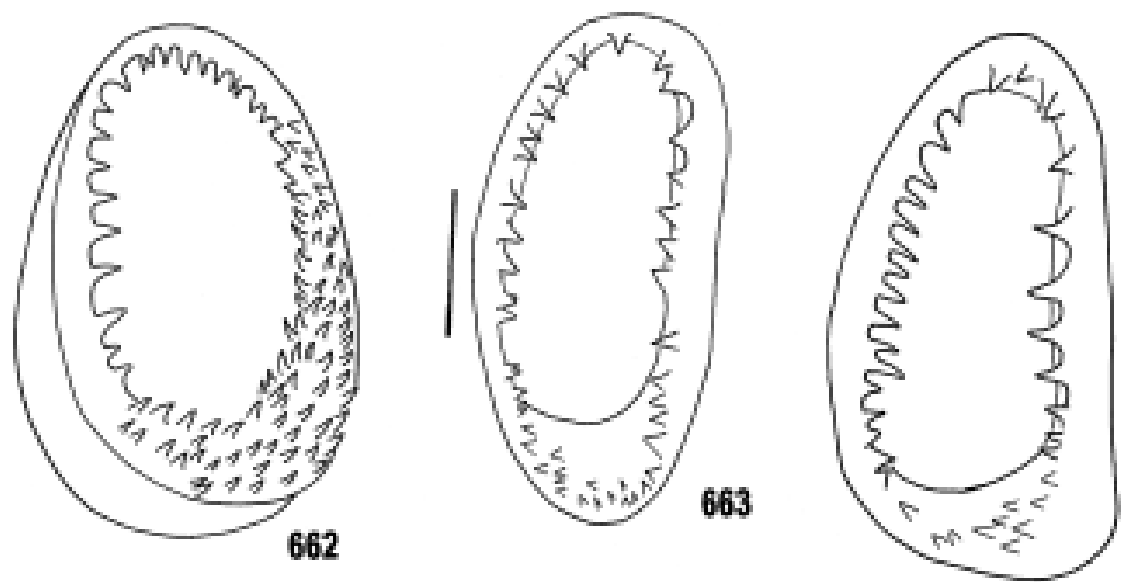

660

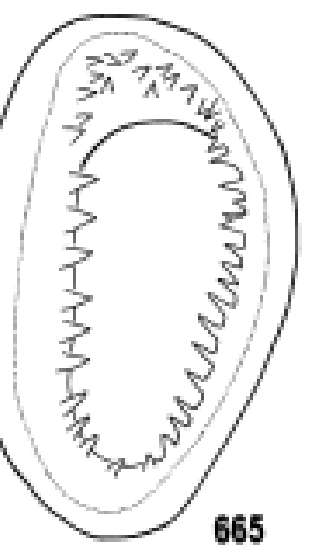

664
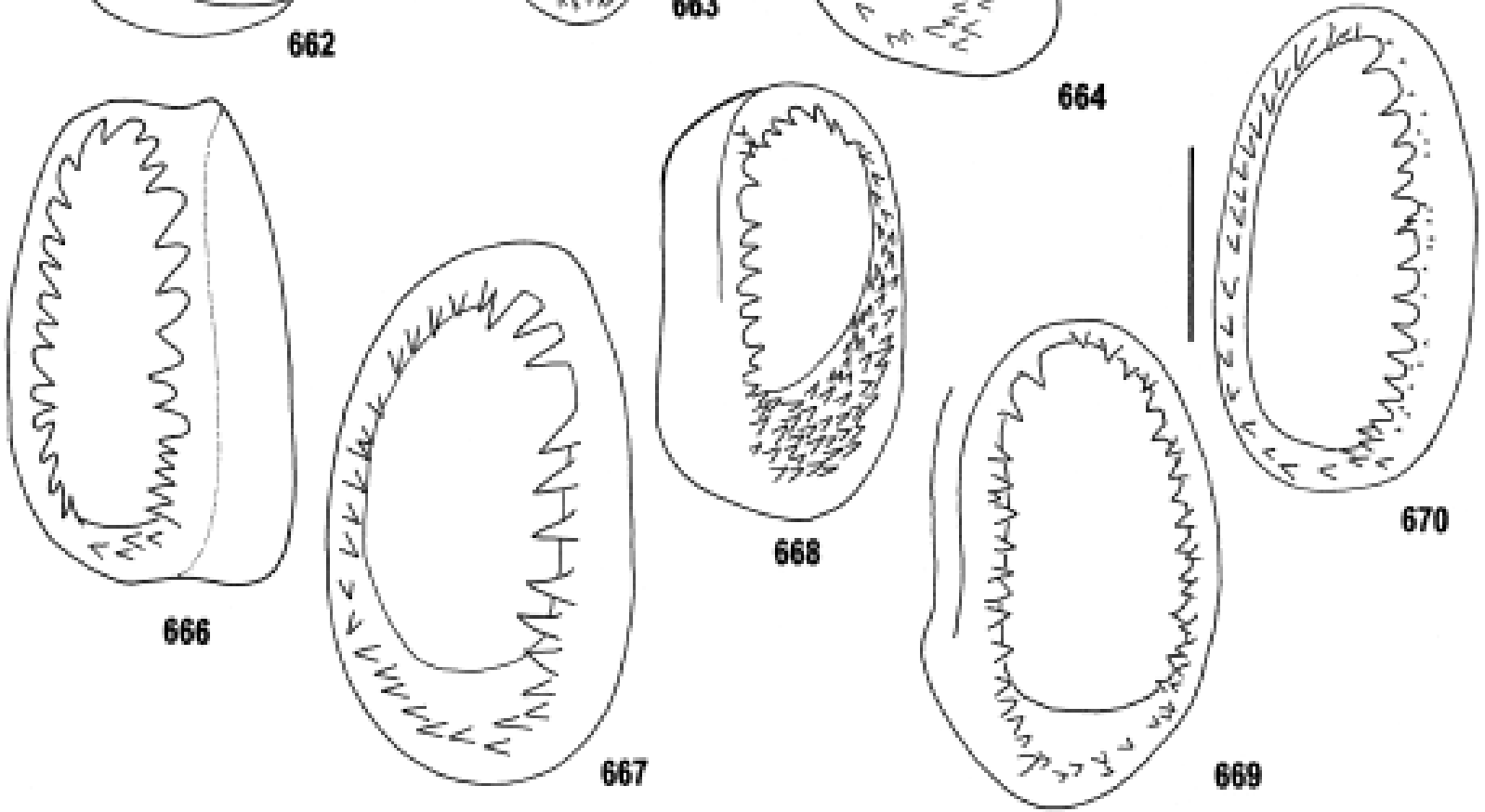

Figs. 658-670. Sclerotized piece of colleterial gland: 658, C. silbermanni (Sayaaxche, MZSP); 659, C. smaragdinus (15 mi E Douglas, MZSP); 660, C. spinipennis sp. nov. (Paratype); 661, C. sulcatus (Saint Croix, MZSP); 662, C. tartarus (Laguna Lake, MZSP); 663, C. validus; 664, C. villei (Medio Calima, MZSP); 665, C. virens (Itacoatiara, MZSP); 666, C. virgatipennis sp. nov. (Paratype); 667, C. virginalis (Guaymas, MCZC); 668, C. viridipilis (Pennsylvania, MZSP); 669, C. zonatus (Ilha de Buzios, MZSP); 670, C. webbi (Bill Williams Fork, MZSP). Bars = 0.5 mm. Figs 658, $660,666-668,670 ; 661,662,664,665,669$, respectively, to the same scale. 


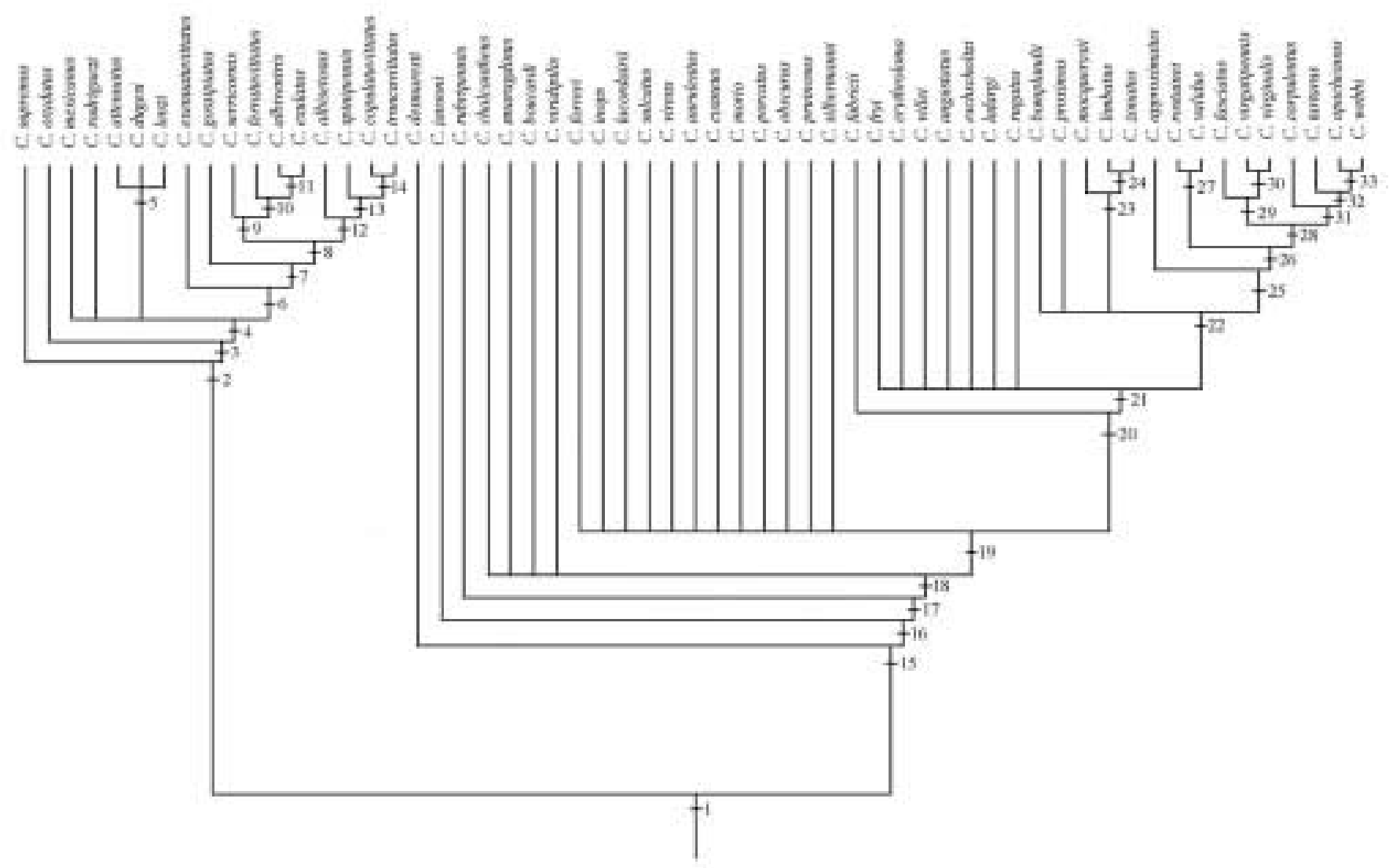

Fig. 671. Phylogenetic hypothesis of Chalcolepidius species. Strict consensus cladogram $(\mathrm{CI}=46, \mathrm{RI}=81)$ of 2,636 more parcimonious trees $(\mathrm{L}$ = 256). $(*$ = convergence; $\mathrm{R}=$ reversal $)$.

Branch 1: 17.1, 20.1, 23.1, 25.1; Branch 2: 12.1*, 13.1*, 24.2*, 26.2*, 31.1*, 32.1, 33.1, 35.4; Branch 3: 28.2, 34.1, 45.1*; C. oxydatus: 30.1*; Branch 4: 26.3*; 42.1, 45.2, 46.1; C. mexicanus: $2.1^{*}, 12.2^{*}, 13.2^{*}, 24.3^{*}, 28.3^{*}, 35.8 ;$ C. rodriguezi: $2.1^{*}, 2^{24.3 * ;}$ BRANCh $5: 1.1^{*}, 13.2^{*}, 14.1^{*}$, 15.1*, 16.1R, 24.1R, 35.5; C. attenuatus: 26.2R; C. dugesi: 12.2*, 35.7*, 52.1; C. lenzi: 29.3*, 35.7*; BRANCH 6: 9.1*; C. extenuatuvittatus: 10.4*, 30.1*; Branch 7: 3.1*, 4.2*; BRANCH 8: 6.1*; BRANCH 9: 9.2*, 45.1R; C. serricornis: 13.2*, 28.3*; BRANCH 10: 28.1R, 42.0R; C. ferratuvittatus: 6.2*, 7.1*, 26.2R, 30,1*, 35.3R; BRANCH 11: 5.1*, 8.4*. 10.4*, 34.0R; C. albiventris: 9.1R, 28.3*; C. exulatus: 35.6*; BRANCH 12: 5.1*; C. albisetosus: $4.3^{*}, 6.2^{*}, 7.1^{*}, 30.1^{*}$; BRANCh 13: 8.2, 26.2R; C. spinipennis: 8.5*, 9.2*, 30.1*, 35.3R; BRANCH 14: 24.1R, 42.0R; C. copulatuvittatus: 10.2*, 15.1*, 28.1R; C. truncuvittatus: 8.5*, 16.1R; BRANCH 15: 16.3, 18.2, 19.1, 36.1*, 37.1, 38.1, 39.2*, 40.2, 41.1, 43.1, 44.1; C. desmarestii: 15.3, $21.2^{*}, 24.2^{*}, 30.1^{*}, 35.6^{*}, 36.3^{*}, 49.1^{*}, 50.5$; BRANCH 16: 28.4*, 32.2*; C. jansoni: 30.1*; 36.3, 44.2*; BRANCH 17: 12.1*, 13.1*, 22.1, 26.3*, $49.1^{*}, 50.1^{*}, 51.1,52.2^{*}, 53.1$; C. rubripennis: $14.1^{*}, 15.1^{*}, 16.2 \mathrm{R}, 52.3^{*} ;$ Branch 18: 1.1*, 26.4, 27.1, 28.5, 39.1R, 40.6, 50.3; C. chalcantheus: 39.2*, 40.4R, 47.1*, 48.1*; C. smaragdinus: $12.3^{*}, 13.2^{*}, 15.1^{*}, 26.3 \mathrm{R}, 27.0 \mathrm{R}, 28.4 \mathrm{R}, 29.3^{*}, 32.0 \mathrm{R}, 36.0 \mathrm{R}, 47.1^{*}, 48.1^{*} ;$ C. boucardi: $13.2^{*}$, $15.2^{*}, 32.0 \mathrm{R}, 34.2^{*}, 35.2^{*}, 38.2,43.2 ;$ C. viridipilis: $12.3^{*}, 13.2^{*}, 31.1^{*}, 35.2^{*}, 44.2^{*}, 50.4^{*} ;$ BRANCH 19: 1.0R, 12.0R, 13.0R, 21.2*, 24.3*, 32.3, 33.2, 36.2*, 50.1R, 52.3*; C. forreri: 29.2; C. inops: $12.2^{*}, 13.2^{*}, 15.2,24.2 \mathrm{R}, 40.1 \mathrm{R}, 50.4^{*}$; C. lacordairii: $36.1 \mathrm{R} ;$ C. virens: $36.1 \mathrm{R} ;$ C. aurulentus: $9.1^{*}, 10.1$; C. cyaneus: $9.1^{*} ;$ C. porcatus: $9.1^{*}, 36.1 \mathrm{R}, 50.2^{*} ;$ C. obscurus: $29.1^{*} ;$ C. pruinosus: $24.2 \mathrm{R}, 29.1^{*} ;$ C. silbermanni: $29.1^{*}, 35.2^{*}, 50.2^{*}$; Branch 20: $3.1^{*}, 4.2^{*}, 9.2^{*}$; Branch $21: 5.1^{*}, 6.1^{*}, 8.3 ;$ fryi: $6.2^{*}, 7.2^{*}, 8.0 \mathrm{R}$; C. erythroloma: 4.3*, 6.2*, 7.1*, 8.0R, 39.3*, 40.3*; C. villei: 6.2*, 7.2*, 8.0R; C. angustatus: 24.1R, 32.1R, 33.0R; C. lafargi: 8.4*; C. rugatus: 4.3*; BRANCH 22: 8.4*, 9.1R; BRANCH 23: 4.4; Branch 24: 10.3*; BRANCH 25: 10.2*; C. approximatus: 11.1*; Branch 26: 36.1R; BRANCH 27: 9.3; C. rostainei: 50.2*; C. validus: 6.3, 7.0R; BRANCH 28: 10.3*; BRANCH 29: 8.5*; BRANCH 30: 24.2R, 39.3*, 40.5R; C. virgatipennis: 10.4*, 40.3R; C. virginalis: 10.0R, 12.1*, 13.1*, 39.4*; BRANCH 31: 9.2*; C. corpulentus: 8.1R; BRANCH 32: 4.1R, 24.2R; C. tartarus: 11.1*, 12.1*, 13.1*, 24.1R, 32.2R, 34.2*, 36.0R, 50.4*, 52.2R; BRANCH 33: 29.3*, 40.1R; C. apacheanus: $11.1 *, 24.3 *, 36.2 * ;$ C. webbi: $39.4 *$. 

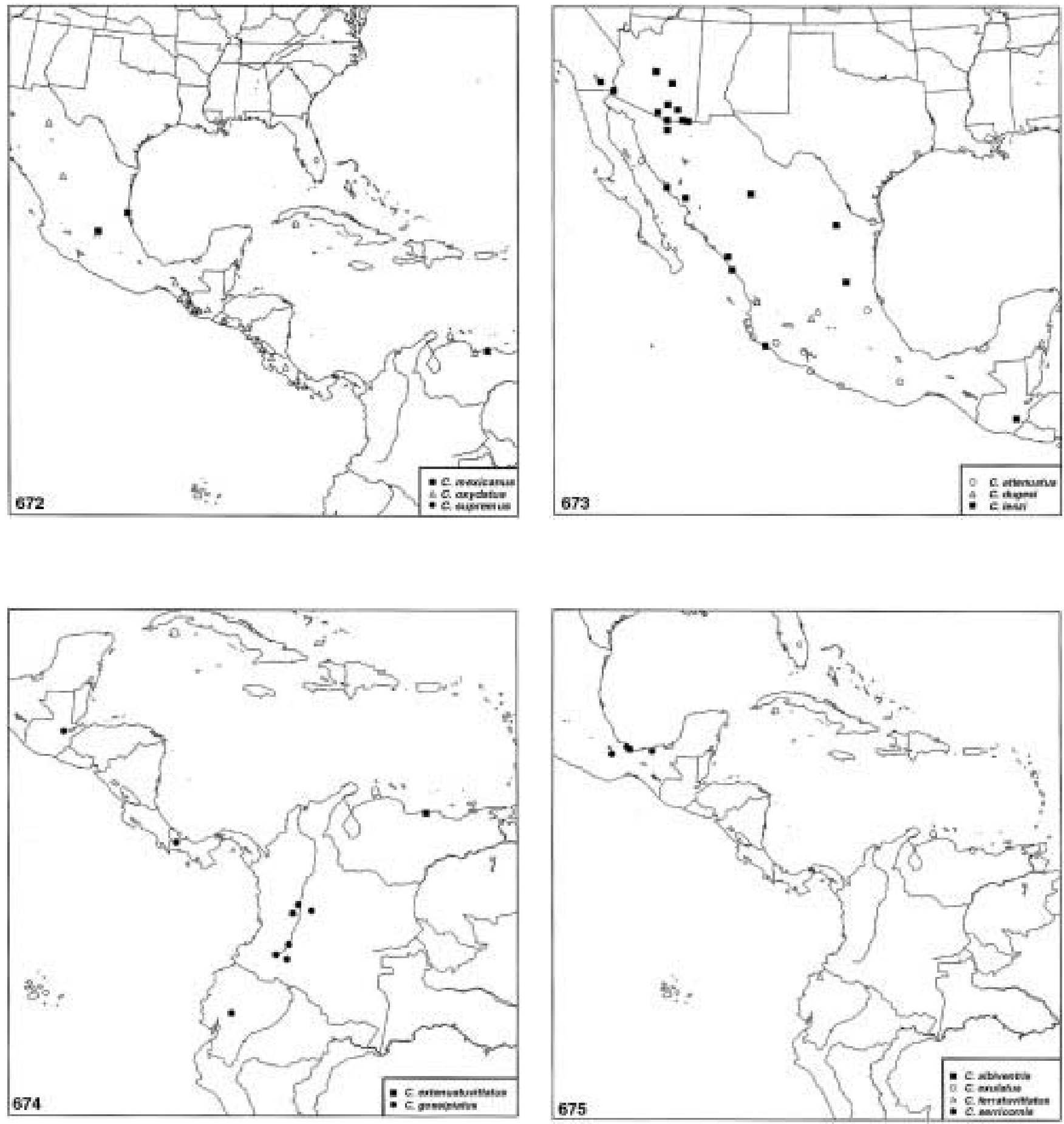

Figs. 672 - 675. Geographical distribuition of Chalcolepidius. 

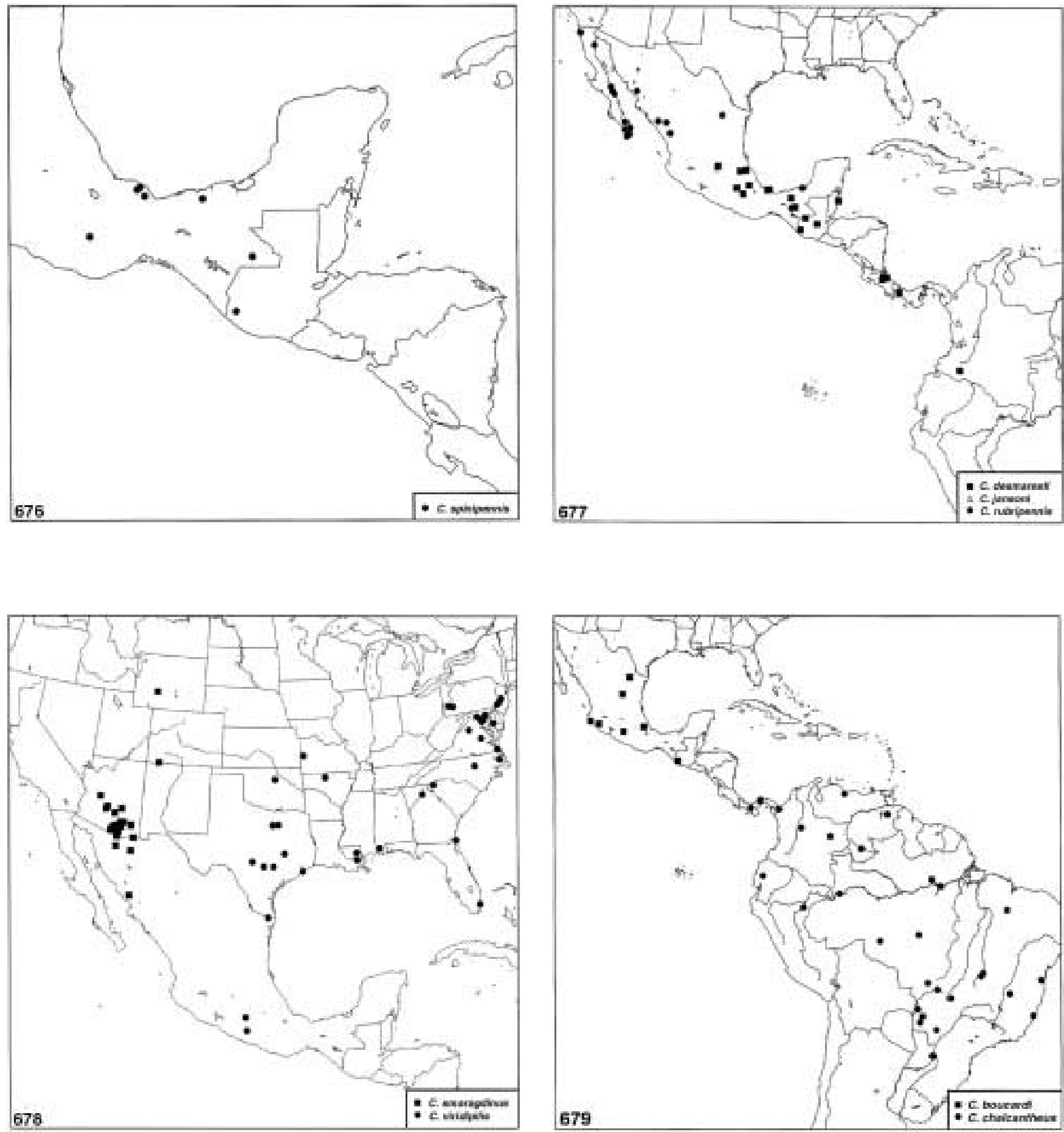

Figs. 676 - 679. Geographical distribuition of Chalcolepidius. 

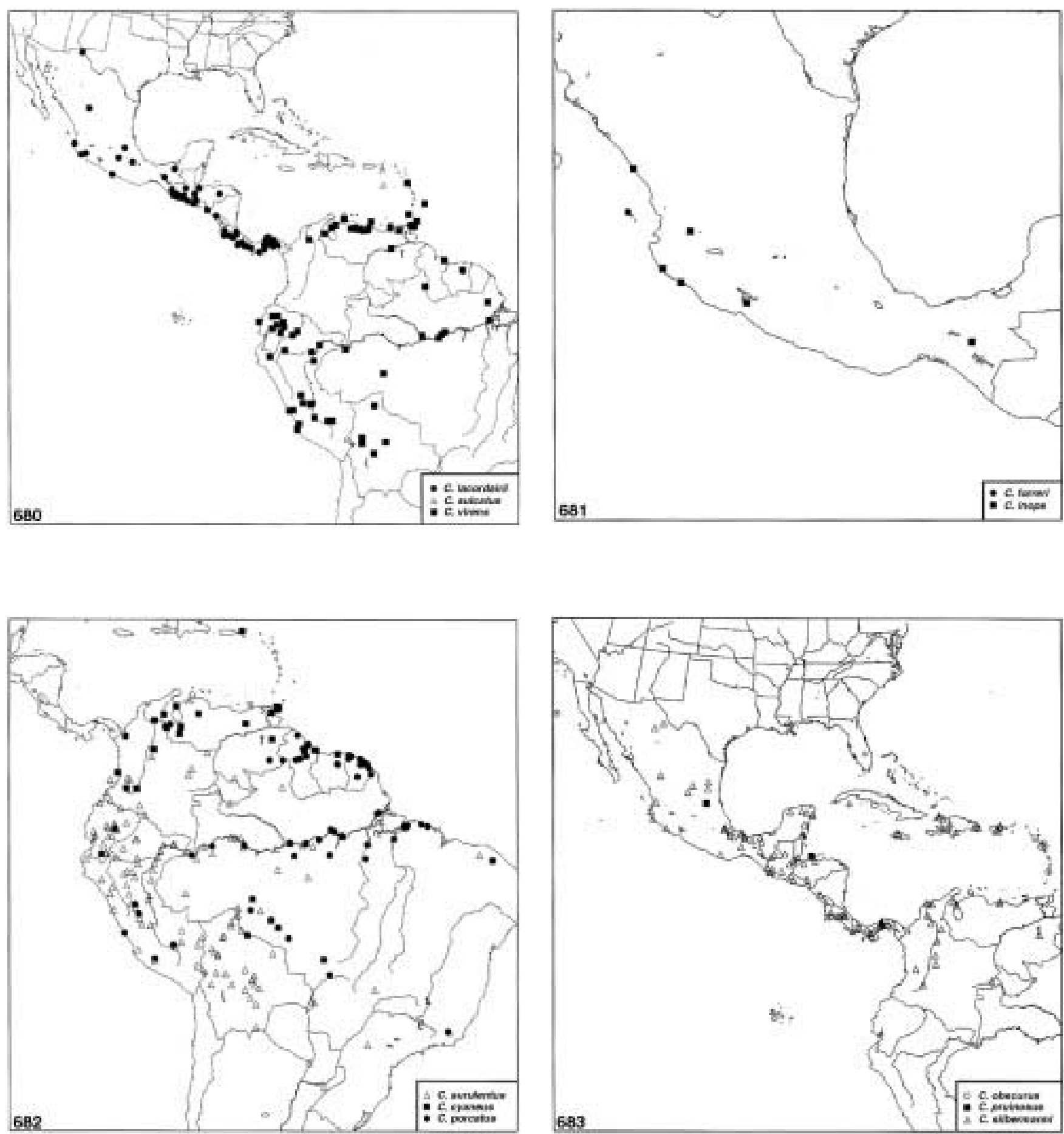

Figs. 680 - 683. Geographical distribuition of Chalcolepidius. 

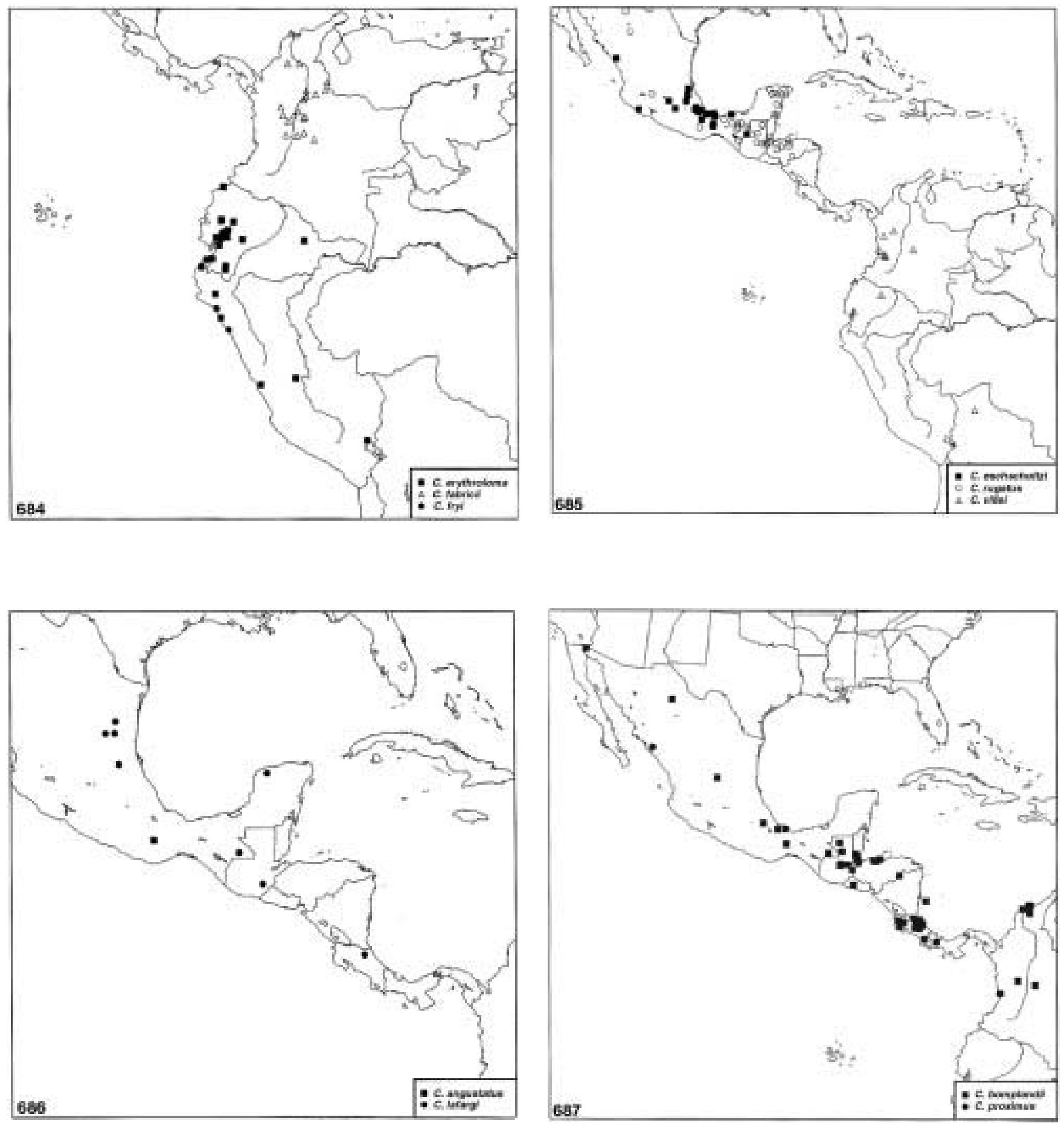

Figs. 684 - 687. Geographical distribuition of Chalcolepidius. 

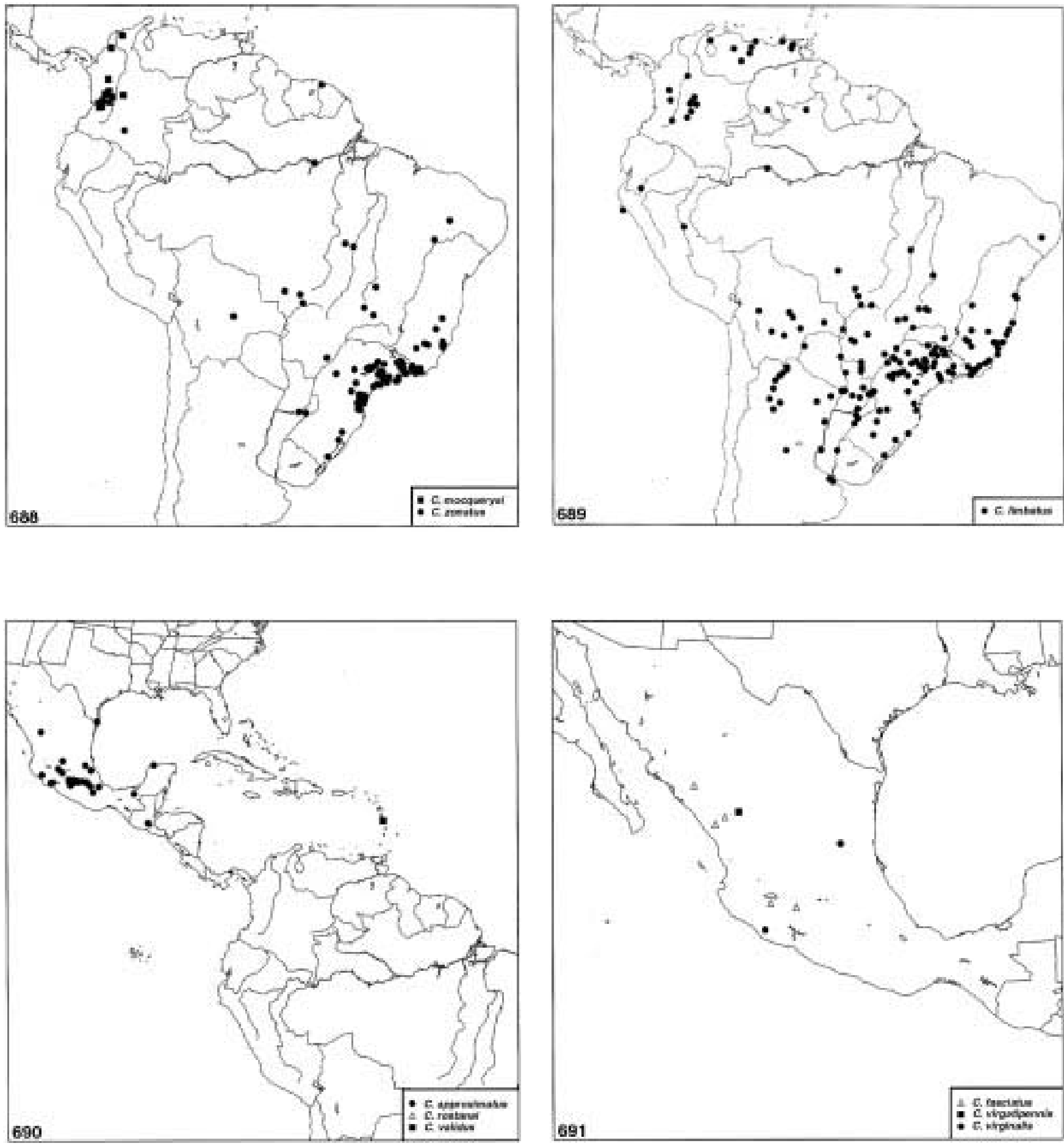

Figs. 688 - 691. Geographical distribuition of Chalcolepidius. 


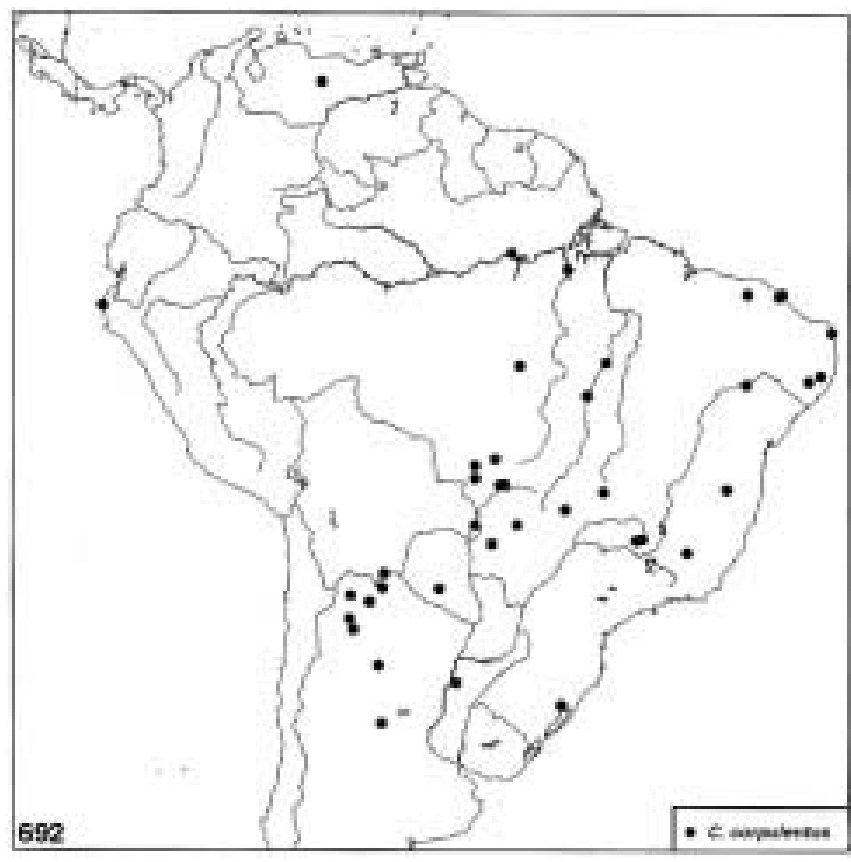

Figs. 692 - 693. Geographical distribuition of Chalcolepidius.

\section{REFERENCES}

Amorim, D. S. 1982. Classificação por sequenciação: uma proposta para denominação dos ramos retardados. Revista brasileira de Zoologia 1(1): $1-9$

Amorim, D. S. 1993. Group*: an additional artifact for sequenced phylogenetic classifications. Revista Nordestina de Biologia 8 (1): 35 38 .

Arnett JR. R. H.; G. A. Samuelson \& G. M. Nishida. 1993. The Insect and Spider collections of the world. (2nd edition). Gainesville, Sandhill Crane Press, 277 p.

Becker, E. C. 1956. Revision of the Nearctic species of Agriotes (Coleoptera: Elateridae). Canadian Entomologist 86 (Suplement 1): 1-101.

Becker, E. C. 1961. The North American Elaterid Types of Otto Schwarz, with a revision of Ctenicera bivittata (Melsheimer) and allies (Coleoptera). Canadian Entomologist 93(3): 161-181.

Blackburn, T. \& D. Sharp. 1885. Memoirs on the Coleoptera of the Hawaiian Islands. ScientificTransactions of the Royal Dublin Society (ser. 2) 3: 119-300.

Blackwelder, R. E. 1944. Checklist of Coleopterous insects of Mexico, Central America, the West Indies and South America. Bulletin of the United States National Museum 185(2):280-303.

Böving, A. G. \& F. C. Craighead. 1931. Illustrated synopsis of the principal larval forms of the order Coleoptera. Entomologica Americana 11: $1-352$.

Bruch, C. 1938-1942. Misceláneas entomológicas. Notas del Museo La Plata 7(57):141-151, $3 \mathrm{pl}$.

Buchanan, L. L. 1935. Thomas Lincoln Casey and the Casey Collection of Coleoptera. Smithsonian Miscellaneous Collections 94(3): $1-15$

Calder, A. A. 1996. Click Beetles. Genera of the Australian Elateridae (Coleoptera). Monographs on Invertebrate Taxonomy, vol. 2. Victoria, CSIRO Publishing, 401 p.

CAndÈze, E. 1857. Monographie des Élatérides. Tome premier. Mémoires de la Societé Royale des Sciences de Liège 12: 1-400, 7 pls.

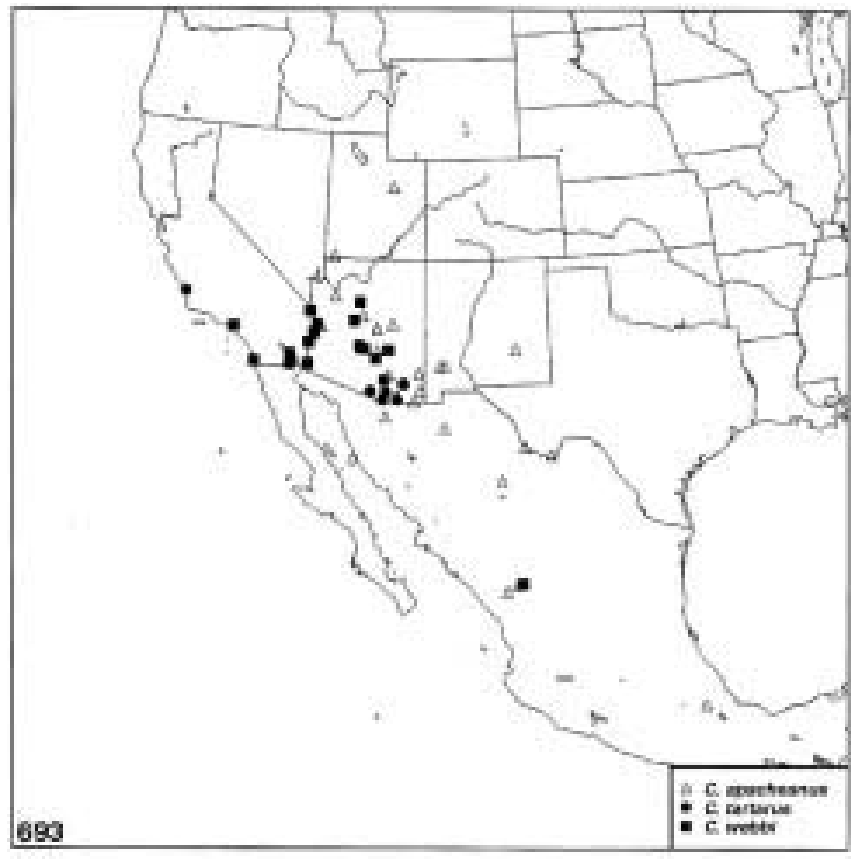

CAndèze, E. 1874. Révision de la Monographie des Élatérides. Mémoires de la Societé Royale des Sciences de Liège 4 (ser. 2): 1-218.

Candèze, E. 1878. Élatérides nouveaux 2. Annales de la Société Entomologique de Belgique (Comptes-rendus) 21: li-cxliii.

Candèze, E. 1881. Élatérides nouveaux III. Mémoires de la Societé Royale des Sciences de Liège 9(2): 1-117.

CANDÈze, E. 1886. Note sur les Élatérides du genre Chalcolepidius Eschs. Bulletin de la Societé Enomologique de Belgique 1886: 65 84.

Candèze, E. 1889. Élatérides nouveaux. Annales de la Société Entomologique de Belgique 33:1-57.

CANDÈze, E. 1890. Description d'une nouvelle espèce d'élatéride du genre Chalcolepidius. Comptus Rendus de la Societé Entomologique de Belgique 12 (ser. 4): 184-185.

CAndèze, E. 1891. Catalogue Méthodique des élatérides connus en 1890. Liège, $H$. Vaillant-Carmanne, xii $+246 \mathrm{p}$.

Candèze, E. 1893. Élatérides Nouveaux $5^{\text {e }}$ fascicule. Mémoires de la Societé Royale des Sciences de Liège 18:1-76.

CAndÈze, E. 1900. Élatérides nouveaux. Septième fascicule. Annales de la Société Entomologique de Belgique 44: 77-101.

Casari-Chen, S. A. 1985. Sistemática e evolução dos Hemirhipini Neotropicais (Pyrophorinae, Elateridae, Coleoptera). Revista Brasileira de Entomologia 29(3/4): 383-423.

Casari-Chen, S. A. 1994. Systematics and evolution of Hemirhipini from Old World and Australia. II. Phylogeny of the tribe including the American genera (Coleoptera, Elateridae, Pyrophorinae). Revista Brasileira de Entomologia 38(1): 161-252.

Casey, T. L. 1891. Coleopterological Notices III. Annals of the New York Academy of Science 6: 9-214.

Casey, T. L. 1907. Notes on Chalcolepidius and the Zopherini. Canadian Entomologist 39: 29-46.

CAsey, T. L. 1911. Notes on the Coccinelidae with some general remarks and synonymy. Memoirs of the Coleoptera 2: 246-254.

Castelnau, F. L. N. C. Laporte Comte De. 1836. Études entomologiques, ou descriptions d'insectes nouveaux et observations sur la synonymie. Revue Enomologique 4: 5-60. 
Castelnau, F. L. N. C. Laporte Comte De. 1840. Histoire naturelle des animaux articulés. Paris (from Horn), v. 1., 324 p.

Champion, G. C. 1894. Biologia Centrali-Americana. Insecta. Coleoptera. Serricornia. Elateridae. London, Taylor \& Francis. Vol.3, part 1: 258-440.

Champion, G. C. 1896. Biologia Centrali-Americana. Insecta. Coleoptera (Elateridae and supplement, Cebrionidae, Rhipidoceridae). London, Taylor \& Francis. Vol.3, part 1: 441-584.

Chevrolat, L. A. A. 1833. Coléoptères du Mexique. Strasbourg, fasc.1, $25 \mathrm{p}$.

Chevrolat, L. A. A. 1935. Coléoptères du Mexique II. Strasbourg, fasc.8, 195-197.

Costa, C. 1971. Descrição de fases imaturas de Pyrophorinae Neotropicais (Coleoptera, Elateridae). Revista Brasileira de Entomologia 15(4): 21-30

Costa, C.; S. A. Vanin \& S. A. Casari-Chen. 1988. Larvas de Coleoptera do Brasil. São Paulo, Museu de Zoologia da Universidade de São Paulo, vi +282 p., 165 est.

DAJoz, R. 1964. Anatomie et importance taxonomique des voies génitales femelles d'origine ectodermique chez le Elateridae. Cahiers Naturaliste 20: $55-72,46$ figs.

Dohrn, C.A. 1881. Exotisches. Stettiner Entomologische Zeitung 42: $445-449$.

DruRY, D. 1837. Ilustrations of Natural History ... London, vol. 3, 76 p., $50 \mathrm{pl}$.

Dugés, D. E. 1885. Métamorphoses du Chalcolepidius zonatus Eschs. Annales de la Société Entomologique de Belgique 29(2): 3239

Erichson, W. F. 1841. Die Arten der Gattung Chalcolepidius Eschschs. Zeitschrift der Entomologie 3: 77-87.

Eschscholtz, J. F. 1829. Eintheilung der Elateriden in Gattungen. Entomologisches Archiv 2: 31-35.

Fabricius, J. C. 1775. Systema entomologiae. Lipsiae, $30+832$ p.

FABricius, J. C. 1777. Genera Insectorum. Kilonii, $14+310$ p.

FABricius, J. C. 1781. Species insectorum. Kilonii, vol. 1, $552 \mathrm{p}$

Fabricius, J. C. 1787. Mantissa insectorum. Hafniae, vol.1, 348 p.; vol. $2,382 \mathrm{p}$.

Fabricius, J. C. 1792. Entomologia systematica. Hafniae,vol. 1, $330+$ $538 \mathrm{p}$

Fabricius, J. C. 1801. Systema eleutheratorum. Kiliae, vol. 1, 506 p.; vol. $2,687 \mathrm{p}$

Fall, H. C. \& Cokerell, 1907. The Coleoptera of New Mexico. Transactions of the American Entomological Society 33: 145272.

FArris, J. S. 1988. Hennig 86, version 1.5. Ann Arbor, James S. Farris. Fleutiaux, E. 1907. Revision des Elateridae du Chili. Revista Chilena de Historia Natural 11: 160-232.

Fleutiaux, E. 1911. Revision des Trixagidae, Melasidae et Elateridae (Col.) des Antilles Françaises. Annales de la Societe Entomologique de France 80: 235-264.

Fleutiaux, E. 1916. Elateridae and Throscidae of the Stanford University Expedition of 1911 to Brazil. Psyche 23: 16-21.

Fleutiaux, E. 1926. Remarques et observations sur le Catalogue des Elateridae, $1^{\text {re }}$ partie, de M. S. Schenkling. Annales de la Societe Entomologique de France 95: 91- 112.

Fleutiaux, E. \& A. Sallé. 1889. Liste des Coléoptères de la Guadeloupe et descriptions d'espèces nouvelles. Annales de la Societe Entomologique de France (ser. 6) 9: 351-484.

Gemminger, M. \& E. von Harold. 1869. Catalogus coleopterorum hucusque descriptorum synonymicus et systematicus. v. 5, 1347-1608.

Germar, E. F. 1840. I. Bemerkungen über Elateriden. Zeitschrift der Entomologie 1840: 241-341, 2 taf.

Gmelin, J. F. 1788. Linné's Systema Naturae ..., edit. 13, v. 1, pt. 4, p. 1517-2224.

Golbach, R. 1976. Clave tentativa de los generos y especies de la subfamilia Hemirhipinae (Col. Elateridae) de Centro y Sudamerica. Acta Zoologica Lilloana 32(2):15-30, 5 figs.

Golbach, R. 1977. Las especies Centro- y Sudamericanas de la Tercera
Seccion del genero Chalcolepidius Eschsch. (Col. Elateridae). Acta Zooologica Lilloana 32(8): 154-163.

Guérin-Méneville, F. E. 1844. Description de quelques coléoptères de la Nouvelle-Grenade. Revue Zoologique 7:8-19.

Herbst, J. F. W. 1786. Erste Mantisse zum Verzeichniss der ersten Klasse meiner Insecten-Sammlung. Archives Insectengesch (7-8): 153182

Herbst, J. F. W. 1801. Natursystem..., v. 9, 344 p.

Heyne, A. \& O. Taschenberg. 1908. Die exotischen Käfer in Wort und Bilt, 27 Lieferungen. Leipzing, 262 p., 39 pl.

Hyslop, J. A. 1916. Elateridae and Throscidae of the Stanford University Expedition of 1911 to Brazil. Psyche 23: 16-21.

Hyslop, J. A. 1921. Genotypes of the Elateridae beetles of the world Proceedings of United States National Museum 58: 621-680.

JANSON, E. W. 1882. Descriptions of six new species of Elateridae, collected by Mr. Clarence Buckley during his second expedition to Ecuador. Cistula Entomologica 3 (pars 26): 33-37.

KIRK, H. B. 1922. Biological Notes on Elateridae and Melasidae (Col.). Entomological News 33: 236-240.

Lacordaire, J. T. 1857. Genera des Coléoptères... Paris, Librairie Encyclopédique de Roret, v.4, 579 p

Leconte, J. L. 1853. Revision of the Elateridae of the United States. Transaction of America Philosophical Society (n.s.) 10: $405-$ 508 .

LinNAEus, C. 1767. Systema naturae. Holmiae, editio decima reformata, v. 1 , pars 2 , p. 533-1327.

Maddison, W. P.; M. J. Donoghue \& D. R. Maddison. 1984. Outgroup analysis and parsimony. Systematic Zoology 33 (1): 83-103.

Nixon, K. C. 1992. Clados, version 1.2. Ithaca, Kevin C. Nixon.

Nixon, K. C. \& J. M. Carpenter. 1993. On outgroups. Cladistics 9(4): 413-426.

Olivier, A. G. 1790. Entomologie... Coléoptères. Paris, v. 2.

Palisot de Beauvois, A. M. F. J. 1805. Insectes recueillis en Afrique et en Amérique. 1805-1821. Paris, 276 p., 90 pl.

PJatakowa, V. 1941. Neue Chalcolepidiinae (Col. Elateridae). Deutsche Entomologische Zeitschrift 1941: 97-110.

Ramos, T. C. 1997. Tree Gardener, versão 2.2.

Schenkling, S. 1925. Elateridae I. Pars 80, p. 1-263. In: S. Schenkling. Coleopterorum Catalogus auspiciis et auxilio W. Junk. Berlin, W. Junk.

Schiodte, J. C. 1869-1870. De metamorphosi eleutheratorum observationes: bidrag til insekternes udviklingshistoire. Naturhistorisk Tidsskrift 6 (3): 467-530.

SCHÖNHERR, C. J. 1817. Synonymia insectorum, oder: Versuch einer Synonymie aller bisher bekannten Insecten; nach Fabricii Systema Eleutheratorum geordnet. v. 1, pt. 3, p.1-506.

Schwarz, O. C. E. 1906a. Coleoptera Fam. Elateridae. Fasc. 46A, p. 1112. In: P. Wystman (ed.). Genera Insectorum. Bruxelles, P. Wystman.

Schwarz, O. C. E. 1906b. Neue Elateriden aus Amerika. Deutsche Entomologische Zeitschrift 1906(1): 97-158.

Sharp, D. \& H. Scott. 1908. Fauna Hawaiiensis or the zoology of the Sandwich (Hawaiian) Isles ...Coleoptera 3. v. 3, pt. 5, p. $367-$ 579, pl. 13-16

Steinheil, E. 1875. Beiträge zur Kenntniss der Fauna von NeuGranada (Trixagidae, Eucnemidae, Elateridae). Col. Hefte, v. 14 , p. $107-136$

Sulzer, J. H. 1776. Abgekurzte Geschichte der Insecten nach dem Linaeischen System. Winterthur, pt. 1, 274 p.; pt. 2, 32 pl.

Toledo-Piza JR, S. De. 1968. Insetos de Piracicaba. Piracicaba, Universidade de São Paulo, Escola Superior de Agricultura "Luis de Queiroz", 123 p., 44 figs.

Watrous, L. E. \& Q. D. WheELER. 1981. The out-group comparison method of character analysis. Systematic Zoology 30 (1): 1-11.

Wiley, E. O. 1981. Phylogenetics. The principles and practice of phylogenetic systematic. New York, John Wiley \& Sons, 348 p.

Xambeu, C. 1912. Moeurs et metamorphoses des insectes. $18^{\mathrm{e}}$ memoire. Elaterides. Première partie. Societas Linneana 59(1): 12-161. 
INDEX

(synonyms in italics)

abbreviatovittatus Pjatakowa, 1941 syn. nov.

abdominalis Casey, 1907

acuminatus Casey, 1907 syn. nov. $\quad .345$

aequinoctialis Castelnau, 1836 ...................................................... 330

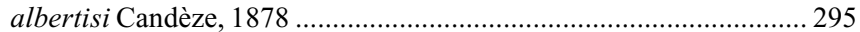

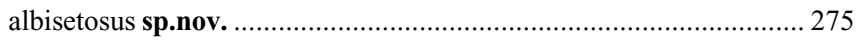

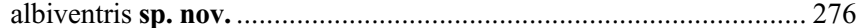

amictus Casey, 1907 syn. nov. ..................................................... 327

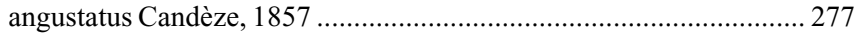

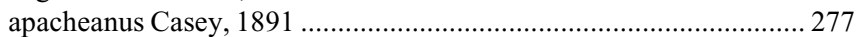

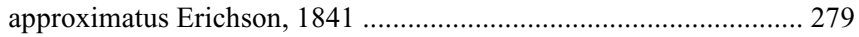

arizonicus Casey, 1907 ........................................................... 345

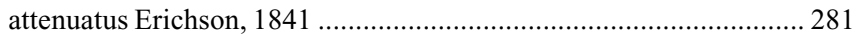

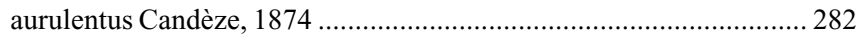

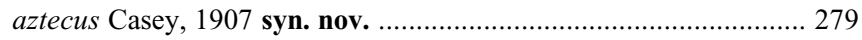

behrensi Candèze, 1886 syn. nov. ............................................... 311

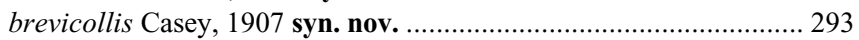

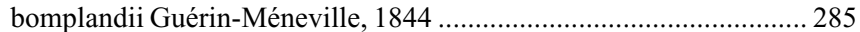

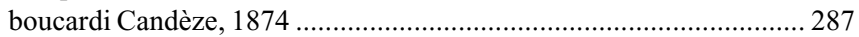

candezei Dohrn, 1881 syn. nov. ................................................. 282

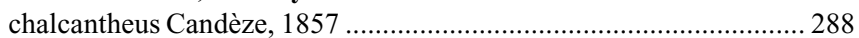

championi Casey, 1907 syn. nov. .................................................. 342

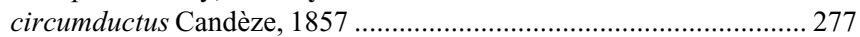

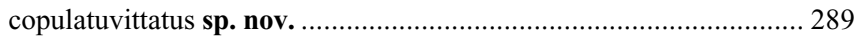

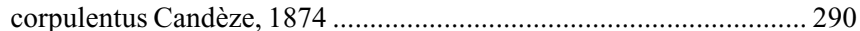

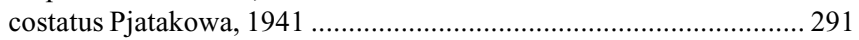

cuneatus Champion, 1894 syn. nov. ............................................. 281

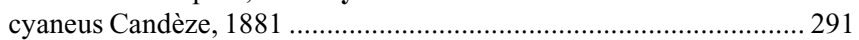

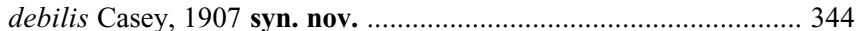

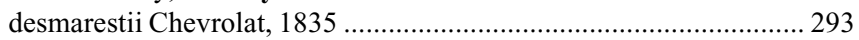

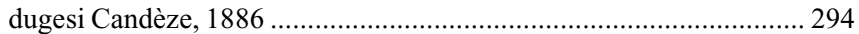

erichsonii Guérin-Méneville, 1844 syn. nov. .................................. 304

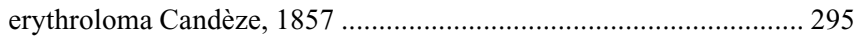

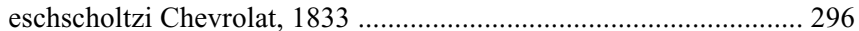

exquisitus Candèze, 1886 syn. nov. ............................................... 307

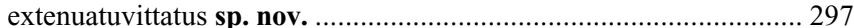

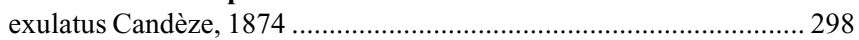

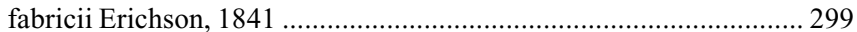

fasciatus sp. nov.

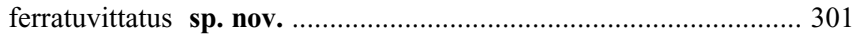

flavostriatus Pjatakowa, 1941 syn. nov. ...................................... 321

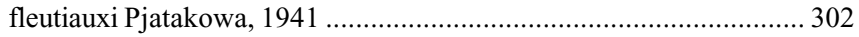

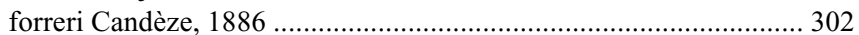

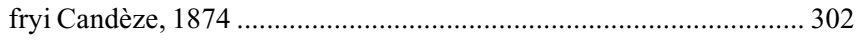

gossipiatus Guérin-Méneville, 1844 ............................................... 303

grossheimi Pjatakowa, 1941 syn. nov. .......................................... 282

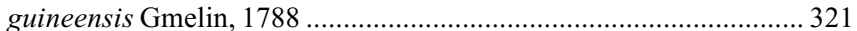

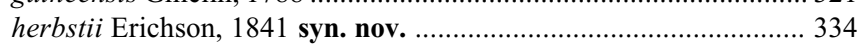

herbstii multistriatus Golbach, 1977 syn. nov. ................................. 321

humboldti Candèze, 1881 syn. nov. .............................................. 285

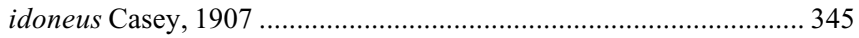

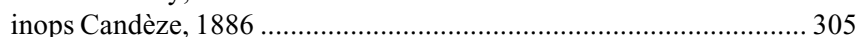

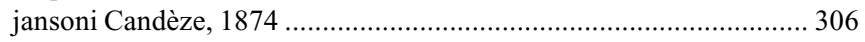

jekeli Candèze, 1874 syn. nov. ................................................ 319

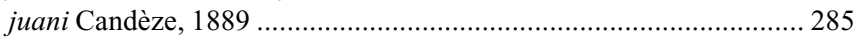

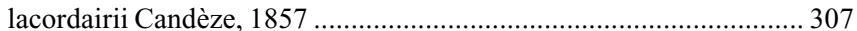

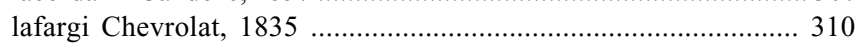

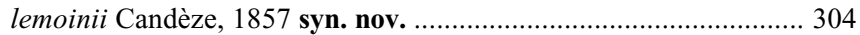

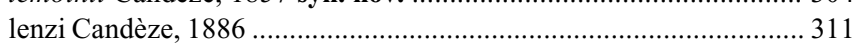

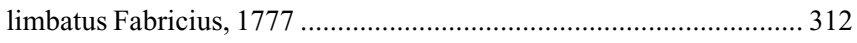

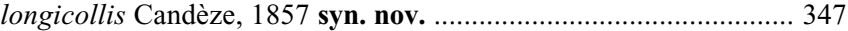

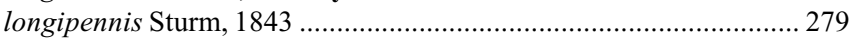

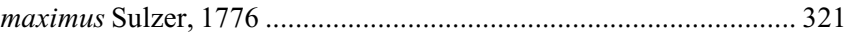

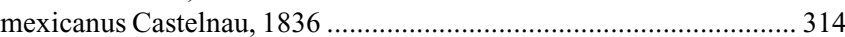

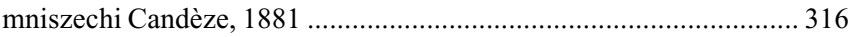

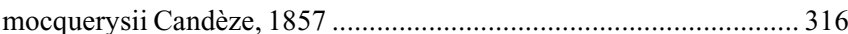

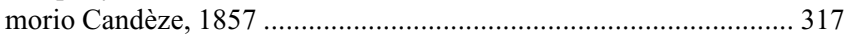

monachus Candèze, 1893 syn. nov. ................................................ 308

mucronatus Candèze, 1889 syn. nov. ............................................ 306

murinus Champion, 1894 syn. nov. ............................................... 305

niger Pjatakowa, 1941 syn. nov. ................................................. 279

nobilis Casey, 1907 syn. nov. .................................................... 278

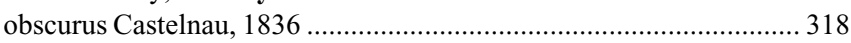

ostentus Casey, 1907 syn. nov. ...................................................... 332

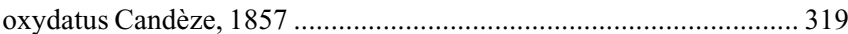

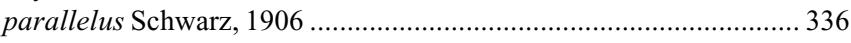

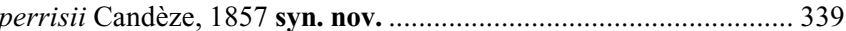

peruanus Candèze, 1886 syn. nov. ............................................ 321

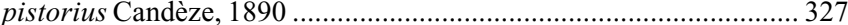

porcatus var. dimidiatus Candèze, 1874 ......................................... 282

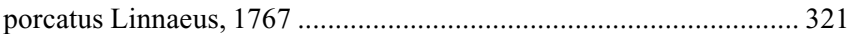

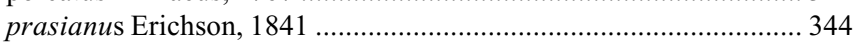

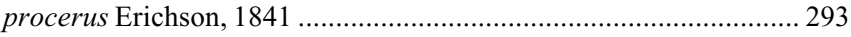

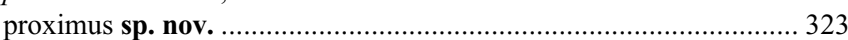

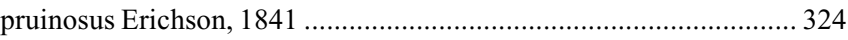

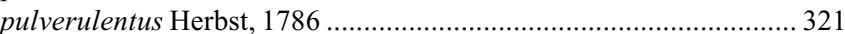

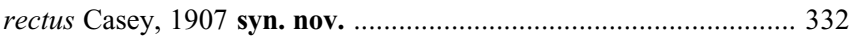

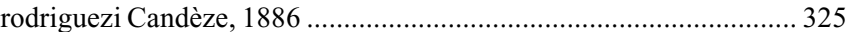

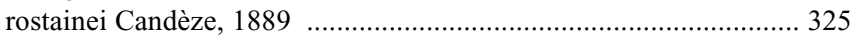

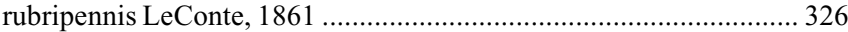

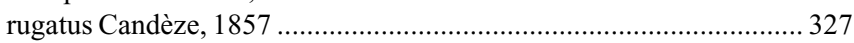

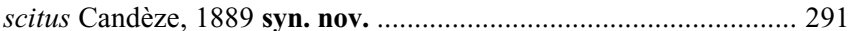

sericeus Erichson, 1841 .......................................................... 330

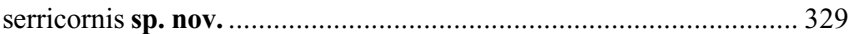

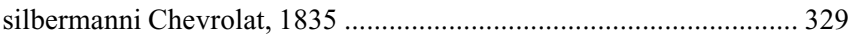

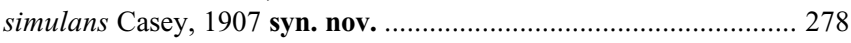

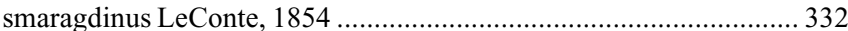

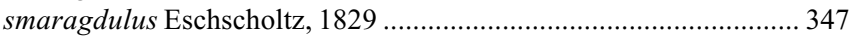

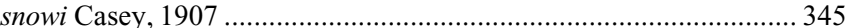

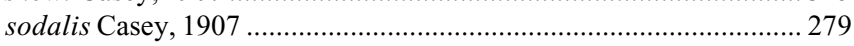

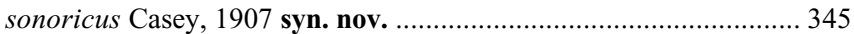

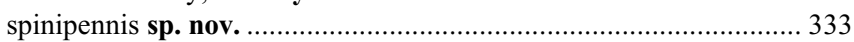

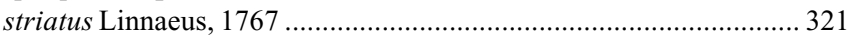

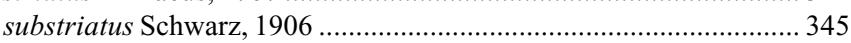

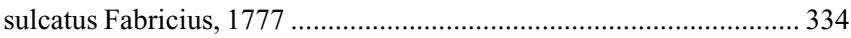

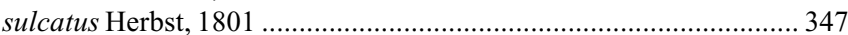

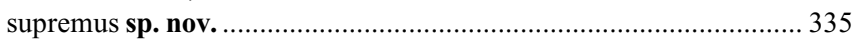

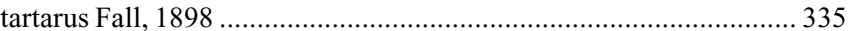

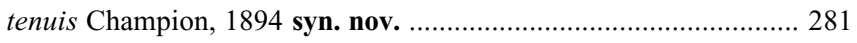

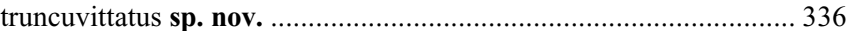

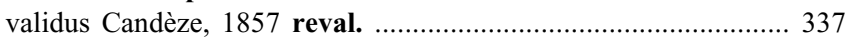

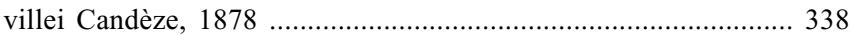

violaceous Pjatakowa, 1941 syn. nov. ........................................... 288

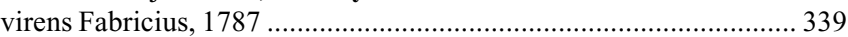

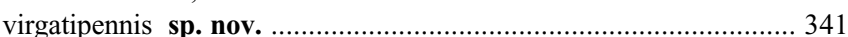

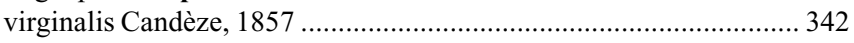

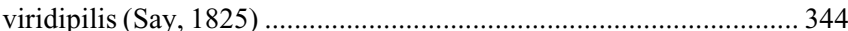

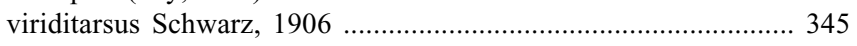

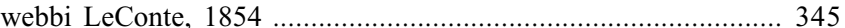

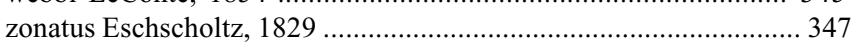

zonatus var. b Candèze, 1874 ................................................. 279

Received in 05.IX.2001; accepted in 30.IV.2002. Publication partially funded by FAPESP. 